\title{
Environmental Effects of Sediment Transport Alteration and Impacts on Protected Species: Edgartown Tidal Energy Project
}

TOPIC AREA II: MARINE SCIENCE AND

HYDROKINETIC SITE-SPECIFIC ENVIRONMENTAL STUDIES

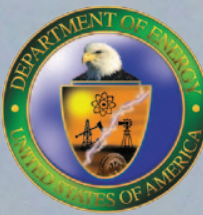

Submitted to: U.S. Department of Energy

December 29, 2012

Funding Opportunity Announcement No. DE-FOA-0000069

HMMH Project No. 303910 



\section{Edgartown Tidal Energy Project}

\section{Environmental Effects of Sediment Transportation Alteration and Impacts on Protected Species}

Topic Area II: Marine Science and Hydrokinetic Site-Specific Environmental Studies Funding Opportunity Announcement: DE-FOA-0000069

Project No. DE-EE0002656

HMMH Report No. 303910

December 29, 2012

Prepared for:

U.S. Department of Energy

Golden Field Office

1617 Cole Blvd.

Mail Stop 1501

Golden, CO 80401-3393

Prepared by:

humh Harris Miller Miller \& Hanson inc.

Harris Miller Miller \& Hanson Inc.

77 South Bedford Street

Burlington, MA 01803

T 781.229.0707

F 781.229 .7939

In Association with:

University of Massachusetts Dartmouth School for Marine Science and Technology Woods Hole Oceanographic Institution

Provincetown Center for Coastal Studies
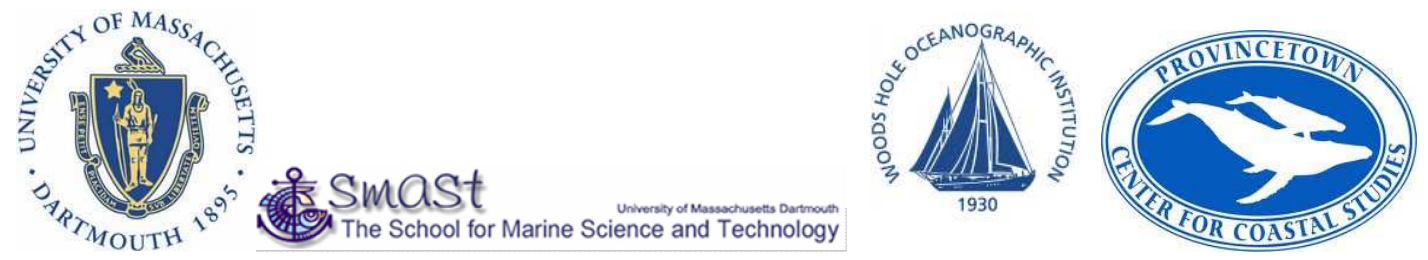



\section{Contents}

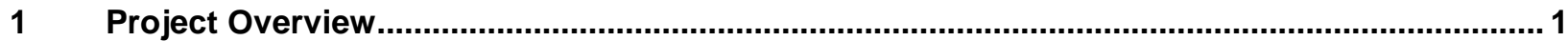

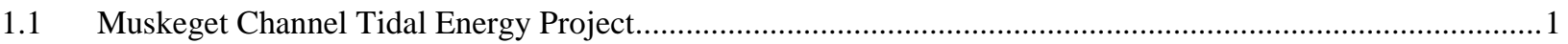

1.1.1 Commercial Scale Pilot Project - Town of Edgartown................................................................................2

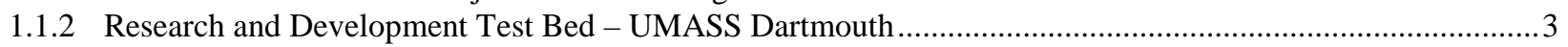

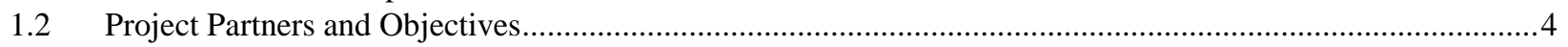

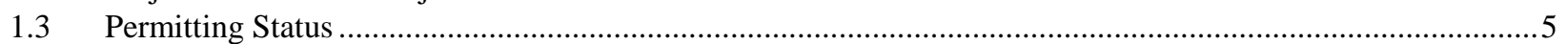

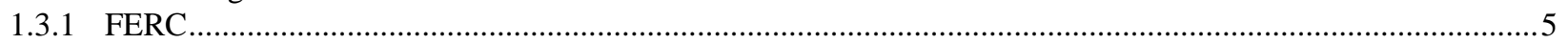

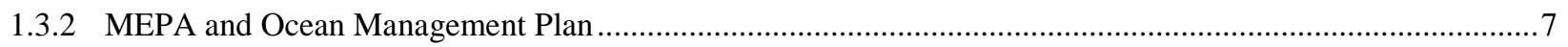

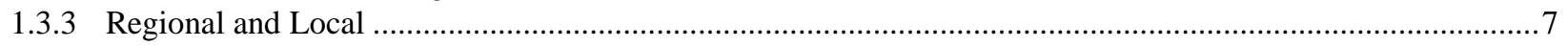

$1.4 \quad$ Importance of Research to Grant Program Goals.........................................................................................

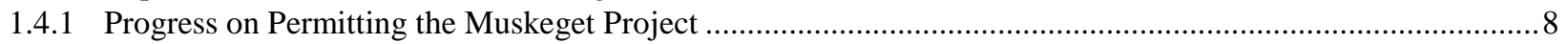

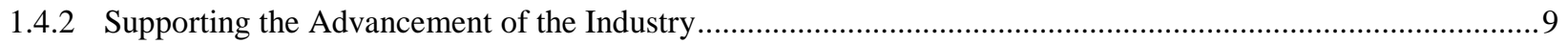

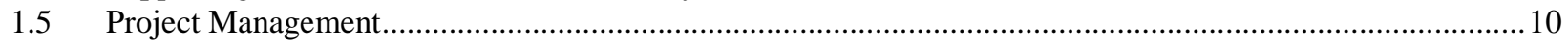

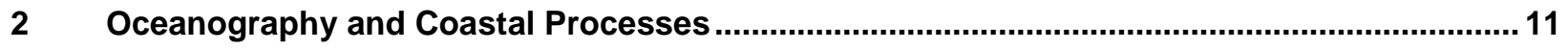

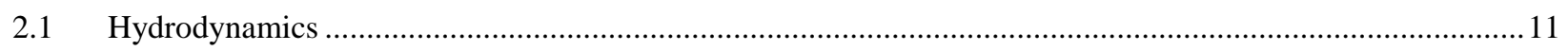

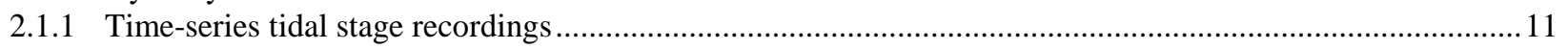

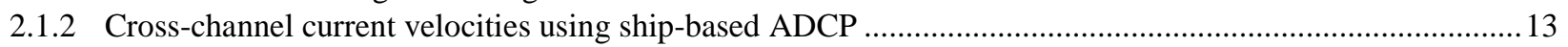

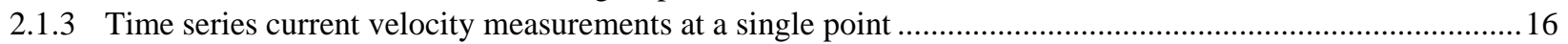

2.1.4 Measurement of Near Bottom Current Velocity and Implications for Scour ................................................ 17

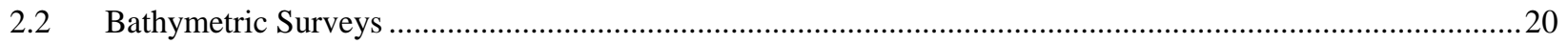

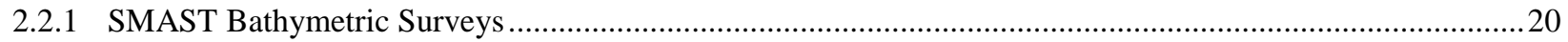

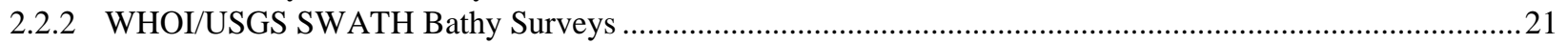

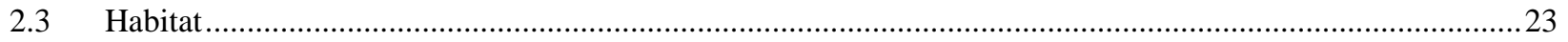

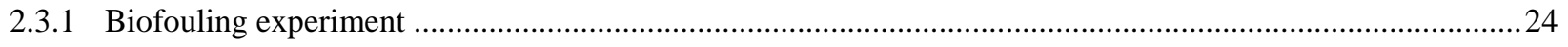

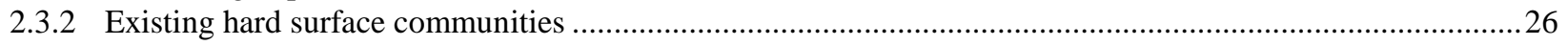

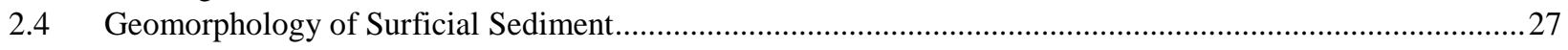

$3 \quad$ Sediment Transport

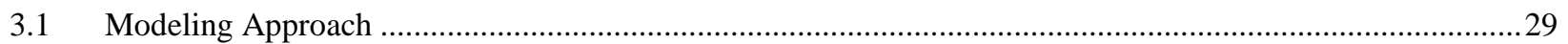

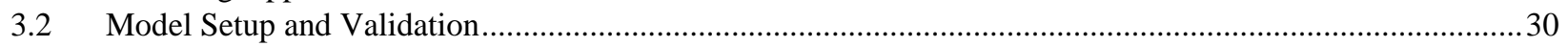

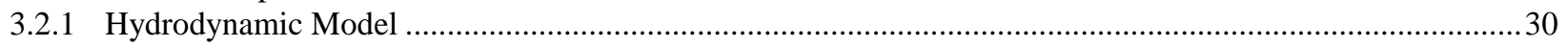

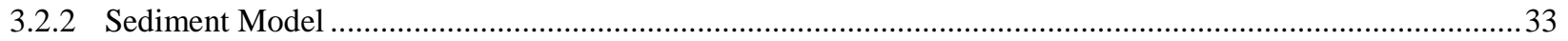

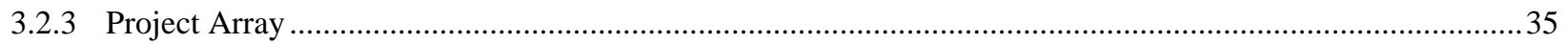

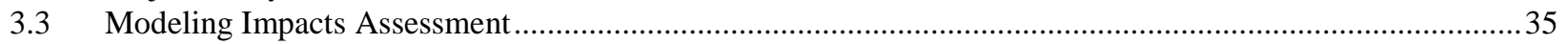

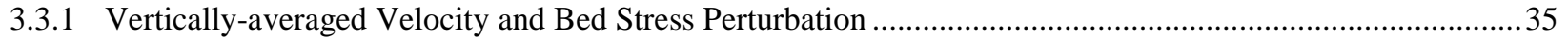

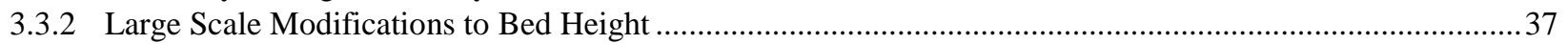

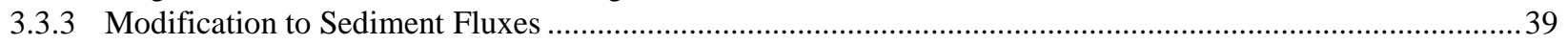

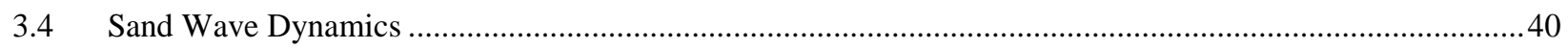

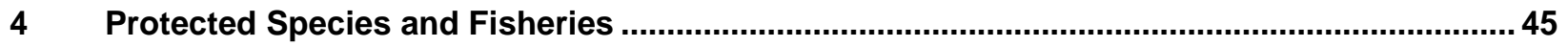

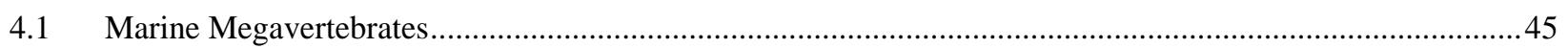

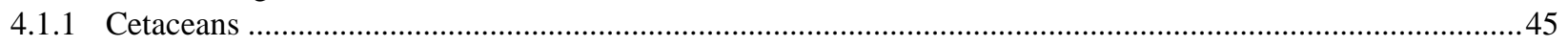

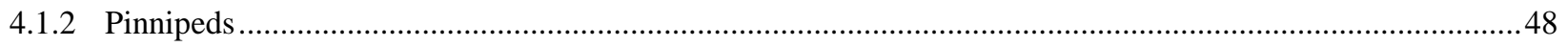

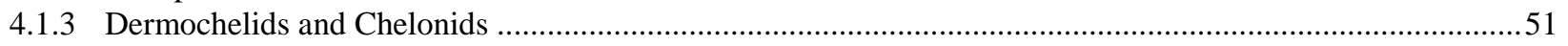

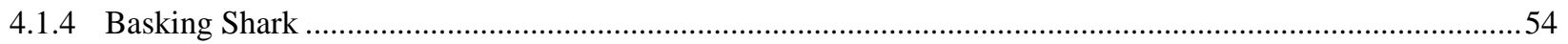

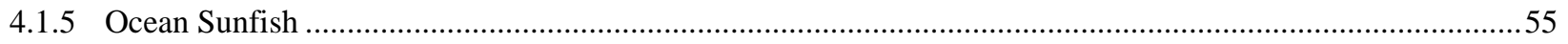

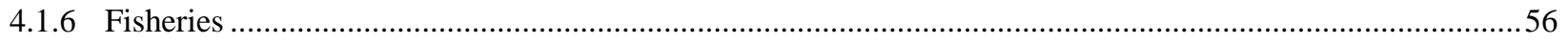

4.2 Summary of Existing Literature on Environmental Impact Studies of Marine Renewable Energy Installations 


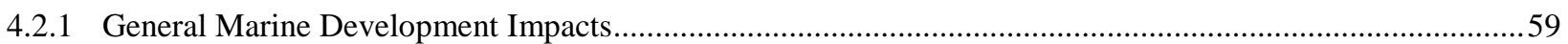

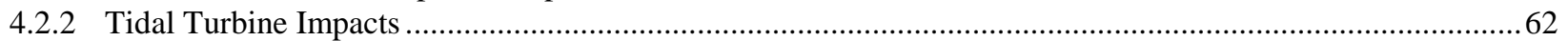

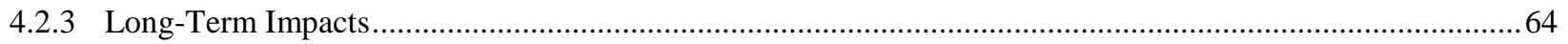

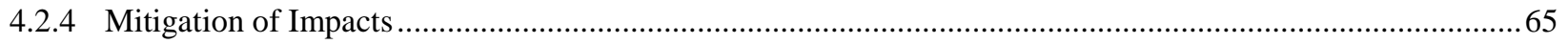

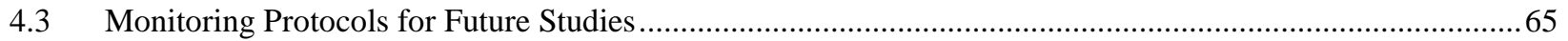

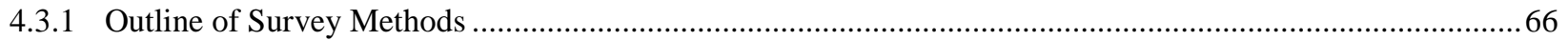

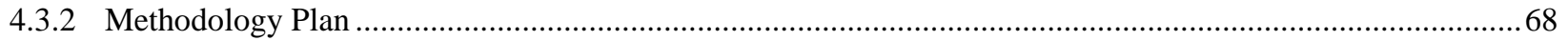

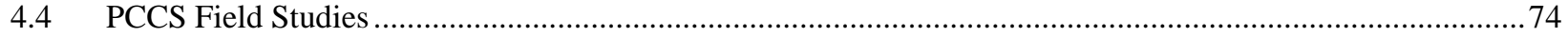

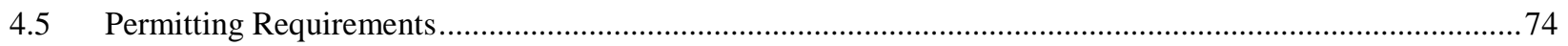

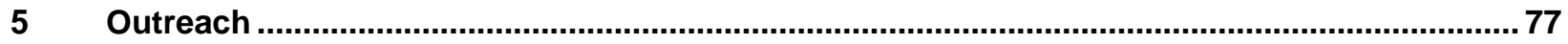

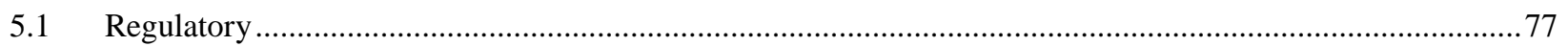

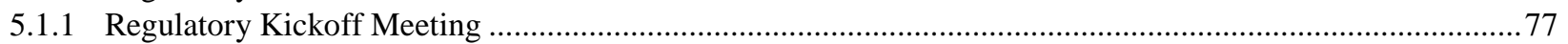

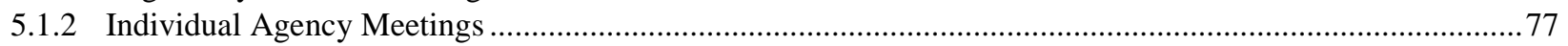

5.1.3 FERC Draft Pilot License Application and Massachusetts EENF …….................................................... 78

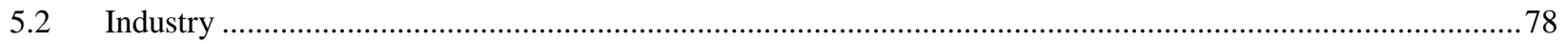

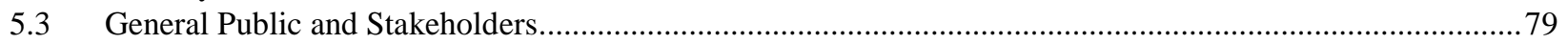

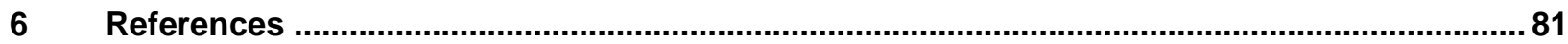

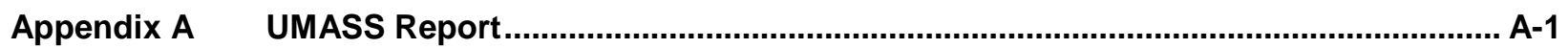

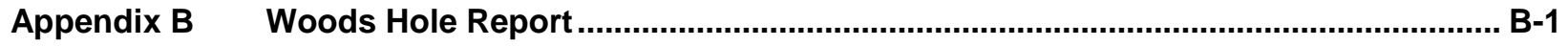

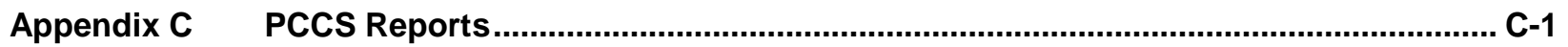

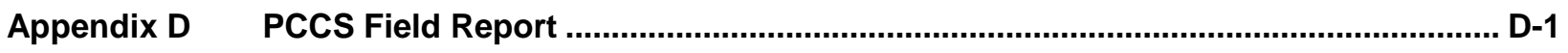

Appendix E UMASS Side Scan Sonar Report ....................................................................

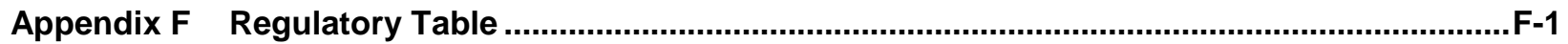

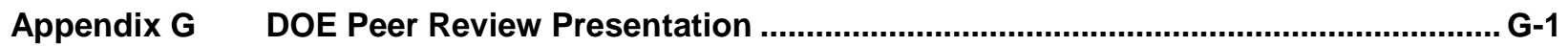

\section{Figures}

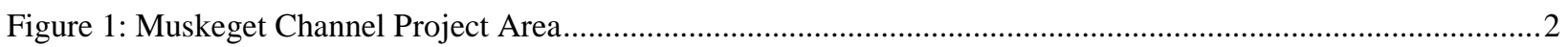

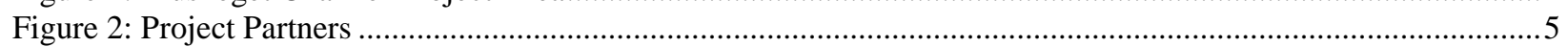

Figure 3: FERC Approved Area for Town of Edgartown's Preliminary Permit .....................................................6

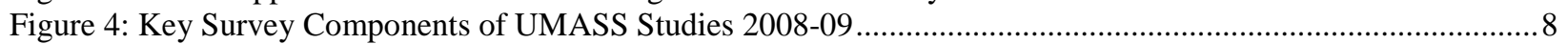

Figure 5: Current Velocities Measured with ADCP along Transects 6 and 7 .......................................................

Figure 6: Tidal Elevation Measurements Showing Time Delay Through Muskeget Channel .................................. 12

Figure 7: Current Velocity Compared to Tide Elevation at Cape Pogue and Muskeget High Velocity Zone..............12

Figure 8: Location of Transects Surveyed with Ship-based ADCP, 2010-11 ........................................................13

Figure 9: Current Velocity Measured at Max Ebb and Flood for Neap Tide at Transect 6.2 ................................. 14

Figure 10: Bottom Mounted Upward Looking ADCP .................................................................................. 16

Figure 11: Current Velocity at Depth Measured by the Bottom Mounted ADCP Between Transects 6 and 7 ...........16

Figure 12: Current Velocity at Depth Measured by the Bottom Mounted ADCP for One 24 Hour Period ................. 17

Figure 13: Concrete Cylinder Equipped with Current Probes to Measure Velocity and Scour..................................18

Figure 14: Pitch and Roll Data Showing Movement of Cylinder as a Result of Scour ............................................ 18

Figure 15: Measurement of Sediment Accretion and Erosion on North Side of Concrete Cylinder .........................19

Figure 16: Time Series Plot Comparing Current Direction and Current Velocity Measured at the North Side of the

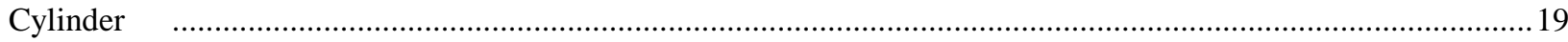

Figure 17: Diver Working Around Cylinder with View of Sea Bed ......................................................................19

Figure 19: Water Depths Measured By Bathymetric Surveys .............................................................................2 
Figure 18: Area of Enhanced Bathymetric Surveys...................................................................................2 21

Figure 20: Areas Surveyed by WHOI and USGS Using SWATH Bathy Method ...........................................22

Figure 21: SWATH Bathy Product for Muskeget Channel Project Area .............................................................23

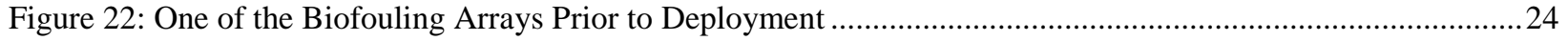

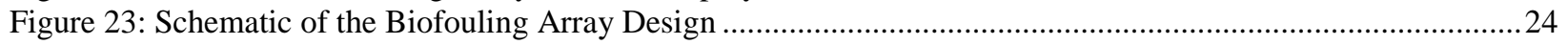

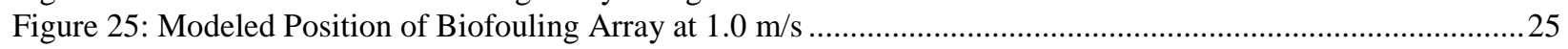

Figure 24: Modeled Position of Biofouling Array at Slack Tide......................................................................25

Figure 26: Untreated Composite Material Approximately Two Months After Deployment .................................26

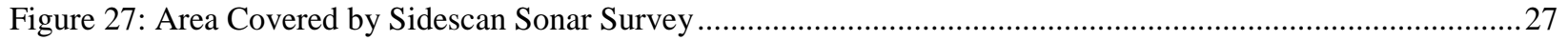

Figure 28: FVCOM Unstructured Grid in Area of Muskeget Channel ..........................................................29

Figure 29: Two Large-Scale Tidal Waves Modeled Using FVCOM ...........................................................31

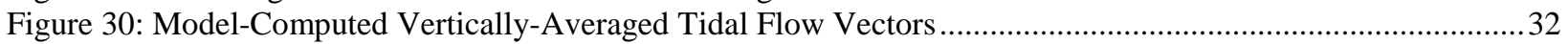

Figure 31: Model Grain Size Distribution Compared to US Seabed and UMASS Data ...........................................34

Figure 32: Difference in Model-Computed Vertically-Averaged Velocity Magnitude and Bedstress at Transect 8 .. 36

Figure 33; Difference in Model-Computed and Natural Bed Thickness over a 30 day Period for Four Different

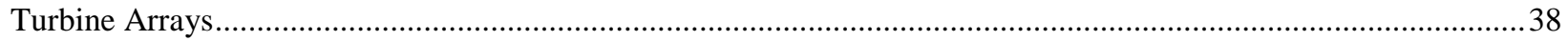

Figure 34: Total Absolute Difference in Bed Volume Modeled Over 30 Days for Four Turbine Array Locations .... 38

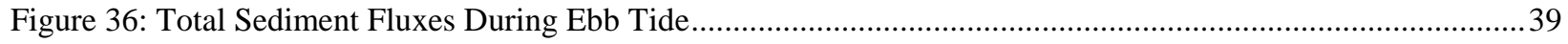

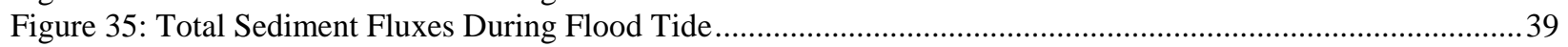

Figure 37: Large Sand Wave Area Southeast of Muskeget Channel ...................................................................41

Figure 38: Sand Waves Along the Proposed Chappaquiddick Cable Alternative ................................................42

Figure 39: Sand Waves Along the Katama Cable Alternative ..................................................................43

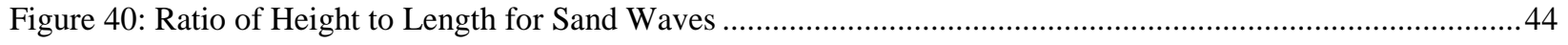

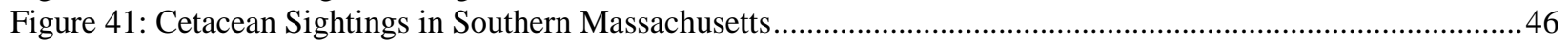

Figure 42: Seal Colonies of Southern Massachusetts ...........................................................................49

Figure 43: Harbor Seal Abundance from Plymouth to Woods Hole, Massachusetts (Payne \& Selzer 1989; Barlas

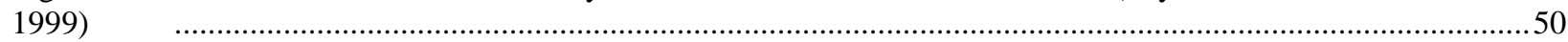

Figure 44: Gray Seal Pup Counts on Muskeget Island, Massachusetts, 1991-2008 (Rough, 1995, 2000; Wood

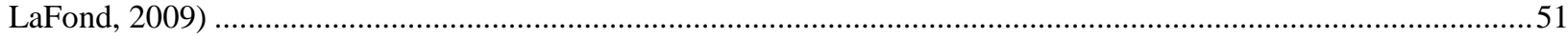

Figure 45: Sea Turtle Sightings in Nantucket Sound from Aerial Surveys .....................................................52

Figure 46: Confirmed Entangled Sea Turtle Sightings Reported to the MASTDN..............................................53

Figure 47: Basking Shark and Ocean Sunfish Sightings for Southern Massachusetts ............................................55

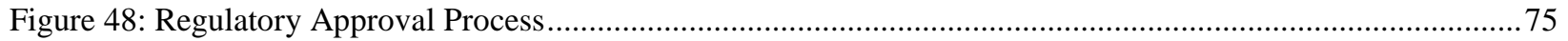

\section{Tables}

Table 1: Sediment Classes and Characteristics for ISE Impact Studies ........................................................35

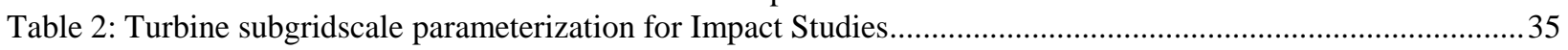

Table 3: Comparison of strandings data from NOAA Fisheries for animals that stranded on or in the vicinity of

Martha's Vineyard, Nantucket, and nearby islands with Right Whale Consortium sightings data for the same region48

Table 4: Fish Species with designated Essential Fish Habitat in the project area...............................................58

Table 5: Operational Objectives for the Muskeget Tidal Project Monitoring and Mitigation Program ....................69

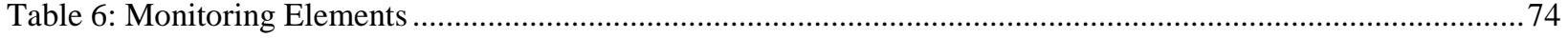

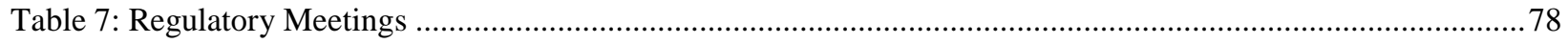

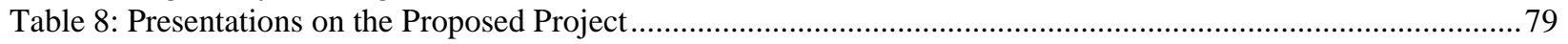

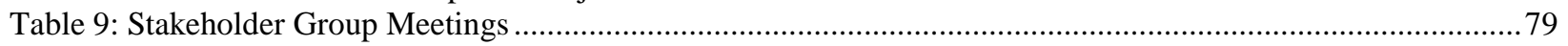





\section{Project Overview}

In March 2008, the Town of Edgartown Massachusetts received a Preliminary Permit from the Federal Energy Regulatory Commission (FERC) to explore the tidal energy potential in Muskeget Channel and file a Draft License Application for development of the site.

In June of 2009, Edgartown assigned Harris Miller Miller \& Hanson Inc. (HMMH) as its Principal Investigator and program manager to pursue funding from the US Department of Energy's Advanced Water Power Program for Marine and Hydrokinetic (MHK) Site-Specific Environmental Studies. The Funding Opportunity Announcement described two primary objectives of the grant program: (1) to collect information necessary for the approval of specific MHK projects; and (2) to contribute to data development useful to the industry as a whole.

The proposed study was divided into two distinct components:

- To model differences in sediment transport alteration and assess corresponding changes in habitat between two leading tidal energy technologies - horizontal open bladed turbines mounted on monopiles, and horizontal helical turbines that float from moorings

- To collect and analyze information on the occurrence of protected species in the project area

In September 2009, HMMH was awarded funding for its proposed study. This report describes the results of the study.

\subsection{Muskeget Channel Tidal Energy Project}

The Islands of Martha's Vineyard and Nantucket are separated from the Massachusetts mainland by Vineyard and Nantucket Sounds; water between the two islands flows through Muskeget Channel. The towns of Edgartown (on Martha's Vineyard) and Nantucket recognize that they are vulnerable to power supply interruptions due to their position at the end of the power grid, and due to sea level rise and other consequences of climate change. The tidal energy flowing through Muskeget Channel has been identified by the Electric Power Research Institute as the strongest tidal resource in Massachusetts waters. 


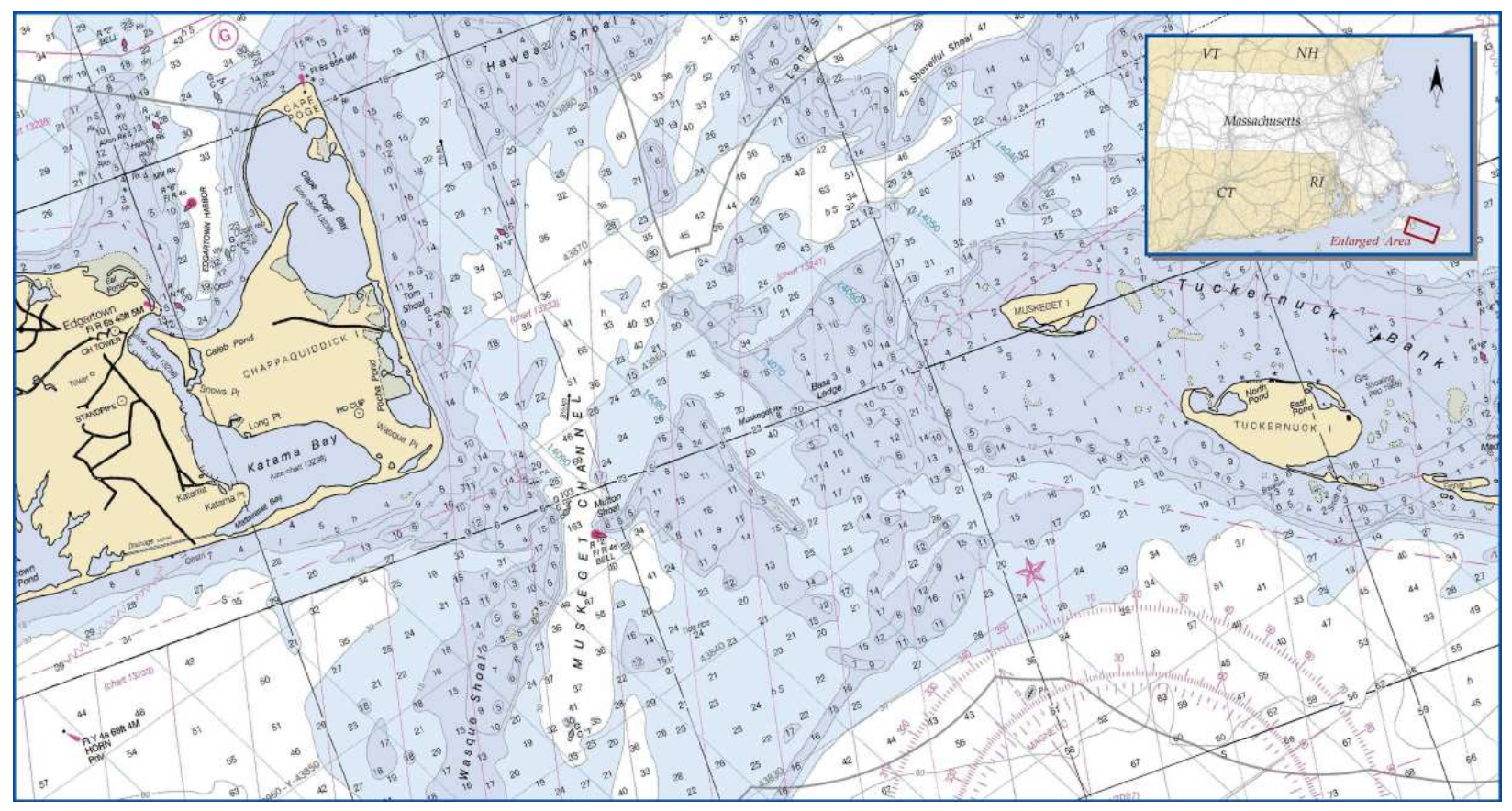

Figure 1: Muskeget Channel Project Area

Muskeget Channel is located between Martha's Vineyard and Nantucket (see Figure 1). Its depth ranges between 40 and 160 feet in the deepest reaches of the channel. It has strong currents that transfer water between Nantucket Sound and the Atlantic Ocean continental shelf to the south. This makes it a treacherous passage for navigation. Current users of the channel are commercial and recreational fishing and cruising boats. The US Coast Guard has indicated that the largest vessel passing through the channel is a commercial scallop dragger with a draft of about 10 feet. The tidal resource in the channel has been measured by the University of Massachusetts-Dartmouth (UMASS) and the peak velocity flow is approximately 5 knots.

The assessment and development of tidal energy in Muskeget Channel includes a commercial scale development project proposed by the Town and a research and development project led by the New England Marine Renewable Center (MREC) located at UMASS.

\subsubsection{Commercial Scale Pilot Project - Town of Edgartown}

The Town of Edgartown proposes to develop an initial 5 MW (nameplate) tidal energy project in Muskeget Channel. The tidal engines have an estimated capacity factor of $25 \%$ and therefore the amount of electricity produced from the $5 \mathrm{MW}$ Pilot Project will be $1.25 \mathrm{MW}$. The electricity will be brought shore by a buried submarine cable landfall in Edgartown either on Chappaquiddick or at Katama.

The project will consist of 14 Tidal Energy Turbines located within Muskeget Channel. 13 of the turbines will be for commercial operation and constitute a nameplate capacity of $5 \mathrm{MW}$. The remaining turbine will be set-aside as a test stand to allow the MREC to test various tidal energy technologies and advance tidal technology research and development in the U.S. (see section below). The 14 turbines will be positioned within the deepest segment of the channel at a minimum depth of 100 feet. The turbines are a minimum of 800 feet apart to accommodate the anchoring system and to avoid "wake loss" (and potential reduced energy production) from down current turbines. 
The type of turbine proposed is a helical turbine with the design provided by Ocean Renewable Power Company, though the future technology and developer will be selected through a public bidding process. The blades rotate like an egg beater capturing the tide's energy during both flood and ebb tides. Several turbines are combined into a single tide engine unit. The dimensions of each unit are 91 feet long and 56 feet deep with a width of 14 feet. The units include an anchoring system that will allow the device some movement in the current. Based on preliminary input on types of vessels that transit through the Channel, the devices will be located 25 feet below the ocean's surface at mean low water.

Two submarine cable alternatives, referred to as the Chappaquiddick and the Katama, are under consideration. The Chappaquiddick alternative would landfall on Martha's Vineyard's east shore on Chappaquiddick while the Katama alternative would landfall on the island's south shore. A proposed substation location is necessary close to the shoreline and on-land transmission upgrades are also expected.

Edgartown proposes to conduct a phased development of the project, which will provide some safeguards should unintended environmental consequences occur during the initial stages of deployment.

\subsubsection{Research and Development Test Bed - UMASS Dartmouth}

The University of Massachusetts at Dartmouth (UMASS) is leading an effort to conduct marine renewable energy research and development in the oceans of southern New England. Its vision is to create a planning area for marine renewable energy study and development referred to as the Northeast Offshore Renewable Energy Innovation Zone (NOREIZ) with in-ocean test sites to develop and demonstrate marine renewable energy (offshore wind, wave, tide) solutions for New England.

At present, there are no designated locations in the United States for marine renewable energy companies to test their products. Creation of a pre-permitted location will accelerate the development and commercialization of these products. The NOREIZ idea is, in part, inspired by the success of the European Marine Energy Centre (EMEC) in Scotland. Many European countries are well ahead of the U.S. in helping to commercialize these products, creating a competitive disadvantage for U.S. firms.

The NOREIZ is a rectangular area bounded to the north by the islands of Martha's Vineyard and Nantucket, and Muskeget Channel, and extending approximately 30 miles south. The near island areas and Muskeget Channel support marine hydrokinetic technology development while areas to the south support transition zone (20-60 meters) and deep water wind turbines. This is the only area in the US that can support development and testing for generators using all of these resources.

The benefits of the NOREIZ include:

- Develops generation technology suitable for northeast, the region with greatest load.

- Lowers the R\&D costs and risks associated with required tests and validation

- Makes it easier and less expensive for these companies to get products to market

- Provides national training site for clean energy engineers and technicians

- Supports Edgartown's and Nantucket's renewable energy generation objectives

As discussed above, one of the sites where Edgartown seeks to obtain approval from FERC would serve as a research and development test bed for UMASS. This would allow UMASS and its MREC partners to coordinate with technology developers on product testing and impact assessment for marine 
hydrokinetic technologies. The test bed would be wired to the mainland separately from the commercial tidal project to allow for distinct measurement and operations from a land-based facility.

In addition, UMASS, in partnership with Commonwealth of Massachusetts Executive Office of Energy and Environmental Affairs (EOEEA), has applied to the Bureau of Ocean Energy Management, Regulation and Enforcement (BOEMRE) for a research lease to establish a permanent Marine Energy Platform for Study, Demonstration and Training (MEP-SDT) in waters approximately 12 miles south of Nantucket. The MEP-SDT will study the environment, demonstrate marine energy technologies, and train marine energy technicians and engineers. The research lease would be located in waters adjacent to and typical off large areas currently being addressed by Requests for Information (RFI) by BOEMRE, and therefore would be of direct interest to developers interested in the waters off of Massachusetts and Rhode Island.

\subsection{Project Partners and Objectives}

The Project Team is led by Harris Miller Miller \& Hanson Inc. (HMMH), environmental consultant and project manager for the Town of Edgartown. HMMH has over 30 years of experience in environmental consulting. Its principal investigator, Stephen Barrett, was involved in the initial meetings when the Town determined that it wished to pursue the Preliminary Permit from FERC. HMMH's responsibility is to ensure that the project supports the Town of Edgartown's objectives of obtaining regulatory approvals. It has achieved this objective through working with the other project partners to generate valuable information, communicating the activities of the project team to a broad group of constituents, and prepared information on the project for review by regulatory officials.

The University of Massachusetts School of Marine Science and Technology (SMAST) provides oceanography and marine science support to the project team. The SMAST is the marine campus of the University of Massachusetts Dartmouth. SMAST focuses on interdisciplinary basic to applied marine sciences and the development of related innovative technologies. In addition to the scholarly marine science and technology communities, the SMAST mission also emphasizes interaction with regional industry, government and non-governmental agencies on compelling regional marine-related issues and technological development. SMAST has undertaken a variety of directed studies to collect data on the existing marine environment in Muskeget Channel. These data are useful for optimizing tidal energy project siting and design to maximize energy production and minimize environmental impact.

Woods Hole Oceanographic Institution (WHOI) is the world's largest private, nonprofit ocean research, engineering and education organization. WHOI is leading the sediment transport modeling tool development. With support from SMAST staff, WHOI has built and calibrated a baseline oceanographic model of Muskeget Channel and incorporated existing sediment transport dynamics. Then it has manipulated the model by incorporating two different tidal energy technologies and arrays sized to produce a $5 \mathrm{MW}$ nameplate capacity. On the large scale, the model produces data on changes in sediment transport and deposition, and alterations in benthic habitats can be predicted.

The Provincetown Center for Coastal Studies (PCCS) is a private, nonprofit research organization whose mission is to conduct scientific research with emphasis on marine mammals of the western North Atlantic, to promote stewardship of coastal and marine ecosystems, and to conduct educational activities that encourage the responsible use and conservation of coastal and marine ecosystems. For this project, PCCS summarized the distribution, abundance, and habitats of marine megavertebrates and fishery resources in the general project area, and identified gaps in the existing knowledge base. It also provided a general review of potential effects of marine renewable energy installations including offshore wind, tidal and wave energy. In addition, it proposed survey methods that could be considered for filling in data gaps and studying site specific impacts. 
The Town of Edgartown is a community of 4,054 people located on the eastern shore of Martha's Vineyard, Massachusetts and holds a FERC Preliminary Permit to explore a hydrokinetic project in Muskeget Channel. The Town of Nantucket which abuts Muskeget Channel to the east is also a formal partner on the FERC Permit. The New England Marine Renewable Energy Center is facilitating testing and development activities on behalf of the University of Massachusetts at Dartmouth. The Massachusetts Clean Energy Center is funding renewable energy efforts in the Commonwealth including those conducted by the project partners in Muskeget Channel. Logos of the organizations affiliated with the project are shown in Figure 2.

\section{www.hmmh.com}

\section{Project Partners}
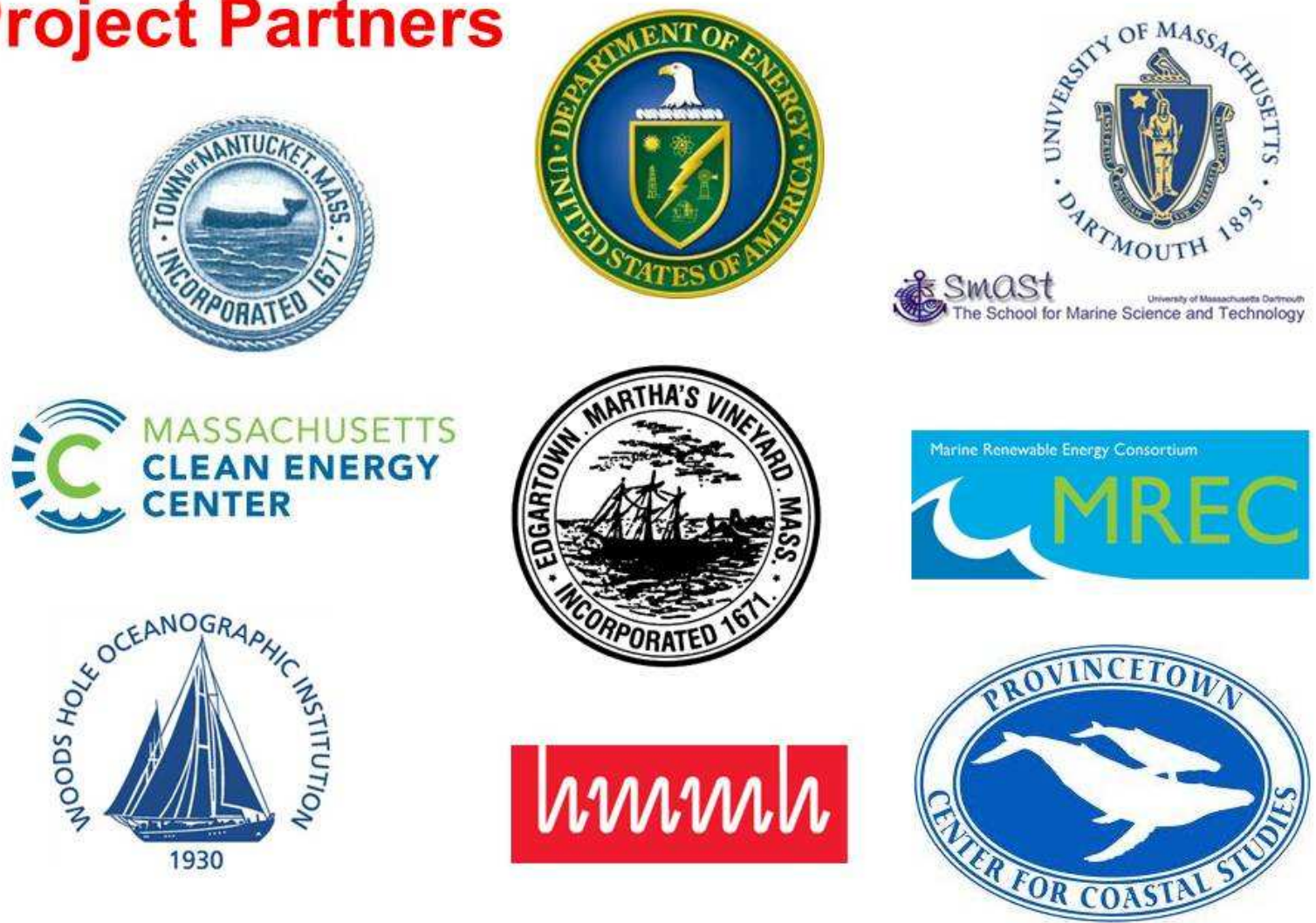

Figure 2: Project Partners

\subsection{Permitting Status}

Permitting the Muskeget Channel Tidal Project requires obtaining approvals from federal, state, regional, and local authorities. The permitting process and its status are summarized below.

\subsubsection{FERC}

The Federal Energy Regulatory Commission (FERC) is the federal agency primarily responsible for licensing hydropower projects. Traditionally, this authority has focused on hydropower generation associated with dams, but more recently has been applied to non-impounded hydropower including hydrokinetics. In administering its authority, it consults with sister federal agencies, such as the U.S. Fish and Wildlife Service, who are responsible for various overseeing other federal laws which may be 
triggered by the proposed project. During its review of a license application for generating new hydropower, FERC consults with sister agencies and stakeholder groups to ensure that the final license is consistent with all federal laws and regulations.

FERC permitting commences with a request by an applicant for an exclusive right to explore a hydropower site. The exclusive right is authorized by FERC through the issuance of a Preliminary Permit. The Town of Edgartown initially applied for a Preliminary Permit in July of 2007. After a public comment period and request for additional information, FERC issued the Preliminary Permit to Edgartown on March 1, 2008. The Preliminary Permit gives Edgartown the exclusive right to apply for a power generation license for power generated from the hydrokinetic energy in the water flowing in this area. As a condition of the Preliminary Permit, Edgartown must submit a Draft Pilot License Application by February 28, 2011. This Pilot License Application must include information on initial consultation with cooperating federal resource agencies.

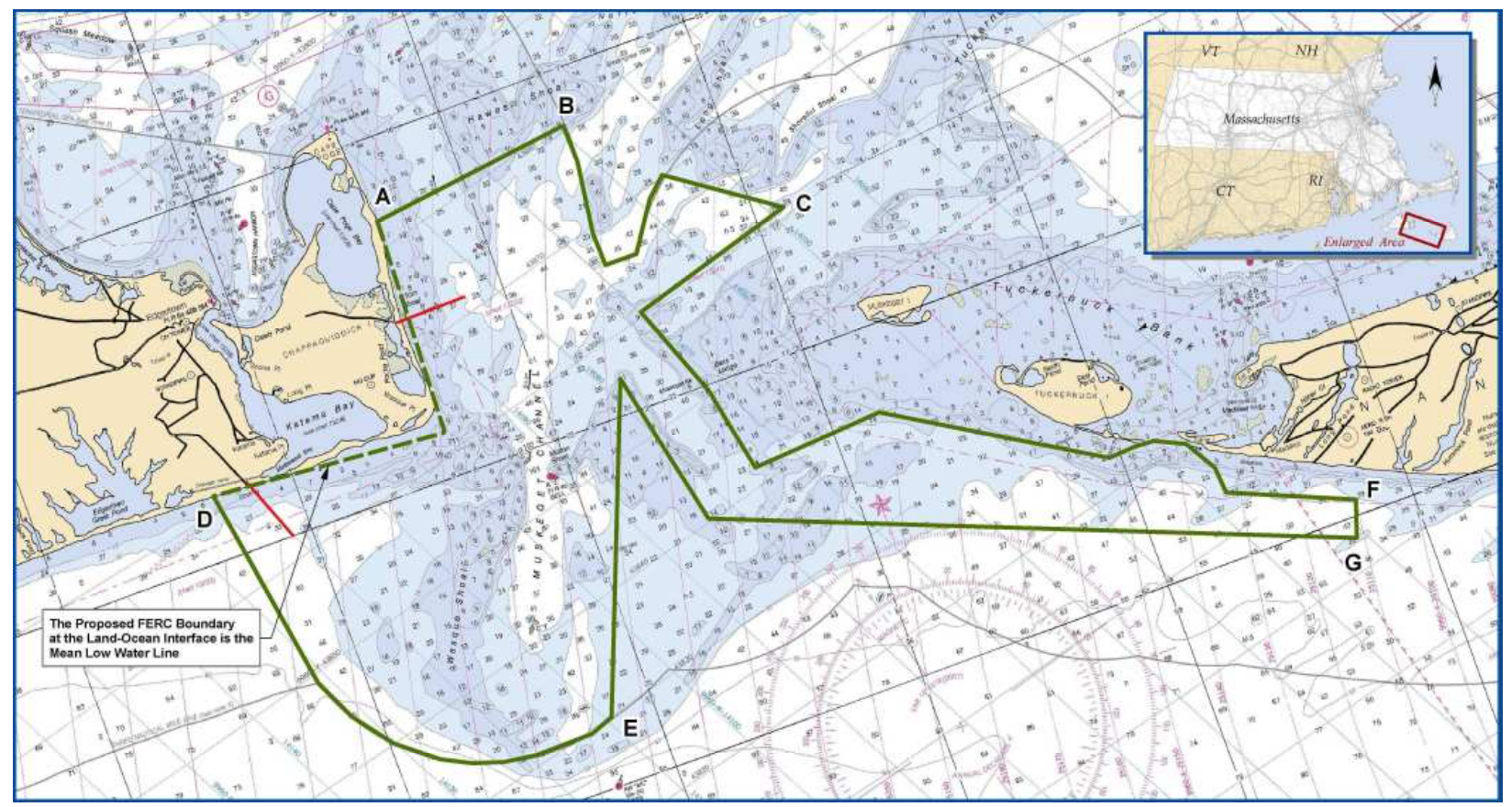

Figure 3: FERC Approved Area for Town of Edgartown's Preliminary Permit

Edgartown filed a Draft Pilot License Application on January 31, 2011. Concurrently it filed an Expanded Environmental Notification Form with the Massachusetts Environmental Policy Act Office initiating a parallel state review of the project (see below). The Draft Pilot License Application included a series of study plans covering resource areas such as protected species, fisheries, and avian species. Edgartown has agreed not to file the Final Pilot License application until a year of pre-construction studies has been completed. Based on the current project schedule, Edgartown expects to file the Final Application in early 2013.

On February 28, 2011, the Town's Preliminary Permit, which is valid for a three year period, expired. The Town immediately applied for a successive Preliminary Permit which was granted on August 2, 2011 and protects Edgartown's rights in Muskeget Channel until July 31, 2014. The current FERC area is shown in Figure 3. 


\subsubsection{MEPA and Ocean Management Plan}

Concurrent with filing the Draft License Application with FERC, Edgartown filed an Expanded Environmental Notification Form (EENF) with the Massachusetts Environmental Policy Act (MEPA) Office. The EENF contained the same level and type of information as provided in the Draft License Application, but also included specific analysis relative to state environmental programs. This allowed agencies and stakeholders to submit comments on both applications with a single comment letter and allow for a coordinated regulatory review.

The EENF included information on the applicability of the project to the Massachusetts Ocean Management Plan. The Ocean Plan was published January 1, 2010. Its primary purpose was to identify areas where offshore wind development could occur in state waters. However, it also communicated planning guidance for tidal energy projects in Massachusetts. The Town of Edgartown actively participated in the development of the Ocean Plan and as a result the plan acknowledges the proposed activities in Muskeget Channel and specified applicability of the plan to commercial and pilot scale tidal projects. Specifically, the Ocean Plan states that pilot scale tidal energy projects are consistent with the Ocean Plan (with the exception of seaward of the Cape Cod National Seashore).

In its EENF, Edgartown requested that the Secretary of Environmental Affairs approve a Single Environmental Impact Report, and thereby a two stage application process consistent with FERC's Draft and Final License Application process. In its Certificate on the EENF, the Secretary determined that a traditional three stage process applies (EENF, Draft Environmental Impact Report [DEIR], Final Environmental Impact Report [FEIR]) and provided the scope of the DEIR. Edgartown anticipates filing a DEIR in the late spring of 2012 and a FEIR concurrent with the FERC Final License Application in early 2013. Once the FEIR Certificate is issued and the MEPA review has concluded, the Department of Environmental Protection and the Massachusetts Office of Coastal Zone Management can issue individual permits under their authority.

\subsubsection{Regional and Local}

The Martha's Vineyard Commission is a regional government authority which reviews and permits development on the island that exceeds certain size and impact thresholds. The review program is referred to as Development of Regional Impact (DRI). Edgartown has had preliminary meetings with MVC staff to brief them about the project. MVC has also provided written comments on the EENF to the MEPA office as part of the state review. Edgartown initially discussed combining the MVC's review with those of the federal and state agencies. However, the level of detail required by the MVC is more akin to that necessary for local permitting and therefore it was decided to make application to MVC once the federal and state reviews concluded.

Local permitting is conducting under the authority of the Town of Edgartown. It is expected that the project will require a zoning approval from the Zoning Board of Appeals. It will also be reviewed by the Edgartown Conservation Commission for work in wetlands or within 100 feet of wetlands.

\subsection{Importance of Research to Grant Program Goals}

The Water Power Grants under Topic II, Environmental Studies, were intended to provide two primary benefits: (1) advance approval of existing projects, and (2) provide information useful to the development of the MHK industry as a whole. 


\subsubsection{Progress on Permitting the Muskeget Project}

The Muskeget Project is unique in that it is proposed by a municipal government and supported by a broad team comprised of academics, scientists, and government who seek to advance both the project and research and development in the area of marine renewable energy. As such, the team provides both the political leadership and the scientific expertise and is dependent on government seed funding to advance the project. The Town of Edgartown is a municipal corporation serving the 4,054 residents and providing them with local government services. It is not an early investor in technology and project development with long time horizons. It is in this context that the value of the DOE Water Power Grant can be measured.

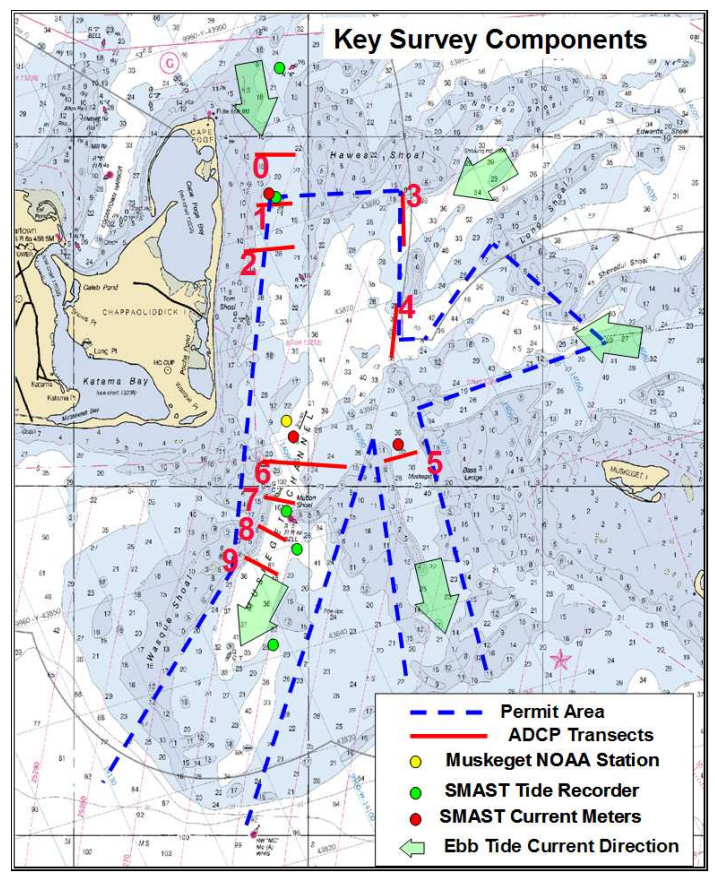

Figure 4: Key Survey Components of UMASS Studies 2008-09
Prior to receiving the DOE grant, Edgartown had applied for and received the FERC Preliminary Permit. It had also benefitted from research conducted by the UMASS SMAST and funded by the Massachusetts Clean Energy Center (MassCEC) to study in detail the characteristics of the ocean currents in Muskeget Channel. Elements of the study are shown in Figure 4. That study, completed in June 2009, confirmed the peak current velocity recorded in Muskeget Channel at 5.2 knots, and focused project development in the deepest and narrowest reach of Muskeget Channel. Figure 5 shows current velocities recorded along Transects 6 and 7. Since receiving the grant from the DOE, the project team has advanced project permitting both through data collection and outreach, both of which are essential to gaining regulatory approvals.

The details of the data collection program are provided in this report. From a summary level, each study component has been used to inform the dialogue with stakeholders and support permit applications. The data generated by the Provincetown Center for Coastal Studies on the occurrence of marine megavertebrates provided essential information on whales, sea turtles, seals, and other large marine animals that might be found in the vicinity of the project and how the project could impact their environment. This information was necessary to engage resource agencies responsible for administering marine mammal and endangered species protection regulatory programs to initiate their impact analysis of the project. 


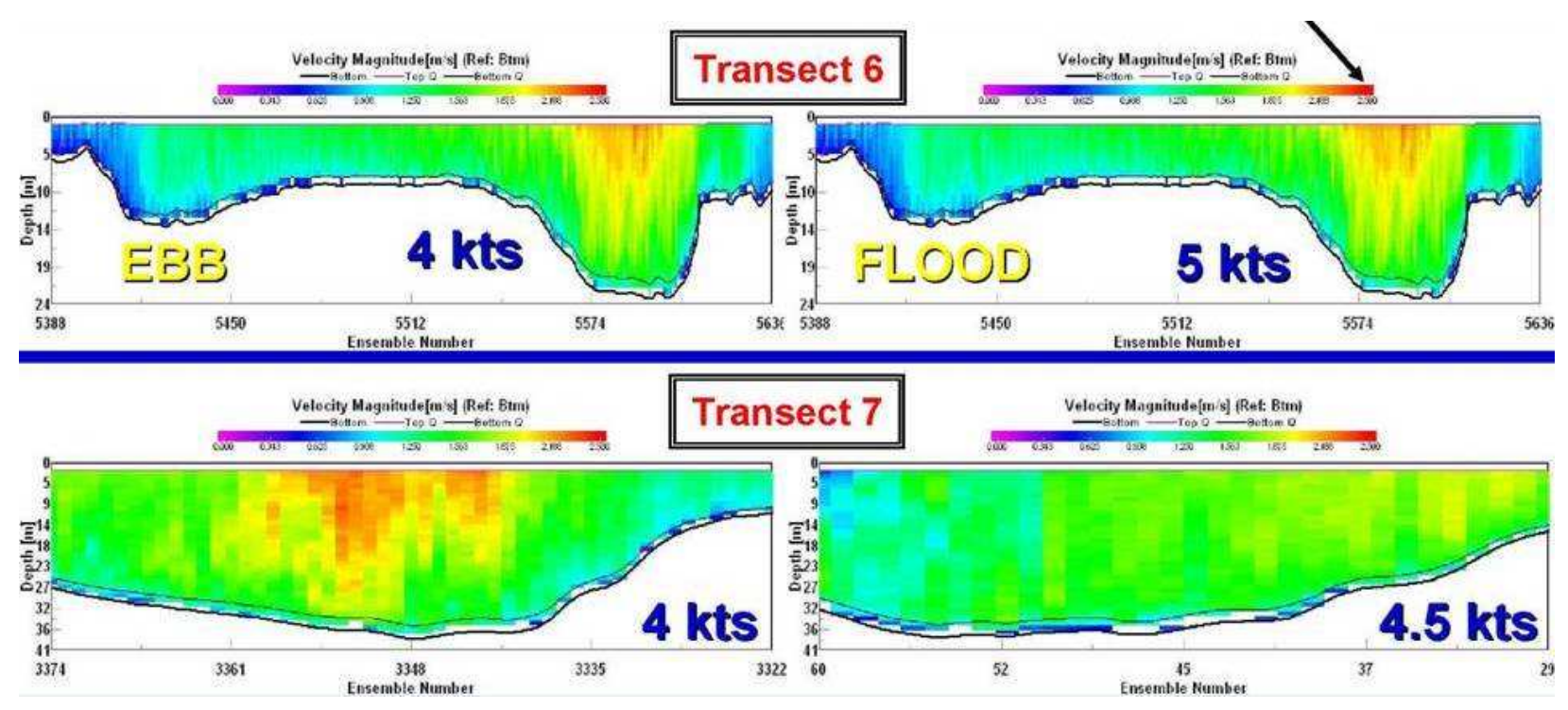

Figure 5: Current Velocities Measured with ADCP along Transects 6 and 7

Supplemental data collection on ocean currents and bathymetry by UMASS SMAST was used by the project team to better understand the environment for both project siting and environmental impact minimization. UMASS directed detailed data collection in the deepest and narrowest reach of Muskeget Channel where preliminary studies funded by the MassCEC identified the strongest currents. The data was used to refine the layout of the $5 \mathrm{MW}$ tidal turbine array to maximize energy production while minimizing impacts on the environment. Bathymetric information generated by the US Geological Survey with assistance from WHOI was used to identify sand wave dynamics in the project area and assess design plans for the turbine anchors and cable placement.

The information collected by the project team was used when meeting with regulatory agencies and interested stakeholder groups to present the elements of the project and potential environmental impacts. Public meetings were convened at the Edgartown Town Hall, with regulatory agencies, at quarterly meetings of the US Coast Guard Safety Group, and at meetings with individual interest groups. The information was incorporated into the FERC Draft Pilot License Application and MEPA EENF to present a comprehensive understanding of the existing environment. Agencies and interest groups provided written public comments on the applications and helped identify additional data collection requirements for licensing the pilot project.

\subsubsection{Supporting the Advancement of the Industry}

The project proposal included as part of the sediment transport study an analysis of changes in sediment transport from two common marine hydrokinetic technologies: horizontal open bladed turbines mounted on monopiles, and horizontal helical turbines that float from moorings. By looking at two designs, Edgartown could generate data to help inform their selection of a preferred design, as well as provide general information that might be useful to the analysis of sediment transport alteration for other project sites. This data will also be useful for other technology and project developers who are utilizing these two common designs.

More generally, all of the environmental studies that have been undertaken with the DOE's support have helped the project advance into the permitting process. These activities have greatly elevated the profile of the project and given it more credibility in the broader public. On the state level, the Muskeget project 
has contributed to marine spatial planning in Massachusetts state waters providing a clearer pathway for pilot tidal projects to obtain statewide environmental approvals. The Massachusetts Department of Environmental Protection, the state agency responsible for issuing wetlands and water permits in coastal waters, has proposed, as part of a regulatory reform initiative, a general permit process for new renewable energy technologies including marine hydrokinetics. In addition, the Massachusetts Clean Energy Center has begun providing funding for technology testing and environmental studies associated with marine energy projects. All of these efforts have been seeded by the grant project summarized in this report.

\subsection{Project Management}

As lead contractor for the project, HMMH was responsible for administering all aspects of the grant requirements including budget management and reporting including the work of our subconsultant team members. We worked closely with each of the project partners to ensure that the individual studies were conducted successfully and on schedule. Toward this end, HMMH convened a kick-off meeting with the team members at the University of Massachusetts Advanced Manufacturing and Technology Center to confirm individual tasks and milestones, and discuss perceived opportunities and obstacles to achieving the project objectives.

HMMH also convened a monthly conference call on the first Wednesday of each month to review project status and discuss any difficulties that have been encountered. Several mechanisms were used to keep DOE staff updated on project progress. HMMH submitted monthly short progress reports with invoices detailing work completed during the previous month. HMMH also completed a quarterly report submitted to DOE staff one month following the end of the quarter. DOE staff also scheduled a quarterly progress conference call to review the written progress report shortly after it was received. 


\section{Oceanography and Coastal Processes}

The University of Massachusetts School of Marine Science and Technology (SMAST) has been implementing a field data collection program to support project siting and environmental impact assessment for the Muskeget Tidal Energy Project. Some of the research provides baseline information to support the sediment transport model analysis prepared jointly by Woods Hole Oceanographic Institution (WHOI) and SMAST, and summarized in Section 3.

SMAST's research and findings are presented in four categories: Hydrodynamics, Bathymetry, Habitat, and Geomorphology of Surficial Sediments. The Bathymetry section also reviews the results of a survey undertaking jointly by WHOI and the US Geological Survey. It is important to note that the dynamic oceanic environment and strong currents of the site presented significant challenges to the research team in most aspects of the data collection program.

\subsection{Hydrodynamics}

In the summers of 2008 and 2009, SMAST conducted hydrodynamic surveys in multiple locations between Martha's Vineyard and Nantucket consistent with the Town of Edgartown's FERC Permit Area. These surveys identified the most promising area for tidal in-stream power generation as the main Muskeget Channel along a north-south axis at depths greater than 50 feet. Current measurements were made using Acoustic Doppler Current Profiling (ADCP) along three transects over a 4.5 mile long area. ADCP surveying was completed during ebbing spring tide conditions to record peak current velocities to establish power generation potential. The surveys recorded maximum current velocity of 5.2 knots meriting additional work on tidal energy at the site.

The objective of the hydrodynamic surveys conducted as part of this project was to better characterize tidal currents over a full lunar cycle, refine the spatial characterization to optimize project siting, and generate baseline data for building the sediment transport model. To achieve this, SMAST developed a hydrodynamic data collection program consisting of four components.

- $\quad$ Time-series tidal stage recording;

- Cross-channel current velocities and flow volumes via ship based ADCP through ebb and flood tidal cycles between previously established Transect 6 and 7;

- Time-series current velocity measurements at a single point at an optimal location in the high velocity zone over a complete lunar cycle using a bottom mounted ADCP; and

- Measurement of near bottom current velocity using a single point current meter attached to a scouring block to quantify effect of a mooring on sediments in the high velocity zone.

\subsubsection{Time-series tidal stage recordings}

Summary:

SMAST made tidal elevation measurements at three locations within Muskeget Channel to determine (1) changes in current velocities relative to tidal stage, and (2) the timing and duration of maximum and minimum velocities relative to tidal elevation changes. By deploying multiple tide gages in the northern and southern portion of Muskeget Channel, it was also possible to identify lags in tide through the Channel. Tide gauges were moored to the sea bottom. Long-term records were adjusted when necessary to reflect NOAA tide gauge datums. The tide records combined with the velocity survey data became critical to the construction of sediment transport models. 


\section{Results:}

Generally, the tide range measured at the northern tide gauge location (Pocha) was larger than the tide range at the southern deployment locations (Mid Channel and Mutton Shoal). The Mid Channel gauge and the Mutton Shoal gauge locations showed a relatively symmetrical tide. As the tides in the Muskeget area are semi-diurnal, the tide gauges also measure the degree to which the two daily tidal cycles (and by association the flow velocity) differed in magnitude. As depicted in Figures 10-12 of Appendix A, it is clear that each location has a distinct high-high tide and a low-high tide each day. Similarly, all three gauge locations exhibit a low-low tide and a high-low tide each day, however, this low tide pattern is most pronounced for the tides measured in the Mid Channel and Mutton Shoal tide gauge locations. Because tide range is generally the prime driver of current velocities through the Channel, this characteristic is significant.

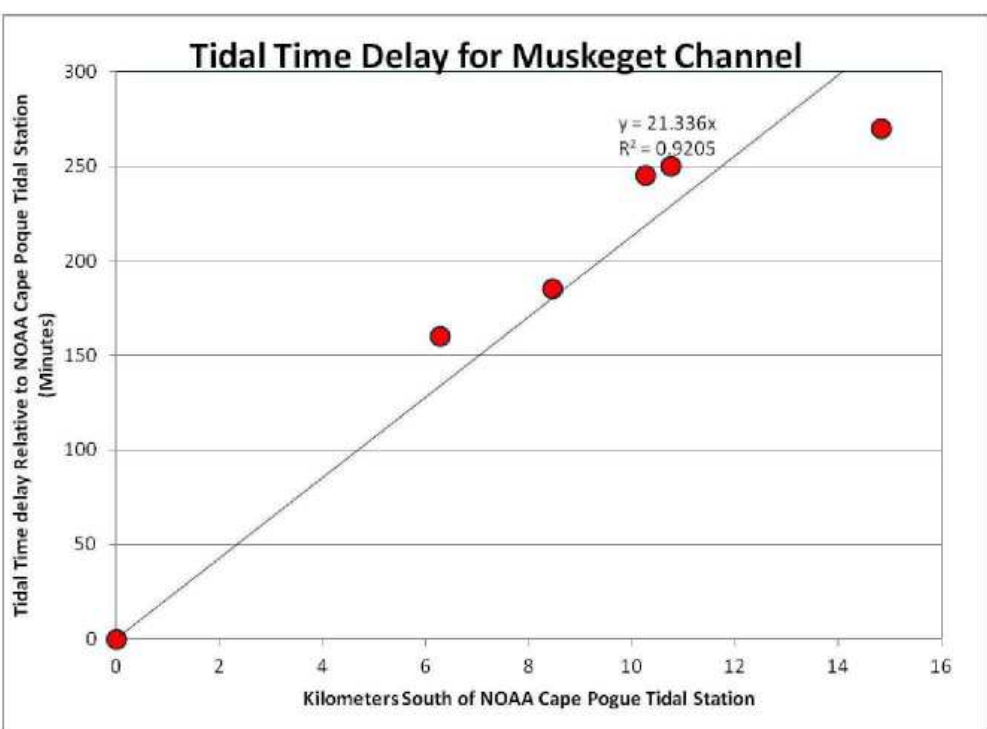

Figure 6: Tidal Elevation Measurements Showing Time Delay Through Muskeget Channel

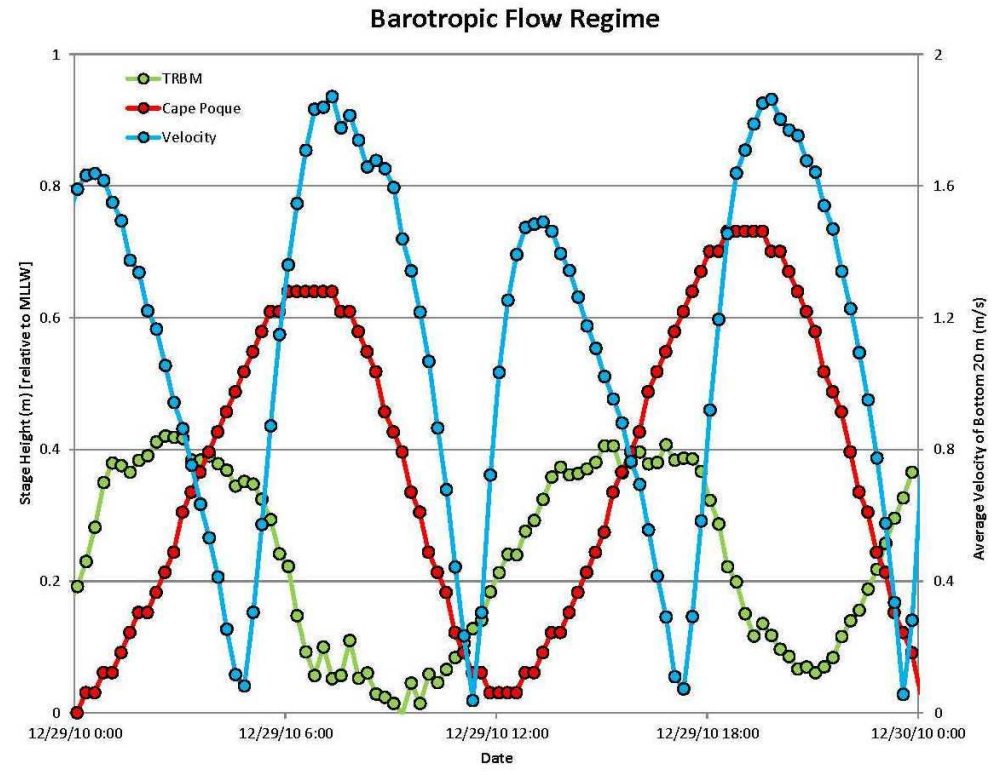

Figure 7: Current Velocity Compared to Tide Elevation at Cape Pogue and Muskeget High Velocity Zone
Tidal data amplitude recorded from the Pocha meter was much larger than from any other meter deployed since 2008. More significantly, there are large asymmetries in the data. Data from the SWATH bathymetric survey and from the single point current meters suggest that an eddy may exist in this region creating flows and tidal signals not typical for the region as a whole. Combining all of the data suggests that intersecting tidal ellipses create significant tidal delays from Muskeget Channel north to the Pocha Light on Chappaquiddick Island (Figure 6). SMAST analyzed this delay by plotting linear distance between the meters versus time of high tide. The results show an estimate of 21 minutes in tide delay per kilometer. This delay in tides is the primary reason for high tidal velocities in the region of Muskeget Channel. Figure 7 shows when tidal stage height was higher at Cape Pogue and the height differential between Cape Pogue and Muskeget Channel was at a maximum, flow was to the south and tidal velocities were greatest. It appears that peak velocities within the channel proper are a result of flow constrained within the narrow channel. 


\subsubsection{Cross-channel current velocities using ship-based ADCP}

\section{Summary:}

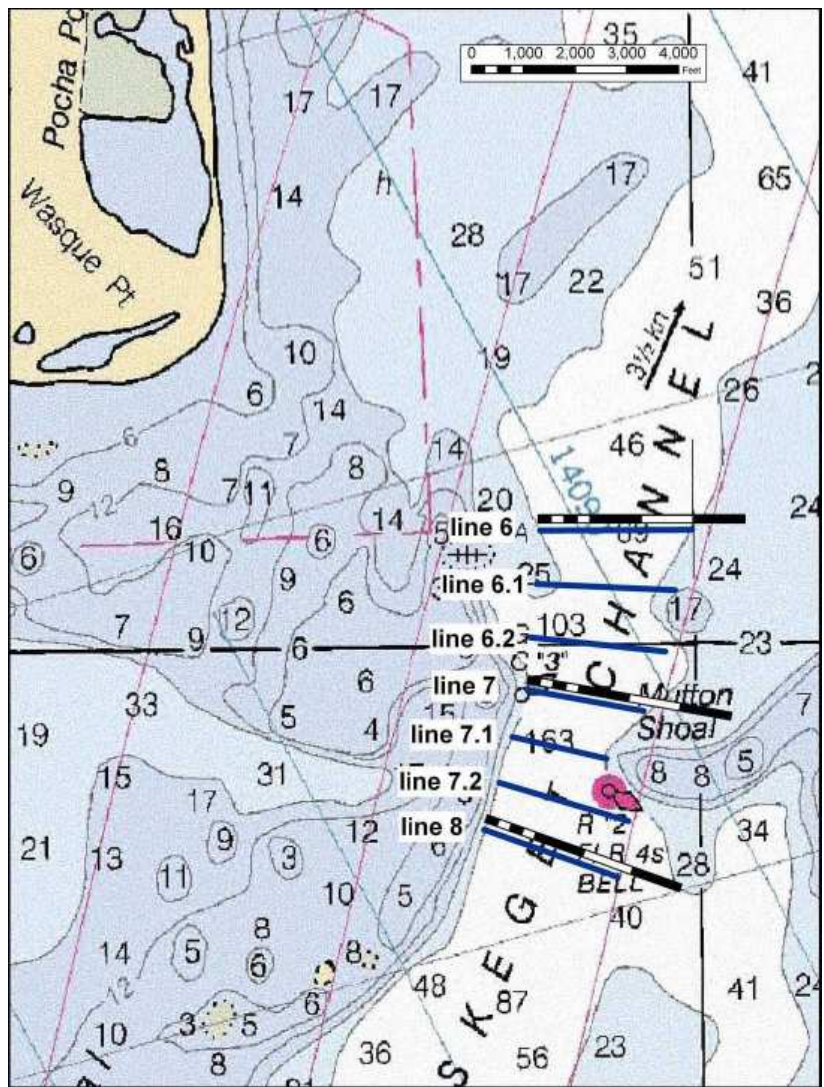

Figure 8: Location of Transects Surveyed with Ship-based ADCP, 2010-11
SMAST completed cross-sectional profiles along multiple transects throughout the Muskeget Channel study area using a ship-mounted ADCP to measure currents and volumetric flow. Seven survey transects were completed through both the ebbing and flooding portions of a tidal cycle (approximately 14 hours in duration) three days preceding a neap phase of the lunar cycle. Previous surveys in 2008-09 were conducted during spring tides. As neap tide produces the smallest tidal range, it was expected that velocities would be the lowest in the lunar cycle. The measurements were made to quantify flow velocities throughout the water column to determine differences in velocity with depth over the tidal cycle. The surveys also provide a finer scale characterization of the currents in the high velocity zone of Muskeget Channel building on previous measurements undertaken in 2008-09 along three main transects referred to as Transect 6 , Transect 7 and Transect 8 . In this effort, Transect 6,7 and 8 were resurveyed, along with new transects in between ( 6.1 and 6.2 located between Transect 6 and 7, and 7.1 and 7.2 between Transect 7 and 8). The location of these transects are shown in Figure 8. The finer scale ADCP surveying data allows the Town of

Edgartown and the UMASS-MREC to refine the demarcation of high energy generation areas to optimize project siting.

\section{$\underline{\text { Results: }}$}

Results for each transect are described below. An example of the velocity mapping for transect 6.2 is provided. Similar graphics illustrating results are provided for each transect in Appendix A.

Transect 6.0: As observed before in 2008-2009, current directions trend north to south during ebb tide and more generally south to north during flood tide. Average maximum water column velocity was 3.25 and 3 knots for ebb and flood tide, respectively. The zone of highest velocity narrowed during flood tides, although the location of highest velocity along the transect was essentially the same. The duration of highest velocity were the same for both the ebb and flood tide spanning at least two monitoring cycles (see Appendix A, Figures 17-20).

Transect 6.1: Current direction showed skewing conformed to the orientation of the channel generally displaying northeast to southwest direction except in the most western portion of the channel where shoaling diverts flow to the southwest during ebb tide. Flood tide direction was south to north. Highest average water column velocities for Muskeget Channel were observed, 3.5 knots on ebb tide and 3 knots on flood tide. The high velocity zone was similarly positioned along the transect during ebb and flood, 
however, unlike the ebb tide, the flood tide channeled significant amount of water onto the shoals. Average water column velocities exceeding 3 knots persisted through two monitoring cycles during the ebb tide, slightly less than 2 knots on the flood tide (see Appendix A, Figures 21-24).

Transect 6.2: Current direction conformed to the orientation of the channel generally displaying northeast to southwest direction during ebb tide, except on the channel margins where constriction of flow produced by the adjacent shoals results in currents directed to the center of the channel. In contrast current direction while generally south to north during the flood tide diverged at the margins. Peak average water column velocities were 3 knots on ebb tide and 2 knots on flood tide (see Figure 9). The high velocity zone was similarly positioned along the transect during ebb and flood; however flood tides did not display discrete high velocity zones. Average water column velocities exceeding 3 knots persisted through two monitoring cycles during the ebb tide, slightly less than 2 knots on the flood tide (see Appendix A, Figures 25-28).

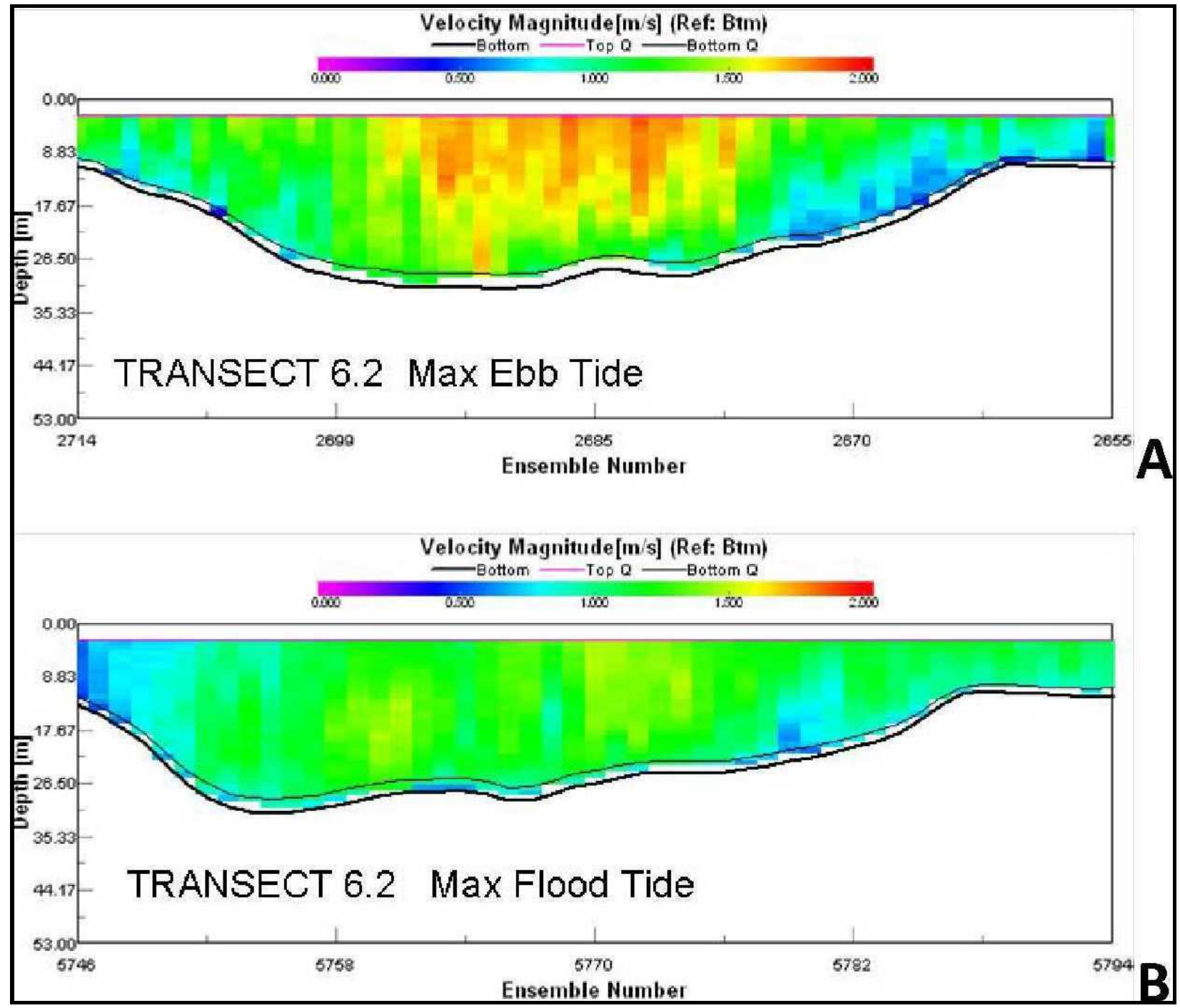

Figure 9: Current Velocity Measured at Max Ebb and Flood for Neap Tide at Transect 6.2 
Transect 7.0: Current direction was essentially along a north-south axis across the entire transect during both ebb and flood tide. Peak average water column velocities were 3.5 knots on ebb tide and 2.75 knots on flood tide. The high velocity zone shifted to the east during flood tide relative to ebb tide and became very diffuse with no defined high velocity zone. Average water column velocities exceeding 3 knots persisted through two monitoring cycles during the ebb tide, slightly less than 2 knots on the flood tide (see Appendix A, Figures 29-32).

Transect 7.1: Current direction was generally along a north south axis during both ebb and flood tides. The channel begins to widen at this transect and become symmetrical. Peak average water column velocities decrease slightly to 3.25 and 2.25 knots on the ebb and flood tides, respectively. The high velocity zone shifted slightly east on the flood tide compared to the ebb tide, but the flood velocity was fairly uniform across most of the transect. Time scales of peak velocity were similar to those seen at Transect 7 (see Appendix A, Figures 33-36).

Transect 7.2: Current direction followed a north-south axis during ebb and flood tides. The channel continues to widen, but significant shoaling on the east side of the transect created asymmetries in the location of the peak velocity zone which was centered in the transect during ebb tide and was pushed eastward during flood tide. Peak average water column velocities continued to decrease; 3 knots was observed on the ebb and 2 knots was observed on the flood. Time scales of peak velocity remained unchanged from Transect 7.1 with two monitoring cycles at peak velocities (see Appendix A, Figures 37 40).

Transect 8.0: Current direction was essentially along a north-south axis across the entire transect during both ebb and flood tide except in the shallowest regions on the eastern end of the transect during ebb tide. Peak average water column velocities were 3 knots on ebb tide and 2 knots on flood tide. The high velocity zone shifted to the east during flood tide relative to ebb tide and became very diffuse with no defined high velocity zone. Average peak water column velocities persisted through two monitoring cycles during the ebb and flood tides (see Appendix A, Figures 41-44).

The high resolution tidal velocity survey confirmed many of the results of the 2008-2009 survey. The area bounded by Transect 6 and Transect 8 represent the area of highest sustained velocities. The current work narrows that zone slightly to include only that area bounded by Transect 6.1-7.2. Unlike the 2008-2009 study which was conducted at peak spring tide, this study was conducted near neap tide conditions and as a result showed current velocities approximately 20-30\% lower than spring tide. While flood tides did not display obvious zones of higher velocity, highest velocities along the transects were usually coincident with the well-defined ebb tide high velocity zone. Furthermore, although the tide direction was noticeably different between the transects, there did not appear to be significant differences between ebb and flood tide direction. Together these results suggest that turbines could capture the maximum current energy available regardless of the tide direction. 


\subsubsection{Time series current velocity measurements at a single point}

\section{Summary:}

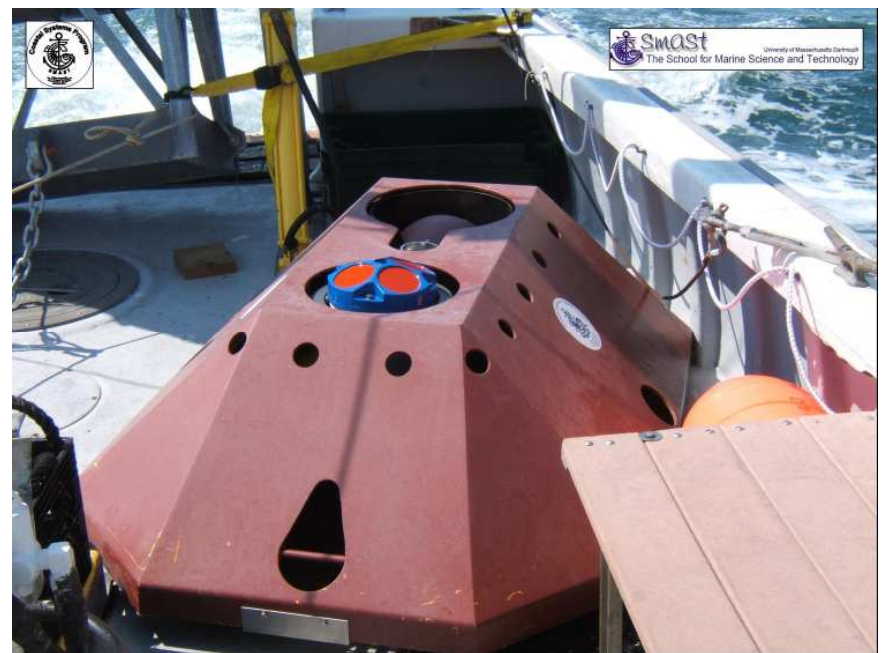

Figure 10: Bottom Mounted Upward Looking ADCP
In conjunction with the ship-based ADCP surveying program, SMAST deployed a bottom mounted upward looking ADCP in a trawl resistant bottom mount (see Figure 10). The bottom-mounted ADCP collected near continuous current measurements through the entire water column at a single point strategically located between Transects 6 and 7 which showed the highest current velocities.

The ADCP instrument was deployed for a complete lunar cycle (November 22, 2010 to January 6,2011 ) to characterize variations in the velocity field as a function of changing phases of the moon while also serving as a validation of velocity measurements obtained during the ship board ADCP surveying

undertaken through that high velocity zone. The overall objective of this deployment was to capture a detailed time series of current velocities which could be used to calculate the average, maximum and minimum current velocities on any given day of the month. In this manner, the full range of current velocities could be determined from maximum currents during spring tide conditions to minimum current velocities that occur under neap tide conditions as well as at lunar quadrature. Using the data collected during the entire lunar cycle, a better understanding was obtained regarding how the current intensity fluctuates over a month. This data enhance the accuracy of forecasting power generation.

\section{$\underline{\text { Results: }}$}

The bottom mounted ADCP data collection record was mostly complete with occasional gaps resulting from sand wave movement over the bottom mount and by turbulence that prevented reconciliation of the 4 beam data (Figure 11). Current directions were consistently north-south. As expected, periodic variations in velocity were seen with respect to diurnal tides and lunar cycles. Subsets of the entire deployment are shown in Appendix A, Figures 50-53, including the time series velocity magnitude during the period that the shipboard ADCP transects were being measured, and the velocity magnitudes recorded for neap, quadrature, and spring tides, respectively. December 10 velocities were among the lowest observed exceeding $1.6 \mathrm{~m} / \mathrm{s}$ in the surface waters only during ebb tides. These results are consistent with those collected during the transect measurements.

The neap tide velocities were expected to be the lowest recorded, however the velocity magnitudes during one ebb tide were significantly higher. Wind forcing of

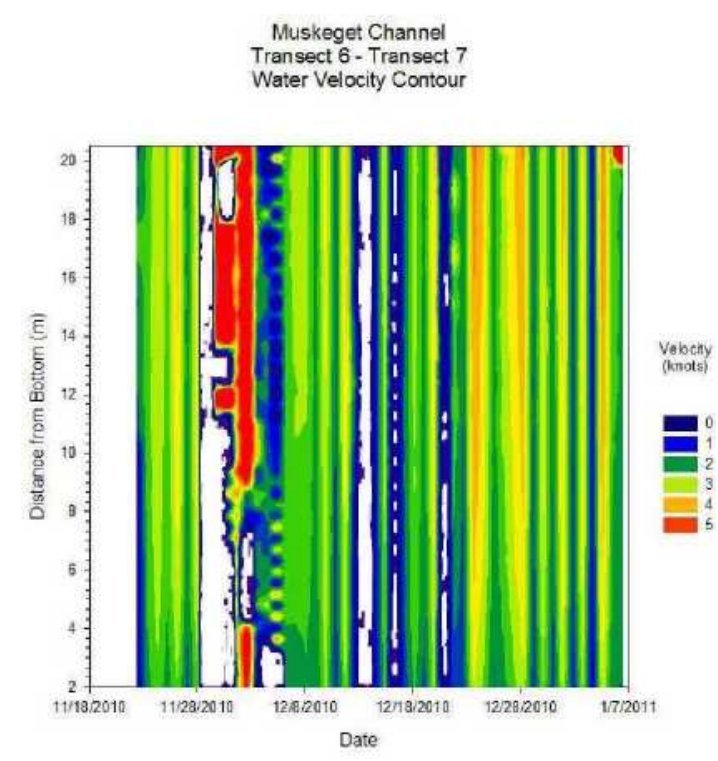

Figure 11: Current Velocity at Depth Measured by the Bottom Mounted ADCP Between Transects 6 and 7 
water through the channel is believed to account for this behavior with support provided by the truncated flood tide and extended slack tide immediately prior. Diurnal asymmetries in the ebb and flood tide velocities were small with a difference of $15-20 \%(1.8 \mathrm{~m} / \mathrm{s}$ vs. $2.2 \mathrm{~m} / \mathrm{s})$. Similar differences were observed between successive flood tides. Under quadrature conditions, velocity magnitudes were similar, but slack tide intervals were symmetric as compared to neap tide conditions. The main difference was in the depth to which the maximum velocity zone extends from the surface down into the water column. Although the maximum velocities were similar, the average velocity for the water column increased as the surface high velocity zone extended further down in the water column.

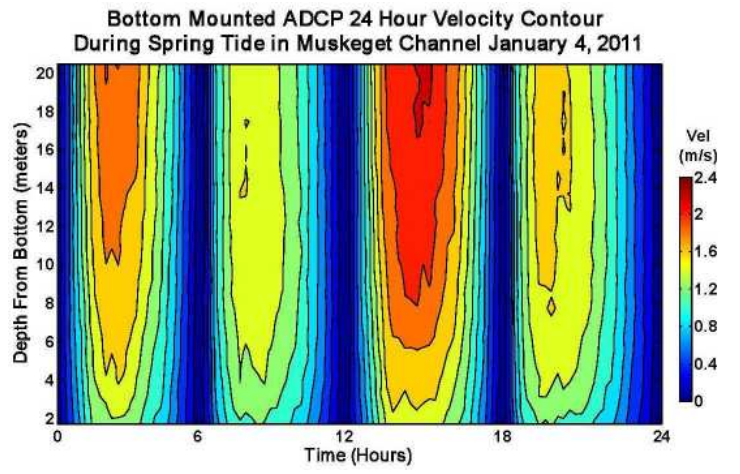

Figure 12: Current Velocity at Depth Measured by the Bottom Mounted ADCP for One 24 Hour Period
Spring tide conditions presented in Figure 12) demonstrated similar velocities and symmetry as quadrature conditions with a further increase in depth of the high velocity zone extending down from the surface. Thus maximum velocities recorded were similar throughout the lunar cycle, yet mean water column velocity increased from neap to spring tides by involving a greater portion of the total water column. While the vertical differences in velocity magnitude may create challenges for some turbine designs, the upper velocity threshold remains relatively constant simplifying the engineering required to meet maximum velocities

\subsubsection{Measurement of Near Bottom Current Velocity and Implications for Scour}

\section{Summary:}

Particularly in high velocity areas, the placement of hard structures on or into the bottom alters sediment transport potentially resulting in new scour and deposition zones. Alteration of sediment deposition and erosion is an important consideration for marine renewable energy structures for engineering and design purposes and in understanding potential habitat impacts. Habitat change primarily results from either enhanced erosion (removal) or changes the sediment grain size distribution. This study looked at changes in sediment using a combination of sediment transport modeling (macro scale) and field manipulations (micro scale) methods. The sediment transport modeling is discussed in Section 3. Site specific field manipulations to measure near bottom current velocities and associated scour around a mooring structure are described below.

SMAST conducted a sediment scour investigation using a large concrete cylinder to represent footing for a larger mooring system for a tidal turbine (see Figure 13). The cylinder measured approximately 3.5 feet in diameter and 3.5 feet high, and weighed 1,404lbs. The cylinder was placed on the sea bottom in the high velocity zone of Muskeget Channel and changes in bottom morphology and sediment gran size in the immediate vicinity of the scouring block were documented. For a 40 day period (March 15 - April 23, 2010), the scouring block was instrumented with two acoustic doppler current meters on opposing sides of the cylinder allowing for the acquisition of current measurements on the up and down gradient sides of the scouring block. Both ADCP instruments were aligned in the downward position facing the sediment surface. The collected current velocities were related to the observed scouring patterns associated with the ebb and flood tide conditions which generally are known to have differing current intensities (i.e., ebb tide generally having stronger current velocities then flood tide). Prior to deployment, the side of the concrete cylinder was marked at 6 inch intervals in order to measure the degree to which sediment accrete or erode away from the base of the structure as the tide shifts direction through a tidal cycle. 


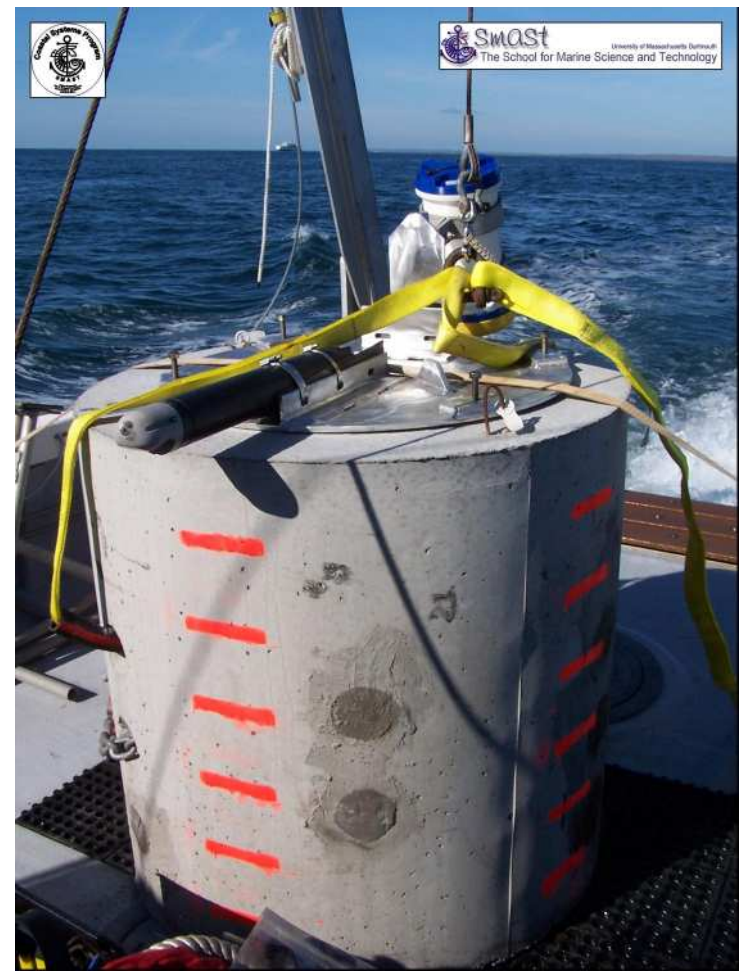

Figure 13: Concrete Cylinder Equipped with Current Probes to Measure Velocity and Scour
The concrete cylinder was deployed from the research vessel using a winch and A-frame and was guided to the bottom by diver so that the cylinder was deployed in a level and upright position. To insure that the instruments would be properly aligned along the northsouth axis of the channel and into the current, a mounting plate was constructed allowing the diver to orientate the instruments once the cylinder was positioned on the sea bed. Additionally, at the time the concrete cylinder was initially deployed, the diver retrieved one sediment

grab from approximately 10 meters distant from the side of the cylinder as well as three cores from adjacent to the cylinder. The grab obtained 10 meters distant from the cylinder served as a control sample representative of natural benthic conditions while the three sediment cores adjacent the concrete cylinder were obtained for grain size analysis prior to any scouring effects. 40-days post deployment, the cylinder was re-visited and a diver descended to the bottom to remove the instruments for data download. During instrumental retrieval, the diver was also able to obtain a second grab sample from 10 meters distant from the side of the cylinder. Additionally, the diver was able to

obtain visual documentation of the scouring and settling that had occurred around the base of the cylinder over the course of the 40 day deployment. Unfortunately, the current started increasing to the point that the diver could not retrieve a second set of sediment cores from immediately adjacent to the cylinder in order to perform a post scour grain size analysis. As such, SMAST scientists qualitatively estimated the sediment characteristics from the underwater photographs obtained prior to removing the instruments. A second attempt to collect post-scouring sediment samples during deployment of the bio-fouling array was unsuccessful because the array deployment took longer than expected and the current became too strong requiring that the dive be aborted before sediment samples could be retrieved. On a third attempt (August 2011), the cylinder could not be located because the surface expressions had been compromised and it was deemed unsafe to conduct a free descent in strong current.

\section{Results:}

Two different acoustic instruments were utilized to quantify the current velocities around the base of the concrete cylinder which were associated with the observed level of scour. Pressure data obtained from the Aquadopp Profiler indicated that excessive scour around the cylinder caused the cylinder to sink into the sand until it reached on a more stable cobble layer. Pitch and roll data illustrated in Figure 14 shows that after the first 48 hours following deployment, the cylinder reached a stable substrate and did not move for the duration of the 40 day deployment. The plot of acoustic backscatter signal strength provided as Figure 15 confirms this finding (the bottom position marked

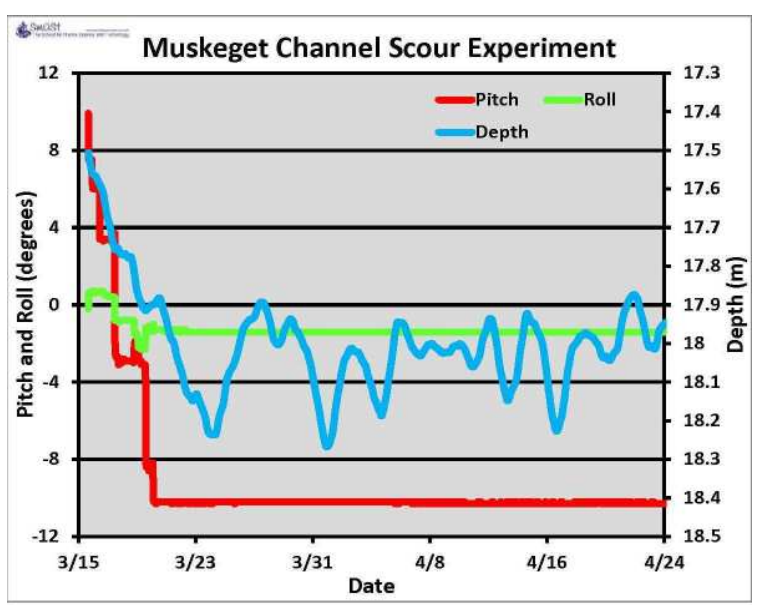

Figure 14: Pitch and Roll Data Showing Movement of Cylinder as a Result of Scour 
by dashed black line). Material moves around the cylinder and is deposited on the lee side of the cylinder during each tidal cycle. This barchan-type sand structure deposit varied in height between 0.2 and 0.6 meters. The height, and thus the quantity of material roughly changes between spring and neap tides, but displays a lag of 24-36 hours. Data obtained from the ADCP on the reverse side of the cylinder is similar though opposite in phase.

Visual inspection of the cylinder indicates that the area influenced by the cylinder does not exceed a radius of two cylinder diameters in line with the current and less than one cylinder diameter normal to the current direction.

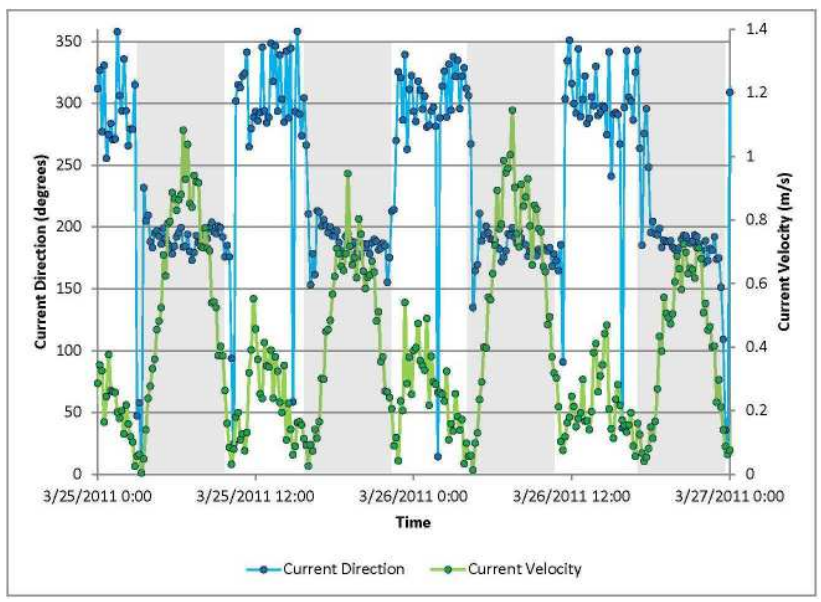

Figure 16: Time Series Plot Comparing Current Direction and Current Velocity Measured at the North Side of the Cylinder

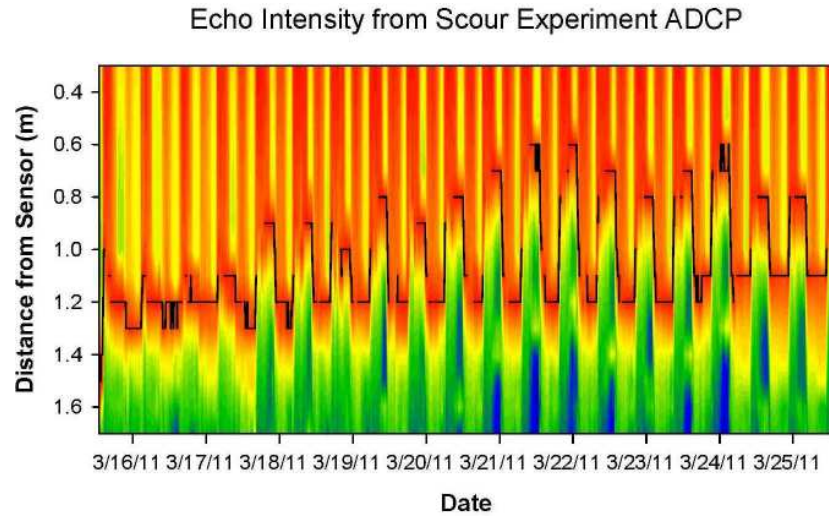

Figure 15: Measurement of Sediment Accretion and Erosion on North Side of Concrete Cylinder

Time series measurements show the gross influence of the cylinder on near bottom current velocities. The velocity measurements unaffected by the cylinder are significantly greater than those in the lee of the cylinder (Figure 16). The plot shows results facing north in the ebb tide direction. Average ebb tide velocity (0.3-1.0 $\mathrm{m}$ from the sensor head) for March 25-27 was $0.7 \mathrm{~m} / \mathrm{s}$ and flood tide velocity resulting from interference with the cylinder was $0.3 \mathrm{~m} / \mathrm{s}$. In profile, the velocity vectors show relatively unimpacted flow over the cylinder from 0.3 to $0.6 \mathrm{~m}$; below $0.6 \mathrm{~m}$, velocity magnitude was similar, however, the direction was often reversed indicating significant eddies which created the sediment structures observed during recovery.

Photographed observation of scouring made by diver at the time the current profilers were retrieved from the cylinder confirmed the current velocity measurements. As suggested by the data (acoustic backscatter, pitch and roll, and depth data) which showed the cylinder reaching an equilibrium depth, the cylinder was observed to be resting on a relatively stable gravel sediment mixed with cobbles. Based on the current flow (ebb vs. flood) around the base of the cylinder, the diver observed medium to coarse sand and gravel scouring away from the down gradient side and accreting on the up gradient side of the cylinder (Figure 17). Finer sand sediments observed when the cylinder was first lowered to the sea bed had been scoured away from the base of the cylinder allowing it to settle to the gravel and cobble layer. Observations suggest a very dynamic sedimentary environment whereby mooring structures associated with deployed tidal devices would be subject to a

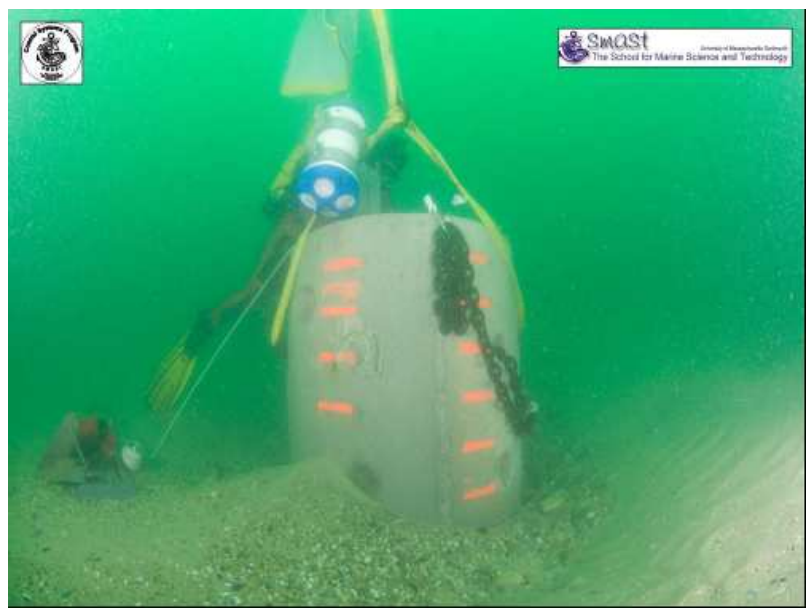

Figure 17: Diver Working Around Cylinder with View of Sea Bed 
constant cycle of sediment scour and accretion on a diurnal basis. While these scouring effects would be very localized, it would have an effect on benthic organisms. Though more detailed studies is necessary, it is important to note that this high velocity zone of Muskeget Channel appears to have very limited benthic infauna and epi-fauna and has very similar physical and sedimentary characteristics as the dynamic inlets of regional estuaries such as Chatham Harbor, Pleasant Bay, and Plymouth Harbor (all of which have very low documented benthic communities).

Sediment grain size distribution measured adjacent to the scour cylinder during deployment was typical of the sand waves which are endemic in the region of Muskeget Channel. Grain sizes are skewed towards the coarser material. Approximately 80 percent of the sediment was greater than $1 \phi$, and the grain size distribution was consistent throughout the top $20 \mathrm{~cm}$. This depth corresponds to the change in the cylinder depth observed during the first 48 hours after deployment. As seen in Figure 14, sand waves at the time of recovery moved around the cylinder, and scouring exposed the underlying gravel and cobbles. Future work being planned for the summer 2012 field season is going to focus on the depth and spatial extent of the cobble layer using sub-surface profiling technology.

\subsection{Bathymetric Surveys}

The basis for existing bathymetry in Muskeget Channel is limited to 80 year old data. Developing a comprehensive understanding of the channel bathymetry is fundamental to refining siting for the $5 \mathrm{MW}$ pilot tidal energy project as well as understanding sediment dynamics. In addition, detailed survey can provide information on the dynamic nature of large scale bedforms. Two separate but complementing bathymetric survey efforts were undertaking by SMAST and WHOI/USGS. Each is described below.

\subsubsection{SMAST Bathymetric Surveys}

\section{Summary:}

SMAST conducted preliminary bathymetric survey work in connection with its ADCP measurements in summer of 2008, which showed significant sand movement and shoaling within portions of Muskeget Channel. A detailed bathymetric survey was undertaken within the high velocity zone of Muskeget Channel under the present study to (a) confirm the available depth soundings in the NOAA nautical chart of the area, (b) determine changes in the slopes and stability of the deep portion of the main channel and (c) develop a more detailed bathymetric map than presently available. The survey data were also provided to WHOI as part of developing the sediment transport model (see Section 3).

Building on previous survey efforts, UMASS-SMAST conducted additional bathymetric surveying of the critical main channel portion of the Muskeget Channel using a single beam acoustic depth profiler to support the ADCP, tide elevation, and current measurements. Survey lines were run at 50-100 m intervals, with continuous recording of depth $(0.1 \mathrm{ft})$ and location (d-GPS). The data was corrected for the specific changes in tidal elevation occurring over each survey day. The survey area focused on the high velocity zone in the narrowest segment of the channel and in an area to the north that was not covered in 2008-09 for the benefit of the sediment transport model.

\section{Results:}

The area of enhanced survey is shown in Figure 15. The results of the bathymetric survey are shown in Figure 16. 


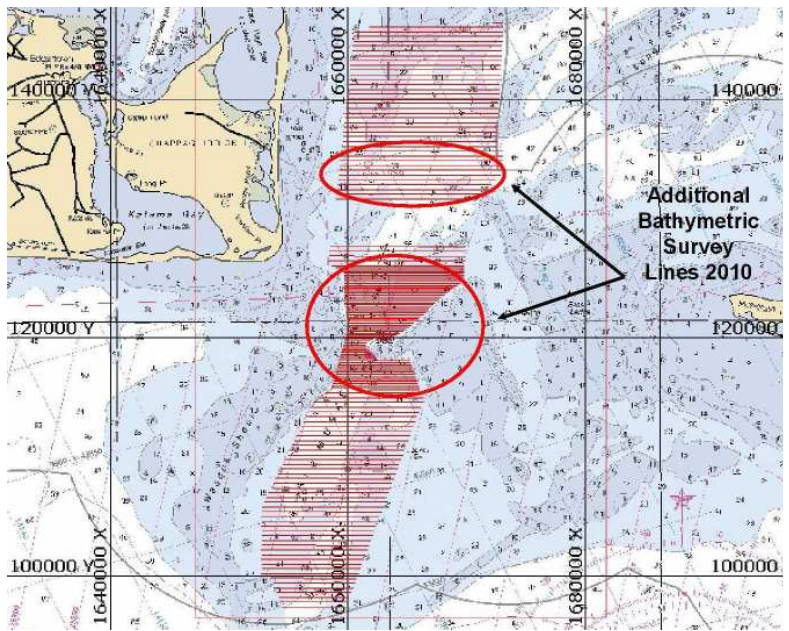

Figure 18: Area of Enhanced Bathymetric Surveys

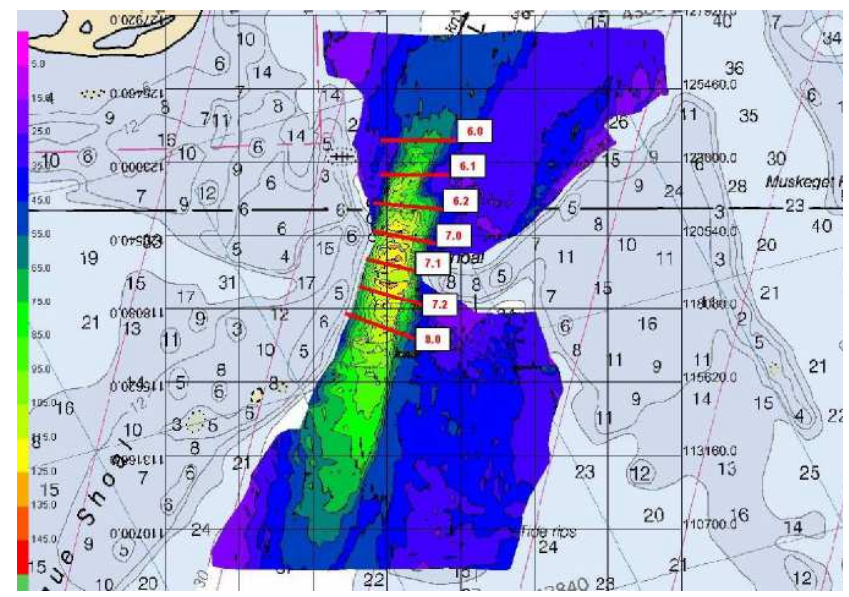

Figure 19: Water Depths Measured By Bathymetric Surveys

\subsubsection{WHOI/USGS SWATH Bathy Surveys}

\section{Summary:}

A high resolution bathymetric survey of Muskeget Channel and surroundings was completed by WHOI and the US Geological Survey in fall of 2010 (Denny et al., 2012). The survey was conducted using an interferometric sonar unit which can measure bathymetry along a swath on either side of the ship track with a width of roughly seven times the water depth. The goals of the survey were to obtain a baseline high resolution bathymetry dataset for Muskeget Channel, characterize the large scale bedforms in the Channel surroundings, and characterize the bedforms in the vicinity of the two potential cable routes by which the installation would be connected with Martha's Vineyard.

The first survey was conducted from 10/12/2010-10/14/2010. The survey included the main channel, a region containing large sand waves to the south of the channel, and two sections along the eastern and southern shores of Martha's Vineyard in the vicinity of the two proposed cable connections (Figure 17). The second survey was completed in a single day on 11/16/2010. Due to survey constraints, only the areas containing large sand waves and the two cable route transects were re-surveyed. The resulting data provides a monthly snapshot at these three locations. A DGPS-RTK was used for navigation and to adjust for tides. The data was projected to the local state plane, gridded at 1-m resolution, and is available for download or access through opendap capable software on a USGS Thredds server. 


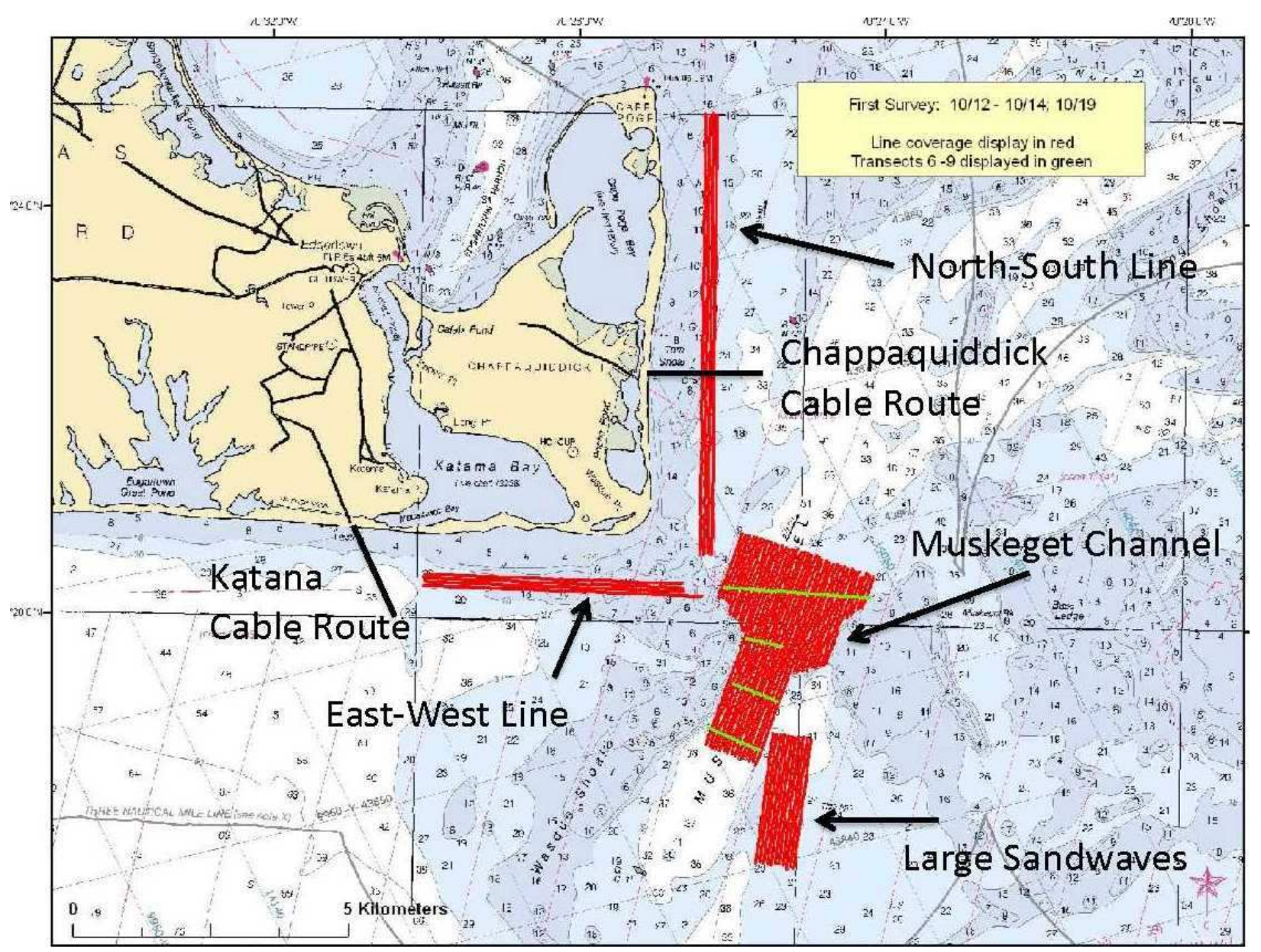

Results:

Figure 20: Areas Surveyed by WHOI and USGS Using SWATH Bathy Method

An image showing the product of the SWATH Bathy surveys conducted in the area where tidal turbines are proposed is provided in Figures 18 below. Analysis of the sand wave dynamics associated with the SWATH Bathy data is presented in Section 3. 

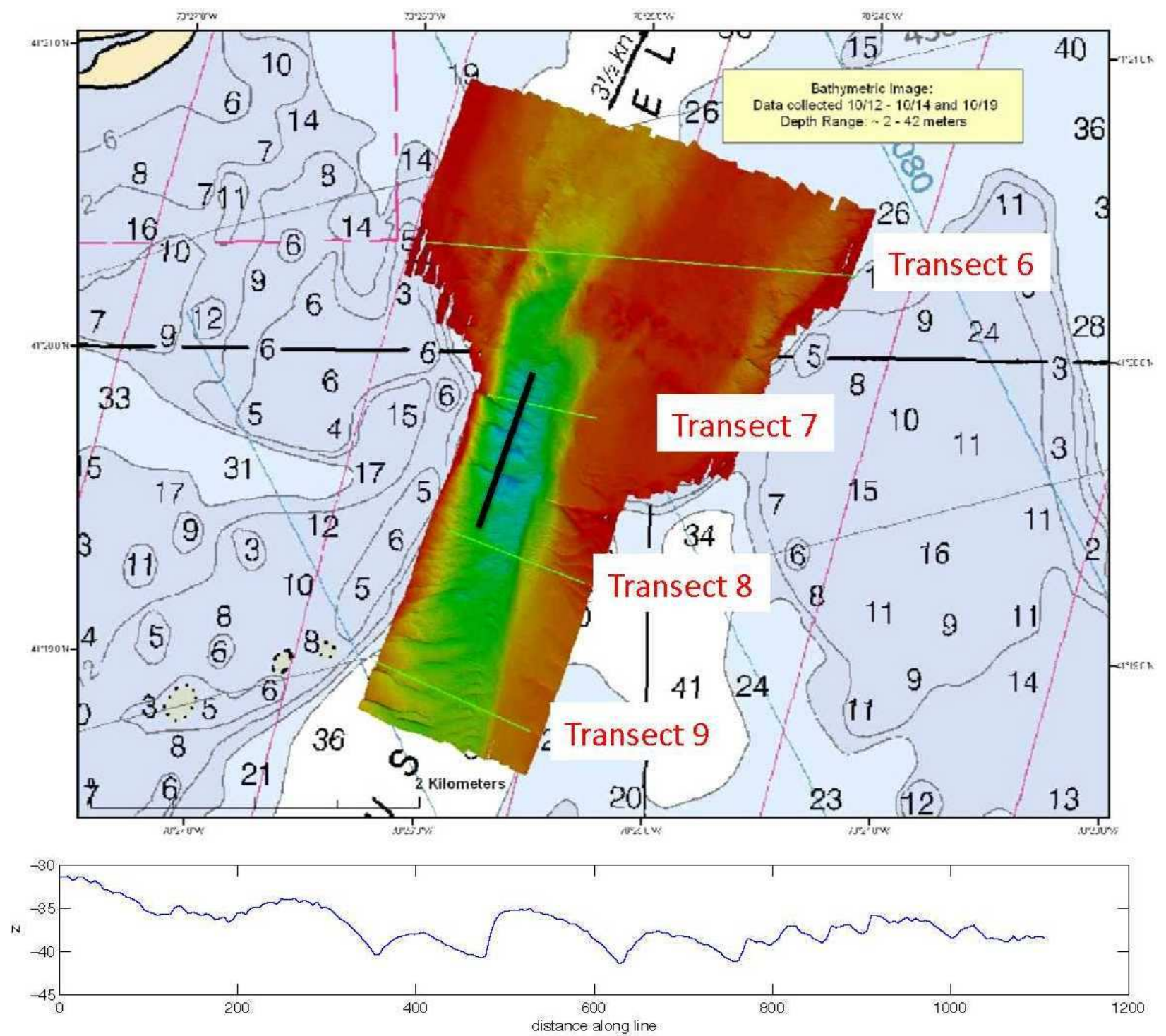

\subsection{Habitat}

Figure 21: SWATH Bathy Product for Muskeget Channel Project Area

Tidal turbines provide hard structures, such as mooring blocks, cables or piles, for attaching organisms to colonize. This colonization of the turbines produces both environmental and operational effects that must be considered. From an environmental perspective, changes in habitat associated with biofouled structures are viewed in relation to surrounding natural habitats. If natural hard bottom or exposed rock exists in the near-field of the installation, then "biofouling" of the turbine structures may be viewed as enhancing the existing habitat. If the locale does not presently support these types of natural communities, then the introduction of new communities and their positive/negative effects on the marine system needs to be evaluated. From an operational perspective, biofouling of marine turbines are likely to have negative consequences on turbine efficiency and, therefore, operators will want to minimize biofouling rates. To address these issues, SMAST proposed two efforts: 
- Determine likely fouling communities to develop on turbine structures using controlled fouling plates (treated and untreated) deployed in the high velocity zone of Muskeget Channel and determine associated fouling rates, and

- Survey area in the near field to the biofouling arrays in order to identify existing hard surface communities.

\subsubsection{Biofouling experiment}

\section{Summary:}

To determine the likely fouling communities to develop on turbine components, SMAST scientists deployed two sets of biofouling arrays using treated and untreated fouling plates made of composite

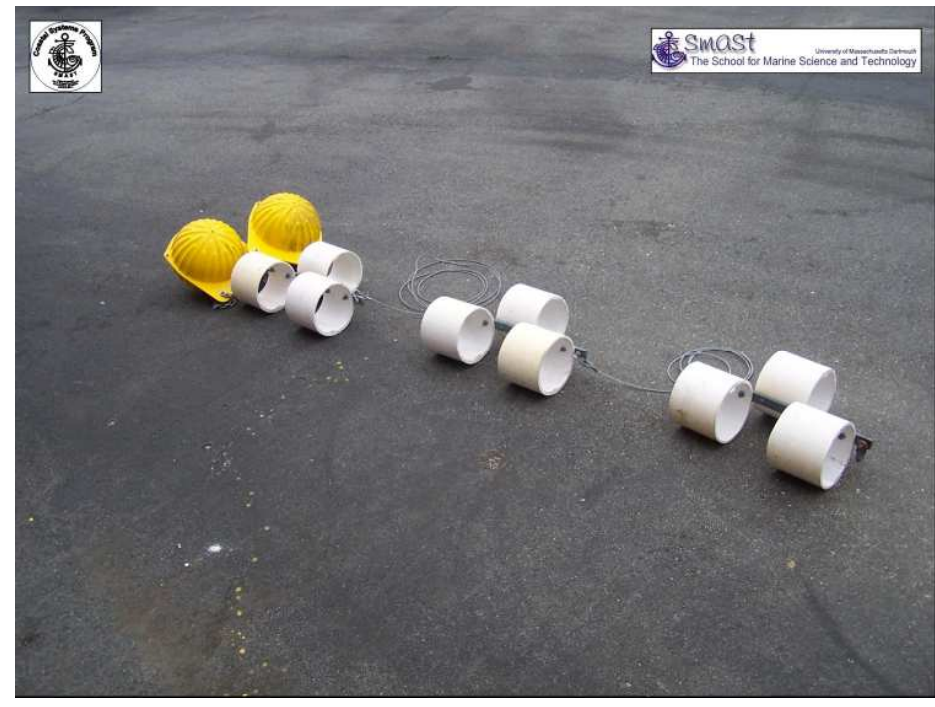

Figure 22: One of the Biofouling Arrays Prior to Deployment materials similar to that utilized for building the OCGen tidal turbine developed by Ocean Renewable Power Company. The arrays were deployed specifically to determine the resulting animal and plant community that become established as well as the rate of fouling. The biofouling arrays were deployed in the high velocity zone of Muskeget Channel being considered for future tidal current energy generation. A photograph of one of the arrays prior to deployment is shown on Figure 19.

Composite material was obtained from Harbor Technologies LLC and fastened to a cable at varying segments to assess biofouling potential at different water depths. The cable included a bottom mooring at one end to hold the cable down and a combination of

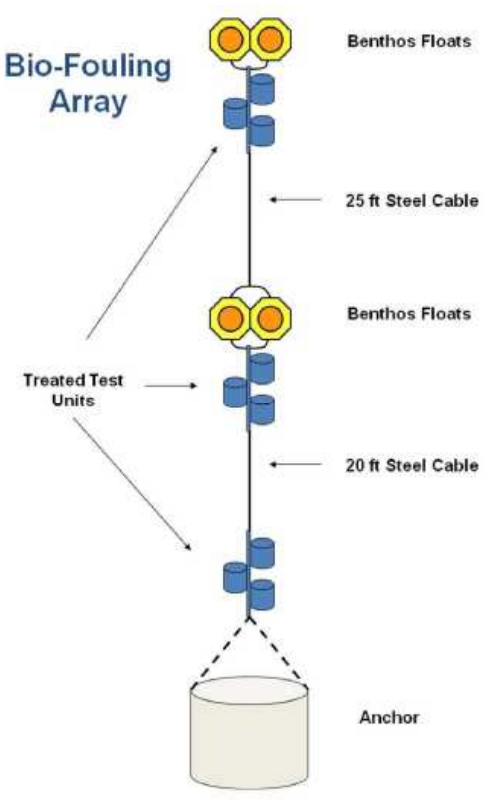

Figure 23: Schematic of the Biofouling Array Design sub-surface floats (benthos balls) and surface expressions (highflyers and hi-visibility low drag buoys) to pull the cable taught. One array of fouling plates was comprised of composite material treated with a commonly used anti-fouling paint (West Marine Bottom Shield, 28\% Cuprous Oxide) while the second array was comprised of bare composite material to act as a control experiment.

Treated and untreated fouling plate units were located at three different water depths along the cable: the proposed depth of the generators ( $\sim 30$ feet from surface), near the sediment surface, and at a mid-depth between the two. The mid depth sample corresponded approximately to the limit of the "photic zone" below the depth proposed for the generators. Each array was constructed with three units consisting of three fouling plates at each depth to allow for replication and time series "harvesting" to asses fouling rates. Figure 20 is a schematic of one of the arrays.

To prevent influence between the arrays, the units were deployed approximately 250 meters from each other within the high velocity zone of Muskeget Channel. The treated array was deployed at a 
depth of approximately 95-100 feet while the untreated array was deployed at a depth of approximately 85-90 feet. The untreated array was deployed on July 11, 2011 and the treated biofouling array was deployed on July 12, 2011.

\section{$\underline{\text { Results: }}$}

To examine the conditions that the test arrays would encounter with the varying current velocities, mooring design simulations were performed using a MatLab based program. Array design, environmental variables, as well as drag and current components were accounted for during the simulations. The minimum (slack tide or $0 \mathrm{~m} / \mathrm{s})$, maximum $(2.0 \mathrm{~m} / \mathrm{s})$ and average $(1.6 \mathrm{~m} / \mathrm{s})$ current velocity variables used in the simulations were based on velocity data acquired from the previously deployed bottom mounted ADCP. As expected, results indicated that the arrays would remain vertical in the water column at slack tides (Figure 21). With the average current velocity $(1.0 \mathrm{~m} / \mathrm{s})$, results demonstrated a shift in the array's vertical position but remained within the desired depth zone(s) within an acceptable range (Figure 22). Under maximum current velocities observed in the high velocity zone of Muskeget Channel $(2.0-2.5 \mathrm{~m} / \mathrm{s})$, the bio-fouling arrays would be positioned approximately 20 feet off the bottom. The test array deployed represents a compromise between all of the various factors. Mooring weight was kept under 1 ton, and the fouling plates were kept within 5 meters of the ideal depth at least $75 \%$ of the time.

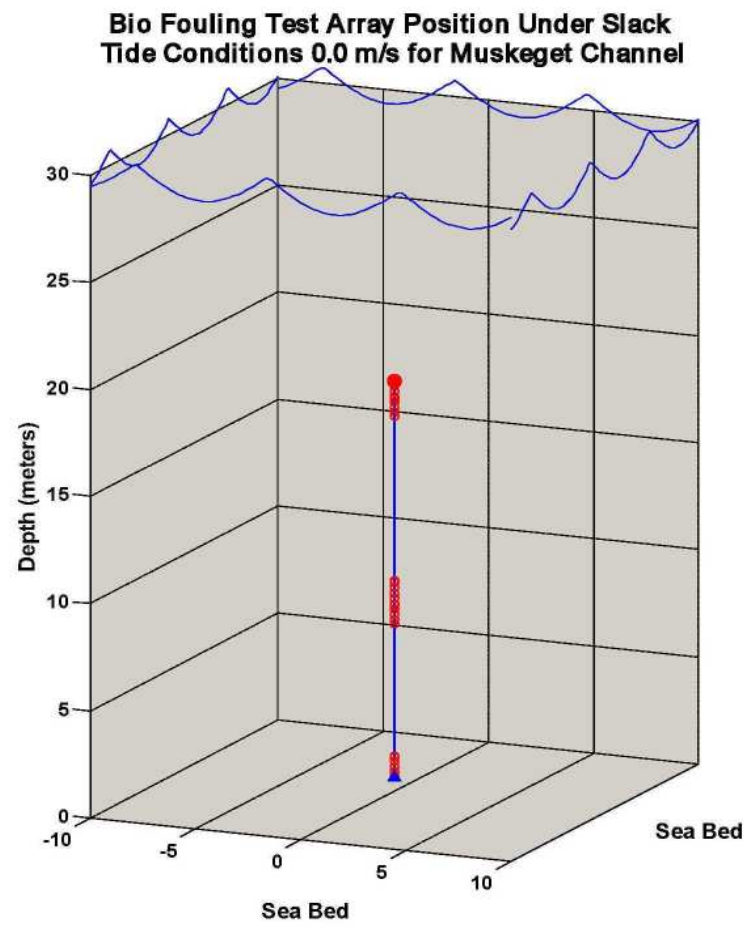

Figure 24: Modeled Position of Biofouling Array at Slack Tide

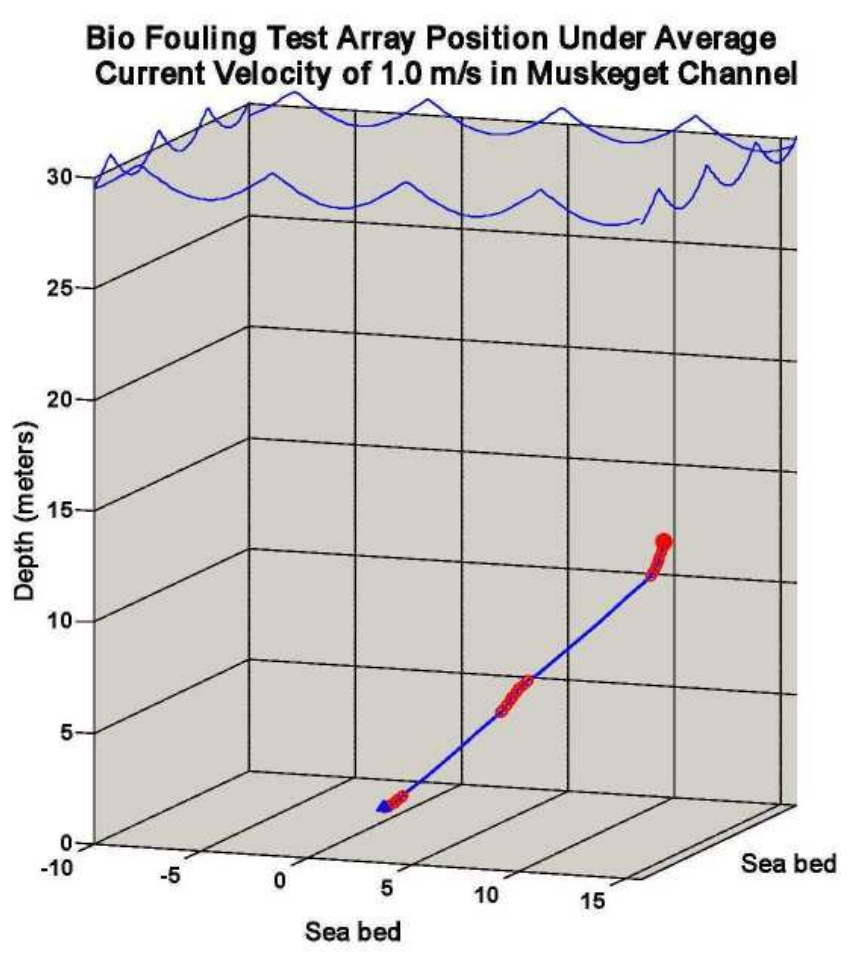

Figure 25: Modeled Position of Biofouling Array at $1.0 \mathrm{~m} / \mathrm{s}$

Forty-five days after deployment (mid-August) the first fouling time point collection was attempted. The short slack tide window and the loss of any surface expression on the array's prevented retrieval. The first "harvest" trip was aborted. A second trip to Muskeget Channel was undertaken in September 2011. During the intervening month, Hurricane Irene passed through northeastern waters generating extreme sea conditions (average wave heights 6-8 meters) south of Martha's Vineyard, thereby significantly affecting the sea surface conditions in Muskeget Channel. SMAST staff was on-site in Muskeget Channel one hour before the slack tide on September 12, 2011 to locate the unmarked treated bio-fouling array but a definitive target could not be identified on which to dive. During passage of the slack tide, the surface 
expression for the untreated array never appeared. Approximately two weeks later (end of September 2011), SMAST staff received a call from a shellfish constable on Martha's Vineyard indicating that a portion of the untreated array had washed ashore on South Beach. The untreated bio-fouling plates retrieved represented the upper water column depth on the array. Inspection of the cable suggests that shock loading during the storm was responsible for the break. Sidescan sonar surveys of the deployment region have not been able to locate any part of either array.

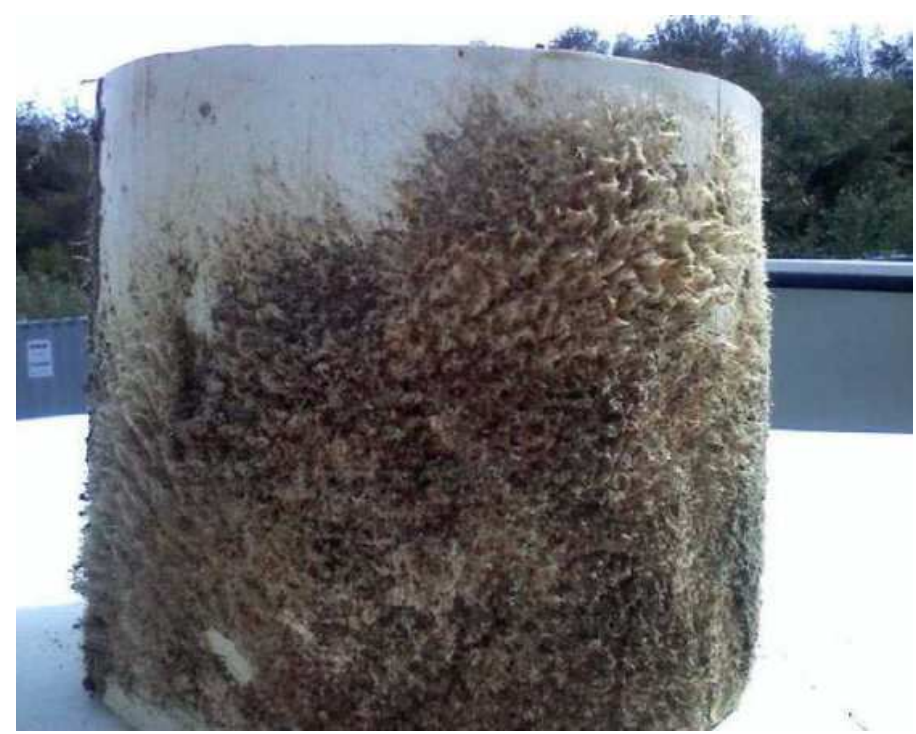

Figure 26: Untreated Composite Material Approximately Two Months After Deployment
In total, one of the three sets of fouling plates on the untreated array was recovered. The other two sets of plates may still be attached to the mooring and resting on the sea bed or may have broken free and are lost. No fouling plates from the treated array have been retrieved to date. The one set of untreated bio-fouling plates that was retrieved spent approximately 2.5 months in the water in the high current velocity zone of Muskeget Channel. The treated plates displayed spotty fouling covering 60-70\% of the outside surface. No fouling was observed on the interior of the cylindrical "plates" (Figure 23). Fouling consisted almost entirely of the algae Pylaiella, a common filamentous brown algae in the region. Despite the prevalence of skeleton shrimp (caprellids) throughout the region,

none were found on the fouling plates, though these organisms may have been lost when the top of the array was in the wash zone of South Beach prior to salvage. No traces of hold fasts or attachment points for hard shell animals were visible. Among the three plates recovered only four small barnacles were observed on the interior of the fouling plate cylinders. The circumstances of the recovery do not rule out the possibility of more extensive biofouling; however the evidence suggests that either the nature of the material or the high velocities may greatly limit the ability of biofouling organisms to become established. Further work will need to be conducted to determine the rates of bioaccumulation on hard structures.

\subsubsection{Existing hard surface communities}

\section{Summary:}

In conjunction with the deployment of the biofouling arrays, a one-time diver survey of the near field area surrounding the mooring structures was undertaken to locate naturally occurring hard bottom communities. To assess the potential effect of fouling communities on turbine components, the existence of natural "fouling" communities were surveyed. Hard bottom areas (rocks) were sought to determine the type of naturally occurring animal communities in the high velocity zone of Muskeget Channel.

However, the areal extent of the diver surveying was limited by the depth of the area being surveyed $\left(\sim 100^{\prime}-120^{\prime}\right)$ and the short duration of the slack tide during which current velocity is low enough to allow the diver to swim the near field area surrounding the biofouling arrays.

Results:

On March 15, 2010 as part of the initial deployment of the scouring experiment, a preliminary survey of the surrounding near field area for naturally occurring hard structures was performed. Utilizing the 
scouring block as the center point, the diver swam 20-25 feet away and conducted a sweep of the surrounding area. The diver observed sand waves ranging in height from 3-5 feet and composed of highly fluid, medium to coarse sand with shell hash from various shellfish species. Beyond this survey perimeter no large structures were observed. On April 25, 2011 during the recovery of the ADCP current profilers from the scouring block, a second diver survey was conducted. The diver observed a change in the bottom topography with sand waves reduced in height ranging to 1.5- 2 feet though composed of the same sediment material. The diver performed a perimeter sweep of the near field area and located no hard structures or fouling communities. Due to the dynamic nature of the high velocity zone, the diver surveys were limited by environmental conditions. Dive operations were limited by the small dive window (20 to 25 minutes) at slack tide. This window is significantly reduced as current velocities increase with the changing of the tides. In addition to safe dive conditions, diver visibility was also affected by environmental variables. Divers experienced a bottom visibility ranging from a minimum of 10 feet to a maximum of 25 feet depending on the physical biological conditions during survey operations. No hard structures or hard bottom communities were detected during these surveys.

\subsection{Geomorphology of Surficial Sediment}

\section{Summary:}

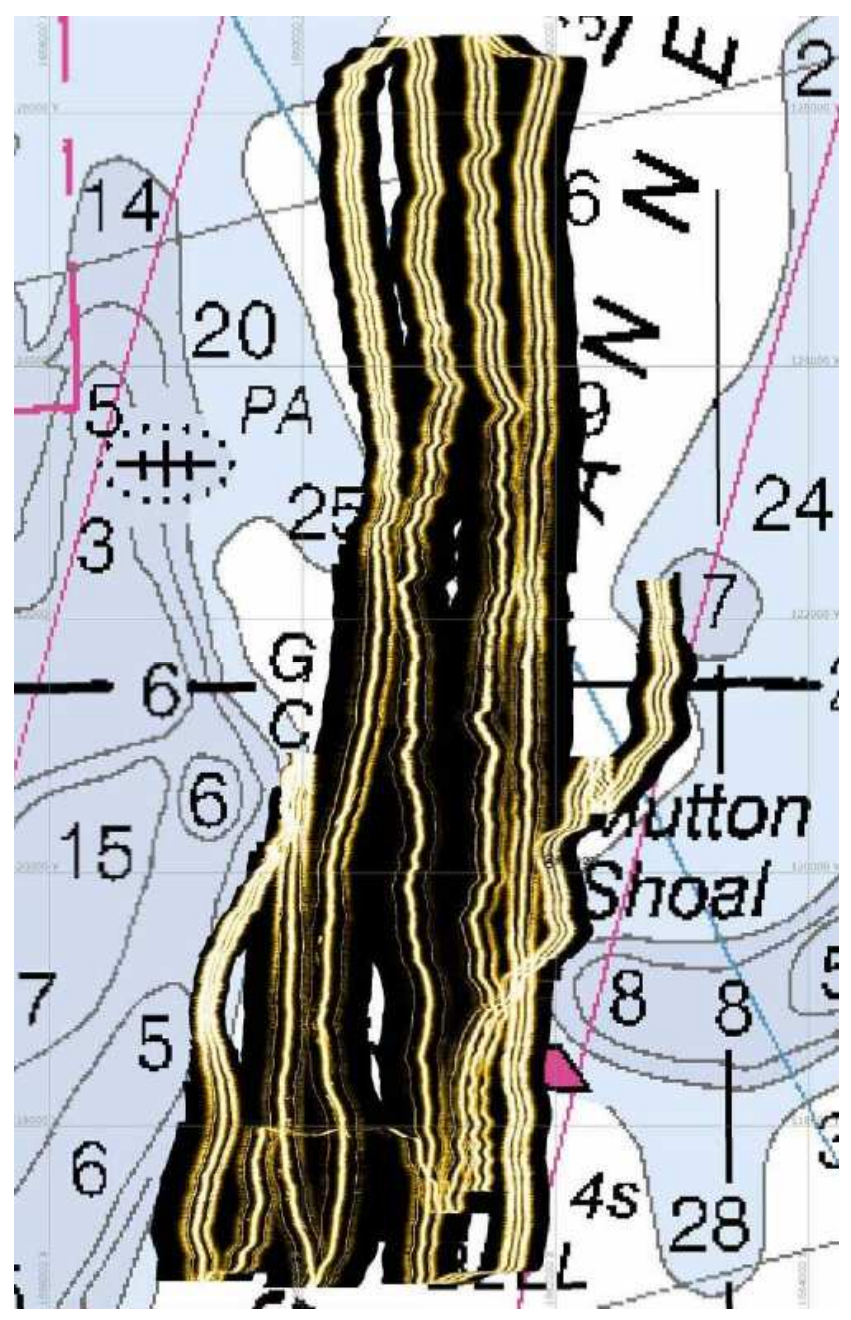

Figure 27: Area Covered by Sidescan Sonar Survey
To enhance the characterization of the seabed for habitat and sediment transport analyses, SMAST had proposed to deploy an OceanServer Technology AUV equipped with an Imagenex 837B multi-beam sonar, an Imagenex side scan sonar, and a Doppler Velocity Log (for underwater navigation between GPS fixes). The AUV would be available to complete high resolution bedform surveying necessary to characterize small-scale roughness and bedforms (likely due to small-scale sand ripples) responsible for bottom stresses. The plan was to use the AUV because it could be flown close to the sea bed, giving the sonar the ability to resolve centimeter size features, thereby yielding a clear picture of the bed roughness. The vehicle also could carry port and starboard side scan sonar that would provide additional information on roughness geometry. Despite a letter of commitment from the manufacturer, SMAST was unable to obtain the AUV for a long enough period of time to complete the bedform surveying in Muskeget Channel. In preparation for AUV deployment in Muskeget Channel, portions of the AUV instrument payload were tested and preliminary missions were undertaken in several other aquatic systems, specifically Ashumet Pond (Falmouth and Mashpee, MA), Mt. Hope Bay/Taunton River (near Fall River, MA) and the Westport River (Westport, MA). However, none of those preliminary missions involved the side scan and multi-beam sonar 
packages. Therefore, in lieu if deploying the AUV in Muskeget, SMAST utilized a traditional side scan sonar (Lowrance, LSS-1) to complete a survey of the high velocity zone of Muskeget Channel. The detailed side scan sonar survey provided bedform context for the current measurements (both near bottom and in the water column), and scour experiment.

\section{Results:}

In conjunction with a search for the fouling moorings displaced by Hurricane Irene, an intensive side scan sonar survey of the area was conducted in October of 2011. The area of coverage is indicated in Figure 24. No evidence was found of the fouling plate moorings. The results of the survey showed the presence of sand waves throughout the area and no hard structures of significant size. Detailed analysis indicated the presence of many smaller objects, possibly boulders, but manmade debris could not be excluded. While relatively large flat areas were present, reflected signal strength could not discriminate between the coarse sand prevalent in the area from areas of gravel and cobbles which could constitute natural hard bottom substrate. Planned work for the next season includes sub-bottom profiling of the area which should provide a more clear view of the bottom stratigraphy including bedrock outcrops and other nontransient hard bottom habitat. 


\section{Sediment Transport}

The Woods Hole Oceanographic Institution (WHOI), in collaboration with the Marine Ecosystem Dynamics Modeling Laboratory (MEDML) at UMASS-SMAST, has undertaken a phenomenological/modeling study of scour, and large-scale morphological changes in Muskeget Channel associated with the proposed Tidal In-Stream Energy Conversion (TISEC) array. The team has also experimentally investigated the question of sand wave generation and migration in the channel based largely on the SWATH bathymetric surveys undertaken with the USGS and described in Section 2.2.2 above. The following section summarizes the development of the model and its projections for sediment transport impacts from the proposed TISEC array. WHOI's complete report is provided in Appendix B.

\subsection{Modeling Approach}

The prediction of possible large-scale morphological changes have been addressed using a coastal circulation hydrodynamic model, FVCOM, coupled to the CSTMS (Community Sediment Transport Modeling System), developed by the United States Geological Survey (USGS) and Woods Hole Coastal and Marine Science Center (USGS-WHSC) in partnership with WHOI and other organizations.

FVCOM is a Fortran90 software package for the simulation of ocean processes in coastal regions (Chen et al., 2003, 2006; Cowles, 2008). The publicly available model has a growing user base and has been employed in a wide variety of applications. The kernel of the code computes a solution of the hydrostatic primitive equations on unstructured grids using a finite-volume flux formulation. The unstructured grid modeling approach is highly advantageous for resolving dynamics in regions with complex shorelines and bathymetry such as the Massachusetts coastal region. Figure 25 shows the grid set-up for the Muskeget Channel Area.

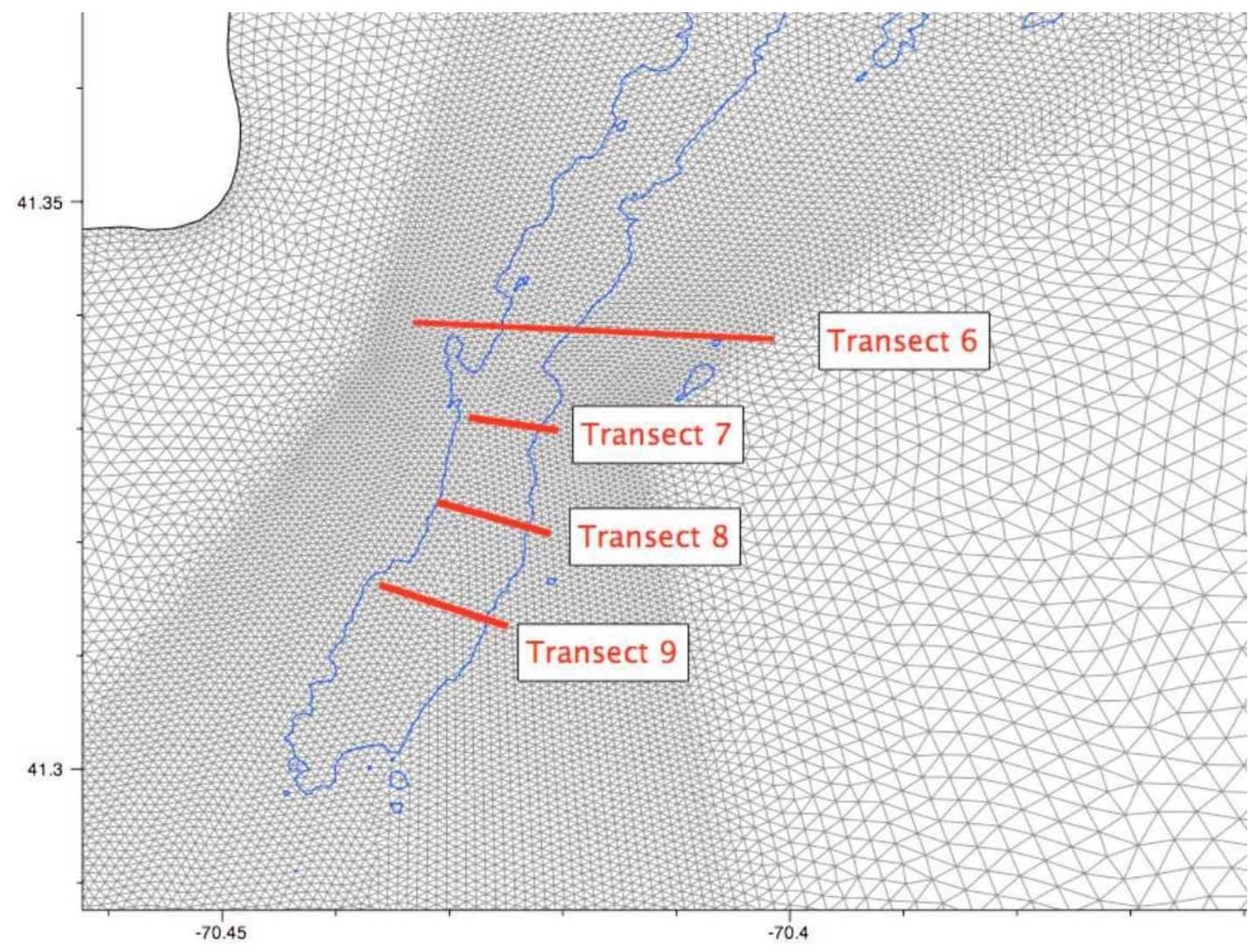

Figure 28: FVCOM Unstructured Grid in Area of Muskeget Channel 
The CSTMS includes transport of both the suspended load and bedload. The number of sediment classes is flexible, and for each class, parameters such as critical shear stress, mean diameter, and settling velocity must be defined. Complex bed dynamics are included with a user-prescribed number of layers defined by the layer number, fractions of each sediment class, an age, and a thickness.

A volumetric subgridscale parameterization has been employed to model the impact of the turbines on the fluid. This approach has been used successfully in wake studies of wind turbines (Réthoré et al., 2010). Additional detail on each of the models is provided in Appendix B.

\subsection{Model Setup and Validation}

\subsubsection{Hydrodynamic Model}

The hydrodynamic model domain includes the entirety of the Massachusetts Coastal waters. The coastline was based on a high resolution product developed by the Massachusetts Coastal Zone Management. The bathymetry is a composite set which included the USGS 3-Arc Second Gulf of Maine database complemented by the NOAA 1/3 Arc-second Nantucket Inundation DEM in the southern portions of Nantucket Sound and the USGS Muskeget SWATH Bathymetry in the main Muskeget Channel. The mesh is locally refined in the vicinity of Muskeget Channel for the purpose of capturing the spatial complexity of the currents in the impact studies. A sequence of three models were developed providing coarse, medium, and fine resolution. This enabled more rapid model development and a formal assessment of grid independence in the results of the impact studies.

The hydrodynamic model is forced at the open boundary using 6 tidal constituents $\left[\mathrm{M}_{2}, \mathrm{~S}_{2}, \mathrm{~N}_{2}, \mathrm{O}_{1}, \mathrm{~K}_{1}\right.$, $\mathbf{M}_{4}$ ]. These constituents were extracted from a large scale tidal model (Chen et al., 2011) and adjusted to improve the harmonic response of sea surface elevation with the domain.

Tidal harmonics at 24 stations are used to validate the five principal components $\left(\mathrm{M}_{2}, \mathrm{~S}_{2}, \mathrm{~N}_{2}, \mathrm{~K}_{1}, \mathrm{O}_{1}\right)$ as well as the principal overtide $\mathbf{M}_{4}$. The tidal dynamics south of Cape Cod are complex owing to the prominent convergence of two large scale tidal waves, one approaching from the Gulf of Maine through the Great South Channel and the other propagating across the New England Shelf (Chen et. al, 2011).

These are shown in Figure 26. Capturing the correct phase and amplitude requires accurate forcing and a model that can resolve properly the coastline and small-scale bathymetric features. 


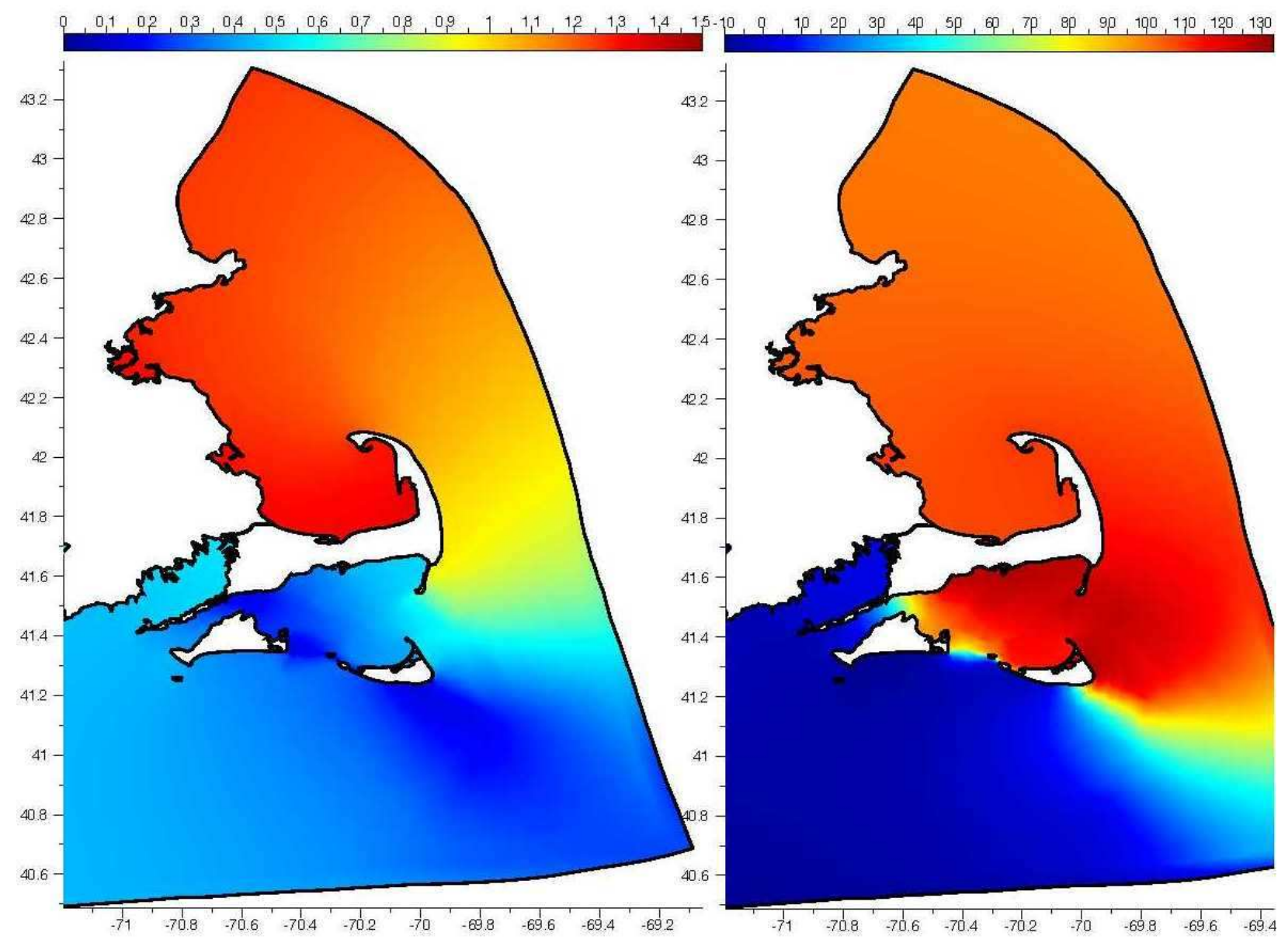

Figure 29: Two Large-Scale Tidal Waves Modeled Using FVCOM

The model can compute vertically-averaged tidal residual flow vectors for M 2 boundary forcing. Figure 27 shows the flow vectors through the Muskeget Channel area and includes the ADCP Transects 6-9 (green lines), 15-m isobath, and locations of the SWATH bathymetry survey. 


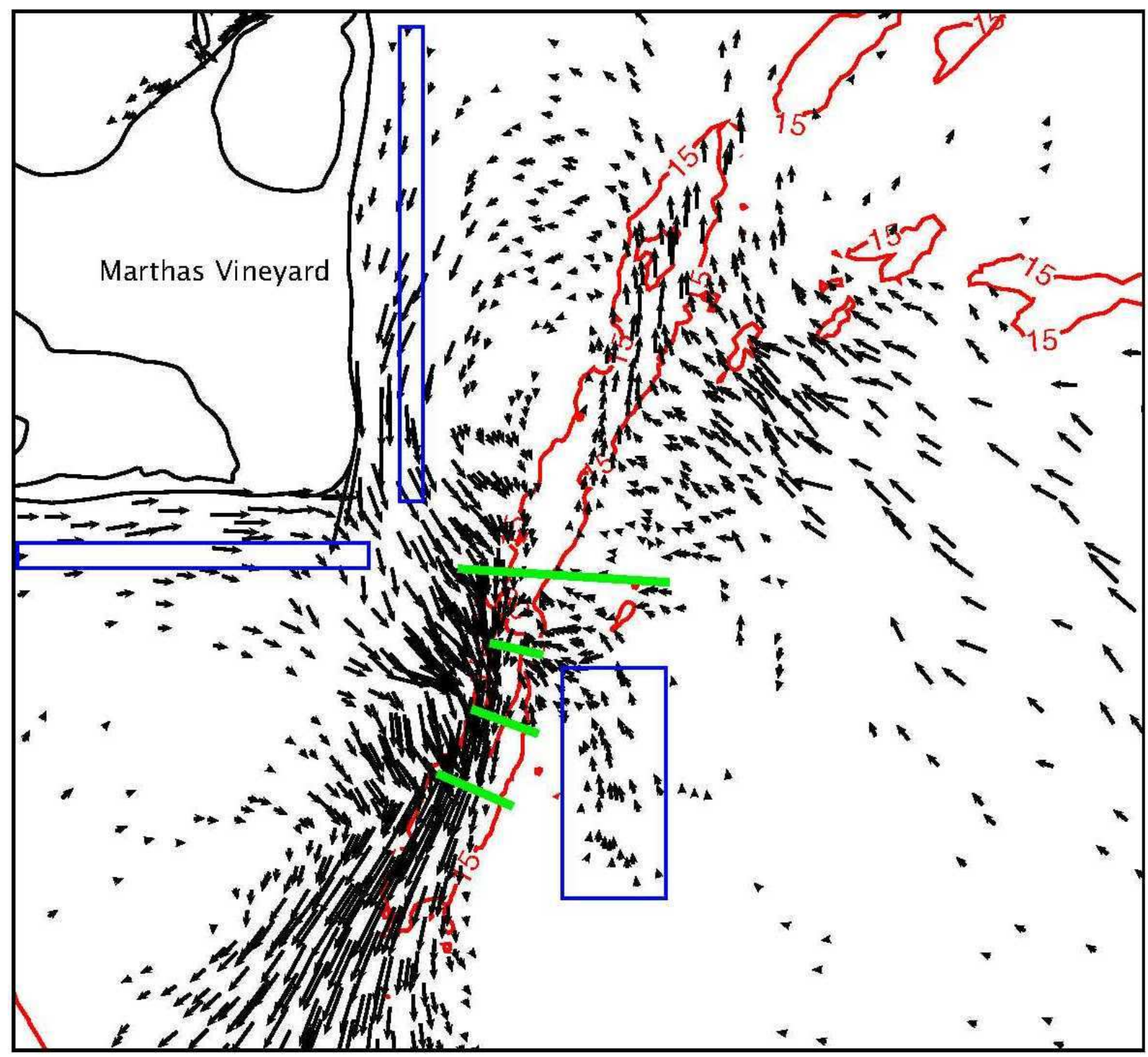

Figure 30: Model-Computed Vertically-Averaged Tidal Flow Vectors

The model-computed velocity fields through transects 6-9 were compared with measurements made by the SMAST Coastal Systems Program during a large spring tide in June 2009 (see Section 2.1 above). The model was run over the same period as the measurements. The model captures well the magnitude of the currents (see Appendix B, Figure III-12a-d) and is able to resolve the complex structure of the flow in the channel. During flood tide, the peak velocity resides in the east part of the channel, and during ebb, it shifts towards the central and western edge of the channel. This is evident at both transects 7 in the deeper portion of the Channel and transect 9 in the shallower regions near the southern extent of Muskeget Channel. There is significant vertical shear in both the observed and model-computed velocity fields. The model can also be used to predict power production potential. Some of this analysis is provided in Appendix B as an example of the model's capabilities. 


\subsubsection{Sediment Model}

To drive the sediment model, an initial distribution of grains must be prescribed. Due to the heterogeneity of the substrate, there were not sufficient measurements in the region to derive the distribution directly from observations. For this reason, WHOI chose to let the model sort the grains under tidal forcing. A two-layer bed was initialized with equal distributions of eight grain sizes ranging from coarse silt $(\phi=$ $4.5)$ to coarse granule $(\phi=-2.5)$ in the Wentworth scale (Table 1). All sediments are treated as noncohesive and the larger sediments (very coarse sand to granule) are generally transported as bedload. Although larger size sediments have been observed (cobble, boulders), much of this would be heterogenous, glacial in origin, and unlikely to be highly mobile at the time scales of our interest given the shear stresses predicted by the model. Parameterizing the effects of such scattered roughness elements on bed stress at the larger model scale is an active area of research.

The model was forced by tides for a period of sixty days at which point the majority of discrete bed points in the model had reached a quasi-steady state distribution. The resulting distribution of mean surficial grain size compares well with spatial distribution derived from the US Seabed (Poppe et al., 2003) database and data acquired by the SMAST (see Figure 28). Coarser sediments are present in the main channel and along the flanks in areas of high stress. Finer sediments are present along Wasque shoals and where the circulation and sediment availability allow for finite fractions to persist. The resulting spatial distribution of fractions of the eight size classes is saved and used to initialize the bed in the ISE experiments described below. 


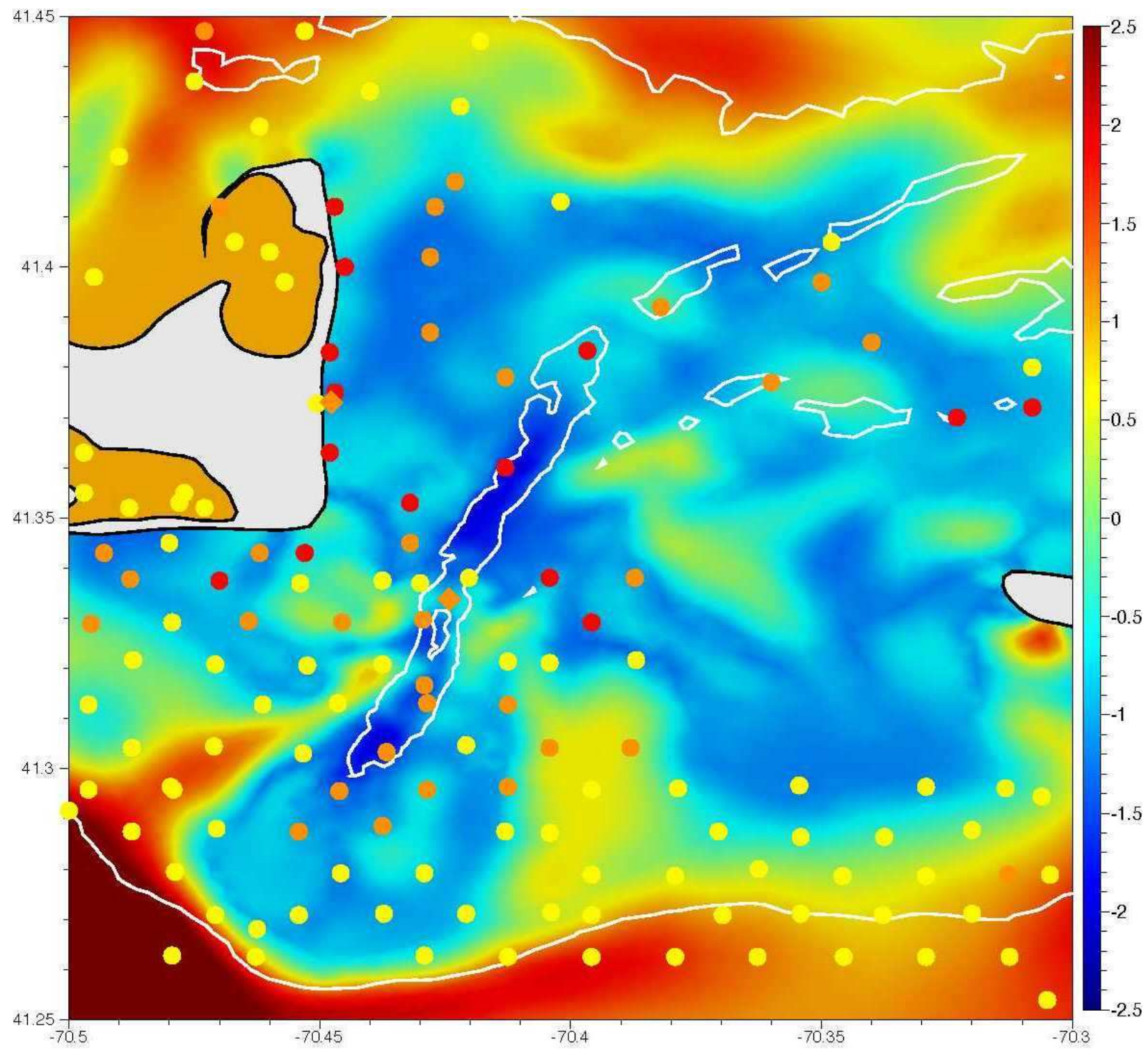

Figure 31: Model Grain Size Distribution Compared to US Seabed and UMASS Data 
Table 1: Sediment Classes and Characteristics for ISE Impact Studies

\begin{tabular}{|l|c|c|c|c|c|}
\hline \multicolumn{1}{|c|}{ Class } & Grain Size(mm) & $\phi$ & Settling Velocity (mm/s) & $\begin{array}{c}\text { Critical Shear Stress } \\
\text { (N) }\end{array}$ & Porosity \\
\hline Coarse Silt & .04 & 4.5 & 1.2 & .1 & 0.5 \\
\hline Very Fine Sand & .09 & 3.5 & 4.73 & .133 & 0.5 \\
\hline Find Sand & .18 & 2.5 & 17.64 & .165 & 0.5 \\
\hline Medium Sand & .35 & 1.5 & 47.21 & .213 & 0.5 \\
\hline Coarse Sand & .71 & .5 & 90.32 & .340 & 0.5 \\
\hline Very Coarse Sand & 1.41 & -.5 & 142.8 & .740 & 0.5 \\
\hline Coarse Granule & 2.83 & -1.5 & 210.3 & 1.92 & 0.5 \\
\hline Granule & 5.66 & -2.5 & 301.63 & 4.70 & 0.5 \\
\hline
\end{tabular}

\subsubsection{Project Array}

Turbine layout and sizing was based on a preliminary assessment for tidal energy in Muskeget Channel by the Ocean Renewable Power Company (ORPC, 2010). Using velocity distributions from ADCP transects acquired by the SMAST in combination with channel bathymetry, ORPC determined the optimal layout for their crossflow turbines for transects 6-9 (Table 2). Their basic turbine design allows for efficient site-specific configuration. These configurations were used to establish the spatial distribution of parameters in Eq III-1 within the FVCOM mesh.

Table 2: Turbine subgridscale parameterization for Impact Studies

\begin{tabular}{|c|c|c|c|c|}
\hline Transect & Baseline Configuration & \# TGUs & Total width $[\mathrm{m}]$ & Total area $\left[\mathrm{m}^{2}\right]$ \\
\hline 6 & 2-TGU & 6 & 166 & 1412 \\
\hline 7 & $4-T G U$ & 9 & 249 & 4238 \\
\hline 8 & $4-T G U$ & 5 & 138 & 2354 \\
\hline 9 & 2-TGU & 5 & 138 & 1177 \\
\hline
\end{tabular}

\subsection{Modeling Impacts Assessment}

The primary use of the model is to evaluate the predicted change in flow velocity as a result of the turbine array and the corresponding effect on sediment transport as described below. The model can also predict the changes in sea level sea surface height, an analysis which is described for Muskeget Channel in Appendix C. The turbine-induced modification to sea level is calculated to very small $(3 \mathrm{~mm})$ primarily because Muskeget is a broad open channel and there is little lateral constraint. This analysis might produce more significant information in areas with more constrained channels.

\subsubsection{Vertically-averaged Velocity and Bed Stress Perturbation}

The model results show the area around the turbines where the velocity field is modified. The results are presented by subtracting the natural (no turbine) flowfields from the turbine-modified. As shown in the results, the change in velocity is generally small compared to the background flow.

A momentum deficit forms in the wake (Figure 29, left panels), extending downstream. During ebb, the velocity defect associated with energy extraction is roughly $5 \mathrm{~cm} / \mathrm{s}$. The velocity magnitude is also reduced upstream of the turbine but the magnitude of the impact is less than $1 \mathrm{~cm} / \mathrm{s}$. In association with the decreased velocities and reduction of momentum is a lateral pressure gradient which drives the flow around the turbine which can be thought of as a partial fence in the water column. The velocity is 
increased on the flanks of the Channel by roughly $2 \mathrm{~cm} / \mathrm{s}$. The modification to the vertically-averaged flow on flood tide (Figure 29, lower left) is spatially similar with a reduced magnitude as the Channel is strongly ebb dominant.
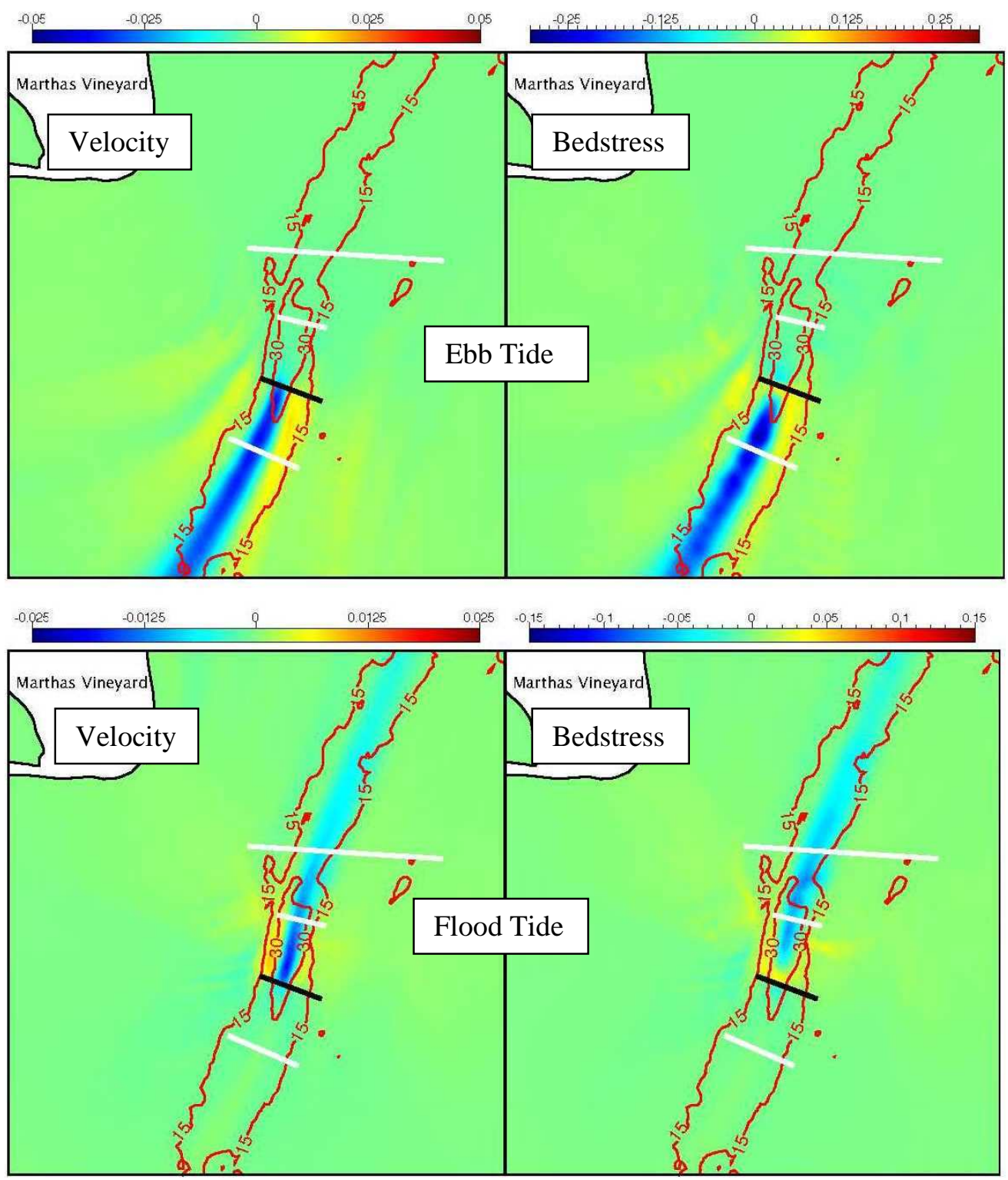

Figure 32: Difference in Model-Computed Vertically-Averaged Velocity Magnitude and Bedstress at Transect 8

Associated with the modifications to the velocity field are perturbations to the bed stress which generally scales as the square of the velocity. During ebb, the model-computed bed stress for an installation at Transect 8 is decreased in the main channel by roughly $0.25 \mathrm{~N}$ and increased along the flanks of the Channel by approximately $0.1 \mathrm{~N}$. On flood tide, a similar pattern appears but the magnitude of bed stress perturbations is reduced accordingly. Spatial distribution of bed stress perturbations for installations at other transects follows the same general pattern with reduced stresses in the channel and enhanced stresses along the edges. In the sediment simulations, it is the current-induced bed stresses that drive the sediment model and thus changes in sediment fluxes are induced solely by perturbations. 


\subsubsection{Large Scale Modifications to Bed Height}

In an initial sediment and erosion (ISE) experiment, hydrodynamic and sediment transport computations are made based on the assumption of an invariant bed topography. Such an approach is widely used as the computational effort is constrained and the difficulties associated with the implementation and solution of an evolution equation for the bed height are avoided. However, since the morphodynamic feedback is not included in an ISE model, the results must be interpreted with caution. The net erosion/deposition predicted by the model are useful for evaluating the spatial variation in the initial adjustment of the bed, but will not be accurate over the long term where the resulting bathymetric changes feed back to the flowfield. Such morphodynamic modeling was beyond the scope work in this project, but would be a logical next step in future efforts. The experiments here were initialized using a spatial distribution of sediment fractions with median size as shown in Figure 28 above. The bed was then allowed to evolve based on net deposition and erosion of the eight sediment classes for 30 days under M2 forcing both with and without turbines. We focused here on the single tidal constituent as it can be more easily upscaled through a number of tidal cycles. By including all six constituents, approximately a full year is needed to experience the entire tidal range.

The relative change in bed heights $(\mathrm{m})$ between turbine-modified and natural simulations forced by M2 tides is shown in Figure 30. These fields should not be interpreted as actual accretion or erosion, rather a net accretion or erosion relative to evolution of the bed in natural flow conditions. In all three cases, there is a net positive change in the bed height which is consistent with effects of the turbines as energy needed to erode and transport sediment is being removed from the system. This net accretion was approximately $15 \%$ of the total absolute change in model computed bed thickness for all four turbine installations. In all four cases, the spatial distribution of relative changes follows the basic pattern of changes in bed stress resulting from the momentum removal (see Figure 29 above). However sediment erosion and deposition is more closely related to the divergence of the bed stress. For installations at all sites there is a positive change in bed thickness in the main channel with a negative change on the flanks of the Channel. Over the thirty day period, this net bed change is approximately $5-10 \mathrm{~cm}$ at the central transects and $2-5 \mathrm{~cm}$ at the northern (transect 6) and southern (transect 9) installations. The total volume associated with the relative change in bed thickness within the domain shown in Figure 30 is shown in Figure 31. It is seen to be monotonically related to the power extracted by the devices. As these experiments were conducted with M2 forcing only, the actual installations would have larger power output (roughly 220\%) and accordingly, larger relative changes in bed heights over a given period. 


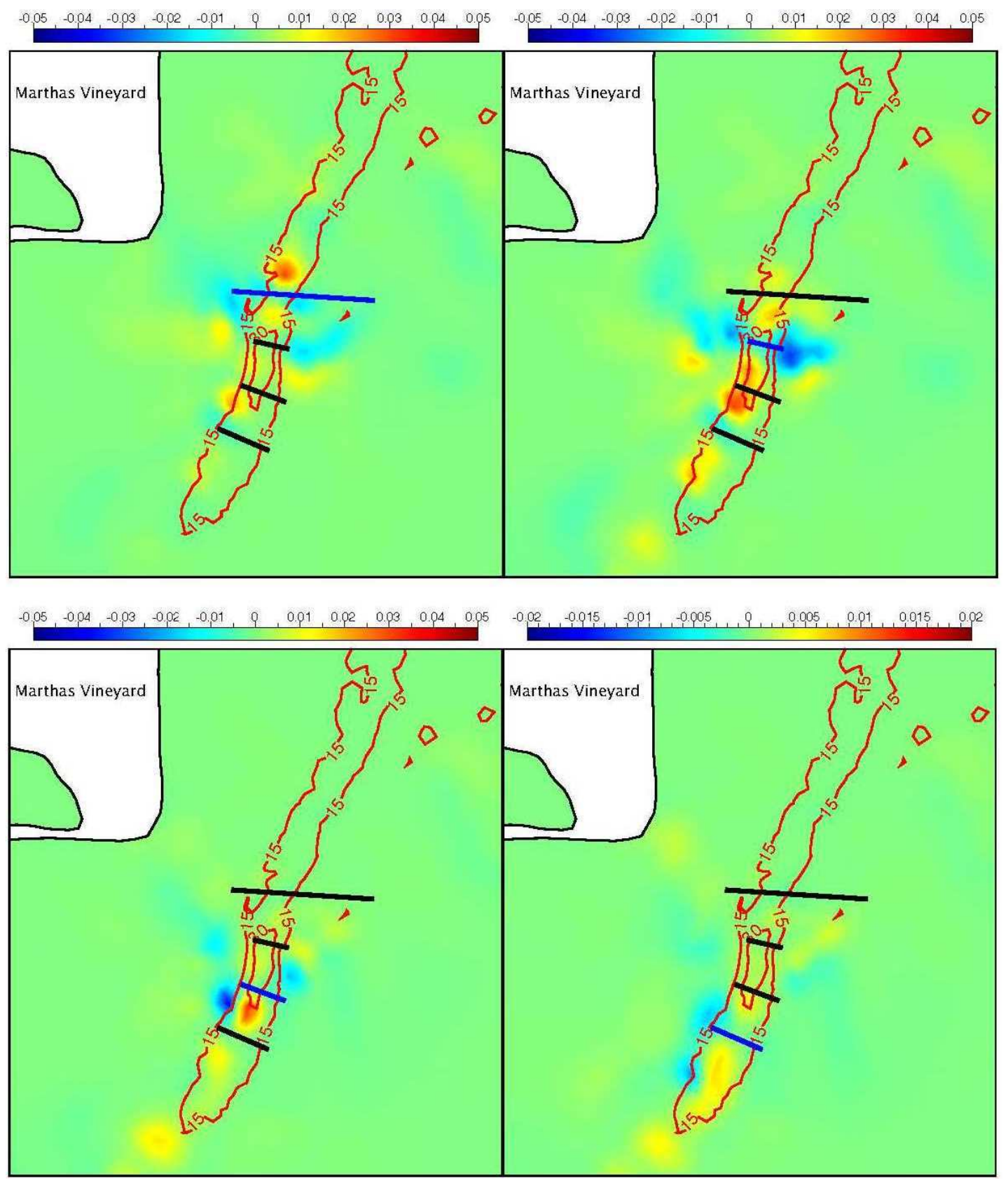

Figure 33; Difference in Model-Computed and Natural Bed Thickness over a 30 day Period for Four Different Turbine Arrays

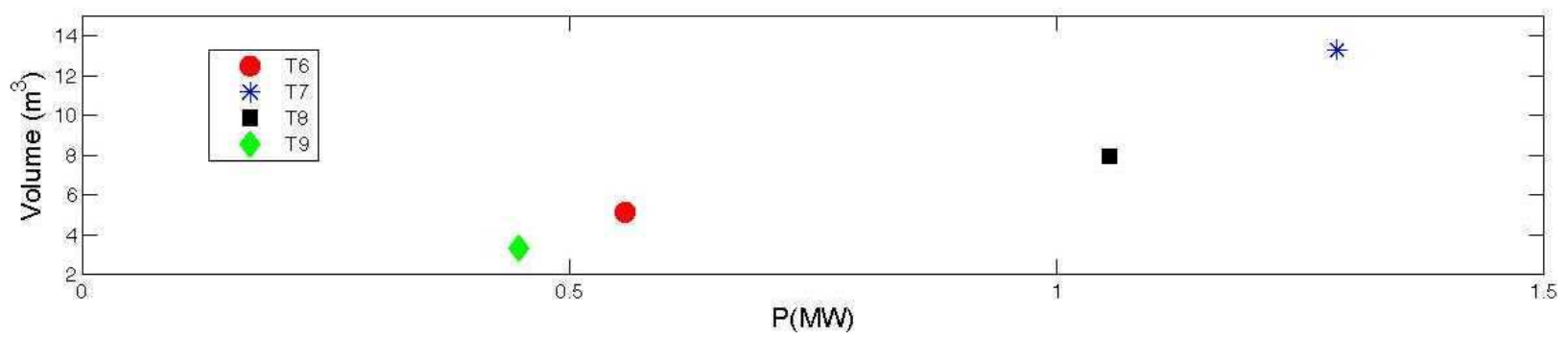

Figure 34: Total Absolute Difference in Bed Volume Modeled Over 30 Days for Four Turbine Array Locations 


\subsubsection{Modification to Sediment Fluxes}

Fluxes of sediment through the Channel were examined along three transects: one north of the area of interest in energy extraction, one south, and one intersecting the primary area of interest between ADCP survey transects 7 and 8 (Figure 32). During flood, the model-computed sediment loads are on the order of $1 \mathrm{~kg} /(\mathrm{m}-\mathrm{s})$ at the central and northern transects with weaker values along the southern transect indicating a convergence of sediment from the east and west flanks of the Channel (Figure 32). During ebb, values are approximately $50 \%$ higher corresponding to the greater shear stress (Figure 33) deriving from the ebb-dominant flow in the nearfield of the main channel.

The effect of energy extraction can be evaluated by subtracting the instantaneous sediment fluxes computed with the subgridscale turbine model in place by the fluxes computed in natural conditions. Flux perturbations are $\mathrm{O}(10) \mathrm{g} /(\mathrm{m}-\mathrm{s})$ corresponding to approximately $1 \%$ of the natural fluxes.

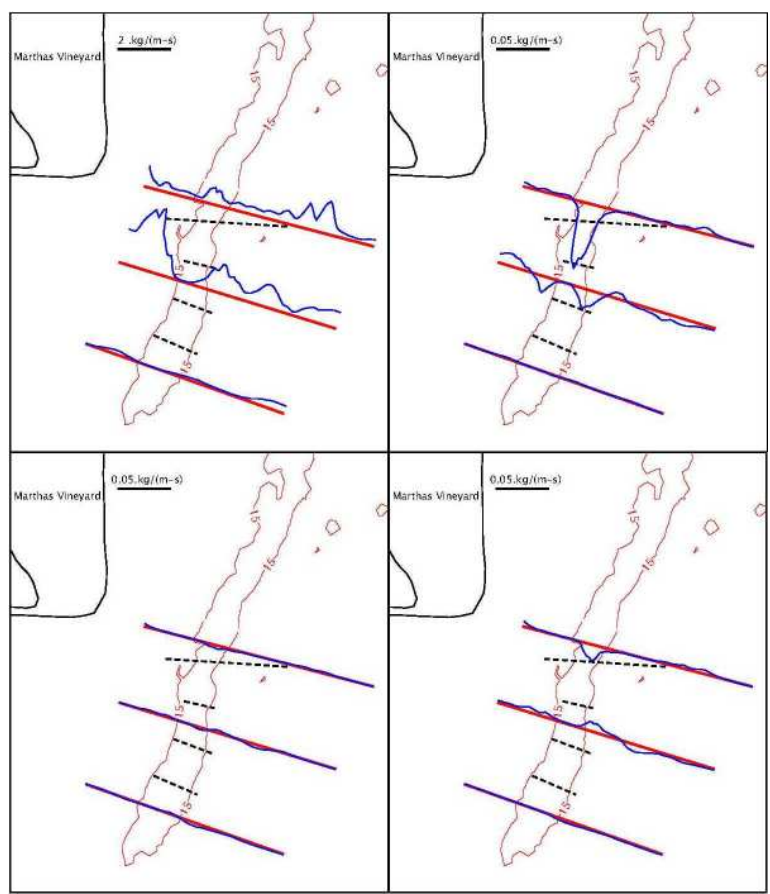

Figure 35: Total Sediment Fluxes During Flood Tide

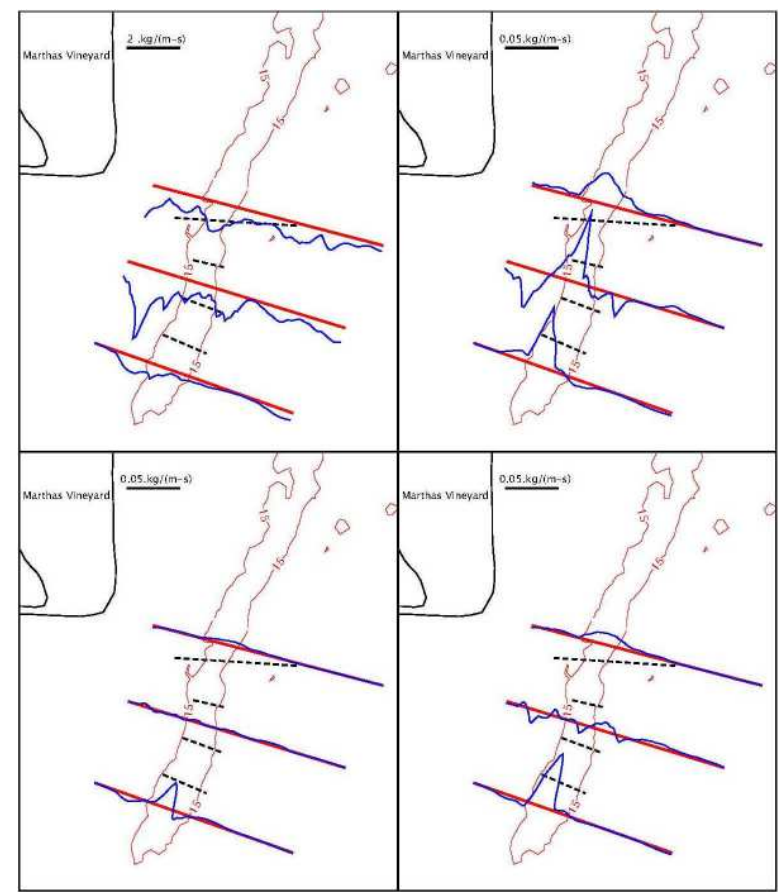

Figure 36: Total Sediment Fluxes During Ebb Tide

During flood, the perturbations to the transect fluxes due to augmentations in the device-influence flowfield are most significant along the central and northern transects where the along-transect distribution reflects the variations in bed height observed during the sediment experiments. The largest defects in the flux occur in the main channel, particularly where a flux transect is proximal to the installation in the downstream direction (e.g. the influence of an ADCP transect 9 installation on the north flux transect). On the edge of the channel, the fluxes are enhanced due to the local increase in bedstress. Transect 9 installation is seen to have only a nominal influence of the load. This is due primarily to the reduced amount of energy harvested at this site in comparison to the proposed installations at transect 7 and 8.

Ebb tide flux augmentations are essentially the reverse of flood with flux defects occurring in the channel and flux enhancements on the flanks except with greater magnitude. The largest along-channel flux defect, on the order of $0.05 \mathrm{~kg} /(\mathrm{m}-\mathrm{s})$, is observed in the central flux transect just downstream of the transect 7 installation. 


\subsection{Sand Wave Dynamics}

Summary:

Sand waves are a seabed feature, which occurs over large, sandy bottoms. Sand waves form as the result of bed stress caused by water flow and move in a similar manner to ocean waves that are driven by wind. They provide an indicator of the overlying water flow dynamics.

Sand wave dynamics in Muskeget Channel had not been characterized prior to the current study. Studies by USGS-WHSC personnel of sand waves over middle ground in Vineyard Sound have observed relatively large amplitude sand waves (with wavelengths of order $100 \mathrm{~m}$ and heights of 3 meters in $20 \mathrm{~m}$ water depth) that have migration rates of order 5-15 $\mathrm{m} /$ month. In broad terms, the tidal flow is responsible for the growth of sand waves (via a coupled flow-sediment instability), whereas the residual (subtidal) circulation, which is asymmetric, is responsible for their migration (Nemeth et al., 2002; 2006).

The strength of the tidal flow over middle ground is weaker than in Muskeget Channel, although the residual currents can be comparable. Based on known information, it is a reasonable expectation that Muskeget Channel is an area of active sand wave dynamics. Understanding sand wave dynamics in the project area is important for predicting potential problems related to design and installation of associated infrastructure, such as anchoring systems and submarine cables, to ensure that they do not become buried or exposed thereby compromising their long-term integrity.

Results:

The deepest part of Muskeget Channel contains a series of fairly symmetric rolling bedforms of roughly 5 -m height and 100-m wavelength. These large bedforms are most closely located to transects 7 and 8 of the SMAST ADCP survey. The current data from these transects also show the most promise for tidal kinetic energy extraction (ORPC, 2010). Given the extremely high shear stresses and mobility of the local dominant substrates, these bedforms should be re-surveyed to assess potential impact on structures, stays, and cable routes. The bedform characteristics and fan extending in the direction of the strong residual current are reminiscent of the well-studied bedforms of San Francisco Bay.

The large amplitude sand waves (Figure 34) have an average wavelength of $225 \mathrm{~m}$ and an average height of $4.5 \mathrm{~m}$. The average upstream slope is .025 and average slip face slope is .08. They are of similar scale to the well-studied sand waves in the Bay of Fundy. Their ratio of height to wavelength falls within two well-known relationships derived from the Bay of Fundy data. While the tidal residual flow in the main Muskeget Channel is predominantly to the south, the large amplitude sand waves lie off the main channel in an area with weak northward residual flow. 

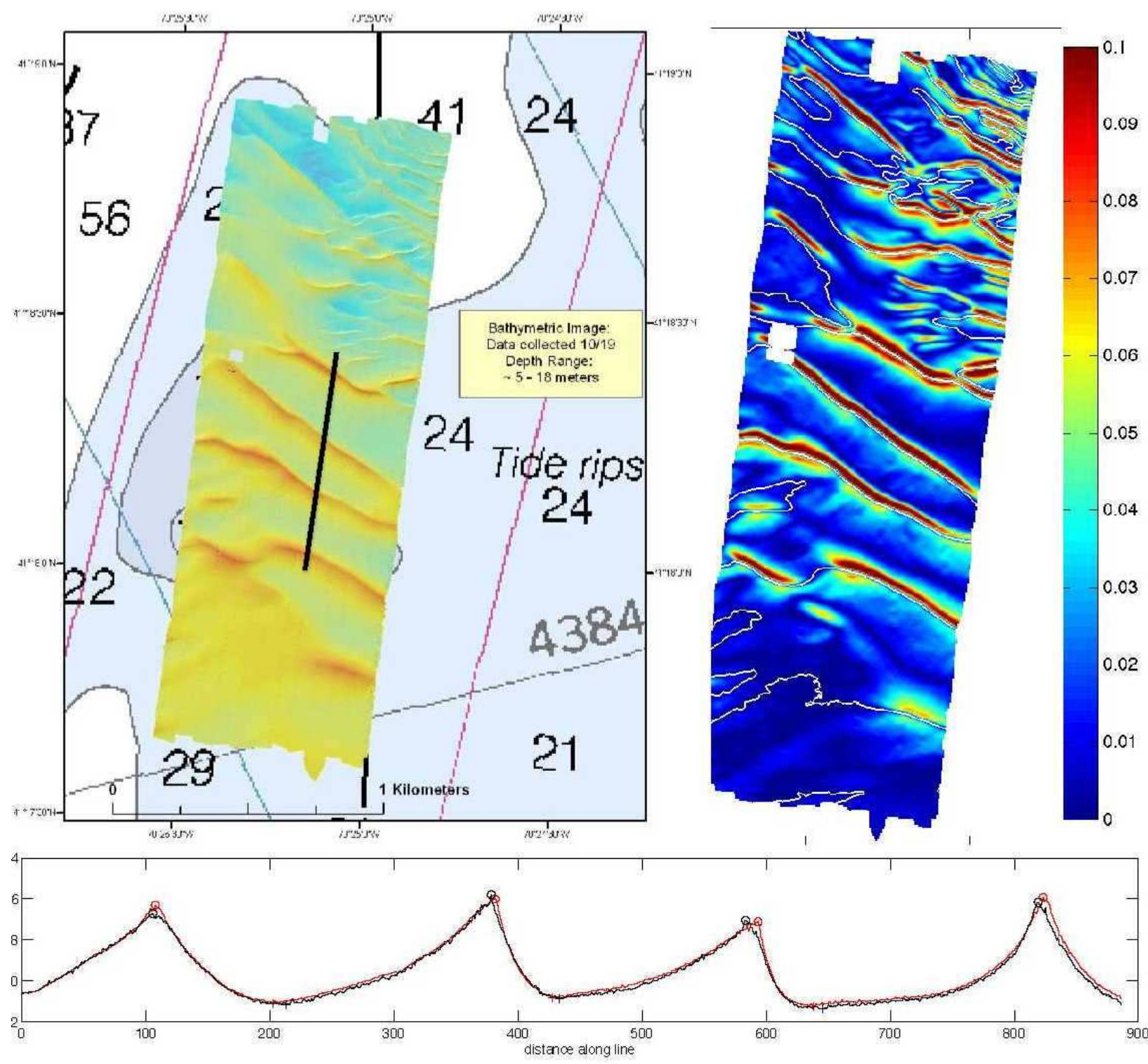

Figure 37: Large Sand Wave Area Southeast of Muskeget Channel

The large sand waves have a clear slip face oriented towards the north which is consistent with the direction of this residual current. If the same transect is taken through the second survey (one month later), crests have moved an average of $5 \mathrm{~m}$ towards the south. Based on crest motion, this would imply a net motion of $17 \mathrm{~cm} /$ day which is similar in magnitude to migration speeds in the Bay of Fundy. However, the profile indicate that the slip face is becoming less steep and that the crest motion is more likely a result of the sand wave relaxing rather than a rigid translation of a fixed waveform.

The north-south survey (see Figure 35) bisects the proposed route of the Chappaquiddick cable route and thus is useful for determining the necessary dredge depth. Sand waves along this transect can be divided into two groups. The northern group is roughly $90 \mathrm{~m}$ in length and $0.7 \mathrm{~m}$ in height and has slip faces oriented to the north. The southern group is shorter with a mean wavelength of $40 \mathrm{~m}$ and height of $0.8 \mathrm{~m}$. This group has a reversed orientation with the slip face on the south side. The slip face orientation of the southern group is also more clearly defined. 
The proposed Chappaquiddick cable route intersects the southern group. Based on the model-computed residual currents (Figure 27), the tidally-driven flow is predominantly southward in the nearshore region of the east-facing portions of Chappaquiddick. The magnitude of the residual current increases towards the southeast point of Martha's Vineyard.

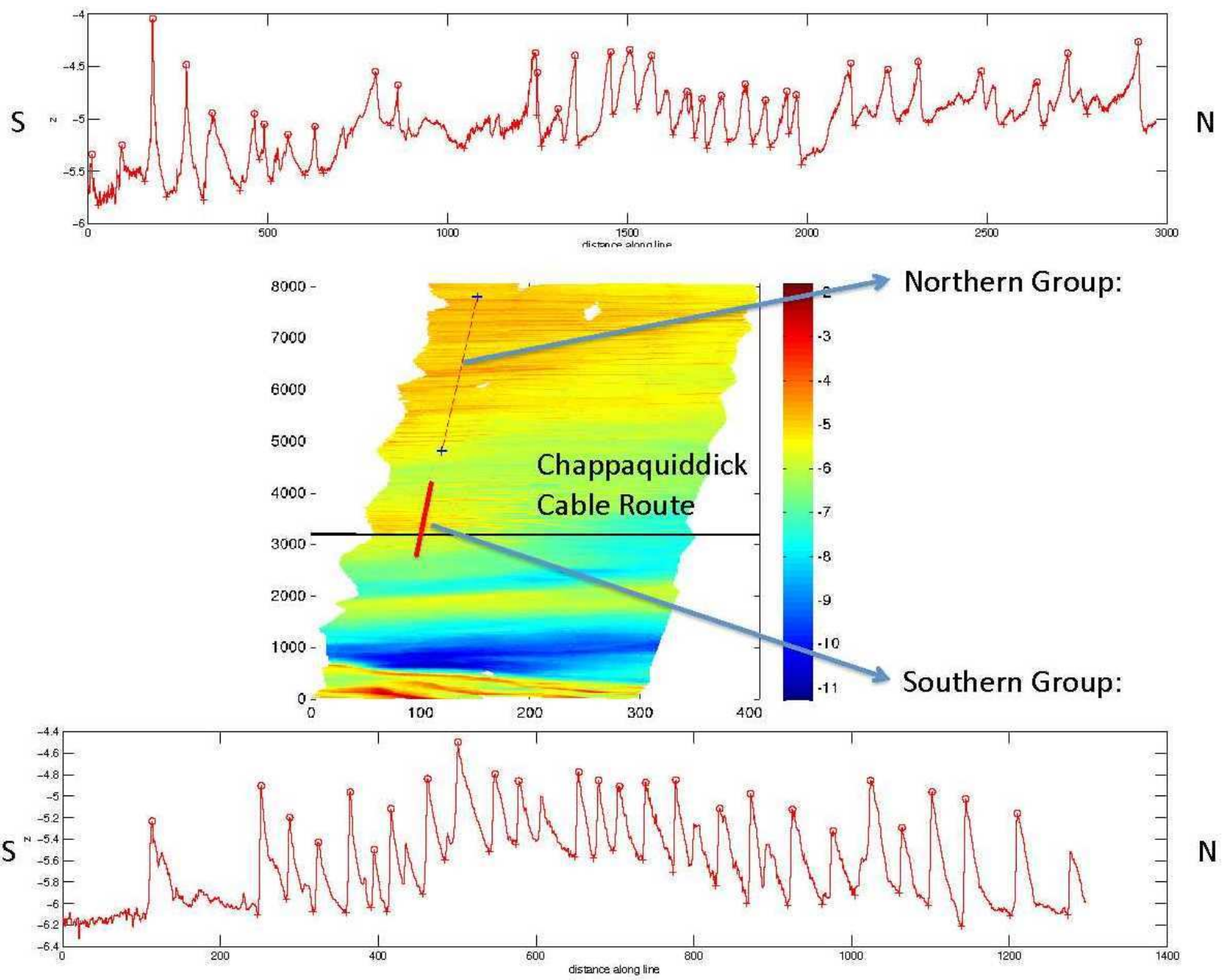

Figure 38: Sand Waves Along the Proposed Chappaquiddick Cable Alternative

The bedforms along the east-west survey (Figure 36) have a mean wavelength of $120 \mathrm{~m}$ and height of $2 \mathrm{~m}$. The slip face is to the east which corresponds with the residual flow direction. These sand waves are occurring roughly $3 \mathrm{~km}$ to the east of the proposed Katama cable route. An inlet to Katama Bay was created during the Patriot's Day storm (April, 2007) and may have some influence on the formation of bedforms in this region through both modifications to hydrodynamic forcing and potentially sediment supply (R. Geyer, P. Traykovski, personal communication). The inlet is migrating eastward. 

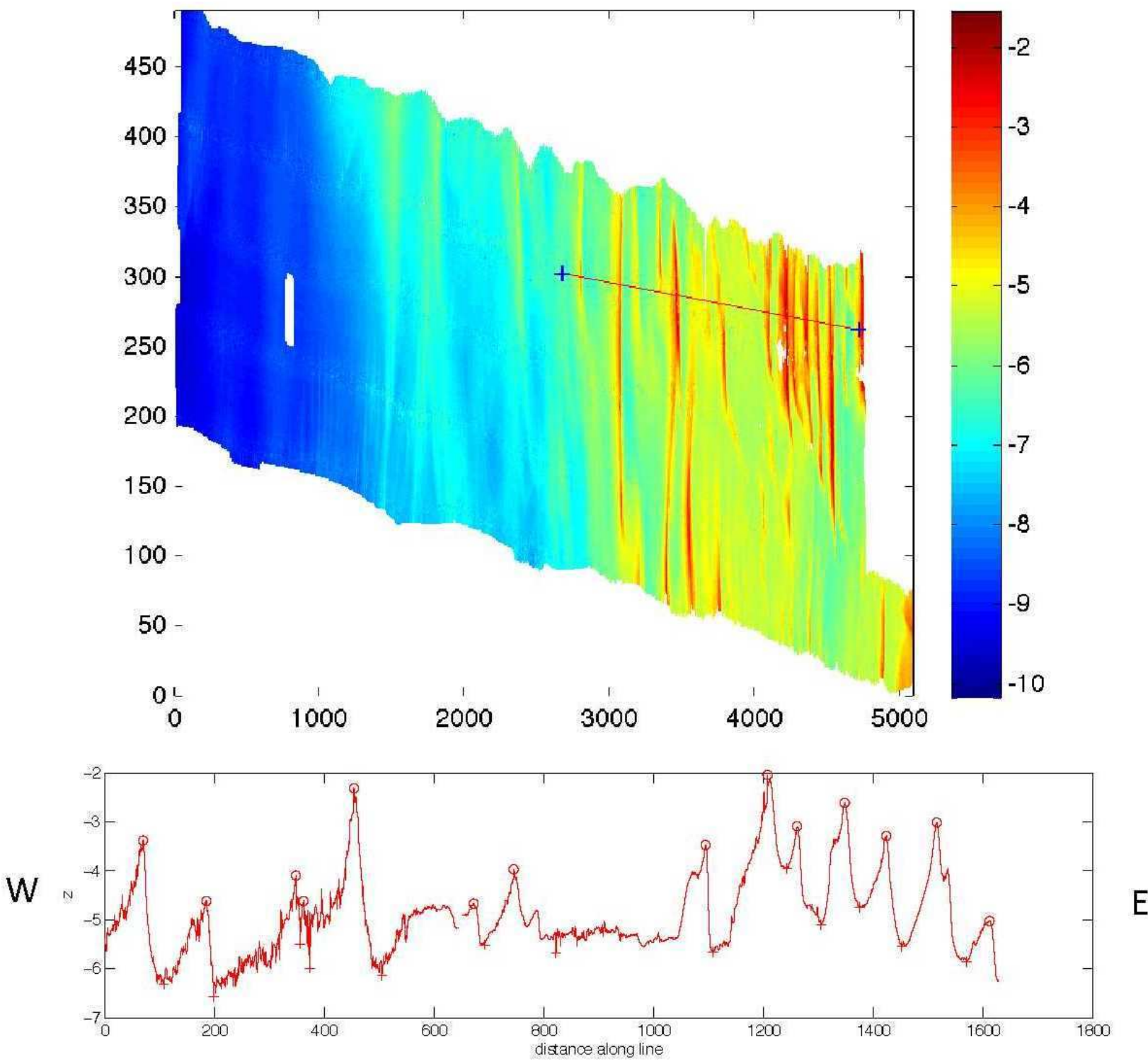

Figure 39: Sand Waves Along the Katama Cable Alternative

Figure 37 compares the ratio of wave height to wavelength for data collected in the Bay of Fundy and Muskeget Channel. As stated above, the ratio of height to wavelength falls within two well-known relationships derived from the Bay of Fundy data. 


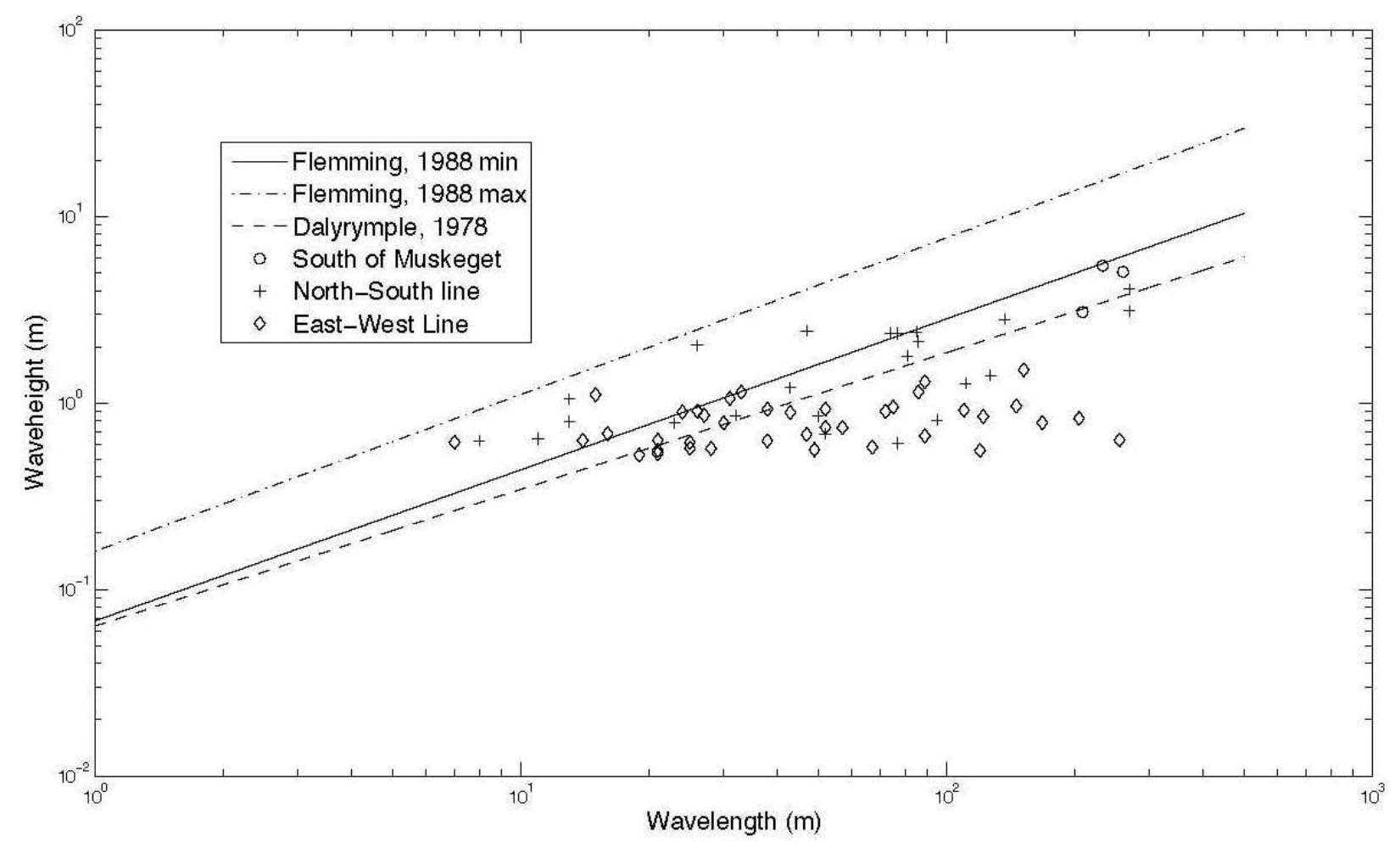

Figure 40: Ratio of Height to Length for Sand Waves 


\section{Protected Species and Fisheries}

The waters of Muskeget Channel provide habitat for a wide array of marine animals and fishes that must be considered in siting and design of the proposed tidal energy project. The Provincetown Center for Coastal Studies (PCCS) has drawn upon its internationally-recognized extensive experience in marine research to provide a detailed accounting of existing information on marine megavertebrates (cetaceans, pinnipeds, sea turtles, basking sharks, and ocean sunfish) and fisheries. PCCS has also reviewed and summarized the literature on impact assessments for marine renewable energy installations (MREIs), described the permitting process, and presented potential monitoring programs to inform the impact assessment analysis for the Muskeget Channel Tidal Energy Project. Its conclusions are presented in two separate but linked reports in Appendix C.

The authors found that there has been little or no directed research on marine megavertebrates in the Nantucket Sound - Muskeget Channel area. Surveys have been done to estimate population size of harbor and gray seals in this area; however these are now out of date. Most of the data on cetaceans and sea turtles discussed in this report are from opportunistic sightings, strandings and entanglements. With the exception of a tagging program on leatherbacks, there is no systematic survey effort on sea turtles in this area. No systematic surveys have been undertaken for basking sharks and ocean sunfish. Fisheries surveys are limited to the Massachusetts Division of Marine Fisheries fall and spring trawl surveys that measure relative abundance of species throughout state waters, but do not measure fine-scale distribution patterns.

Reviewing the existing data is the fundamental first step in understanding potential impacts. Based on this review, PCCS has concluded that baseline monitoring is necessary to assess the abundance and distribution of marine animals and fishes in the Nantucket Sound - Muskeget Channel area followed by monitoring during operation to assess potential impacts. It is relevant to note that the recommendations are being considered by the Town of Edgartown in the context of obtaining a short-term (5-8 year) permit to construct and operate a tidal energy pilot project whose primary purpose is collect information and fill data gaps on the potential environmental impacts of such installations. These recommendations have been used to develop study plans which have been submitted by the Town of Edgartown in its Draft Pilot License Application to FERC.

\subsection{Marine Megavertebrates}

Existing information on the presence of marine megavertebrates in Muskeget Channel and surrounding waters is summarized below. Megavertebrates include cetaceans, pinnipeds (seals), turtles, basking sharks and sunfish. Appendix C provides more detail on the life history of each species.

\subsubsection{Cetaceans}

Broad-scale seasonal distribution patterns of most cetacean species in the waters of the Northeastern United States are relatively well understood (Kenney and Winn, 1986; Kenney et al., 1996; Pittman et al., 2006). However, systematic survey effort has been very low in the waters immediately south of Cape Cod, including the Muskeget Channel area (Pittman et al., 2006; see also Data Summary). This section reviews the occurrence of baleen whales, including endangered North Atlantic Right, fin, sei and humpback whales, and a summary of the occurrence of the endangered sperm whale and several other species of toothed whales.

\subsubsection{Baleen Whales}

North Atlantic right whales (Eubalaena glacialis) are listed as endangered under the U.S. Endangered Species Act. A minimum of 415 individuals were thought to be alive in 2007 (Pettis, 2009). Right whales 
are distributed from winter calving grounds in the waters of the Southeastern United States north to summer feeding grounds in the Bay of Fundy and on the Scotian Shelf, with rare sightings in the Gulf of Mexico and off Greenland and Norway (Winn et al., 1986; Waring et al., 2009). Right whales are present in Cape Cod Bay in winter and spring (Hamilton and Mayo, 1990; Nichols et al., 2008) and the Great South Channel in late spring (Kenney et al., 1995), where they feed on dense concentrations of zooplankton, particularly calanoid copepods (Mayo and Marx, 1990; Beardsley et al., 1996). Pittman et al. (2006) analyzed the limited systematic survey effort available in the area south of Cape Cod, including Muskeget Channel, and noted that right whale sightings-per-unit effort (SPUE) was very low, with 0.18.2 whales sighted per $1,000 \mathrm{~km}$ of survey effort in most of the area. Given the low survey effort in the area, opportunistic sightings warrant further discussion, as do patterns of historical occurrence.

Historical information shows that the nearshore waters off Nantucket Island were productive hunting grounds for shore-based whalers as early as the mid-1600s. Record of catch locations suggest that most were distributed to the south or east with a few documented from Nantucket Sound. As for opportunistic sightings, the North Atlantic Right Whale Consortium keeps a database of right whale sightings recorded in the area (Right Whale Consortium, 2010; Figure 38). Of particular interest is the occurrence of a relatively large number of right whales in winter/spring 2010 in Nantucket, Vineyard and Rhode Island Sounds and the waters immediately south of Nantucket (Kenney, 2010). Sightings in the Sounds reported to the North Atlantic Right Whale Sighting Advisory System during winter and spring 2010 ( $\mathrm{n}=105$; most of which occurred in Rhode Island Sound) presented by Kenney (2010) are included in Figure 2.1. These sightings were not yet entered into the Right Whale Consortium sightings database at the time of this writing. The combination of opportunistic sightings in the past few decades and present-day reports suggests that in some years, particularly during the winter and early spring, right whales may still be found in the near-shore waters of Nantucket Island and Martha's Vineyard as well as Nantucket Sound.
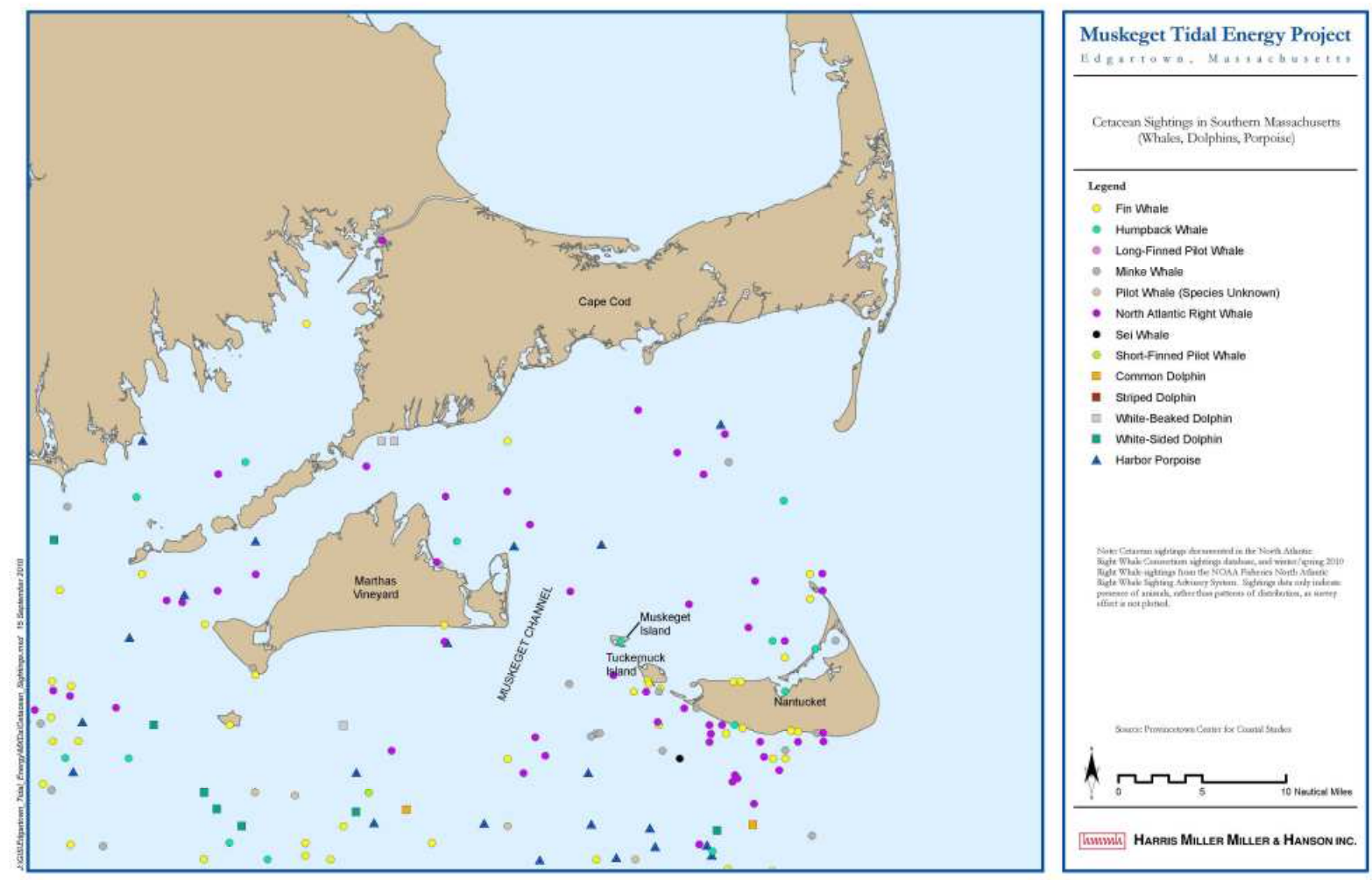

Figure 41: Cetacean Sightings in Southern Massachusetts 
Four other species of baleen whales occur frequently in Northeastern U.S. waters: fin (Balaenoptera physalus), sei (Balaenoptera borealis), humpback (Megaptera novaeangliae) and minke whales (Balaenoptera acutorostrata). All of these except for the minke are listed for protection under the Endangered Species Act. In the study area south of Cape Cod, including Muskeget Channel, SPUE of fin, sei, minke and humpback whales was very low or zero (Pittman et al., 2006). Given the low survey effort in the area, all sightings, including those recorded opportunistically, warrant further discussion. Sightings of fin $(n=141)$, sei $(n=1)$, humpback $(n=27)$, and minke $(n=23)$ whales archived in the North Atlantic Right Whale Consortium sightings database (Right Whale Consortium 2010) were generally distributed to the south of Nantucket Sound. However, this does not necessarily reflect spatial distribution patterns, as systematic survey effort in the study area was distributed in a similar manner. Stranding data obtained from NOAA Fisheries for animals that stranded on or in the vicinity of Martha's Vineyard, Nantucket and nearby islands included records of fin $(n=4)$, sei $(n=1)$, humpback $(n=7)$ and minke $(n=9)$ whales. Stranding data must be interpreted with caution, as unhealthy or otherwise compromised animals may not ordinarily occur in the area, and carcasses can drift from distant locations.

\subsubsection{Toothed Whales}

Numerous species of toothed whales occur off the northeastern U.S., including Atlantic white-sided dolphin (Lagenorhynchus acutus), bottlenose dolphin (Tursiops truncatus), common dolphin (Delphinus delphis), harbor porpoise (Phocoena phocoena), pilot whales (Globicephala spp.), pygmy sperm whale (Kogia breviceps), Risso's dolphin (Grampus griseus), sperm whale (Physeter macrocephalus), striped dolphin (Stenella coeruleoalba) and white-beaked dolphin (Lagenorhynchus albirostris) (Katona et al., 1993). Of these species, only the sperm whale is listed as endangered under the Endangered Species Act.

Pittman et al. (2006) analyzed survey data for the following species as well as unidentified toothed whales and noted low or zero SPUE throughout the area south of Cape Cod, including Muskeget Channel: Atlantic white-side dolphin, bottlenose dolphin, common dolphin, harbor porpoise, pilot whales, Risso's dolphin and white-beaked dolphin. Sightings of toothed whales archived in the North Atlantic Right Whale Consortium sightings database (Right Whale Consortium 2010) were generally distributed to the south of Nantucket Sound (see Figure 38). However, this does not necessarily reflect spatial distribution patterns, as systematic survey effort in the study area was distributed in a similar manner. Stranding data obtained from NOAA Fisheries for animals that stranded on or in the vicinity of Martha's Vineyard, Nantucket and nearby islands are listed below and compared to the Right Whale Consortium sightings data from the broader area including the waters to the south as defined in the Data Summary. The stranding data included the above species as well as the pygmy sperm whale, sperm whale and striped dolphin. The strandings of sperm whales are noteworthy, as the species is listed as endangered under the U.S. Endangered Species Act.

Table 3 presents strandings data for the islands south of Cape Cod as reported by the Right Whale Consortium and NOAA Fisheries. 
Table 3: Comparison of strandings data from NOAA Fisheries for animals that stranded on or in the vicinity of Martha's Vineyard, Nantucket, and nearby islands with Right Whale Consortium sightings data for the same region

\begin{tabular}{|l|c|c|}
\hline \multicolumn{1}{|c|}{ Species } & Right Whale Consortium & NOAA \\
\hline Atlantic white-sided dolphin & 759 & 4 \\
\hline Bottlenose dolphin & - & 31 \\
\hline Common dolphin & 65 & 8 \\
\hline Harbor porpoise & 66 & 22 \\
\hline Pilot whale (all spp.) & 133 & 7 \\
\hline Pygmy sperm whale & - & 8 \\
\hline Risso's dolphin & - & 4 \\
\hline Sperm whale & - & 8 \\
\hline Striped dolphin & 1 & - \\
\hline White-beaked dolphin & 50 & \\
\hline
\end{tabular}

Although caution is necessary when interpreting stranding data as well as sightings data due to lack of systematic effort, it is noteworthy that so few Atlantic white-sided dolphins strand on the islands around the study area when compared to the number of animals documented in the Right Whale Consortium sightings data. Such discrepancies may reflect offshore distributions of this and other species.

\subsubsection{Pinnipeds}

Nantucket Sound is home to a resident gray seal (Halichoerus grypus) population and a seasonal harbor seal (Phoca vitulina concolor) population. Gray seals utilize areas of Nantucket Sound for pupping, molting, foraging and hauling out. Harbor seals are found in Nantucket Sound during the winter months ( $\sim$ September to April) and utilize the Sound for foraging and hauling out. Harbor seals move north of the Massachusetts/New Hampshire border for pupping and molting. Harp (Pagophilus groendlandicus) and hooded (Cystophora cristata) seals also occur sporadically in Nantucket Sound (see Table A1 for strandings data). A review of museum records from 1632 to the present demonstrate that both harbor and gray seals had an historic presence in Nantucket Sound. As reported by Ritchie (1969) harbor and gray seal remains were found in archeological sites on Martha's Vineyard. Seal bounties in Massachusetts and Maine existed during the late $19^{\text {th }}$ and early $20^{\text {th }}$ centuries. Massachusetts ended its bounty in the early 1960's. State and federal protections enacted since then have helped populations rebound over the past 50 years. All marine mammals, including gray seals and harbor seals, are protected by the Marine Mammal Protection Act of 1972 as amended.

\subsubsection{Harbor Seal}

In order to understand the abundance and seasonal distribution of harbor seals in Nantucket Sound, it is necessary to consider the U.S. Atlantic harbor seal population as a whole. Harbor seals use Southern New England (including Nantucket Sound) for hauling out and foraging during the fall, winter and spring but return to Maine (or possibly Canada) for pupping, mating and molting (Waring et al., 2006; Figure 39). Waring et al. (2006) reported that $75 \%$ of the harbor seals radio-tagged in Chatham, Massachusetts during the month of March relocated to Maine later in the spring. Gilbert et al. (2005) describes a 6.6\% rate of increase in the number of harbor seals hauled out during the pupping season from 1981 to 2001 along the Maine coast. The corrected count for 2001 was 99,340 seals and is an estimate of the total U.S. Atlantic harbor seal population. Although not a current estimate, this data set demonstrates a steady increase in the number of harbor seals in U.S. Atlantic waters. 

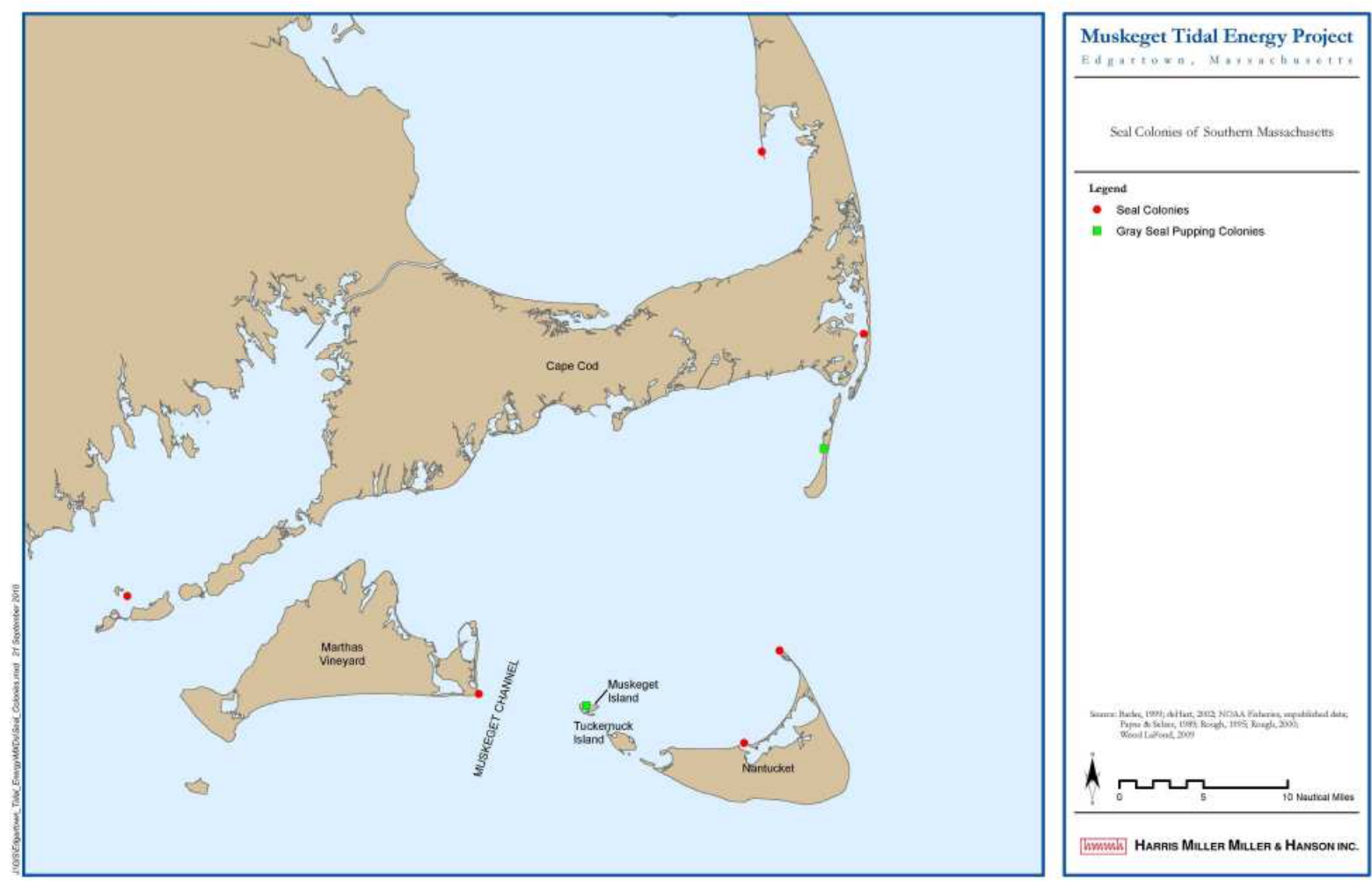

Figure 42: Seal Colonies of Southern Massachusetts

Payne and Selzer (1989) documented winter harbor seal abundance in Southern New England from 1983 through 1987 (Figure 40). As with Gilbert's data set, these data provide evidence of an increase in the number of harbor seals in the Atlantic U.S. This trend is even more apparent when Payne and Selzer's counts are compared to Barlas's (1999). Barlas (1999) collected aerial survey data in the Plymouth to Woods Hole region between 1998 and 1999. This study provides the most recent harbor seal abundance estimates for Southern Massachusetts including Nantucket Sound, and also shows a winter peak in harbor seal abundance. Barlas also surveyed west of Martha's Vineyard and counted 198 harbor seals in March of 1999 on Nomans Land (a National Wildlife Refuge). deHart (2002) documented peak harbor seal abundance in Woods Hole in the February to April time period. He also found a slight increase in the number of harbor seals hauled out in Woods Hole from $2001(n=164)$ to $2002(n=184)$. Counts of harbor seals at the Nantucket jetties (NMFS unpub. data) show presence there during the winter months from 2004 to 2008. Finally, a study of harbor seal abundance and seasonal distribution in Narragansett Bay, Rhode Island (Schroeder, 2000) provides additional evidence of an increase in the number of harbor seals in Southern New England and a seasonal peak during the winter in this region. From these data sets, Monomoy Island (a National Wildlife Refuge) is the only location in Nantucket Sound where there has been a documented decline in the number of harbor seals. This decline has occurred as the Nantucket Sound gray seal has population has been growing. 


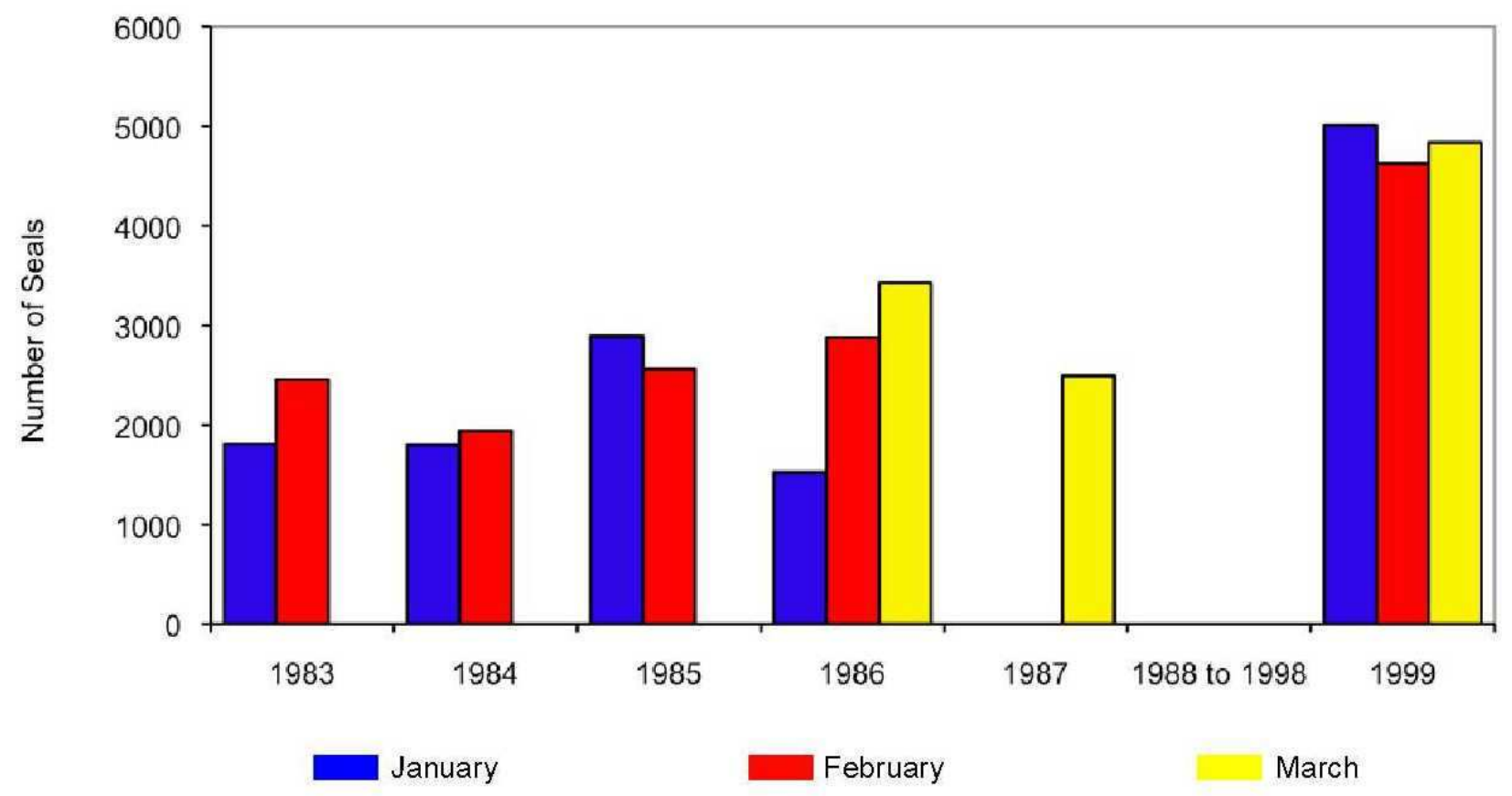

Figure 43: Harbor Seal Abundance from Plymouth to Woods Hole, Massachusetts (Payne \& Selzer 1989; Barlas 1999)

\subsubsection{Grey Seal}

Muskeget Island is the largest gray seal pupping colony in the U.S. Pup counts from aerial survey data are available in Rough (1995, 2000) and Wood LaFond (2009) from 1991 through 2008 (Figure 41). No data is available for 2000. The number of pups born on Muskeget has increased dramatically over this time period. Only 6 pups were born in 1991. Seventeen years later, on 15 January 2008, a minimum of 2,090 pups were counted. The data available outside of the pupping season is older and not as continuous. Reports by Rough $(1995,2000)$ and Barlas (1999) contain gray seal counts during the spring molt season at Muskeget and Monomoy Islands for several years in the 1990s. Although out of date, these counts also show an increase in the number of gray seals in Nantucket Sound during the months of April and May. Ampela (2009) collected scat samples at Muskeget and/or Monomoy Islands during every season from winter 2004 to winter 2008 and thereby documented a continued presence of gray seals in Nantucket Sound. In addition to these sites, when Wasque Shoal is available, gray seals utilize it (Wood LaFond, pers. obs.). Wasque Shoal is located between Nantucket and Martha's Vineyard Islands and periodically appears due to strong currents and storms. Sette (unpublished data) has also documented gray seals on tidal haul-outs near Gull and Penikese Islands (Elizabeth Islands). These studies together provide evidence for an increasing, permanent gray seal population in Nantucket Sound. Whalenet (http://whale.wheelock.edu/), an educational program at Wheelock College funded by the National Science Foundation, has worked with scientists to deploy numerous satellite tags on harbor and gray seals. Thirteen of the tagged seals spent time in Nantucket Sound or around Cape Cod. Results of genetic analyses have shown that U.S. gray seals constitute a trans-boundary stock. To identify the source population for the recovering U.S. gray seal population and to assess the stock structure of gray seals in the Northwestern Atlantic, Wood LaFond (2009) collected a total of 231 tissue samples from both Canadian and U.S. populations for genetic analyses. Samples were collected (mostly from pups) at three sites during the pupping season: Sable Island (Canada), the Gulf of St. Lawrence (Canada) and Muskeget Island (Massachusetts). These analyses showed that there was no significant difference between the three sites sampled, demonstrating that an adequate number of individual gray seals are moving between these pupping sites for the sites to be indistinguishable from each other. See Wood LaFond (2009) for more detail. 


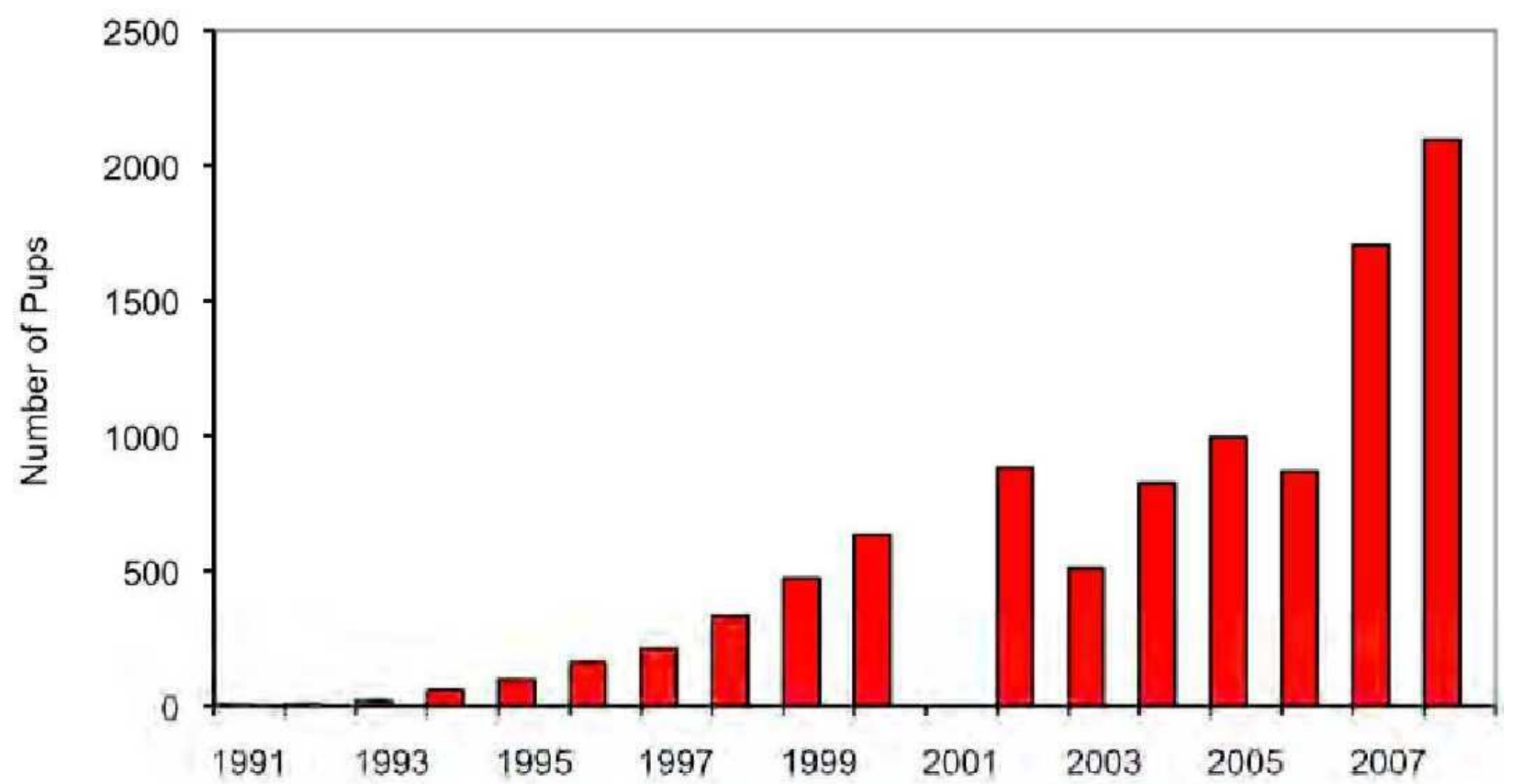

Figure 44: Gray Seal Pup Counts on Muskeget Island, Massachusetts, 1991-2008 (Rough, 1995, 2000; Wood LaFond, 2009)

\subsubsection{Dermochelids and Chelonids}

There are four species of sea turtles that have been recorded in Nantucket Sound either seasonally foraging or transiting the waters south of Cape Cod: leatherback (Dermochelys coriacea), loggerhead (Caretta caretta), green (Chelonia mydas) and Kemp's ridley (Lepidochelys kempi) (Jones, 1886; Lazell, 1976; Lazell, 1980; USFWS and NMFS, 1992; Prescott, 1988; Dwyer et al., 2003; Perkins et al., 2003; Morreale and Standora, 2005; Sadoti et al., 2005; Ernst and Lovich, 2009; http://www.seaturtlesightings.org/, 2010). A fifth species, the hawksbill (Eretmochelys imbricate), is considered to be a "rare" vagrant to New England (Lazell, 1976). Depending on the age and species, sea turtles will typically migrate offshore or south to their nesting beaches in fall as local water temperatures decrease (Bleakney, 1965; Lazell, 1976; Shoop and Kenney, 1992; Wynne and Schwartz, 1999; Ernst and Lovich, 2009). Another marine reptile, the northern diamond-backed terrapin (Malaclemys terrapin), is a salt marsh turtle and year round resident of Massachusetts. While not considered a sea turtle, the northern diamond-backed terrapin inhabits estuaries, rivers, creeks, salt marshes and mud and is known to nest in dry, sandy uplands near its foraging areas (Babcock, 1926; Lazell, 1976; Lewis, 2002; Brennessel, 2007). There are records of northern diamondbacked terrapin from areas along the southwest coastal region of Cape Cod (Babcock, 1926; Lazell, 1976; Brennessel, 2007).

All sea turtles included in this report are listed under the Endangered Species Act (ESA) of 1973 except for the diamond-backed terrapin, which is listed by Massachusetts as threatened. The leatherback, Kemp's ridley and hawksbill are listed as endangered at the federal and state level; the loggerhead and green are listed as threatened at the federal and state level (NMFS and USFWS, 1991a; NMFS and USFWS, 1991b; USFWS and NMFS, 1992; NMFS and USFWS, 1995; NMFS and USFWS, 1998b; NMFS and USFWS, 2007a, 2007b, 2007c, 2007d; http://

www.mass.gov/dfwele/dfw/nhesp/species_info/mesa_list/mesa_list.htm, 2010). The International Union for Conservation of Nature (IUCN) Red List categorizes loggerhead and green sea turtles as "endangered" (Marine Turtle Specialist Group, 1996a; Seminoff, 2004), while the leatherback, Kemp's ridley and hawksbill are listed as "critically endangered" (Marine Turtle Specialist Group, 1996b; Martinez, 2000; Mortimer and Donnelly, 2008). 
Data on sea turtle distribution and abundance has been collated from a number of sources.

The Sea Turtle Sighting Hotline for Southern New England Boaters was initiated in 2002. Its primary goals are to document where and when sea turtles are seen in Southern New England waters and to alert boaters to the presence of sea turtles in the summer and fall. Data points included in the hotline database do not represent a systematic survey, nor do they represent an accurate count of sea turtles since multiple calls may report the same individual turtle. The majority of hotline reports are from waters around Cape Cod, including Buzzards Bay, Vineyard Sound, Nantucket Sound and Cape Cod Bay. Hotspots have been noted off Sakonnet Point (Rhode Island) and near Lucas Shoal in Vineyard Sound. Many of the August sightings are from the recreational fishing areas south of Martha's Vineyard and Nantucket Islands. Sightings are plotted on maps posted on the hotline's website: www.seaturtlesightings.org (K. Moore Dourdeville, pers. comm., 24 August 2010).

The Massachusetts Audubon Society conducted aerial surveys for seabirds associated with the Cape Wind Project. During its avian surveys, it also collected opportunistic information on sea turtles. These data points are presented on Figure 42.
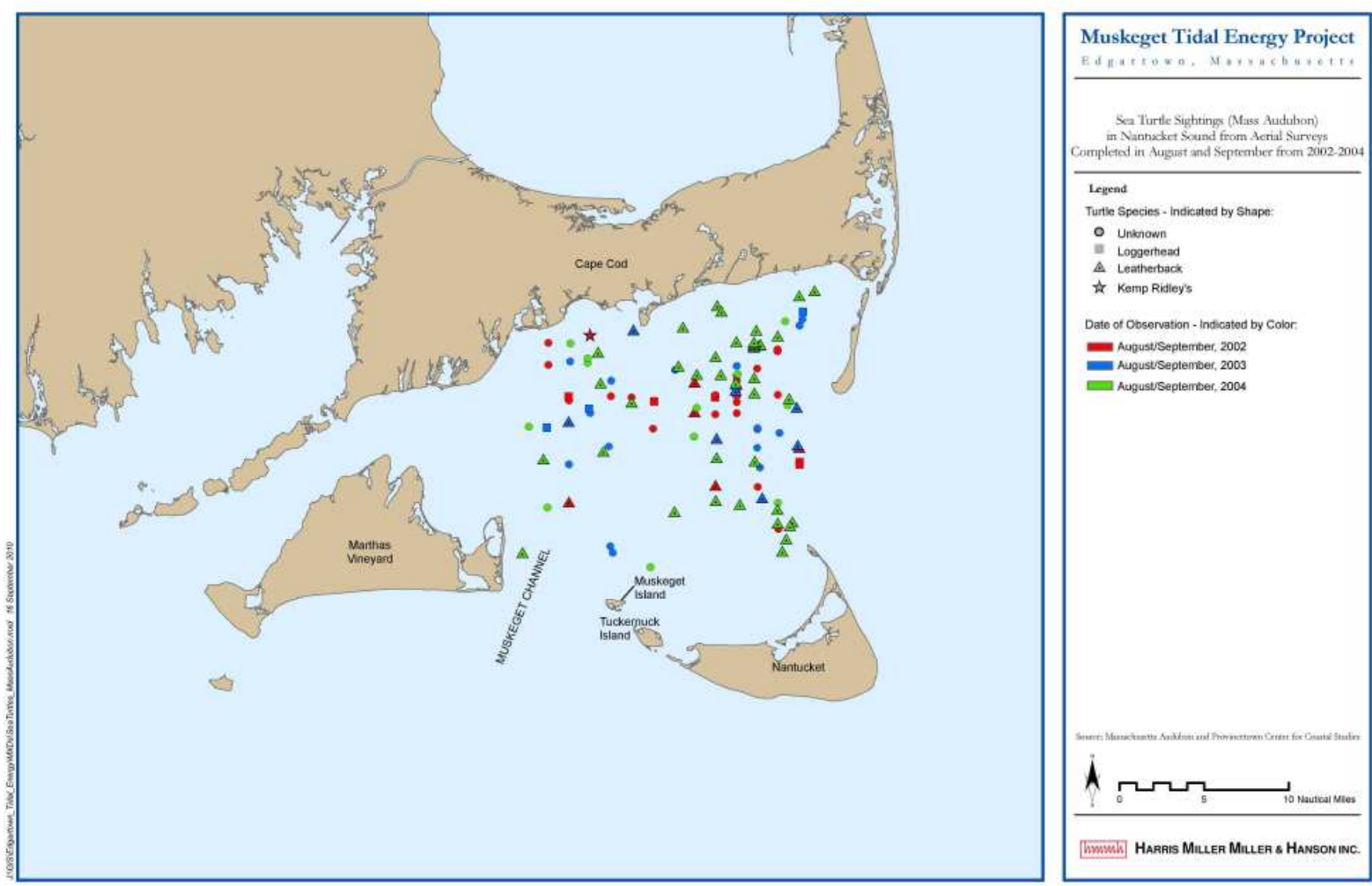

Figure 45: Sea Turtle Sightings in Nantucket Sound from Aerial Surveys

Since initiating satellite tagging of leatherback turtles in Nantucket Sound, researcher Kara Dodge from the University of New Hampshire Large Pelagics Research Center has tagged twenty leatherbacks off Massachusetts. Based on her track analysis, three of the twenty turtles may have navigated through Muskeget Channel during the monitoring period. No turtles in her study took up residence in Muskeget Channel for any period of time, primarily using it to move between Nantucket Sound and regions south of Martha's Vineyard and Nantucket Islands. In 2008, George Breen, a spotter pilot utilized by the research team, reported seeing three leatherbacks using Muskeget Channel. Based on her work to date, Dodge suggests that leatherbacks appear to favor areas where tidal fronts may entrain and aggregate gelatinous 
zooplankton, thus forming dense prey patches and enabling leatherbacks to forage efficiently (K. Dodge, pers. comm., 26 August 2010).

In late fall and winter when the ocean environment cools, sea turtles remaining in Massachusetts waters can become "cold stunned," a form of hypothermic reaction caused by prolonged exposure to cold water temperatures (http://www.nero.noaa.gov/prot_res/stranding/cold.html). Severely cold-stunned turtles become lethargic and drift helplessly, resulting in animals coming ashore alive (Lazell, 1976). As summarized in Dodge et al. (2008) from 1979 to 2002, 1,289 sub-adult and adult cold-stunned marine turtles were discovered stranded on Cape Cod beaches. Of those turtles stranded, 76.6\% were Kemp's ridley, $21.1 \%$ loggerhead, $2.3 \%$ green and $0.03 \%$ hybrid. These data and other reports suggest that the northeast coast might be an important foraging area for these species (Lazell, 1976; Lazell, 1980; Burke et al., 1991; Morreale and Sandora, 2005).

The Massachusetts Sea Turtle Disentanglement Network (MASTDN) was formed to respond to and document bycatch issues related to sea turtles in and around the state waters of Massachusetts. From its inception in 2005 to the present (12 September 2010), MASTDN has received 77 confirmed entanglement reports. Of those, 46 reports are from the waters of Nantucket Sound, Vineyard Sound and Buzzards Bay (Figure 43). Entanglement reports are received seasonally from May to October with a peak during August. A majority of the reports in the study area involve leatherback sea turtles $(n=44,96 \%)$, with only two $(n=2,4 \%)$ involving species other than leatherbacks: one loggerhead and one turtle unidentifiable due to decomposition. Support for this work is provided by ESA Section 6 in conjunction with Massachusetts Division of Marine Fisheries. Data can only be used for the purpose of this literature review and should not be used for any other reason or application without the express written consent of PCCS.
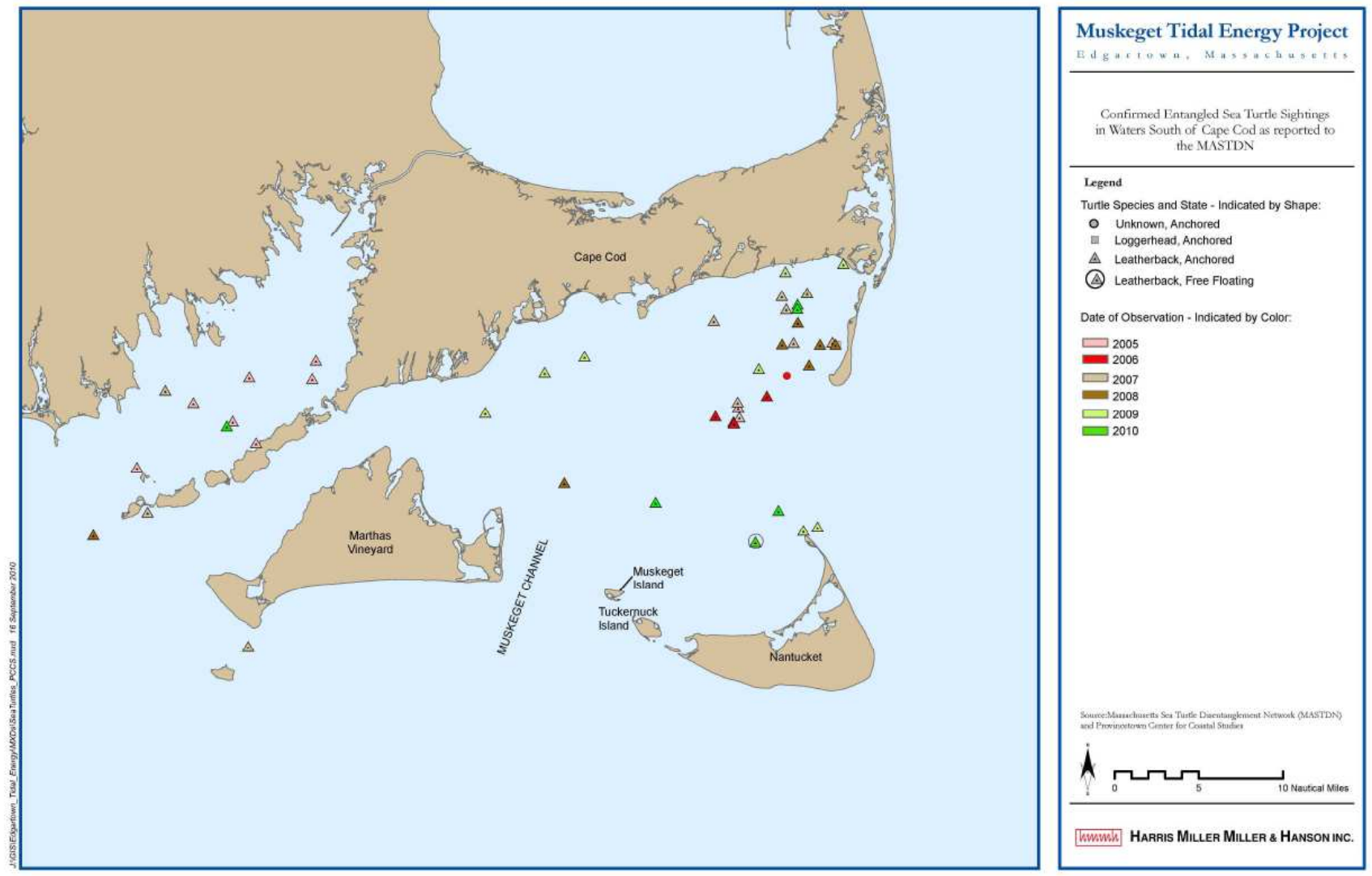

Figure 46: Confirmed Entangled Sea Turtle Sightings Reported to the MASTDN 


\subsubsection{Basking Shark}

The common name of the basking shark, Cetorhinus maximus, refers to its appearance of "basking" while feeding at the surface. The basking shark is the second largest fish in the world (over $9 \mathrm{~m}$ total length), second in size only to the whale shark. Basking sharks are filter feeders, straining zooplankton from the water using gill rakers inside their gill slits, which extend almost completely around the head and are located behind their conical snout and large mouth (Martin and Harvey-Clark, 2004). The aforementioned features render the basking shark easily identifiable.

The basking shark is distributed circumglobally, occurring in the North and South Atlantic Oceans, Mediterranean Sea, North and South Pacific Oceans, Sea of Japan, off southern Australia and around New Zealand (Compagno, 2001). Canadian records from both Atlantic and Pacific waters indicate C. maximus occurs in most coastal temperate waters where temperatures exceed 6-7 ${ }^{\circ} \mathrm{C}$ (Campana et al., 2008), and recent tagging efforts indicate that migrations to tropical waters also occur (Skomal et al., 2009).

The life history of basking sharks is poorly understood; however, long lifespan, slow growth and low fecundity likely render this species vulnerable to reductions in population (Martin and Harvey-Clark, 2004). Despite advances in understanding of the species' distributional ecology, data are lacking on population structure and size with which to assess conservation status (Sims et al., 2008). Relative abundance indices in U.S. waters have exhibited little variation since 1979 (Campana et al., 2008). Basking sharks are listed under Appendix II of the Convention on International Trade in Endangered Species of Wild Fauna and Flora (CITES) and listed as "vulnerable" globally and "endangered" in the Northeastern Atlantic and in the North Pacific by the International Union for Conservation of Nature (IUCN; Sims, 2008). In U.S. waters, federal regulations prohibit fishermen from possessing basking sharks.

Sighting frequency of basking sharks off the northeast U.S. is highest from May-August (Kenney et al., 1985; Campana et al., 2008). Sightings in the vicinity of the study area in the North Atlantic Right Whale Consortium sightings database $(n=104)$ reflected a similar temporal distribution and generally occurred south of Martha's Vineyard and Nantucket Islands (Figure 44; Right Whale Consortium, 2010). However, this does not necessarily reflect spatial distribution patterns, as systematic survey effort in the study area was distributed in a similar manner. Two additional sightings recorded during 2003-2004 aerial seabird surveys conducted by the Massachusetts Audubon Society in Nantucket Sound (See Data Summary) are included in Figure 44; Skomal (2007) summarized opportunistic examinations of stranded basking sharks in Massachusetts coastal waters, noting that six of seven fish examined (one of which was stranded on Martha's Vineyard) were immature, suggesting that study area waters may serve as secondary nursery habitat for the species. 

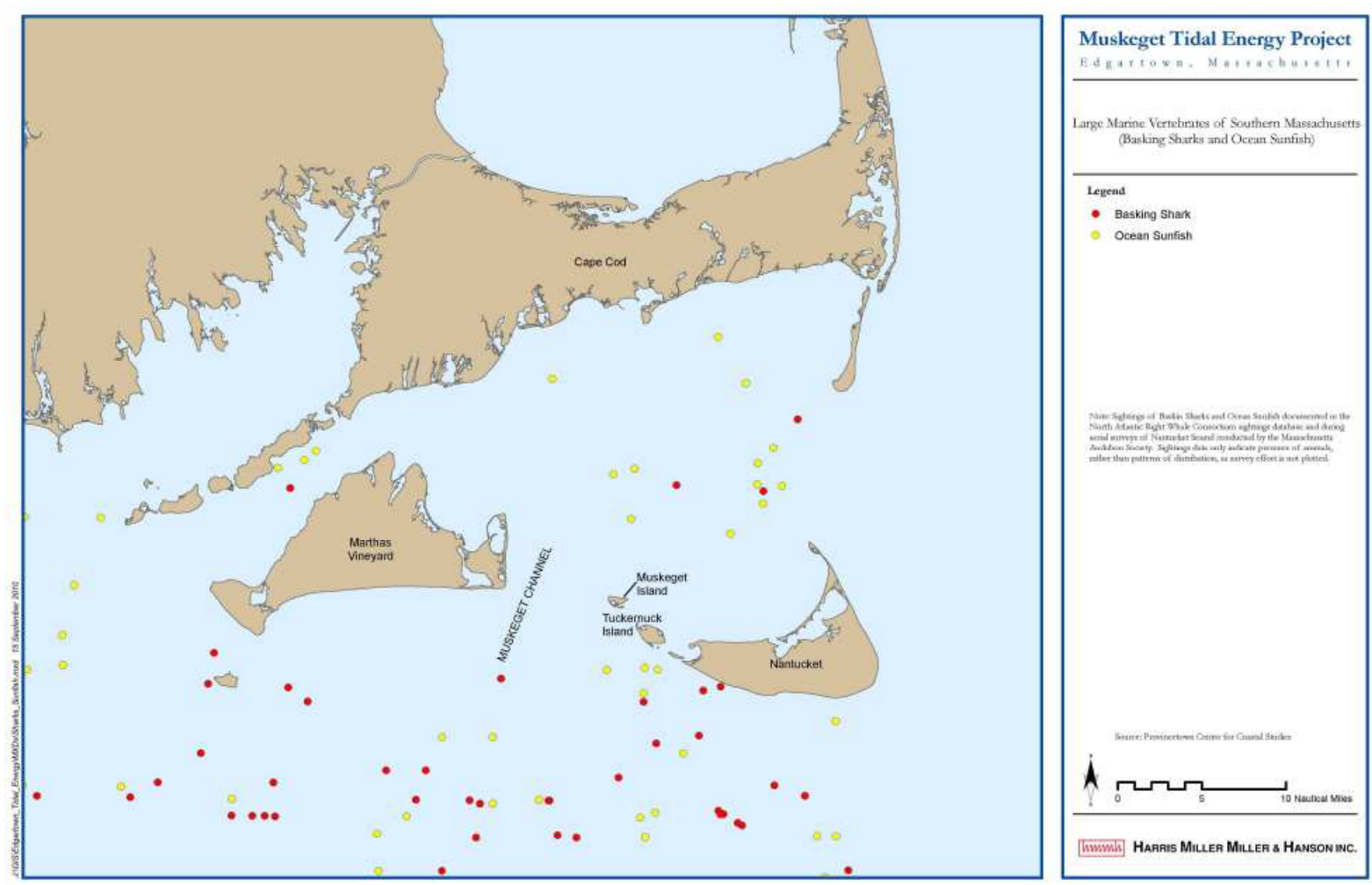

Figure 47: Basking Shark and Ocean Sunfish Sightings for Southern Massachusetts

\subsubsection{Ocean Sunfish}

The ocean sunfish (Mola mola) is the largest bony fish in mass - a $2.7 \mathrm{~m}$ record-length specimen weighed $2.3 \mathrm{mt}$ (Pope et al., 2010). There are virtually no fisheries for M. mola, although they are frequently bycaught in other fisheries (e.g. Silvani et al., 1999), and much of the species' biology and ecology remains unknown. Distribution is worldwide in temperate and tropical seas, but an accurate accounting of range or abundance is nonexistent due to the lack of fisheries and the associated data collection. No quantitative information exists on diet or habitat requirements, and while many observations indicate near-surface feeding on gelatinous zooplankton, stomach contents and recent telemetry studies indicate than ocean sunfish may be omnivorous and feed throughout the water column (Pope et al., 2010). Bigelow and Schroeder (1953) reported that stomachs of all specimens brought to the Bureau of Fisheries in Woods Hole appeared to contain remnants of jellies, ctenophores, or salps.

Due to the lack of data, conservation status of this species is difficult to assess. Kenney (1995) estimated ocean sunfish abundance from aerial surveys in the shelf waters from Cape Hatteras north to the Gulf of Maine, noting that abundance in Southern New England waters peaked in summer and declined to zero in winter and distribution patterns were similar to those of leatherback turtles. Sightings in the vicinity of the study area in the North Atlantic Right Whale Consortium sightings database $(n=37)$ reflected a similar temporal distribution and generally occurred south of Martha's Vineyard and Nantucket Islands (Figure 44; Right Whale Consortium, 2010). However, this does not necessarily reflect spatial distribution patterns, as systematic survey effort in the study area was distributed in a similar manner (See Data Summary). Sadoti et al. (2005) noted 17 sightings of ocean sunfish in August and September of 20022004 during aerial surveys for seabirds in Nantucket Sound, but did not plot sighting locations. Sighting locations from 2003-2004 surveys were obtained from the Massachusetts Audubon Society (See Data Summary) and are included in Figure 44. 


\subsubsection{Fisheries}

There is little readily available data with which to evaluate the specific importance of the Muskeget Channel study area to commercial and recreational fisheries (DT\&A, 2006). During the Massachusetts Ocean Management Plan development process, the Muskeget Channel area was designated as an area of "medium importance" to fisheries resources based on analysis of 30 years of trawl survey data (Commonwealth of Massachusetts, 2009). Mapping of commercial fisheries activity indicated that "low" to "medium" levels of commercial fishing activity occur in Muskeget Channel. The Channel and surrounding waters are considered to be of "high importance" to recreational fisheries based primarily on landings data and interview-based surveys (Commonwealth of Massachusetts, 2009).

While the above analyses used a spatially-explicit approach to identify areas of importance to fisheries, the trawl surveys were designed to measure relative abundance of species rather than fine-scale distribution patterns, and effort is scarce in the Muskeget Channel area (King et al., 2010). Further, many species, including pelagics, shellfish and forage fish, are not vulnerable to capture during the surveys, which occur only in spring and fall (Commonwealth of Massachusetts, 2009; King et al., 2010). The maps of fishing effort were also interpolated from fisheries-dependent data collected at coarser spatial scales. While the Ocean Management Plan process incorporated a detailed spatial analysis, it is impossible to make species- and fishery-specific interpretations of the maps at the scale of an area the size of Muskeget Channel. Therefore, the following section will focus on fisheries activity and resources within the larger Nantucket Sound area, with specific reference to Muskeget Channel when possible.

\subsubsection{Commercial Fisheries}

Recent attempts to characterize the fisheries of Nantucket Sound have been hampered by absent or overlapping data on effort and landings (MMS, 2009). Fisheries-dependent data are generally binned into either state or federal statistical reporting areas. The Muskeget Channel study area falls within Massachusetts Division of Marine Fisheries (DMF) Area 10 (Nantucket Sound) and Area 12 which includes state waters (3 $\mathrm{nm}$ from shore) to the south of Martha's Vineyard and Nantucket (http://www.mass.gov/dfwele/dmf/commercialfishing/inshore_areas.htm). Most of the project falls within federal NOAA Fisheries statistical Area 538, which includes Nantucket and Vineyard Sounds as well as Buzzards Bay, although the much larger Area 537 borders the study area to the south.

In studies of the fisheries of Nantucket Sound for the Cape Wind Energy Project, a subarea of Area 538 that roughly overlaps DMF Area 10, called Area 075, was used to define federal landings within the Sound (ESS, 2006a). The coarse spatial scale of the publicly available data from Nantucket Sound as assembled by ESS (2006a) and reviewed by MMS (2009) renders it difficult to make conclusions about specific gears or species within the Muskeget Channel study area. The following is a summary of available information on commercial fisheries within Nantucket Sound, based largely on the review conducted by MMS (2009), except where otherwise cited.

Commercial fisheries in Nantucket Sound are diverse, targeting many species of fish and invertebrates, including squid, conch, quahogs, fluke, sea bass, bluefish, striped bass, Atlantic mackerel and lobster. Fishing gears employed in the Sound include otter trawls, dredges, weirs, seines, traps, pots and hand lines. The dominant gear type in the Sound (Area 538/075) reported via federal Vessel Trip Reports (VTRs) is the otter trawl. Interpretation of landings data even at this large scale must be done with caution due to the overlap between state- and federally-reported fisheries, as well as gaps in federally-reported landings due to vessels with state-only permits (e.g. Massachusetts Coastal Access Permits for squid and fluke; Wiersma, 2008). The top ten federally-reported species of finfish (including squid; annual average catch in weight) from 1998-2007, in decreasing order of percent total catch, were squid, fluke, Atlantic mackerel, black sea bass, scup, bluefish, menhaden, butterfish, winter flounder and king whiting, together comprising $99 \%$ of all landings in Nantucket Sound. Squid accounted for 50\% of total annual average 
catch, while the second largest component (fluke) was $14 \%$ of the total. Within Massachusetts waters, virtually all squid landings occur within Nantucket Sound and neighboring Vineyard Sound in spring and summer (McKiernan and Pierce, 1995). Federally-reported landings of shellfish are dominated by conch (88\%) and include ocean quahogs, surf clams, hard clams and horseshoe crabs, comprising 99\% of 19982007 VTR catches (MMS, 2009).

State-reported landings in Nantucket Sound (DMF Area 10) primarily include squid and finfish catches from hook and line, fish weirs, gillnets lobster and fish pots, as well shellfish landings collected by municipalities. Weir fishing effort occurs primarily in the Northeastern Sound. The top ten state-reported species of finfish (including squid; annual average catch in weight) from 1998-2007, in decreasing order of percent total catch, were black sea bass, Atlantic mackerel, squid, fluke, scup, striped bass, menhaden, bluefish, butterfish and bonito, together comprising $99 \%$ of all landings in Nantucket Sound. Statereported landings of shellfish are dominated by conch (72\%) and include hard clams and lobsters, comprising $99 \%$ of 1998-2007 DMF catches (MMS, 2009).

Distribution of fisheries effort in state waters around the boundaries of the Sound is mapped in the Massachusetts Ocean Management Plan, but is not specific to species or gear type. Federal VTR data were mapped by MMS (2009), indicating that squid catches were concentrated in the central portion of the Sound north of Muskeget Channel, fluke catches were primarily located on the eastern side of the Sound with a small concentration northwest of Muskeget Channel and shellfish landings were concentrated on the eastern side of the Sound. Cape Poge Bay, which lies immediately west of Muskeget Channel, contains eelgrass habitat which supports a variable but productive bay scallop fishery, which contributed 57\% of Martha's Vineyard's total 1991-2004 bay scallop landings (MacKenzie, 2008). Surveys of commercial fishermen fishing in the Sound indicated that mobile gear fishing effort followed the above patterns, with minimal effort in the Muskeget Channel area (off Cape Poge). Summer hookand-line fishing for bluefish and striped bass, as well as fall trawling for fluke and hook-and-line fishing for black sea bass and tautog, were among the fishing activities undertaken at a "medium" activity level (15-30\% of active vessels fishing); no activity in the Channel was listed as greater than $30 \%$ of active fishing effort (ESS, 2006b). Hall-Arber et al. (2004) interviewed commercial fishermen who fished in the Sound and noted that fishing primarily occurs during spring, summer and fall, with little winter effort. Participating fishermen mapped their knowledge of fishing effort, indicating that mobile gear effort was concentrated in the central and eastern portions of the Sound, while "other" gears were used in the remainder of the Sound, including the Muskeget Channel area. No mobile gear (e.g. otter trawl) fishing effort was indicated in the Channel. Limited sample sizes and a focus on the area of the proposed Cape Wind energy project indicate that the results of the Hall-Arber et al. (2004) and ESS (2006b) studies should be interpreted cautiously.

The Muskeget Channel study area straddles the boundary between two ten-minute squares within which Essential Fish Habitats (EFH) are designated under the 1996 amendments to the Magnuson-Stevens Fishery Conservation and Management Act (MSFCMA). Most of the study area falls within the 10minute square between $41^{\circ} 20^{\prime}-41^{\circ} 30^{\prime} \mathrm{N}$ and $70^{\circ} 20^{\prime}-70^{\circ} 30^{\prime} \mathrm{W}$. Discussion will be limited to those species with EFH designations found within the above boundaries because the adjacent square to the south encompasses only a small portion of the study area and a larger area of other habitat types south of the Sound. This discussion is intended to highlight species of potential importance should a formal EFH assessment be conducted and is not an exhaustive summary of species for which EFH assessment may be necessary. A formal EFH consultation process coupled with an understanding of the potential project impacts will better inform this discussion and the list of species for which EFH may need to be considered. The table below includes 18 species (16 fish, 2 invertebrates) for which EFH has been designated between $41^{\circ} 20^{\prime}-41^{\circ} 30^{\prime} \mathrm{N}$ and $70^{\circ} 20^{\prime}-70^{\circ} 30^{\prime} \mathrm{W}$, and does not include additional EFHdesignated species in the ten-minute square to the south. 
Table 4: Fish Species with designated Essential Fish Habitat in the project area

\begin{tabular}{|l|c|c|c|c|}
\hline \multicolumn{1}{|c|}{ Species } & Eggs & Larvae & Juvenile & Adult \\
\hline Atlantic cod & & & & $X$ \\
\hline Winter flounder & $\mathrm{X}$ & $\mathrm{X}$ & $\mathrm{X}$ & $\mathrm{X}$ \\
\hline Yellowtail flounder & & & $\mathrm{X}$ & $\mathrm{X}$ \\
\hline Long finned squid & $\mathrm{N} / \mathrm{A}$ & $\mathrm{N} / \mathrm{A}$ & $\mathrm{X}$ & $\mathrm{X}$ \\
\hline Atlantic butterfish & $\mathrm{X}$ & $\mathrm{X}$ & $\mathrm{X}$ & $\mathrm{X}$ \\
\hline Atlantic mackerel & $\mathrm{X}$ & $\mathrm{X}$ & $\mathrm{X}$ & $\mathrm{X}$ \\
\hline Summer flounder & $\mathrm{X}$ & $\mathrm{X}$ & $\mathrm{X}$ & $\mathrm{X}$ \\
\hline Scup & $\mathrm{N} / \mathrm{A}$ & $\mathrm{N} / \mathrm{A}$ & $\mathrm{X}$ & $\mathrm{X}$ \\
\hline Black sea bass & $\mathrm{N} / \mathrm{A}$ & $\mathrm{X}$ & $\mathrm{X}$ & $\mathrm{X}$ \\
\hline Surf clam & $\mathrm{N} / \mathrm{A}$ & $\mathrm{N} / \mathrm{A}$ & $\mathrm{X}$ & $\mathrm{X}$ \\
\hline King mackerel & $\mathrm{X}$ & $\mathrm{X}$ & $\mathrm{X}$ & $\mathrm{X}$ \\
\hline Spanish mackerel & $\mathrm{X}$ & $\mathrm{X}$ & $\mathrm{X}$ & $\mathrm{X}$ \\
\hline Cobia & $\mathrm{X}$ & $\mathrm{X}$ & & $\mathrm{X}$ \\
\hline Blue shark & & & $\mathrm{X}$ & $\mathrm{X}$ \\
\hline Bluefin tuna & & & $\mathrm{X}$ & $\mathrm{X}$ \\
\hline Shortfin mako shark & & & $\mathrm{X}$ \\
\hline Little skate & & & & \\
\hline Winter skate & & & & \\
\hline
\end{tabular}

\subsubsection{Recreational Fisheries}

Attempts to assess the extent of recreational fisheries in Nantucket Sound have encountered similar challenges to studies of commercial fishing due to lack of data or absence of spatially-explicit information. In order to examine the potential effects of the Cape Wind project on recreational fisheries, MMS (2009) summarized NOAA Fisheries Marine Recreational Fisheries Statistics Survey (MRFSS) 2005-2007 data and noted that the top eight species, representing 99\% of the catch by weight, were bluefish, scup, striped bass, fluke, black sea bass, little tunny, bonito and tautog. Highest recreational fishing pressure occurs during the summer months, during the seasonal peak of tourism. Shore-based fishing accounted for $73 \%$ of average annual effort, while private/rental vessels represented $25 \%$ and party/charter vessels the remainder (MMS, 2009). Data collected in 1998-2007 from federally-permitted charter vessels subject to VTR reporting requirements indicated that the top species landed were scup (74\%), squid, black sea bass, fluke, bluefish, tautog, striped bass and sea robin, together comprising nearly $100 \%$ of the total catch. Surveys targeting recreational fishing charter/party vessel operators indicated that preferred target species included striped bass, scup and tunas, with other target species including bluefish, bonito, black sea bass and fluke (Battelle, 2003).

Federally-reporting (VTR) charter vessel landings primarily were recorded in the northern portion of the Sound (MMS, 2009). Survey respondents noted that during half-day charters, Muskeget Channel was among the top $40 \%$ of sites fished and the Tuckernuck area to the east was targeted by $24 \%$ of trips, while 9\% of full-day trips targeted shoals around Tuckernuck Island (Battelle, 2003). One charter fisherman from a small sample surveyed by ESS (2006b) noted that he fished 50\% of the time in Nantucket Sound, off Falmouth and off Cape Poge (western side of Muskeget Channel). Surf casting for bluefish and striped bass has been reported to be popular off Wasque Point, on the western side of Muskeget Channel (DT\&A, 2006). As is the case with the surveys of commercial fishermen, the above studies by Battelle (2003) and 
ESS (2006b) need to be interpreted with caution due to small sample sizes and their focus on the Cape Wind site.

\subsection{Summary of Existing Literature on Environmental Impact Studies of Marine Renewable Energy Installations}

At present, the main form of renewable energy generation in the marine environment is wind power. Wave and tidal energy conversion devices have been in development in recent years with several pilot projects being tested in the waters of Canada, the U.K. and the U.S. While some of the effects of introducing marine renewable energy installations (MREIs) to the marine environment may be the same regardless of the installation involved, other effects will be device-specific. Effects will vary with the stage (construction, operation and decommissioning) and scale of the project and will depend on location and the ecosystem in that area.

This section provides a summary of the existing literature on and knowledge of the effects of MREIs on marine megavertebrates. Here, the term "marine megavertebrates" encompasses all of the larger marine vertebrate species commonly encountered in coastal and offshore habitats; e.g. cetaceans (whales, dolphins and porpoises), pinnipeds (seals and sea lions), marine turtles and large fish including basking sharks and sunfish. Seabirds are often considered to be part of this group and thus are also discussed. The literature shows a relatively small amount of data on impacts from operating tidal turbines. The installation of pilot projects conditioned on collecting monitoring data will help fill data gaps on potential impacts before larger installations are considered.

\subsubsection{General Marine Development Impacts}

Marine development produces potential impacts associated with vessel operation, infrastructure development, and utility operations.

Underwater Noise: Underwater anthropogenic noise in the oceans is increasing due to activities such as commercial shipping, seismic exploration, marine construction and sonar technology (e.g. NRC 2003, McKenna and IFAW 2008). This is a growing cause for concern as our understanding develops about the negative effects, both immediate and long-term, of noise on marine life. Underwater noise is especially relevant for cetaceans, as they rely on sound as their main form of communication, often over distances of tens or hundreds of kilometers (e.g. Weilgart, 2007 and references therein). Depending on the context in which the often-complex vocalizations of cetaceans are produced, their masking by anthropogenic noise could affect foraging efficiency and the ability of conspecifics to maintain group coherence for functions such as reproduction (Croll et al., 2001). Any such disturbances could lead to reduced fitness in a local population. For example, Payne and Webb (1971; referred to in Croll et al., 2001) estimated that low frequency noise from shipping traffic may have reduced the area over which blue and fin whales can communicate by several orders of magnitude; from an estimated $2.1 \times 106 \mathrm{~km}^{2}\left(6 \times 105 \mathrm{~nm}^{2}\right)$ in reshipping times to about $2.1 \times 104 \mathrm{~km}^{2}\left(6 \times 103 \mathrm{nmi}^{2}\right)$ in present-day conditions. Several recent environmental assessments for offshore wind farms have identified pile driving as the activity that has the greatest potential to impact local cetacean populations. Edrén et al. (2010) reported lower numbers of gray and harbor seals hauling out in a nearby (4 km from construction) seal sanctuary during pile driving activities for a wind farm in Danish waters. Brandt et al. (2009) reported that harbor porpoises in Danish waters appeared to leave the area of pile driving activity during and immediately after a pile driving event. The effect appeared to be lessened at greater distances from the activity. Nowacek et al. (2007) provide a comprehensive review of the behavioral and acoustic responses of cetaceans to anthropogenic noise. In response to the recent need for systematic, objective and science-based interpretation of the available data on the effects of anthropogenic noise on protected species, Southall et al. (2007), utilizing 
the full body of scientific data on marine mammal hearing and the effects of noise on hearing and behavior, developed recommendations regarding noise exposure criteria for marine mammals.

The FERC Pilot License issued to ORPC included conditions to minimize the potential impacts of pile driving. To avoid adverse effects to marine mammals and Atlantic salmon, a time of year restriction was put in place prohibiting pile driving between April 10 and November 7 in any year for Phase I

construction. Based on implementation of adaptive management plan, FERC will determine if the time of year restriction is necessary for Phase II construction. In addition, the FERC found that pile driving will adversely affect gray and harbor seal, harbor porpoise, and Atlantic white-sided dolphin, all of which are protected under the Marine Mammal Protection Act, thus requiring ORPC to negotiate an incidental harassment authorization (IHA) with NMFS for construction activities. NMFS subsequently issued an IHA which permitted pile driving to proceed in accordance with approved mitigation procedures including a bubble curtain, the establishment of a 500 radius exclusion zone, and deployment of protected species observers with authority to cease construction if a protected species is sighted. No such restrictions were placed on Verdant Power for its Roosevelt Island Tidal Energy (RITE) Project. Instead, the License required Verdant to an Underwater Noise Monitoring and Evaluation Plan to assess the potential impacts of noise during project operation and implement adaptive management measures accordingly.

Increased Vessel Traffic: The response of small cetaceans to motorized vessels may be a reaction to noise, visual cues or a combination of both (e.g. Richardson et al., 1995; Bejder et al., 1999; Lesage et al., 1999). In addition to affecting cetacean behavior, vessel traffic can be a cause of direct mortality. Collisions between vessels and cetaceans, termed "ship strikes," have been documented in many areas around the world and for numerous species of whale (e.g. Panigada et al., 2006; Douglas et al., 2008; Elvin and Taggart 2008) and dolphin (e.g. Bloom and Jager, 1994; Elwen and Leeney, 2010). Issues which may arise from the physical presence of vessels include immediate effects such as animal-vessel collisions, medium-term effects such as evasive behavior by animals experiencing stress and longer-term effects such as decreased fitness or even habitual avoidance of areas where disturbance is common (e.g. Constantine, 2001; Hastie et al., 2003; Lusseau, 2004; Lusseau, 2005; Bejder et al., 2006; Lusseau et al., 2009). Vessel traffic will invariably increase in offshore areas where MREIs are planned and located, not only during the construction phase but on an ongoing basis thereafter as maintenance and, eventually, decommissioning and removal of these structures will be required.

In ORPC's FERC Pilot License, FERC concluded "While there may be an increase in vessel traffic and barge presence during installation and maintenance activities, this increase will be small."

Electromagnetic Fields: Marine life relies on electro and magnetic sense for many life functions. Electrosense of elasmobranchs is well understood. The effect of anthropogenic sources and how they alter natural field and their functions is not as well understood. Demersal species are at a higher risk of exposure than pelagic species (BOEM 2011). Magnetosensitive species are more likely to be able to detect EMFs from DC cables than AC. Taxa include sea turtles, some marine mammals, and some decapod crustaceans (BOEM 2011).

The magnetic component of EMF has the potential to affect magnetosensitive species such as bony fish, elasmobranchs, marine mammals and sea turtles (Wiltschko and Wiltschko, 2005; Luschi et al., 2007; Gould, 2008). According to Gill et al. (2005), there are many fish species within the U.K. waters which are potentially sensitive to EMF given that these EMF components appear to be within their range of detection. The consequences for the fish, however, are unknown. It is also possible that animals using geomagnetic cues as navigation aids during migration, such as turtles and baleen whales, may be affected by magnetic fields, although the role of such cues for various species remains poorly understood 
(Lohmann et al., 2008). Overall, the potential effects of EMF are difficult to predict and at present, and much more research is required (Gill, 2005; Gill et al., 2005; Öhman et al., 2007).

Electromagnetic fields (EMF) can be emitted from undersea power transmission cables such as those associated with offshore wind farm developments and, possibly, tidal power generators. Shielding and burial of cables insulates the electrical fields, but not the magnetic fields. Weak secondary electrical fields can be created by passage of moving organisms through the magnetic fields. Both phenomena are anticipated to be localized. Despite the fact that the available biological information allows only a preliminary level of impact assessment, modeling indicates that the electromagnetic fields emitted by undersea power cables are limited spatially (both vertically and horizontally). This spatial limitation must be considered in any impact assessment as it reduces the risk that any given organism will be exposed (BOEM 2011). BOEM is presently undertaking a field study to observe marine life near power cable which is expected to be completed in 2015 .

Artificial Reefs: The placement of fixed structures on the seabed can have an "artificial reef" effect on the area. An artificial reef is defined as one or more objects of natural or human origin deployed purposefully on the sea floor, usually used to enhance recreational fishing and diving opportunities in the marine environment (Sutton and Bushnell, 2007). Adding vertical profile and surface area to the marine environment allows for growth of sedentary organisms, which in turn support other species. Use of antifouling surface to deter growth of marine organisms can limit this effect. In a study of offshore wind farms in Danish waters, Maar et al. (2009) reported considerable aggregations of blue mussels on turbine pillars which created local hotspots of biological activity and changed ecosystem dynamics in the area. Petersen and Malm (2006) likewise suggest that the reef effect of offshore wind farms can have a significant effect on local species assemblages and biological structure, and that the importance of this impact may have been overlooked in many environmental impact assessments to date. An increase in the productivity of an area may actually attract marine vertebrates by providing a food resource. Cables and chain (which may be used for anchoring submerged structures such as tidal turbines), power lines and free-moving components on the surface or in the water column can present a hazard to some submarine species. Both large and small cetaceans as well as basking sharks and turtles are frequently entangled in fixed fishing gear (e.g. Julian and Beeson, 1998; Berrow, 2004; Garrison, 2005; Read et al., 2006). Bottom-to-surface lines, such as the end-lines of lobster fishing gear, are a well-known entanglement risk for humpback whales, right whales and numerous other species (e.g. Volgenau et al., 1995; Moore et al., 2004; Brillant and Trippel, 2010). Potential effects of the attraction will depend on the nature of the structure.

Fisheries Exclusion Zones: The introduction of artificial structures will often exclude fishing activity due to potential fishing gear entanglement and navigational hazards. Thus, even without enforced exclusion, the waters inside the boundary of most MREIs will become inaccessible to many fisheries, and become de facto no-take zones (NTZ). A growing body of evidence suggests that NTZs and other forms of highlyprotected Marine Protected Areas (MPAs) are ecologically beneficial to both the protected area itself and to nearby areas. Benefits include enhanced stocks and individual fish or shellfish size (e.g. Cole et al., 1990; Babcock et al., 1999; Beukers-Stewart et al., 2005; Blyth-Skyrme et al., 2006) due to recovery from overfishing (Thurstan and Roberts, 2010) and protection of benthic environments from damaging fishing techniques such as bottom trawling (e.g. Thrush et al., 1998; Blyth et al., 2004). The changes in community structure that can result from the designation of protected areas can also show higher trophic complexity as well as increased primary and secondary productivity (Babcock et al., 1999). Whether the installation is having an impact on marine organisms in the NTZ will depend on the nature of the facility. Nevertheless, if sites are appropriately designed to minimize impacts, they might increase local biodiversity and benefit the wider marine environment by protecting living marine resources within their boundaries (Friedlander et al., 2007) and by providing "recruitment subsidy" (Gerber et al., 2003; Sale et al., 2005) and "spillover effects" (DeMartini, 1993) (i.e., larvae, juveniles and adults produced in or 
utilizing the protected area will later move to adjacent areas, potentially bolstering fisheries surrounding the MPA). However, Blyth-Skyrme (2010) highlighted the importance of recognizing the potential disruption to commercial fishing activities, through loss of fishing grounds or gear restrictions, posed by the establishment of MREIs such as offshore wind farms.

Decommissioning: If located in Massachusetts state waters, MREI structures are licensed under the state's tidelands law and regulations (301CMR 9.27). These regulations require the removal of structures "upon nullification, expiration or revocation" of the license. U.S. federal regulations also require that structures be removed and the seafloor cleared of all obstructions (30CFR Chapter II, Part 285.90). A set of impacts similar to those associated with construction are likely during this phase. For structures based on pilings, noise levels during decommissioning could be lower than during construction, as the pilings will likely be cut to below seabed level rather than being fully removed.

\subsubsection{Tidal Turbine Impacts}

Tidal stream energy is derived from the kinetic energy of the moving flow of high velocity sea currents created by the movement of the tides; this is analogous to the way a wind turbine operates in air. These unique waters can provide habitats for particular marine animals and fishes.

Fine-scale oceanographic features can be of great importance to pelagic predators (Wolanski and Hamner, 1988), providing enhanced concentrations of prey species which can be easily exploited by cetaceans, seabirds and large fishes. Many marine predators are known to forage in tidally driven oceanographic features, where they exploit predictable aggregations of prey. For example, bottlenose dolphins (Tursiops truncates; Mendes et al., 2002), harbor porpoises (Pierpoint, 2008), foraging seabirds (Hunt and Schneider, 1987) and basking sharks (Sims and Quayle, 1998) have been associated with tidal intrusion fronts or tide "races." Harbor porpoises, fin and minke whales congregate to feed within localized upwellings and fronts in the Bay of Fundy (Gaskin and Smith, 1979; Watts and Gaskin, 1985; Johnston et al., 2005a, b). Several species of tuna (e.g. albacore, Thunnus alalunga) have also been documented to forage at oceanic fronts (Fiedler and Bernard, 1987). The fact that marine megavertebrates and seabirds in coastal environments associate spatially with such areas of high tidal flow highlights the need (importance) of considering the potential for associated negative interactions.

The disruption and reduction of the net flow of water may affect the distribution of prey species (Parker, 1993; Fry, 2005), water turbidity, or the ability of predators to hunt efficiently in these areas. We do not currently have a good understanding of the level to which these effects will occur and how that in turn will impact the predatory species which utilize these areas. Watts and Gaskin (1985) found a decline in the number of porpoises sighted on transects in the Bay of Fundy with increasing current speed, which they suggest is due to avoidance of shallow, turbulent areas which are energetically expensive for the animals to occupy. Gaskin and Watson (1985) also documented greater relative abundance of harbor porpoises in Fish Harbor, Canada during neap tides than during stronger spring tides. Thus a reduction in downstream tidal flow caused by a tidal energy facility may alter feeding efficiency for small cetaceans forcing a local population to shift its range. The amount of current reduction necessary to result in a significant change is not known, but is likely to be proportional to the scale of the project. Modeling studies and field data suggest that minimal change in flow will occur from pilot scale projects. The three year environmental study of the Marine Current Turbine in Strangford Lough Northern Ireland concluded "changes to tidal flow were measured using Acoustic Doppler Current Profiling (ADCP). The data showed no evidence of significant change to the ambient velocity or flow direction within the Lough, subsequent to the installation of the turbine" (MCT 2011). The reduction is water flow from the proposed Muskeget Project is calculated in work conducted by Woods Hole and UMASS in Section 3 of this report. 
Wilson et al. (2007) point out that rotating underwater turbines (models with open blades) present the most likely circumstance for collisions with marine vertebrates. The blade tips of these devices will likely move at speeds of about $12 \mathrm{~ms}$, or 23 knots. However, the force of a collision is affected by speed and mass. A recent report by the DOE modeled the forces associated with the spinning of the blades of the Open Hydro turbine with detailed biological data about the physiology of orca tissues and found that strike forces were not great enough to break the skin (PNNL 2012). In addition, five years of underwater video of the OpenHydro Turbine at the European Marine Energy Center in Scotland has observed no strike to marine mammals. The video monitoring is coupled with shore-based observers which have observed marine mammals in the local area (EMEC 2012).

The potential for animals to avoid collisions with marine renewable devices will vary from species to species and will depend on factors such as body size, social behavior (especially schooling or group structure), foraging tactics, curiosity, underwater agility and sensory abilities (Wilson et al., 2007). A number of studies have been conducted in recent years which are useful in understanding the risk of a strike. Wilson et al. (2007) developed a model to investigate the potential encounter rate between 100 tidal turbines off the Scottish coast and local populations of harbor porpoises and herring of welldocumented abundance. In one year of operation, the model predicted that $2 \%$ of the local herring population and 3.6 to $10.7 \%$ of the porpoise population would encounter an operational turbine. While encounters do not equate to collisions, there is no information at present on how marine organisms will react to such an encounter. More recent field studies are not consistent with the magnitude of impact predicted in Wilson's predictions.

Viehman (2012) conducted hydroacoustic surveys using two DIDSON units over a 24 hour period in Cobscook Bay Maine to assess existing distribution of fish species as well as assess their interactions with a pilot tidal turbine developed by Ocean Renewable Power Company. Viehman concluded that a greater proportion of fish interacted with the turbine when it was still rather than rotating, and at night rather than day. Fish reacted further away from the device during the day than at night. For small and medium fish, the type of interaction shifted from avoidance of the turbine during the day to entrance at night; large fish mainly avoided the turbine. No fish were observed striking the turbine.

Studies conducted by the Electric Power Research Institute (EPRI) looked at impacts of two hydrokinetic turbines on trout (EPRI 2011). The two turbine designs evaluated were the Lucid spherical turbine (LST) developed by Lucid Energy Technologies and the Welka UPG developed by Current-to-Current. The LST is a Darrieus-type (cross-flow) turbine and the Welka UPG is a horizontal-axis propeller turbine. Survival and injury for selected species and size groups were estimated for each turbine operating at two approach velocities (and corresponding turbine rotational speeds) by releasing treatment fish directly upstream and control fish downstream of the operating units. Immediate and total survival rates for rainbow trout tested with the LST were greater than $99 \%$ for all sets of test conditions, except for total survival of the larger fish tested at an approach velocity of $2.1 \mathrm{~m} / \mathrm{s}$, which was $98.4 \%$. When adjusted for control data, the percent of turbine exposed fish (which either passed around or through the turbine) that were descaled was low, ranging from 0.0 to $4.5 \%$. For the Welka UPG, immediate and total turbine passage survival rates for rainbow trout were $100 \%$ for the smaller fish evaluated at both approach velocities and the larger fish tested at the lower velocity $(1.5 \mathrm{~m} / \mathrm{s})$. Immediate and total survival of the larger fish evaluated at the higher velocity $(2.1 \mathrm{~m} / \mathrm{s})$ were both $99.4 \%$. In addition, the authors concluded that "observations of fish behavior, particularly avoidance at a very close distance to moving blades, provide strong evidence as to how fish are likely to react when approaching a wide range of hydrokinetic turbine designs in the field."

The tidal turbine in Strangford Loch, Northern Ireland has been in place since 2007 (Bedford and Fortune, 2010; Davison and Mallows, 2005). The evidence so far from environmental impact assessment studies suggests no fatal interactions between seals and the turbine blades (from examination of dead stranded 
seal carcasses), nor does the turbine appear to present a barrier to harbor porpoise movement (from analysis of acoustic monitoring data).

It has been suggested that tidal flow installations could lead to changes in tidal level, turbidity and sedimentation, which could impact estuary ecosystems (Gordon, 1994). Changes in sediment transport around an installation may particularly affect salt marsh habitats, which in turn could impact species such as the Northern diamond-backed terrapin. Some information on effects to tidal elevation, turbidity, and sedimentation specific to the proposed project is provided in Sections 2 and 3.

\subsubsection{Long-Term Impacts}

In anticipating what effect various MREIs have on the marine ecosystems, longer-term effects at the population level also need to be considered. It is possible that some species will develop avoidance skills to deal with circumstances which may otherwise cause them harm or may become habituated to impacts such as noise and turbidity. They may exhibit short-term changes in behavior in response to anthropogenic disturbance (e.g. Bejder et al., 1999; Hastie et al., 2003; Lusseau, 2003).

Alternatively, certain areas may be abandoned by species whose environment has been changed as the result of the introduction of MREIs; short-term avoidance strategies may lead to long-term displacement (Lusseau, 2004). Abandonment of otherwise favorable habitats by cetaceans due to anthropogenic disturbance has been observed in the past (e.g. Bryant et al., 1984; Jefferson, 2000). Lusseau (2005) suggested that avoidance of a key habitat area by bottlenose dolphins, as a result of pressure from boat traffic, could have demographic impacts at a population level.

Experience at the most intensively studied MREI project in operation has provided different conclusions from those reported above. The Sea-Gen Monitoring Program on the MCT Project in Strangford Lough Northern Ireland conducted three years of studies on marine mammals that occur in local waters. The final report (Royal Haskonig 2011) reached the following conclusions:

- No major impacts on marine mammals have been detected across the 3 years of post-installation monitoring.

- Porpoise activity declined during installation; however there have been no long term changes in abundance of either seals or porpoises which can be attributed to the presence or operation of the device.

- A few of the metrics monitored were naturally highly variable and therefore comparisons between phases lacked suitable statistical power to confidently rule out undetected changes - this was particularly the case for grey seals and porpoise sighting rates from the shore based visual observation. However, given the wide ranging nature of these species it is unlikely that any changes at this spatial scale would have a significant effect at the population level.

- Seals and porpoises regularly transit past the operating turbine, clearly demonstrating a lack of any barrier effect.

- The only changes observed after three years of operation of the device have been relatively small scale changes in the behaviour and distribution of seals and harbour porpoises, suggestive of a degree of local avoidance of the device.

- Overall the seals transited at a relatively higher rate during periods of slack tide, indicating avoidance but also this slack water window when the turbine is not operating or is moving very slowly, ensures that there is always an opportunity for transit past the turbine. 
- This avoidance reduces the risk of any direct interactions with the moving rotors and suggests that both seals and porpoises have the capacity to adjust their distributions at local scales in response to a potential hazard.

It is also important to recognize that the response of one species of marine megavertebrate to any given source of disturbance will not be indicative of responses by other species. Watkins (1986) documented species-specific changes in behavior, both positive and negative, in relation to vessels over a 25-year period. Data are lacking in this area and should be one point of focus for monitoring pilot installations.

\subsubsection{Mitigation of Impacts}

Much in the same way as pingers, seal-scarers and other Acoustic Deterrent Devices (ADDs) have been developed to deter cetaceans and seals away from trawl nets and fish farms (with varying degrees of success; e.g. Hodgson et al., 2007; Berrow et al., 2008; Caretta et al., 2008; Gazo et al., 2008; Leeney et al., 2008), it may be possible to develop new technologies to alert animals to the presence of tidal turbines or other MREI structures. However, even if such devices are initially effective, animals can also become habituated to these devices, making them less effective over time (Dawson et al., 1998; Cox et al., 2001). Deterrents will not work for all species, as different species have different primary senses and different visual, olfactory and auditory capabilities.

Vocalizations and echolocation are essential to communication and environmental exploration for cetaceans, so deterrents using noise work well for this group of species. Because MREIs emit sound when they operate, cetaceans may detect their presence well before a direct encounter. Sea turtles and pelagic fishes are highly visual predators, thus visual cues most likely play an important role (Southwood et al., 2008). The reliance of some species on visual cues may also suggest that detection of MREI devices at night may be compromised; directed research will be required to address whether this will be a concern. Since many species of megavertebrate are known to exhibit diel patterns of habitat use (e.g. Goold, 2000; Elwen et al., 2006), it will be essential to use acoustic monitoring to at least provide data on cetacean habitat use around MREIs at night as well as during the day, in order to assess risk levels outside of daylight hours. Measuring noise in high current flow areas is difficult because of the high level of ambient or background sound generated by flowing water (ORPC 2010). The use of sonar devices to detect approaches by marine megavertebrates, as utilized in the SeaGen tidal turbine project in Stangford Lough, may also be beneficial in addressing this issue (Bedford and Fortune, 2010).

\subsection{Monitoring Protocols for Future Studies}

In designing environmental monitoring protocols for sites of proposed MREIs, no single standard will be universally applicable. The survey techniques, size of the study area, design and duration of the survey will all depend upon the area itself, the species found there and their conservation status, the nature and scale of the planned MREI and the duration of the construction period. As highlighted in Inger et al. (2009), a systematic review of previous experience and studies in the field of impact assessments for MREIs combined with solid study design are key to appropriately assessing the impacts of MREIs.

This report outlines methods for monitoring marine megavertebrate populations and for documenting spatiotemporal variation in patterns of habitat use and behavior. It then provides a set of objectives for monitoring the impacts to marine megavertebrate populations, and alternatives to consider specific to the Muskeget Channel MREI project to improve the understanding of potential impacts prior to approval of long-term deployments. A recommended methodology plan is outlined.

A combination of several techniques is required to appropriately monitor marine megavertebrate species around tidal turbine sites. Visual data collection for marine megavertebrates involves boat-based surveys and/or aerial surveys, which will be more appropriate for some species (e.g., sea turtles) than others (e.g., 
non-breathing basking sharks). The use of Static Acoustic Monitoring (SAM) at offshore wind farm sites is now standard practice in many areas (e.g. Tougaard et al., 2004; Carstensen et al., 2006) providing useful information for specific animal groups (e.g. odontocetes). Conducting these surveys in tidally dynamic sites presents significant challenges due to strong tides and complex oceanographic features.

It should be noted that there is little device specific information for long-term MHK deployments with the exception of Sea-Gen's Project in Strangford Lough. We understand that one of the goals of the FERC pilot program is to deploy devices such that device specific information can be collected and potential impacts better understood. Studies approved as part of the Pilot License issued by FERC for Verdant Power's RITE Project and ORPC's Cobscook Bay Project will provide useful information to the industry in coming years. Monitoring of pilot tidal turbine installations may not need to resolve as many environmental assessment questions as those for full-scale installations that will be operational for a number of years. However there are baseline data that must be collected prior to pilot operations in order to accurately assess post-installation changes.

\subsubsection{Outline of Survey Methods}

\subsubsection{Aerial Surveys}

Visual surveys (aerial and/or boat-based) are an accepted and well-established methodology for assessing abundance and distribution of most cetacean species. Such platforms allow for the collection of valuable species presence information for less common cetacean species or those for which acoustic monitoring is not yet well developed. By using distance sampling methodology (Buckland et al., 2001), which is the accepted means of generating absolute abundance estimates for these species, region-specific abundance estimates can be calculated. In order to be useful, distance sampling surveys must be carried out frequently and according to a strict survey design with even coverage throughout the study area.

Aerial surveys are an effective means of covering large study areas within a manageable period of time. They are also less weather-dependent than boat-based surveys, although detection probabilities, especially for smaller species such as harbor porpoises, are affected by higher sea states just as for shipboard surveys (Palka, 1995; Teilmann, 1995). Aerial surveys are well-established as an acceptable method for surveying for cetaceans (e.g. SCANS I \& II; Hammond et al., 2002), seals (e.g. Matthiopoulos et al., 2004; Cronin et al., 2006) and turtles (e.g. Marsh \& Saalfeld, 1989; Jean et al., 2010), and they have also been used to assess relative or "apparent" abundance of fish species such as basking sharks and sunfish (Leeney et al., in review; Houghton et al., 2006; Campana et al., 2008). In fact, for basking sharks and species such as right whales, which can spend long periods of time just beneath the water surface rendering them invisible to vessel-based observers, aerial surveys can be an excellent means of detection. This method can also be used to collect valuable photo-identification data on endangered species such as the North Atlantic right whale (e.g. Leeney et al., 2008, 2009).

\subsubsection{Visual Surveys from Platforms or Land}

Land-based counts of hauled-out seals (pinnipeds) have been used extensively as a means of calculating population size and patterns of habitat use (e.g. Pomeroy et al., 2005; Leeney et al., 2010). Relative to other methodologies for studying marine mammals, it is a safe and easy method. Numbers of seals hauling out also varies with season, and so counts throughout the year will provide data on this seasonal pattern. Visual surveys, from both land-based sites and at-sea platforms, provide site-specific data on temporal variation and can also provide the opportunity to collect useful data on surface behaviors. By carrying out visual surveys at a range of tidal states and times of day over several years, a fuller understanding of the temporal patterns of habitat use specific to a site can be gained. This, combined with data on species which might be inclined to dive or swim in the vicinity of tidal turbines or which appear unable to detect the moving turbines underwater from a safe distance, can then lead to an assessment of 
"high risk" species and time periods (e.g. seasons, states of tide, times of day) of greatest collision risk. Behavior sampling can be carried out using Ad Libitum or Focal-Animal sampling techniques (Altmann, 1974), depending on the context, and should likewise be collected in a range of conditions and in both impact and control situations.

\subsubsection{Static Acoustic Monitoring}

Acoustic monitoring is becoming widely accepted as an efficient way to collect valuable long-term datasets on cetacean habitat use for EIS purposes (e.g. Teilmann et al., 2002; Carstensen et al., 2006; Tougaard et al., 2009; Thompson et al., 2010). Diederichs et al. (2009) reported that static acoustic monitoring (SAM) using T-PODs (the predecessors of C-PODs) or other devices provides good data on harbor porpoises, and potentially other odontocete species, at a high temporal but low spatial resolution. Deploying several SAM devices in the area of interest overcomes the issue of spatial resolution. Statistical analysis from areas with low and high porpoise densities proved that a $30 \%$ change in harbor porpoise presence can be proved with a sample size of 3-11 SAM units (Diederichs et al., 2009). The initial baseline data review should inform, to a great extent, the choice of acoustic monitoring technique to be used. The species present, their detectability using acoustic techniques and how necessary it is deemed to have fine-scale data on spatio-temporal patterns of habitat use of particular species should all factor into the choice of acoustic monitoring tool. C-PODs are only suitable for monitoring cetacean species which use echolocation. They have been used extensively to monitor spatio-temporal patterns of habitat use for many species of odontocetes including harbor porpoises (e.g. Tougaard et al., 2009) and bottlenose dolphins (e.g. Leeney et al., 2007; Philpott et al., 2007). Autonomous seafloor recording units, referred to as "pop-ups," are considerably more expensive and complex to deploy. They are used to collect data on vocalizations from baleen whales such as North Atlantic right whales (Clark et al., 2010).

SAM at tidal energy sites will present a number of unique challenges that will need to be addressed in order to effectively collect, analyze and interpret the data collected by this means.

- Moorings for SAM equipment present a very specific challenge in areas where tidal turbines are planned, since the characteristics of these areas necessarily pose a risk that gear will move or be swept away. Moorings need to be flexible but extremely resilient to deal with the dynamic nature of this environment.

- Noise-modeling specific to a given site will need to be conducted. Tidally dynamic areas are highnoise areas since there is both water moving at high speeds and transfer or movement of bottom sediment. Noise-modeling will provide an understanding of the acoustic environment so that the detectability of various species, the range at which they can be detected and the variability in those parameters with temporal and environmental conditions can be well understood and incorporated into any analysis of SAM data.

- Background research on the species likely to be encountered in the region, as well as the types of vocalizations each species produces, will be essential in order to first select the most appropriate SAM technology to be used in the area and then to interpret the data collected. There is a paucity of data on vocalizations, especially echolocation, of many cetacean species.

- Focal studies are needed on certain species for which data are lacking. Such studies should be carried out prior to commencement of monitoring and should involve direct hydrophone recordings of the vocalizations of the target species in concert with data collection on group size and behavior.

- Calibration of SAM equipment will be essential to insure that the outputs are comparable between units and/or sites. The assumption should not be made that all units, even of any one design, have identical sensitivities and detection functions unless this is guaranteed by the manufacturer. On a wider scale, there is a great need for a detailed comparison of various pieces of acoustic monitoring equipment to be made. This will allow for rates of detection, habitat use, activity and behaviors to be compared between projects and over much wider regions. 


\subsubsection{Environmental Risk Thresholds}

In working to meet the above objectives, it will be essential to define the terms "significant change/ modification" and "significant decline," for the purposes of conservation management. Firstly, the change must be detected. This will be achieved using an appropriate sampling design and monitoring techniques. The magnitude of the change having been evaluated, it must be attributed either to an effect of the MREI or to something else. Finally, the magnitude of the change must be set in the context of local, regional and national trends in abundance and distribution in order to determine whether such a level of change is considered significant for a population. That is, are the effects likely to be long-term or to be of detriment to the population of a whole? EMEC (2008) provides a table detailing the criteria to be used to assess potential and residual environmental impacts, including both ecological and socio-economic effects, which may prove a useful reference in addressing the above issues. Similarly, the use of the term "important" in reference to habitat areas for marine mammals also requires definition. In this case, if a species is rare (e.g. North Atlantic right whale) or locally rare (such as a species at the limit of its range) and is found to utilize the habitat at all, or if it is numerous but large numbers (a percentage of the regional population should be defined here) utilize the habitat at least seasonally, the area should be considered important. For all cetacean and pinniped species, it will be necessary to refer to the US Endangered Species and Marine Mammal Protection Acts for guidance relating to the significance of a given impact at the individual, community and population level. It should also be noted that the detection of significant change does not necessarily signify a negative effect of the turbine installation. Some changes to the area may benefit marine megavertebrates and may support greater levels of habitat use; these will nonetheless be important to document. However, natural and cyclical variations in the environment should be accounted for within the survey design and thus should not be a source for significant differences between datasets.

\subsubsection{Methodology Plan}

Table 5 outlines the objectives to be achieved by the monitoring and mitigation program for the proposed Muskeget Channel tidal energy project. The methods to be used to address these objectives are detailed below. This methodology plan is based on accepted survey and mitigation techniques, previous research and practical experience at other MREI sites and established, good scientific practice. Reference has been made to the Environmental Impact Assessment guidelines developed by the European Marine Energy Center (EMEC, 2008). 
Table 5: Operational Objectives for the Muskeget Tidal Project Monitoring and Mitigation Program

\begin{tabular}{|c|c|c|}
\hline Element & Objective & Measurement \\
\hline \multirow[t]{4}{*}{$\begin{array}{l}\text { Marine Mammals } \\
\text { (general) }\end{array}$} & $\begin{array}{l}\text { No marine mammal mortalities } \\
\text { (directly or indirectly as a result of a } \\
\text { non-fatal injury) occur as a } \\
\text { consequence of physical interaction } \\
\text { with the turbine rotors. }\end{array}$ & $\begin{array}{l}\text { 1. Post mortem evaluation of carcass strandings and } \\
\text { assessment of cause of death. } \\
\text { 2. Investigation of any carcasses sighted during aerial surveys. } \\
\text { 3. Health assessment of large whales during aerial surveys; } \\
\text { collection of observational data on seal condition during haul- } \\
\text { out counts. } \\
\text { 4. Platform-based observations/video of behavior near } \\
\text { turbines, if possible. } \\
\text { 5. If risk level is considered high, the turbines could be } \\
\text { configured to stop when marine mammals are within a safe } \\
\text { zone. SeaGen originally included such a condition but it was } \\
\text { suspended due to low risk. }\end{array}$ \\
\hline & $\begin{array}{l}\text { Establishment of an active sonar } \\
\text { system which detects marine } \\
\text { megavertebrates at sufficient range } \\
\text { from the turbine to allow a } \\
\text { precautionary shutdown to occur } \\
\text { automatically }\end{array}$ & $\begin{array}{l}\text { 1. Number of sonar detections and shutdown events. } \\
\text { 2. Matching of sonar detections to platform-based sightings } \\
\text { for species identification, where possible. }\end{array}$ \\
\hline & $\begin{array}{l}\text { Relative abundance of marine } \\
\text { mammals in Muskeget Channel is } \\
\text { not significantly modified by the } \\
\text { operation of the turbines. }\end{array}$ & $\begin{array}{l}\text { 1. Assessment of abundance and distribution in control and } \\
\text { impact sites, before, during and after construction. An } \\
\text { adequate baseline ("before") dataset would comprise two } \\
\text { years of data. } \\
\text { 2. Statistical comparison of patterns of variation in abundance } \\
\text { and distribution (aerial, haul-out and platform-based counts). } \\
\text { 3. Similar comparison of hauled-out seal counts in the region } \\
\text { over the same time scale. }\end{array}$ \\
\hline & $\begin{array}{l}\text { Sub-surface noise generated by the } \\
\text { turbines does not cause a level of } \\
\text { disturbance to marine mammals } \\
\text { sufficient to displace them from } \\
\text { areas important for foraging and } \\
\text { social activities }\end{array}$ & $\begin{array}{l}\text { 1. Measurement of zone of audibility and zone of disturbance } \\
\text { at full power operation; description of noise environment. } \\
\text { 2. Assessment of overlap of augmented (with turbine } \\
\text { operation) noise environment with vocalization and hearing } \\
\text { frequency ranges of most common species (and species of key } \\
\text { interest). } \\
\text { 3. Number of marine mammals underwater sighted in close } \\
\text { proximity ( } 50 \mathrm{~m} \text { ) to the turbines per hour (if possible, from } \\
\text { platform or imaging techniques) }\end{array}$ \\
\hline \multirow[t]{2}{*}{$\begin{array}{l}\text { Marine mammals: } \\
\text { Pinnipeds (seals) }\end{array}$} & $\begin{array}{l}\text { The turbines do not cause a } \\
\text { significant change in the use of } \\
\text { important seal haul-out sites within } \\
\text { or adjacent to the region. }\end{array}$ & $\begin{array}{l}\text { Haul-out site seal numbers from aerial surveys and haul-out } \\
\text { site counts }\end{array}$ \\
\hline & $\begin{array}{l}\text { Seals are not excluded from } \\
\text { important foraging habitat or social } \\
\text { areas within the Muskeget Channel } \\
\text { area as a result of the installation and } \\
\text { operation of the turbines. }\end{array}$ & $\begin{array}{l}\text { Comparison of sightings frequency over space and time (from } \\
\text { haul-out site counts and aerial survey data) in pre-operational, } \\
\text { construction and operational periods }\end{array}$ \\
\hline
\end{tabular}




\begin{tabular}{|c|c|c|}
\hline Element & Objective & Measurement \\
\hline & $\begin{array}{l}\text { The number of harbor and gray seal } \\
\text { adults and pups does not decline } \\
\text { significantly as a result of the } \\
\text { installation and operation of the } \\
\text { turbines. }\end{array}$ & $\begin{array}{l}\text { Population estimates derived from aerial survey and haul-out } \\
\text { counts to establish baseline data for "local" populations. } \\
\text { Estimates to be set within the context of historical data. }\end{array}$ \\
\hline & $\begin{array}{l}\text { Cetaceans are not excluded from } \\
\text { important foraging habitat or social } \\
\text { areas within the Muskeget Channel } \\
\text { area as a result of the installation and } \\
\text { operation of the turbines. }\end{array}$ & $\begin{array}{l}\text { 1. Abundance and distribution (from aerial survey data) in } \\
\text { pre-operational, construction and operational periods. } \\
\text { 2. Comparison of SAM data between before and after } \\
\text { construction/operation and in control and impact sites. SAM } \\
\text { data may also provide indices of behavior (e.g. assessment of } \\
\text { buzz train production rate associated with feeding). }\end{array}$ \\
\hline \multirow[t]{2}{*}{$\begin{array}{l}\text { Marine mammals: } \\
\text { Cetaceans (whales and } \\
\text { dolphins) }\end{array}$} & $\begin{array}{l}\text { The turbines do not displace } \\
\text { cetaceans from the immediate region } \\
\text { or adjacent areas. }\end{array}$ & $\begin{array}{l}\text { 1. SAM data analysis at a range of scales. } \\
\text { 2. Sighting data from platform-based observers if possible. }\end{array}$ \\
\hline & $\begin{array}{l}\text { No mortalities of basking sharks or } \\
\text { sunfish (directly or indirectly as a } \\
\text { result of a non-fatal injury) occur as } \\
\text { a consequence of physical interaction } \\
\text { with the turbine rotors. }\end{array}$ & $\begin{array}{l}\text { 1. Post-mortem evaluation of carcass strandings and } \\
\text { assessment of cause of death. } \\
\text { 2. Investigation of any carcass sighted during aerial surveys. }\end{array}$ \\
\hline $\begin{array}{l}\text { Basking sharks and } \\
\text { Sunfish }\end{array}$ & $\begin{array}{l}\text { The turbines do not cause a } \\
\text { significant change in habitat use by } \\
\text { these species. }\end{array}$ & $\begin{array}{l}\text { Comparison of sightings frequency over space and time (from } \\
\text { aerial survey data) in pre-operational, construction and } \\
\text { operational periods). }\end{array}$ \\
\hline Turtles & $\begin{array}{l}\text { The turbines do not injure or displace } \\
\text { turtles from areas they might } \\
\text { otherwise utilize. }\end{array}$ & $\begin{array}{l}\text { 1. Post-mortem evaluation of carcass strandings and } \\
\text { assessment of cause of death. } \\
\text { 2. Comparison of sightings frequency over space and time } \\
\text { (from aerial survey data) in pre-operational, construction and } \\
\text { operational periods). }\end{array}$ \\
\hline Seabirds & $\begin{array}{l}\text { The turbines do not injure or displace } \\
\text { foraging diving birds from important } \\
\text { areas within Muskeget Channel. }\end{array}$ & $\begin{array}{l}\text { Sightings frequency of diving and rafting birds as well as } \\
\text { behavior data from platform-based, video and/or aerial } \\
\text { surveys. }\end{array}$ \\
\hline
\end{tabular}

\subsubsection{Study Design}

A scientifically sound monitoring design is essential to accurately detect potential impacts when monitoring changes associated with conservation management (Underwood, 1994, 1995) and Inger et al. (2009) has suggested as much for MREIs. For impact studies in relation to offshore wind farms, a BACI (Before-After/Control-Impact) design has been recommended (Diederichs et al., 2009). A BACI design adds power to EIA monitoring by providing comparative datasets for the area prior to any construction or operation (i.e. a baseline) as well as during construction and/ or operation at the planned MREI site and at an area outside the zone of impact. It thus incorporates and reflects the effects of any natural cycles or additional impacts in the area unrelated to the impact of the MREI. However, while BACI study design provides the conceptual framework within which to detect anthropogenic effects, there are many practical problems associated with detecting human influences on population abundance and distribution. One main issue is that the temporal variance of many populations is great; that is, abundance data for any 
given population in a given area, particularly for highly mobile marine megavertebrates, is very "noisy." Thompson et al. (2010) documented a response by harbor porpoises to wind turbine installation activities using SAM. Their findings highlighted the fact that uncertainty regarding cetacean distribution and the scale of disturbance effects limits the effectiveness with which BACI studies can be interpreted. These challenges are further complicated when assessing changes associated with a small-scale pilot project with a limited footprint. Another key issue is that temporal patterns in regional abundances of a given species are rarely the same from one place to another.

These two problems create difficulties in identifying unusual patterns of change in what is already a very interactive and variable measurement. The power to accurately detect such changes due to anthropogenic effects can be significantly increased by using asymmetrical design. That is, using one impacted site and several control locations (Underwood, 1994). The incorporation of more than one control site is key because there will be different temporal patterns at different sites, and in a comparison of the impacted site with only one "control," there is the possibility that the two sites will have very different patterns of variation.

Planning ahead of time is essential to the implementation of an effective environmental impact assessment. Diederichs et al. (2009) suggest that impact studies on offshore wind farms should ideally comprise two years of "before impact" data, the construction period itself and at least two years of the operational phase. The authors advise that if longer-lasting effects are detected, the study should be extended during the operational phase.

\subsubsection{Methods}

Aerial Surveys: Aerial surveys will enable the detection of most marine megavertebrate species of interest - cetaceans, seals and turtles. Sunfish and basking sharks may be seasonally detectable, depending on water temperature and other conditions. Aerial surveys should cover not only the offshore proposed study site and at least two control sites (beyond-BACI design), but also all known nearby seal haul-out areas (South Monomoy Island, Muskeget Island, Wasque Shoal, Great Point Nantucket and Nantucket Harbor), so that the number of seals on land can be assessed.

Distance sampling (Buckland et al., 2001): This will generate abundance estimates within the study area and will thus enable a more accurate assessment of any effect of construction or operation within a BACIstructured study design. Aerial surveys of seal haul-out sites do not require transect methodology and would thus be best placed at the start or end of a survey flight or run as a separate flight. Seal haul-out surveys may need to employ photography and generate counts from post-survey photo analysis.

Communication with local right whale aerial survey teams (PCCS and NEFSC) will be extremely useful in ascertaining whether any injured right whales are observed in adjacent areas. Data collected within the Muskeget Channel area can also supplement the data collected by the teams, since this region currently falls outside of the focal study areas of both teams but is, nonetheless, of considerable interest for this species. During the 2010 PCCS right whale monitoring season, right whales were sighted in the Rhode Island Sound area adjacent to Muskeget Channel, thus it is likely that some individuals utilized these waters (T. Cole, pers. comm., May 2010). If, during the distance sampling protocol aerial surveys for the Muskeget project, right whales are sighted in either control or impact sites, it is recommended that the sighting be communicated to both teams, whereupon they can arrange, if practical, for a second flight in the area to collect detailed photo-identification data on the individual right whales utilizing this habitat. This will be of benefit not only to the New England Aquarium North Atlantic Right Whale Catalogue and the scientific community's overall understanding of the ecology of this species, but it will also provide additional data for the Muskeget team on the proportion of this endangered population using the installation area. This in turn will inform how best to mitigate for potential disturbance effects to this species, which will require special consideration. 
Acoustic Environmental Monitoring: Mapping the "soundscape" of the site (i.e., measuring the zone of audibility and the zone of disturbance at full power operation and describing the full spectrum of frequencies and noise levels produced and the variability therein with different sea state conditions) is important to be able to separate "background" noises from those of odontocetes. This will allow for a detection of change in the acoustic environment with the installation of the turbines and of potential acoustic threats to marine megavertebrates as a result. These measurements will facilitate the fine-tuning of SAM for cetaceans by creating a good understanding of the "background noise" and variations therein, over which cetacean vocalizations will have to be detected.

Use of a broadband frequency hydrophone at both the impact and control areas to collect information on the type of background noise is recommended. Replicate samples should be collected at a range of tidal states (slack tide and at a range of ebb and flood speeds) in all months of the year or, at the very least, during spring tides or the days leading up to peak spring tide, when the environment will be noisiest. Sampling should occur about a kilometer up and downstream of the intended turbine deployment location, and the sampling regime should be repeated both before and after the installation. Recording for some distance away from the exact location provides a description of the receiving environment. Ideally this work should be carried out in standardized conditions (e.g., relative to other activities in the area).

The use of SAMS drifting ears should be considered depending on the state of the technology. These recorders summarize the soundscape at frequencies from $50 \mathrm{~Hz}$ to $46 \mathrm{kHz}$ and allow the representation of these data in map format for the site (developed by the Scottish Association of Marine Scientists and used by EMEC, Scottish Power Renewables, Scottish Government and OpenHydro in the U.K. and North America). Higher frequency recordings using a hydrophone could be carried out in parallel from the vessel used to deploy and recover the drifters.

Moored hydrophones in high-flow areas present considerable problems. At peak flow rates, which are the periods of greatest interest and also likely of highest collision risk for megavertebrates, recording needs to be free of noise generated within the hydrophone. Since flow noise associated with the passage of water around a hydrophone unit increases with flow speed, this issue is difficult to resolve.

Static Acoustic Monitoring: All odontocetes studied to date appear to produce echolocation clicks as a means of searching for prey, exploring their environment and possibly for inter-species communication. A study by Akamatsu et al. (2007) documented an almost continuous use of echolocation by wild, tagged harbor porpoises; less than $4 \%$ of the tagged time comprised silent periods lasting more than 50 seconds. This behavior makes species such as the harbor porpoise especially well-suited to monitoring by acoustic means.

Multiple SAM units should be placed at both control and impact sites, in such a way as to allow for calculation of the effect of distance from the impact (construction at the turbine site and, eventually, the turbine itself). The SAM data can also provide habitat use indices (e.g. Detection-Positive Minutes per hour) which can be used in statistical analyses as abundance data would be, thus allowing for a beyondBACI analysis. Environmental impact assessments in Danish and German waters have used various numbers and layouts of T-PODs (the predecessor to the C-POD) depending on the site and resources available (Leeney and Tregenza, 2006).

Replicate units (allowing for both replication and for back-up in case of unit malfunction) should be placed at increasing distance increments from the turbines to examine the impact range. As some studies have documented an effect of pile driving on cetaceans beyond $21 \mathrm{~km}$ from the source, it is recommended that SAM units are placed at distances of between 2 and $5 \mathrm{~km}$ out to a distance of at least $30 \mathrm{~km}$. The same deployment structure should be in place at control site(s). C-PODs (www.chelonia.co.uk) or a 
similar technology (Aquatec and Woods Hole Oceanographic Institute have produced similar monitoring tools) have been deployed successfully.

Species-specific acoustic Studies: Several species which are likely to occur in the control and impact sites have not been studied before using C-PODs. Additionally, there are not good existing data on the echolocation characteristics of many species, such as the Atlantic white-sided dolphin (Lagenorhychus acutus). In order for the SAM effort to be most effective, supporting work is recommended to characterize the click characteristics of at least several species that are very likely to be encountered in the area, for which data on echolocation characteristics are deficient. This will involve targeted vessel-based searches for specific species followed by acoustic sampling in the close vicinity of these species using a hydrophone with high sampling rates which can measure frequencies above $200 \mathrm{kHz}$. Collection of data on species, group size and behavior will accompany the acoustic sampling. These data will then inform how best to set the C-PODs for monitoring the area of interest and will also enable a more accurate analysis of the resulting SAM data. Equipment used is a calibrated hydrophone, amplifier and sound card or oscilloscope.

Land-based Surveys for Stranded Pinnipeds: On the islands of Monomoy and Muskeget, regular (2-4 per month) searches for beached carcasses of seals should be carried out in every month of the year. Any carcasses should be extensively photographed and standard data collection for stranded pinnipeds should be carried out. Any animals displaying injuries which could be associated with turbine blade trauma should be removed for necropsy, if possible.

At-sea Platform-Based Observations: The SeaGen turbine in Strangford Lough, Northern Ireland, is one of the world's first full-scale, operational tidal turbines (http://www.seageneration.co.uk/). It has been in place since 2008. The structure of this turbine, with a platform above water, is such that observations of the water directly surrounding the turbine could be made. Marine mammal observers have now been replaced by active sonar, which shuts down the turbine operation when any marine mammal is detected within a $50 \mathrm{~m}$ radius of the turbine (Bedford and Fortune, 2010). Such a setup, allowing for in situ observations of the occurrence of marine megavertebrates in close vicinity to the turbines, would be beneficial to understanding the effect these structures have on the Muskeget Channel environment. Platform observations would allow the collection of detailed data on occurrence and behavior of various species in the immediate vicinity of the turbines as well as direct confirmation of any immediately apparent negative or nonnegative effects.

Underwater Imaging: There remain several questions that will be difficult to address, such as the underwater response of diving birds as well as species such as basking sharks to submerged, moving turbine blades. Although the underwater environment is likely to be turbid, a trial of an underwater video camera affixed to one of the turbine bodies is recommended. For comparatively little effort, such a technique may provide a rare glimpse of the behaviors exhibited by certain species in close proximity to these structures.

An alternative method that shows promise is sonar imaging. A multi-beam imaging sonar, such as DualFrequency Identification Sonar (DIDSON) has already been proposed as part of the draft fisheries study plan for the site and, if incorporated into the study plan, will be deployed on one of the turbine structures to record information on fish behavior and direct impacts from the tidal turbines. Such technology is able to produce images of targets that pass through its sonar field-of-view. The DIDSON produces a nearvideo quality that allows observation of underwater behaviors of various species in turbid and nighttime conditions. Although not established as a technique for surveying marine megavertebrates, a sonar imaging system has been used with some success at the Strangford Lough tidal turbine (Bedford and Fortune, 2010). Since small fish species can be detected with this technique, it is likely to work for larger animals as well. Equipment used is the DIDSON Long Range model maximizes the amount of 
observable area in front of and behind the module. This model has an approximately $29^{\circ}$ beam width and a $14^{\circ}$ beam elevation. http://www.soundmetrics.com/

These monitoring elements are summarized in Table 6, along with target species for each method, recommended sampling frequency, duration of the sampling and any notes regarding safety or other considerations.

Table 6: Monitoring Elements

\begin{tabular}{|c|c|c|c|c|}
\hline Method & Target & Frequency & Duration & Comment \\
\hline Aerial & All & 2 per month & $\begin{array}{l}\text { Two years prior } \\
\text { through installation }\end{array}$ & $\begin{array}{l}\text { Collect baseline data on } \\
\text { species composition, } \\
\text { abundance, habitat use }\end{array}$ \\
\hline Stranding & Seals & 2-4 per month & $\begin{array}{l}\text { During turbine } \\
\text { installation and one } \\
\text { year operation }\end{array}$ & \\
\hline SAM1 & Odontocetes & Continuous at 3 sites & $\begin{array}{l}\text { Two years prior } \\
\text { through installation }\end{array}$ & \multirow{2}{*}{$\begin{array}{l}\text { Collect baseline data on } \\
\text { species composition } \\
\text { SAM costs may require } \\
\text { choice of one/ other } \\
\text { technique. What are } \\
\text { priority species? }\end{array}$} \\
\hline SAM2 & My \& Od & Continuous at 3 sites & $\begin{array}{l}\text { Two years prior } \\
\text { through installation }\end{array}$ & \\
\hline Seascape Acoustic & Background Noise & $\begin{array}{l}3 \text { replicate samples per } \\
\text { year }\end{array}$ & $\begin{array}{l}\text { Two years prior } \\
\text { through installation }\end{array}$ & $\begin{array}{l}\text { Collect background data } \\
\text { for comparison with in- } \\
\text { water pilot device }\end{array}$ \\
\hline $\begin{array}{l}\text { Species-specific } \\
\text { Acoustic }\end{array}$ & Odontocetes & 2-3 weeks prior to SAM & One month & $\begin{array}{l}\text { Identification of data } \\
\text { deficient species required }\end{array}$ \\
\hline Platform Observations & All & $\begin{array}{l}\text { 3-4 hour samples once } \\
\text { per week }\end{array}$ & $\begin{array}{l}\text { Two years prior } \\
\text { through installation }\end{array}$ & $\begin{array}{l}\text { Likely only possible at } \\
\text { impact site }\end{array}$ \\
\hline Sonar & All & Continuous & $\begin{array}{l}\text { Two years prior } \\
\text { through installation }\end{array}$ & $\begin{array}{l}\text { Likely only practical at } \\
\text { impact site }\end{array}$ \\
\hline Video/Sonar & All & $\begin{array}{l}\text { Trial 3-4 weeks at start } \\
\text { of project }\end{array}$ & $\begin{array}{l}\text { If successful, } 24 \text { hour } \\
\text { sampling in each } \\
\text { project phase }\end{array}$ & $\begin{array}{l}\text { Only practical at impact } \\
\text { site }\end{array}$ \\
\hline
\end{tabular}

\subsection{PCCS Field Studies}

In the summer of 2012, PCCS undertook some initial field studies of protected species in the Muskeget Channel Area. The results of these studies are provided in Appendix D.

\subsection{Permitting Requirements}

The Muskeget Channel Tidal Project is subject to review by regulatory agencies authorized by local, regional, state, and federal laws. Some agencies issue permits while others provide comment to cooperating permit-issuing agencies which must be considered (by law) in the permit issuance. Because there is already a considerable amount of information about the environmental permitting processes in New England, the intent of this section of the report was to provide a summary of the process in a tabular and graphical form to be displayed on a website for public consumption. This information has been posted on the Muskeget Tidal Energy Project webpage hosted on the New England Marine Renewable Energy Center's website at the url address: http://www.mrec.umassd.edu/resources/muskegettidalproject/. 
Appendix E provides a detailed table listing each of the regulatory activities the Muskeget Project is subject to. The table includes the following information:

- Agency: name of the agency responsible under the law for administering the regulatory program.

- Authority/Action: a citation for the law providing regulatory authority and the permit or license to be issued.

- Intent/Requirements: a summary explanation of the regulation and its purpose.

- Process/Timeline: the steps and schedule for permit application review including mandated public comment periods and legal notices if any.

Figure 48 below illustrates the regulatory review process in a graphical format showing the interrelationship between different jurisdictions and the role of public input.

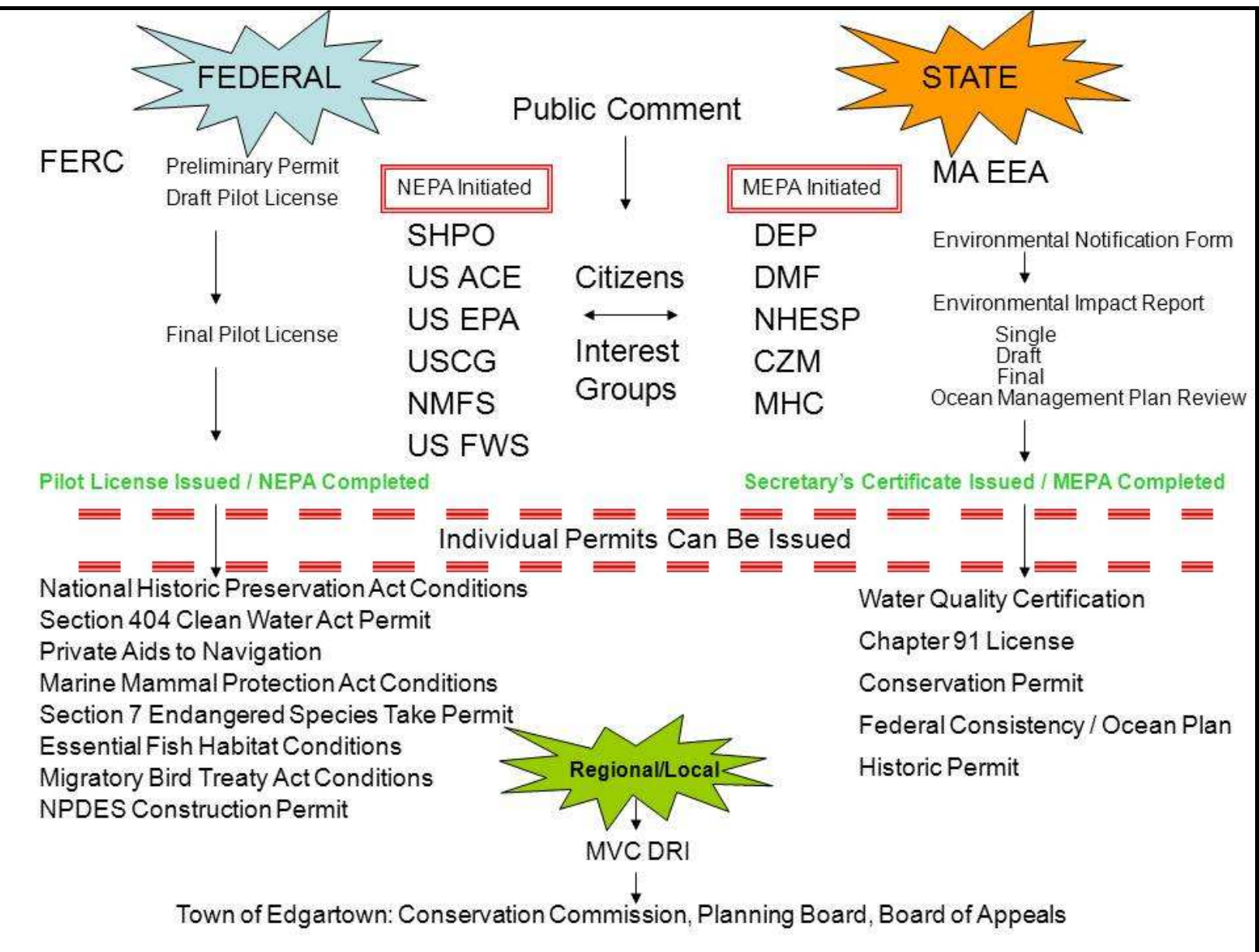

Figure 48: Regulatory Approval Process 
(This page intentionally left blank) 


\section{Outreach}

HMMH was responsible for managing the grant funded research and reporting information on the studies and the broader tidal energy project to regulators and the general public. The following section reviews the outreach activities undertaking with support from the DOE grant.

\subsection{Regulatory}

One of the fundamental objectives of the Advanced Water Power Grant is to collect information that will support the permitting of tidal energy projects. The project team was mindful of this objective in preparing the scope of work and is confident that the data collected will be central to answering questions posed by regulatory authorities. To ensure that agency personnel understand the study objectives and methods, and can proactively provide the team with feedback during the data collection and analysis period, HMMH coordinated with key agency personnel throughout the project. These meeting build upon communications conducted by HMMH and Edgartown through the ocean planning process triggered by passage of the Massachusetts Oceans Act on July 9 of 2008.

\subsubsection{Regulatory Kickoff Meeting}

A meeting was convened at the US Environmental Protection Agency (EPA) Region I office with federal and state regulatory staff to provide an overview of the proposed Muskeget Channel Tidal Energy Project and plan to implement DOE funded studies. Federal agencies that were represented included EPA, National Marine Fisheries Service (NMFS), US Fish and Wildlife Service (FWS), and US Army Corps of Engineers (ACE). State agency representatives included Division of Marine Fisheries (DMF), and Coastal Zone Management (CZM). Following the kickoff meeting, a separate presentation was made on the same day to state officials including staff from the Executive Office of Energy and Environmental Affairs (EEA), Massachusetts Environmental Policy Act (MEPA), Coastal Zone Management (CZM), and the Massachusetts Clean Energy Center (MassCEC). In both cases, staff became aware of the project and $\mathrm{HMMH}$ and representatives from the Town answered initial questions about the project.

\subsubsection{Individual Agency Meetings}

Multiple individual meetings with federal, state, and local regulatory agencies were conducted over the past two years as part of the project consultation associated with the FERC Draft Pilot License Application and the MEPA Expanded Environmental Notification Form (EENF) which were concurrently filed on January 31, 2010.

The following table lists the dates of individual meetings and their purpose. 
Table 7: Regulatory Meetings

\begin{tabular}{|l|l|l|}
\hline \multicolumn{1}{|c|}{ Date } & \multicolumn{1}{c|}{ Objency } \\
\hline $3 / 17 / 10$ & USCG Marine Safety Meeting & Overview \\
\hline $5 / 28 / 10$ & DMF, NMFS & Draft Fisheries and Protected Species Study Plans \\
\hline $7 / 26 / 10$ & MVC & Overview \\
\hline $9 / 7 / 10$ & MEPA, CZM, DEP, EEA & Pre EENF meeting \\
\hline $10 / 5 / 10$ & DEP, CZM & Pre EENF meeting \\
\hline $3 / 7 / 11$ & FERC/MEPA & Public Meeting for DPLA and EENF \\
\hline $4 / 7 / 11$ & USCG Marine Safety Meeting & Update, Summer Demonstration \\
\hline $7 / 25 / 11$ & Wampanoag Tribe of Gay Head & FERC Consultation \\
\hline $11 / 14 / 11$ & MVC & Update \\
\hline $12 / 5 / 11$ & NMFS, DMF & Review of Fisheries and Protected Species Study Plans \\
\hline $12 / 22 / 11$ & DEP & Proposed Regulatory Reform for MHK \\
\hline $1 / 12 / 12$ & DEP & Proposed Regulatory Reform for MHK \\
\hline $11 / 20 / 12$ & DEP-Southeast Region & Staff Meeting \\
\hline $12 / 4 / 12$ & Northeast Regional Ocean Council & Marine Spatial Planning \\
\hline
\end{tabular}

\subsubsection{FERC Draft Pilot License Application and Massachusetts EENF}

On January 31, 2011, Edgartown filed its NOI and DPLA with FERC, and concurrently filed the complementary state application under the Massachusetts Environmental Policy Act (MEPA) initiating a parallel state and federal review process. A joint FERC and MEPA public meeting and site visit was conducted at the Edgartown Town Hall and landfall alternative locations on March 7, 2011. FERC issued a letter on April 1, 2011 with a request for additional information to support a Final License application and required that the information be submitted by August 8, 2011. MEPA issued a Certificate on the Expanded Environmental Notification Form on April 8, 2011 and provided the scope for a Draft Environmental Impact Report (DEIR). Due to commitments made by the Town to collect predeployment environmental data associated with study plans filed with the DPLA, the Town requested in a letter dated August 11, 2011 that FERC grant an extension on filing the additional information associated with the Final Pilot License Application, moving the submission date to November 15, 2012.

\subsection{Industry}

$\mathrm{HMMH}$ has been interacting with the marine hydrokinetic industry in different formats as part of the implementation of the DOE-funded project.

HMMH has been coordinating with staff at Ocean Renewable Power Company which has provided information on turbine and anchor system design to inform the Muskeget Project layout. HMMH has also been participating in conferences and webinars sharing useful information. The Principal Investigator has made formal presentations on the project at the following industry forums. 
Table 8: Presentations on the Proposed Project

\begin{tabular}{|l|l|l|}
\hline \multicolumn{1}{|c|}{ Date } & \multicolumn{1}{|c|}{ Forum } & \multicolumn{1}{|c|}{ Participation } \\
\hline $9 / 27 / 10$ & Annex IV Workshop in Dublin Ireland & Participant \\
\hline $10 / 28 / 10$ & Marine Tech Summit - Dalian China & Presentation \\
\hline $11 / 2 / 10$ & MREC Technical Conference & Presentation \\
\hline $1 / 27 / 11$ & Marine Oceanographic Technology Network & Presentation \\
\hline $4 / 8 / 11$ & Boston College - Ireland Professional Exchange (Energy and Environmental) & Presentation \\
\hline $11 / 2 / 11$ & Department of Energy Peer Review Forum & Presentation \\
\hline $6 / 19 / 12$ & EnergyOcean & Presentation \\
\hline
\end{tabular}

The Principal Investigator also participated in DOE-sponsored webinars.

\subsection{General Public and Stakeholders}

The public outreach portion of the project is aimed at supporting more broadly both the permitting process and the industry's public profile. This objective was be achieved by communicating the elements of the environmental studies program and the broader project to local and regional stakeholders and describing how the data collection will answer questions about potential environmental impacts that will be of particular interest to the local communities. HMMH and Edgartown worked closely with UMASS MREC on public outreach activities to build on their previous work. Outreach complemented previous discussions with municipal Boards in the Towns of Edgartown and Nantucket.

The following table lists the stakeholder and public meeting convened on the project.

Table 9: Stakeholder Group Meetings

\begin{tabular}{|l|l|l|}
\hline \multicolumn{1}{|c|}{ Date } & \multicolumn{1}{c|}{ Porum } & \multicolumn{1}{c|}{ Participation } \\
\hline $3 / 29 / 10$ & Edgartown Selectmen (televised) & Project status \\
\hline $6 / 22 / 10$ & Vineyard Energy Cooperative & Overview \\
\hline $6 / 22 / 10$ & The Trustees of the Reservations & Overview \\
\hline $7 / 26 / 10$ & Edgartown Selectmen (televised) & Project Status \\
\hline $3 / 7 / 11$ & FERC / MEPA Public Meeting & DPLA and EENF Applications \\
\hline $5 / 27 / 11$ & Cape Cod Hook Fishermen's Association & Overview \\
\hline $6 / 8 / 11$ & State Senator Daniel Wolf and staff & Overview \\
\hline $7 / 25 / 11$ & Martha's Vineyard Chamber of Commerce & Overview \\
\hline $11 / 14 / 11$ & Edgartown Selectmen (televised) & Project Status \\
\hline $11 / 14 / 11$ & Dukes County Fishermen's Association & Overview \\
\hline $1 / 24 / 12$ & New England Fisheries Management Council Habitat Committee & Overview \\
\hline
\end{tabular}


(This page intentionally left blank) 


\section{References}

\section{Chapter 3}

Chen, C., H. Huang, R.C. Beardsley, Q. Xu, R. Limeburner, G.W. Cowles, Y. Sun, J. Qi, H. Lin, 2011. Tidal dynamics in the Gulf of Maine and New England Shelf: An application of FVCOM, Journal of Geophysical Research, in press.

Chen, C, R. C. Beardsley and G. Cowles, (2006). An unstructured grid, finite-volume coastal ocean model (FVCOM) system. Special Issue entitled "Advance in Computational Oceanography", Oceanography, 19(1), 78-89.

Chen, C., H. Liu, and R. Beardsley, (2003) An unstructured grid, finite-volume, three-dimensional, primitive equations ocean model: Application to coastal ocean and estuaries. Journal of Atmospheric and Ocean Technology, 20 (1), 159-186.

Cowles, G., (2008), "Parallelization of the FVCOM Coastal Ocean Model”, International Journal of High Performance Computing Applications 22(2) 177-193.

Denny, J.F., Danforth, W.W., and Signell, R., (2012), Swath Bathymetric Data collected within Muskeget Channel, MA. USGS Open-File Report, 2012-XXXX (in prep).

Kobayashi, M. H., J. M. C. Pereira and J. C. F. Pereira (1999). A conservative finite-volume secondorder-accurate projection method on hybrid unstructured grids. J. Comput. Phys., 150, 40-45.

Madala, R. V., and S. A. Piacsek (1977). A semi-implicit numerical mode for baroclinic oceans, $J$. Comput. Phys., 23, 167-178.

Meyer-Peter, E., Müeller, R., (1948). Formulas for bedload transport. In: Report on the 2nd Meeting International Association Hydraulic Structure Research. Stockholm, Sweden, pp. 39-64.

ORPC, (2010). Preliminary Tidal Energy Assessment for Muskeget Channel. Technical Report prepared for Harris, Miller, Miller, and Hanson Inc. for the Town of Edgartown, MA, 12 pp.

Poppe, L.J., Paskevich, V.F., Williams, S.J., Hastings, M.E., Kelley, J.T., Belknap, D.F., Ward, L.G., FitzGerald, D.M., and Larsen, P.F. (2003). Surficial Sediment Data from the Gulf of Maine, Georges Bank, and Vicinity: A GIS Compilation. U.S. Geological Survey Open-File Report 03-001.

Réthoré, P.E., Sørensen, N.N., and Bechmann, A. (2010). CFD Model of wind turbine wake in atmospheric turbulence using body forces. Proceedings of the IEA Offshore Wake Workshop, Ris $\emptyset, 2009$.

Warner, J. C., Sherwood, C. R., Signell, R. P., Harris, C. K., and Arango, H. G. (2008) Development of a three-dimensional, regional, coupled wave, current, and sediment- transport model. Computers \& Geosciences, 34, 1284-1306

\section{Chapter 4}

Abbasi, S.A. and Abbasi, N. 2000. The likely adverse environmental impacts of renewable energy sources. Applied Energy 65: 121-144.

Ahrenholz, D.W. 1991. Population biology and life history of the North American menhadens, Brevoortia spp. Marine Fisheries Review 53(4): 1-19 
Akamatsu, T., Hatakeyama, T., Kojima, H. and Soeda, H. 1992. The rate at which a harbor porpoise uses echolocation at night. In: J. A. Thomas, R. A. Kastelein, and A. Y. Supin (Eds). Marine Mammal Sensory Systems. Plenum Press, New York. pp. 299-315.

Akamatsu, T., Teilmann, J., Miller, L.A., Tougaard, J., Dietz, R., Wang, D., Wang, K., Siebert, U. and Naito, Y. 2007: Comparison of echolocation behavior between coastal and riverine porpoises. Deep-Sea Res. 54: 290-297.

Allen, G.M. 1916. The whalebone whales of New England. Memoirs of the Boston Society of Natural History 8(2): 107-322.

Allen, J.A. 1888. History of North American pinnipeds, a monograph of the walruses, sea-lions, sea-bears and seals of North America. U.S. Geological and geographical survey of the territories. Miscellaneous publications. No $12.785 \mathrm{pp}$.

Allison, T.D., Jedrey, E. and Perkins, S. 2008. Avian issues for offshore wind development. Marine Technology Society Journal 42 (2): 28-38.

Altmann, J. 1974. Observational study of behavior: sampling methods. Behavior 49: 227-267.

Ampela, K. 2009. The diet and foraging ecology of gray seals (Halichoerus grypus) in the United States Waters. Ph.D. Dissertation. The City University of New York. 176 pp.

Andersson, M.H., Dock-Åkerman, E., Ubral-Hedenberg, R. and Öhman, M.C. 2007. Swimming behavior of roach (Rutilus rutilus) and three-spined stickleback (Gasterosteus aculeatus) in response to wind power noise and singletone frequencies. Ambio 36: 636-638.

Andrews, J.C. and Mott, P.R. 1967. Grey seals at Nantucket, Massachusetts. Journal of Mammalogy 48(4): 657-8.

Arnold, J.M., and Williams-Arnold, L.D. 1977. Chapter 5: Cephalopoda: Decapoda. Reproduction of Marine Invertebrates. In: A. C. Geise and J. S. Pearse (Eds). Molluscs: Gastropods and Cephalopods. Volume 4. Academic Press, New York.

Atlantic States Marine Fisheries Commission (ASMFC). 2003. Amendment 6 to the interstate fishery management plan for Atlantic striped bass. Atlantic States Marine Fisheries Commission Fishery Management Report No. 41.63 pp.

Atlantic States Marine Fisheries Commission (ASMFC). 2009. 2009 review of the Atlantic States Marine Fisheries Commission fishery management plan for Atlantic striped bass: 2008 fishing year. Retrieved from http://www. asmfc.org/speciesDocuments/stripedBass/reports/fmpreviews/sbfmpreview2009.pdf.

Atlantic States Marine Fisheries Commission (ASMFC). 2010. Atlantic Menhaden Stock Assessment and Review Panel Report. Stock Assessment and Review Report No. 10-02. 325 pp.

Au, W.W.L. and Green, M. 2000. Acoustic interaction of humpback whales and whale-watching boats. Marine Environmental Research 49: 469-481.

Babcock, H.L. 1926. The Diamond-Back Terrapin in Massachusetts. Copeia. No. 150, Jan. 25, 1926, pp. 101-104.

Babcock, R.C., Kelly, S., Shears, N.T., Walker, J.W. and Willis, T.J. 1999. Changes in community structure in temperate marine reserves. Marine Ecology Progress Series 189: 125-134. 
Barlas, M.E. 1999. The distribution and abundance of harbor seals (Phoca vitulina concolor) and gray seals (Halichoerus grypus) in southern New England, winter 1998- summer 1999. M.A. Thesis. Boston University, $52 \mathrm{pp}$.

Barrios, I. and Rodriguez, A. 2004. Behavioral and environmental correlates of soaring-bird mortality at onshore wind turbines. Journal of Applied Ecology 41: 72-81.

Battelle. 2003. Recreational intercept survey. Prepared for Cape Wind Associates, L.L.C. January 2003.

Beardsley, R.C., Epstein, A.W., Chen, C., Wishner, K.F., Macaulay, M. C. and Kenney, R.D. 1996. Spatial variability in zooplankton abundance near feeding right whales in the Great South Channel. Deep Sea Research II 43: 1601-1625.

Bearzi, G., Agazzi, S., Gonzalvo, J., Costa, M., Bonizzoni, S., Politi, E., Piroddi, C. and Reeves, R.R. 2008a. Overfishing and the disappearance of short-beaked common dolphins from western Greece. Endangered Species Research 5: 1-12.

Bearzi, G., Fortuna, C.M. and Reeves, R.R. 2008b. Ecology and conservation of common bottlenose dolphins Tursiops truncatus in the Mediterranean Sea. Mammal Review 39(2): 92-123. doi: 10.1111/j.13652907.2008.00133.x.

Bedford, G. and Fortune, F. 2010. SeaGen Biannual EMP update. 21 April 2010. Report ref. 9S8562/R/303719/ Edin, 31 pp. Retrieved from http://www.seageneration.co.uk/downloads/SeaGen\%20biannual\%20report\%20 April\%202010.PDF.

Bejder, L., Dawson, S. and Harraway, J.A. 1999. Responses by Hector's dolphins to boats and swimmers in Porpoise Bay, New Zealand. Marine Mammal Science 15: 738-750.

Bejder L., Samuels A., Whitehead H. and Gales N. 2006. Interpreting short-term behavioral responses to disturbance within a longitudinal perspective. Animal Behavior 72: 1149-1158.

Berrow, S.D. 1994. Incidental capture of elasmobranchs in the bottom set gill-net fishery off the south coast of Ireland. Journal of Marine Biological Association UK 74: 837-847.

Berrow, S., Cosgrove, R., Leeney, R.H., O’Brien, J., McGrath, D., Dalgard, J. and LeGall, Y. 2008. Effects of acoustic deterrents on the behavior of common dolphins (Delphinus delphis). Journal of Cetacean Research and Management 10: 227-233.

Beukers-Stewart, B.D., Vause, B.J., Mosley, M.W.J., Rossetti, H.L. and Brand, A.R. 2005. Benefits of closed area protection for a population of scallops. Marine Ecology Progress Series 298: 189-204.

Bigelow, H.B. and Schroeder, W.C. 1953. Fishes of the Gulf of Maine. Fishery Bulletin of the Fish and Wildlife Service Vol. 53. 577 pp.

Bjorndal, K.A. 1997. Foraging ecology and nutrition of sea turtles. Pages 199-233. In: P.L. Lutz and J.A. Musick (Eds). The Biology of Sea Turtles. CRC Press, New York.

Bleakney, J.S. 1965. Reports of marine turtles from New England and Eastern Canada. Canadian Field Naturalist. 1965(79): 120-128.

Block, E. 2008. Tidal power: an update. Renewable Energy Focus 9 (6): 58-61.72 Marine Megavertebrates and Fishery Resources in the Nantucket Sound - Muskeget Channel Area 
Blyth-Skyrme, R.E. 2010. Options and opportunities for marine fisheries mitigation associated with windfarms. Draft report for Collaborative Offshore Wind Research Into the Environment contract FISHMITIG09. COWRIE Ltd, Nature Bureau, Newbury, UK. 125 pp. Retrieved from http://www.offshorewindfarms.co.uk/Assets/ Windfarms\%20and\%20Fisheries\%20Mitigation\%20Final\%20Report_Draft_1st\%20April.pdf.

Blyth, R.E., Kaiser, M.J., Edwards-Jones, G. and Hart, P.B. 2004. Implications of a zoned fishery management system for marine benthic communities. Journal of Applied Ecology 41: 951-961.

Blyth-Skyrme, R.E., Kaiser, M.J., Hiddink, J., Edwards-Jones, G. and Hart, P.J.B. 2006. Conservation Benefits of Temperate Marine Protected Areas: Variation among Fish Species. Conservation Biology 20 (3): 811-820.

Boehlert, G.W., McMurray, G.E. and Tortorici, C.E. 2008. Ecological Effects of Wave Energy Development in the Pacific Northwest, 174 p. U.S. Department of Commerce, NOAA Technical Memorandum NMFS-F/SPO-92.

Bogomolni, A.L., Pugliares, K.R., Sharp, S.M., Patchett, K., Harry, C.T., LaRocque, J.M., Touhey, K.M. and Moore, M. 2010. Mortality trends of stranded marine mammals on Cape Cod and southeastern Massachusetts, USA, 2000 to 2006. Diseases of Aquatic Organisms 88: 143-155.

Boskovic, R., Kovacs, K.M., Hammill, M.O. and White, B.N. 1996. Geographic distribution of mitochondrial DNA haplotypes in grey seals. Canadian Journal of Zoology 74: 1787-1796.

Bowen, D.W., Ellis, S.L., Iverson, S.J. and Boness, D.J. 2003. Maternal and newborn life-history traits during periods of contrasting population trends: implications for explaining the decline of harbor seals (Phoca vitulina), on Sable Island. Journal of Zoology 261: 155-163.

Brandt, M., Diederichs, A., Höschle, C., Wollheim, L. and Nehls, G. 2010. The use of seal scarers during offshore pile driving: an effective mitigation measure for harbor porpoises (Phocoena phocoena)? Poster presentation, 24th Conference of the European Cetacean Society, Stralsund, Germany, April 2010.

Brennessel, B. 2007. The Northern Diamond-backed Terrapin: Habitat, Management, and Conservation. Wheaton College, Norton, Massachusetts.

Brodie, P.F., Sameoto, D.D. and Sheldon, R.W. 1978. Population densities of euphausiids off Nova Scotia as indicated by net samples, whale stomach contents and sonar. Limnology and Oceanography 23: 1264-1267.

Brodziak, J.K.T. and Rosenberg, A.A. 1993. A method to assess squid fisheries in the north-west Atlantic. ICES Journal of Marine Science 50: 187-194.

Bryant, P.J., Lafferty, C.M. and Lafferty, S.K. 1984. Reoccupation of Laguna Guerrero Negro, Baja California, Mexico, by gray whales. In: M.L. Jones, S.L. Swartz and S. Leatherwood (Eds). The gray whale Eschrichtius robustus. Academic Press, New York, pp. 375-387.

Buchsbaum, R., Pederson, J. and Robinson, W.E. (Eds). 2005. The decline of fisheries resources in New England: evaluating the impact of overfishing, contamination, and habitat degradation. MIT Sea Grant College Program Publication No. 05-5. 175 pp.

Buckland, S.T., Anderson, D.R., Burnham, K.P., Laake, J.L., Borchers, D.L. and Thomas, L. 2001. Introduction to Distance Sampling. Estimating abundance of biological populations. Oxford University Press, Oxford, UK. 
Buckstaff, C. 2004. Effects of boats on dolphin vocal behavior. Marine Mammal Science 20: 709-725.

Burke, V.J., Standora, E.A. and Morreale, S.J. 1991. Factors affecting strandings of cold-stunned juvenile Kemp's ridley and loggerhead sea turtles in Long Island, NY. Copeia 1991 (4): 1136-1138.

Burns, J.J. 2009. Harbor seal and Spotted Seal. In Encyclopedia of Marine Mammals, 2nd edition. Academic Press, Burlington, MA. pp. 533-542.

Cada, G.F., Ahlgrimm, J., Bahleda, M., Bigford, T., Damiani Stavrakas, S., Hall, D., Moursund, R. and Sale, M. 2007. Potential impacts of hydrokinetic and wave energy conversion technologies on aquatic environments. Fisheries 32: 174-181.

Campana, S.E., Gibson, J., Brazner, J., Marks, L., Joyce, W., Gosselin J.F., Kenney, R. D., Shelton, P., Simpson, M. and Lawson, J. 2008. Status of Basking Sharks in Atlantic Canada. Canadian Science Advisory Secretariat Research Document 2008/004. 67 pp.

Caretta, J.V., Barlow, J. and Enriquez, L. 2008. Acoustic pingers eliminate beaked whale bycatch in a gill net fishery. Marine Mammal Science 24 (4): 956-961.

Carr, A. 1987. Impact of non-degradable marine debris on the ecology and survival outlook of sea turtles. Marine Pollution Bulletin. 18: 352-356.

Carstensen, J., Henriksen, O.D. and Teilmann, J. 2006. Impacts of offshore wind farm construction on harbor porpoises: acoustic monitoring of echolocation activity using porpoise detectors (T-PODs). Marine Ecology Progress Series 321: 295-308.

CITES. 2007. "Appendices" (SHTML). Convention on International Trade in Endangered Species of Wild Flora and Fauna. Retrieved from http://www.cites.org/eng/app/appendices.shtml.

Clark, C.W., Brown, M.W. and Corkeron, P. 2010. Visual and acoustic surveys for North Atlantic right whales, Eubalaena glacialis, in Cape Cod Bay, Massachusetts, 2001-2005: Management implications. Marine Mammal Science DOI: 10.1111/j.1748-7692.2010.00376.x.

Commonwealth of Massachusetts. 2009. Massachusetts Ocean Management Plan. December 2009. Retrieved from http://www.env.state.ma.us/eea/mop/final-v1/.

Compagno, L.J.V. 2001. Sharks of the world. An annotated and illustrated catalogue of shark species known to date. Volume 2: Bullhead, mackerel and carpet sharks (Heterodontiformes, Lamniformes and Orectolobiformes). FAO Species Catalogue for Fisheries Purposes No. 1, Vol. 2: 269 pp. Food and Agriculture Organization of the United Nations. Rome. 269 pp.

Constantine, R. 2001. Increased avoidance of swimmers by wild bottlenose dolphins (Tursiops truncatus) due to long-term exposure to swim-with-dolphin tourism. Marine Mammal Science 17: 689-702.

Cox, T.M., Read, A.J., Swanner, D., Urian, K. and Waples, D. 2003. Behavioral responses of bottlenose dolphins, Tursiops truncatus, to gillnets and acoustic alarms. Biological Conservation 115: 203-212.

Cox, T.M., Read, A.J., Solow, A. and Tregenza, N. 2001. Will harbor porpoises (Phocoena phocoena) habituate to pingers? Journal of Cetacean Research and Management 3: 81-86.

Croll, D.A., Clark, C.A., Calambokidis, J., Ellison, W.T. and Tershy, B.R. 2001. Effect of anthropogenic low-frequency noise on the foraging ecology of Balaenoptera whales. Animal Conservation 4: 13-27. 
Cronin, M.A., Duck, C.D. and O'Cadhla, O. 2006. Aerial surveying of grey seal breeding colonies on the Blasket Islands, Co. Kerry, the Inishkea Group, Co. Mayo and the Donegal Coast, Ireland. Journal for Nature Conservation 15: 73-83.

Cross, J.N., Zetlin, C.A., Berrien, P.L., Johnson, D.L. and McBride, C. 1999. Essential fish habitat source document: butterfish, Peprilus triacanthus, life history and habitat characteristics. NOAA Technical Memorandum NMFS-NE-145. 42 pp.

Dal Ferro, B. 2006. Wave and tidal energy its emergence and the challenges it faces. Refocus 7: 46-48. doi:10.1016/S1471-0846(06)70574-1.

Davison, A. and Mallows, T. 2005. Strangford Lough Marine Current Turbine Environmental Statement (Non-technical summary). Royal Haskoning Ltd. June 2005. 4 pp. Retrieved from http://www.seageneration.co.uk/ downloads/EIS Non Technical Summary.pdf.

deHart, P.A.P. 2002. The distribution and abundance of harbor seals (Phoca vitulina concolor) in the Woods Hole region. M.A. Thesis. Boston University, Boston, MA. 88 pp.

DeMartini, E.E. 1993. Modelling the potential of fishery reserves for managing Pacific coral reef fishes. Fishery Bulletin 91: 414-427.73 6 - Reference

Denny, E. 2009. The economics of tidal energy. Energy Policy 37 (5): 1914-1924.

Devine Tarbell \& Associates, Inc. (DT\&A). 2006. Instream tidal power in North America: environmental and permitting issues. Report No. EPRI-TP-007-NA . Prepared for Electric Power Research Institute, Inc. June 2006. $163 \mathrm{pp}$.

Di Iorio, L. and Clark, C.W. 2010. Exposure to seismic survey alters blue whale acoustic communication. Biology Letters 6 (1): 51-54.

Diederichs, A., Brandt, M., Wollheim, L., Höschle, C. and Nehls, G. 2010. Responses of harbor porpoises (Phocoena phocoena) to pile driving measured with passive acoustic monitoring. Oral presentation, 24th Conference of the European Cetacean Society, Stralsund, Germany, April 2010.

Diederichs, A., Hennig, V. and Nehls, G. 2008. Investigations of the bird collision risk and the responses of harbor porpoises in the offshore wind farms Horns Rev, North Sea, and Nysted, Baltic Sea, in Denmark. Part II: Harbor porpoises. BioConsult/ Universität Hamburg report. 100 pp.

Diederichs, A., Nehls, G., Dähne, M., Adler, S., Koschinski, S. and Verfuß, U. 2008. Methodologies for measuring and assessing potential changes in marine mammal behavior, abundance or distribution arising from the construction, operation and decommissioning of offshore windfarms. BioConsult SH report to COWRIE Ltd. 91 pp. Retrieved from http://www.offshorewindfarms.co.uk/Assets/CHANGE0607\%20Final\%20version\%20 2010.pdf.

Diederichs, A. Hennig, V. and Nehls, G. 2008. Investigations of the bird collision risk and the responses of harbor porpoises in the offshore wind farms Horns Rev, North Sea, and Nysted, Baltic Sea, in Denmark. Part II: Harbor porpoises. Final Report. 96 pp.

Dodge, K.D., Prescott, R., Lewis, D., Murle, D. and Merigo, C. 2008. A review of cold-stunned strandings on Cape Cod Massachusetts from 1979-2003. In: Proceedings of the 24th annual symposium on sea turtle biology and conservation. NOAA Technical Memorandum. 
Douglas, A.B., Calambokidis, J., Raverty, S., Jeffries, S.J., Lambourn, D.M. and Norman, S.A. 2008. Incidence of ship strikes of large whales in Washington State. Journal of the Marine Biological Association of the United Kingdom 88: 1121-1132.

Drohan, A.F., Manderson, J.P. and Packer, D.B. 2007. Essential fish habitat source document: black sea bass, Centropristis striata, life history and habitat characteristics. NOAA Technical Memorandum NMFS-NE-200. 68 pp.

Dwyer, K.L., Ryder, C.E. and Prescott, R. 2003. Anthropogenic mortality of leatherback sea turtles in Massachusetts waters. p. 260. In: J.A. Seminoff (compiler). Proceedings of the Twenty-Second Annual Symposium on Sea Turtle Biology and Conservation. NOAA Technical Memorandum NMFS-SEFSC503.

Eaton, G.F. 1898. Prehistoric fauna of Block Island. American Journal of Science 6(32): 137-161.

Edrén, S.M., Andersen, S.M., Teilmann, J., Carstensen, J., Harders, P.B., Dietz, R. and Miller, L.A. 2010. The effect of a large Danish offshore wind farm on harbor and gray seal haul-out behavior. Marine Mammal Science 26 (3): 614-634.

Elvin, S.S. and Taggart, C.T. 2008. Right whales and vessels in Canadian waters. Marine Policy 32 (3): 379-386.

Elwen, S.H., Meÿer, M.A., Best, P.B., Kotze, P.G.H., Thornton, M. and Swanson, S. 2006. Range and movements of female Heaviside's dolphins Cephalorhynchus heavisidii as determined by satellite telemetry. Journal of Mammalogy 87: 866-877.

EMEC (European Marine Energy Centre). 2008. Environmental Impact Assessment (EIA) guidance for developers at the European Marine Energy Centre. 22 pp. Retrieved from

http://www.emec.org.uk/pdf/EMEC\%20 EIA\%20Guidelines\%20GUIDE003-01-03\%2020081106.pdf.

Erickson, W.P., Johnson, G.D., Strickland, M.D., Young Jr., D.P., Sernka, K.J. and Good, R.E. 2001. Western Eco-Systems Technology Inc. Avian Collisions with Wind Turbines: A Summary of Existing Studies and Comparisons to Other Sources of Avian Collision Mortality in the United States. Western Ecosystems Technology Inc., August 2001. 62 pp.

Ernst, C.H. and Lovich J.E. 2009. Turtles of the United States and Canada - 2nd Edition. The John Hopkins University Press, Baltimore, Maryland.

ESS Group, Inc. (ESS). 2006a. Fisheries data report for the Cape Wind Energy Project. Prepared for Cape Wind Associates, L.L.C. November 2006.

ESS Group, Inc. (ESS). 2006b. Survey of commercial and recreational fishing activities in Nantucket Sound. Prepared for Cape Wind Associates, L.L.C. April 2006.

Evans, P.G.H. (Ed). 2008. Proceedings of the ASCOBANS/ ECS Workshop - Offshore wind farms and marine mammals: Impacts and methodologies for assessing impacts. ECS Special Publication Series 49, Feb 2008. 68 pp.

Fayram, A.H. and deRisi, A. 2007. The potential compatibility of offshore wind power and fisheries: an example using bluefin tuna in the Adriatic Sea. Ocean and Coastal Management 40: 597-605.

Ferland, A. 1999. Feeding habits of harbor seals (Phoca vitulina concolor) along the coast of Cape Cod, Massachusetts and the northern Gulf of Maine. M.A. Thesis. Boston University, Boston, MA. 46 pp. 
Fiedler, P.C. and Bernard, H.J. 1987. Tuna aggregation and feeding near fronts observed in satellite imagery. Continental Shelf Research 7: 871-881.

Foote, A.D., Osborne, R.W. and Hoelzel, A.R. 2004. Whale-call response to masking boat noise. Nature. (London) 428: 910.

Fraenkel, P.L. 2006. Tidal Current Energy Technologies. Ibis 148: 145-151.

Friedlander, A.M., Brown, E. and Monaco, M.E. 2007. Coupling ecology and GIS to evaluate efficacy of marine protected areas in Hawaii. Ecological Applications 17: 715-730.

Fry, C. 2005. All at sea (tidal power). Power Engineer 19: 24-27.

Garrison, L. 2005. Estimated bycatch of marine mammals and turtles in the US Atlantic pelagic longline fleet during 2004. NOAA Technical Memorandum NMFS-SEFSC-531, 57 pp.

Garthe, S. and Huppop, O. 2004. Scaling possible adverse effects of marine wind farms on seabirds: developing and applying a vulnerability index. Journal of Applied Ecology 41: 724-734.

Gaskin, D.E. 1984. The harbor porpoise Phocoena phocoena (L.): regional populations, status and information on direct and indirect catches. Report to the International Whaling Commission 34 SC/35/SM24

Gaskin, D.E. and Smith, G.J.D. 1979. Observations on marine mammals, birds and environmental conditions in the Head Harbor region of the Bay of Fundy. In: Scaratt DJ (ed) Evaluation of recent data relative to potential oil spills in the Passamaquoddy area. Fish Mar Serv Tech Rep 901: 69-86.

Gaskin, D.E. and Watson, A.P. 1985. The harbor porpoise, Phocoena phocoena, in Fish Harbor, New Brunswick, Canada: occupancy, distribution and movements. Fishery Bulletin 83: 427-442.

Gazo, M., Gonzalvo, J. and Aguilara, A. 2008. Pingers as deterrents of bottlenose dolphins interacting with trammel nets. Fisheries Research 92 (1): 70-75.

Gerber, L.R., Botsford, L.W., Hastings, A., Possingham, H.P., Gaines, S.D., Palumbi, S.R. and Andelman, S. 2003. Population models for marine reserve design: a retrospective and prospective synthesis. Ecological Applications 87: S47-S64.

Gilbert, J., Waring, G., Wynne, K. and Guldager, N. 2005. Changes in abundance of harbor seals in Maine, 1981- 2001. Marine Mammal Science 21 (3): 519-535.

Gilbert, J., Schurman, V. R. and Richardson, D.T. 1977. Actual and potential distribution and populations of grey seals in New England. Prepared for the Marine Mammal Commission, Washington D.C. 50 pp.

Gill, A.B. 2005. Offshore renewable energy: ecological implications of generating electricity in the coastal zone. Journal of Applied Ecology 42: 605-615.

Gill, A.B., Gloyne-Phillips, I., Neal, K.J. and Kimber, J.A. 2005. The potential effects of electromagnetic fields generated by sub-sea power cables associated with offshore wind farm developments on electrically and magnetically sensitive marine organisms - a review. COWRIE 1.5 Electromagnetic fields Review. July 2005, 128 pp.

Goold, J. 2000. A diel pattern in vocal activity of short-beaked common dolphins, Delphinus delphis. Marine Mammal Science 16: 240-244. 
Gordon, D.C. 1994. Intertidal ecology and potential power impacts, Bay of Fundy, Canada. Biological Journal of the Linnean Society 51: 17-23. doi: 10.1111/j.1095-8312.1994.tb00940.x.

Gosner, K.L. 1978. A field guide to the Atlantic seashore. Boston, MA. Houghton-Mifflin Co. 329 pp.

Gould, J.L. 2008. Animal navigation: the evolution of magnetic orientation. Current Biology 18: R482R484. doi:10.1016/j.cub.2008.03.052.

Hall-Arber, M., Bergeron, D. and Ryznar, R. 2004. Commercial fishing in Nantucket Sound: considerations pertinent to the proposed wind farm on Horseshoe Shoal. Massachusetts Fishermen's Partnership. Retrieved from http://www.fishermenspartnership.org/pdf/Nantucket-Sound-Report.pdf.

Hamilton, P.K. and Mayo, C.A. 1990. Population characteristics of right whales (Eubalaena glacialis) observed in Cape Cod and Massachusetts Bays, 1978-1986. Reports of the International Whaling Commission Special Issue 12: 203-208.

Hammond, P.S., Berggren, P., Benke, H., Borchers, D.L., Collet, A., Heide-Jørgensen, M.P., Heimlich, S., Hiby, A.R., Leopold, M.F. and Øien, N. 2002. Abundance of harbor porpoise and other cetaceans in the North Sea and adjacent waters. Journal of Applied Ecology 39: 361-376.

Hannah, J. 1998. Seals of Atlantic Canada and the Northeastern United States: a field guide. IMMA Inc., Guelph, Canada. 33 pp.

Hastie, G.D., Wilson, B., Tufft, L.H. and Thompson, P.M. 2003. Bottlenose dolphins increase breathing synchrony in response to boat traffic. Marine Mammal Science 19: 74-84.

Hatfield, E.M.C. and Cadrin, S.X. 2002. Geographic and temporal patterns in size and maturity of the longfin inshore squid (Loligo pealeii) off the northeastern United States. Fishery Bulletin 100: 200-213.

Hays, G.C., Farquhar, M.R., Luschi, P., Teo, S.L.H. and Thys, T.M. 2009. Vertical niche overlap by two ocean giants with similar diets: oceanic sunfish and leatherback turtles. Journal of Experimental Marine Biololgy and Ecology 370:134-143. doi:10.1016/j.jembe.2008.12.009.

Henriksen, O.D., Carstensen, J., Tougaard, J. and Teilmann, J. 2004. Effects of the Nysted offshore wind farm construction on harbor porpoises - annual status report for the acoustic T-POD monitoring programme during 2003. Report to the Ministry of the Environment, Denmark, June 2004. 33 pp. Retrieved from http://193.88.185.141/Graphics/Energiforsyning/Vedvarende_energi/Vind/havvindmoeller/vvm\%20 R\%C3\%B8dsand/havpattedyr/PODnysted_2004.pdf.

Hendrickson, L. and Jacobson, L. 2006. Longfin inshore squid. In: Status of fishery resources off the northeastern US. Retrieved from http://www.nefsc.noaa.gov/sos/spsyn/iv/lfsquid/archives/31_LoligoInshoreSquid_2006.pdf.

Herbert, G.M.J., Iniyan, S., Sreevalsan, E. and Rajapandian, S. 2007. A review of wind energy technologies. Renewable and Sustainable Energy Reviews 11: 1117-1145.

Hewer, H.R. 1974. British Seals. New York, New York: Taplinger Publishing Co. Inc.

Hodgson, A.J., Marsh, H., Delean, S. and Marcus, L. 2007. Is attempting to change marine mammal behavior a generic solution to the bycatch problem? A dugong case study. Animal Conservation 10: 263273. 
Holt, M.M., Noren, D.P., Veirs, V., Emmons, C.K. and Veirs, S. 2009. Speaking up: Killer whales (Orcinus orca) increase their call amplitude in response to vessel noise. Journal of the Acoustical Society of America 125 (1): EL27-32. DOI: 10.1121/1.3040028

Houghton, J.D.R., Doyle, T.K., Davenport, J. and Hays, G.C., 2006. The ocean sunfish Mola mola: insights into distribution, abundance and behavior in the Irish Sea and Celtic Seas. Journal of the Marine Biological Association of the United Kingdom 86, 1237-1243.

Hunt, G.L. and Schneider, D.C. 1987. Scale-dependent processes in the physical and biological environment of marine birds. In: J.P. Croxall (Ed). Seabirds feeding ecology and role in the marine ecosystems. Cambridge University Press, Cambridge. pp. 7-42.

Inger, R., Attrill, M.J., Bearhop, S., Broderick, A.C., Grecian, W. J., Hodgson, D.J., Mills, C., Sheehan, E., Votier, S.C., Witt, M.J. and Godley, B.J. 2009. Marine renewable energy: potential benefits to biodiversity? An urgent call for research. Journal of Applied Ecology 46: 1145-1153.

Inger, R., Attrill, M.J., Bearhop, S., Broderick, A.C., Grecian, W. J., Hodgson, D.J., Mills, C., Sheehan, E., Votier, S.C., Witt, M.J. and Godley, B.J. 2009. Marine renewable energy: potential benefits to biodiversity? An urgent call for research. Journal of Applied Ecology 46: 1145-1153.

Innis, C.J., Tlusty, M., Merigo, C. and Weber, E.S. 2007. Metabolic and respiratory status of cold-stunned Kemp's ridley sea turtles (Lepidochelys kempii). Journal of Comparative Physiology B 177: 623-630.

International Whaling Commission. 2001. Report of the Workshop on Status and Trends of Western North Atlantic Right Whales. The Journal of Cetacean Research and Management Special Issue 2: 61-87.

James, M.C., Ottensmeyer, C.A. and Myers, R.A. 2005. Identification of high-use habitat and threats to leatherback sea turtles in northern waters: new directions for conservation. Ecology Letters 8: 195-201.

Jean, C., Ciccione, S., Ballorain, K., Georges, J.-Y. and Bourjea, J. 2010. Ultralight aircraft surveys reveal marine turtle population increases along the west coast of Reunion Island. Oryx 44: 223-229.

Jefferson, T.A. 2000. Population biology of the Indo-Pacific humpbacked dolphin in Hong Kong waters. Wildlife Monographs 144: 1-65.

Johnson, A., Salvador, G., Kenney, G., Robbins, J., Kraus, S., Landry, S. and Clapham, P. 2005. Fishing gear involved in entanglements of right and humpback whales. Marine Mammal Science 21 (4): 635-645.

Johnston, D.W., Thorne, L.H. and Read, A.J. 2005a. Fin whales Balaenoptera physalus and minke whales Balaenoptera acutorostratus exploit a tidally driven island wake ecosystem in the Bay of Fundy. Marine Ecology Progress Series 305: 287-297.

Johnston, D.W., Westgate, A.J. and Read, A.J. 2005b. Effects of fine-scale oceanographic features on the distribution and movements of harbor porpoises Phocoena phocoena in the Bay of Fundy. Marine Ecology Progress Series 295: 279-293.

Johnston, D.W. 2002. The effect of acoustic harassment devices on harbor porpoises (Phocoena phocoena) in the Bay of Fundy, Canada. Biological Conservation 108 (1): 113-118.

Joint Nature Conservation Committee. 2009. Annex B - Statutory nature conservation agency protocol for minimizing the risk of disturbance and injury to marine mammals from piling noise. Retrieved from https://www. og.decc.gov.uk/environment/jncc_protocol.pdf. 
Julian, F. and Beeson, M. 1998. Estimates of marine mammal, turtle, and seabird mortality for two California gillnet fisheries: 1990-1995. Fishery Bulletin 96 (2): 271-284.

Kastelein, R.A., Hoek, L., Jennings, N., de Jong, C.A.F., Terhune, J.M. and Dieleman, M. 2010. Acoustic mitigation devices (AMDs) to deter marine mammals from pile driving areas at sea: Audibility and behavioral response of a harbor porpoise and harbor seals. COWRIE Ref: SEAMAMD-09, Technical Report 31st July 2010. Retrieved from http://www.offshorewindfarms.co.uk/Assets/Final\%20report\%20COWRIE\%20Ref\%20 SEAMAMD09.pdf.

Katona, S.K., Rough, V. and Richardson, D.T. 1993. A field guide to whales, porpoises and seals from Cape Cod to Newfoundland. Washington, D.C. Smithsonian Institution. 316 pp.

Katona, S.K., Rough, V. and D.T. Richardson. 1983. A Field Guide to the Whales Porpoises and Seals of the Gulf of Maine and Eastern Canada, Cape Cod to Newfoundland. 3rd edition. Charles Scribner's Sons. New York. 255 pp.

Kenney, R.D. 2010. Right whales in Rhode Island Sound: April 2010. Right Whale News 18(2): 5-10.

Kenney, R. 2005. Freezer Paleostratigraphy: Rediscovery of an early gray seal stranding from Block Island, RI. Poster presentation at the 16th Biennial Meeting on the Biology of Marine Mammals, San Diego, California.

Kenney, R.D., Payne, P. M., Heinemann, D.W. and Winn, H.E. 1996. Chapter 10: Shifts in northeast shelf cetacean distributions relative to trends in Gulf of Maine/Georges Bank finfish abundance. The Northeast Shelf Ecosystem: Assessment, Sustainability, and Management. K. Sherman, N. Jaworski, and T. J. Smayda, eds. Cambridge, MA. Blackwell Science.

Kenney, R.D. 1995. Preliminary assessment of competition for prey between leatherback turtles and ocean sunfish in northeast shelf waters. Pp. 144-147 in Proceedings of the Fifteenth Annual Symposium on Sea Turtle Biology and Conservation. NOAA Technical Memorandum NMFS-SEFSC-387.

Kenney, R.D. and Winn, H.E. 1986. Cetacean high-use habitats of the northeast United States continental shelf. Fishery Bulletin 84: 345-357.

Kenney, R.D., Winn, H.E. and Macaulay, M.C. 1995. Cetaceans in the Great South Channel, 1979-1989: right whale (Eubalaena glacialis). Continental Shelf Research 15: 385-414.

Kenney, R.D., Owen, R.E. and Winn, H.E. 1985. Shark distributions off the northeast United States from marine mammal surveys. Copeia 1985: 220-223.

Ketten, D.R. 1995. Estimates of blast injury and acoustic trauma zones for marine mammals from underwater explosions. In: Sensory Systems of Aquatic Mammals. Kastelein R.A., Thomas J.A., Nachtigall P.E. (ed.s). De Spil Publishers, Woerden, The Netherlands. ISBN 90-72743-05-9.

King, J.R., Camisa, M.J. and Manfredi, V.M. 2010. Massachusetts Division of Marine Fisheries trawl survey effort, lists of species recorded, and bottom trawl temperature trends, 1978-2007. Massachussetts Division of Marine Fisheries Technical Report TR-38. 157 pp.

King, J.E. 1983. Seals of the World. 2nd edition Oxford England: Oxford University Press. 62 Marine Megavertebrates and Fishery Resources in the Nantucket Sound - Muskeget Channel Area 
Knowlton, A.R. and Kraus, S.D. 2001. Mortality and serious injury of the northern right whales (Eubalaena glacialis) in the western North Atlantic Ocean. The Journal of Cetacean Research and Management Special Issue 2: 193-208.

Kraus, S.D., Brown, M.W., Caswell, H., Clark, C.W., Fujiwara, M., Hamilton, P.K., Kenney, R.D., Knowlton, A.R., Landry, S., Mayo, C.A., McLellan, W.A., Moore, M.J., Nowacek, D.P., Pabst, D.A., Read, A.J. and Rolland, R.M. 2005. North Atlantic right whales in crisis. Science 309: 561-562.

Krijgsveld, K.L., Lensink, R., Schekkerman, H., Wiersma, S., Poot, M.J.M., Meesters, E.H.W.G. and Dirksen, S. 2005. Baseline studies North Sea wind farms: fluxes, flight paths and altitudes of flying birds 2003-2004. Bureau Waardenburg bv and Alterra, commissioned by the National Institute for Coastal and Marine Management, The Hague, 192 S.

Langston, R.H.W. and Pullan, J.D. 2003. Windfarms and birds: an analysis of windfarms on birds, and guidance on environmental assessment criteria and site selection issues. RSPB / BirdLife International Report to the Council of Europe (Bern Convention). T-PVS / Inf (2003) 12.

Larsen, P. 1981. Potential environmental consequences of tidal power development seaward of tidal barrages. Oceans 13: 908-912.

Lazell, J.D., Jr. 1976. This broken archipelago: Cape Cod and the islands, reptiles and amphibians. Quadrangle Press, New York Times Book Co., New York, 260 pp.

Lazell, J.D. 1980. New England waters: Critical habitat for marine turtles. Copeia 1980 (2): 290-295.

Leeney, R.H., Berrow, S., McGrath, D., O’Brien, J., Cosgrove, R. and Godley, B.J. 2007. Effects of pingers on the behavior of bottlenose dolphins. Journal of the Marine Biological Association, UK 87: 129-133.

Leeney, R.H., Broderick, A.C., Mills, C., Sayer, S., Witt, M.J. and Godley, B.J. 2010. Abundance, distribution and haul-out behavior of grey seals (Halichoerus grypus) in Cornwall and the Isles of Scilly, UK. Journal of the Marine Biological Association of the UK. Published online, June 2010.

Leeney, R.H., Broderick, A.C., Witt, M.J., Richardson, P.B., Jarvis, D.S., Buchanan, J. and Godley, B.J. (In review) Marine megavertebrates of Cornwall and the Isles of Scilly: relative abundance and distribution.

Leeney, R.H. and Chronic, J. 2010. PCCS Right Whale Aerial Survey Program Safety Policy and Operating Procedures Manual. Produced for the Provincetown Center for Coastal Studies. 28 pp.

Leeney, R.H., Stamieszkin, K., Mayo, C.A. and Marx, M. 2009. Surveillance, monitoring and management of North Atlantic right whales in Cape Cod Bay and adjacent waters - 2009. Report to DMF. Provincetown Center for Coastal Studies, USA.

Leeney, R.H., Stamieszkin, K., Jaquet, N., Mayo, C.A., Osterberg, D. and Marx, M. 2008. Surveillance, monitoring and management of North Atlantic right whales in Cape Cod Bay and adjacent waters - 2008. Report to DMF. Provincetown Center for Coastal Studies, USA.

Leeney, R.H. and Tregenza, N.J.C. (Eds) 2006. Proceedings of the workshop: Static Acoustic Monitoring of Cetaceans, held at the 20th Annual Meeting of the European Cetacean Society, Gdynia, Poland, 2nd April 2006. ECS Newsletter 46 - Special Issue, July 2006. Retrieved from http://www.seaturtle.org/mtrg/personnel/SAM_report.shtml. 
Lelli, B., Harris, D.E. and Aboueissa, S. 2009. Seal bounties in Maine and Massachusetts, 1888 to 1962. Northeastern Naturalist 16 (2): 239-254.

Lemon, M., Lynch, T.P., Cato, D.H. and Harcourt, R.G. 2006. Response of travelling bottlenose dolphins (Tursiops aduncus) to experimental approaches by a powerboat in Jervis Bay, New South Wales, Australia. Biological Conservation 127 (4): 363-372.

Lesage, V., Barrette, C., Kingsley, M.C.S. and Sjare, B. 1999. The effect of vessel noise on the vocal behavior of belguas in the St. Lawrence River estuary, Canada. Marine Mammal Science 15: 65-84.

Lewis, D. 2002. Diamond-backed Terrapin Summary for Outer Cape Cod. Report to NHESP. Westborough, MA.

Little, E.A. 1981. The Indian contribution to alongshore whaling at Nantucket. Nantucket Historical Association Nantucket Algonquian Studies 8: 1-65.

Little, E.A. 1988. Nantucket whaling in the early 18th century. In W. Cowan, ed. Papers of the Nineteenth Algonquian Conference, pp. 111-131. Carleton University, Ottawa.

Lohmann, K.J., Lohmann, M.F. and Endres, C.S. 2008. The sensory ecology of ocean navigation. Journal of Experimental Biology 211: 1719-1728.

Lusch, P., Benhamou S., Girard C., Ciccione S., Roos D., Sudre J. and Benvenuti S. 2007. Marine turtles use geomagnetic cues during open-sea homing. Current Biology 17: 126-133.

Lusseau, D. 2003. Effect of tour boats on the behavior of bottlenose dolphins: Using Markov chains to model anthropogenic impacts. Conservation Biology 17 (6): 1785-1793

Lusseau, D. 2004. The hidden cost of tourism: Effects of interactions with tour boats on the behavioral budget of two populations of bottlenose dolphins in Fiordland, New Zealand. Ecology and Society 9 (1): art. 2.

Lusseau, D. 2005. Residency pattern of bottlenose dolphins Tursiops spp. in Milford Sound, New Zealand, is related to boat traffic. Marine Ecology Progress Series 295: 265-272.76 Marine Megavertebrates and Fishery Resources in the Nantucket Sound - Muskeget Channel Area

Lusseau, D., Bain, D.E., Williams, R. and Smith, J.C. 2009. Vessel traffic disrupts the foraging behavior of southern resident killer whales Orcinus orca. Endangered Species Research 6: 211-221.

Lutcavage, M.E., Plotkin, P., Witherington and Lutz, P.L. 1997. Human impacts on sea turtle survival. In: The Biology of Sea Turtles, Vol. 1. P.L. Lutz and J. Musick (Eds) CRC Press, Boca Raton, Fla. pp. 387410.

Lutz, P.L., and Alfaro-Shulman, A.A. 1991. The effects of chronic plastic ingestion on green sea tutles. Report NOAASB21-WCH06134, U.S. Dept. of Commerce, Miami, FL.

Maar, M., Bolding, K., Petersen, J.K., Hansen, J.L.S. and Timmermann, K. 2009. Local effects of blue mussels around turbine foundations in an ecosystem model of Nysted off-shore wind farm, Denmark. Journal of Sea Research 62: 159-174.

MacKenzie, C.L., Jr. 2008. The bay scallop, Argopecten irradians, Massachusetts through North Carolina: its biology and the history of its habitats and fisheries. Marine Fisheries Review 70 (3-4): 6-79. 
Madsen, P.T., Wahlberg, M., Tougaard, J., Lucke, K. and Tyack, P.L. 2006. Wind turbine underwater noise and marine mammals: Implications of current knowledge and data needs. Marine Ecology Progress Series 309: 279-295.

Marine Turtle Specialist Group 1996a. Caretta caretta. In: IUCN 2010. IUCN Red List of Threatened Species. Version 2010.3. Retrieved from http://www.iucnredlist.org.

Marine Turtle Specialist Group 1996b. Lepidochelys kempii. In: IUCN 2010. IUCN Red List of Threatened Species. Version 2010.3. Retrieved from http://www.iucnredlist.org.

Marquez, M.R., Burchfeild, P.M., Diaz, F.J., Sanchez, P.M., Carrasco, A.M., Jimeniez Q.C., Leo P.A., Bravo G.R. and Pena V.J. 2005. Status of the Kemp's Ridley turtle, Lepidochelys kempii, Chelonian Conservation Biology 4: 761-766.

Marsh, H. and Saalfeld, W.K. 1989. Aerial Surveys of Sea Turtles in the Northern Great Barrier Reef Marine Park. Australian Wildlife Research 16: 239-49.

Martin, R.A. and Harvey-Clark, C. 2004. Threatened fishes of the world: Cetorhinus maximus (Gunnerus 1765) (Cetorhinidae). Environmental Biology of Fishes 70: 122.

Massachusetts reptile and amphibian list. 2010. Retrieved from http://www.mass.gov/dfwele/dfw/wildlife/facts/.../ herp_list.htm.

Mate, B.R., Nieukirk, S.L. and Kraus, S.D. 1997. Satellite-monitored movements of the northern right whale. Journal of Wildlife Management 61: 1393-1405.

Matthiopoulos, J., McConnell, B., Duck, C. and Fedak, M. 2004. Using satellite telemetry and aerial counts to estimate space use by grey seals around the British Isles. Journal of Applied Ecology 41: 476491.

Mayo, C.A. and Marx, M.K. 1990. Surface foraging behavior of the North Atlantic right whale, Eubalaena glacialis, and associated zooplankton characteristics. Canadian Journal of Zoology 68: 22142220.

McKiernan, D.J. and Pierce, D.E. 1995. Loligo squid fishery in Nantucket and Vineyard Sounds. Massachusetts Division of Marine Fisheries Technical Report TR-1. 62 pp.

Mendes, S., Turrell, W., Lütkebohle, T. and Thompson, P. 2002. Influence of the tidal cycle and a tidal intrusion front on the spatio-temporal distribution of coastal bottlenose dolphins. Marine Ecology Progress Series 239: 221-229.

Michel, J., Dunagan, H., Boring, C., Healy, E., Evans, W., Dean, J.M., McGillis, A. and Hain, J. 2007. Worldwide Synthesis and Analysis of Existing Information Regarding Environmental Effects of Alternative Energy Uses on the Outer Continental Shelf. pp. 254. U.S. Department of the Interior, Minerals Management Service, Herndon, VA,MMSOCS Report 2007-038.

Mid-Atlantic Fishery Management Council (MAFMC). 2010. Current stock status of MAFMC-managed species. Retrieved from http://www.mafmc.org/MAFMC_Stock_Status_CURRENT.pdf.

Minerals Management Service (MMS). 2009. Cape Wind Energy Project Final Environmental Impact Statement. January 2009. Retrieved from http://www.boemre.gov/offshore/AlternativeEnergy/PDFs/FEIS/Cape $\% 20$ Wind\%20Energy\%20Project\%20FEIS.pdf. 
Moore, M.J., Knowlton, A.R., Kraus, S.D., McLellan, W.A. and Bonde, R.K. 2004. Morphometry, gross morphology and available histopathology in North Atlantic right whale (Eubalaena glacialis) mortalities (1970-2002). Journal of Cetacean Research and Management 6: 199-214.

Morreale, S.J. and Standora, E.A. 1993. Occurrence, movement, and behavior of the Kemp's ridley and other sea turtles in New York waters. Final Report April 1988-March 1993. 70 pp.

Morreale, S.J. and Standora, E.A. 1998. Early life stage ecology of sea turtles in northeastern U.S. waters. U.S. Dep. Commer. NOAA Tech. Mem. NMFS-SEFSC-413, 49 pp.

Morreale, S.J., and Standora, E.A. 2005. Western North Atlantic waters: crucial developmental habitat for Kemp's ridley and loggerhead sea turtles. Chelonian Conservation Biology 4: 872-882.

Mortimer, J.A and Donnelly, M. 2008. Eretmochelys imbricata. In: IUCN 2010. IUCN Red List of Threatened Species. Version 2010.3. www.iucnredlist.org. Downloaded 09 September 2010.

Morton, A.B. and Symonds, H.K. 2002. Displacement of Orcinus orca (L.) by high amplitude sound in British Columbia, Canada. ICES Journal of Marine Science 59: 71-80.

Musick, J.A. and Limpus, C.J. 1997. Habitat utilization and migration in juvenile seaturtles. Pp. 137-164 In: Lutz, P.L., and J.A. Musick, (Eds). The Biology of Sea Turtles. CRC Press, New York. 432 pp.

Myers, L. and Bahaj, A.S. 2005. Simulated electrical power potential harnessed by marine current turbine arrays in the Alderney Race. Renewable Energy 30: 1713-1731.

National Research Council. 1990. Decline of the Sea Turtles: Causes and Prevention. National Academy Press, Washington, D.C. 259 pp.

NMFS USFWS (National Marine Fisheries Service and U.S. Fish and Wildlife Service). 2001. Stock assessments of loggerhead and leatherback sea turtles and an assessment of impacts of the pelagic longline fishery on the loggerhead and leatherback sea turtles of the western North Atlantic. NOAA Technical Memorandum. NFS-SEFC-455.

NMFS USFWS (National Marine Fisheries Service and U.S. Fish and Wildlife Service). 1992. Recovery Plan for Leatherback Turtles in the U.S., Caribbean, Atlantic and Gulf of Mexico. Silver Springs, Maryland. Retrieved from http://ecos.fws.gov/docs/recovery_plan/920406.pdf.

NMFS USFWS (National Marine Fisheries Srvice and U.S. Fish and Wildlife Service). 2007a. 5-Year Review: Summary and Evaluation, Green Sea Turtle (Chelonia mydas). Silver Spring, Maryland. Retrieved from http:// www.nmfs.noaa.gov/pr/pdfs/species/greenturtle_5yearreview.pdf.

NMFS USFWS (Natinal Marine Fisheries Service and U.S. Fish and Wildlfie Service). 2007b. 5 Year Review: Summary and Evaluation, Leatherback Turtle (Dermochelys coriacea). Silver Spring, Maryland. Retrieved from http://www.nmfs.noaa.gov/pr/pdfs/species/leatherback_5yearreview.pdf.

NMFS USFWS (National Marine Fisheries Service and U.S. Fish and Wildlife Service). 2008. Recovery Plan for the Northwest Atlantic Population of the Loggerhead Sea Turtle (Caretta caretta), Second Revision. Silver Spring, MD. Retrieved from http://www.nmfs.noaa.gov/pr/pdfs/recovery/loggerhead_5yearreview.pdf.

National Marine Fisheries Service and U.S. Fish and Wildlife Service. 1993. Recovery Plan for Hawksbill Turtles in the U.S. Caribbean Sea, Atlantic Ocean, and Gulf of Mexico. National Marine Fisheries Service, St. Petersburg, Florida. 
National Marine Fisheries Services - Northeast Regional Office. 55 Great Republic Drive, Gloucester, Massachusetts, 01930.

Nedwell, J.R., Langworthy, J. and Howell, D. 2004. Assessment of sub-sea acoustic noise and vibration from offshore wind turbines and its impact on marine wildlife; initial measurements of underwater noise during construction of offshore windfarms, and comparison with background noise. Subacoustech Report Reference: 544R0424, November 2004, To: COWRIE, The Crown Estate, 16 Carlton House Terrace, London, SW1Y 5AH. 68 pp. Retrieved from

http://www.subacoustech.com/information/downloads/reports/544R0424.pdf.

Nelson, P.A., Behrens, D., Castle, J., Crawford, G., Gaddam, R.N., Hackett, S.C., Largier, J., Lohse, D.P., Mills, K.L., Raimondi, P.T., Robart,M., Sydeman, W.J., Thompson, S.A. and Woo, S. 2008. Developing Wave Energy in Coastal California: Potential Socio-Economic and Environmental Effects. California Energy Commission, PIER Energy-Related Environmental Research Program \& California Ocean Protection Council CEC- 500- 2008-083.

Nichols, O.C., Kenney, R.D. and Brown, M.W. 2008. Spatial and temporal distribution of North Atlantic right whales (Eubalaena glacialis) in Cape Cod Bay, and implications for management. Fishery Bulletin 106: 270-280.60 Marine Megavertebrates and Fishery Resources in the Nantucket Sound - Muskeget Channel Area

Nowacek, D.P., Thorne, L.H., Johnston, D.W. and Tyack, P.L. 2007. Responses of cetaceans to anthropogenic noise. Mammal Review 37 (2): 81-115.

NRC (National Research Council). 1990. Decline of the sea turtles: causes and prevention. National Academy Press, Washington, D.C.

NRC (National Research Council). 2003. Ocean Noise and Marine Mammals. National Academies Press, Washington, D.C.

Oberweger, K. and Goller, F. 2001. The metabolic cost of birdsong production. Journal of Experimental Biology 204: 3379-3388.

Öhman, M.C., Sigray, P. and Westerberg H. 2007. Offshore wind farms and the effects of electromagnetic fields on fish. Ambio 36: 630-633.

ORPC. 2012. Final Pilot License. Issued by the Federal Energy Regulatory Commission. February 27, 2012. http://www.orpc.co/content.aspx?p=h3jCHHn6gcg\%3d

ORPC. 2010. Presentation on Acoustic Monitoring Program.

Overholtz, W. 2006a. Atlantic mackerel. In: Status of fishery resources off the northeastern US. Retrieved from http://www.nefsc.noaa.gov/sos/spsyn/pp/mackerel/archives/23_AtlanticMackerel_2006.pdf.

Overholtz, W. 2006b. Butterfish. In: Status of fishery resources off the northeastern US. Retrieved from http:// www.nefsc.noaa.gov/sos/spsyn/op/butter/archives/24_Butterfish_2006.pdf.

Packer, D.B., Griesbach, S.J., Berrien, P.L., Zetlin, C.A., Johnson, D.L. and Morse, W.W. 1999. Essential fish habitat source document: summer flounder, Paralichthys dentatus, life history and habitat characteristics. NOAA Technical Memorandum NMFS-NE-151. 88 pp.

Palka, D. 1995. Effects of Beaufort sea state on the sightability of harbor porpoises in the Gulf of Maine. Report to the International Whaling Commission SC/47/SM26. 
Panigada, S., Pesante, G., Zanardelli, M., Capoulade, F., Gannier, A. and Weinrich, M.T. 2006. Mediterranean fin whales at risk from fatal ship strikes. Marine Pollution Bulletin 52 (10): 1287-98.

Parks, S.E., Clark, C.W. and Tyack, P.L. 2007. Short- and long-term changes in right whale calling behavior: the potential effects of noise on acoustic communication. Journal of the Acoustical Society of America 122 (6): 3725-31.

Parker, D.M. 1993. Environmental implications of tidal power generation. Science, Measurement and Technology, IEE Proceedings A 140: 71-75.

Payne, R. and Webb, D. 1971. Orientation by means of long range acoustic signaling in baleen whales. Annals of the New York Academy of Science 188: 110-141.

Payne, P.M. and Schneider, D.C. 1984. Yearly changes in abundance of harbor seals, Phoca vitulina, at a winter haul-out site in Massachusetts. Fishery Bulletin 82: 440-442.

Payne, P.M. and Selzer, L.A. 1989. The distribution, abundance and selected prey of the harbor seal, Phoca vitulina concolor, in southern New England. Marine Mammal Science 5(2): 173-192.

Pearce-Higgins, J.W., Stephen, L., Langston, R.H.W. and Bright, J.A. 2008. Assessing the cumulative impacts of wind farms on peatland birds: a case study of golden plover Pluvialis apricaria in Scotland. Mires \& Peat 4: 1-13. Retrieved from http://www.mires-and-peat.net/map04/map_04_01.pdf.

Pelc, R. and Fujita, R.M. 2002. Renewable energy from the ocean. Marine Policy 26: 471-479.

Petersen, J.K. and Malm, T. 2006. Offshore windmill farms: threats to or possibilities for the marine environment. Ambio 35: 75-80.

Pettis, H. 2009. North Atlantic Right Whale Consortium annual report card (01 November - 30 April 2009). International Whaling Commission Scientific Committee Meeting SC/61/BRG11.

Philpott, E., Englund, A., Ingram, S. and Rogan, E. 2007. Using T-pods to the echolocation of coastal bottlenose dolphins. Journal of the Marine Biological Association 87: 11-17.

Pierpoint, C. 2008. Harbor porpoise (Phocoena phocoena) foraging strategy at a high energy, near-shore site in south-west Wales, UK. Journal of the Marine Biological Association of the UK 88 (6): 1167-1173.

Pittman, S., Costa, B., Kot, C., Wiley, D. and Kenney, R.D. 2006. Chapter 5: Cetacean distribution and diversity. An Ecological Characterization of the Stellwagen Bank National Marine Sanctuary Region. NOAA National Centers for Coastal Ocean Science. Silver Spring, MD. NOAA Technical Memorandum NOS NCCOS 45. 356 pp.

PNNL. 2012. Assessment of Strike of Adult Killer Whales by an OpenHydro Tidal Turbine Blade. Prepared for the Department of Energy under Contract DE-AC05-76RL01830. February 2012. http://www.snopud.com/Site/Content/Documents/tidal/ai_final/AppK_KillerWhaleStrike.pdf

Pomeroy, P.P., Redman, P.R., Ruddell, S.J.S., Duck, C.D. and Twiss, S.D. 2005. Breeding site choice fails to explain interannual associations of female grey seals. Behavioral Ecology and Sociobiology 57: 546-556. doi 10.1007/s00265-004-0882-6.

Pope, E.C., Hays, G.C., Thys, T.M., Doyle, T.K., Sims, D.W., Queiroz, N., Hobson, V.J., Kubicek, L. and Houghton, J.D.R. 2010. The biology and ecology of the ocean sunfish Mola mola: a review of current 
knowledge and future research perspectives. Reviews in Fish Biology and Fisheries (Online: 19 January 2010). doi: 10.1007/ s11160-009-9155-9

Popper, A.N., Fewtrell, J., Smith, M.E. and McCauley, R.D. 2003. Anthropogenic sound: effects on the behavior and physiology of fishes. Marine Technology Society Journal 37: 35-40.

Popper, A.N. and Hastings, M.C. 2009. The effects of human-generated sound on fish. Integrative Zoology 4: 43-52.

Prescott, R.L. 1988. Leatherbacks in Cape Cod Bay, Massachusetts, 1977-1987. NMFS ESA Section 7 Biological Opinion, Cape Wind Energy Project: 83-84.

Read, A.J., Drinker, P. and Northridge, S. 2006. Bycatch of Marine Mammals in U.S. and Global Fisheries. Conservation Biology 20 (1): 163-169.

Reeves, R.R., Breiwick, J.M. and Mitchell, E.D. 1999. History and estimated kill of right whales, Balaena glacialis, in the northeastern United States, 1620-1924. Marine Fisheries Review 61(3): 1-36.

Reeves, R.R., Stewart, B.S. and Leatherwood, S. 1992. The Sierra Club Handbook of Seals and Sirenians. Sierra Club Books, San Francisco, CA. 359 pp.

Rice. D.W. 1998. Marine Mammals of the World. Systematics and Distribution. Special Publication Number4. The Society for Marine Mammalogy. Allen Press, Lawrence, KS. 231 pp.

Richardson, W.J., Greene, Jr. C.R., Malme, C.I. and Thomson, D.H. 1995. Marine Mammals and Noise. Academic Press, San Diego, California.

Riedman, M. 1990. The Pinnipeds, Seals, Sea Lions and Walruses. University of California Press, Berkeley, Los Angeles, Oxford. 439 pp.

Right Whale Consortium. 2010. North Atlantic Right Whale Consortium Sightings Database 07/08/2010 (New England Aquarium, Boston, MA, U.S.A.).

Ritchie, W.A. 1969. The Archaeology of Martha's Vineyard. Garden City, NJ: The Natural History Press.

Robbins, J. 2007. Structure and dynamics of the Gulf of Maine humpback whale population. Ph.D. dissertation, University of St. Andrews. 179 pp.

Roper, C.L., Sweeney, M.J. and Nauen, C.E. 1984. FAO species catalogue. Vol. 3. Cephalopods of the World: an annotated and illustrated catalogue of species of interest to fisheries. FAO Fisheries Synopsis No. 125, Vol. 3. 277 pp.

Rosenfeld, M., George, M. and Terhune, J.M. 1988. Evidence of autumnal harbor seal, Phoca vitulina, movement from Canada to the United States. Canadian Field-Naturalist. 102(3): 527-529.

Rough, V. 1981. A Small Population of Grey Seals at Nantucket, MA. Draft Report for NMFS Contract \# 41USC252@3. $92 \mathrm{pp}$.

Rough, V. 1983. Report on Nantucket Grey Seals, Winter and Spring 1983. NMFS PO\# NA-83-FB-A00075. $11 \mathrm{pp}$.

Rough, V. 1990. Gray seal pupping at Monomoy National wildlife Refuge, winter 1990. Report to the Marine Mammal Commission. 7 pp. 
Rough, V. 1991a. Muskeget gray seals, winter and spring, 1991. Report to the Marine Mammal Commission. 14 pp.

Rough V. 1991b. Gray seal pupping at Monomoy National wildlife Refuge, winter 1991. Report to the Marine Mammal Commission. 7 pp.

Rough, V. 1992. Muskeget gray seals, winter and spring, 1992. Report to the Marine Mammal Commission. 13 pp.

Rough, V. 1993. Muskeget gray seals, winter and spring, 1993. Report to the Marine Mammal Commission. 17 pp.

Rough, V. 1994. Progress report on southern New England seal surveys, 1 January- 18 February. Report to the Marine Mammal Commission. 4 pp.

Rough, V. 1994. Progress report on southern New England seal surveys, 19 February- 31 March. Report to the Marine Mammal Commission. 5 pp.

Rough, V. 1994. Progress report on southern New England seal surveys, 1 April- 31 May. Report to the Marine Mammal Commission. 4 pp.

Rough, V. 1995. Gray seals in Nantucket Sound, Massachusetts, winter and spring, 1994. Final Report to the Marine Mammal Commission in Fulfillment of Contract T10155615. 28 pp.

Rough, V. 2000. Report on Nantucket Sound gray seals for Natural Heritage \& Endangered Species Program. 8 pp.

Royal Haskonig Enhancing Society. 2011. SeaGen Environmental Monitoring Programme - Final Report. January 16, 2011. http://www.marineturbines.com/Seagen-Technology/Environmental-Impact

Rulifson, R. and Dadswell, M. 1987. Mortality of fish passing through tidal, low-head hydropower turbines and possible mitigation strategies. Oceans 19: 944-949.

Sadoti, G., Allison T., Perkins S., Jedrey E., Jones A. 2005. A survey of tern activity within Nantucket Sound, Massachusetts during the 2004 fall staging period. Final Report for Massachusetts Technology Collaborative. Massachusetts Audubon Society, Lincoln, MA. 26 pp.

Sale, P.F., Cowen, R.K., Danilowicz, B.S., Jones, G.P., Kritzer, J.P., Lindeman, K.C., Planes, S., Polunin, N.V.C., Rus, G.R., Sadovy, Y.J. and Steneck, R.S. 2005. Critical science gaps impede use of no-take fishery reserves. Trends in Ecology and Evolution 20: 74-80.

Samuel, Y., Morreale, S.J., Clark, C.W., Greene, C.H. and Richmond, M.E. 2005. Underwater, low frequency noise in a coastal sea turtle habitat. Journal of the Acoustical Society of America 117: 14651472.

Sarti Martinez, A.L. 2000. Dermochelys coriacea. In: IUCN 2010. IUCN Red List of Threatened Species. Version 2010.3. Retrieved from http://www.iucnredlist.org.

Schevill, W.E., Moore, K.E. and Watkins, W.A. 1981. Right whale, Eubalaena glacialis, sightings in Cape Cod waters. Woods Hole Oceanographic Institution Technical Report WHOI-81-50.

Schneider, D.C. and Payne, P.M. 1983. Factors affecting haul-out of harbor seals at a site in southeastern Massachusetts. Journal of Mammalogy 64 (3): 518-520. 
Schroeder, C.L. 2000. Population status and distribution of the harbor seal in Rhode Island waters. M.S. Thesis. University of Rhode Island, Kingston, RI. 197 pp.

Sekiguchi, K. 1995. Occurrence, behavior and feeding habits of harbor porpoises (Phocoena phocoena) at Pajaro Dunes, Monterey Bay, California. Aquatis Mammals 21: 91-103.

Seminoff, J.A. 2004. Chelonia mydas. In: IUCN 2010. IUCN Red List of Threatened Species. Version 2010.3. www.iucnredlist.org. Downloaded 09 September 2010.

Shepherd, G. 2006a. Black sea bass. In: Status of fishery resources off the northeastern US. Retrieved from http://www.nefsc.noaa.gov/sos/spsyn/og/seabass/archives/16_BlackSeaBass_2006.pdf.

Shepherd, G. 2006b. Bluefish. In: Status of fishery resources off the northeastern US. Retrieved from http://www.nefsc.noaa.gov/sos/spsyn/op/bluefish/archives/25_Bluefish_2006.pdf.

Shepherd, G., and Packer, D. B. 2006. Essential fish habitat source document: bluefish, Pomatomus saltatrix, life history and habitat characteristics. NOAA Technical Memorandum NMFS-NE-198. 89 pp.

Shoop C. R. and Kenney R.D. 1992. Seasonal distribution and abundances of loggerhead and leatherback sea turtles in waters of the Northeastern United States. Herpetological Monographs 6: 43-67.

Silvani L., Gazo M. and Aguilar A. 1999. Spanish driftnet fishing and incidental catches in the western Mediterranean. Biological Conservation 90: 79-85.

Sims, D.W., Queiroz, N., Doyle, T.K., Houghton, J.D.R. and Hays, G.C. 2009. Satellite tracking of the world's largest bony fish, the ocean sunfish (Mola mola) in the North East Atlantic. Journal of Experimental Marine Biology and Ecology 370: 127-133. doi:10.1016/ j.jembe.2008.12.011.

Sims, D.W., Southall, E.J., Tarling, G.A. and Metcalfe, J.D. 2005. Habitat-specific normal and reverse diel vertical migration in the plankton-feeding basking shark. Journal of Animal Ecology 74: 755-761.

Sims, D.W. 2008. Sieving a living: a review of the biology, ecology and conservation status of the plankton-feeding basking shark Cetorhinus maximus. Advances in Marine Biology 54: 171-220.

Sims, D.W. and Quayle, V.A. 1998. Selective foraging behavior of basking sharks on zooplankton in a small scale front. Nature 393: 460-464.

Skomal, G.D. 2007. Shark nursery areas in the coastal waters of Massachusetts. American Fisheries Society Symposium 50: 17-33.

Skomal, G.B., Zeeman, S.I., Chisholm, J.H., Summers, E.L., Walsh, H.J., McMahon, K.W. and Thorrold, S.R. 2009. Transequatorial migrations by basking sharks in the western North Atlantic Ocean. Current Biology 19: 1-4.68 Marine Megavertebrates and Fishery Resources in the Nantucket Sound - Muskeget Channel Area

Skomal, G. Massachusetts Marine Fisheries, PO Box 68, Vineyard Haven, MA 02568.

Southall, B., Bowles, A.E., Ellison, W.T., Finneran, J.J., Gentry, R.L., Greene Jr., C.R., Kastak, D., Ketten, D.R., Miller, J.H., Nachtigall, P.E., Richardson, W.J., Thomas, J.A. and Tyack, P.L. 2007. Marine Mammal Noise Exposure Criteria: Initial Scientific Recommendations. Aquatic Mammals 33 (4).

Steimle, F.W., Zetlin, C.A., Berrien, P.L., Johnson, D.L. and Chang, S. 1999. Essential fish habitat source document: scup, Stenotomus chrysops, life history and habitat characteristics. NOAA Technical Memorandum NMFS-NE-141. 39 
Stewart, G.B., Pullin, A.S. and Coles, C.F. 2007. Poor evidence-base for assessment of wind farm impacts on birds. Environmental Conservation 34: 1-11.

Studholme, A.L., Packer, D.B., Berrien, P.L., Johnson, D.L., Zetlin, C.A. and Morse, W.W. 1999. Essential fish habitat source document: Atlantic mackerel, Scomber scombrus, life history and habitat characteristics. NOAA Technical Memorandum NMFS-NE-141. 35 pp.

Sutherland, W.J., Bailey, M.J., Bainbridge, I.P., Brereton, T., Dick, J.T.A., Drewitt, J., Dulvy, N.K., Dusic, N.R., Freckleton, R.P., Gaston, K.J., Gilder, P.M., Green, R.E., Heathwaite, L., Johnson, S.M., Macdonald, D.W., Mitchell, R., Osborn, D., Owen, R.P., Pretty, J., Prior, S.V., Prosser, H., Pullin, A.S., Rose, P., Stott, A., Tew, T., Thomas, C.D., Thompson, D.B.A., Vickery, J.A., Walker, M., Walmsley, C., Warrington, S., Watkinson, A.R., Williams, R.J., Woodroffe, R. and Woodroof, H.J. 2008. Future novel threats and opportunities facing UK biodiversity identified by horizon scanning. Journal of Applied Ecology 45: 821-833.78 Marine Megavertebrates and Fishery Resources in the Nantucket Sound Muskeget Channel Area

Sutherland, G., Foreman, M. and Garrett, C. 2007. Tidal current energy assessment for Johnstone Strait, Vancouver Island. Proceedings of the Institution of Mechanical Engineers, Part A: Journal of Power and Energy 221 (2): 147-157.

Taylor, D. 2004. Wind energy. In: G. Boyle (Ed). Renewable Energy: Power for a sustainable future. Oxford University Press, Oxford. pp. 244-293.

Teilmann, J., Henriksen, O.D. and Carstensen, J. 2001. Status report of the pilot project: "Porpoise detectors (PODs) as a tool to study potential effects of offshore windfarm on harbor porpoises at Rødsand". Technical report. Ministry of the Environment and Energy, Denmark, June 2001.

Teilmann, J. 1995. Influence of seastate on abundance estimates of harbor porpoise (Phocoena phocoena). Report to the International Whaling Commission SC/47/SM45.

Teilmann, J., Henriksen, O.D., Cartensen, J. and Skov, H. 2002. Monitoring effects of offshore windfarms on harbor porpoises using PODs (porpoise detectors). Ministry of the Environment, Denmark. $95 \mathrm{pp}$.

Terceiro, M. 2006a. Summer flounder. In: Status of fishery resources off the northeastern US. Retrieved from http://www.nefsc.noaa.gov/sos/spsyn/fldrs/summer/archives/08_SummerFlounder_2006.pdf.

Terceiro, M. 2006b. Scup. In: Status of fishery resources off the northeastern US. Retrieved from http://www. nefsc.noaa.gov/sos/spsyn/og/scup/archives/15_Scup_2006.pdf.

Thompson, P.M., Lusseau, D., Barton, T., Simmons, D., Rusin, J. and Bailey, H. 2010. Assessing the responses of coastal cetaceans to the construction of offshore wind turbines. Marine Pollution Bulletin 60: 1200-1208.22 Marine Megavertebrates and Fishery Resources in the Nantucket Sound - Muskeget Channel Area

Thomsen, F., Lüdemann, K., Kafemann, R. and Piper, W. 2006. Effects of offshore wind farm noise on marine mammals and fish. Biola, Hamburg, Germany on behalf of COWRIE Ltd.

Thorpe, T.W. 1999. Economic Analysis of Wave Power Devices. AEA Technology, Oxfordshire, UK. 6 pp. Retrieved from http://www.wave-

energy.net/Library/Economic\%20Analysis\%20of\%20Wave\%20Power.pdf 
Thrush, S.F., Hewitt, J.E., Cummings, V.J., Dayton, P.K., Cryer, M., Turner, S.J., Funnell, G.A., Budd, R.G., Milburn, C.J. and Wilkinson, M.R. 1998. Disturbance of the marine benthic habitat by commercial fishing: Impacts at the scale of the fishery. Ecological Applications 8: 866-879. doi:10.1890/10510761(1998)008[0866:DOTMBH]2.0.CO;2.

Thurstan, R.H. and Roberts, C.M. 2010. Ecological Meltdown in the Firth of Clyde, Scotland: Two Centuries of Change in a Coastal Marine Ecosystem. PLoS ONE 5(7): e11767.

doi:10.1371/journal.pone.0011767

Tougaard, J., Carstensen, J., Henriksen, O.D., Teilmann, J. and Hansen, J.R. 2004. Harbor porpoises on Horns Reef - effects of the Horns Reef wind farm. National Environmental Research Institute, Roskilde, Denmark, 69 pp.

Tougaard, J., Carstensen, J., Teilmann, J., Skov, H. and Rasmussen, P. 2009. Pile driving zone of responsiveness extends beyond $20 \mathrm{~km}$ for harbor porpoises (Phocoena phocoena (L.)). Journal of the Acoustical Society of America 126 (1): 11-14.

Tougaard, J., Carstensen, J., Henriksen, O.D., Skov, H. and Teilmann, J. 2003: Short-term effects of the construction of wind turbines on harbor porpoises at Horns Reef. Technical report to Techwise A/S. Hedeselskabet Roskilde, Denmark. 72 pp.

Tougaard, J., Henriksen, O.D. and Miller, L.A. 2009b. Underwater noise from three types of offshore wind turbines: Estimation of impact zones for harbor porpoises and harbor seals. Journal of the Acoustical Society of America 125 (6): 3766-3773.

Tyack, P., Gordon, J. and Thompson, D. 2003. Controlled exposure experiments to determine the effects of noise on marine mammals. Marine Technology Society Journal 37 (4): 41-53.

Underwood, A.J. 1994. On beyond BACI: sampling designs that might reliably detect environmental disturbances. 4(1): 3-15.

Underwood, A.J. 1995. Ecological research and (and research into) environmental management. Ecol. Appl. 5(1): 232-247.

U. S Fish and Wildlife Service and National Marine Fisheries Service. 1992. Recovery Plan for the Kemp's Ridley Sea Turtle (Lepidochelys kempii) National Marine Fisheries Service, St. Petersburg, Florida.

Verdant Power. 2012. Final Pilot License. Issued by the Federal Energy Regulatory Commission. January 23, 2012. http://www.ferc.gov/media/news-releases/2012/2012-1/01-23-12-order.pdf

Volgenau L., Kraus S.D. and Lien J. 1995. The impact of entanglements on two substocks of the western North Atlantic humpback whale, Megaptera novaeangliae. Canadian Journal of Zoology 73: 1689-1698.

Wade, P.R. and Angliss, R.P. 1997. Guidelines for assessing marine mammal stocks: Report of the GAMMS Workshop April 3-5, 1996, Seattle, Washington. NOAA Tech. Memo. NMFS-OPR-12. 93 pp.

Wahlberg, M. and Westerberg, H. 2005. Hearing in fish and their reactions to sound from offshore wind farms. Marine Ecology Progress Series 288: 295-309.

Waring, G.T., Gilbert, J.R., Loftin J. and Cabana, N. 2006. Short-term movements of Radio-tagged Harbor Seals in New England. Northeastern Naturalist 13 (1): 1-14. 
Waring, G.T., Josephson, E., Fairfield-Walsh, C.P. and Maze-Foley, K. (Eds). 2009. U.S. Atlantic and Gulf of Mexico Marine Mammal Stock Assessments - 2009. NOAA Technical Memorandum NMFSNE-210; 440 pp. Retreived from http://www.nmfs.noaa.gov/pr/sars/species.htm.

Waring, G.T., Josephson, E., Maze-Foley, K. and Rosel, P.E. (Eds) 2009. U.S. Atlantic and Gulf of Mexico Marine Mammal Stock Assessments - 2009. NOAA Technical Memorandum NMFS-NE-213. $528 \mathrm{pp}$.

Waters, J.H. 1967. Gray seal remains from southern New England archaeological sites. Journal of Mammalogy 48 (1): 139-141.

Watts, P. and Gaskin, D.E. 1985. Habitat index analysis of the harbor porpoise Phocoena phocoena in the southern coastal Bay of Fundy, Canada. Journal of Mammalogy 66: 733-744. 796 - Reference

Weilgart, L.S. 2007. The impacts of anthropogenic ocean noise on cetaceans and implications for management. Canadian Journal of Zoology 85: 1091-1116.

Whitman, A.A. and Payne, P.M. 1990. Age of harbor seals, Phoca vitulina concolor, wintering in southern New England. Canadian Field-Naturalist. 104 (4): 579-582.

Wiersma, J. 2008. An economic analysis of mobile gear fishing within the proposed wind energy generation facility site on Horseshoe Shoal. Massachusetts Fishermen's Partnership.

Wilhelmsson, D., Malm, T. and Öhman, M.C. 2006. The influence of offshore windpower on demersal fish. ICES Journal of Marine Science 63: 775-784.

Williams, R., Bain, E., Trites, A. and Ford, J. 2002. Behavioral responses of killer whales to a 'leapfrogging' vessel. Journal of Cetacean Research and Management 4: 305-310.

Wilson, B. Batty, R. S., Daunt, F. and Carter, C. 2007. Collision risks between marine renewable energy devices and mammals, fish and diving birds. Report to the Scottish Executive. Scottish Association for Marine Science, Oban, Scotland, PA37 1QA. 110 pp.

Wilson, J.C., Elliot, M., Cutts, N.D., Mander, L., Mendão, V., Perez-Dominguea, R. and Phelps, A. 2010. Coastal and Offshore Wind Energy Generation: Is It Environmentally Benign? Energies 3: 1383-1422.

Wiltschko, W. and Wiltschko, R. 2005. Magnetic orientation and magnetoreception in birds and other animals. Journal of Comparative Physiology A - Neuroethology and Sensory Neural and Behavioral Physiology 191: 675-693. doi:10.1007/s00359-005-0627-7.

Winn, H.E., Price, C.A. and Sorensen, P.W. 1986. The distributional biology of the right whale (Eubalaena glacialis) in the western North Atlantic. Reports of the International Whaling Commission Special Issue 10: 129-138.61

Witherington B.E. and Martin R.E. 2000. Understanding, assessing and resolving light-pollution problems on sea turtle nesting beaches, 2nd ed. Rev. Florida Marine Research Institute Technical Report TR-2.73 pp.

Witzell W.N. 1999. Distribution and relative abundance of sea turtles caught incidentally by the U.S. pelagic longline fleet in the western North Atlantic Ocean, 1992-1995. Fisheries Bulletin 97: 200-211.

Wolanski, E. and Hamner, W.M. 1988. Topographically controlled fronts in the ocean and their biological significance. Science 241: 177-181. 
Wood, S., Brault, S. and Gilbert, J. 2007. 2002 Aerial Surveys of Grey Seals in the Northeastern United States. NAMMCO Scientific Publication, Volume 6, Grey Seals in the North Atlantic and the Baltic.

Wood LaFond, S.A. 2009. The dynamics of recolonization: a study of the gray seal (Halichoerus grypus) in the Northeast U.S. Ph.D. Dissertation. University of Massachusetts, Boston, MA. 88 pp.64 Marine Megavertebrates and Fishery Resources in the Nantucket Sound - Muskeget Channel Area

Yearicks E.F., Wood, R.C., Johnson W.S. 1981. Hibernation of the Northern diamondback Terrapin (Melaclemys terrapin). Estuaries 4(1): 78-80.67 6 - Reference

Yen, P.P.W., Sydeman, W.J. and Hyrenbach, K.D. 2004. Marine bird and cetacean associations with bathymetric habitats and shallow-water topographies: implications for trophic transfer and conservation. Journal of Marine Systems 50: 79-99. 


\section{Appendix A UMASS Report}





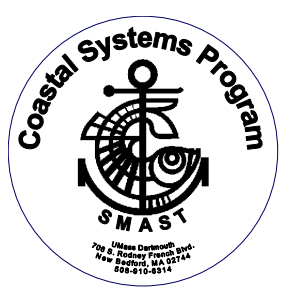

\title{
Environmental Effects of Sediment Transport Alteration and Impacts on Protected Species: Edgartown Tidal Project
}

\section{Topic Area II: Marine Science and Hydrokinetic Site Specific Environmental Studies}

\author{
A UMASS Dartmouth Partnership Project between \\ SMAST - Coastal Systems Program (CSP) \\ and \\ Harris, Miller, Miller and Hanson Inc. (HMMH)
}

Submitted by:

\author{
Dr. Brian L. Howes \\ Mr. Roland Samimy, M.S., M.A. \\ Dr. David Schlezinger \\ Mr. Michael Bartlett \\ Mrs. Jennifer Benson \\ Coastal Systems Program \\ School of Marine Science and Technology \\ University of Massachusetts Dartmouth \\ Submitted to: \\ United States Department of Energy
}

January 15, 2011 


\section{Table of Contents}

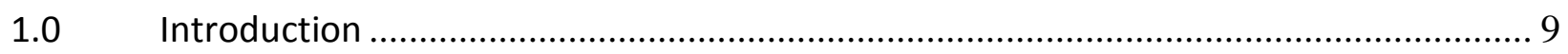

2.0 Description of Data Collection Program ............................................................... 15

2.1 Field Data Collection (PHYSICAL - Hydrodynamic) .......................................... 15

A. Tide Data Collection ………………………………………………………... 15

C. Bathymetric Survey in Region of Future Pilot Tidal Technology Deployment.........17

D. Long-term Current Recording using Bottom Mounted ADCP .................................17

E. Near Bottom Current Velocity Measurements utilizing Downward Looking Acoustic Velocity Meter for Documenting Scouring around a Mooring .................................... 19

2.2 Field Data Collection (BIOLOGICAL - Habitat Assessment) .............................. 21

F. Determining likely Fouling Communities Post-construction using Fouling Plates and determine Associated Fouling Rates............................................................. 21

G. Survey area in the near field to the bio-fouling arrays in order to identify existing

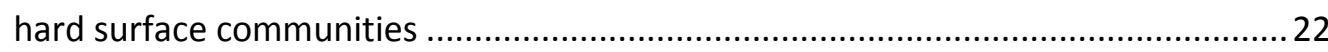

2.3 Field Data Collection (PHYSICAL - Geomorphology of Surficial Sediments) .... 22 H. Bedform Surveying of Near Field Area Surrounding Bio-Fouling Arrays in the High Velocity Zone of Muskeget Channel ...................................................................22

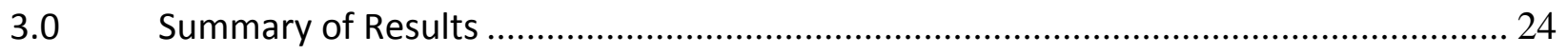

$3.1 \quad$ Tide Data Collection ..................................................................................... 25

3.2 Ship Based Acoustic Doppler Current Profiling .............................................. 33

3.3 Bathymetric Survey in Region of Future Pilot Tidal Technology Deployment . 68

3.4 Time-series Current Velocity Measurements at a Single Point in the High Velocity Zone over a Complete Lunar Cycle using Bottom Mounted ADCP.................. 70 3.5 Measurement of Near-bottom Current Velocity using ADCP's attached to a Scouring Block to Quantify Effect of a Mooring on Sediment in the High Velocity Zone of Muskeget Channel ............................................................................................. 76

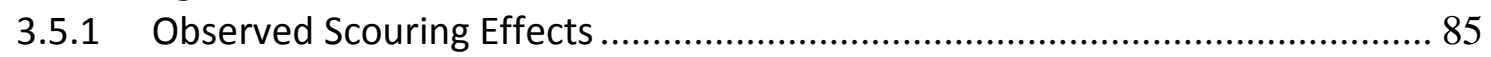

3.5.2 Sediment Grain-size Distribution..................................................................... 86

3.6 Assess likely Fouling Communities Post-construction using Fouling Plates and

Determine Associated Fouling Rates ............................................................................ 88

3.7 Survey Area in the Near field to the Bio-fouling Arrays in order to Identify

Existing Hard Surface Communities............................................................................ 95

3.8 Side-scan Sonar for High Resolution Bedform Surveying to Characterize Smallscale Roughness and Bedforms Responsible for Bottom Stresses............................... 96

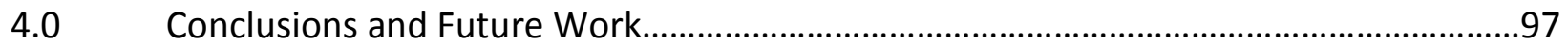




\section{List of Figures}

Figure 1 - General location (circled area) of Muskeget Channel and the initial survey area from which 2008-2009 baseline data collection was obtained to focus the higher level data collection supported by the Department of Energy Grant (DOE069).

Figure 2 - Location of temperature-depth recorders (TDRs) to correct bathymetry surveying for changing tidal stage as the survey was being completed and further clarify lags in tide height across Muskeget Channel (north to south) ............................................................................. 15

Figure 3 - Location of additional ship based ADCP surveying undertaken in the high velocity zone where the scouring and bio-fouling experiments were undertaken ............................................. 16

Figure 4. Additional bathymetric survey of the high velocity zone in Muskeget Channel completed in 2010. Bathymetric survey lines were spaced 50-100 meters apart to provide increased spatial coverage of the bottom contour.....

Figure 5 - Acoustic Doppler Current Profiler (ADCP) deployed in Muskeget Channel using a trawl resistant bottom mount (TRBM) with an acoustic release to aid in retrieval ........................ 18

Figure 6 - Concrete cylinder (scouring block) instrumented with downward looking current meters to measure current velocity around the base (up-gradient and down-gradient) of the structure

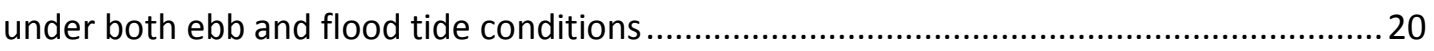

Figure 7 - Bio-fouling array (untreated) with three sets of fouling "plates" (surface, middle, bottom) arranged in triplicate for determining rate at which bio-fouling occurs on composite material utilized in the construction of a tidal turbine generating unit (ORPC OCGen

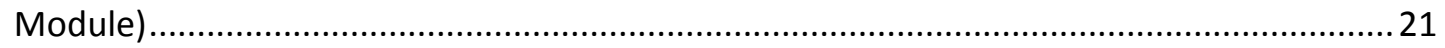

Figure 8 - Locations of previous data collection (2008-2009) aimed at determining the viability of the general area between Martha's Vineyard and Nantucket Island for hydrokinetic energy development. The Town of Edgartown FERC permit area (blue dashed line) served as a guide for initial baseline data collection. The zone presently being considered for tidal energy development is bounded by Transect 6 and Transect 8 adjacent Mutton Shoal ...... 25

Figure 9 - Location of three temperature/depth recorders (TDR) deployed in Muskeget Channel in 2010 27

Figure 10 - Measured tide stage (feet) in the Tom Shoal portion of Muskeget Channel (north of the high current velocity zone of Muskeget Channel and adjacent the navigational aid C5. TDR data was adjusted for reference to MLLW and NOAA predicted tides at Cape Pogue. Deployment period August 8, 2010 to September 1, 2010. Data presented depicts one week of tidal stage. .29

Figure 11 - Measured tide stage (feet) in the middle portion of Muskeget Channel (approximately midway between the high current velocity zone of Muskeget Channel and the navigation aid C5 adjacent to Tom Shoal. TDR data was adjusted for reference to MLLW and NOAA predicted tides at Cape Pogue. Deployment period August 8, 2010 to October 5, 2010. Data presented depicts one week of tidal stage ......................................................................... 30

Figure 12 - Measured tide stage (feet) in the northern portion of the high velocity zone of Muskeget Channel in the vicinity of Transect 6 (blue line). TDR deployed on Mutton Shoal and adjusted for reference to MLLW and NOAA predicted tides at Cape Pogue. Deployment period August 8, 2010 to October 5, 2010. Data presented depicts one week of tidal stage 
Figure 13. Plot of the times of high and low tides at 5 tide recorder locations south of Cape Pogue against the NOAA Cape Pogue tide station show a consistent pattern of tidal time delays throughout the study region. The tide station plotted $15 \mathrm{~km}$ south of Cape Pogue represents the TRBM deployed in $100 \mathrm{ft}$ of water within the throat of the channel............. 32

Figure 14. Plot of tidal stage measured at the TRBM (bottom-mounted ADCP between Transect 6 and Transect 7 deployed under this grant) and the NOAA Cape Pogue Tide station. Tidal delays are evident. Peak tidal velocities are coincident with maximum separation of the tidal elevations between the two stations.

Figure 15 - Location of previously surveyed transects (red) as well as new transects surveyed under this grant (black). It should be noted that three transects $(6,7,8)$ initially surveyed in $2008 / 2009$ were also surveyed in 2010 36

Figure 16 - Location of additional ship based ADCP surveying undertaken in the high velocity zone where the scouring and bio-fouling experiments were undertaken

Figure 17-Current/Depth profile along Transect 6. Maximum ebb tide (Cycle 5) is displayed in panel A; maximum flood tide (cycle 10) is displayed in panel $B$. Scale is in $\mathrm{m} / \mathrm{s}$. The west end of the transect is on the left and the east end of the transect is on the right 40

Figure 18 -- Plot of depth averaged (top to bottom of water column) along-channel (i.e., perpendicular to ADCP transect line) velocities measured using the ADCP at Transect 6 of the 2011 Muskeget Channel survey. Each line represents velocity measurements recorded during the indicated survey cycle (as shown by the numbers at the start and end of each line). Positive velocities indicate flood currents directed to the north, into Nantucket Sound ..... 41

Figure 19-- Vector plot of depth averaged ADCP measurements for Transect 6 of the December 2011 survey of Muskeget Channel. A). Maximum flood velocities from survey Cycle 10 and B). Maximum ebb velocities from survey Cycle 5. Vectors indicate magnitude of the measurement by their length, and also direction, relative to true north. A two knot scale vector is shown for reference

Figure 20-- Velocity magnitude ( $\mathrm{N}+\mathrm{E})$ profiles measured along Transect 6 of the 2011 survey A). during Cycle 5 (max ebb) and B). during Cycle 10 (max flood). Profiles are shown for individual ensembles measured along the transect line.... 43

Figure 21-- Current/Depth profile along Transect 6.1. Maximum ebb tide (Cycle 5) is displayed in panel A; maximum flood tide (cycle 10) is displayed in panel B. Scale is in $\mathrm{m} / \mathrm{s}$. The west end of the transect is on the left and the east end of the transect is on the right. 44

Figure 22-- Plot of depth averaged (top to bottom of water column) along-channel (i.e., perpendicular to ADCP transect line) velocities measured using the ADCP at Transect 6.1 of the 2011 Muskeget Channel survey. Each line represents velocity measurements recorded during the indicated survey cycle (as shown by the numbers at the start and end of each line). Positive velocities indicate flood currents directed to the north, into Nantucket Sound ..... 45

Figure 23-- Vector plot of depth averaged ADCP measurements for Transect 6.1 of the December 2011 survey of Muskeget Channel. A). Maximum flood velocities from survey Cycle 10 and B). Maximum ebb velocities from survey Cycle 5 . Vectors indicate magnitude of the measurement by their length, and also direction, relative to true north. A two knot scale vector is shown for reference. 46

Figure 24-- Velocity magnitude ( $\mathrm{N}+\mathrm{E})$ profiles measured along Transect 6.1 of the 2011 survey $\mathrm{A})$. during Cycle 5 (max ebb) and B). during Cycle 10 (max flood). Profiles are shown for individual ensembles measured along the transect line....

Figure 25-- Current/Depth profile along Transect 6.2. Maximum ebb tide (Cycle 5) is displayed in panel A; maximum flood tide (cycle 10) is displayed in panel B. Scale is in $\mathrm{m} / \mathrm{s}$. The west end of the transect is on the left and the east end of the transect is on the right. 48 
Figure 26-- Plot of depth averaged (top to bottom of water column) along-channel (i.e., perpendicular to ADCP transect line) velocities measured using the ADCP at Transect 6.2 of the 2011 Muskeget Channel survey. Each line represents velocity measurements recorded during the indicated survey cycle (as shown by the numbers at the start and end of each line). Positive velocities indicate flood currents directed to the north, into Nantucket Sound .....49

Figure 27-- Vector plot of depth averaged ADCP measurements for Transect 6.2 of the December 2011 survey of Muskeget Channel. A). Maximum flood velocities from survey Cycle 10 and B). Maximum ebb velocities from survey Cycle 5 . Vectors indicate magnitude of the measurement by their length, and also direction, relative to true north. A two knot scale

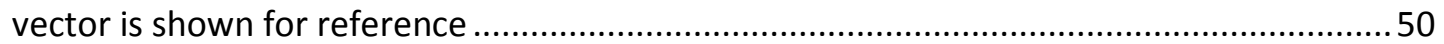

Figure 28- Velocity magnitude $(\mathrm{N}+\mathrm{E})$ profiles measured along Transect 6.2 of the 2011 survey $\mathrm{A}$ ). during Cycle 5 (max ebb) and B). during Cycle 10 (max flood). Profiles are shown for individual ensembles measured along the transect line ....................................................5 51

Figure 29- Current/Depth profile along Transect 7. Maximum ebb tide (Cycle 5) is displayed in panel A; maximum flood tide (cycle 10) is displayed in panel B. Scale is in $\mathrm{m} / \mathrm{s}$. The west end of the transect is on the left and the east end of the transect is on the right 52

Figure 30 -- Plot of depth averaged (top to bottom of water column) along-channel (i.e., perpendicular to ADCP transect line) velocities measured using the ADCP at Transect 7 of the 2011 Muskeget Channel survey. Each line represents velocity measurements recorded during the indicated survey cycle (as shown by the numbers at the start and end of each line). Positive velocities indicate flood currents directed to the north, into Nantucket Sound ..... 53

Figure 31-- Vector plot of depth averaged ADCP measurements for Transect 7 of the December 2011 survey of Muskeget Channel. A). Maximum flood velocities from survey Cycle 10 and B). Maximum ebb velocities from survey Cycle 5 . Vectors indicate magnitude of the measurement by their length, and also direction, relative to true north. A two knot scale vector is shown for reference. 54

Figure 32-- Velocity magnitude ( $\mathrm{N}+\mathrm{E})$ profiles measured along Transect 7 of the 2011 survey A). during Cycle 5 (max ebb) and B). during Cycle 10 (max flood). Profiles are shown for individual ensembles measured along the transect line.... 55

Figure 33 - Current/Depth profile along Transect 7.1. Maximum ebb tide (Cycle 5) is displayed in panel A; maximum flood tide (Cycle 10) is displayed in panel B. Scale is in $\mathrm{m} / \mathrm{s}$. The west end of the transect is on the left and the east end of the transect is on the right............................56

Figure 34- Plot of depth averaged (top to bottom of water column) along-channel (i.e., perpendicular to ADCP transect line) velocities measured using the ADCP at Transect 7.1 of the 2011 Muskeget Channel survey. Each line represents velocity measurements recorded during the indicated survey cycle (as shown by the numbers at the start and end of each line). Positive velocities indicate flood currents directed to the north, into Nantucket Sound .....57

Figure 35-- Vector plot of depth averaged ADCP measurements for Transect 7.1 of the December 2011 survey of Muskeget Channel. A). Maximum flood velocities from survey Cycle 10 and B). Maximum ebb velocities from survey Cycle 5 . Vectors indicate magnitude of the measurement by their length, and also direction, relative to true north. A two knot scale vector is shown for reference..... 58

Figure 36-- Velocity magnitude ( $\mathrm{N}+\mathrm{E})$ profiles measured along Transect 7.1 of the 2011 survey $\mathrm{A})$. during Cycle 5 (max ebb) and B). during Cycle 10 (max flood). Profiles are shown for individual ensembles measured along the transect line.... 59

Figure 37-- Current/Depth profile along Transect 7.2. Maximum ebb tide (Cycle 5) is displayed in panel A; maximum flood tide (cycle 10) is displayed in panel B. Scale is in $\mathrm{m} / \mathrm{s}$. The west end of the transect is on the left and the east end of the transect is on the right. 60 
Figure 38 - Plot of depth averaged (top to bottom of water column) along-channel (i.e., perpendicular to ADCP transect line) velocities measured using the ADCP at Transect 7.2 of the 2011 Muskeget Channel survey. Each line represents velocity measurements recorded during the indicated survey cycle (as shown by the numbers at the start and end of each line). Positive velocities indicate flood currents directed to the north, into Nantucket Sound .....61

Figure 39-- Vector plot of depth averaged ADCP measurements for Transect 7.2 of the December 2011 survey of Muskeget Channel. A). Maximum flood velocities from survey Cycle 10 and B). Maximum ebb velocities from survey Cycle 5 . Vectors indicate magnitude of the measurement by their length, and also direction, relative to true north. A two knot scale vector is shown for reference 62

Figure 40-- Velocity magnitude $(\mathrm{N}+\mathrm{E})$ profiles measured along Transect 7.2 of the 2011 survey $\mathrm{A})$. during Cycle 5 (max ebb) and B). during Cycle 10 (max flood). Profiles are shown for individual ensembles measured along the transect line....

Figure 41-- Current/Depth profile along Transect 8. Maximum ebb tide (Cycle 5) is displayed in panel A; maximum flood tide (cycle 10) is displayed in panel B. Scale is in $\mathrm{m} / \mathrm{s}$. The west end of the transect is on the left and the east end of the transect is on the right 64

Figure 42 -- Plot of depth averaged (top to bottom of water column) along-channel (i.e., perpendicular to ADCP transect line) velocities measured using the ADCP at Transect 8 of the 2011 Muskeget Channel survey. Each line represents velocity measurements recorded during the indicated survey cycle (as shown by the numbers at the start and end of each line). Positive velocities indicate flood currents directed to the north, into Nantucket Sound ..... 65

Figure 43-- Vector plot of depth averaged ADCP measurements for Transect 8 of the December 2011 survey of Muskeget Channel. A). Maximum flood velocities from survey Cycle 10 and B). Maximum ebb velocities from survey Cycle 5 . Vectors indicate magnitude of the measurement by their length, and also direction, relative to true north. A two knot scale vector is shown for reference .66

Figure 44-- Velocity magnitude $(\mathbf{N}+\mathbf{E})$ profiles measured along Transect 8 of the 2011 survey A). during Cycle 5 (max ebb) and B). during Cycle 10 (max flood). Profiles are shown for individual ensembles measured along the transect line. .67

Figure 45 - Area of additional fine scale bathymetric mapping in the high velocity zone of Muskeget Channel where future tidal turbine deployments are being planned and in a more northern location not previously surveyed in 2008/2009

Figure 46. Additional finer scale bathymetric map of the high velocity zone in Muskeget Channel completed in 2010. Bathymetric survey lines were spaced 50 meters apart to provide increased spatial coverage of the bottom contour. Also displayed on the map are the additional ADCP transects surveyed in 2010 to determine optimal velocities for potential turbine installation sites for future power generation ....................................................... 70

Figure 47-Bathymetric map of the high velocity zone in Muskeget Channel showing the location of the bottom mounted ADCP unit. 71

Figure 48 - ADCP deployed November 2010 to measure current velocity over a complete lunar cycle in the high velocity zone of Muskeget Channel..... 71

Figure 49 - Contour plot of current velocity for the bottom $20 \mathrm{~m}$ of the water column over the deployment period at a single point along Transect 6.2. Data was collected using the bottom mounted ADCP logging once every 15 minutes between November 22, 2010 and January 6,2011 . Areas in white represent times when data quality was poor due to fouling or extreme turbulence..... 72

Figure 50 - Hour Velocity Contour Plot of the current velocities within the high velocity zone of Muskeget Channel three days prior to a first quarter lunar (Neap tide) cycle. The highest velocities 
occurred during the ebb tides. These measurements support the shipboard ADCP surveys that were conducted on December 10, 2010 ............................................................... 73

Figure 52 - 24 hour velocity contour plot displaying current velocities during a quadrature between the Neap and Spring lunar tide cycles. Maximum velocities ranged between 1.6 to $2.3 \mathrm{~m} / \mathrm{s}$ ( 3.1-4.5 knots) from the surface to 16 meter depth during the ebb tides. ........................ 75

Figure 53 - Spring tide velocity contour plot for a 24 hour period from the bottom mounted ADCP deployed within the high velocity zone in Muskeget Channel. Maximum current velocities ranged between 1.7 to $2.4 \mathrm{~m} / \mathrm{s}$ ( 3.3-4.7 knots) through the first 16 meters of the water

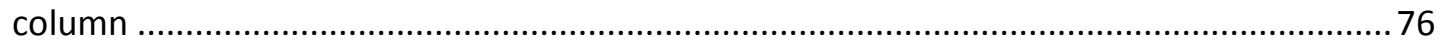

Figure 54 - Location of the concrete cylinder deployed as a scour mooring to document sediment alterations resulting from high velocity currents flowing around the mooring under ebb and flood tide conditions. Position of the scour mooring is shown relative to bio-fouling arrays 1 (untreated) and 2 (treated) as well as position of ADCP surveying completed along Transects 6 and 7 that demarcate the optimal high velocity zone for future tidal turbine deployments under the Town of Edgartown FERC permit 78

Figure 55 - Theoretical mooring system to support a OCGen Tidal Turbine from Ocean Renewable Power Company. The smaller scale concrete cylinder deployed for the scouring investigation was selected to mimic the sediment effect induced by one foot of the mooring system (red circle)... .79

Figure 56 - Concrete cylinder deployed in the high velocity zone of Muskeget Channel and utilized to investigate sediment scour and settling that might result from tidal turbine moorings ...... 79

Figure 57 - Pitch, Roll and Depth data obtained from the Aquadopp Profiler deployed on the concrete cylinder utilized for the scouring investigation. Pitch and roll both remain constant after an initial $48 \mathrm{hr}$ settling period. Slight variations in Depth (atmosphere corrected pressure) reflect small uncompensated changes in tide, sea state etc.

Figure 58 - Plot of backscatter echo intensity through time obtained with Aquadopp Profiler. Blanking distance was $0.35 \mathrm{~m}$. Black stepped line indicates the distance to the sediment surface inferred from maximum backscatter intensity. The cylinder rests on the sediment surface as the sediment is eroded from beneath. Deposition and erosion of a barchan composed primarily of gravel occurs during each change in tidal direction.......................................... 82

Figure 59-Time series measurements of current velocity and direction from March 25 through March 27 shortly after the scour cylinder reached its final depth. Velocities and directions were averaged for depths of 0.3-0.6 m. Ebb tide periods are shaded. The time frame reflects peak Spring tides conditions. .83

Figure 60-Time series profiles of current vectors measures by the Aquadopp profiler. Time, tide state and incoming velocity are noted at the top of each panel. Vectors are centered on the depth bin measured, vector magnitudes are proportional and vector directions follow a compass rose convention where the top of the page represents North and the bottom of the page represents South. .85

Figure 61 - Observed sediment scouring and accretion around the base of the concrete cylinder deployed for the scouring investigation and serving as a scaled down analog to a portion of a mooring system for tidal turbine installation on the sea bed. Finer grained sand has been scoured away to reveal a stable gravel and cobble layer.... 86

Figure 62-Grain size distribution surrounding scour cylinder at the time of deployment. Distribution was typical of sand waves in the vicinity of Muskeget Channel.....

Figure 63 - Treated (left) and untreated (right) arrays prior to deployment in the high velocity zone of Muskeget Channel 89 
Figure 64 - Schematic of bio-fouling array as deployed in the high velocity zone of Muskeget Channel (treated and un-treated).

Figure 65 - Bio-fouling array shown to remain in a vertical position under idealized slack tide conditions $(0.0 \mathrm{~m} / \mathrm{s}$ current velocity).

Figure 66. Bio Fouling Array shown becomes diagonal within in the depth zone under the average current velocity of $1.0 \mathrm{~m} / \mathrm{s}$. Drag forces caused by the array components and increased current velocity shift the array to a diagonal position.

Figure 67 - Position of the bio-fouling arrays 1 (untreated) and 2 (treated) relative to the scour mooring deployed for sediment alteration investigation. Transects 6 and 7 demarcate the optimal high velocity zone for future tidal turbine deployments under the Town of Edgartown FERC permit. 93

Figure 68 - Observed bio-accumulation on one of three un-treated fouling plates deployed in the high velocity zone of Muskeget Channel. The plate was positioned on the bio-fouling array to represent bio-fouling occurring in the upper portion of the water column. The bioaccumulation depicted resulted from being submerged for approximately 10 weeks......... 95

Figure 69 - Map depicting the side scan sonar surveying undertaken in the high velocity zone of Muskeget Channel. Survey data revealed the area was dominated by featureless bottom with the exception of significant sand waves. 


\subsection{Introduction}

In partial satisfaction of the United States Department of Energy (USDOE) grant received jointly by: 1 ) Harris, Miller, Miller and Hanson Inc. (HMMH, Prime Investigator), 2) the University of MassachusettsDartmouth, Coastal Systems Program within the UMASS-D School for Marine Science and Technology (Technical Team Member), 3) Woods Hole Oceanographic Institution (Technical Team Member), 4) Provincetown Center for Coastal Studies (Technical Team Member) and 5) Batelle Ocean Sciences, provided as follows is the summary of findings from field surveys of Muskeget Channel (Massachusetts State Waters) in support of future deployment of hydrokinetic energy generation technologies. The field surveys were conducted by the Coastal Systems Program (UMASS-SMAST) which was responsible for investigations related specifically to alterations of benthic habitats.

It should also be noted that while this summary report was developed to meet the requirements of the DOE grant, in addition, the data collected under this award is being shared with the Town of Edgartown to meet specific requirements of their permit from the Federal Energy Regulatory Commission (FERC) to investigate the viability of a tidal energy project in the waters between Martha's Vineyard and Nantucket (specifically Muskeget Channel and surrounding waters). Finally, the scientific investigation undertaken through this grant is also being made available to the UMASS Marine Renewable Energy Center (MREC) in support of that Center's stated goal of accelerating the deployment of marine renewable energy technologies in an environmentally sound manner within U.S. waters through the establishment of a Northeast Renewable Energy Innovation Zone (NOREIZ).

The Coastal Systems Program working in collaboration with MREC undertook the initial baseline oceanographic surveying to determine that Muskeget Channel had viable tidal currents for marine hydrokinetic energy development. The field surveys described herein build upon those initial (20082009) baseline data collection efforts and advance the understanding of the hydrodynamic and environmental characteristics of Muskeget Channel. Through this ever increasing level of understanding of the Muskeget Channel environment, it is possible to eventually undertake production of renewable energy from tides in a manner that minimizes the potential impacts on this marine environment.

Background: Prior to the existing DOE grant that is the focus of this report, a partnership was formed between the Coastal Systems Program (UMASS-SMAST) and the UMASS Marine Renewable Energy Center (MREC) to: (a) determine if Muskeget Channel had sufficient tidal velocities to support hydrokinetic power generation and (b) determine potential environmental impacts of deployment of generators and associated infrastructure (moorings, cables, etc). The initial data collection effort in Muskeget Channel was conducted with the support from the Massachusetts Technology Collaborative (now called the Massachusetts Clean Energy Council). The initial data collection effort was focused on baseline surveys (physical and biological) of the Muskeget Channel area in Nantucket Sound and the greater region between Muskeget Island and Martha's Vineyard. These surveys included the use of both shipboard and moored instrumentation to measure current velocity, tide stage, and bathymetry and sampling of sediment and water column characteristics. The findings of the initial baseline data 
collection were presented in a 2009 report to the MTC, Marine Renewable Energy Survey of Muskeget Channel, December 2009. The overarching goal of the initial data collection effort in Muskeget Channel was to provide site-specific survey information that could be used to support siting decisions relative to various ocean renewal energy technologies. The site specific surveying was completed at a level of detail that previously did not exist and went well beyond the characterization of Muskeget Channel as was undertaken by the Electric Power Research Institute (EPRI-TP-006-MA, 2006)

Based upon the initial data collection effort on the velocity field within Muskeget Channel in 2008-09, it was clear that hydrokinetic energy generation potential using underwater turbines does exists within the southern region of Muskeget Channel which falls in the Town of Edgartown FERC permit area for tidal power development. However, it also became clear that additional velocity surveying and environmental data collection would be required to further refine the best locations for deployment of tidal energy generation technologies and understand the effects these deployments could potentially have on the marine environment, particularly the benthic habitat.

What also became clear from the initial 2008-2009 data collection effort was for reasons of water depth and/or low tidal velocity, most of the Muskeget Channel region appears to be unsuitable for hydrokinetic power generation using existing technologies. Fortunately, the initial current velocity data collected from the southern region of the Channel under the 2008-2009 MTC grant was sufficiently promising to continue to move forward toward implementation of a tidal energy project under the Town of Edgartown FERC Permit process as well as inform MREC in the establishment of a test bed for tidal power as part of the development of a Northeast Offshore Renewable Energy Innovation Zone (NOREIZ).

The initial data collection to assess the viability of tidal currents in Muskeget Channel for energy production was critical in focusing the follow-on characterizations of currents and benthos as undertaken through the US DOE award (USDOE Funding Opportunity Announcement No. DE-FOA0000069). The higher order data collection on tidal currents and potential alterations to benthic habitats resulting from technology deployments was largely limited to the highest current velocity zone in Muskeget Channel.

Muskeget Channel extends approximately from Muskeget Island (western most island in Nantucket County) to the easternmost shore of Chappaquiddick Island on Martha's Vineyard (Dukes County) as depicted in Figure 1. The main channel generally runs north-south near Chappaquiddick Island adjacent the Town of Edgartown, MA. While initial oceanographic surveys assessed the whole of Muskeget Channel relative to hydrokinetic generation potential, the results ultimately focused this investigation on the higher flow region in the vicinity of Mutton Shoals, at the southern end of Muskeget Channel just prior to discharging to Atlantic waters south of Martha's Vineyard and Nantucket Island. 


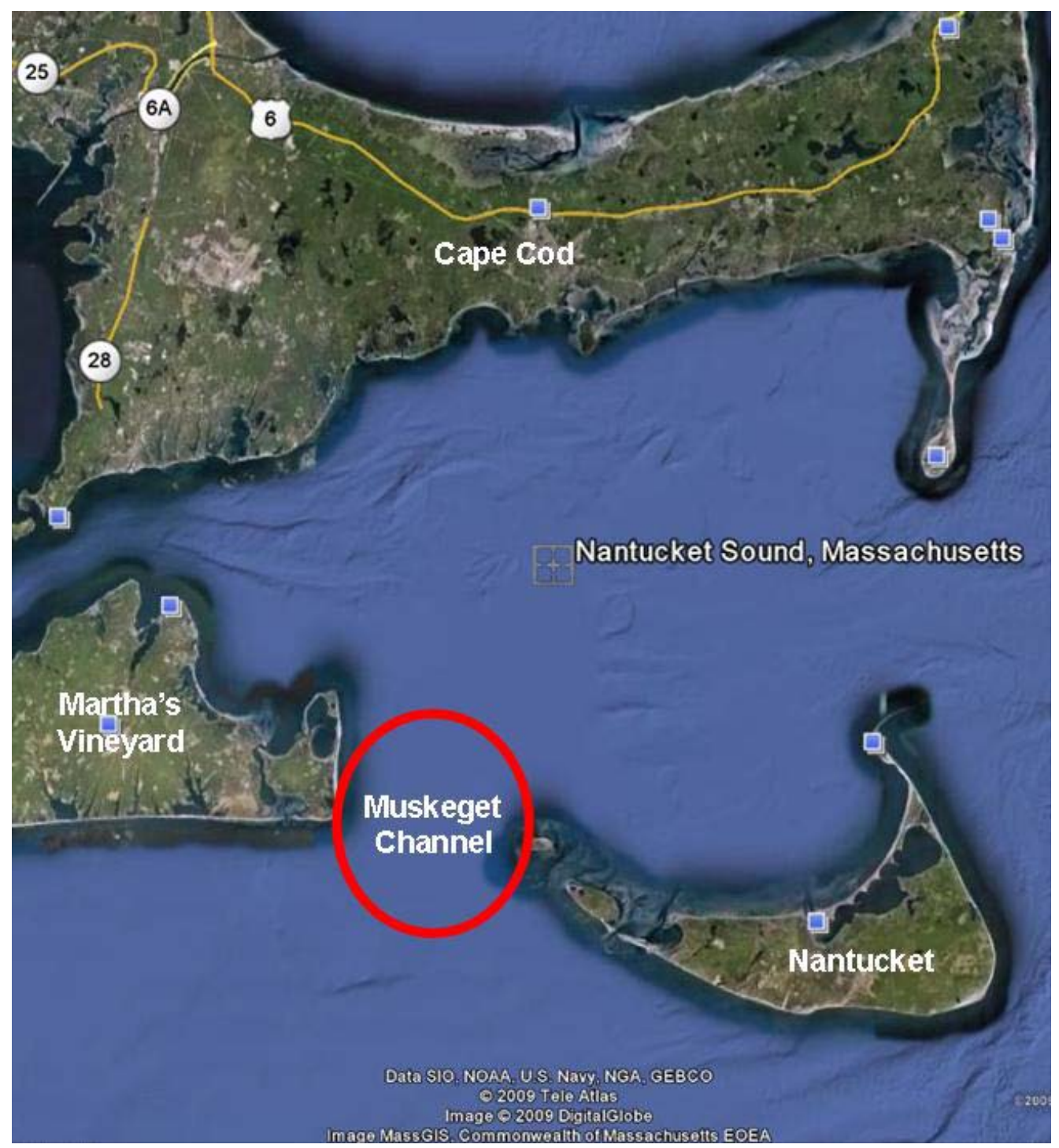

Figure 1 - General location (circled area) of Muskeget Channel and the initial survey area from which 2008-2009 baseline data collection was obtained to focus the higher level data collection supported by the Department of Energy Grant (DOE069).

In the current investigation, Harris, Miller, Miller and Hanson, Inc. (HMMH) served as the overall leader of the project with the ultimate goal of securing more specific current velocity data as well as an understanding of sediment transport and potential alteration to benthic habitats as a result of future tidal energy projects in these waters. The information developed through this grant was tailored towards meeting both the requirements of a FERC permit held by the Town of Edgartown as well as establishing a pre-permitted ocean energy test site to be developed under the umbrella of the UMASS Marine Renewable Energy Center (MREC). The SMAST-Coastal Systems Group (CSP), as one member of a larger project team, was specifically tasked to gather detailed current velocity data (near bottom as well as the entire water column) in addition to data pertaining to sediment scour around mooring structures and the potential for bio-fouling of tidal turbine technology in a high current velocity marine 
environment. As such, surveying as well as the deployment of instruments and experiments utilized the field and laboratory resources of the SMAST-CSP group and its collaborators, which simplified logistical planning and provided an efficient means for maximum data collection. Available resources included a variety of oceanographic instrumentation for field data collection on ocean physics and biological habitats, water quality and biologic resources, in addition to the resources of a full analytical facility.

The overarching goal of the CSP data collection effort on Muskeget Channel for the DOE grant was to provide a detailed understanding of site-specific current velocity in the area of Muskeget Channel most likely to be used for tidal power generation as well as benthic information to support future siting decisions relative to various ocean renewal energy technologies, specifically:

1. How do tidal currents vary spatially and temporally in the highest velocity zone of Muskeget Channel;

2. What are the potential effects to benthic communities in the high velocity zone of Muskeget Channel due to scouring should tidal turbine technologies be deployed in this environment using moorings;

3. How susceptible are tidal energy generators to bio-fouling and to what extent will the biofouling of generators and moorings drive changes in the local biology

To address the data collection goals, the Coastal Systems Program within the University of Massachusetts-Dartmouth, School for Marine Science and Technology (UMASS-SMAST) proposed two research elements: 1 ) In-depth ADCP Surveying and time-series velocity measurements of potential tidal generation area and 2) bio-fouling and sediment transport as it relates to installation of tidal generation technology.

The specific tasks summarized in the present report to support the two proposed research elements include:

- Ship based field surveys of current velocities along additional transects in the high velocity zone of Muskeget Channel using a downward looking acoustic doppler current profiler;

- Measurement of current velocities over a complete lunar cycle at a single point in the high velocity zone using an upward looking ADCP deployed in a trawl resistant bottom mount;

- Measurement of tidal stages at multiple locations along the north-south axis of Muskeget Channel to further refine understanding of lags in tidal currents;

- Field surveys of biological parameters to support evaluation of potential environmental impacts resulting from deployment of energy generation technologies; 
Data Collected by Field Program: The data collection effort was conducted over approximately a two year period including the 2009 and 2010 summer field seasons. The analysis of data collected was under the direction of Dr. Brian L. Howes, Director of the Coastal Systems Program at SMAST-UMD with the assistance of CSP Research Coordinators, Mr. Roland Samimy and Dr. David Schlezinger. SMAST-CSP under the management of $\mathrm{HMMH}$, Inc. conducted all the required instrument deployments and data collection while a limited number of technical specialists with proven capabilities and experience within the region were integrated into the effort to assist with some high end data processing, primarily related to the ADCP effort.

Assessment of environmental and biological conditions in the high velocity zone of Muskeget Channel where undertaken in concert with physical characterization of the Muskeget Channel high velocity zone to obtain necessary detail for optimal placement of future tidal turbine arrays as well as to collect data to describe the degree to which scouring effects may be generated in association with the mooring of tidal turbine arrays. Data collected on current velocities through the high velocity zone as well as near the bottom where communicated to the other technical team members responsible for parameterizing the sediment transport model of the Muskeget Channel area. In addition, the sediment transport modeling team was provided with surficial sediment characteristics from sediment sampling under taken by the Coastal Systems Program under this grant. Lastly, bio-fouling experiments were undertaken in the high velocity zone of Muskeget Channel in order to advance the understanding of the degree to which future tidal turbine arrays may bio-foul and how that may drive effects on the local ecology.

The information gathered through the bio-fouling experiments is valuable to technology/energy developers as it assists them in developing strategies for minimizing bio-fouling, thus maintaining tidal turbine efficiencies, while also enabling developers to address permitting questions regarding the potential environmental impacts of deploying tidal turbine arrays in the marine environment. All the above mentioned information gathered through this grant is also serving to inform the University of Massachusetts-Dartmouth in its development of a "test bed" for marine renewable energy projects (wind, wave, tidal) under MREC and also to support the data collection criteria of the Town of Edgartown FERC Permit. Data collection and synthesis focused on the following:

\section{Field Data Collection (PHYSICAL - Hydrodynamic)}

A) Time-series tidal stage recording,

B) Cross-channel current velocities and flow volumes via ship based Acoustic Doppler Current Profiling (ADCP) through ebb and flood tidal cycles between previously established Transect 6 and 7 ,

C) Bathymetric surveying of high velocity zone in Muskeget Channel,

D) Time-series current velocity measurements at a single point at an optimal location in the high velocity zone over a complete lunar cycle using a bottom mounted ADCP,

E) Measurement of near bottom current velocity using a single point current meter attached to a scouring block to quantify effect of a mooring on sediments in the high velocity zone. 


\section{Field Data Collection (BIOLOGICAL - Habitat Assessment)}

F) Determine likely fouling communities to develop post-construction using controlled fouling plates (treated and un-treated) deployed in the high velocity zone of Muskeget Channel and determine associated fouling rates,

G) Survey area in the near field to the bio-fouling arrays in order to identify existing hard surface communities.

\section{Field Data Collection (PHYSICAL - Geomorphology of Surficial Sediments)}

H) An OceanServer Technology AUV equipped with a Imagenex 837B multi-beam sonar, a Imagenex sidescan sonar, and a Doppler Velocity Log (for underwater navigation between GPS fixes) was to be used for high resolution bed-form surveying necessary to characterize smallscale roughness and bed-forms responsible for bottom stresses.

The tasks required for fulfilling the data needs and goals of the project are described in Section 2.0. 


\subsection{Description of Data Collection Program}

\subsection{Field Data Collection (PHYSICAL - Hydrodynamic)}

\section{A. Tide Data Collection}

Measurement of tidal elevation was made at multiple (3) locations within Muskeget Channel and surrounding waters (Figure 2) to determine how tidal current velocities correspond to changes in tidal stage and the timing and duration of maximum and minimum velocities relative to tidal elevation changes. By deploying multiple tide gages at strategic locations in the northern and southern portion of the Muskeget Channel study area, it was also possible to determine lags (offsets) in the propagation of the tidal signal through the Channel. The tide records combined with the velocity survey data will become critical input terms in the construction of sediment transport models developed for future studies of mooring / foundation systems for tidal generators. Tide gauges were moored to the bottom and the long-term records were adjusted when necessary to reflect NOAA tide gauge datums. Deployment locations were chosen to fill gaps in the North-South transect established in earlier TDR deployments. East-West positions, relative to the channel, compliment other studies (Pocha TDR), and provide replication (Mutton Shoal TDR) of previous deployments.

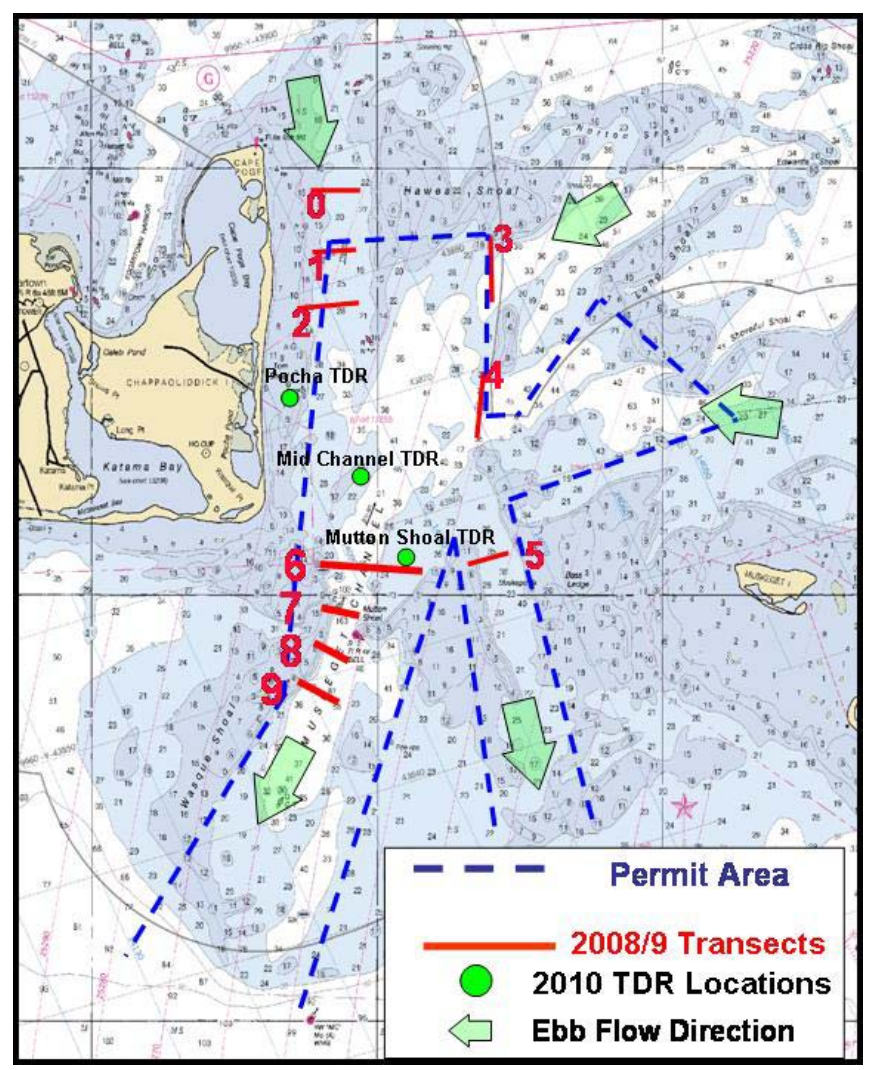

Figure 2 - Location of temperature-depth recorders (TDRs) to correct bathymetry surveying for changing tidal stage as the survey was being completed and further clarify lags in tide height across Muskeget Channel (north to south). 


\section{B. Ship Based Acoustic Doppler Current Profiling}

Cross-sectional profiles of currents and volumetric flow were measured along multiple transects throughout the Muskeget Channel study area using a ship mounted Acoustic Doppler Current Profiler (ADCP). Seven (7) survey transects were completed through both the ebbing and flooding portions of a tidal cycle (approximately 14 hours in duration) three days preceding a neap phase of the lunar cycle. The measurements were made to determine the flow velocities throughout the water column to allow determination of the depths and timing of maximum and minimum velocities (i.e. determine differences in velocity with depth over the tidal cycle) and provide a finer scale characterization of the currents in the high velocity zone of Muskeget Channel. The ADCP surveying undertaken in partial fulfillment of this grant builds upon previous current velocity measurements that were undertaken in 2008 and 2009 along three main transects referred to as Transect 6, Transect 7 and Transect 8 . In this effort, Transect 6,7 and 8 were resurveyed, however, additional transects ( 2 transects $\{6.1$ and 6.2$\}$ located between Transect 6 and 7 and 2 transects $\{7.1$ and 7.2$\}$ between Transect 7 and 8) were surveyed as well. The finer scale ADCP surveying data has been important for the Town of Edgartown, energy developers and the UMASS-MREC as a way of further screening the Town of Edgartown FERC permit area and refine the demarcation of areas of high energy generation potential for more optimal siting of future tidal turbine arrays. Current profiles were completed along transects situated strategically across Muskeget Channel (Figure 3), such that currents throughout the area could be measured in greater detail. The information was also collected to validate future hydrodynamic models related to the site.

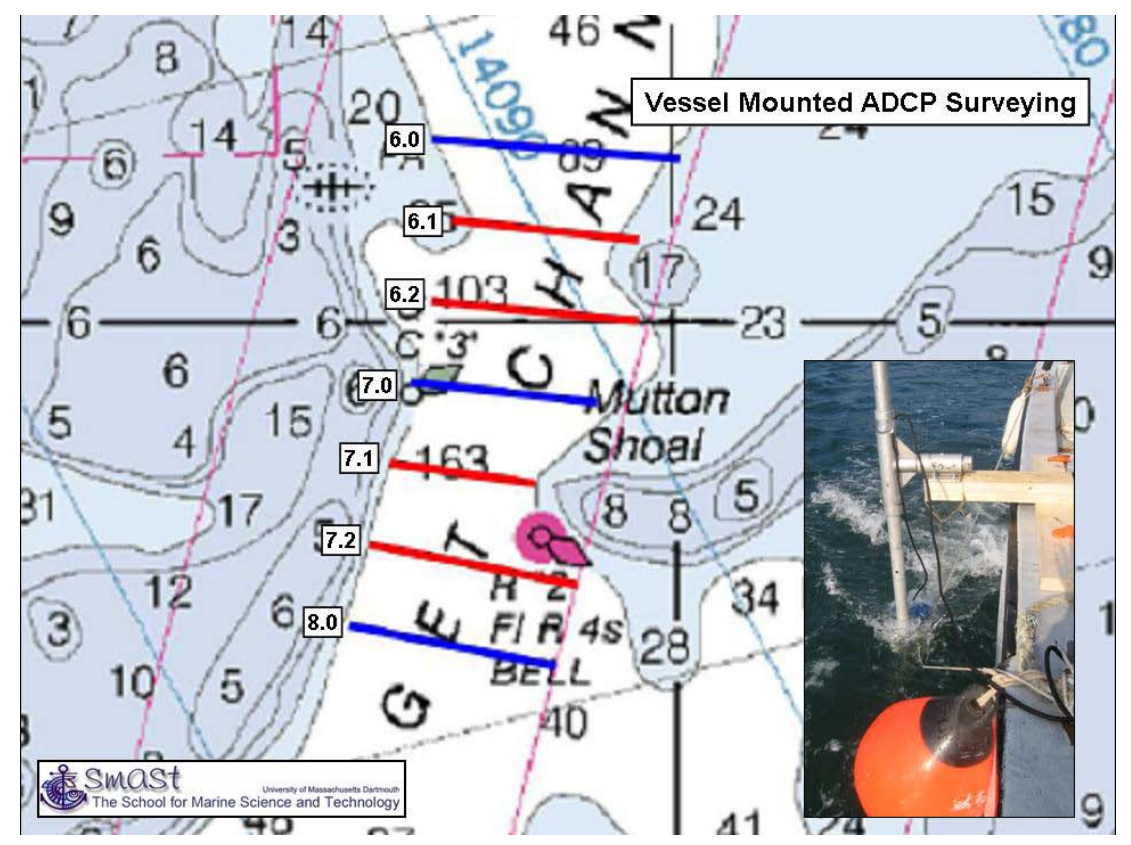

Figure 3 - Location of additional ship based ADCP surveying undertaken in the high velocity zone where the scouring and bio-fouling experiments were undertaken. 


\section{Bathymetric Survey in Region of Future Pilot Tidal Technology Deployment}

A detailed bathymetric survey was conducted to determine the bathymetry within the specific area of Muskeget Channel that showed the strongest current velocities for a future deployment of a tidal energy generating technology (Figure 4). Survey lines were run at approximately $50-100 \mathrm{~m}$ intervals with continuous recording of depth $(0.1 \mathrm{ft}$ ) and location (DGPS). A bathymetric map was produced as a project deliverable, for the purpose of supporting siting decisions. The data was corrected for the specific changes in tidal elevation occurring over each survey day using the Mutton Shoal TDR.

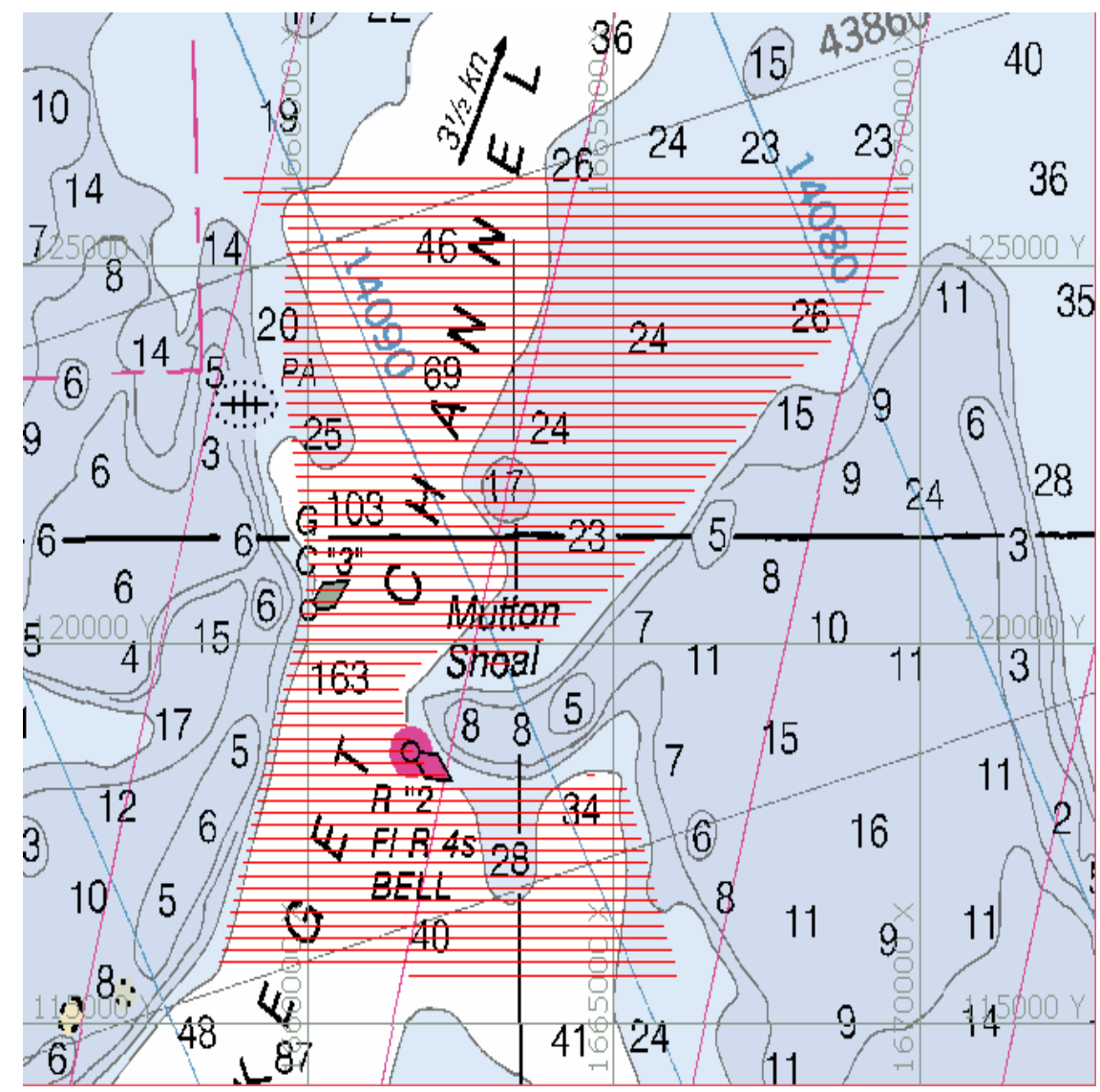

Figure 4. Additional bathymetric survey of the high velocity zone in Muskeget Channel completed in 2010. Bathymetric survey lines were spaced 50-100 meters apart to provide increased spatial coverage of the bottom contour.

\section{Long-term Current Recording using Bottom Mounted ADCP}

In conjunction with the ship based ADCP surveying mentioned above, a bottom mounted upward looking ADCP was deployed in a trawl resistant bottom mount (Figure 5) to capture near continuous current measurements through the entire water column at a single point strategically located between Transects 6 and 7 which showed the highest current velocities. The ADCP instrument was deployed for 
a complete lunar cycle ( $\sim 30$ days) to characterize variations in the velocity field as a function of changing phases of the moon while also serving as a validation of velocity measurements obtained during the ship board ADCP surveying undertaken along transects $(6.0,6.1,6.2,7.0,7.1,7.2,8.0)$ located through that high velocity zone. The overall objective of this deployment was to capture a detailed time series of current velocities which could be used to calculate the average, maximum and minimum current velocities on any given day of the month. In this manner, the full range of current velocities could be determined from maximum currents during spring tide conditions to minimum current velocities that occur under neap tide conditions as well as at lunar quadrature. Using the data collected during the entire lunar cycle, a better understanding was obtained regarding how the current intensity fluctuates over a month. This data will be available to future energy developers in order to make power generation predictions. Future work will address whether this data may be used to model velocities along Transects 6 and 7, thus providing the data required to estimate power generation for this zone of the channel.

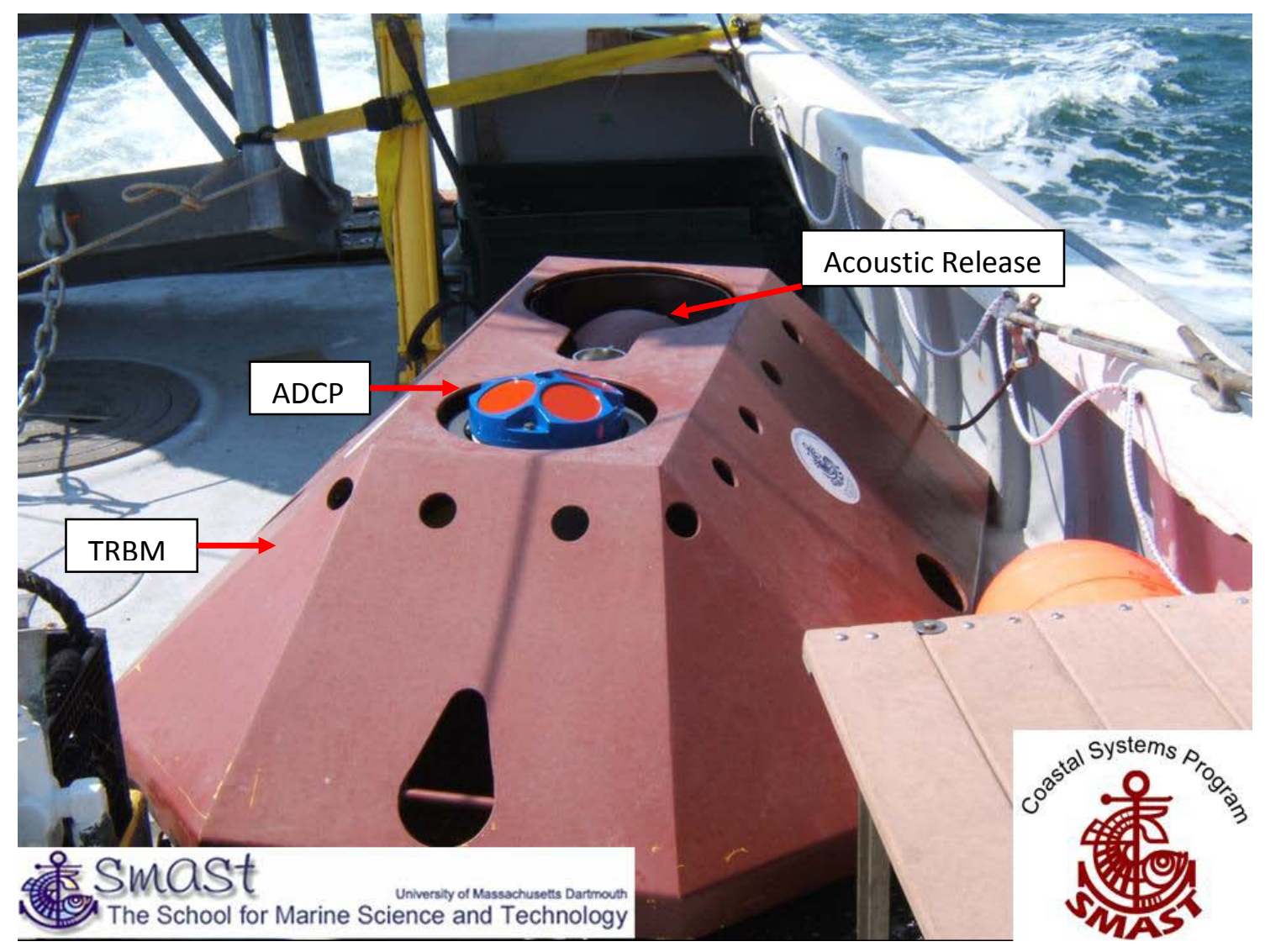

Figure 5 - Acoustic Doppler Current Profiler (ADCP) deployed in Muskeget Channel using a trawl resistant bottom mount (TRBM) with an acoustic release to aid in retrieval. 
E. Near Bottom Current Velocity Measurements utilizing Downward Looking Acoustic Velocity Meter for Documenting Scouring around a Mooring

Particularly in high velocity areas, the placement of hard structures on or into the bottom alters sediment transport potentially resulting in new scour and deposition zones. The alteration of sediment deposition and erosion plays an important role in the design of the renewable energy structures and the potential changes in local benthic habitat. The major habitat change results from either enhanced erosion (removal) or changing the sediment grain size distribution. In this grant, sediment transport alteration was investigated using a combination of sediment transport modeling (macro scale) and field manipulations (micro scale). The sediment transport modeling was undertaken by other technical team members from Woods Hole Oceanographic Institution and UMASS-SMAST while site specific field manipulations to measure near bottom current velocities and associated scour around a mooring structure was completed exclusively by scientists from UMASS-SMAST Coastal Systems Program.

The sediment alteration (scour) investigation was focused on the deployment of a large concrete cylinder as an analog for a portion of what would be a larger mooring system for a tidal turbine. The cylinder (aka. scouring block) was placed on the bottom of the high velocity zone in Muskeget Channel and the resulting changes in bottom morphology in the immediate vicinity of the scouring block was documented. Changes in sediment grain size were also documented over the course of the deployment through sediment sampling. For a one month period the scouring block was instrumented with two acoustic doppler current meters facing opposite directions to capture both the incoming flood and ebb tide velocity fields as well the velocity fields resulting from interaction with the cylinder. An AquaDopp (Nortek) and Workhorse Sentinel (RDI/Teledyne) ADCP were positioned on opposite sides of the cylinder and configured to make similar measures spatially and temporally. Both ADCP instruments were aligned in the downward position facing the sediment surface (Figure 6). Positioning the instruments in this configuration enabled the acquisition of current measurements on the up and down gradient sides of the scouring block. The collected current velocities were related to the observed scouring patterns associated with the ebb and flood tide conditions which generally are known to have differing current intensities (ebb tide generally having stronger current velocities then flood tide). 


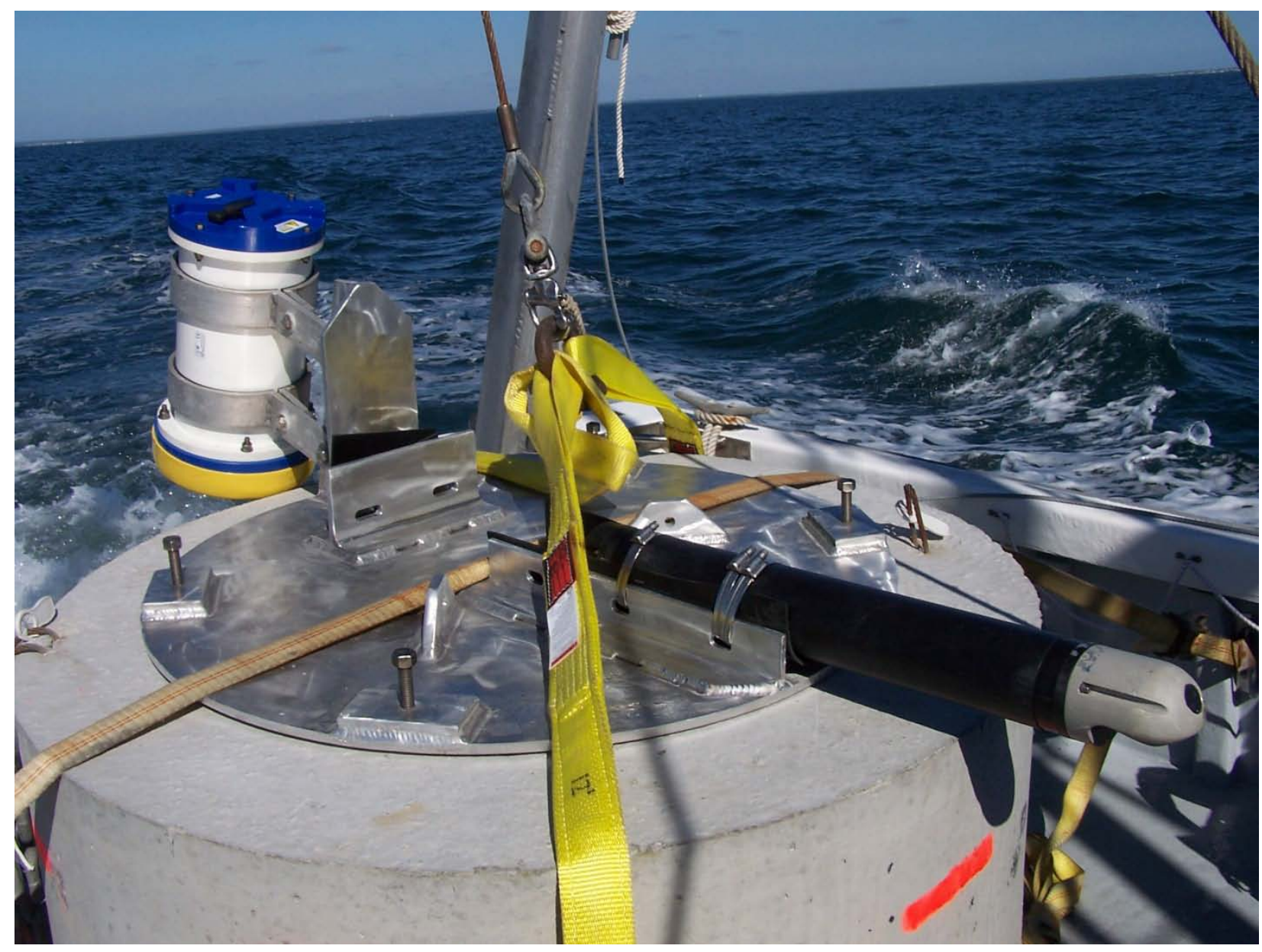

Figure 6 - Concrete cylinder (scouring block) instrumented with downward looking current meters to measure current velocity around the base (up-gradient and down-gradient) of the structure under both ebb and flood tide conditions.

The sediment alteration investigation was undertaken in the area of Muskeget Channel currently being considered for future pilot scale deployments of tidal current generating units under the existing Town of Edgartown Preliminary Permit issued by the Federal Energy Regulatory Commission (FERC). The data on sediment grain size and scour, coupled with the current velocity and bathymetry data from the site were used to parameterize and validate a sediment transport model developed by technical team members from the Woods hole Oceanographic institution. This data will also be used during future permitting in order to address issues related to potential scouring caused by mooring structures for tidal turbine arrays and potential effects on bottom communities. 


\subsection{Field Data Collection (BIOLOGICAL - Habitat Assessment)}

\section{F. Determining likely Fouling Communities Post-construction using Fouling Plates and determine}

\section{Associated Fouling Rates}

Tidal turbines provide hard structures for organisms to colonize, whether mooring blocks, cables or piles. For example, wind turbines on monopiles create a potentially "new" habitat for colonization of sessile marine organisms that may enhance or alter a water column dominated system. If sufficient hard bottom or exposed rock exists in the near-field of future tidal turbine arrays in the high velocity zone of Muskeget Channel, then "bio-fouling" recruitment may be viewed as enhancing environmental diversity and may increase recreational use of the waters for fishing as seen with oil platforms. If, on the other hand, the locale does not presently support these types of resulting communities, then an analysis of the likely communities to be introduced and their positive/negative effects on the marine system is warranted to address potential ecological impacts resulting from introducing hard structures to an area generally devoid of such features. To address these issues, estimates of the likely fouling communities to become established post-construction needs to be determined, as well as the types of these communities presently extant in the area.

In the present effort, CSP scientists deployed two sets of bio-fouling arrays to determine the likely fouling communities to develop post-construction using treated and un-treated fouling plates made of composite materials (Figure 7) similar to that utilized for building the OCGen tidal turbine developed by Ocean Renewable Power Company. The bio-fouling arrays were deployed in the high velocity zone of Muskeget Channel being considered for future tidal current energy generation. The bio-fouling arrays were anchored to moorings of a smaller scale then what would actually be used to anchor a full scale tidal turbine generating unit, however, the smaller scale moorings still served as an adequate analog for the type of hard structures that would be introduced in the deployment of a tidal turbine array for power generation.

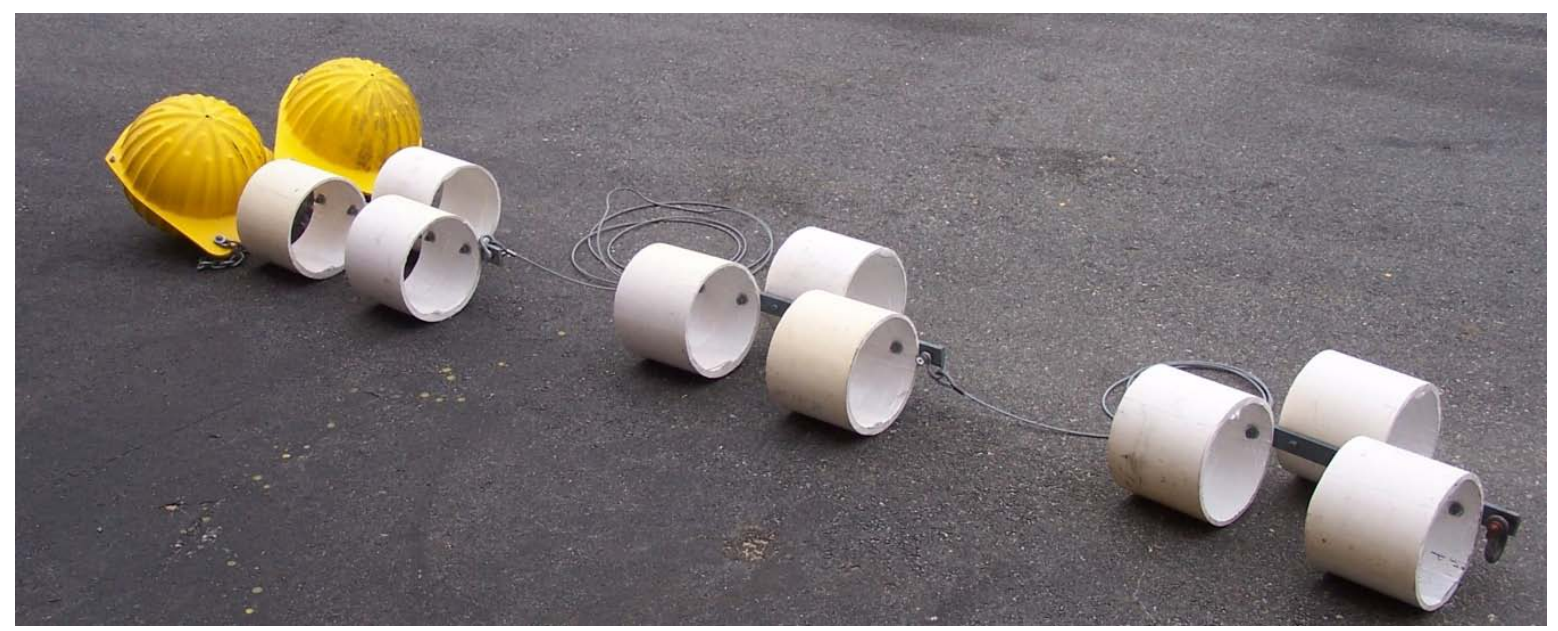

Figure 7 - Bio-fouling array (untreated) with three sets of fouling "plates" (surface, middle, bottom) arranged in triplicate for determining rate at which bio-fouling occurs on composite material utilized in the construction of a tidal turbine generating unit (ORPC OCGen Module). 
To assess post-construction fouling communities, two arrays of fouling plates were constructed by positioning pieces of composite material obtained from Harbor Technologies LLC at varying depths along a cable attached to bottom mooring and pulled taught by a combination of sub-surface floats (benthos balls) as well as surface expressions (high-flyers and hi-visibility low drag buoys). One array of fouling plates was comprised of composite material treated with a commonly used anti-fouling paint (West Marine Bottom Shield, 28\% Cuprous Oxide) while the second array was positioned approximately 250 meters away from the treated array and was comprised of bare composite material to act as a control experiment. The arrays were deployed specifically to determine the resulting animal and plant community that become established as well as the rate of fouling. The focus of the bio-fouling experiment was on determining what would become established, rather than the short-term evolution of the community. Treated and un-treated fouling plate units were deployed the proposed depth of the generators, near the sediment surface and at a mid depth. The mid depth sample corresponded approximately to the limit of the "photic zone" below the depth proposed for the generators which, given the characteristics of the tidal currents through the high velocity zone, would have to be deployed closer to the surface and middle portion of the water column and not close to the bottom. Each array was constructed with three units consisting of three fouling plates at each depth to allow for replication and time series "harvesting" to asses fouling rates.

\section{G. Survey area in the near field to the bio-fouling arrays in order to identify existing hard surface communities}

In conjunction with the deployment of the bio-fouling arrays, a one time diver survey of the near field area surrounding the mooring structures was undertaken to locate naturally occurring hard bottom communities. To assess the potential effect of fouling communities, the existence of natural "fouling" communities were surveyed. Hard bottom areas (rocks) were sought to determine the type of naturally occurring animal communities in the high velocity zone of Muskeget Channel, however, the areal extent of the diver surveying was limited by the depth of the area being surveyed ( 100'-120') and the short duration of the slack tide during which current velocity is low enough to allow the divers to swim the near field area surrounding the bio-fouling arrays.

\subsection{Field Data Collection (PHYSICAL - Geomorphology of Surficial Sediments)}

\section{$\underline{\text { H. Bedform Surveying of Near Field Area Surrounding Bio-Fouling Arrays in the High Velocity Zone of }}$ Muskeget Channel}

Initially, it was anticipated that an OceanServer Technology AUV equipped with an Imagenex 837B multibeam sonar, an Imagenex side scan sonar, and a Doppler Velocity Log (for underwater navigation between GPS fixes) would be available to complete high resolution bed-form surveying necessary to characterize small-scale roughness and bed-forms (likely due to small-scale sand ripples) responsible for bottom stresses. The plan was to use the AUV because it could be flown close to the sea bed, giving the sonar the ability to resolve centimeter size features, thereby yielding a clear picture of the bed roughness. The vehicle also could carry port and starboard side scan sonar that would provide additional 
information on roughness geometry. Despite a letter of commitment from the manufacturer, the CSP Technical Team was unable to obtain the AUV for a long enough period of time to complete the bedform surveying in Muskeget Channel. In preparation for AUV deployment in Muskeget Channel, portions of the AUV instrument payload were tested and preliminary missions were undertaken in several other systems, specifically Ashumet Pond, Mt. Hope Bay/Taunton River and the Westport River, however, none of those preliminary missions involved the side scan and multi-beam sonar packages. Therefore, in the interest of satisfying this specific element of the grant it was decided that traditional side scan sonar (Lowrance, LSS-1) would be utilized to complete a survey of the high velocity zone of Muskeget Channel where the scouring and bio-fouling investigations were completed along with the month long deployment of the bottom mounted ADCP. A detailed side scan sonar survey of this area was utilized to put the current measurements, both near bottom and in the water column, and observed scouring into the context of the bed-form across the area. These data will be made available to developers and MREC as planning proceeds for future deployment of tidal turbine arrays as well as the inclusion of this area of Muskeget Channel into the Northeast Renewable Energy Innovation Zone (NOREIZ) in the process of establishment. 


\subsection{Summary of Results}

Data discussed herein were collected primarily in the summer and fall of 2010 and 2011 as described in Section 2.0. It is important to note that these data build on previous data collection efforts undertaken to determine whether Muskeget Channel should even be considered as having sufficient hydrokinetic potential to make it worth developing for marine renewable energy production. Data collection under previous grants was primarily focused on baseline measurements of current velocities throughout the waters between Martha's Vineyard and Nantucket Island, generally referred to as Muskeget Channel. These current measurements were focused on trying to identify the different areas that had sufficient current velocities for tidal energy production. Under these previous baseline investigations, in total, five (5) specific areas were considered for preliminary ADCP surveying and single point current meter deployment. Under the previous characterization effort, nine transects were surveyed for current velocity and four deployments of an upward looking bottom mounted single point current meter were undertaken (Figure 8). Along with the current measurements, temperature/depth recorders (TDR) were deployed along the main longitudinal axis of the channel in order to reconcile tidal stage with current intensities as well as to determine if there were any time lags in tidal stage from north to south across the general area.

Based on these previous data collection activities (2008-2009), only one zone was deemed to exhibit strong enough currents for potential energy generation. The high velocity zone is essentially bounded by Transect 6 and Transect 8 as depicted in Figure 8 . Data collection activities under this grant were focused on the high current velocity zone of Muskeget Channel in the vicinity of Mutton Shoal where the channel narrows significantly as it passes between two relatively stable shoals to the east and west. The physical data collected under this grant enhances the characterization of currents in the high velocity zone and establishes a more refined picture of the physical forces driving sediment transport and potential scour resulting from the placement of structures on the seabed analogous (though scaled down) to future tidal turbine moorings. Biological data also collected begins to establish an ecological baseline for the high velocity zone which will have to be expanded through future investigations. 


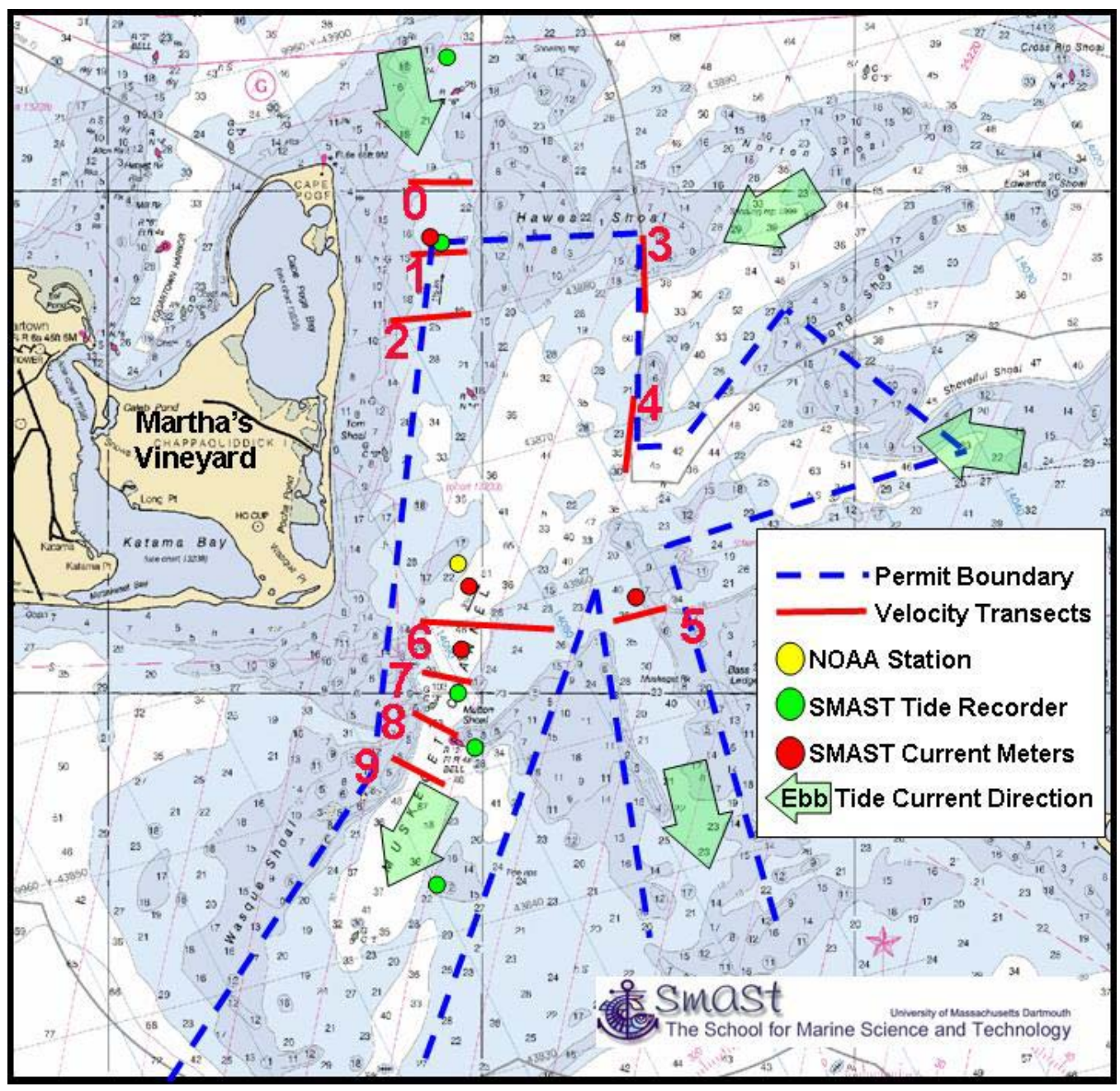

Figure 8 - Locations of previous data collection (2008-2009) aimed at determining the viability of the general area between Martha's Vineyard and Nantucket Island for hydrokinetic energy development. The Town of Edgartown FERC permit area (blue dashed line) served as a guide for initial baseline data collection. The zone presently being considered for tidal energy development is bounded by Transect 6 and Transect 8 adjacent Mutton Shoal.

\section{Field Data Collection (PHYSICAL - Hydrodynamic)}

\subsection{Tide Data Collection}

In support of the ship based ADCP surveying as well as the current velocity measurements made at a single point in the high velocity zone over a lunar cycle using a bottom mounted ADCP, measurement of tidal elevations were made at multiple (3) locations (Figure 9) within the main longitudinal axis of Muskeget Channel using temperature/depth recorders (TDR). These three deployments augment past 
TDR deployments undertaken by the SMAST-Coastal Systems Program which measured tidal stages across a broader area from north of Cape Pogue to south of Muskeget Channel in the vicinity of the navigational buoy (Green Can "1"). TDR deployments along the main N-S axis of Muskeget Channel from Toms Shoal to Mutton Shoal were conducted to further refine estimates of tidal delays in stage through the Town of Edgartown FERC permit area and to be able to relate measured velocities to variations in tidal stage. 


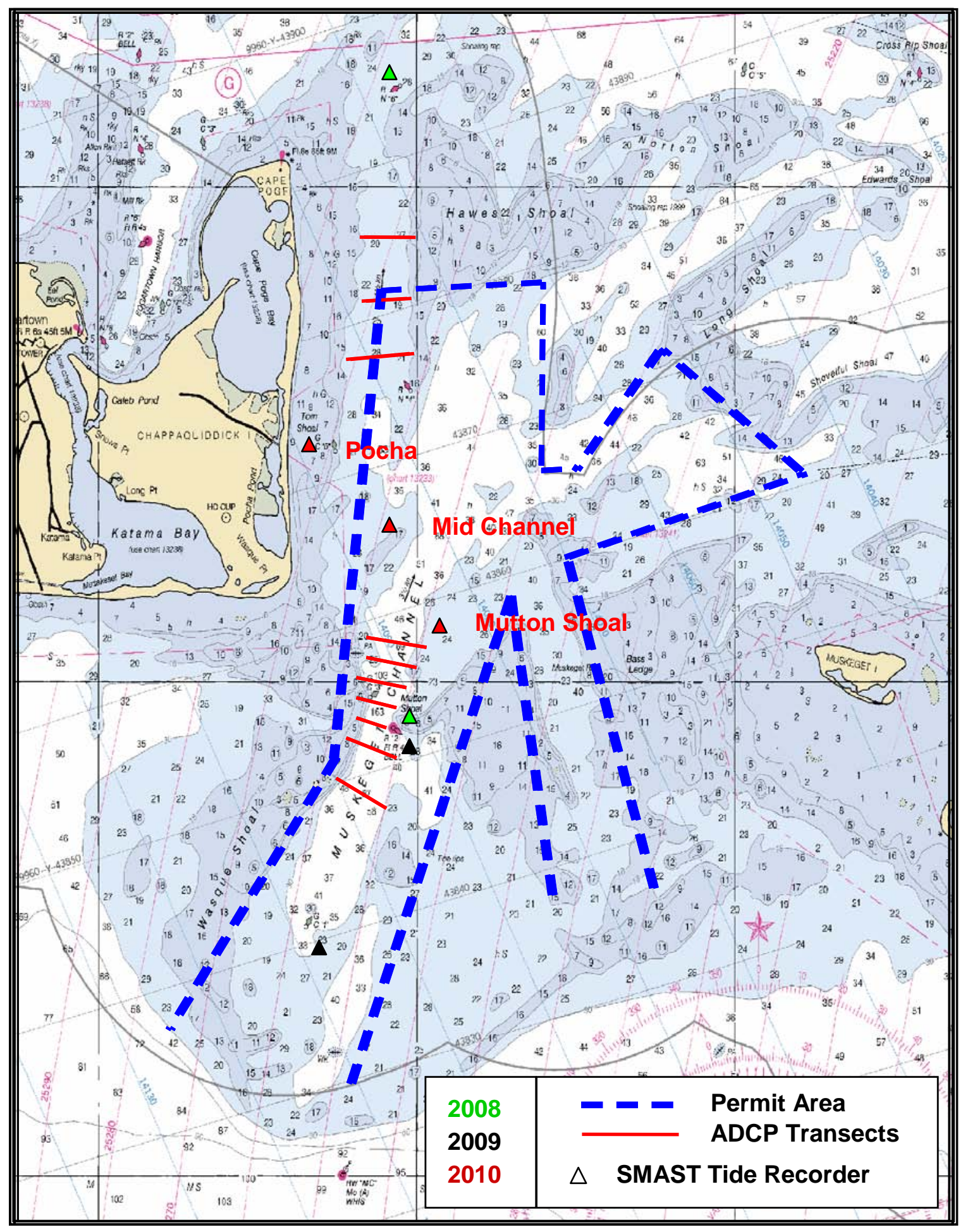

Figure 9- Location of three temperature/depth recorders (TDR) deployed in Muskeget Channel in 2010. 
Two of the three (Mutton Shoal TDR and Mid Channel TDR) TDR deployments covered two lunar cycles (August 8, 2010 to October 5, 2010) and were referenced to a common datum (MLLW) and related back to the NOAA tidal predictions at Cape Pogue. The third meter (Pocha) was able to be recovered before downgraded Hurricane Earl passed SSW of Cape cod. As the magnitude of tidal stage does not vary significantly from one month to the next, it was then possible to relate tidal stage to current velocity measured during the ADCP surveys completed on December 10, 2010. In addition, the tide elevation data was required to correct for changes in water depth that occur during the bathymetric data collection so as to generate an accurate bathymetric map of the region.

Deployments typically consisted of two meters deployed so as to identify differences in the timing of high and low tides between the northern and southern regions of the Channel. Additionally, the data was used to identify the timing of mid ebb and mid flood tide for comparison to the timing of maximum velocities along specific transects and at the single point selected for the long term deployment of the TRBM (Mutton Shoal TDR). In this manner it was possible to determine the period during a particular tidal cycle when maximum current velocity should occur.

Generally, the tide range measured at the northern tide gage deployment location (Pocha) was larger than the tide range measured at the southern deployment locations (Mid Channel and Mutton Shoal) and both the Mid Channel gauge and the Mutton Shoal gauge locations showed a relatively symmetrical tide. As the tides measured in this area are semi-diurnal tides, the tide gauges were also deployed to determine the degree to which the two tidal cycles, and by association the flow velocity, differed in magnitude. As depicted in Figures 10 - 12, it is clear that each location has a distinct high-high tide and a low-high tide each day. Similarly, all three gauge locations exhibit a low-low tide and a high-low tide each day, however, this low tide pattern is most pronounced for the tides measured in the Mid Channel and Mutton Shoal tide gauge locations. This is significant as tide range is generally the prime driver of current velocities through the Channel. Measuring velocities and tidal changes throughout Muskeget Channel was necessary to determine the proportion of any given day current velocities will be above the specific velocity threshold to drive power generation by today's technologies. 


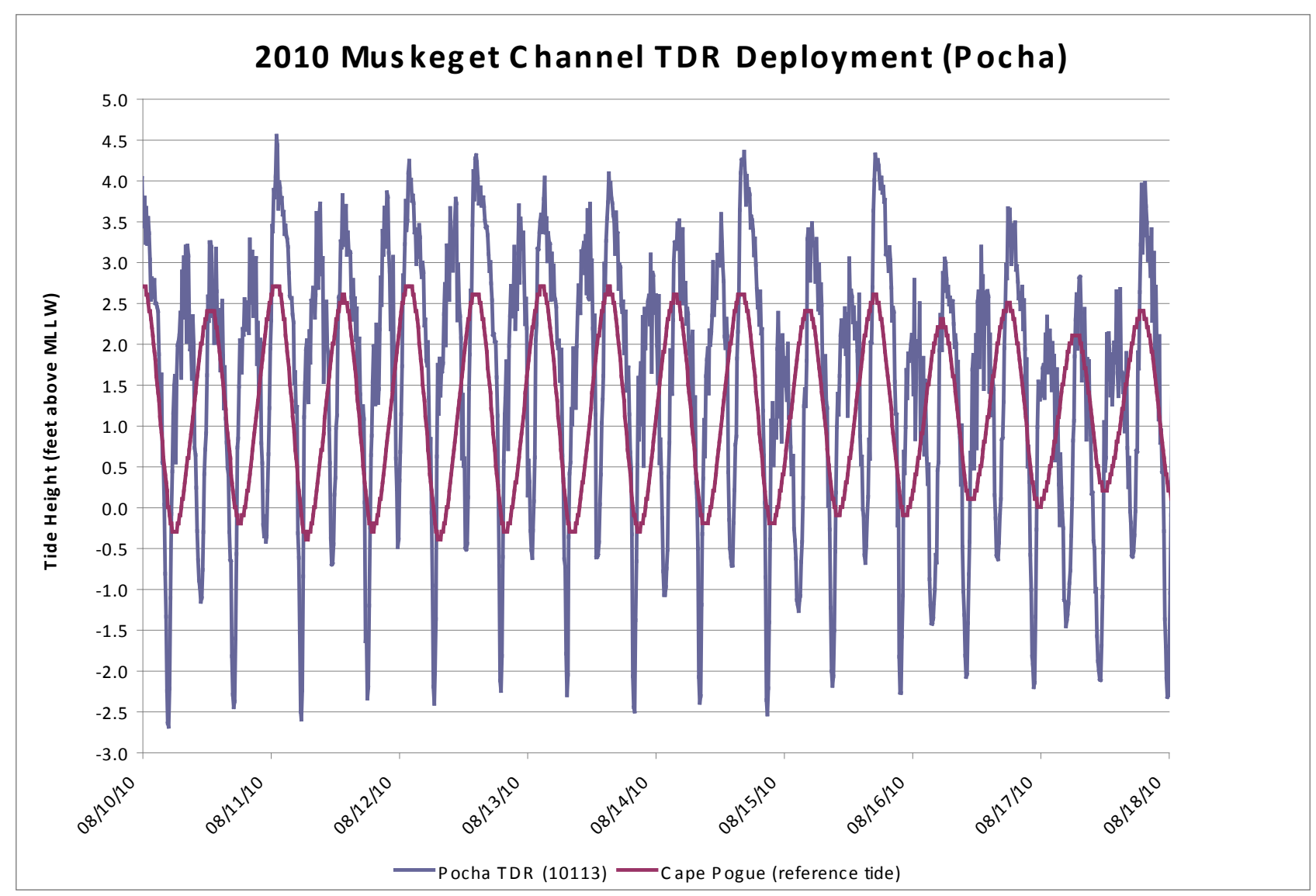

Figure 10 - Measured tide stage (feet) in the Tom Shoal portion of Muskeget Channel (north of the high current velocity zone of Muskeget Channel and adjacent the navigational aid C5. TDR data was adjusted for reference to MLLW and NOAA predicted tides at Cape Pogue. Deployment period August 8, 2010 to September 1, 2010. Data presented depicts one week of tidal stage. 


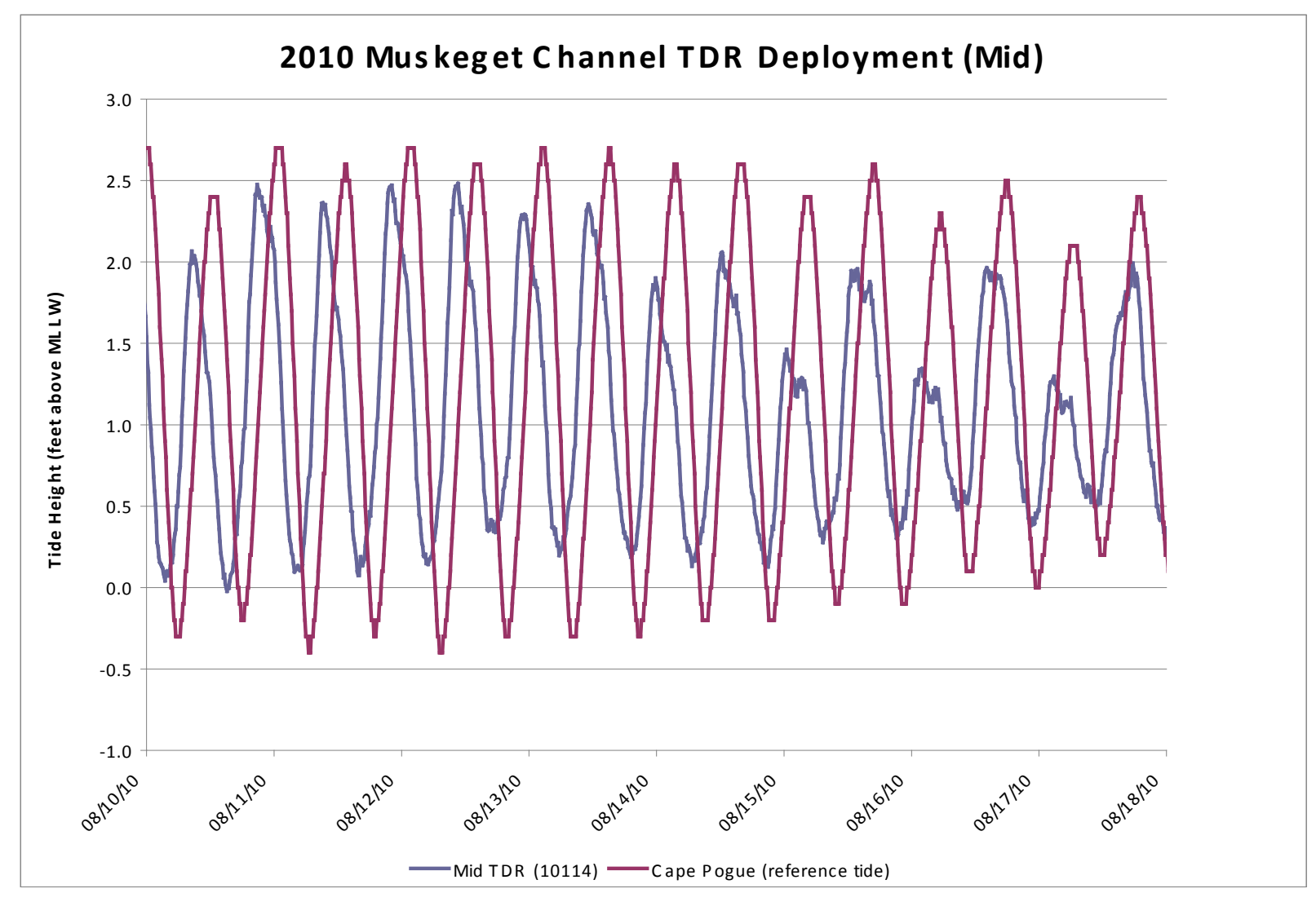

Figure 11 - Measured tide stage (feet) in the middle portion of Muskeget Channel (approximately midway between the high current velocity zone of Muskeget Channel and the navigation aid C5 adjacent to Tom Shoal. TDR data was adjusted for reference to MLLW and NOAA predicted tides at Cape Pogue. Deployment period August 8, 2010 to October 5, 2010. Data presented depicts one week of tidal stage. 


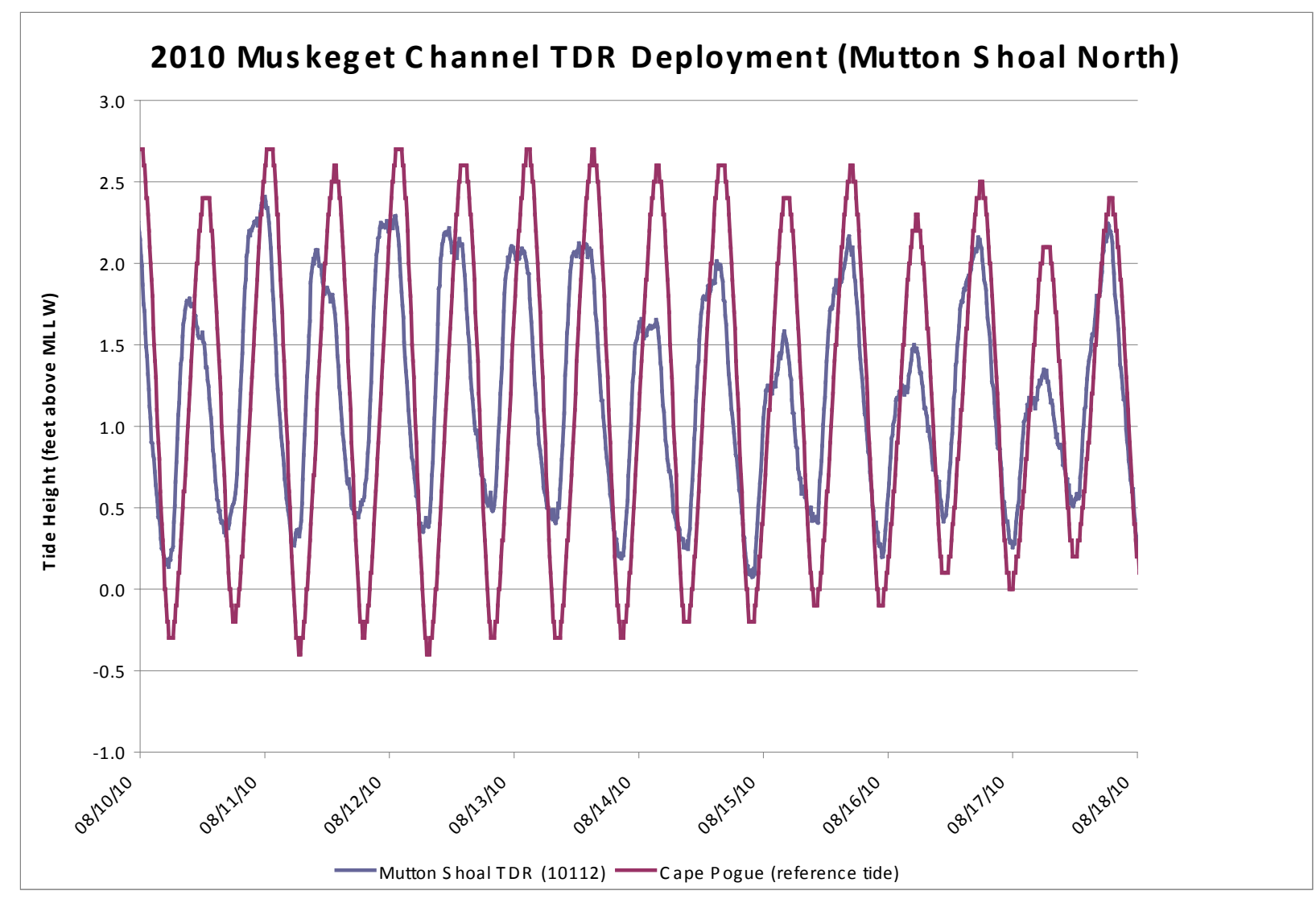

Figure 12 - Measured tide stage (feet) in the northern portion of the high velocity zone of Muskeget Channel in the vicinity of Transect 6 (blue line). TDR deployed on Mutton Shoal and adjusted for reference to MLLW and NOAA predicted tides at Cape Pogue. Deployment period August 8, 2010 to October 5, 2010. Data presented depicts one week of tidal stage.

Tidal data amplitude from the Pocha meter was much larger than from any other meter deployed since 2008. More significantly, there are large asymmetries in the data. Data from the SWATH survey and from single point current meters suggest that an eddy may exist in this region creating flows and tidal signals not typical for the region as a whole. Combining the remaining stage data a coherent picture emerges. The effect of intersecting tidal ellipses is to create significant tidal delays from Muskeget Channel north to the Pocha Light on Chappaquidick Island (Figure 13). By plotting linear distance versus time of high tide an estimate of 21 minutes tide delay per kilometer was determined. This delay in tides is the primary reason for high tidal velocities in the region of Muskeget Channel. A seen in Figure 14 when tidal stage height was higher at Cape Pogue flow was to the south and tidal velocities were highest when the height differential between Cape Pogue and Muskeget Channel was at a maximum. It appears that peak velocities within the channel proper are a result of flow constrained within the narrow channel. The third tidal ellipse that intersects this region may be responsible for the lack of 
exact registry between zero velocity and instances when the tidal elevations were the same at the two locations.

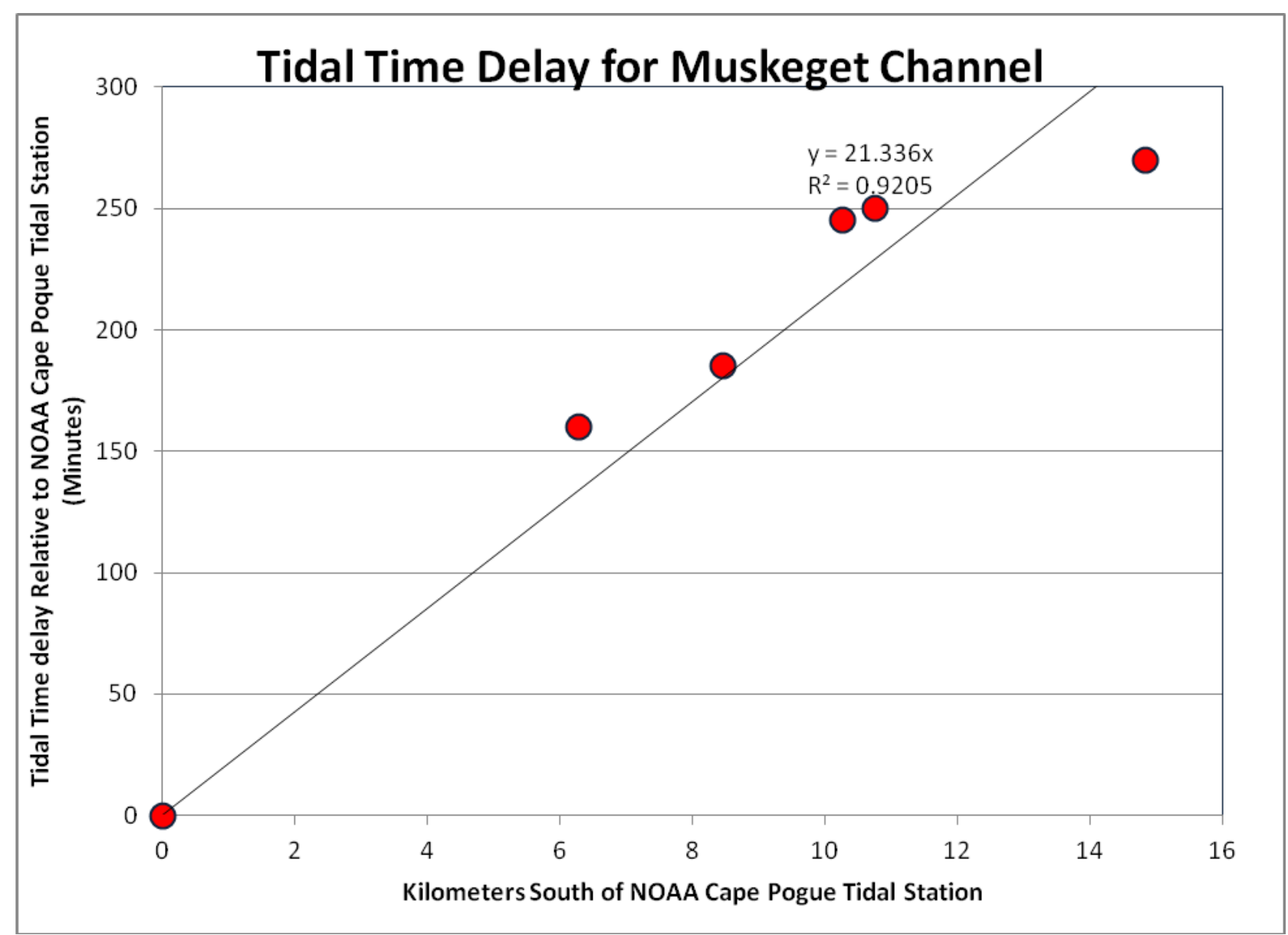

Figure 13. Plot of the times of high and low tides at 5 tide recorder locations south of Cape Pogue against the NOAA Cape Pogue tide station show a consistent pattern of tidal time delays throughout the study region. The tide station plotted $15 \mathrm{~km}$ south of Cape Pogue represents the TRBM deployed in 100 $\mathrm{ft}$ of water within the throat of the channel. 


\section{Barotropic Flow Regime}

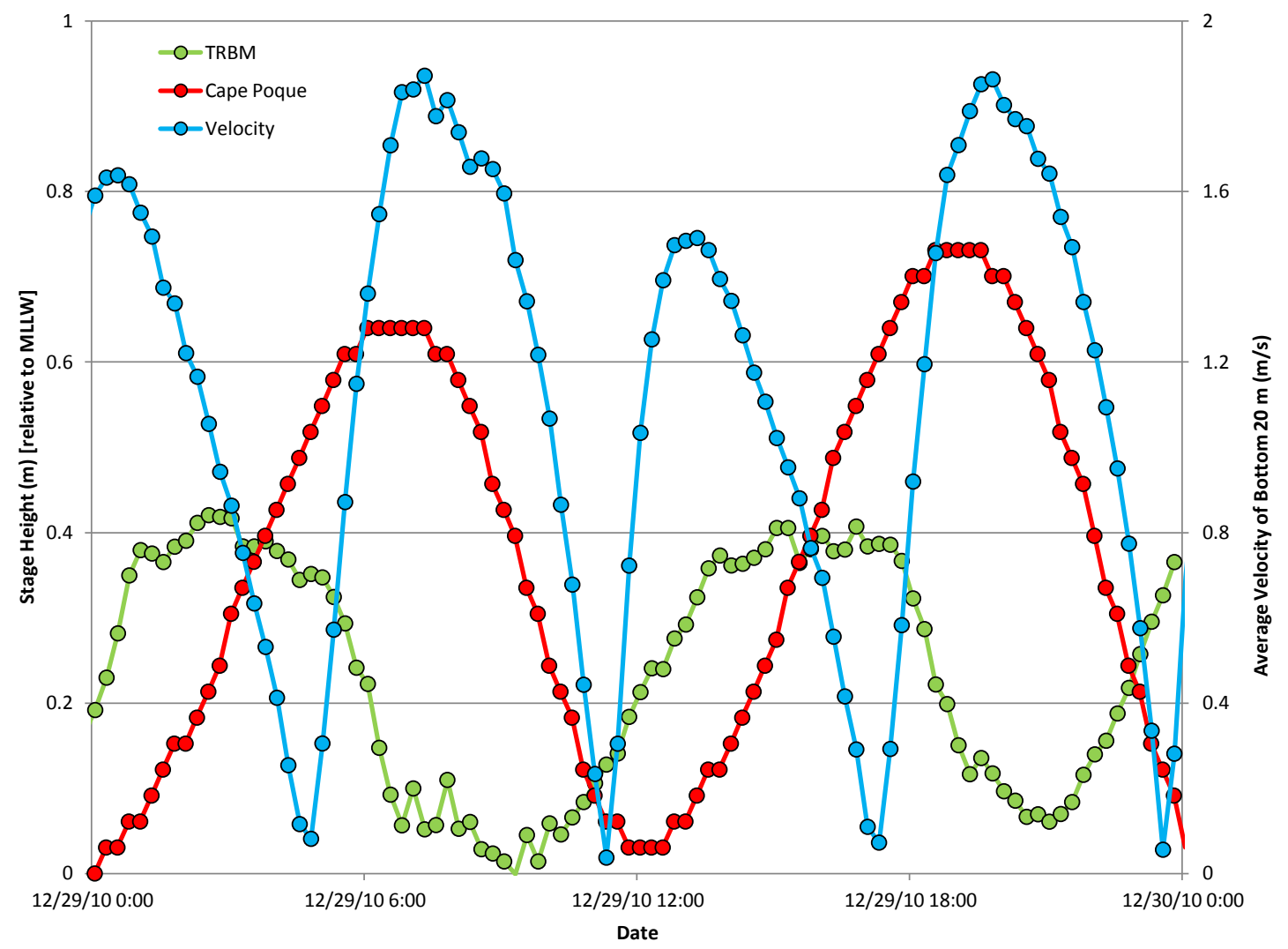

Figure 14. Plot of tidal stage measured at the TRBM (bottom-mounted ADCP between Transect 6 and Transect 7 deployed under this grant) and the NOAA Cape Pogue Tide station. Tidal delays are evident. Peak tidal velocities are coincident with maximum separation of the tidal elevations between the two stations.

\subsection{Ship Based Acoustic Doppler Current Profiling}

Hydrodynamic surveying in 2008 and 2009 along seven transects (T0, T1, T2, T6, T7, T8 and T9, see Figure 15) throughout critical portions of the Town of Edgartown FERC Permit Area revealed the most promising area for tidal in-stream power generation using existing technology to be the deep narrow part of the main Muskeget Channel. The high current velocity zone is an area of the channel situated along a north-south axis starting approximately at the northern end at the 50 foot depth contour and extending to a southern boundary south of Mutton Shoals also around the 50 foot depth contour. Acoustic Doppler Current Profiling (ADCP) in this area of highest tidal energy potential was previously completed along four transects (Transect 6.0, 7.0, 8.0, 9.0) over a 4.5 mile long area. ADCP surveying 
was completed during ebbing spring tide conditions in 2008 (T0, T1, T2, T6) and ebbing spring tide conditions in 2009 (T7, T8, T9) to determine if there was sufficient velocity in the area to make tidal power generation a viable undertaking in these waters. Surveying revealed that tidal currents were sufficient; however, it became clear that it would be necessary to characterize the velocity field under flooding spring tide conditions as well as under both ebbing and flooding neap tide conditions. Given the relatively large spacing between previously completed transects in the area and the need for deployment of a large number of tidal generating units, additional surveying along more closely spaced transects was undertaken to refine the characterization of the velocity field in that critical deployment area. In the context of the existing Town of Edgartown Preliminary Permit issued by the FERC, high resolution ADCP surveying at strategically spaced transects is critical to determining the number of tidal generating units that can be deployed in the area as well as positioning and subsequently, the economic viability of tidal energy generation in this area. Additionally, the high resolution characterization of the velocity field through the Muskeget Channel deployment area will be critical to: 1 ) the parameterization and validation of the sediment transport modeling for understanding how future turbine deployments could affect bed-form as well as 2 ) to address questions of potential near-field and far-field changes in current patterns.

Cross-sectional profiles of current flow in Muskeget Channel were obtained by measuring velocity along four new and previously un-surveyed transects $(6.1,6.2,7.1,7.2)$ as well as resurveying three previous transects $(6.0,7.0,8.0)$. Under this grant, ship based ADCP surveying was achieved along a total of 7 transects located in the high velocity zone of the channel. The transects surveyed were spaced approximately 500 meters apart to provide a high resolution characterization of the velocity field through this critical area of Muskeget Channel (Figures 16). Current profiling was completed through ebb and flood cycles under nearly neap conditions relative to the phase of the lunar cycle for the month of December 2010. The current measurements were made three days prior to true neap tide conditions due to weather considerations. Neap tide occurred on December 13, 2010 and the ADCP surveying was conducted on December 10, 2010. As such, measured currents were relatively close to the minimum current velocities to be encountered by future energy developers at the Muskeget Channel site. Through these measurements it was possible to determine the flow velocities throughout the water column as well as the depths of maximum and minimum velocities and the longitudinal variation in the velocity field along a specific transect. All seven transects were surveyed over a complete tidal cycle ( 14 hours) and complement surveying undertaken in 2008 and 2009.

\section{Previous results from 2008-2009 surveys}

- Velocity was generally higher on ebb versus flood tide by 10\%-20\%.

- Current velocities within the narrow, high velocity zone of Muskeget Channel were strongest along Transects 6 and 7. The area defined by these transects show the greatest potential for supporting a tidal energy project and tidal turbine arrays should be positioned appropriately to maximize the number of units that can be effectively deployed in that area. 
- The velocity field at Transect 8 showed a significant decline relative to Transects 7. Although maximum velocities approached 3 knots, these lower velocities are generally insufficient to meet the criteria for tidal power generation with existing technologies (nominally $\sim 4$ knots for capital return).

- The highest velocities within the survey area were observed along Transect 6 within the southern region of Muskeget Channel, just north of Mutton Shoal. This region differs from the other regions of the FERC permit area as the Channel becomes narrower and more defined with deeper water. As a result, the characteristics of the flow field are noticeably different than the more northern Transects 0,1 and 2 that exhibit general uniformity in the velocities ranging from 1-2 knots. Transect 6 shows clear variations in cross-channel velocities as well as vertical changes in flow with depth. Maximum spring tide current velocities ranged from 0.8 to $2.00 \mathrm{~m} / \mathrm{s}$ (1.55 knots -3.88 knots) with the highest velocities generally within the surface $\sim 40$ feet of the water column on both the ebb and flood tides.

- Just south of Transect 6, Transect 7 is located close to the narrowest part of the main channel. Transect 7 also shows relatively strong currents with maximum ebb tide currents exceeding 4 knots and approaching 5 knots. Similarly, maximum flood tide velocities approached 4 knots, however, these flood tide velocities were clearly lower than ebb tide velocities. Ebb tide currents across Transect 7 appear to flow relatively consistently from the northeast to the southwest and on the flood tide more south to north. Similar to results from surveying along Transect 6, the current velocities along Transect 7 also show clear variation with depth with the stronger tidal currents being generally within the surface 40 to 60 feet of water.

- Transect 8, located south of transects 6 and 7, is below the narrowest reach of Muskeget Channel. It clearly supports weaker tidal currents than along Transects 6 or 7 , with maximum flood tide currents exceeding 3 knots and approaching 4 knots but generally below 3 knots, while maximum ebb tide velocities approached 4 knots $^{1}$. Based on all other surveys, it is likely that ebb tide velocities are slightly weaker than flood tide velocities on this transect. Similar to flow directions along Transect 7, ebb tide currents across Transect 8 move consistently from the northeast to the southwest, while flood waters move more south to north. As observed along Transect 6 and Transect 7, current velocities decrease with depth with the strongest velocities being within the surface $\sim 40$ feet of water.

\footnotetext{
${ }^{1}$ The ebb tide survey was shortened by deteriorating weather and increasing sea state.
} 


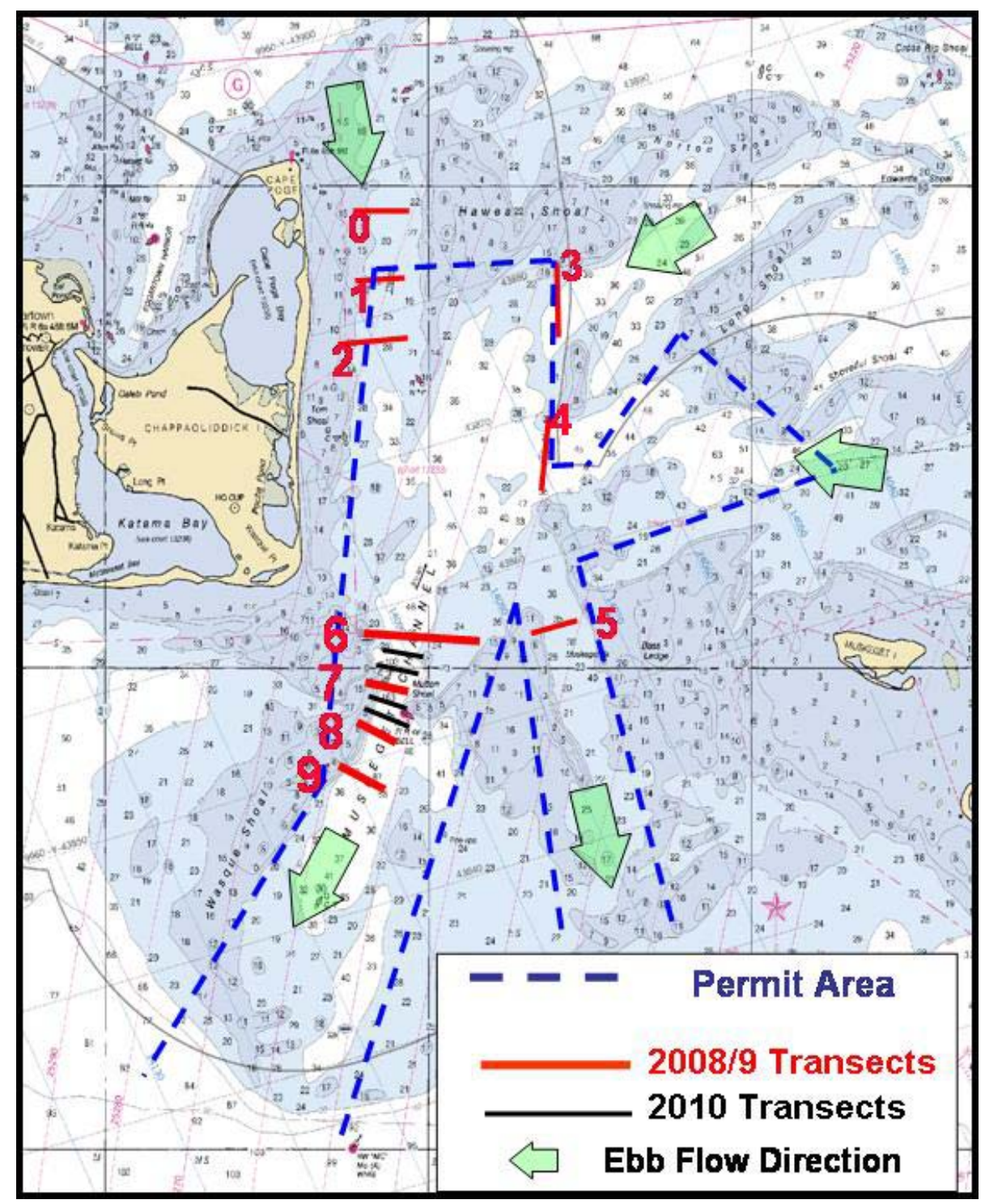

Figure 15 - Location of previously surveyed transects (red) as well as new transects surveyed under this grant (black). It should be noted that three transects $(6,7,8)$ initially surveyed in $2008 / 2009$ were also surveyed in 2010. 


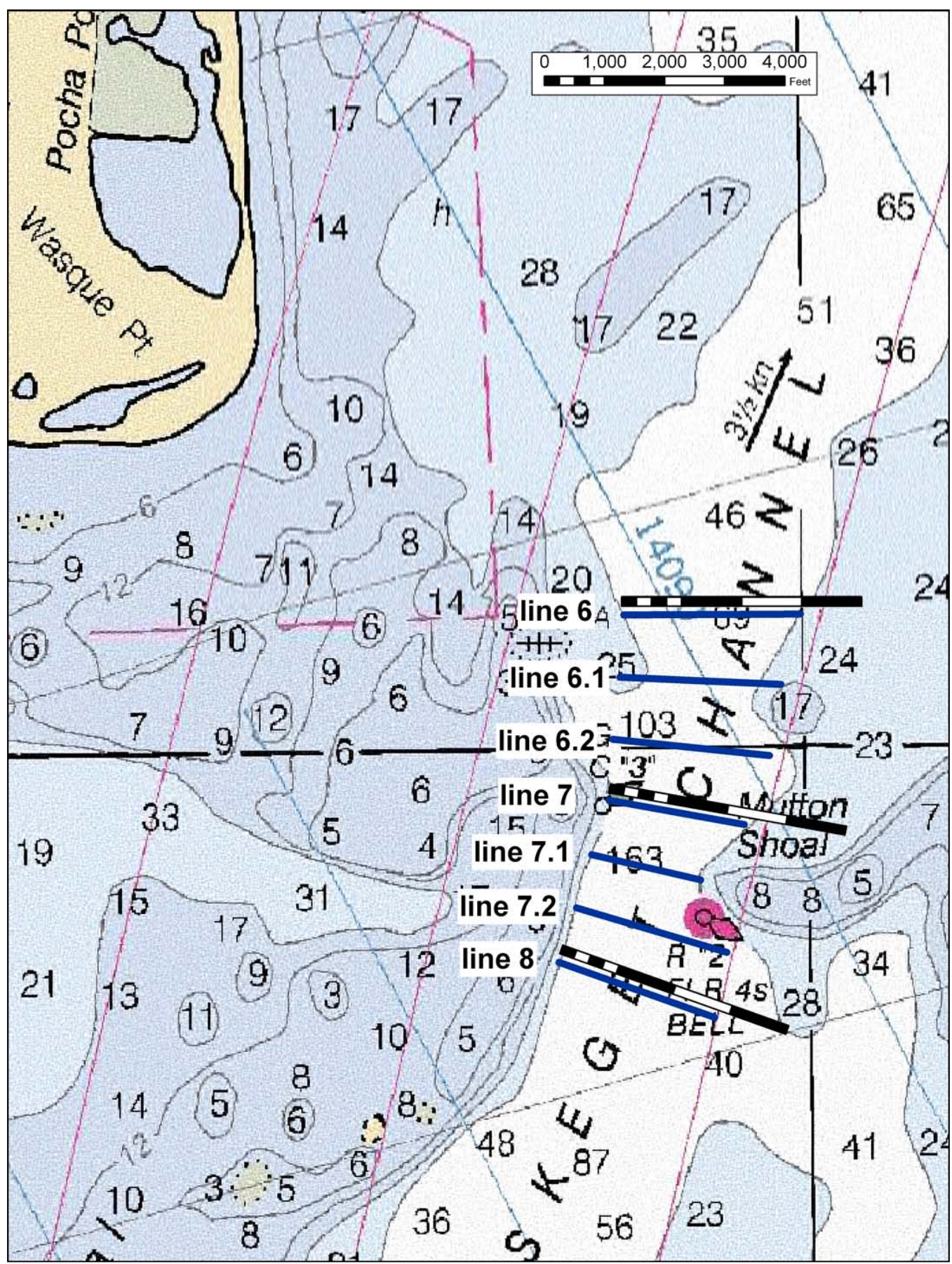

Figure 16 - Location of additional ship based ADCP surveying undertaken in the high velocity zone where the scouring and bio-fouling experiments were undertaken. 


\section{Ship based ADCP Transect Survey Results 2011 (3 days preceding NEAP Tide)}

Transect 6.0: As observed before in 2008-2009 current directions trend north to south during ebb tide and more generally south to north during flood tide. Average maximum water column velocity was 3.25 and 3 knots for ebb and flood tide, respectively. The zone of highest velocity narrowed during flood tides, although the location of highest velocity along the transect was essentially the same. The duration of highest velocity were the same for both the ebb and flood tide spanning at least two monitoring cycles (Figures 17-20).

Transect 6.1: Current direction showed skewing that conformed to the orientation of the channel generally displaying northeast to southwest direction except in the most western portion of the channel where shoaling diverts flow to the southwest during ebb tide. Flood tide direction was south to north. Highest average water column velocities for Muskeget Channel were observed, 3.5 knots on ebb tide and 3 knots on flood tide. The high velocity zone was similarly positioned along the transect during ebb and flood, however unlike the ebb tide the flood tide channeled significant amount of water onto the shoals. Average water column velocities exceeding 3 knots persisted through two monitoring cycles during the ebb tide, slightly less than two on the flood tide (Figures 21-24).

Transect 6.2: Current direction conformed to the orientation of the channel generally displaying northeast to southwest direction during ebb tide, except on the channel margins where constriction of flow produced by the adjacent shoals results in currents directed to the center of the channel. In contrast current direction while generally south to north during the flood tide diverged at the margins. Peak average water column velocities were 3 knots on ebb tide and 2 knots on flood tide. The high velocity zone was similarly positioned along the transect during ebb and flood; however flood tides did not display discrete high velocity zones. Average water column velocities exceeding 3 knots persisted through two monitoring cycles during the ebb tide, slightly less than two on the flood tide (Figures 2528).

Transect 7.0: Current direction was essentially along a north-south axis across the entire transect during both ebb and flood tide. Peak average water column velocities were 3.5 knots on ebb tide and 2.75 knots on flood tide. The high velocity zone shifted to the east during flood tide relative to ebb tide and became very diffuse with no defined high velocity zone. Average water column velocities exceeding 3 knots persisted through two monitoring cycles during the ebb tide, slightly less than two on the flood tide (Figures 29-32).

Transect 7.1: Current direction was generally along a north south axis during both ebb and flood tides. The channel begins to widen at this transect and become symmetrical. Peak average water column velocities decrease slightly to 3.25 and 2.25 knots on the ebb and flood tides, respectively. The high velocity zone shifted slightly east on the flood tide compared to the ebb tide, but the flood velocity was fairly uniform across most of the transect. Time scales of peak velocity were similar to those seen at Transect 7 (Figures 33-36).

Transect 7.2: Current direction followed a north south axis during ebb and flood tides. The channel continues to widen, but significant shoaling on the east side of the transect created asymmetries in the 
location of the peak velocity zone which was centered in the transect during ebb tide and was pushed eastward during flood tide. Peak average water column velocities continued to decrease; 3.0 knots was observed on the ebb and 2 knots was observed on the flood. Time scales of peak velocity remained unchanged from Transect 7.1 with two monitoring cycles at peak velocities (Figures 37-40).

Transect 8.0: Current direction was essentially along a north-south axis across the entire transect during both ebb and flood tide except in the shallowest regions on the eastern end of the transect during ebb tide. Peak average water column velocities were 3.0 knots on ebb tide and 2.0 knots on flood tide. The high velocity zone shifted to the east during flood tide relative to ebb tide and became very diffuse with no defined high velocity zone. Average peak water column velocities persisted through two monitoring cycles during the ebb and flood tides (Figures 41-44).

The high resolution tidal velocity survey confirmed many of the results of the 2008-2009 survey. The area bounded by Transect 6 and Transect 8 represent the area of highest sustained velocities. The current work narrows that zone slightly to include only that area bounded by Transect 6.1-7.2. Unlike the 2008-2009 work which was conducted at peak Spring tide, the current work was conducted near neap tide conditions and as a result showed lower velocities approximately 20-30\% lower. While Flood tides did not display obvious zones of higher velocity, highest velocities along the transects were usually coincident with the well defined ebb tide high velocity zone. Furthermore, although the tide direction was noticeably different between the transects, there did not appear to be significant differences between ebb and flood tide direction. Together these results suggest that turbines could capture the maximum current energy available regardless of the tide direction. 

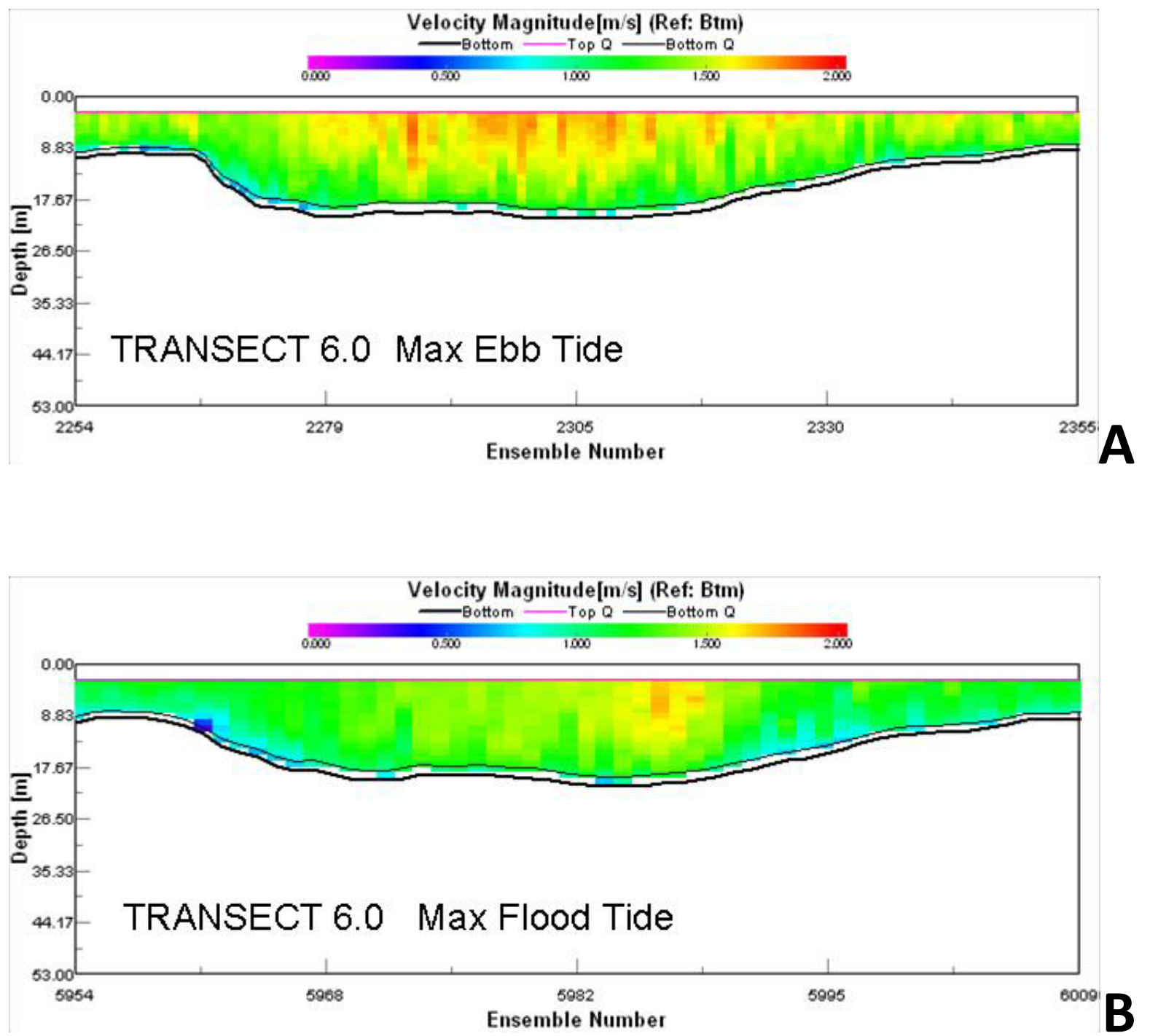

Figure 17-Current/Depth profile along Transect 6. Maximum ebb tide (Cycle 5) is displayed in panel A; maximum flood tide (cycle 10) is displayed in panel B. Scale is in $\mathrm{m} / \mathrm{s}$. The west end of the transect is on the left and the east end of the transect is on the right. 


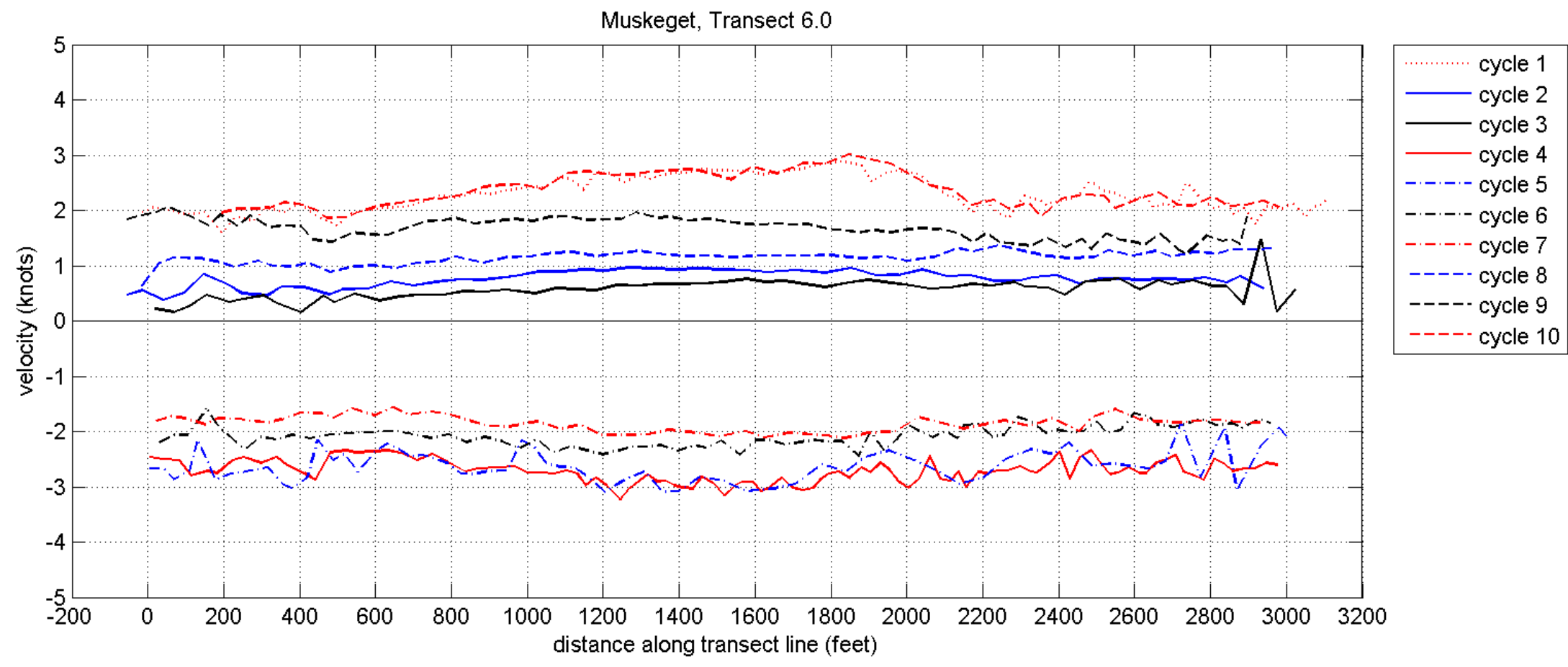

Figure 18 -- Plot of depth averaged (top to bottom of water column) along-channel (i.e., perpendicular to ADCP transect line) velocities measured using the ADCP at Transect 6 of the 2011 Muskeget Channel survey. Each line represents velocity measurements recorded during the indicated survey cycle (as shown by the numbers at the start and end of each line). Positive velocities indicate flood currents directed to the north, into Nantucket Sound. 

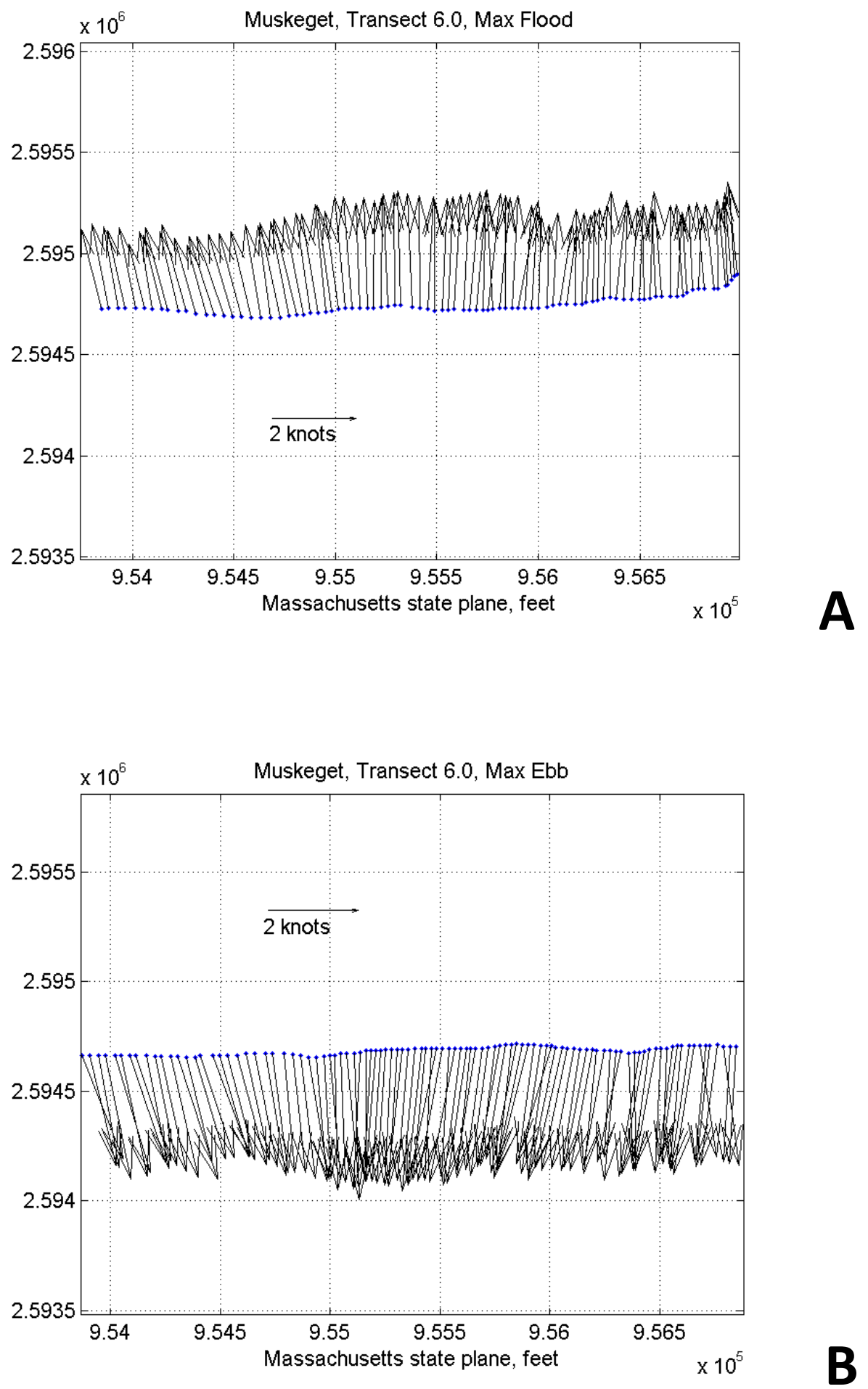

Figure 19-- Vector plot of depth averaged ADCP measurements for Transect 6 of the December 2011 survey of Muskeget Channel. A). Maximum flood velocities from survey Cycle 10 and B). Maximum ebb velocities from survey Cycle 5. Vectors indicate magnitude of the measurement by their length, and also direction, relative to true north. A two knot scale vector is shown for reference. 


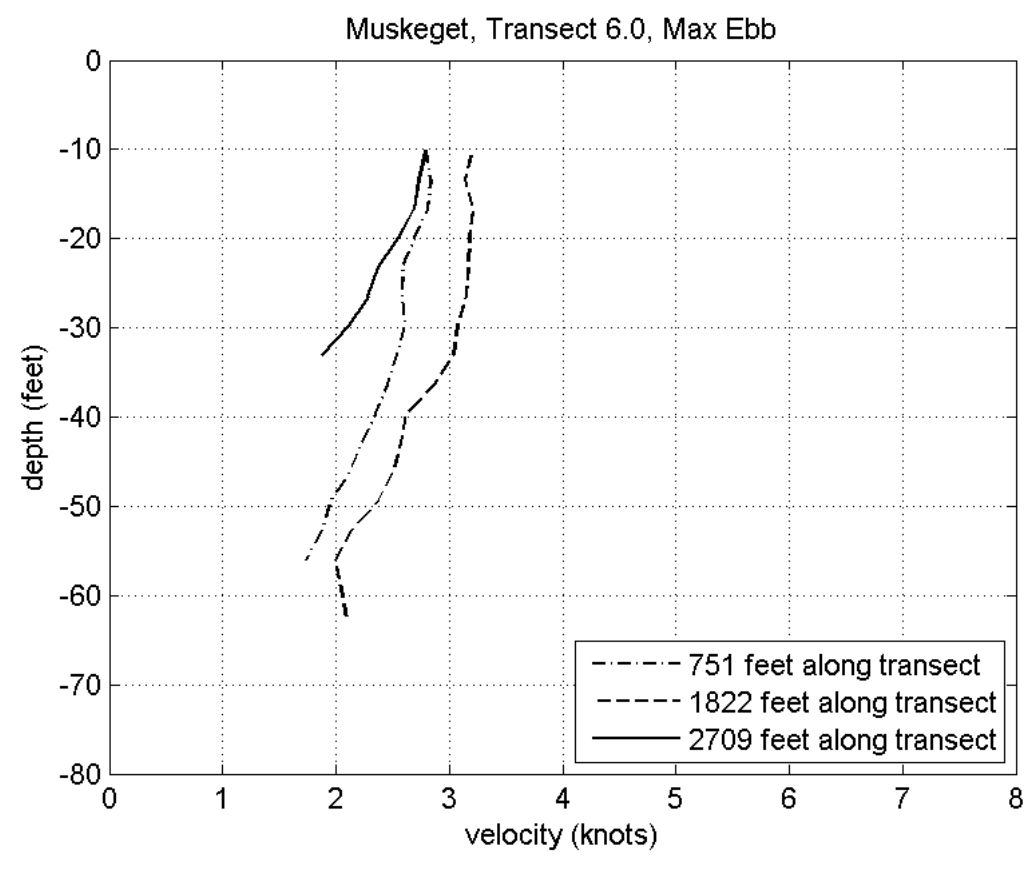

A

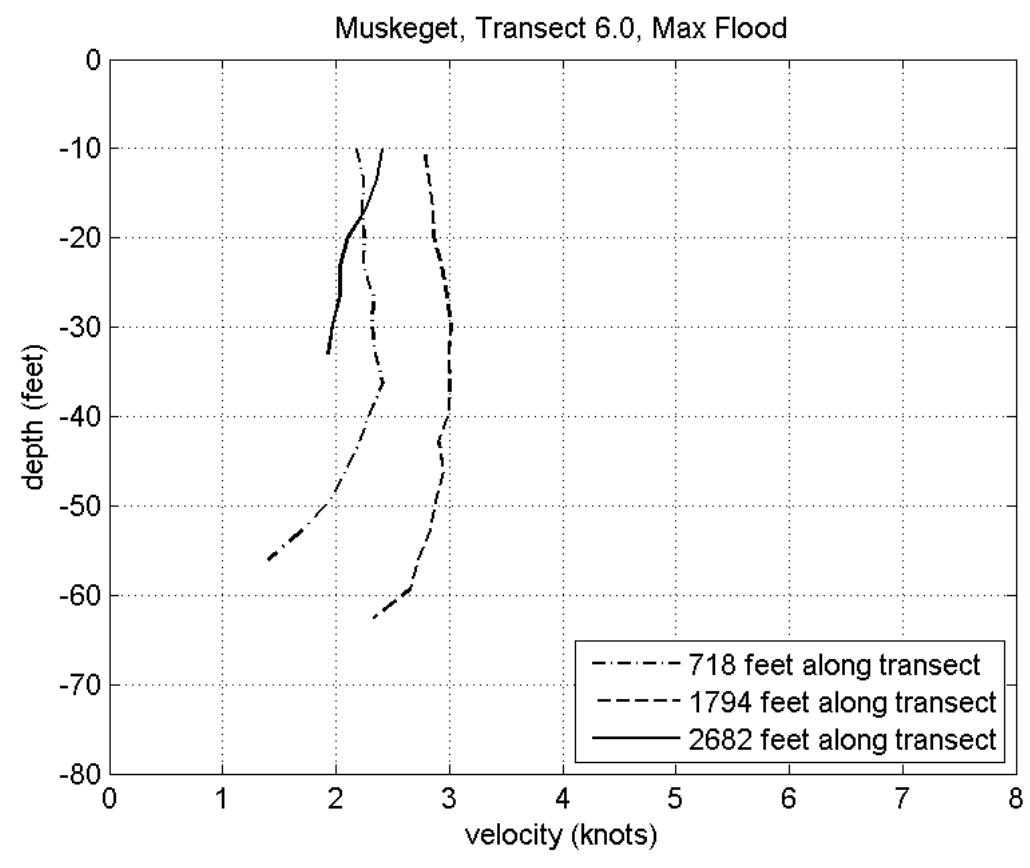

B

Figure 20-- Velocity magnitude (N+E) profiles measured along Transect 6 of the 2011 survey A). during Cycle 5 (max ebb) and B). during Cycle 10 (max flood). Profiles are shown for individual ensembles measured along the transect line. 

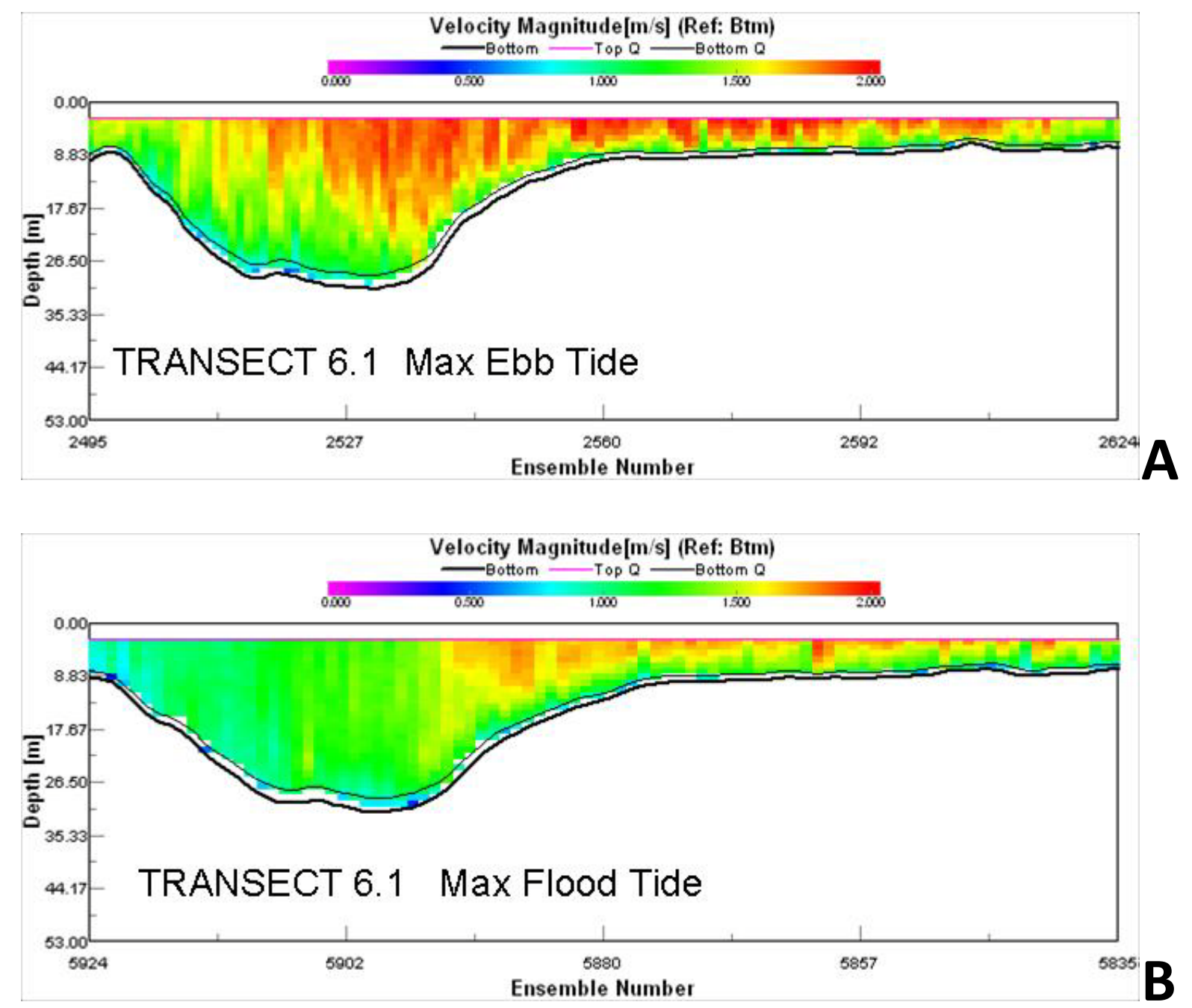

Figure 21-- Current/Depth profile along Transect 6.1. Maximum ebb tide (Cycle 5) is displayed in panel A; maximum flood tide (cycle 10) is displayed in panel B. Scale is in $\mathrm{m} / \mathrm{s}$. The west end of the transect is on the left and the east end of the transect is on the right. 


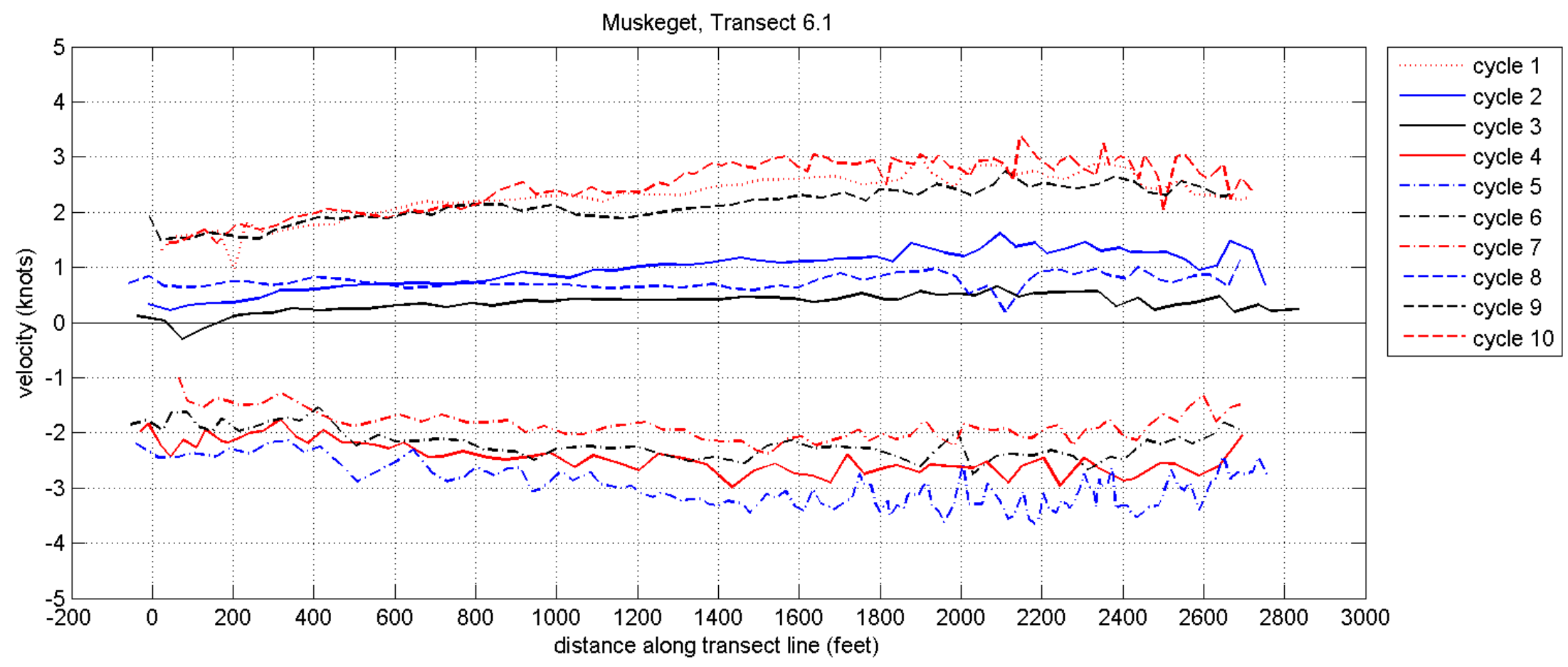

Figure 22-- Plot of depth averaged (top to bottom of water column) along-channel (i.e., perpendicular to ADCP transect line) velocities measured using the ADCP at Transect 6.1 of the 2011 Muskeget Channel survey. Each line represents velocity measurements recorded during the indicated survey cycle (as shown by the numbers at the start and end of each line). Positive velocities indicate flood currents directed to the north, into Nantucket Sound. 

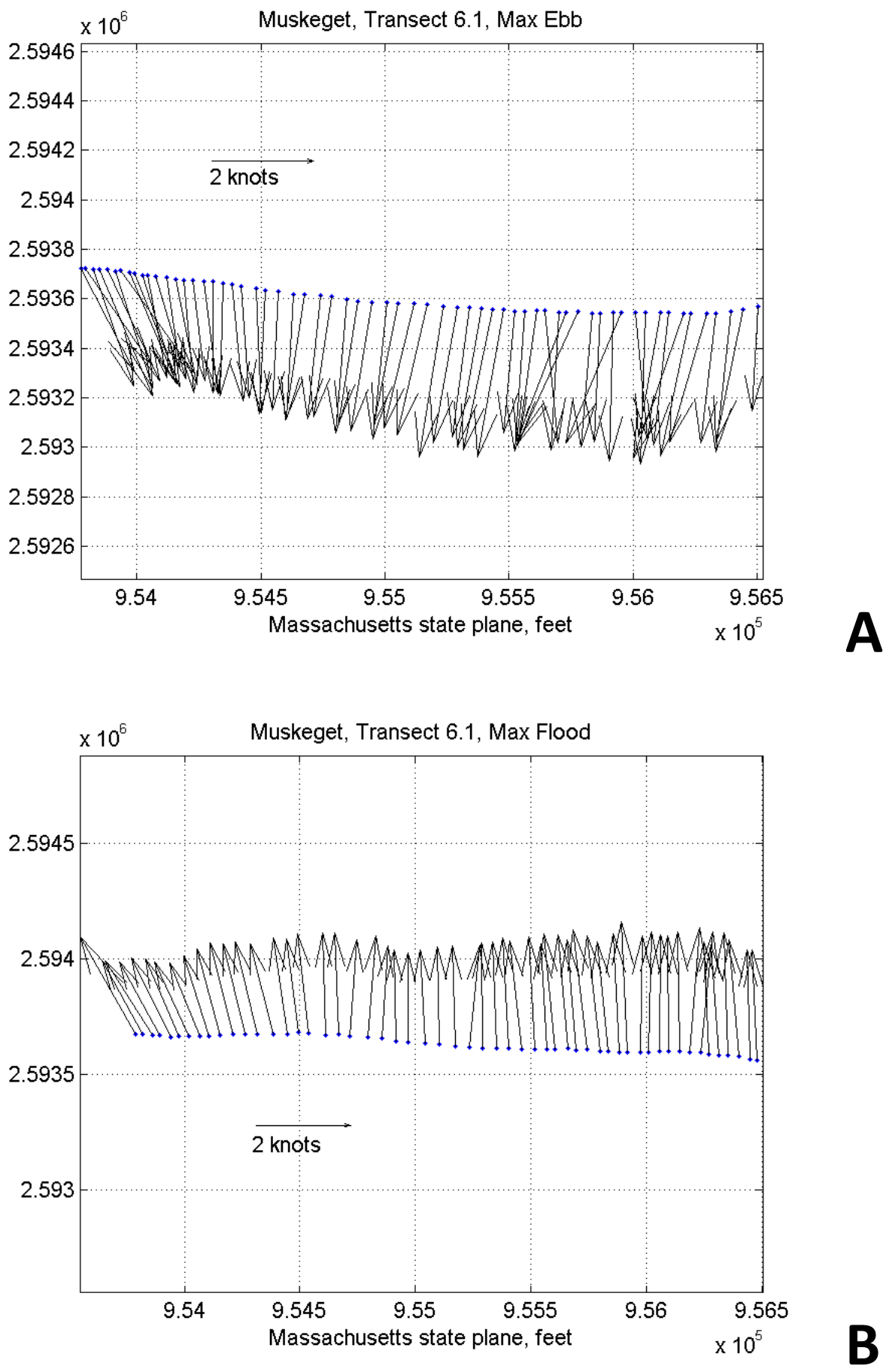

Figure 23-- Vector plot of depth averaged ADCP measurements for Transect 6.1 of the December 2011 survey of Muskeget Channel. A). Maximum flood velocities from survey Cycle 10 and B). Maximum ebb velocities from survey Cycle 5. Vectors indicate magnitude of the measurement by their length, and also direction, relative to true north. A two knot scale vector is shown for reference. 


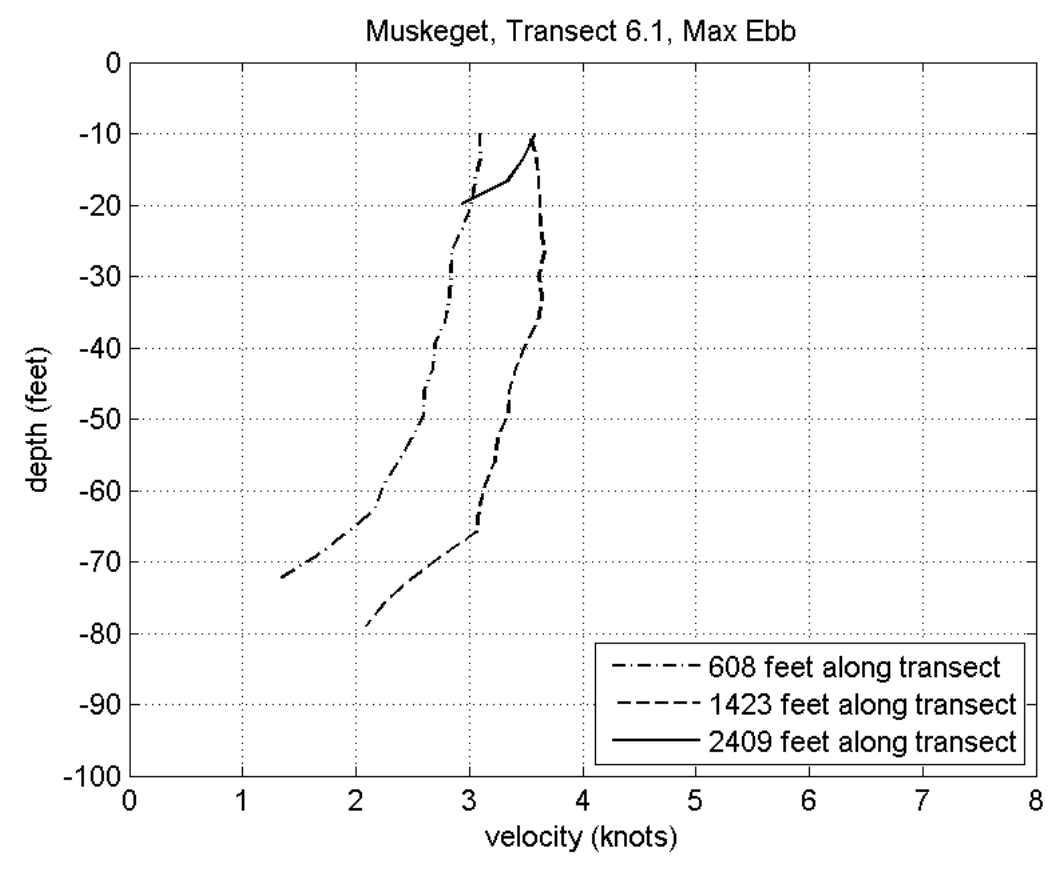

A

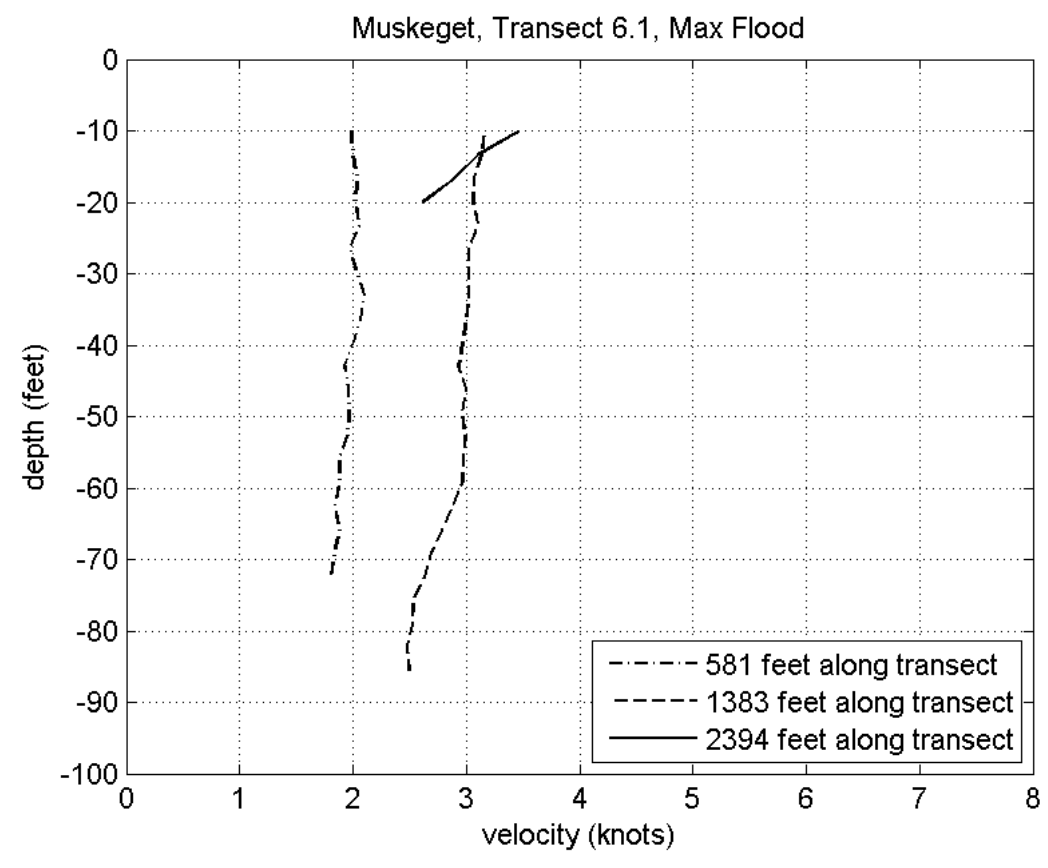

B

Figure 24-- Velocity magnitude (N+E) profiles measured along Transect 6.1 of the 2011 survey A). during Cycle 5 (max ebb) and B). during Cycle 10 (max flood). Profiles are shown for individual ensembles measured along the transect line. 

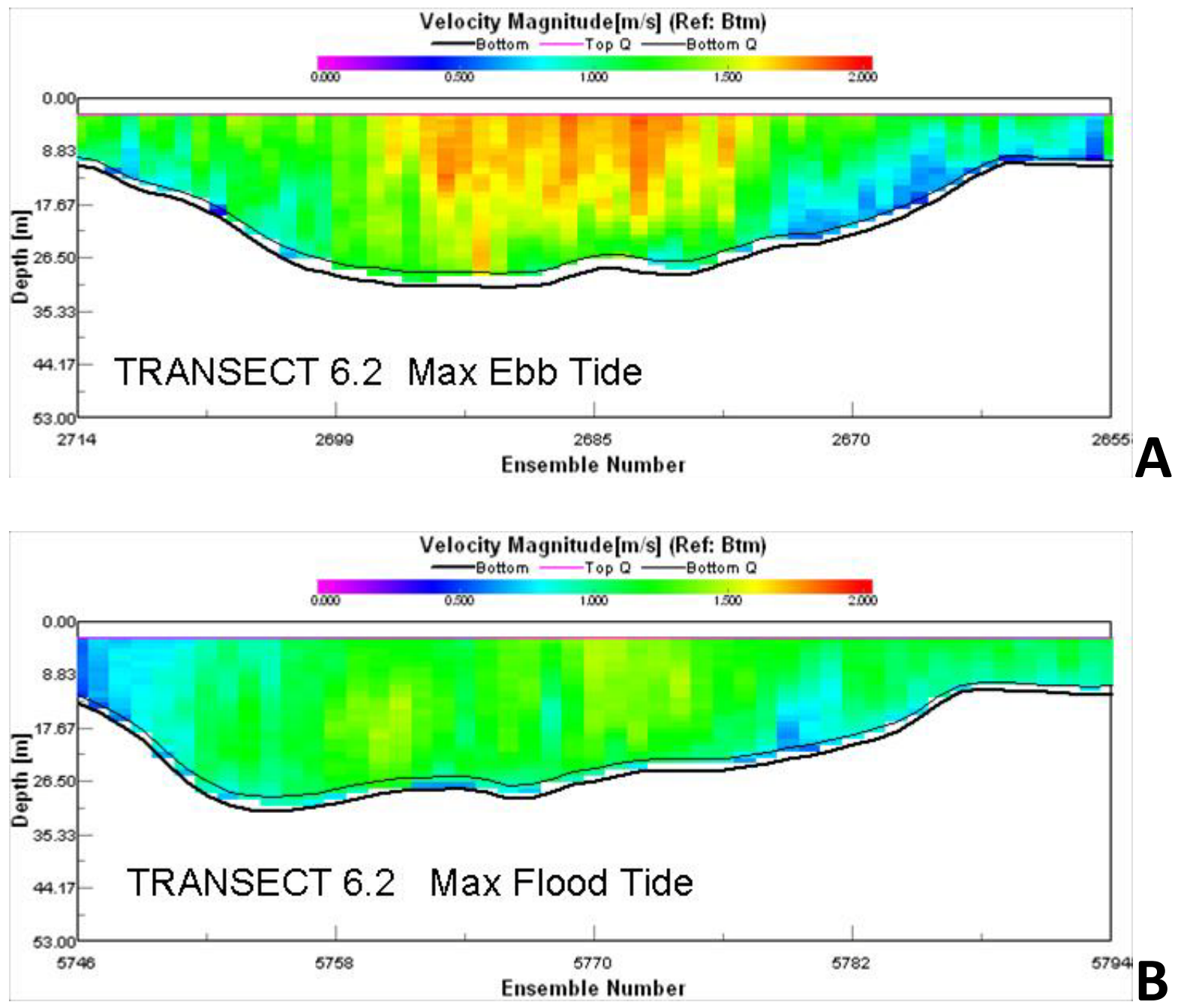

Figure 25-- Current/Depth profile along Transect 6.2. Maximum ebb tide (Cycle 5) is displayed in panel A; maximum flood tide (cycle 10) is displayed in panel B. Scale is in $\mathrm{m} / \mathrm{s}$. The west end of the transect is on the left and the east end of the transect is on the right. 


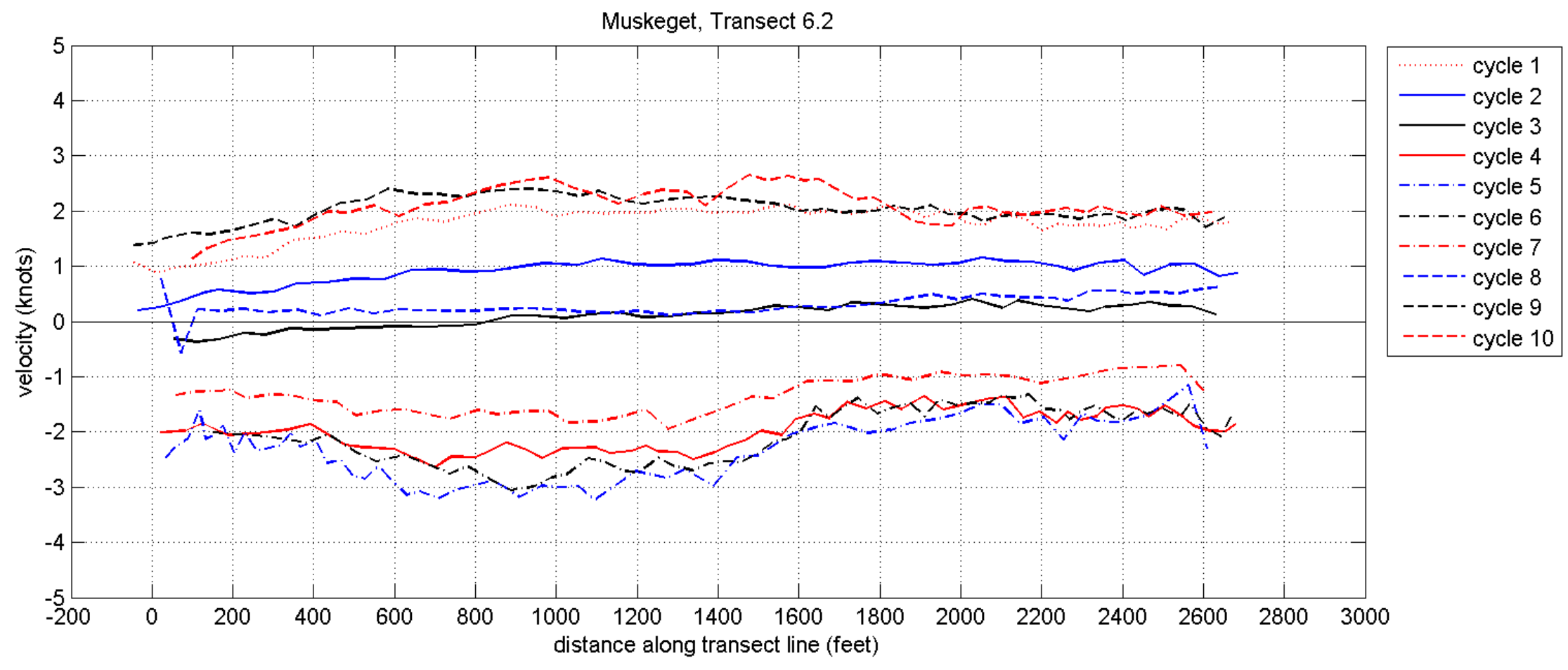

Figure 26-- Plot of depth averaged (top to bottom of water column) along-channel (i.e., perpendicular to ADCP transect line) velocities measured using the ADCP at Transect 6.2 of the 2011 Muskeget Channel survey. Each line represents velocity measurements recorded during the indicated survey cycle (as shown by the numbers at the start and end of each line). Positive velocities indicate flood currents directed to the north, into Nantucket Sound. 

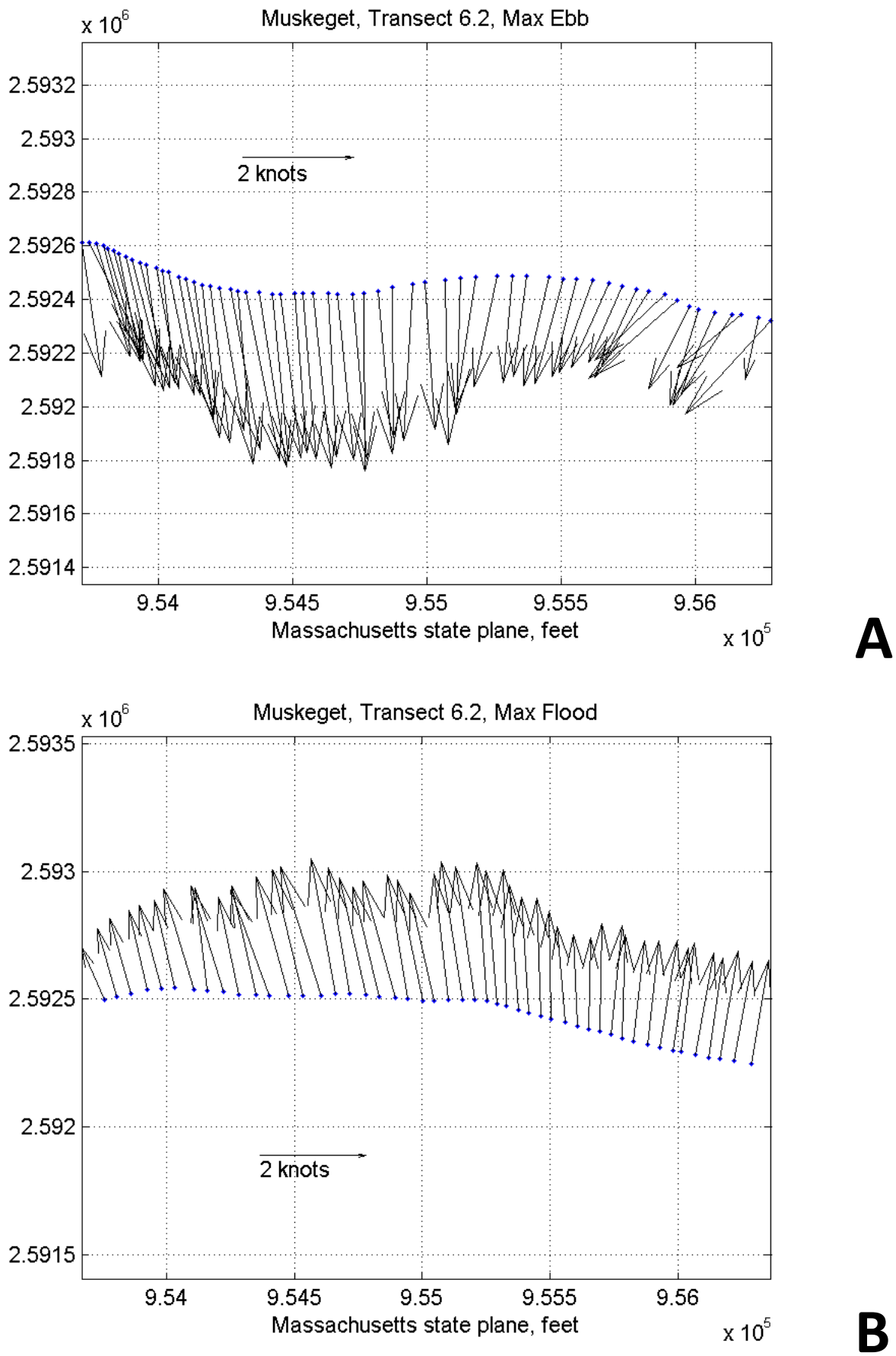

Figure 27-- Vector plot of depth averaged ADCP measurements for Transect 6.2 of the December 2011 survey of Muskeget Channel. A). Maximum flood velocities from survey Cycle 10 and B). Maximum ebb velocities from survey Cycle 5. Vectors indicate magnitude of the measurement by their length, and also direction, relative to true north. A two knot scale vector is shown for reference. 


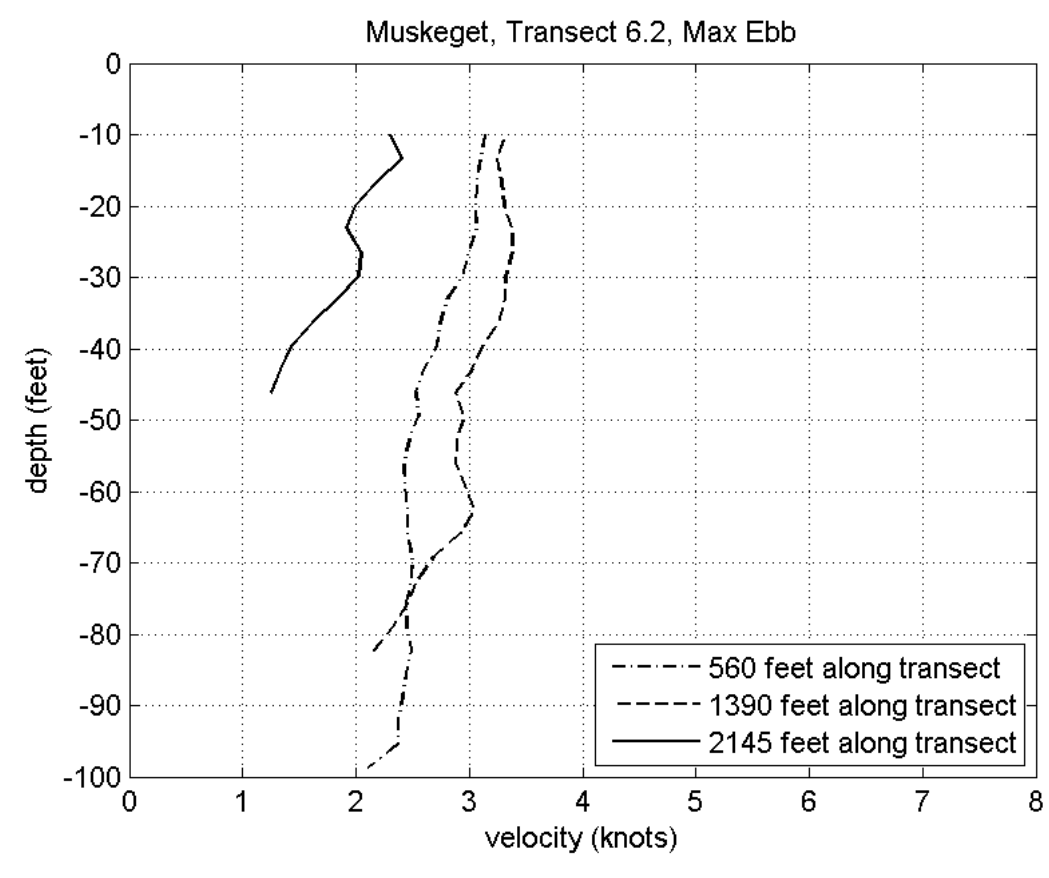

A

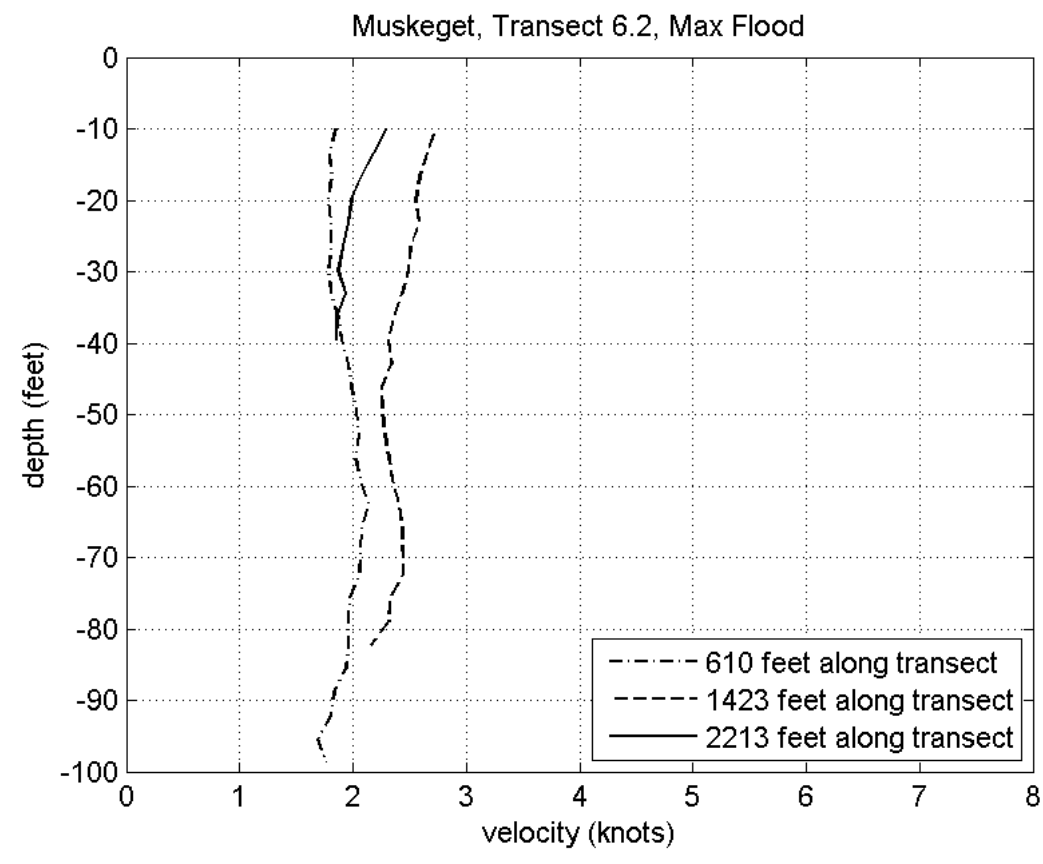

Figure 28- Velocity magnitude ( $\mathrm{N}+\mathrm{E}$ ) profiles measured along Transect 6.2 of the 2011 survey A). during Cycle 5 (max ebb) and B). during Cycle 10 (max flood). Profiles are shown for individual ensembles measured along the transect line. 

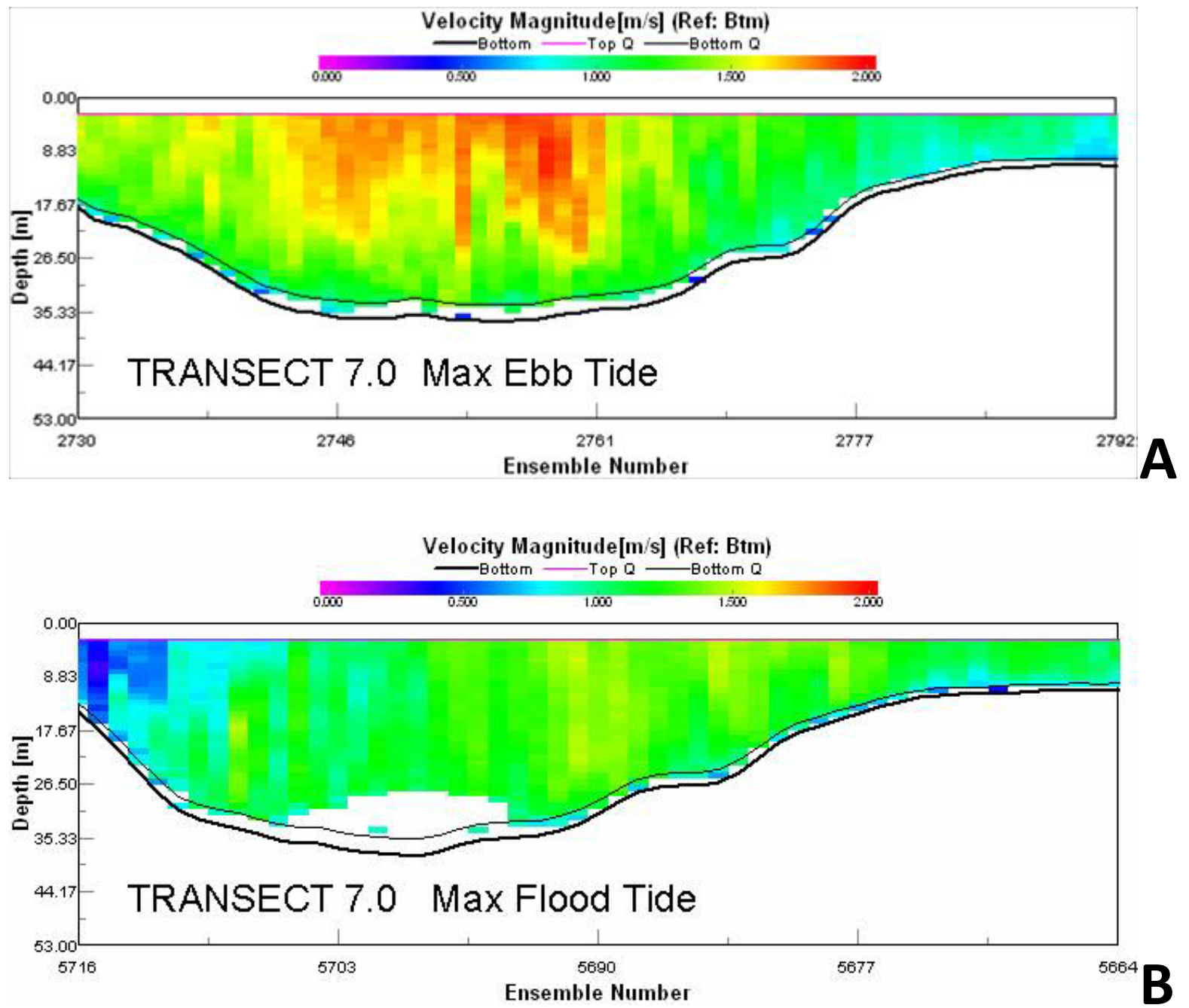

Figure 29-Current/Depth profile along Transect 7. Maximum ebb tide (Cycle 5) is displayed in panel A; maximum flood tide (cycle 10) is displayed in panel B. Scale is in $\mathrm{m} / \mathrm{s}$. The west end of the transect is on the left and the east end of the transect is on the right. 


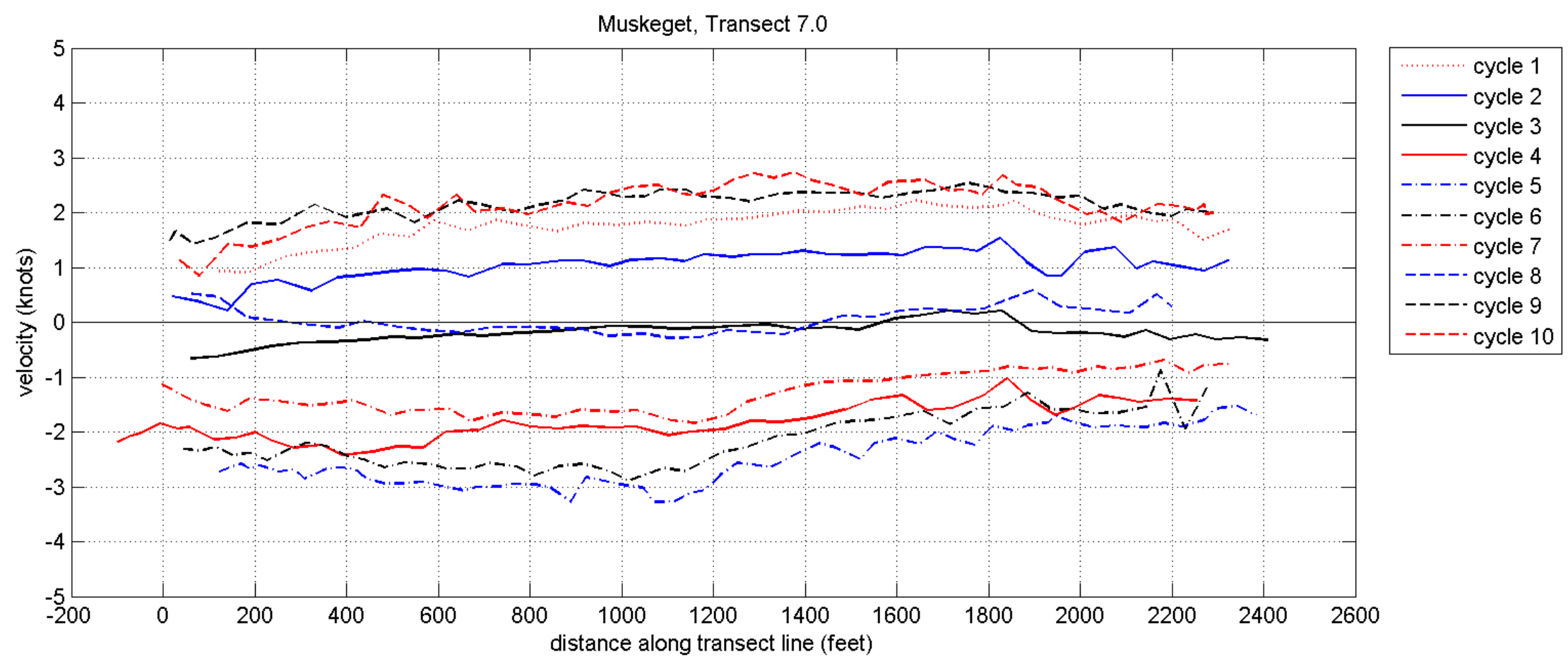

Figure 30 -- Plot of depth averaged (top to bottom of water column) along-channel (i.e., perpendicular to ADCP transect line) velocities measured using the ADCP at Transect 7 of the 2011 Muskeget Channel survey. Each line represents velocity measurements recorded during the indicated survey cycle (as shown by the numbers at the start and end of each line). Positive velocities indicate flood currents directed to the north, into Nantucket Sound. 

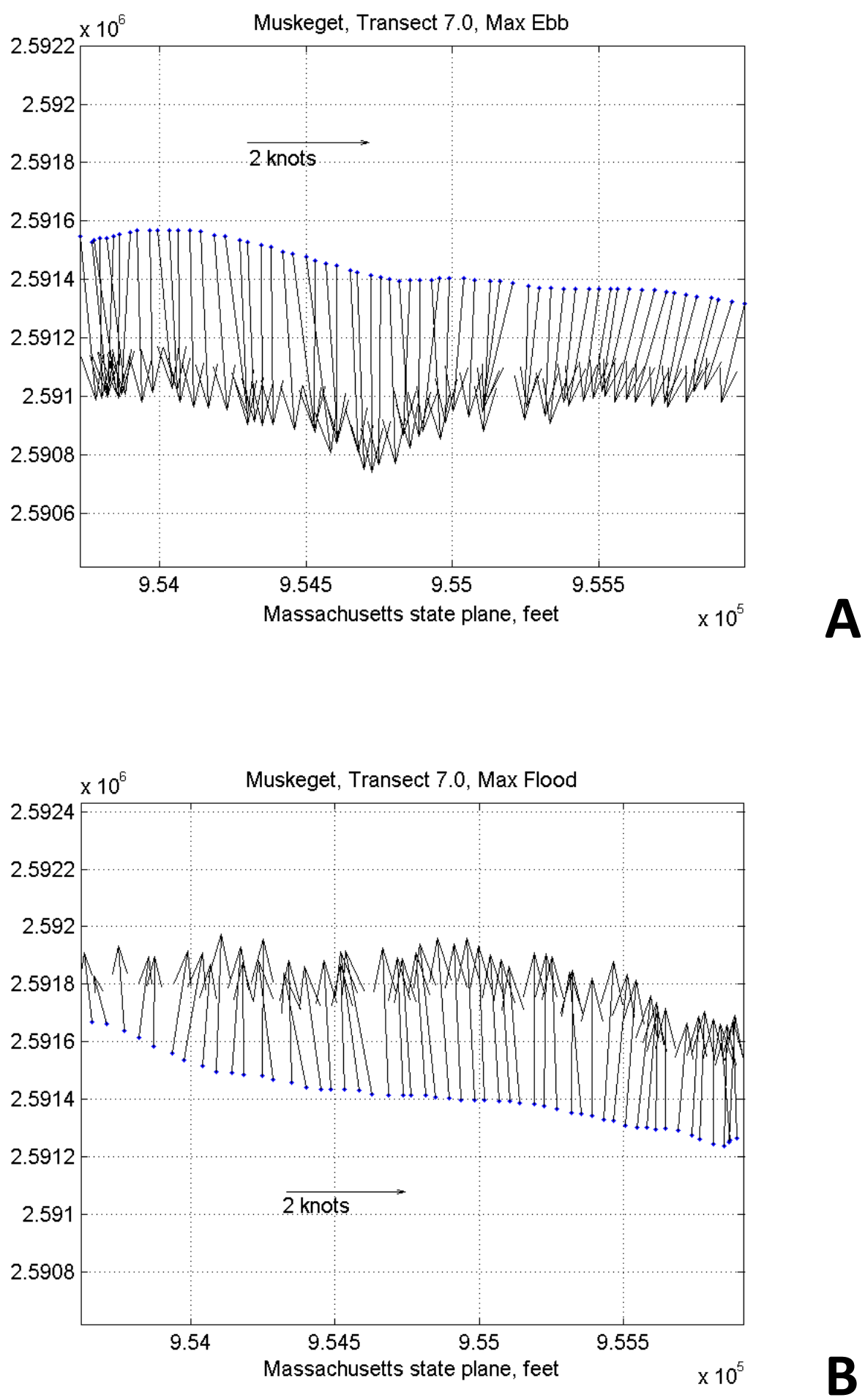

Figure 31-- Vector plot of depth averaged ADCP measurements for Transect 7 of the December 2011 survey of Muskeget Channel. A). Maximum flood velocities from survey Cycle 10 and B). Maximum ebb velocities from survey Cycle 5. Vectors indicate magnitude of the measurement by their length, and also direction, relative to true north. A two knot scale vector is shown for reference. 


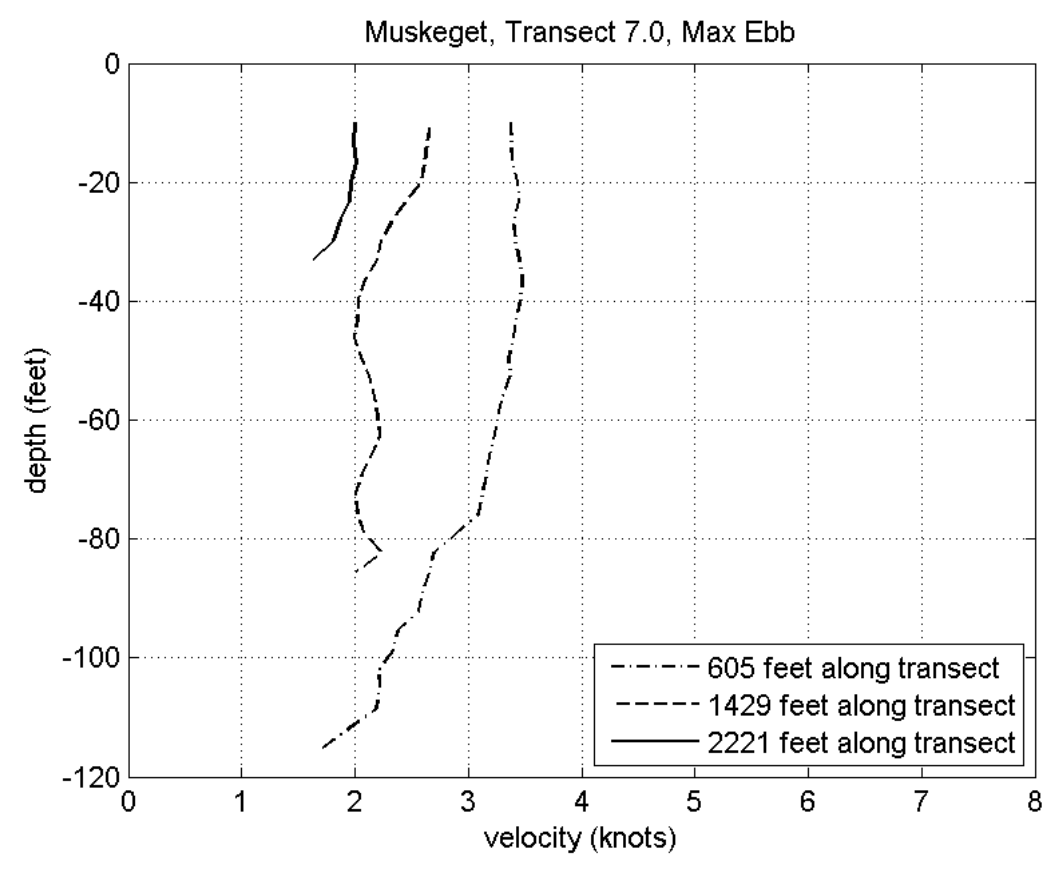

A

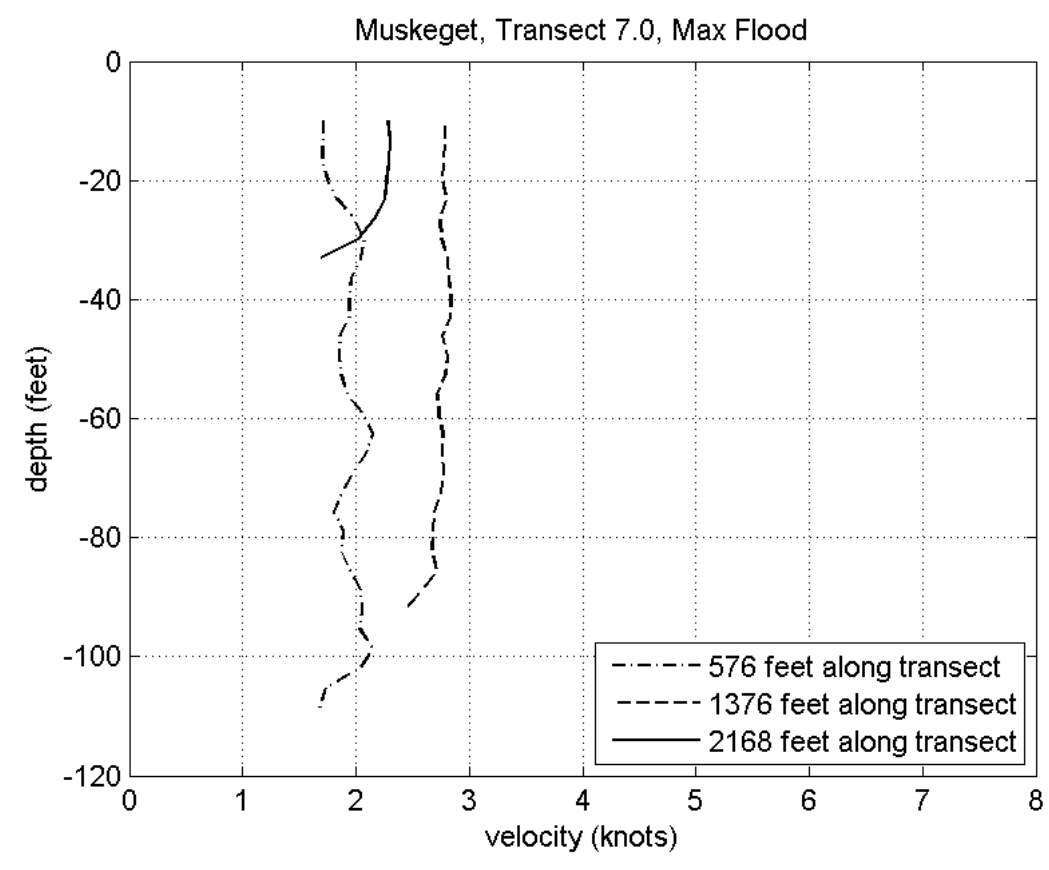

Figure 32-- Velocity magnitude ( $\mathrm{N}+\mathrm{E})$ profiles measured along Transect 7 of the 2011 survey $\mathrm{A})$. during Cycle 5 (max ebb) and B). during Cycle 10 (max flood). Profiles are shown for individual ensembles measured along the transect line. 

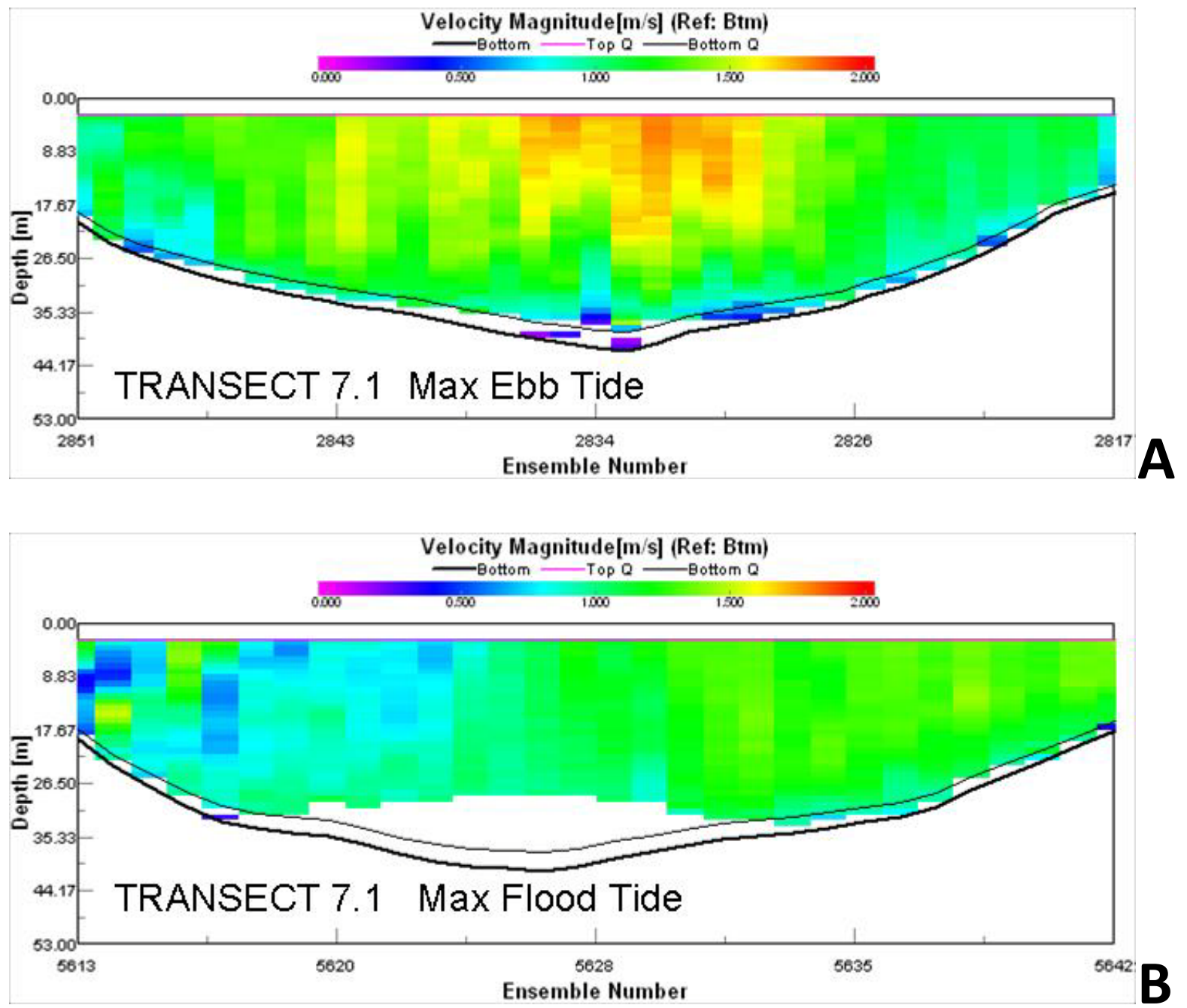

Figure 33 - Current/Depth profile along Transect 7.1. Maximum ebb tide (Cycle 5 ) is displayed in panel A; maximum flood tide (Cycle 10) is displayed in panel B. Scale is in $\mathrm{m} / \mathrm{s}$. The west end of the transect is on the left and the east end of the transect is on the right. 


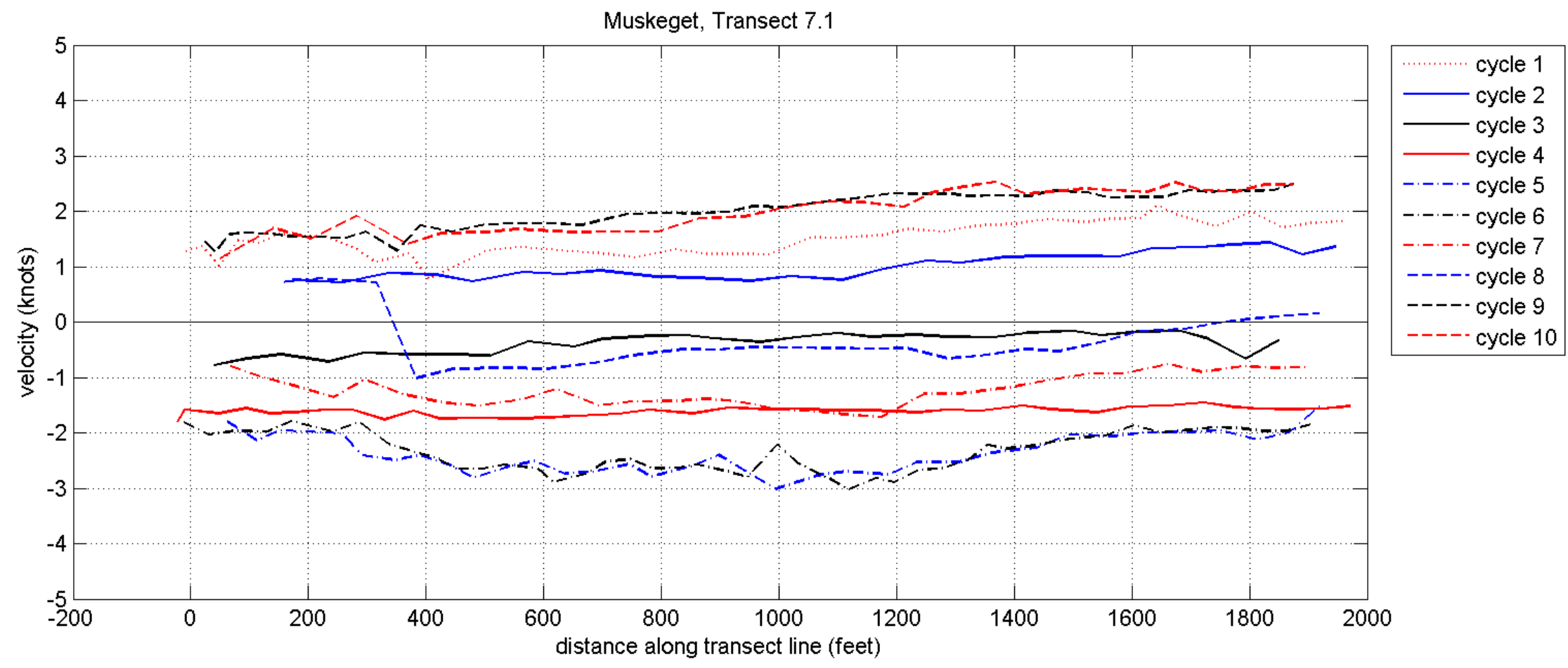

Figure 34- Plot of depth averaged (top to bottom of water column) along-channel (i.e., perpendicular to ADCP transect line) velocities measured using the ADCP at Transect 7.1 of the 2011 Muskeget Channel survey. Each line represents velocity measurements recorded during the indicated survey cycle (as shown by the numbers at the start and end of each line). Positive velocities indicate flood currents directed to the north, into Nantucket Sound. 

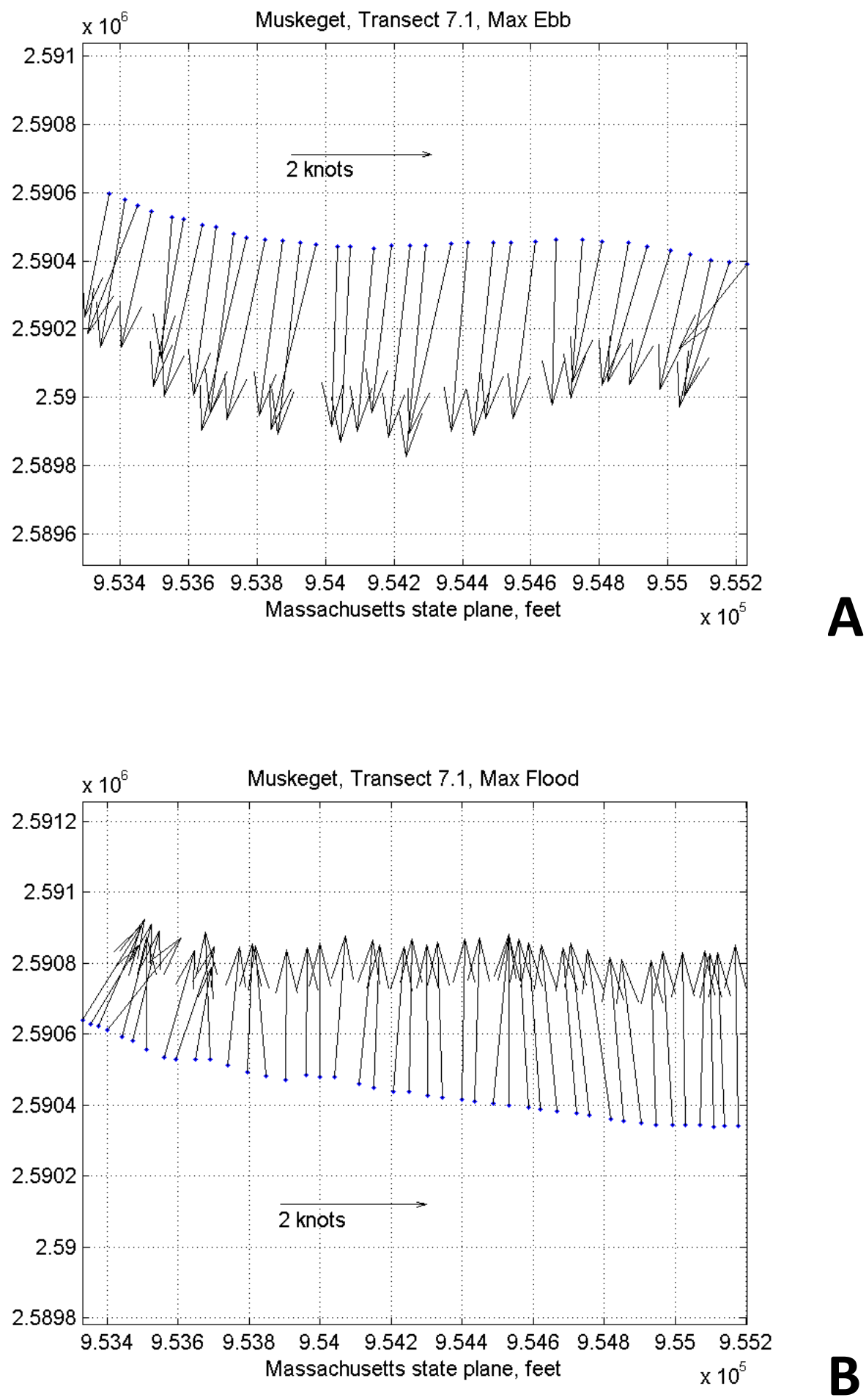

Figure 35-- Vector plot of depth averaged ADCP measurements for Transect 7.1 of the December 2011 survey of Muskeget Channel. A). Maximum flood velocities from survey Cycle 10 and B). Maximum ebb velocities from survey Cycle 5 . Vectors indicate magnitude of the measurement by their length, and also direction, relative to true north. A two knot scale vector is shown for reference. 


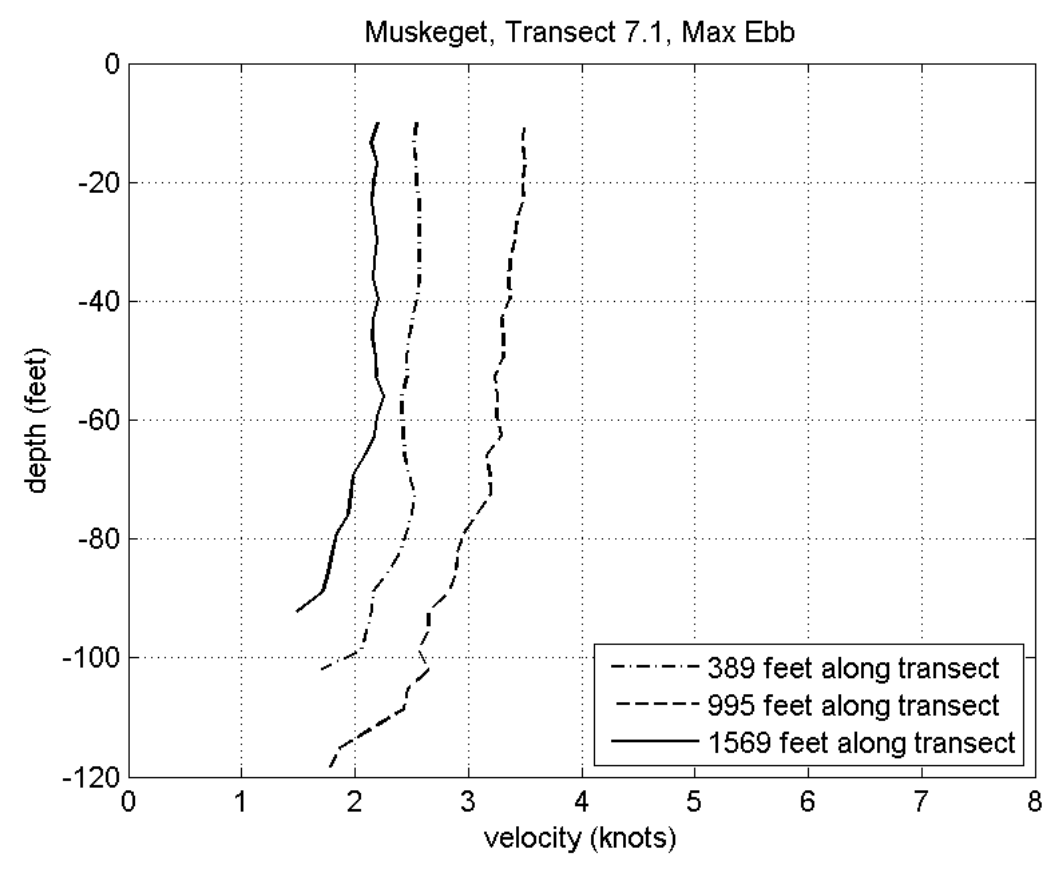

A

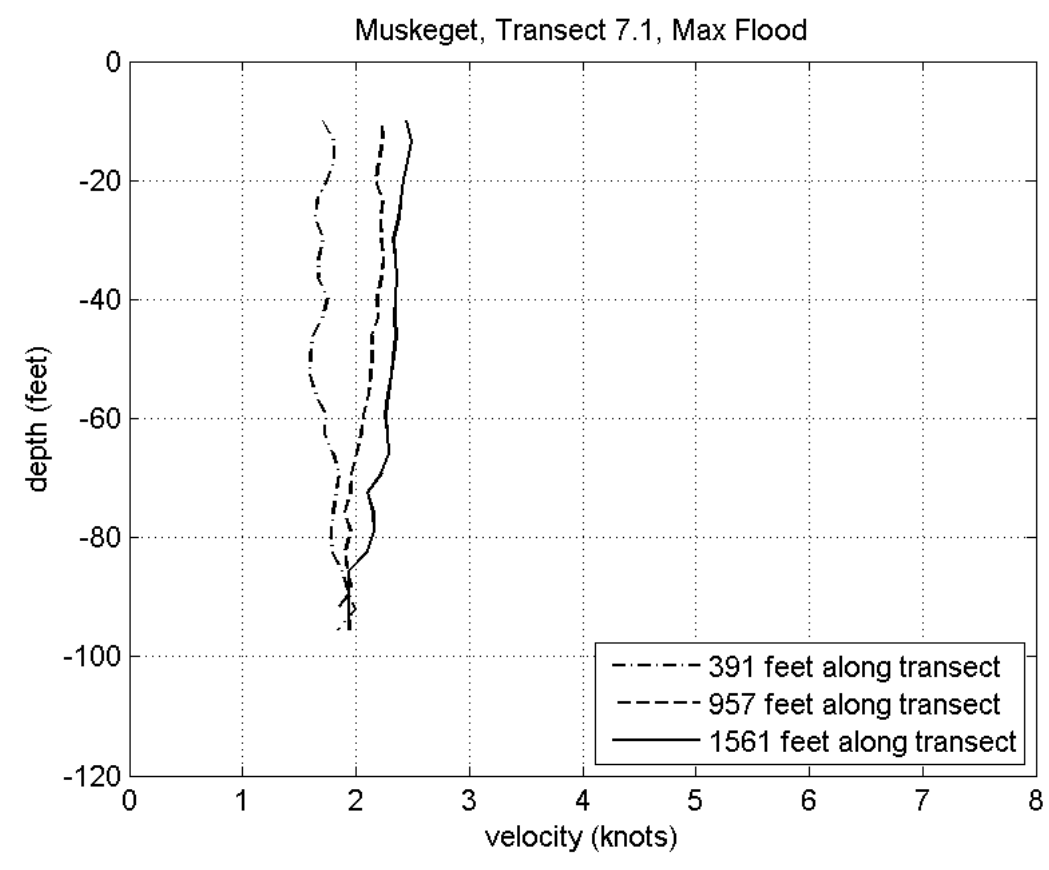

Figure 36-- Velocity magnitude (N+E) profiles measured along Transect 7.1 of the 2011 survey $A)$. during Cycle 5 (max ebb) and B). during Cycle 10 (max flood). Profiles are shown for individual ensembles measured along the transect line. 

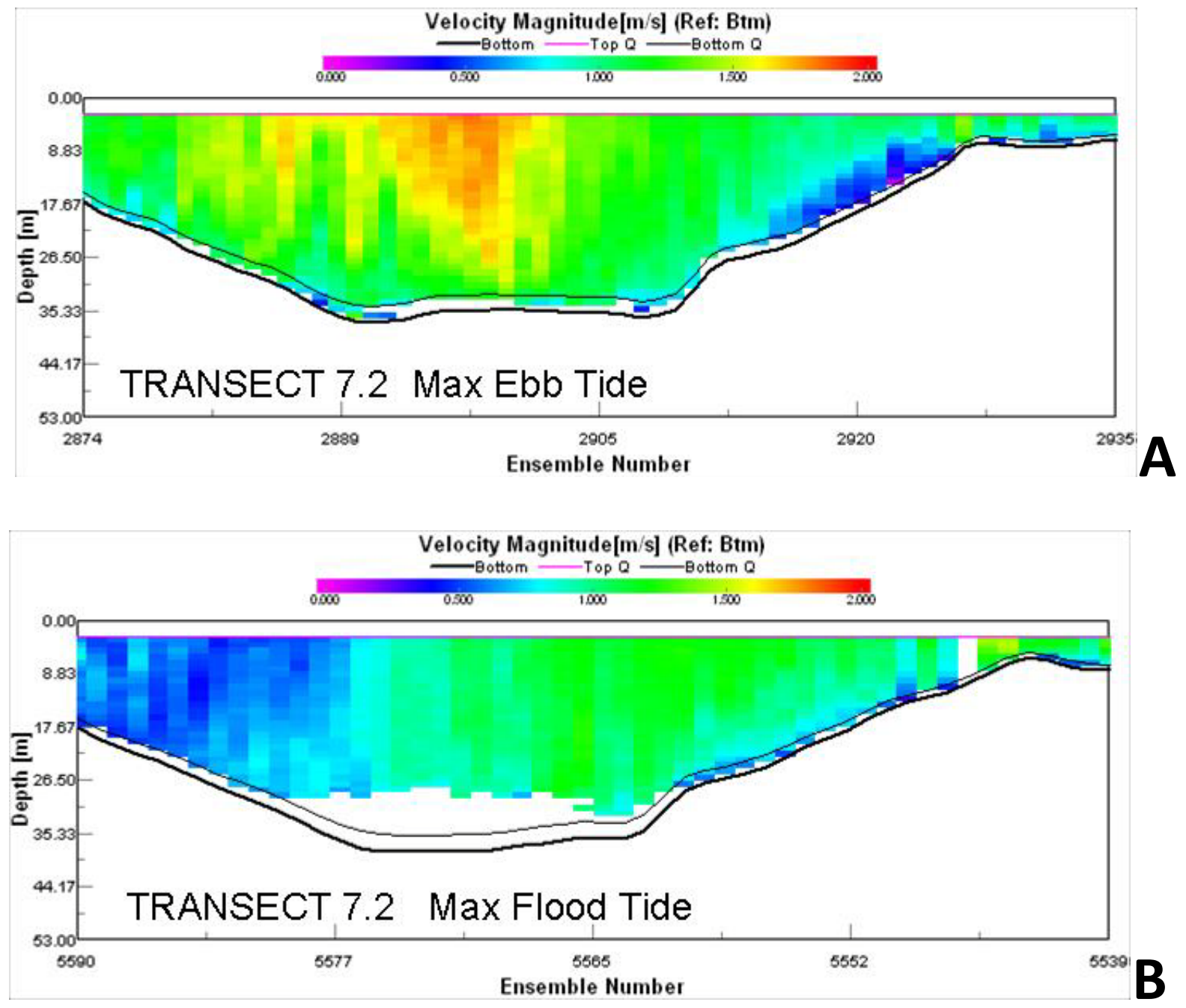

Figure 37-- Current/Depth profile along Transect 7.2. Maximum ebb tide (Cycle 5) is displayed in panel A; maximum flood tide (cycle 10) is displayed in panel B. Scale is in $\mathrm{m} / \mathrm{s}$. The west end of the transect is on the left and the east end of the transect is on the right. 


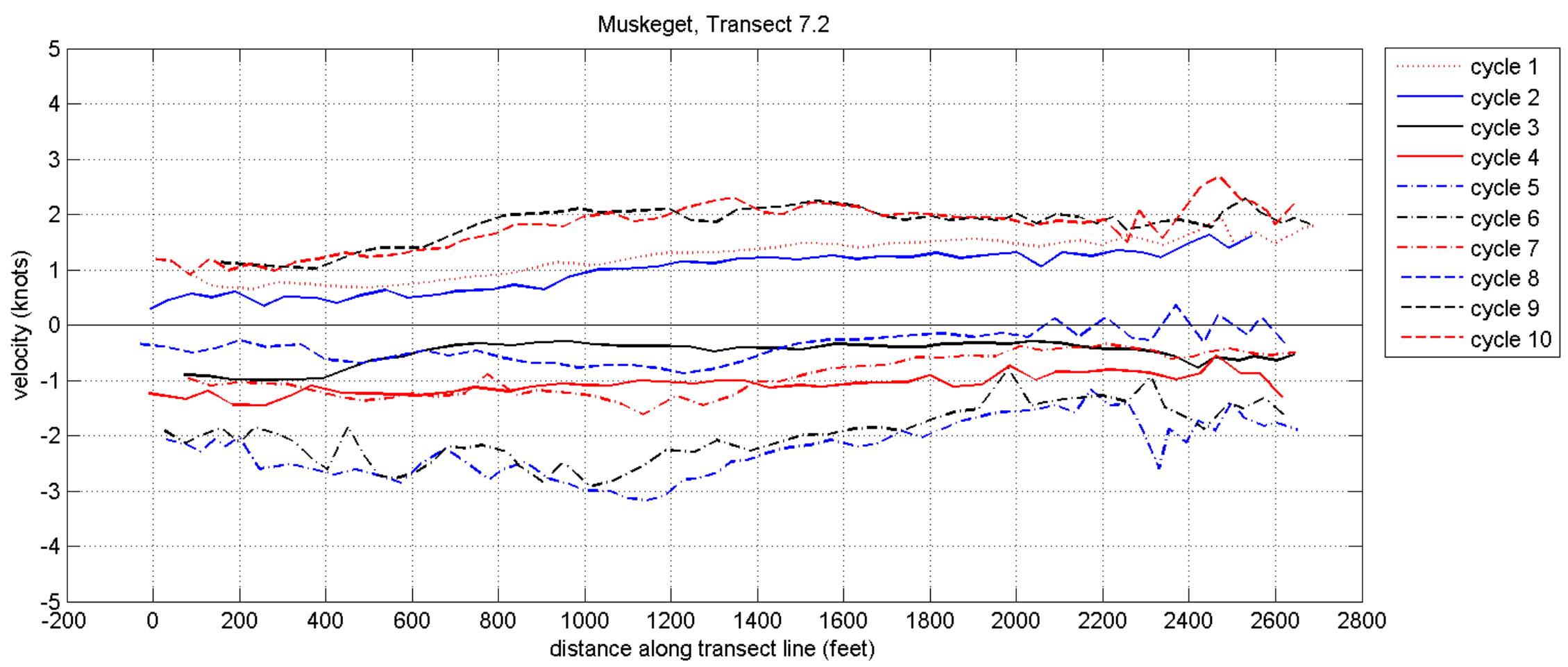

Figure 38 - Plot of depth averaged (top to bottom of water column) along-channel (i.e., perpendicular to ADCP transect line) velocities measured using the ADCP at Transect 7.2 of the 2011 Muskeget Channel survey. Each line represents velocity measurements recorded during the indicated survey cycle (as shown by the numbers at the start and end of each line). Positive velocities indicate flood currents directed to the north, into Nantucket Sound. 


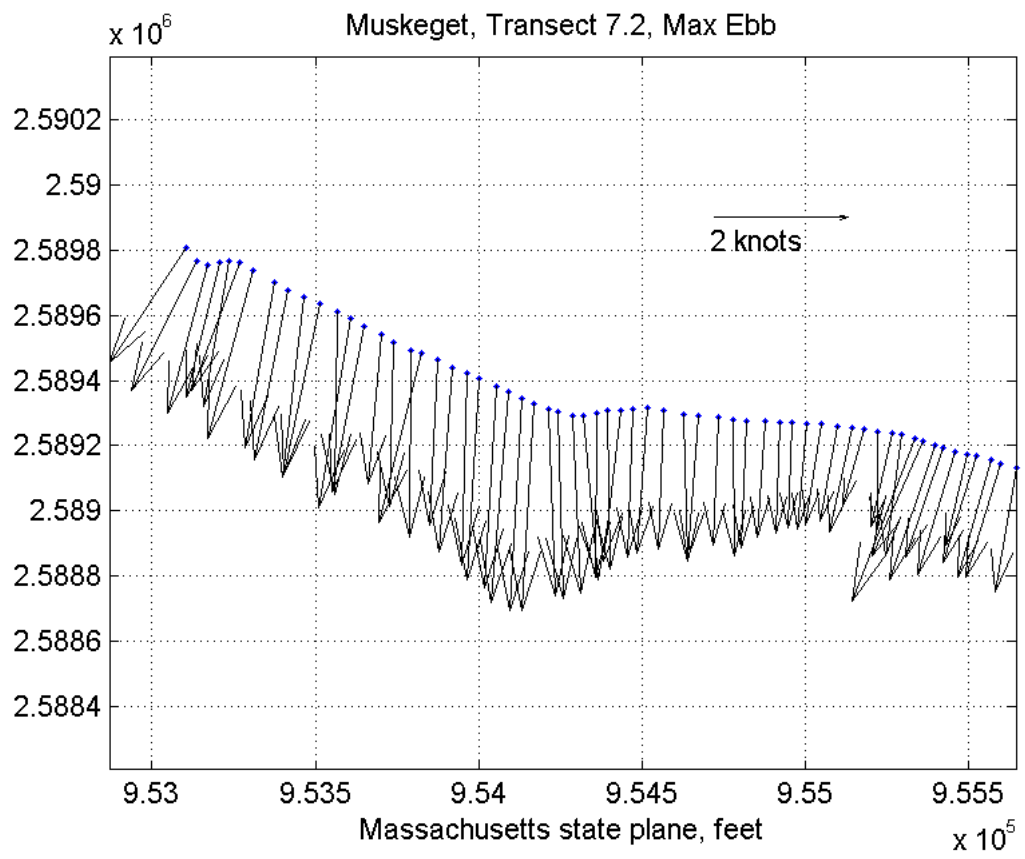

A

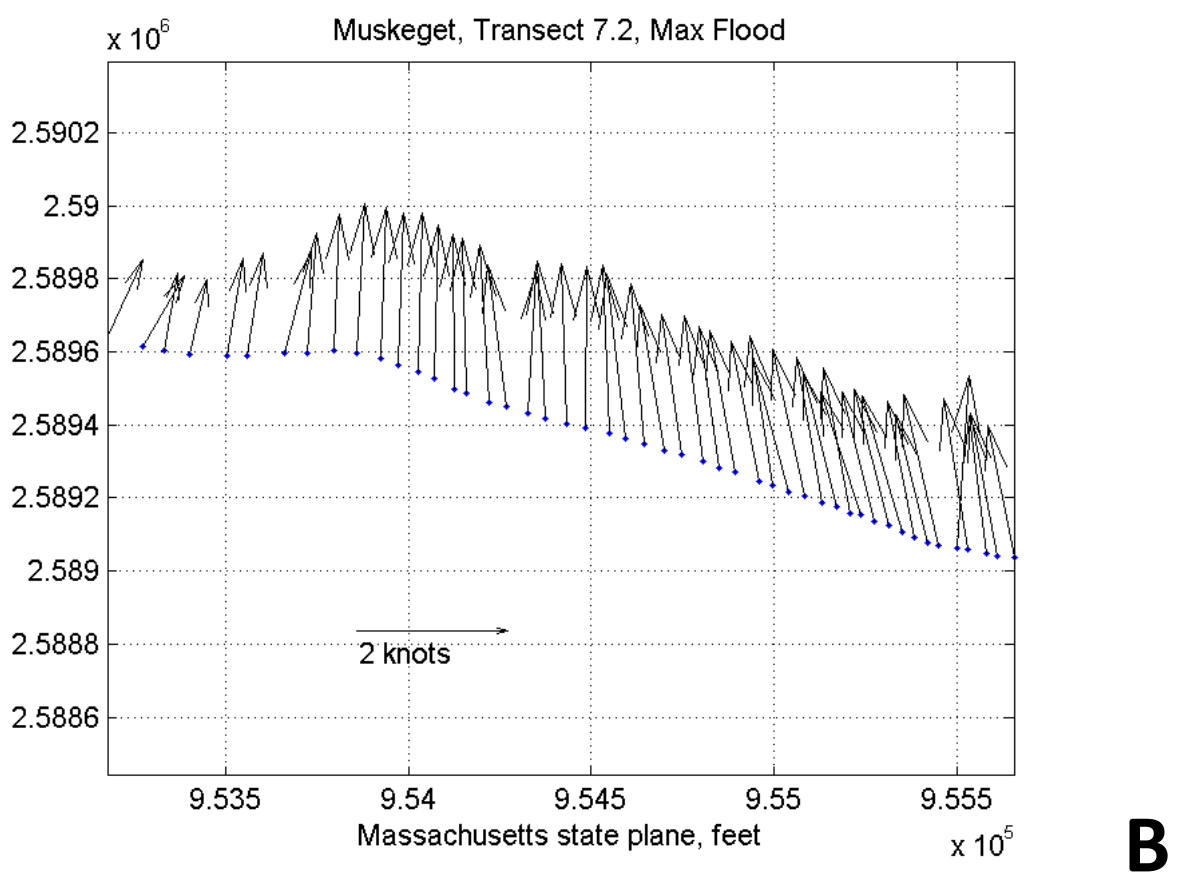

Figure 39-- Vector plot of depth averaged ADCP measurements for Transect 7.2 of the December 2011 survey of Muskeget Channel. A). Maximum flood velocities from survey Cycle 10 and B). Maximum ebb velocities from survey Cycle 5 . Vectors indicate magnitude of the measurement by their length, and also direction, relative to true north. A two knot scale vector is shown for reference. 


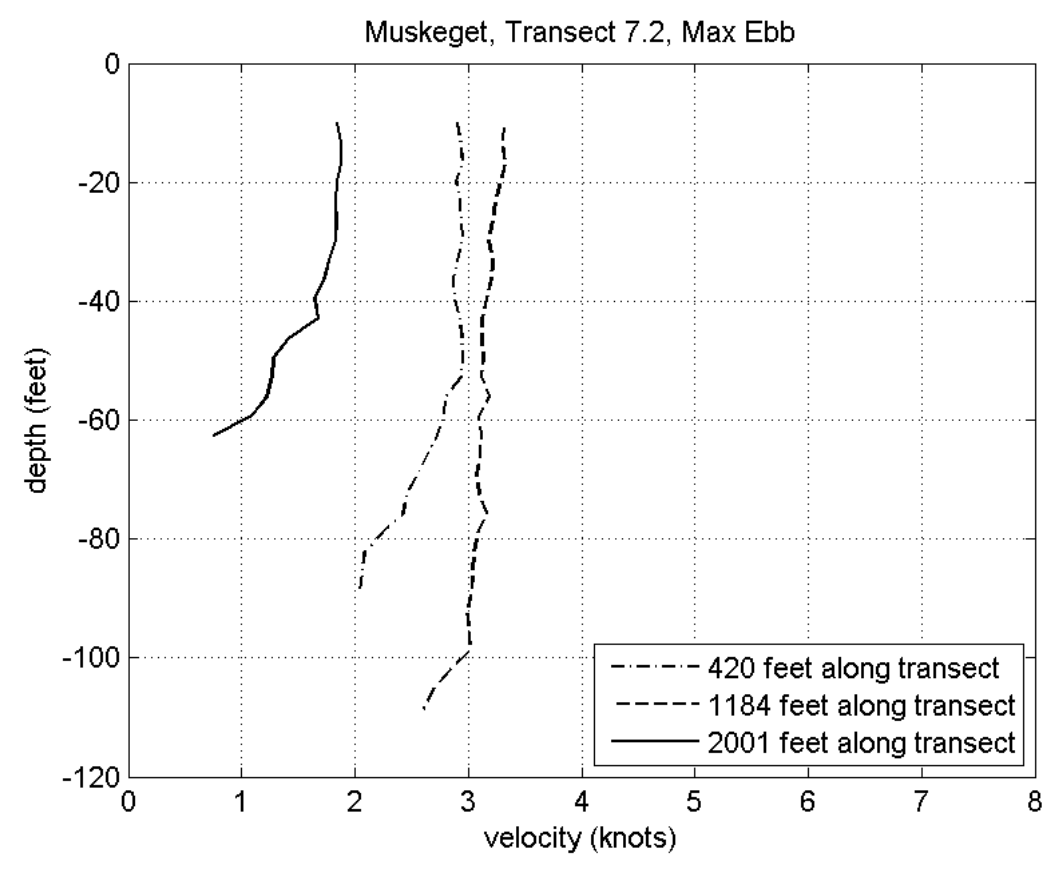

A

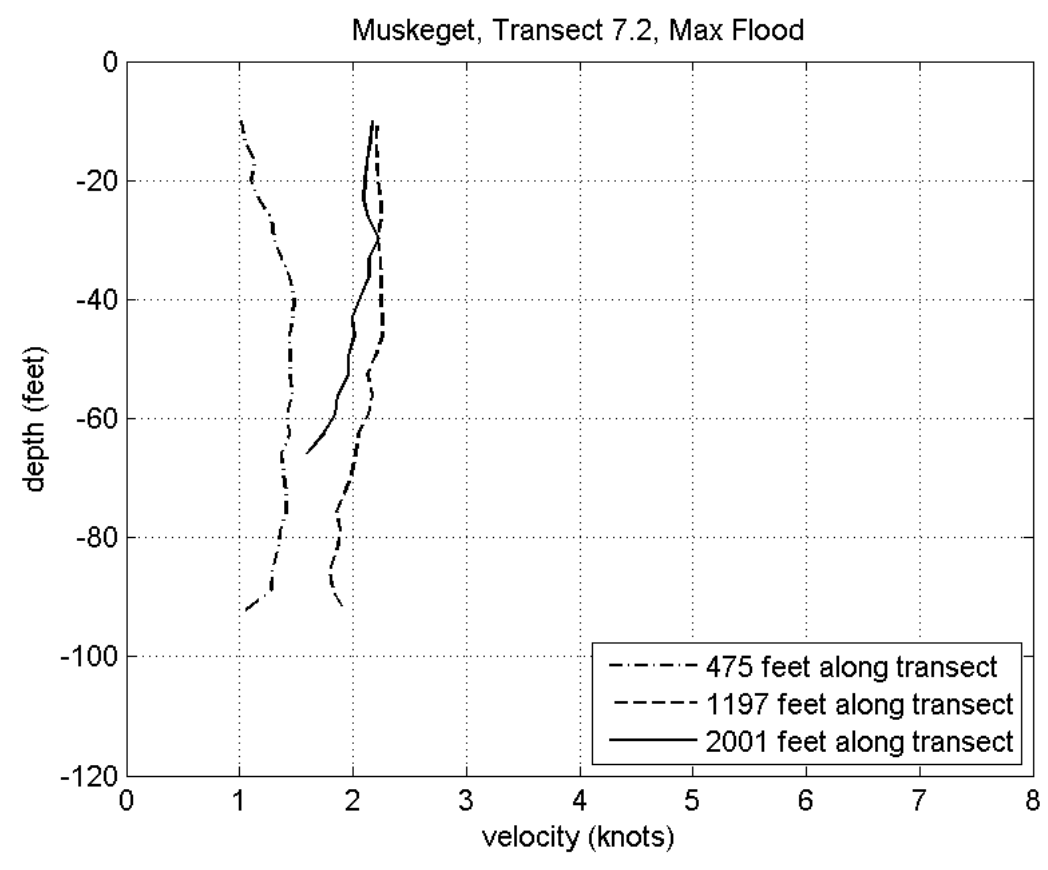

Figure 40-- Velocity magnitude (N+E) profiles measured along Transect 7.2 of the 2011 survey A). during Cycle 5 (max ebb) and B). during Cycle 10 (max flood). Profiles are shown for individual ensembles measured along the transect line. 

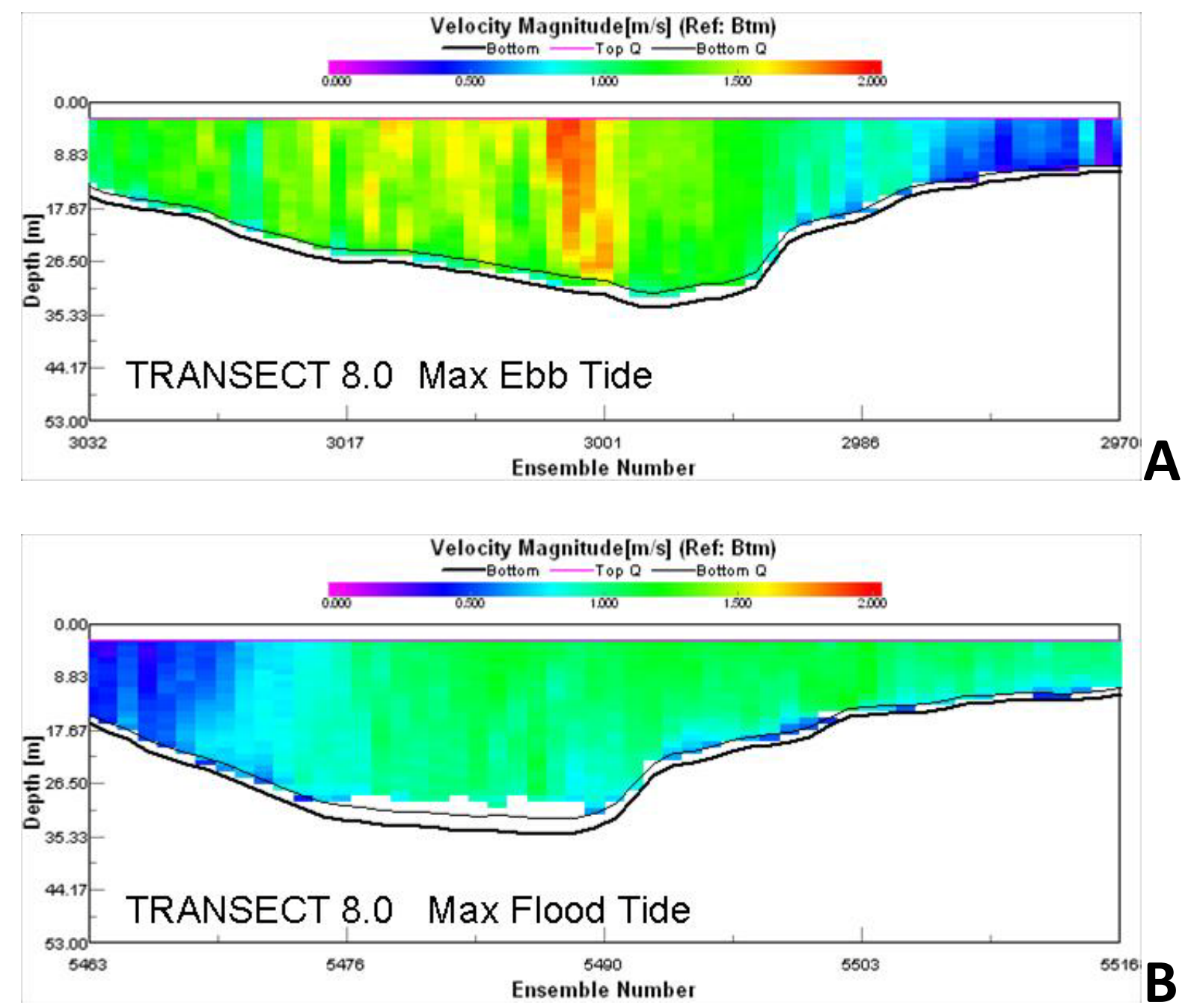

Figure 41-- Current/Depth profile along Transect 8. Maximum ebb tide (Cycle 5) is displayed in panel A; maximum flood tide (cycle 10) is displayed in panel B. Scale is in $\mathrm{m} / \mathrm{s}$. The west end of the transect is on the left and the east end of the transect is on the right. 


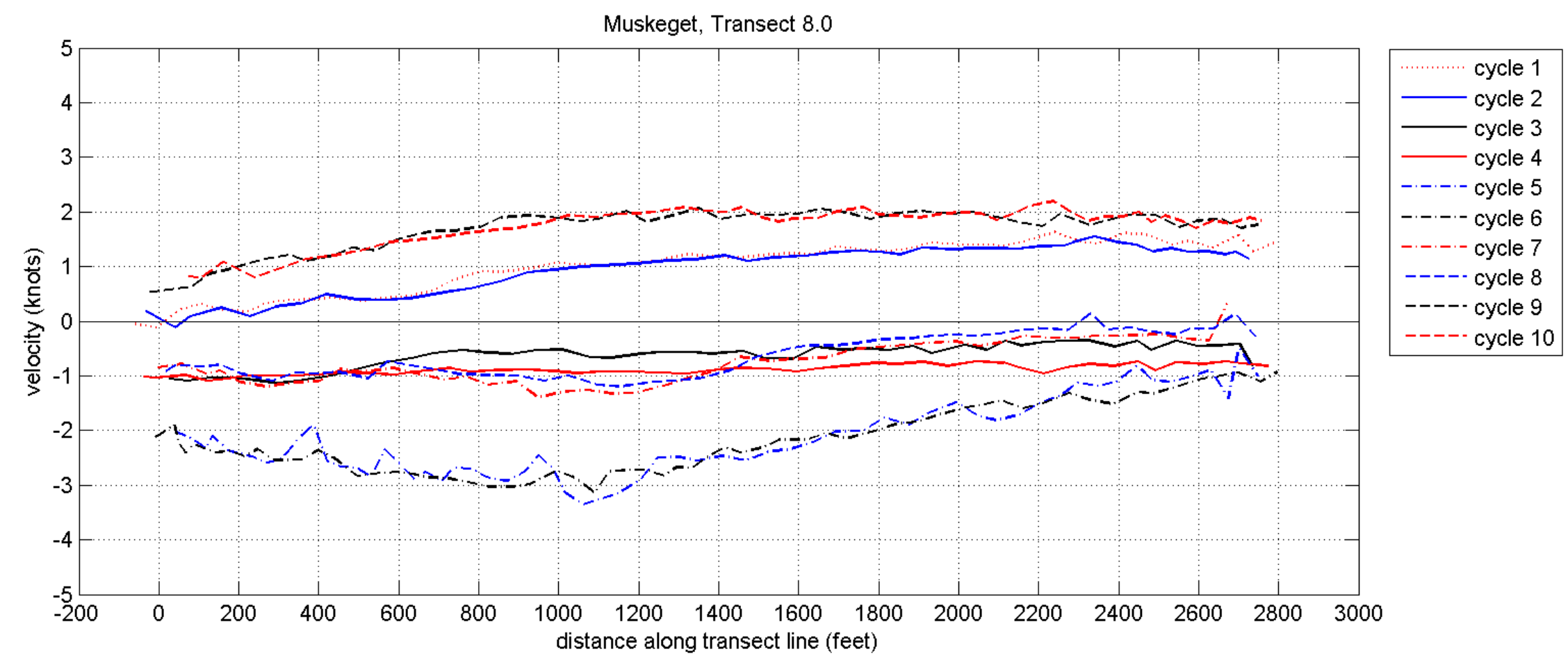

Figure 42 -- Plot of depth averaged (top to bottom of water column) along-channel (i.e., perpendicular to ADCP transect line) velocities measured using the ADCP at Transect 8 of the 2011 Muskeget Channel survey. Each line represents velocity measurements recorded during the indicated survey cycle (as shown by the numbers at the start and end of each line). Positive velocities indicate flood currents directed to the north, into Nantucket Sound. 

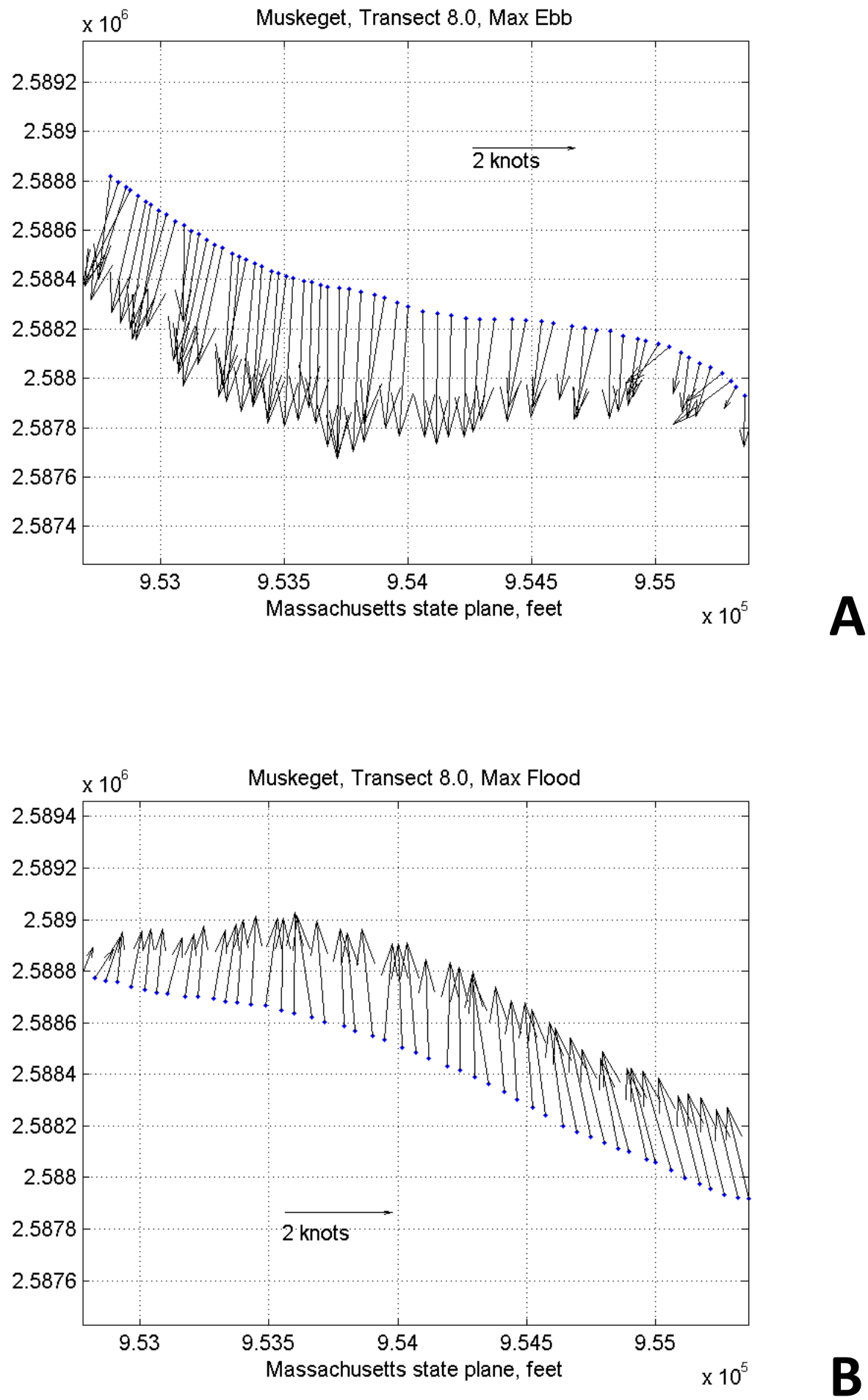

Figure 43-- Vector plot of depth averaged ADCP measurements for Transect 8 of the December 2011 survey of Muskeget Channel. A). Maximum flood velocities from survey Cycle 10 and B). Maximum ebb velocities from survey Cycle 5. Vectors indicate magnitude of the measurement by their length, and also direction, relative to true north. A two knot scale vector is shown for reference. 


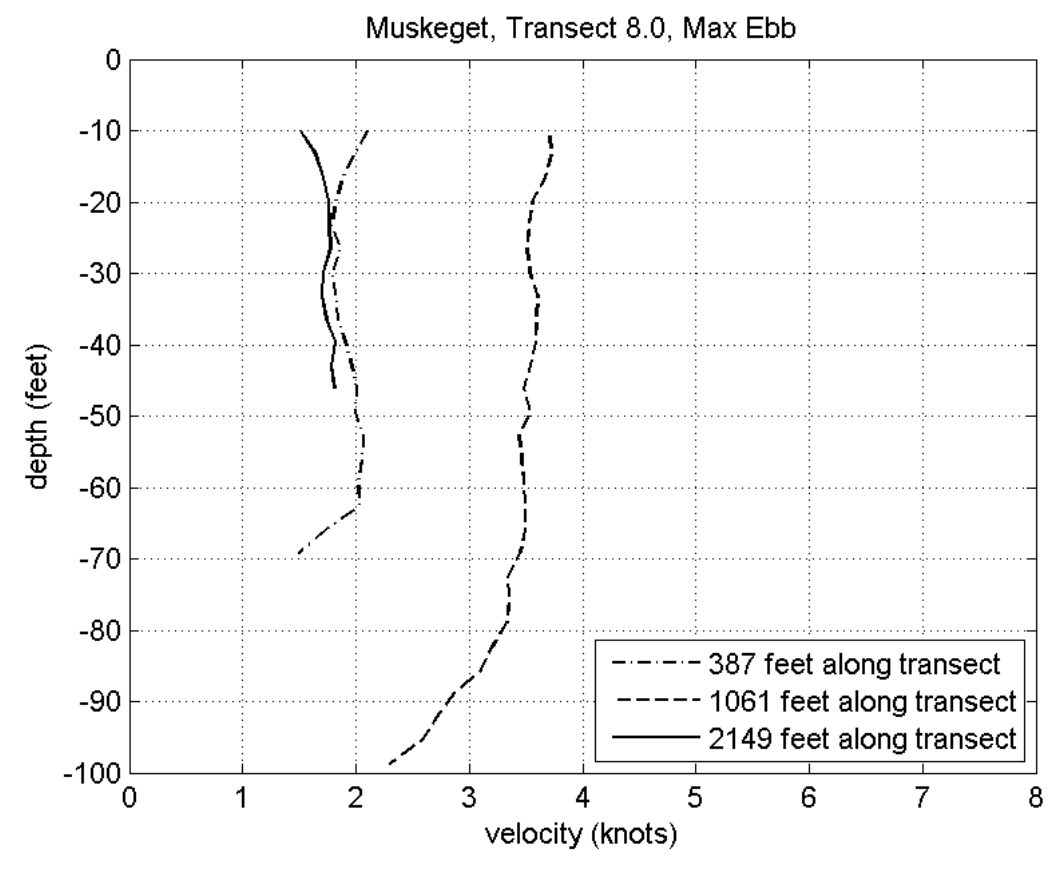

A

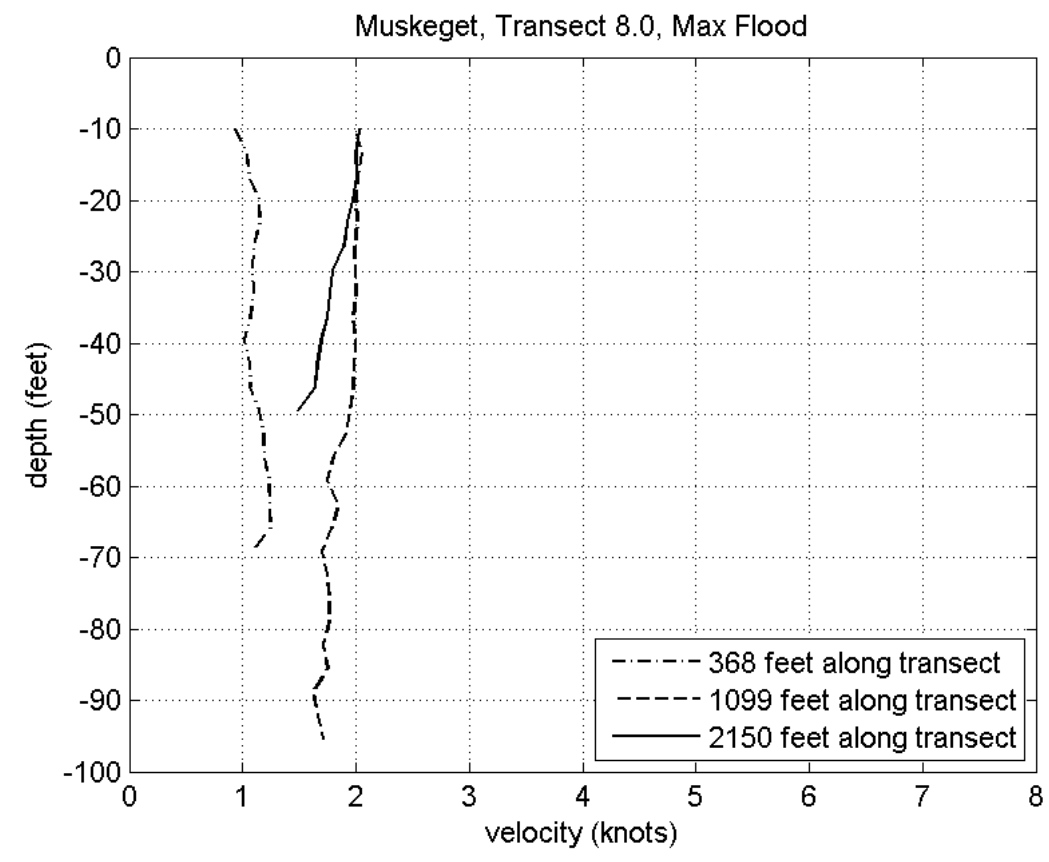

Figure 44-- Velocity magnitude ( $\mathbf{N}+\mathbf{E})$ profiles measured along Transect 8 of the 2011 survey $\mathbf{A})$. during Cycle 5 (max ebb) and B). during Cycle 10 (max flood). Profiles are shown for individual ensembles measured along the transect line. 


\subsection{Bathymetric Survey in Region of Future Pilot Tidal Technology Deployment}

The basis for existing bathymetry in Muskeget Channel is limited to 80 year old data. Developing a comprehensive understanding of the channel bathymetry is fundamental to refining the conceptual siting of a 5MW pilot tidal energy project, and for completing the proposed environmental studies and impact assessments. UMASS-SMAST conducted preliminary bathymetric survey work in connection with its Acoustic Doppler Current Profiling (ADCP) measurements in summer of 2008. UMASS-SMAST and WHOI each has collected additional bathymetric measurements to support the objectives of their proposed research under this grant. The result is a valuable bathymetry product that will be useful to future assessment of the Town of Edgartown tidal energy project and to the larger community of ocean user groups. The bathymetric mapping effort was necessary based upon findings from 2008 and 2009 data collection efforts that showed significant sand movement and shoaling within portions of Muskeget Channel. Therefore, a detailed bathymetric survey was undertaken within the high velocity zone of Muskeget Channel to (a) confirm the available depth soundings in the NOAA nautical chart of the area, (b) determine changes in the slopes and stability of the deep portion of the main channel and (c) develop a more detailed bathymetric map than presently available. In addition, more bathymetric surveying was undertaken to further reduce a gap in the original bathymetry survey that was undertaken in $2008 / 2009$. That gap was located to the north of the high velocity zone and in shallower water and a lower current environment not well suited to the deployment of tidal turbines. Nonetheless, it was deemed valuable to close the "gap" in previous bathymetry surveying as it would inform sediment transport modeling and enhance understanding of sand movement from the shallower waters of the channel to the deeper waters that define the high velocity zone, an area where diver observation documented the presence of large (1.0-1.5 meter high) sand waves overlying a gravel/cobble bottom.

A small gap in the bathymetry still exists to the north of the primary study area. Filling the remainder of the gap was not given priority due to marginal currents and relatively shallow depths. In general there was rough correspondence between the current survey and the underlying NOAA chart, though there were few depth measurements in the deepest portion of the channel and no attempt at constructing isobaths. Comparison with the NOAA charts indicates that some features may have moved as much as 200 meters since the chart was created. Movement of the least stable bottom features such as shoals, spits may reflect seasonal or meterological inputs, some of this uncertainty may be removed by comparing multiple images through time, including the available SWATH images generated by WHOI and the USGS.

Building on previous survey efforts, UMASS-SMAST conducted additional bathymetric surveying of the critical high velocity zone of the main channel portion of the Muskeget Channel to support ADCP, tide elevation, and current measurements. This region is associated with the scoured out deep hole where Muskeget Channel narrows at the level of Mutton Shoal and current velocities increase to $>4$ knots, sufficient to meet the requirements of existing tidal energy technologies (Figure 45). Survey lines were run at $50 \mathrm{~m}$ intervals, with continuous recording of depth $(0.1 \mathrm{ft})$ and location (DGPS). This reduction in survey line spacing from the original 100 meter intervals provides for a more detailed mapping of the bottom topography (Figure 46). All bathymetric data collected during these surveys were corrected for 
variances in tidal elevation. It should be noted that while the bathymetric map produced for this study is of high resolution and accuracy, it is not intended for navigational use. Rather it is to serve as a guide for placement of tidal turbine arrays and to place the velocity measurements into a bathymetric context.

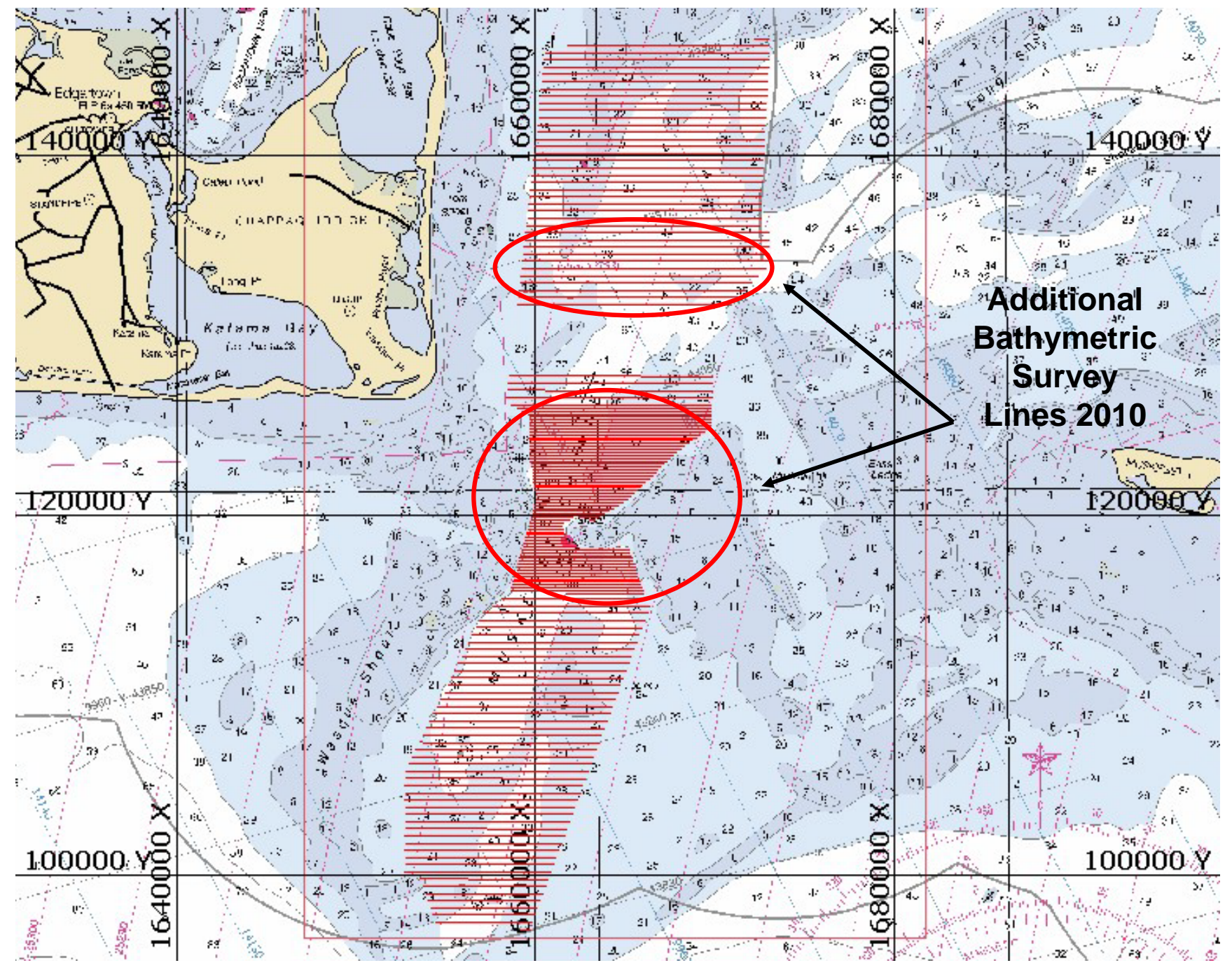

Figure 45 - Area of additional fine scale bathymetric mapping in the high velocity zone of Muskeget Channel where future tidal turbine deployments are being planned and in a more northern location not previously surveyed in $2008 / 2009$. 


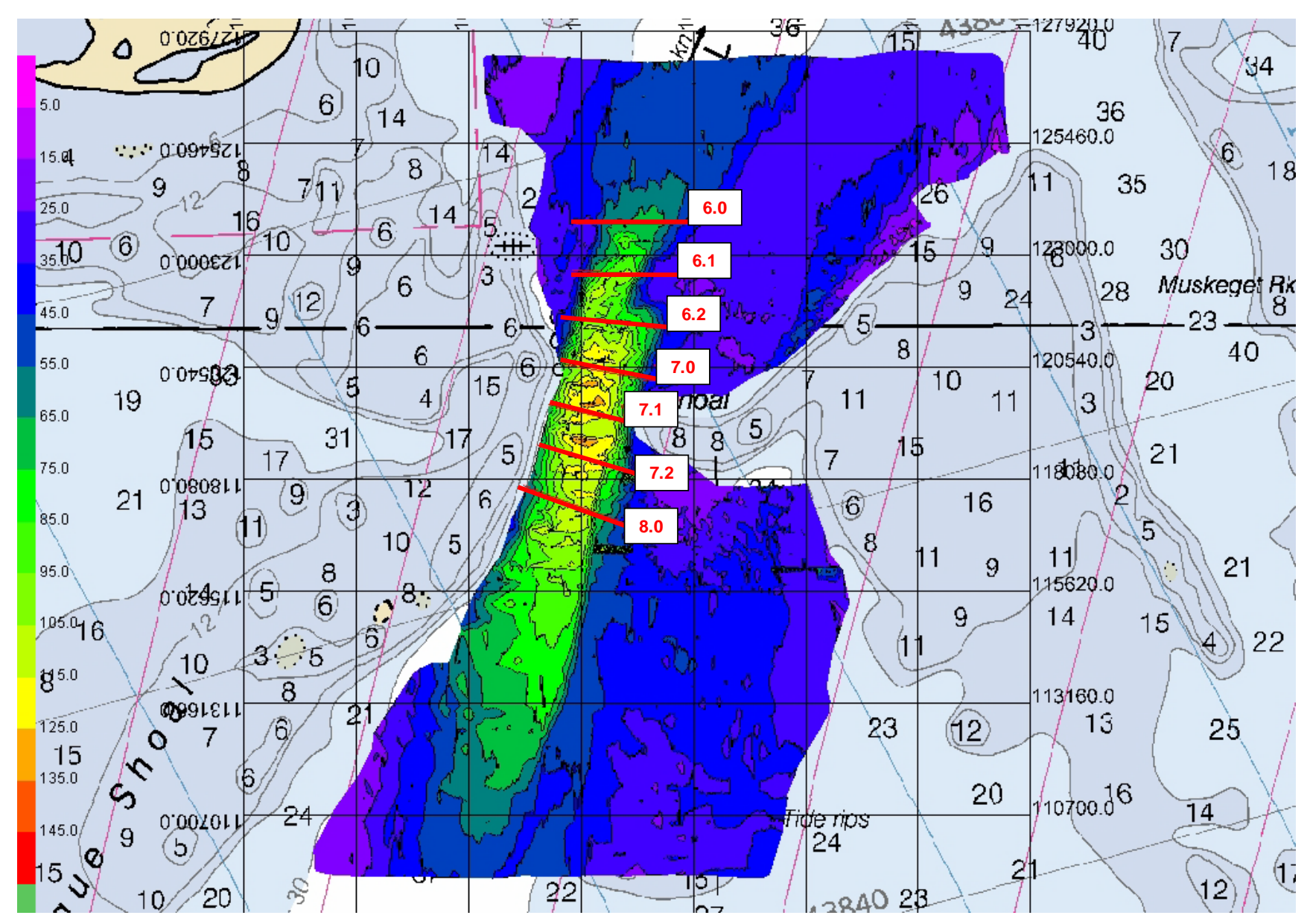

Figure 46. Additional finer scale bathymetric map of the high velocity zone in Muskeget Channel completed in 2010. Bathymetric survey lines were spaced 50 meters apart to provide increased spatial coverage of the bottom contour. Also displayed on the map are the additional ADCP transects surveyed in 2010 to determine optimal velocities for potential turbine installation sites for future power generation.

\subsection{Time-series Current Velocity Measurements at a Single Point in the High Velocity Zone over a Complete Lunar Cycle using Bottom Mounted ADCP}

In conjunction with the previously discussed ship-based ADCP surveying along individual transects (6.0, $6.1,6.2,7.0,7.1,7.2,8.0$ ) a bottom mounted upward looking ADCP was deployed to capture near continuous current measurements through a portion of the water column in the area that showed the strongest currents based on data collection along the transects (Figure 47 and 48). This instrument was deployed on November 22, 2010 and was retrieved on January 6, 2011. Deployment duration was focused to cover at least one full lunar cycle such that variations in the velocity field could be quantified as a function of changing phases of the moon. The bottom mounted ADCP also served as a validation of velocity measurements obtained during the ADCP surveying being positioned the high velocity end of transect 6.2. The overall objective was to capture the average, maximum and minimum velocities and 
flows for evaluating the number of locations that can be utilized for deployment of tidal generating units and how the monthly fluctuations in current intensity might affect future power generation in this area.

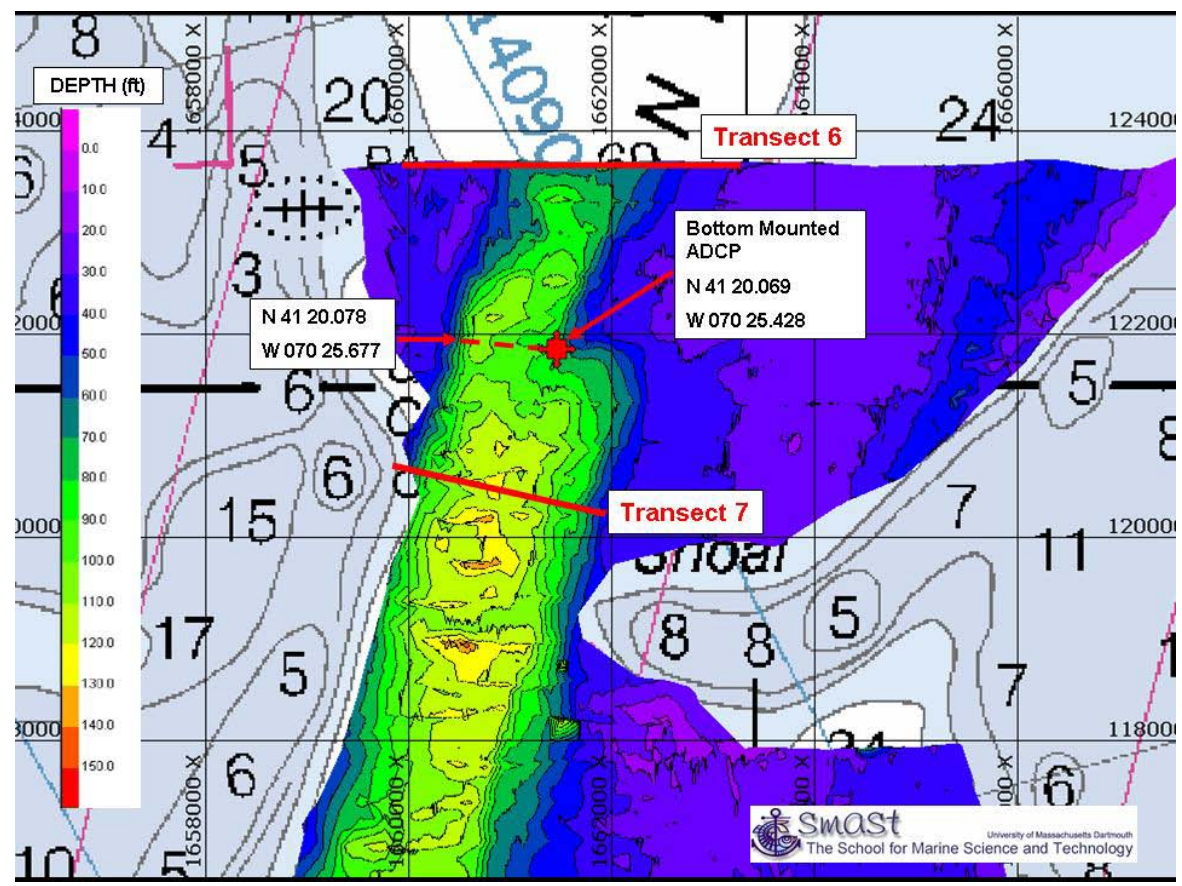

Figure 47-Bathymetric map of the high velocity zone in Muskeget Channel showing the location of the bottom mounted ADCP unit.

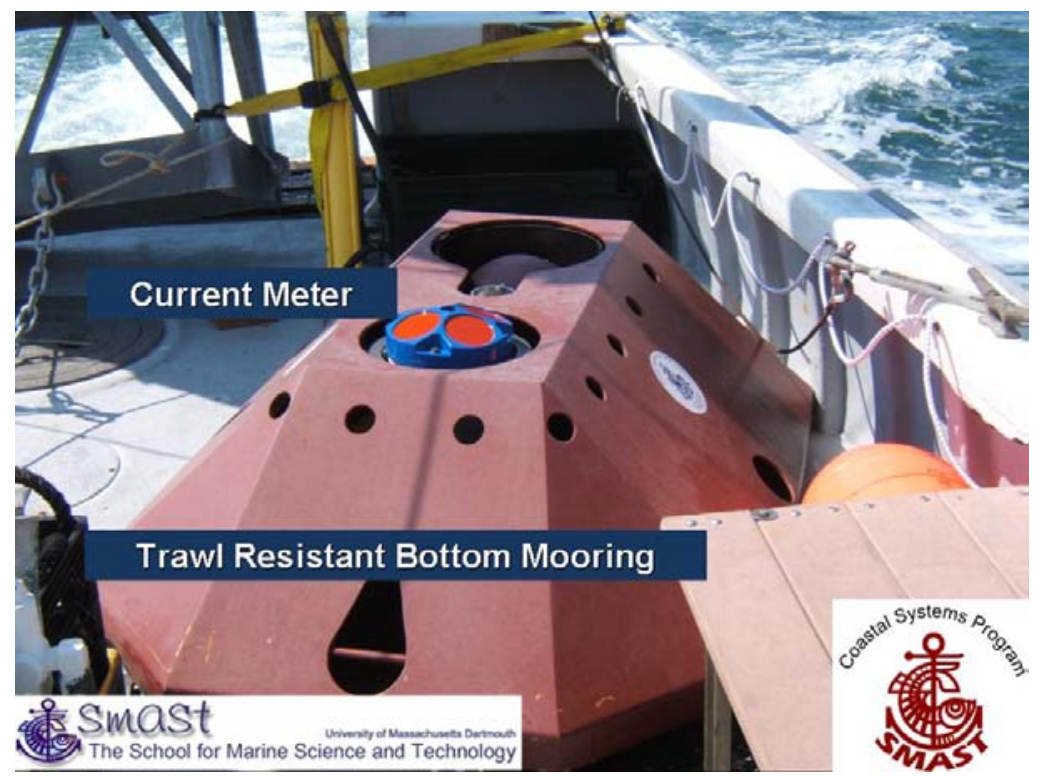

Figure 48 - ADCP deployed November 2010 to measure current velocity over a complete lunar cycle in the high velocity zone of Muskeget Channel. 
The bottom mounted ADCP record was mostly complete with occasional gaps resulting from sand wave movement over the bottom mount and by turbulence that prevented reconciliation of the 4 beam data (Figure 49). Current directions were consistently North-South. As expected, periodic variation in velocity was seen with respect to diurnal tides and lunar cycles. Subsets of the entire deployment are shown in Figures 50-53. Figure 50 shows the time series velocity magnitude during the period that the shipboard ADCP transects were being measured. The remaining figures 51-53 show the velocity magnitudes recorded for Neap, Quadrature, and Spring tides, respectively. December 10 velocities were among the lowest observed (Figure 50), exceeding $1.6 \mathrm{~m} / \mathrm{s}$ in the surface waters only during ebb tides. These results are consistent with those collected during the transect measurements.

Muskeget Channel

Transect 6 - Transect 7

Water Velocity Contour

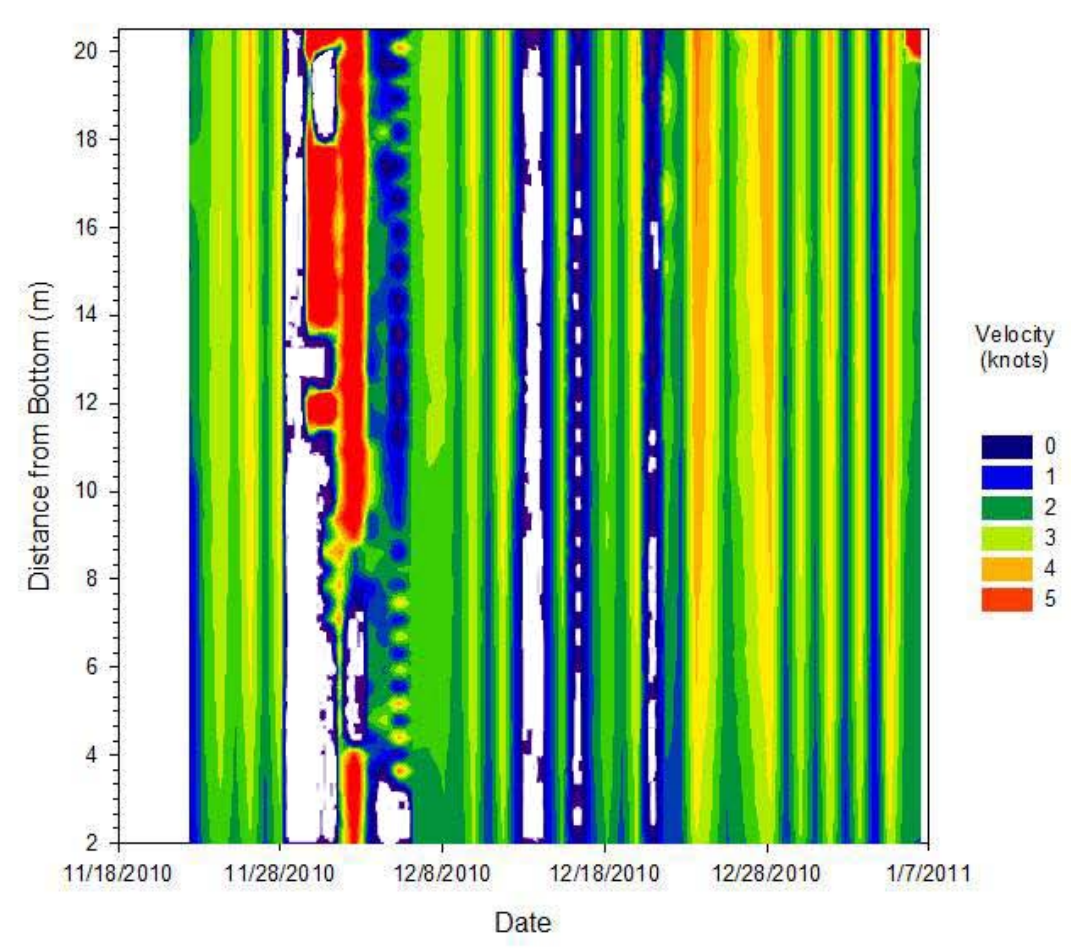

Figure 49 - Contour plot of current velocity for the bottom $20 \mathrm{~m}$ of the water column over the deployment period at a single point along Transect 6.2. Data was collected using the bottom mounted ADCP logging once every 15 minutes between November 22, 2010 and January 6, 2011. Areas in white represent times when data quality was poor due to fouling or extreme turbulence. 


\section{Bottom Mounted ADCP 24 Hour Velocity Contour 3 Days Before Neap Tide for Muskeget Channel December 10, 2010}

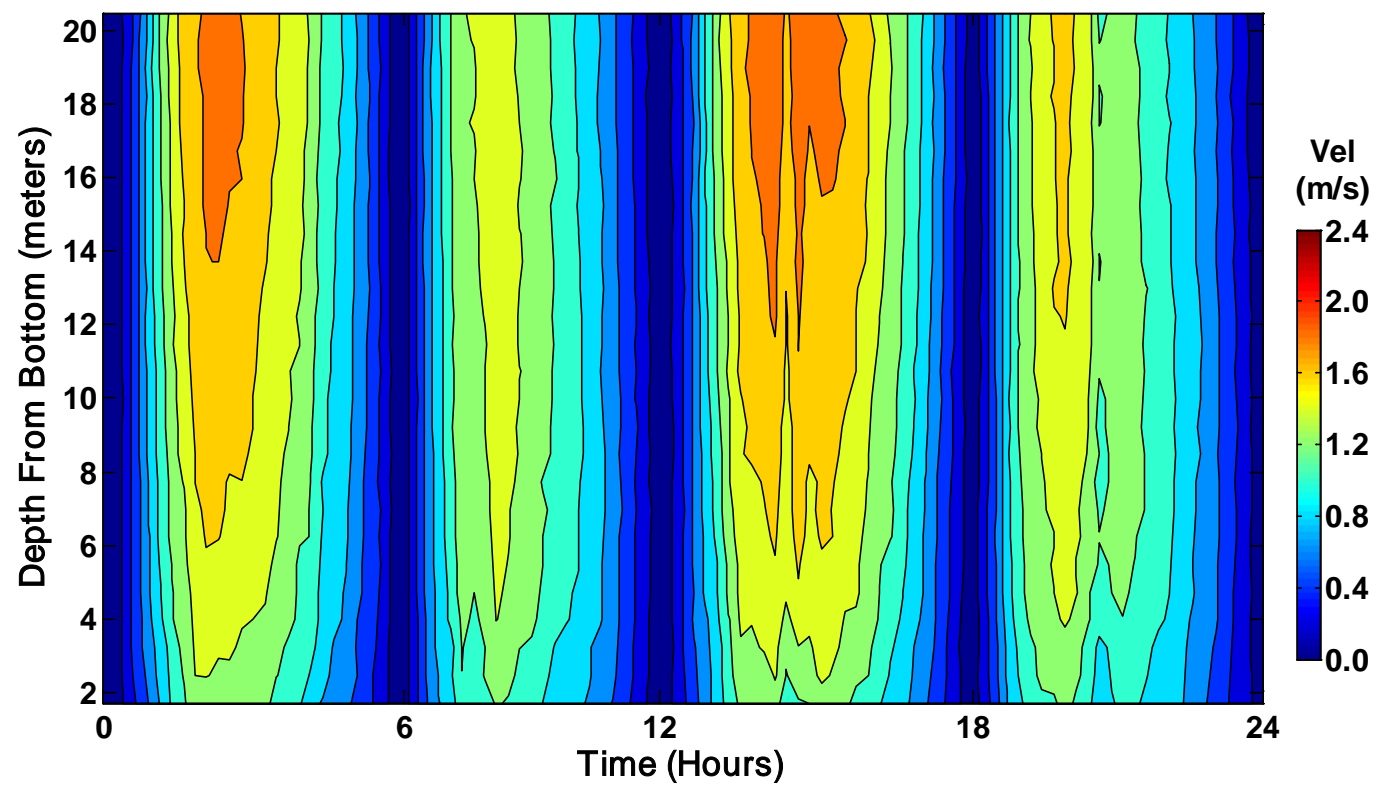

Figure 50 - Hour Velocity Contour Plot of the current velocities within the high velocity zone of Muskeget Channel three days prior to a first quarter lunar (Neap tide) cycle. The highest velocities occurred during the ebb tides. These measurements support the shipboard ADCP surveys that were conducted on December 10, 2010.

The Neap tide velocities were expected to be the lowest recorded, however the velocity magnitudes during one ebb tide were significantly higher than seen in Figure 50. Wind forcing of water through the channel is believed to account for this behavior with support provided by the truncated flood tide and extended slack tide immediately prior. Diurnal asymmetries in the ebb and flood tide velocities were small with a difference of $15-20 \%(1.8 \mathrm{~m} / \mathrm{s}$ vs. $2.2 \mathrm{~m} / \mathrm{s})$ (Figure 51). Similar differences were observed between successive flood tides.

Under quadrature conditions (Figure 52) velocity magnitudes were similar, but slack tide intervals were symmetric as compared to neap tide conditions. The main difference was in the depth to which the maximum velocity zone extends from the surface down into the water column. Although the maximum velocities were similar, the average velocity for the water column increased as the surface high velocity zone extended further down in the water column.

Spring tide conditions (Figure 53) demonstrated similar velocities and symmetry as Quadrature conditions with a further increase in depth of the high velocity zone extending down from the surface. Thus maximum velocities recorded were similar throughout the lunar cycle, yet mean water column 
velocity increased from neap to spring tides by involving a greater portion of the total water column. While the vertical differences in velocity magnitude may create challenges for some turbine designs, the upper velocity threshold remains relatively constant simplifying the engineering required to meet maximum velocities

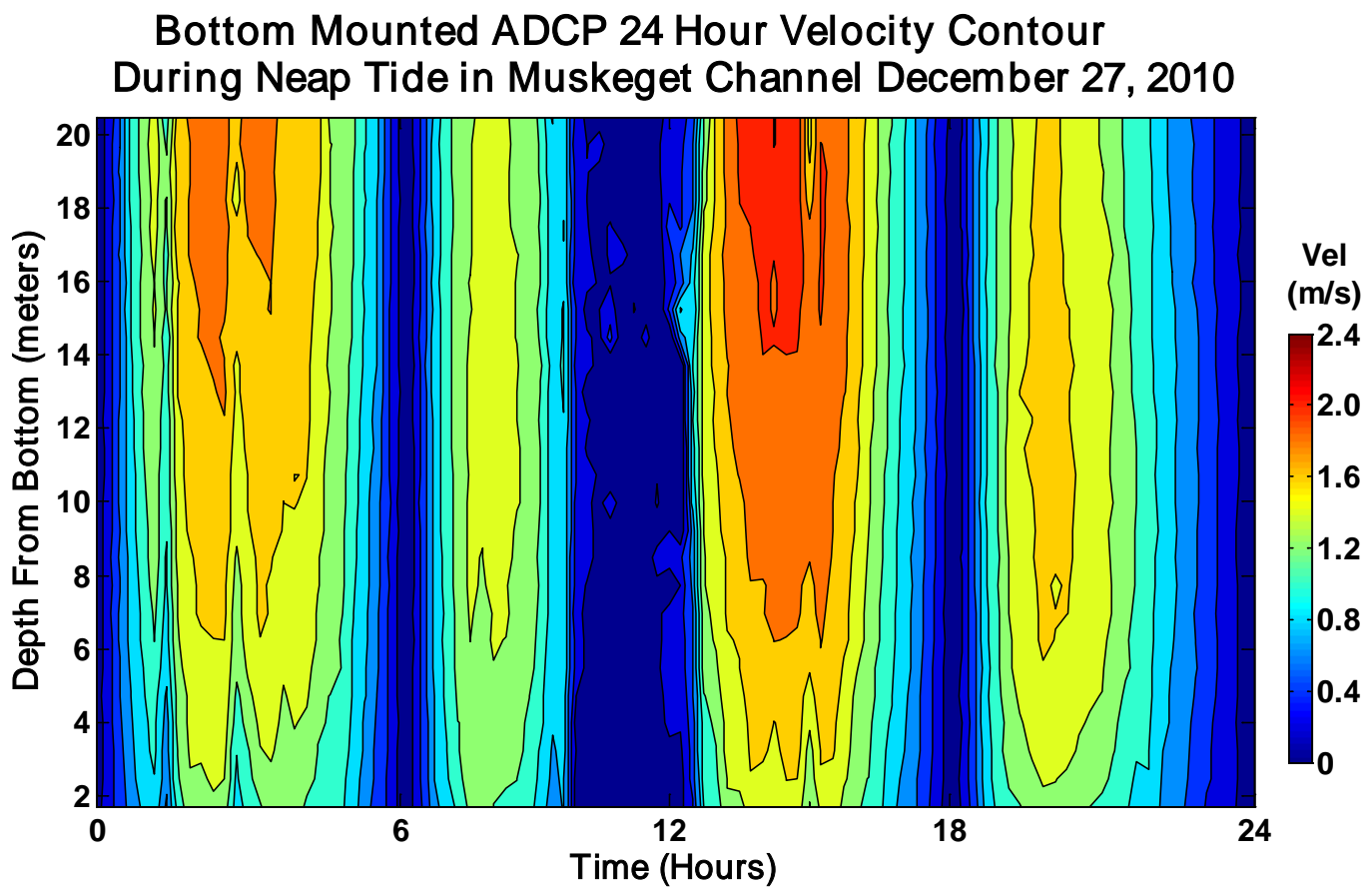

Figure 51 - 24 Hour Velocity contour plot during a true Neap tide in the high velocity zone of Muskeget Channel. Current velocities are at a maximum during the ebb tide conditions. Maximum velocities ranged from 1.6 to $2.3 \mathrm{~m} / \mathrm{s}$ ( 3.1-4.5 knots). 


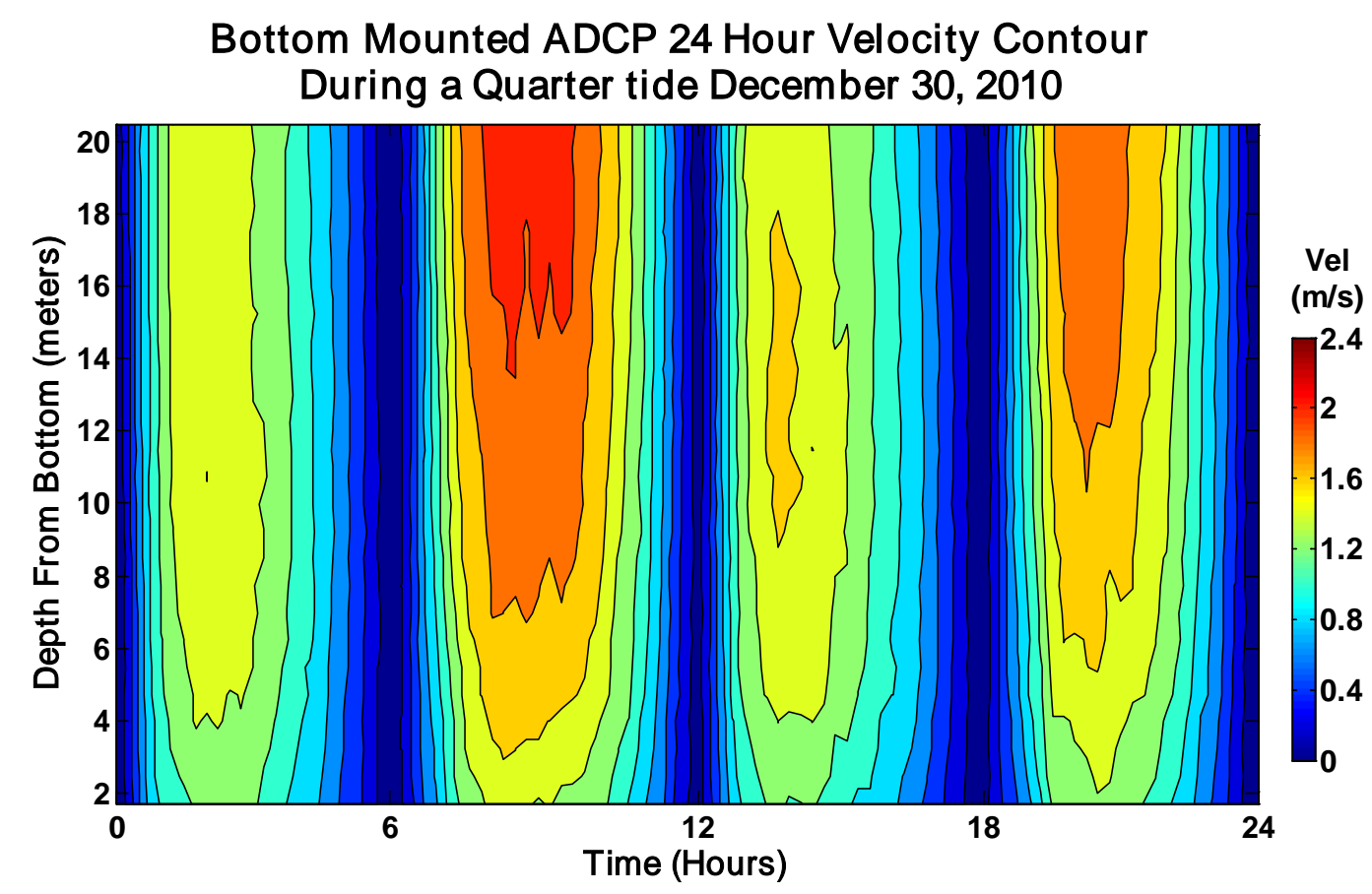

Figure 52 - 24 hour velocity contour plot displaying current velocities during a quadrature between the Neap and Spring lunar tide cycles. Maximum velocities ranged between 1.6 to $2.3 \mathrm{~m} / \mathrm{s}$ ( 3.1-4.5 knots) from the surface to 16 meter depth during the ebb tides. 


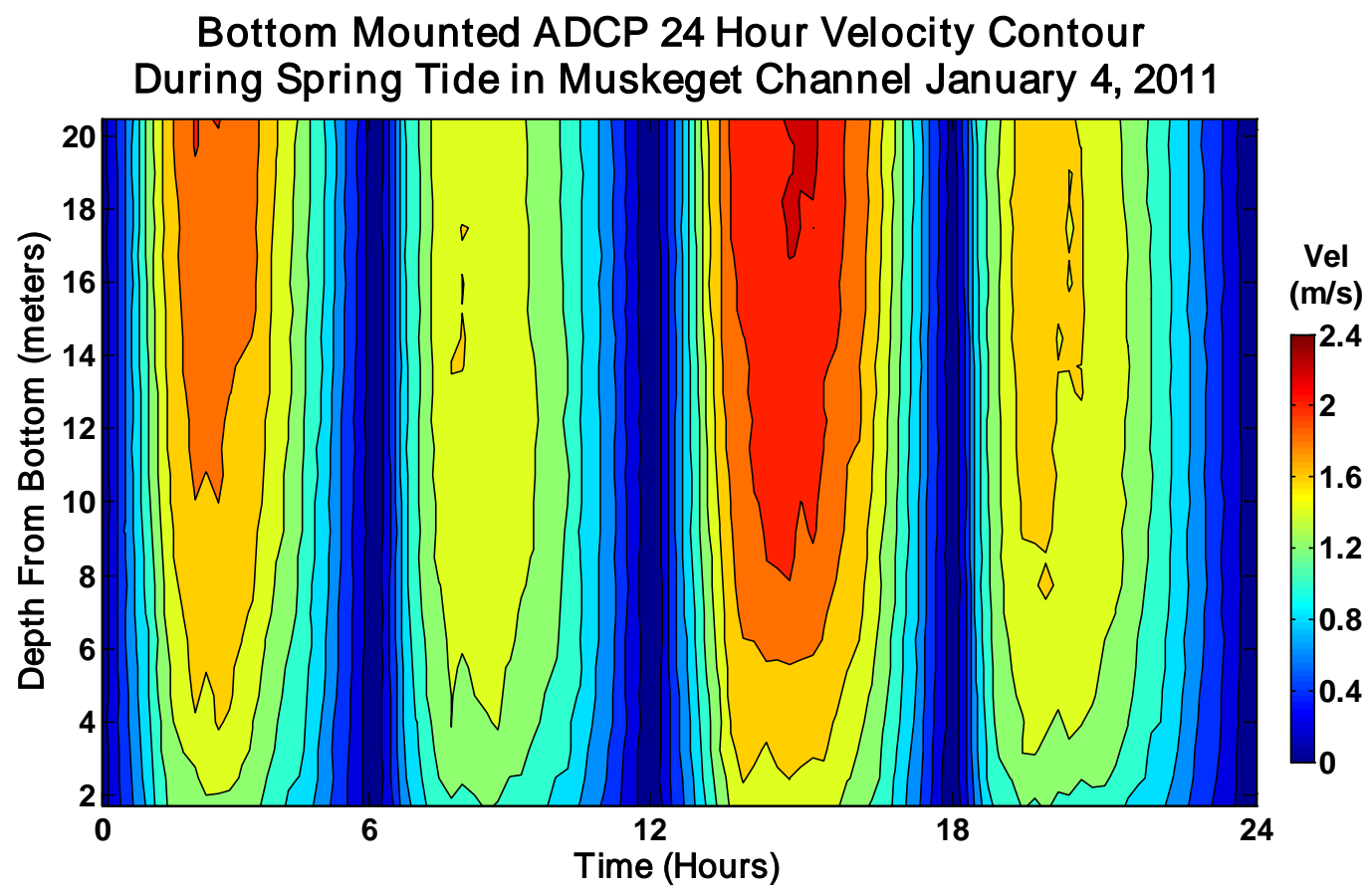

Figure 53 - Spring tide velocity contour plot for a 24 hour period from the bottom mounted ADCP deployed within the high velocity zone in Muskeget Channel. Maximum current velocities ranged between 1.7 to $2.4 \mathrm{~m} / \mathrm{s}(\sim 3.3-4.7$ knots) through the first 16 meters of the water column.

\subsection{Measurement of Near-bottom Current Velocity using ADCP's attached to a Scouring Block to Quantify Effect of a Mooring on Sediment in the High Velocity Zone of Muskeget Channel}

Particularly in high velocity areas, the placement of hard structures on or into the bottom alters sediment transport potentially resulting in new zones of scour or erosion and deposition. The alteration of sediment deposition and erosion plays an important role in the design of the renewable energy structures and potential changes in local habitat. The major habitat change results from either enhanced erosion (removal) or changing the sediment grain size distribution in the immediate vicinity of a mooring structure. Sediment transport alteration was investigated using a combination of field manipulations undertaken by UMASS-SMAST Coastal Systems Program scientists as well as through sediment transport modeling which was undertaken by a team of scientists from Woods Hole Oceanographic (WHOI) and UMASS-SMAST.

The sediment alteration investigations involving field manipulations were focused primarily on the placement of a hard structure on the sea bed in the high velocity zone of Muskeget Channel (Figure 54) and documenting the resulting changes in the sediment characteristics as they are influenced by currents passing around the structure. The structure utilized was intended to be a scaled down analog 
to a theoretical mooring system which would be used for anchoring a tidal turbine device (Figure 55). The structure that was deployed was a concrete cylinder approximately 3.5 feet in diameter and 3.5 feet high weighing 1,404lbs. Scour around the concrete cylinder and grain size were determined over a one month period. The scour investigation was undertaken in the area of Muskeget Channel currently being considered for future pilot scale deployments of tidal current generating units under the existing Town of Edgartown Preliminary Permit issued by the Federal Energy Regulatory Commission (FERC).

Two different acoustic devices were mounted on top of the concrete cylinder in order to measure near bottom current velocities that drive the scouring of sediments around the structure (Figure 56). Both instruments were downward facing velocity meters measuring current velocity from the sediment surface to approximately 1 meter above the bottom. One meter was an RDI Sentinel Workhorse $(1.2 \mathrm{MHz})$ while the other instrument was a Nortek Aquadopp Profiler $(1 \mathrm{MHz})$, both instruments made velocity measurements at 10 minute intervals (bin size $10 \mathrm{~cm}$ ). The instruments were mounted $180^{\circ}$ apart on a turntable that was oriented so that the instruments could measure both the incoming current profile and the current profile resulting from interaction with the cylinder, regardless of the tide direction. The instrumented concrete cylinder was deployed on March 15, 2010 and the instruments were retrieved on April 23, 2010 for a total deployment of 40 days. The structure remained on the sea bed and was utilized as an anchor for one of two bio-fouling arrays discussed in Section 3.6. Presently, the structure is still on the sea bed and CSP scientists plan to continue the periodic monitoring of the structure to see how biota accretes over time and the degree to which the structure attracts fish and other marine life. Prior to deployment, the side of the concrete cylinder was also marked at 6 inch intervals in order to document the degree to which sediments accrete or erode away from the base of the structure as the tide shifts direction through a tidal cycle. 


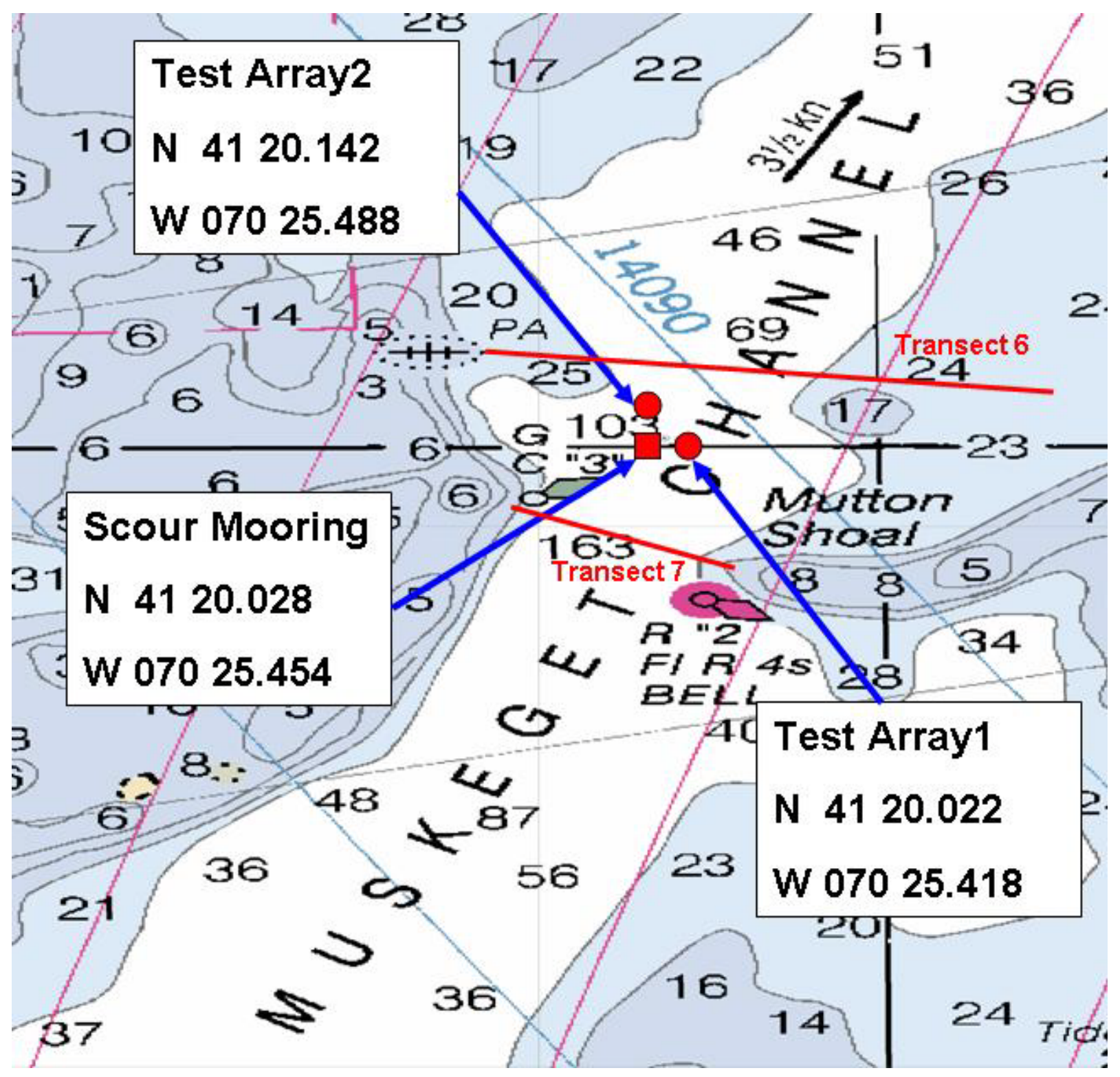

Figure 54 - Location of the concrete cylinder deployed as a scour mooring to document sediment alterations resulting from high velocity currents flowing around the mooring under ebb and flood tide conditions. Position of the scour mooring is shown relative to bio-fouling arrays 1 (untreated) and 2 (treated) as well as position of ADCP surveying completed along Transects 6 and 7 that demarcate the optimal high velocity zone for future tidal turbine deployments under the Town of Edgartown FERC permit. 


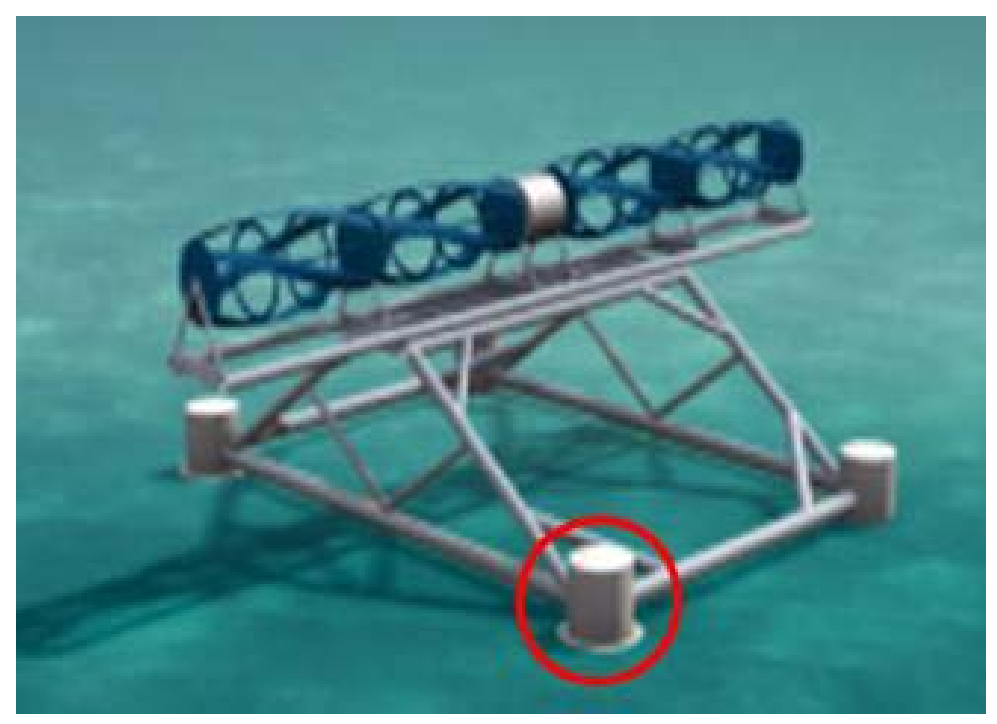

Figure 55 - Theoretical mooring system to support a OCGen Tidal Turbine from Ocean Renewable Power Company. The smaller scale concrete cylinder deployed for the scouring investigation was selected to mimic the sediment effect induced by one foot of the mooring system (red circle).

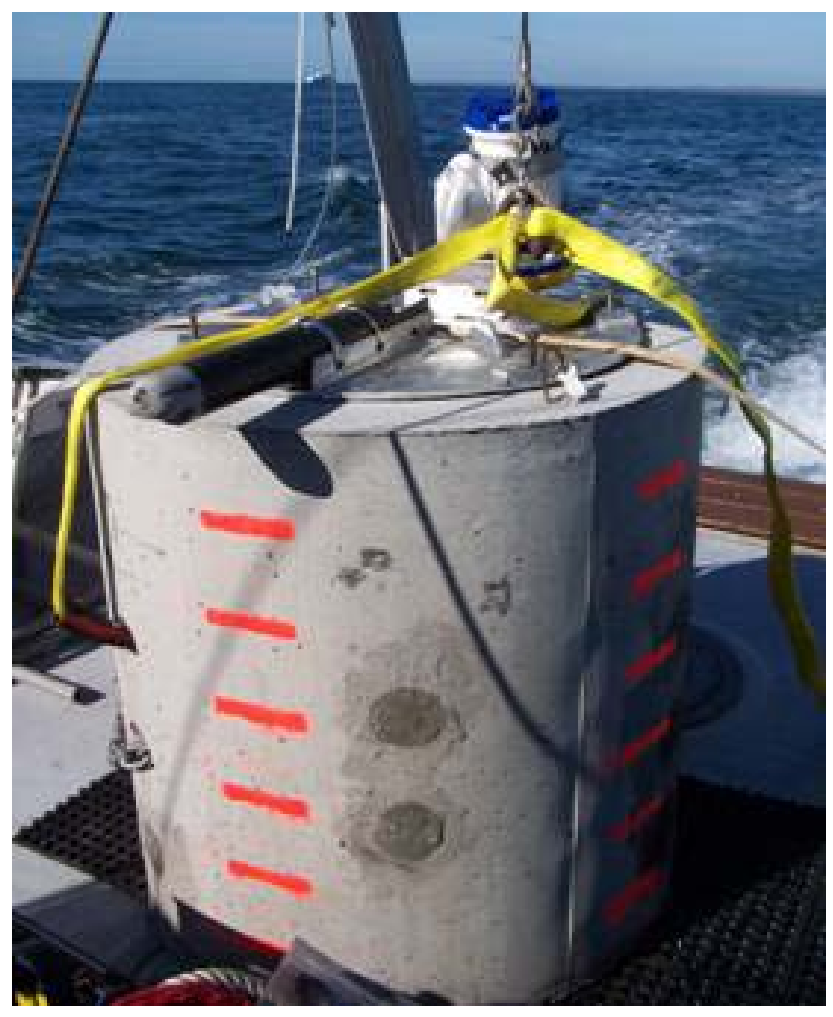

Figure 56 - Concrete cylinder deployed in the high velocity zone of Muskeget Channel and utilized to investigate sediment scour and settling that might result from tidal turbine moorings. 
The concrete cylinder was deployed from the research vessel using a winch and A-frame and was guided to the bottom by diver to insure the cylinder was level and up-right. To insure that the instruments would be properly aligned along the north-south axis of the channel and into the current, a mounting plate was specifically constructed to enable the diver to orientate the instruments once the cylinder was positioned on the sea bed. Additionally, at the time the concrete cylinder was initially deployed, the diver retrieved one sediment grab from approximately 10 meters distant from the side of the cylinder as well as three cores from adjacent to the cylinder. The grab obtained 10 meters distant from the cylinder served as a control sample representative of natural benthic conditions while the three sediment cores adjacent the concrete cylinder were obtained for grain size analysis prior to any scouring effects. 40days post deployment, the cylinder was re-visited and a diver descended to the bottom to remove the instruments for data download. During that instrumental retrieval, the diver was also able to obtain a second grab sample from 10 meters distant from the side of the cylinder. Additionally, the diver was able to obtain visual documentation of the scouring and settling that had occurred around the base of the cylinder over the course of the 40 day deployment. Unfortunately, the current started increasing to the point that the diver could not retrieve a second set of sediment cores from immediately adjacent to the cylinder in order to perform a post scour grain size analysis. As such, CSP scientists qualitatively estimated the sediment characteristics from the underwater photographs obtained prior to removing the instruments. A second attempt to collect post-scouring sediment samples was unsuccessful at the time the bio-fouling array was being deployed because the deployment of the array took longer than expected and the current became too strong and the dive had to be aborted before sediment samples could be retrieved. On a third attempt (August 2011), the cylinder could not be located because the surface expressions had been compromised and it was deemed unsafe to conduct a free descent in strong current. As previously mentioned, the cylinder remains on the bottom and sediment sample collection by diver from the scoured area adjacent the cylinder is planned when the structure it is revisited to document biotic growth.

\section{Near-field Current Flow}

Two different acoustic instruments were utilized to quantify the current velocities around the base of the concrete cylinder which were associated with the observed level of scour. Pressure data obtained from the Aquadopp Profiler indicated that excessive scour around the cylinder caused the cylinder to sink into the sand until it reached on a more stable cobble layer. This was also confirmed by a plot of the pitch and roll data (Figure 57) obtained from the Aquadopp Profiler and verified by RDI Sentinel which showed that after the first 48 hours following deployment, the cylinder reached a stable substrate and did not move for the duration of the 40 day deployment.

The plot of acoustic backscatter signal strength (Figure 58) shows the bottom position (approximately marked by dashed black line). The entire cylinder sank into the sand over the first 48 hours and then rested at a stable level. Material moves around the cylinder and is deposited on the lee side of the cylinder during each tidal cycle. This barchan type structure varies in height between 0.2 and 0.6 meters. The height, and thus the quantity of material roughly varies with the Spring and Neap tides, but displays a lag of 24-36 hours. Data obtained from the ADCP on the reverse side of the cylinder is similar though opposite in phase. Visual inspection of the cylinder indicates that the area influenced by the cylinder 
does not exceed a radius of two cylinder diameters in line with the current and less than one cylinder diameter normal to the current direction.

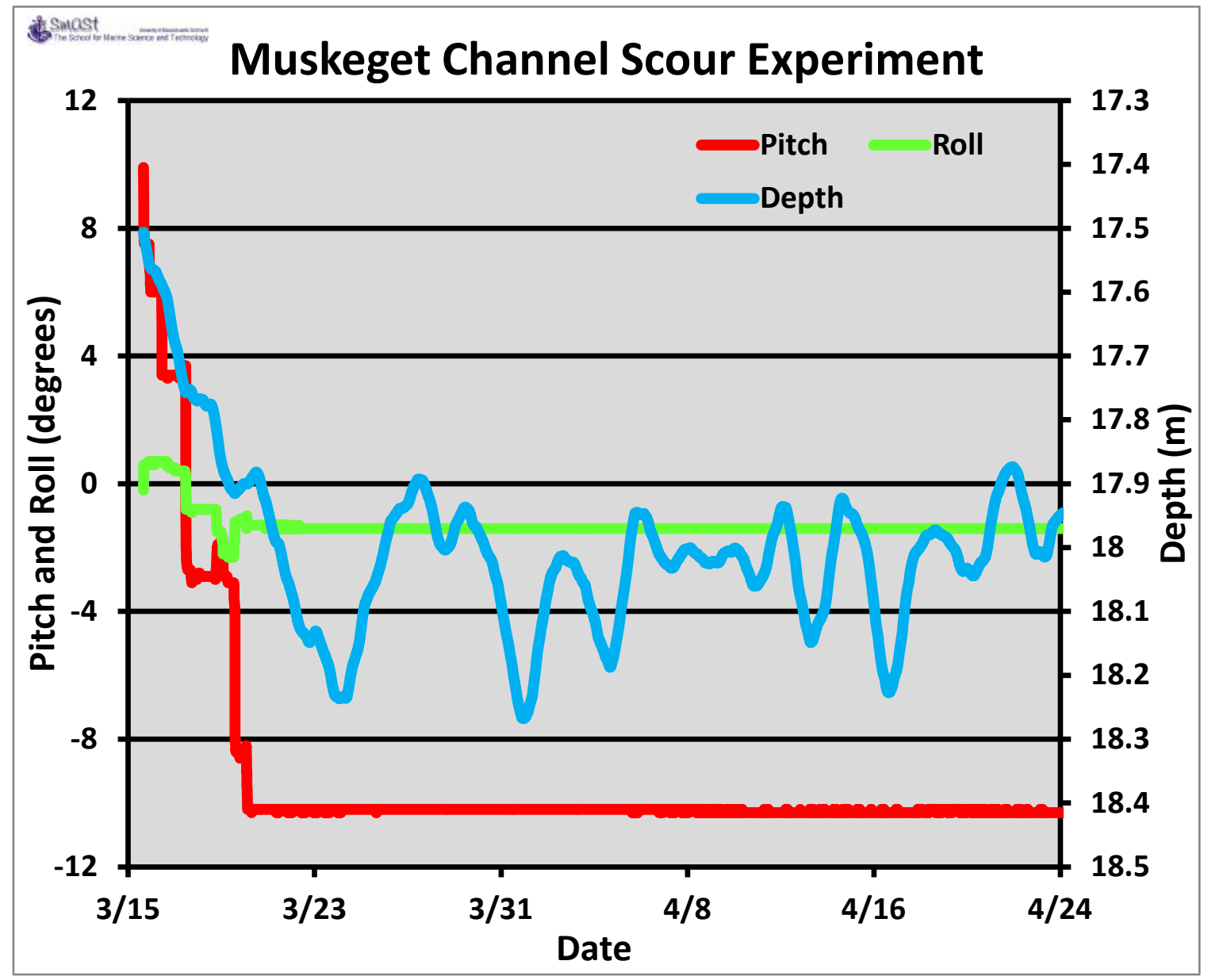

Figure 57 - Pitch, Roll and Depth data obtained from the Aquadopp Profiler deployed on the concrete cylinder utilized for the scouring investigation. Pitch and roll both remain constant after an initial $48 \mathrm{hr}$ settling period. Slight variations in Depth (atmosphere corrected pressure) reflect small uncompensated changes in tide, sea state etc. 


\section{Echo Intensity from Scour Experiment ADCP}

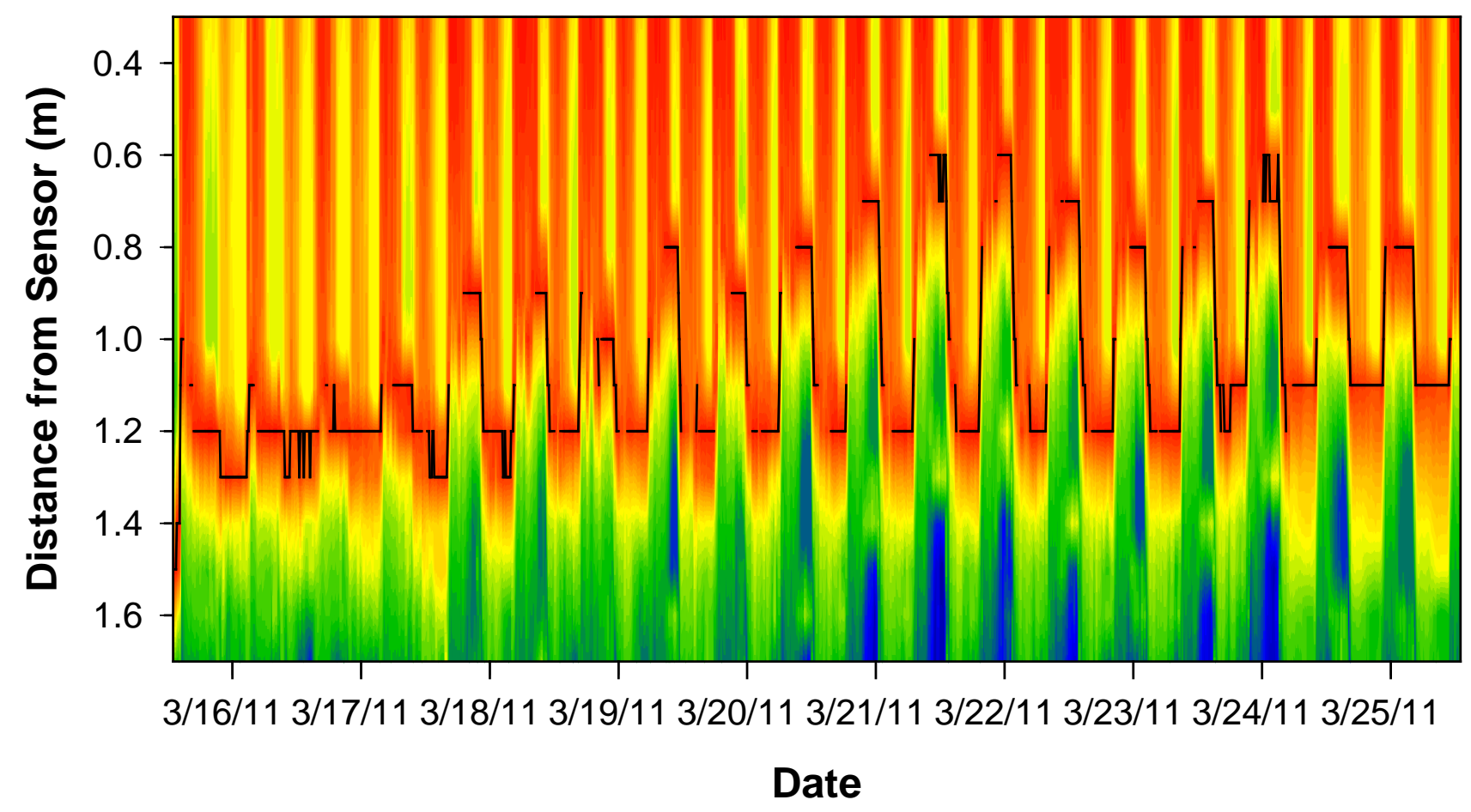

Figure 58 - Plot of backscatter echo intensity through time obtained with Aquadopp Profiler. Blanking distance was $0.35 \mathrm{~m}$. Black stepped line indicates the distance to the sediment surface inferred from maximum backscatter intensity. The cylinder rests on the sediment surface as the sediment is eroded from beneath. Deposition and erosion of a barchan composed primarily of gravel occurs during each change in tidal direction.

Time series measurements show the gross influence of the cylinder on near bottom current velocities. The current velocity measurements unaffected by the cylinder are significantly greater than those in the lee of the cylinder (Figure 59). The plot shows results from the Aquadopp facing north in the ebb tide direction. Average ebb tide velocity (0.3 -1.0 m from the sensor head) for March 25-27 was $0.7 \mathrm{~m} / \mathrm{s}$ and flood tide velocity resulting from interference with the cylinder was $0.3 \mathrm{~m} / \mathrm{s}$ ). In profile the velocity vectors show relatively unimpacted flow over the cylinder from 0.3 to $0.6 \mathrm{~m}$; below $0.6 \mathrm{~m}$ velocity magnitude was similar, however, the direction was often reversed indicating significant eddies which created the sediment structures observed during recovery (Figure 60). 


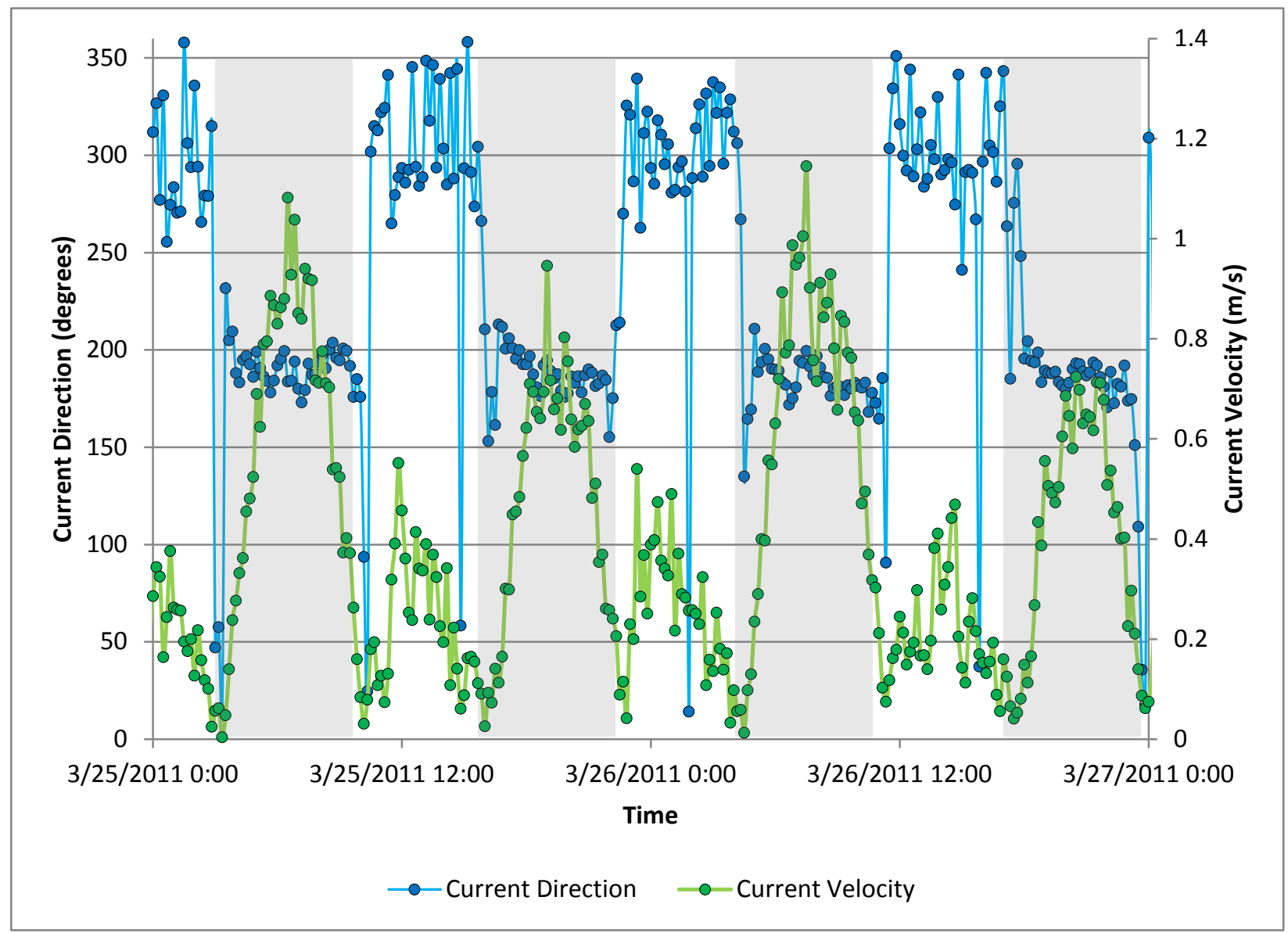

Figure 59-Time series measurements of current velocity and direction from March 25 through March 27 shortly after the scour cylinder reached its final depth. Velocities and directions were averaged for depths of 0.3-0.6 $\mathrm{m}$. Ebb tide periods are shaded. The time frame reflects peak Spring tides conditions. 


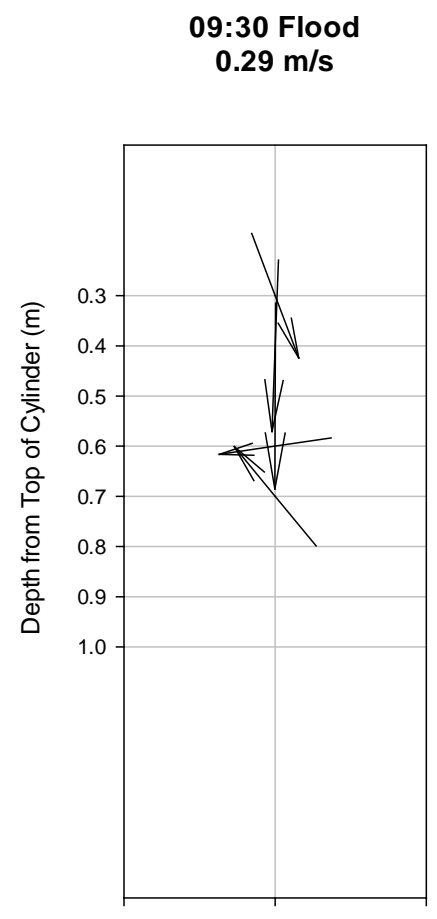

10:30 Flood

$0.37 \mathrm{~m} / \mathrm{s}$

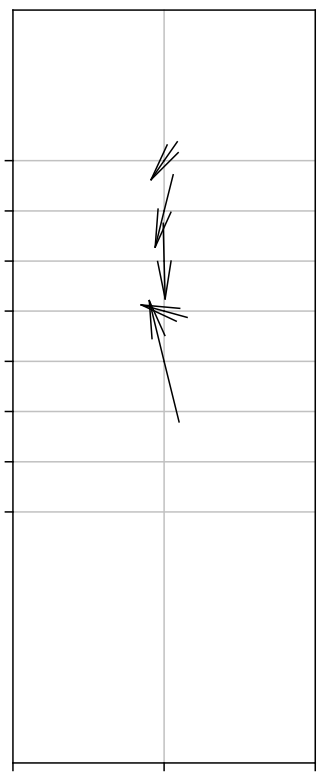

17:30 Ebb

$0.51 \mathrm{~m} / \mathrm{s}$

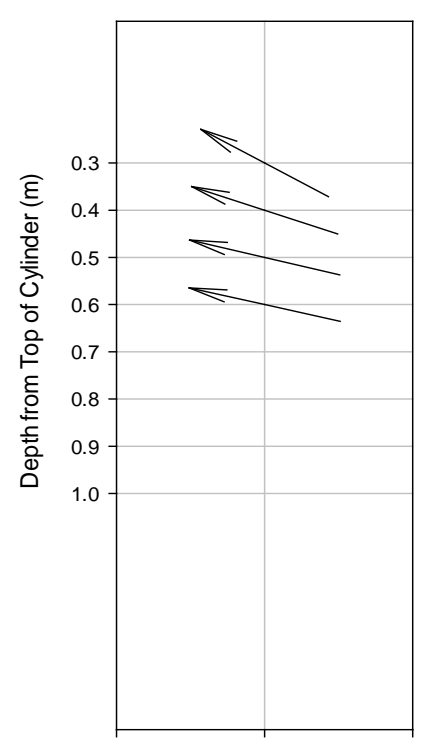

11:30 Flood

$0.81 \mathrm{~m} / \mathrm{s}$

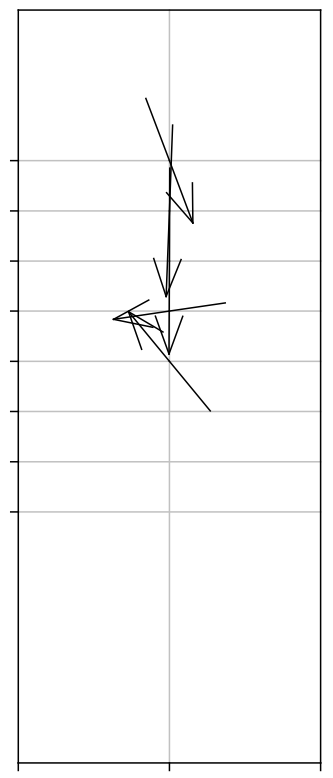

19:30 Ebb

$0.91 \mathrm{~m} / \mathrm{s}$

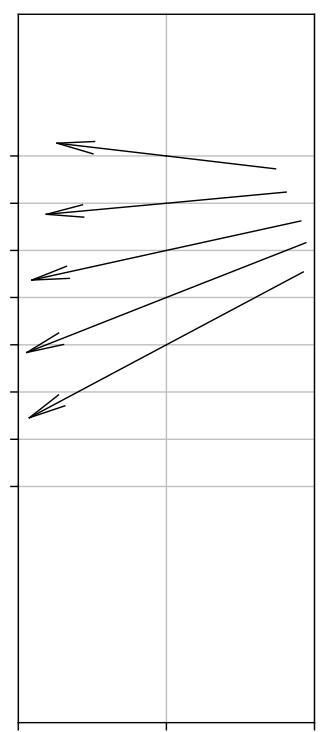

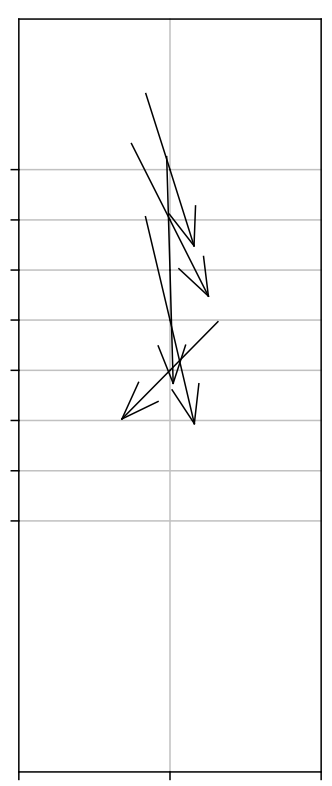

12:30 Flood

$0.94 \mathrm{~m} / \mathrm{s}$

20:30 Ebb

$0.79 \mathrm{~m} / \mathrm{s}$

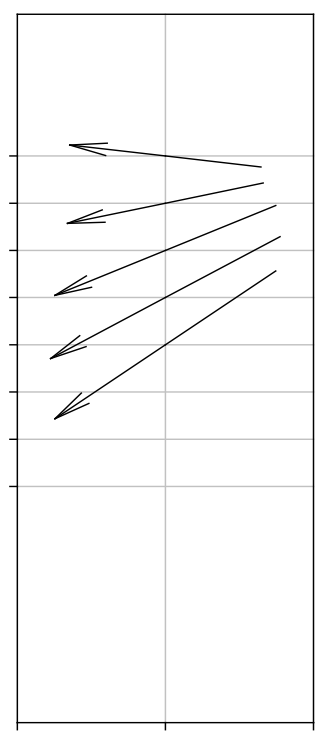


13:30 Flood

$0.75 \mathrm{~m} / \mathrm{s}$

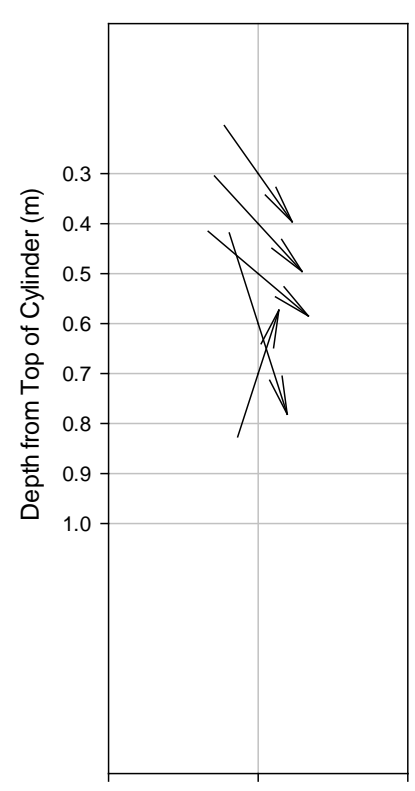

14:30 Flood

$0.56 \mathrm{~m} / \mathrm{s}$

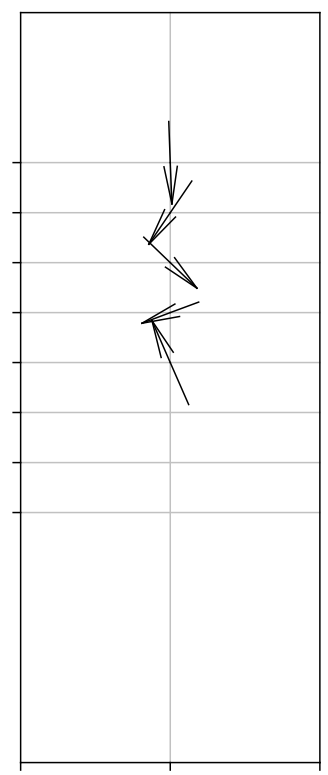

15:30 Flood/Slack

$0.3 \mathrm{~m} / \mathrm{s}$

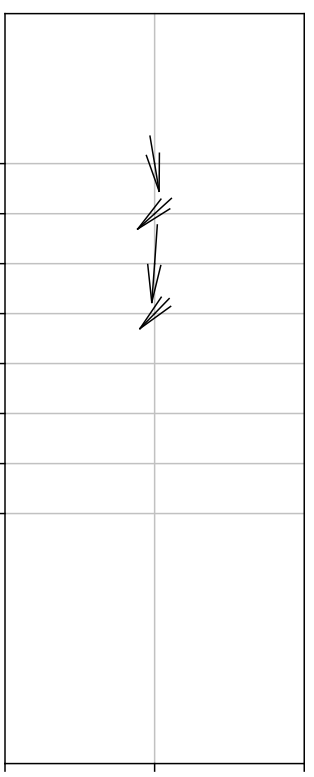

16:30 Ebb

$0.14 \mathrm{~m} / \mathrm{s}$

Figure 60-Time series profiles of current vectors measures by the Aquadopp profiler. Time, tide state and incoming velocity are noted at the top of each panel. Vectors are centered on the depth bin measured, vector magnitudes are proportional and vector directions follow a compass rose convention where the top of the page represents North and the bottom of the page represents South.

\subsubsection{Observed Scouring Effects}

Photographed observation of scouring made by diver at the time the current profilers were retrieved from the cylinder confirmed the current velocity measurements. As suggested by the current velocity measurements, pressure data, acoustic back scatter, pitch, roll and depth data the cylinder was observed to be resting on a relatively stable gravel sediment mixed with cobbles. Based on the current flow (ebb vs. flood) around the base of the cylinder, the diver observed medium to coarse sand and gravel scouring away from the down-gradient side and accreting on the up-gradient side of the cylinder (Figure 61). Finer sand sediments that were initially observed when the cylinder was first lowered to the sea bed had been scoured away from the base of the cylinder allowing it to settle to the gravel and cobble layer. Observations suggest a very dynamic sedimentary environment where by mooring structures associated with deployed tidal devices would be subject to a constant cycle of scour and accretion of sediments on a diurnal basis. While these scouring effects would be very localized, it would have an affect on benthic organisms. It should be noted though that in general this high velocity zone of Muskeget Channel appears to have very limited benthic infauna and epi-fauna and has very similar physical and sedimentary characteristics as the dynamic inlets of estuaries such as Chatham Harbor, Pleasant Bay and Plymouth Harbor (all of which have very low documented benthic communities). 


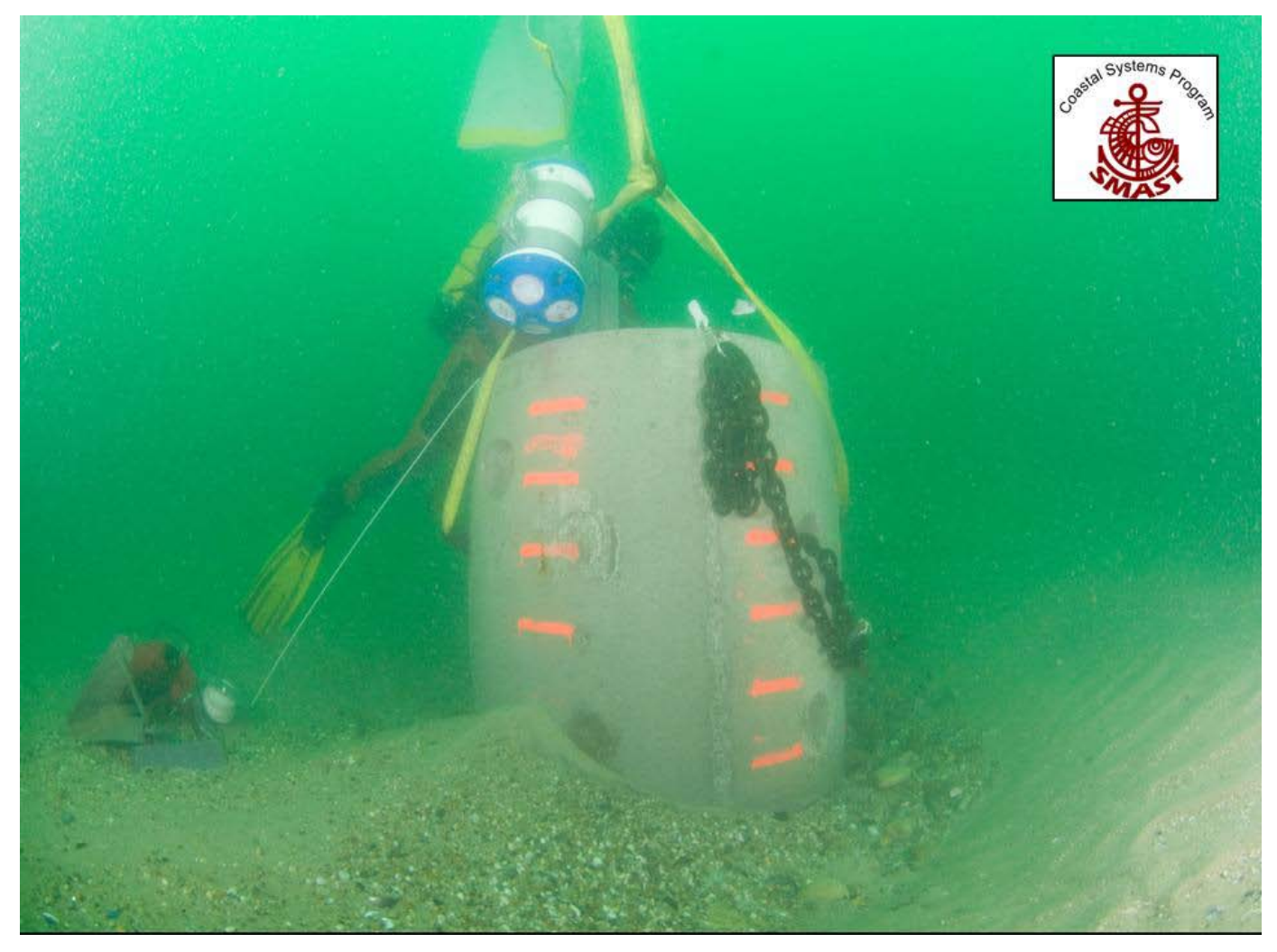

Figure 61 - Observed sediment scouring and accretion around the base of the concrete cylinder deployed for the scouring investigation and serving as a scaled down analog to a portion of a mooring system for tidal turbine installation on the sea bed. Finer grained sand has been scoured away to reveal a stable gravel and cobble layer.

\subsubsection{Sediment Grain-size Distribution}

Sediment grain size distribution measured adjacent to the scour cylinder during deployment was typical of the sand waves which are endemic in the region of Muskeget Channel. Grain sizes are skewed towards the coarser material (Figure 62). Approximately 80 percent of the sediment was greater than $1 \phi$, and the grain size distribution was consistent throughout the top $20 \mathrm{~cm}$. This depth corresponds to the change in the cylinder depth observed during the first 48 hours after deployment. As seen in Figure 59 sand waves at the time of recovery moved around the cylinder and scouring exposed the underlying gravel and cobbles. Future work being planned for the summer 2012 field season is going to focus on the depth and spatial extent of the cobble layer using sub-surface profiling technology. 
These sediment grain size data coupled with the near bottom current velocity measurements and bathymetry data from the site were used to parameterize and validate a sediment transport model. Sediment transport modeling was undertaken in a collaborative manner between scientists from Woods Hole Oceanographic Institution and UMASS-SMAST and is discussed in a separate section of the report. The main objective of the model was to evaluate potential changes in sediments or bed forms resulting from placement of hard bottom structures to support renewable energy platforms. Data collected under this grant and sediment transport modeling results will be critical to advancing the overall understanding of how mooring systems for tidal current generating devices interact with the marine environment in Muskeget Channel as well as areas of high current and similar sediment characteristics elsewhere.

\section{Scour Cylinder Surround Sediment Grain Size Distribution}

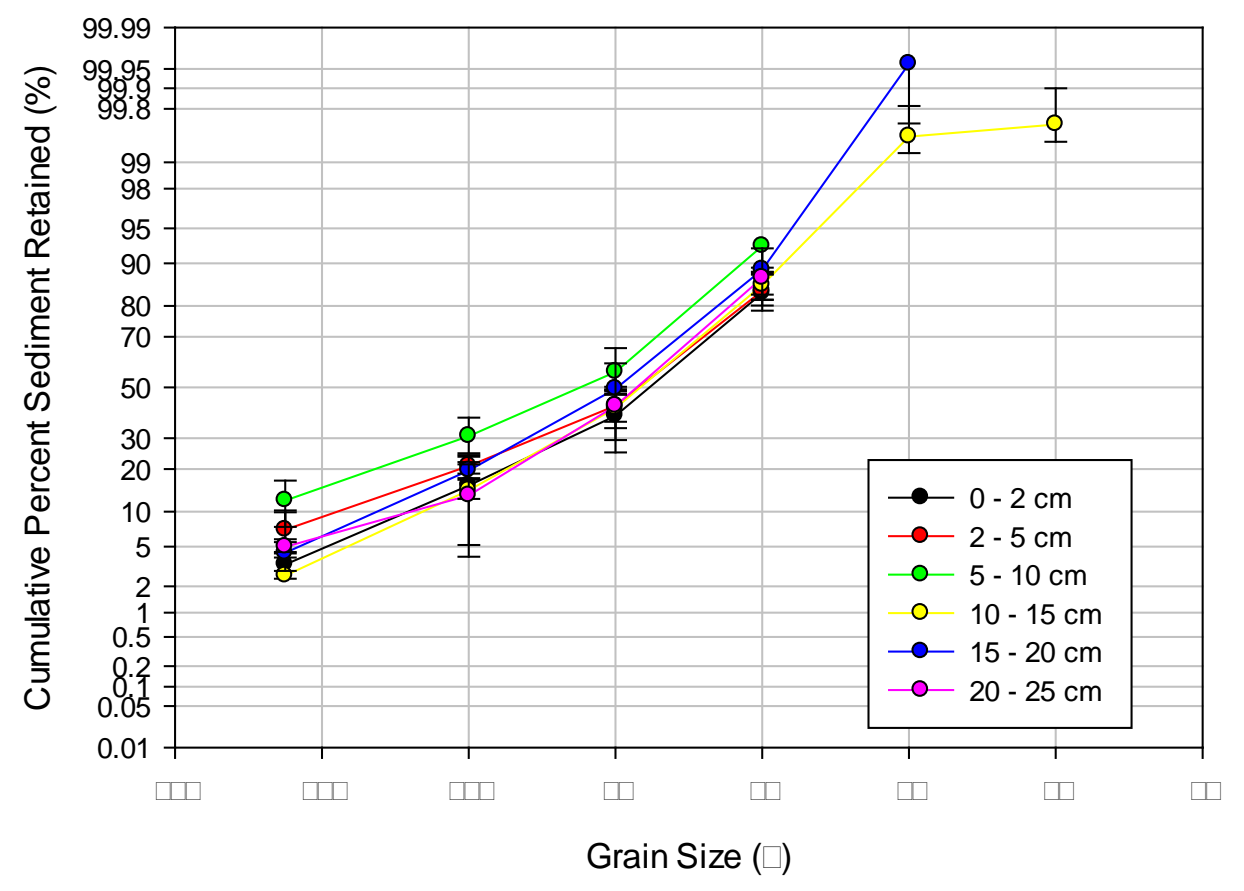

Figure 62-Grain size distribution surrounding scour cylinder at the time of deployment. Distribution was typical of sand waves in the vicinity of Muskeget Channel. 


\section{Field Data Collection (BIOLOGICAL - Habitat Assessment)}

\subsection{Assess likely Fouling Communities Post-construction using Fouling Plates and Determine Associated Fouling Rates}

Under an existing FERC Permit held by the Town of Edgartown, several arrays of tidal turbines are envisioned for deployment in the high velocity zone of Muskeget Channel. Tidal turbines provide hard structures for organisms to colonize, whether mooring blocks, cables or piles. As such, under this grant CSP scientists proposed to investigate the degree to which materials similar to that used for construction of tidal turbines would bio-foul over time in the vigorous flows encountered in Muskeget Channel. To assess post-construction fouling communities, fouling plates were used to determine the resulting animal and plant community that might become established and the fouling rates. The biofouling experiments focused on determining what will become established, rather than the short-term evolution of the community. Two bio-fouling arrays (each a component of the overall experiment) were deployed with multiple fouling plates at three depths to allow for replication and time series "harvesting" to asses fouling rates. One array consisted of untreated fouling plates while the second was treated with anti-fouling paint commonly used for marine applications and potentially for treating tidal turbines (Figure 63 and 64).

While tidal turbines are presently made of a variety of materials depending on the manufacturer, only one technology developer was willing to donate material to this program. For this grant CSP scientists secured composite material that constitutes the frame of an OCGen tidal turbine generator developed and manufactured by Ocean Renewable Power Company. As ORPC was voluntarily participating in the bio-fouling experiment, ORPC engineers were most interested in the bio-fouling of the composites rather than the elements of the tidal turbine generator that were comprised of more traditional material such as steal. Additionally, the composite material makes up a large fraction of the overall turbine generating unit. Therefore, the fouling plates utilized to build the bio-fouling arrays were made of the same composite material as used to construct the generators. For the experiment, it was planned that the fouling plates would be deployed at the proposed depth of the generators, near the sediment surface and at a mid depth. The mid-depth plates would correspond to the limit of the photic zone. Each bio-fouling array was anchored to the sea bed using a concrete mooring and consisted of three sets of fouling plates (surface, mid, bottom) and each set was composed of three "plates". To examine the conditions that the test arrays would encounter with the varying current velocities, mooring design simulations were performed using a MatLab based program. Array design, environmental variables, as well as drag and current components were accounted for during the simulations. The minimum (slack tide), maximum $(2.0 \mathrm{~m} / \mathrm{s})$ and average $(1.6 \mathrm{~m} / \mathrm{s})$ current velocities variables used in the simulations were based on velocity data acquired from the previously deployed bottom mounted ADCP. As expected results indicated that the arrays would remain vertical in the water column at slack tides (Figure 65). With the average current velocity $(1.0 \mathrm{~m} / \mathrm{s})$, results demonstrated a shift in the array's vertical position but remained within the desired depth zone(s) within an acceptable range (Figure 66); under maximum current velocities observed in the high velocity zone of Muskeget Channel (2.0-2.5 m/s) the bio-fouling 
arrays would be positioned approximately 20 feet off the bottom (Figure 66). The test array deployed represents a compromise between all of the various factors. Mooring weight was kept under 1 ton, and the fouling plates were kept within 5 meters of the ideal depth at least $75 \%$ of the time. The depth zone occupied by the plates in the array represented that proposed in a full build out scenario. To prevent influence between the arrays, each of the units were deployed with approximately 250 meter separation within the high velocity zone of Muskeget Channel (see Figure 547). Sufficient separation was also necessary to keep the two different arrays from becoming tangled with each other during the changing of the tides. The treated array was deployed at a depth of approximately 95-100 feet while the untreated array was deployed at a depth of approximately 85-90 feet. The treated bio-fouling array was deployed on July 12, 2011 and the untreated array was deployed on July 11, 2011.

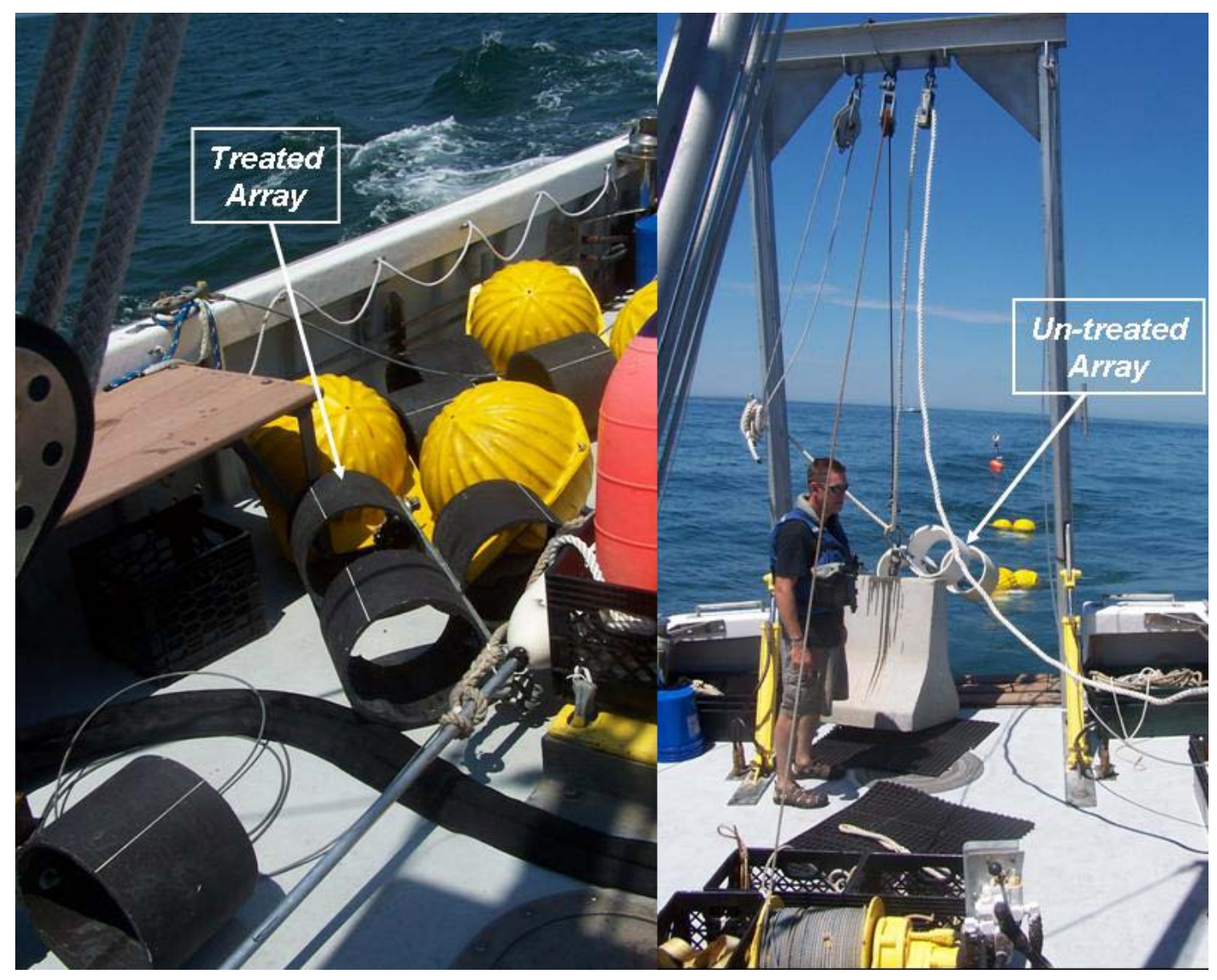

Figure 63 - Treated (left) and untreated (right) arrays prior to deployment in the high velocity zone of Muskeget Channel. 


\section{Bio-Fouling Array}

Array

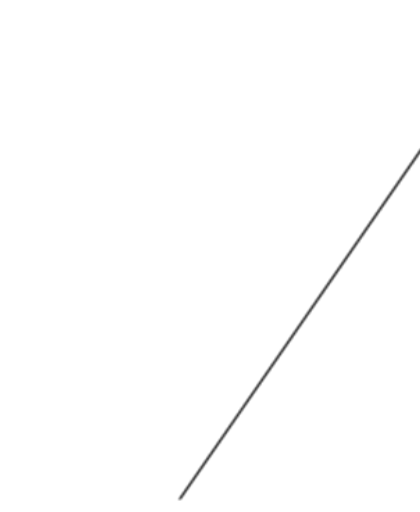

(1)

(ᄋ)

Benthos Floats

$\longleftarrow \quad 25 \mathrm{ft}$ Steel Cable

Treated Test

Units
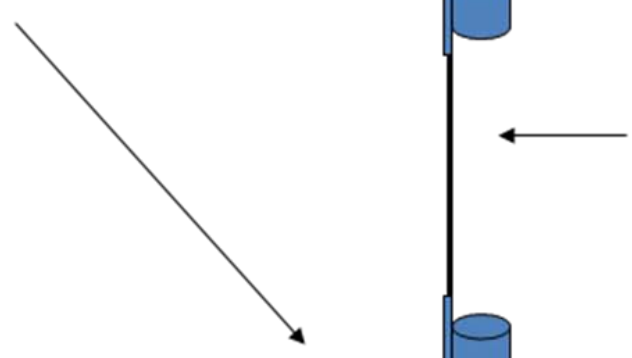

\section{$20 \mathrm{ft}$ Steel Cable}

\section{Benthos Floats}

\section{Anchor}

Figure 64 - Schematic of bio-fouling array as deployed in the high velocity zone of Muskeget Channel (treated and un-treated) 


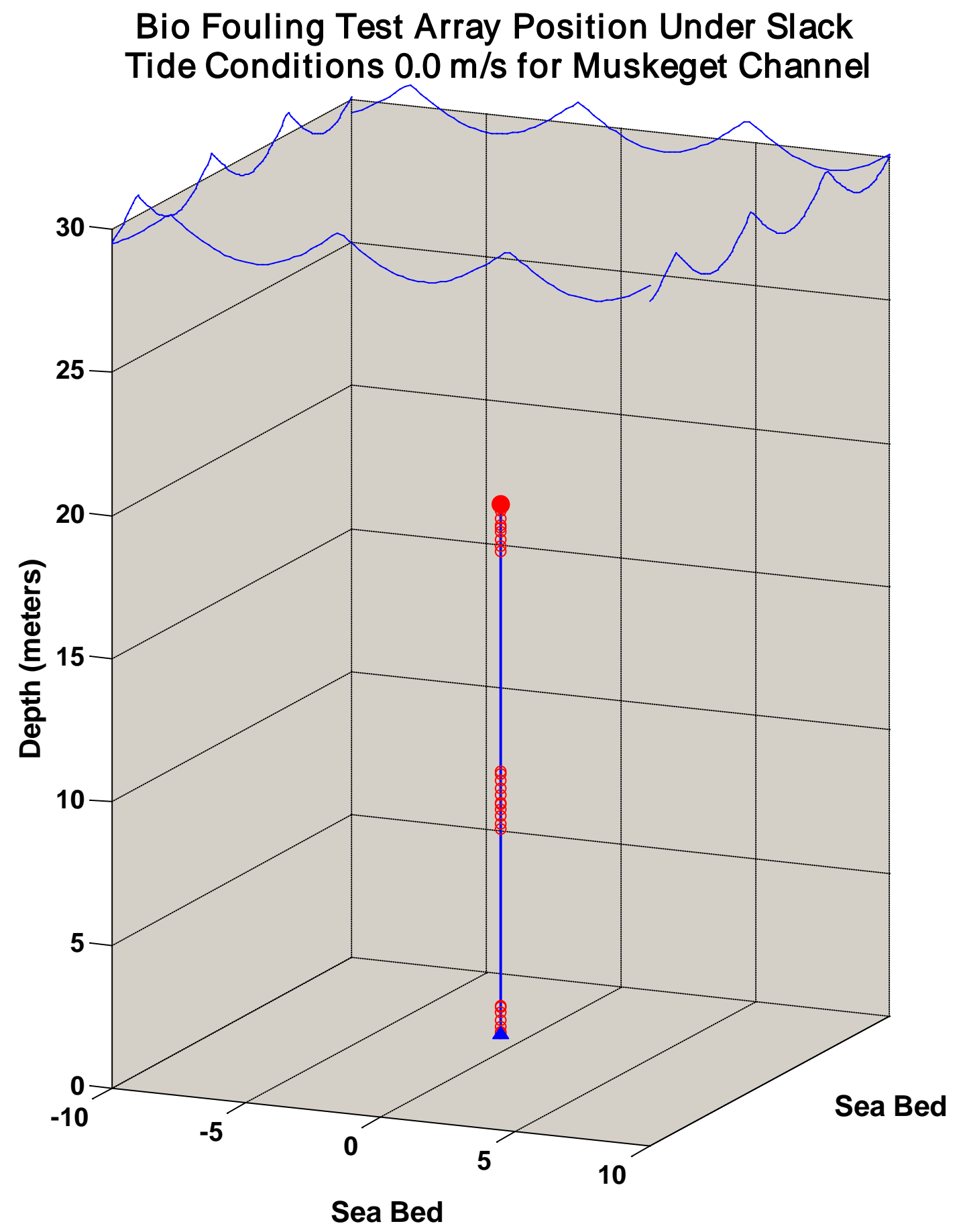

Figure 65 - Bio-fouling array shown to remain in a vertical position under idealized slack tide conditions $(0.0 \mathrm{~m} / \mathrm{s}$ current velocity). 


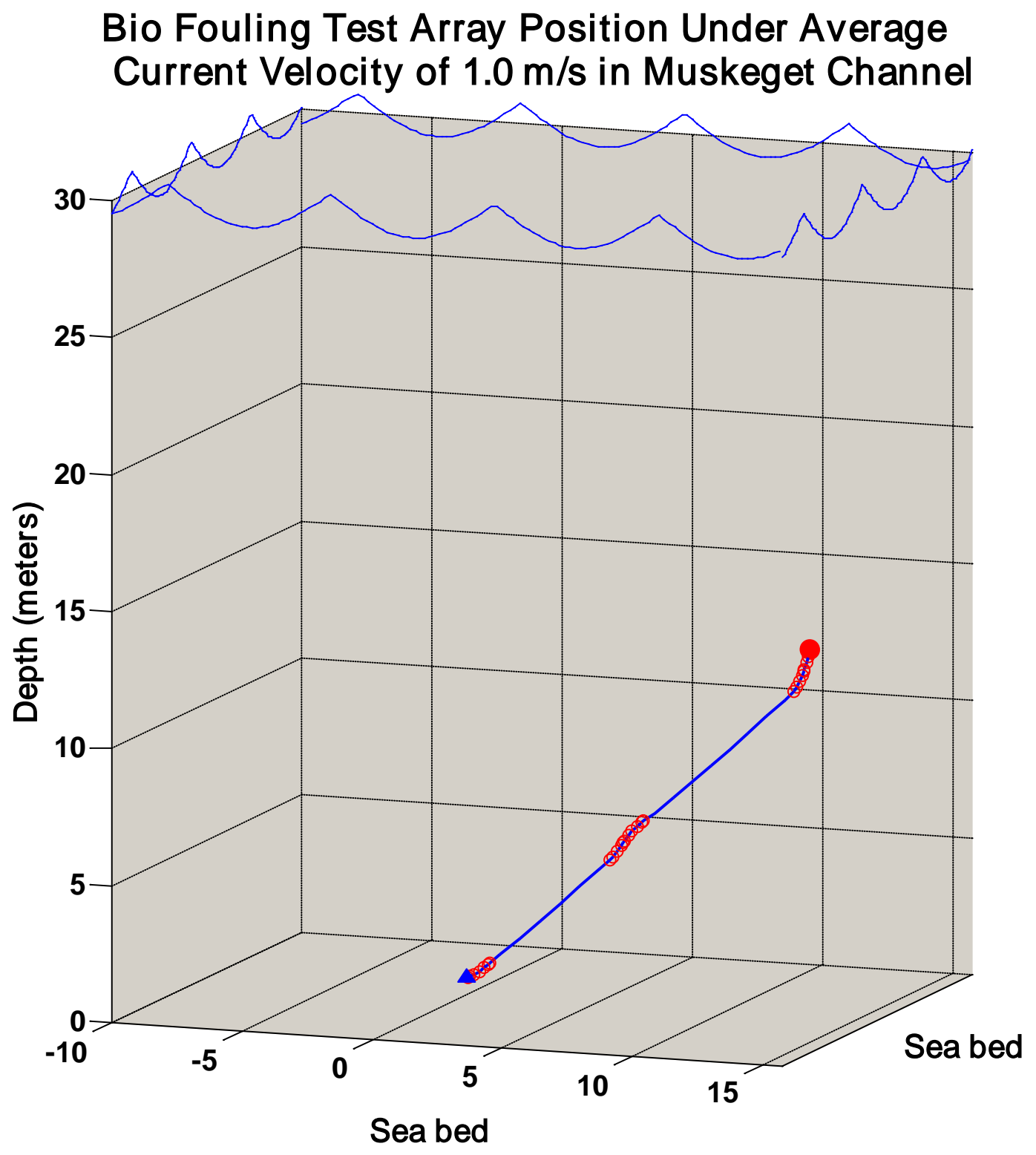

Figure 66. Bio Fouling Array shown becomes diagonal within in the depth zone under the average current velocity of $1.0 \mathrm{~m} / \mathrm{s}$. Drag forces caused by the array components and increased current velocity shift the array to a diagonal position. 


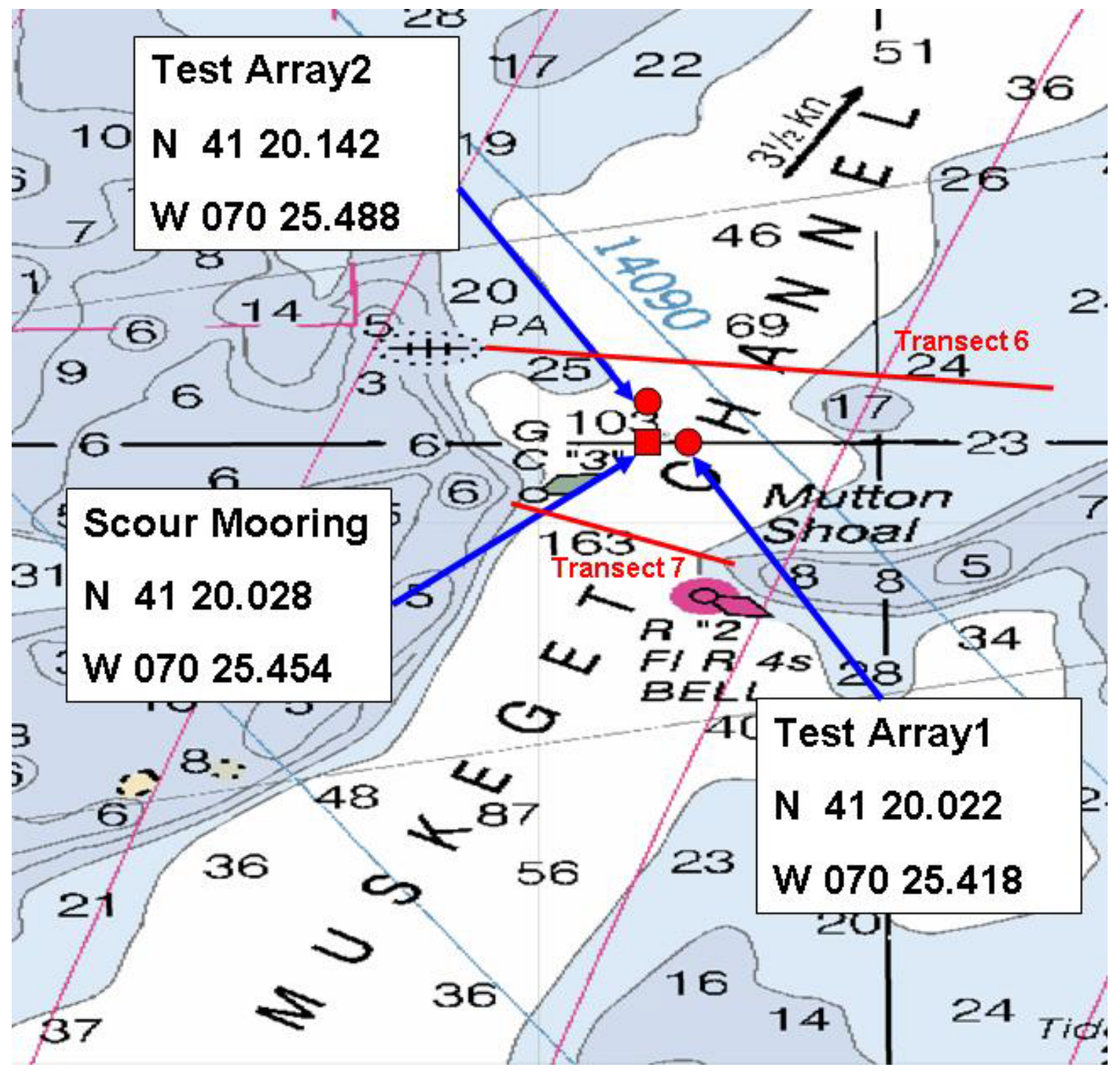

Figure 67 - Position of the bio-fouling arrays 1 (untreated) and 2 (treated) relative to the scour mooring deployed for sediment alteration investigation. Transects 6 and 7 demarcate the optimal high velocity zone for future tidal turbine deployments under the Town of Edgartown FERC permit. 
Forty-five days after deployment (mid August) the first fouling time point collection was attempted. The short slack tide window and the loss of any surface expression on the array's prevented retrieval. The first attempt to "harvest" the time point 1 (mid-August 2011) plates from both the treated and untreated arrays was aborted. A second trip to Muskeget Channel was undertaken in Sept 2011 to locate the treated array and re-attempt the retrieval of the time point 1 plates from all depths on both the treated and untreated arrays. During the intervening month, Hurricane Irene passed through northeastern waters generating extreme sea conditions (average wave heights 6-8 meters) in waters south of Martha's Vineyard, thereby significantly affecting the sea surface conditions in Muskeget Channel. CSP staff was on site in Muskeget Channel one hour before the slack tide on September 12, 2011 to locate the unmarked treated bio-fouling array but a definitive target could not be identified on which to dive. During passage of the slack tide the surface expression for the untreated array never surfaced. Approximately two weeks later (end of September 2011), CSP staff received a call from a shellfish constable on Martha's Vineyard indicating that a portion of the untreated array had washed ashore on South Beach. The untreated bio-fouling plates retrieved represented the upper water column depth on the array. Inspection of the cable suggests that shock loading during the storm was responsible for the break. Sidescan sonar surveys of the deployment region have not been able to locate any part of either array.

In total, one of the three sets of fouling plates on the untreated array was recovered. The other two sets of plates may still be attached to the mooring and resting on the sea bed or may have broken free and are lost. No fouling plates from the treated array have been retrieved to date. The one set of untreated bio-fouling plates that was retrieved spent approximately 2.5 months in the water in the high current velocity zone of Muskeget Channel. The treated plates displayed spotty fouling covering 60-70 $\%$ of the outside surface. No fouling was observed on the interior of the cylindrical "plates". (Figure 68). Fouling consisted almost entirely of the algae Pylaiella, a common filamentous brown algae in the region. Despite the prevalence of skeleton shrimp (caprellids) throughout the region none were found on the fouling plates, though these organisms may have been lost when the top of the array was in the wash zone of South Beach prior to salvage. No traces of hold fasts or attachment points for hard shell animals were visible. Among the three plates recovered only four small barnacles were observed on the interior of the fouling plate cylinders. The circumstances of the recovery do not rule out the possibility of more extensive biofouling, however the evidence suggests that either the nature of the material or the high velocities may greatly limit the ability of biofouling organisms to become established. Further work will need to be conducted to determine the rates of bioaccumulation on hard structures within the permit area and the ramifications for periodic cleaning of turbine generating units and how to do so in a safe and cost effective manner given the difficult working conditions. If biofouling proves to be more extensive, numerous hard structures deployed for energy generation may profoundly affect the community structure of the area, much as oil platforms can act as artificial reefs recruiting fauna and flora to create new biomes. 


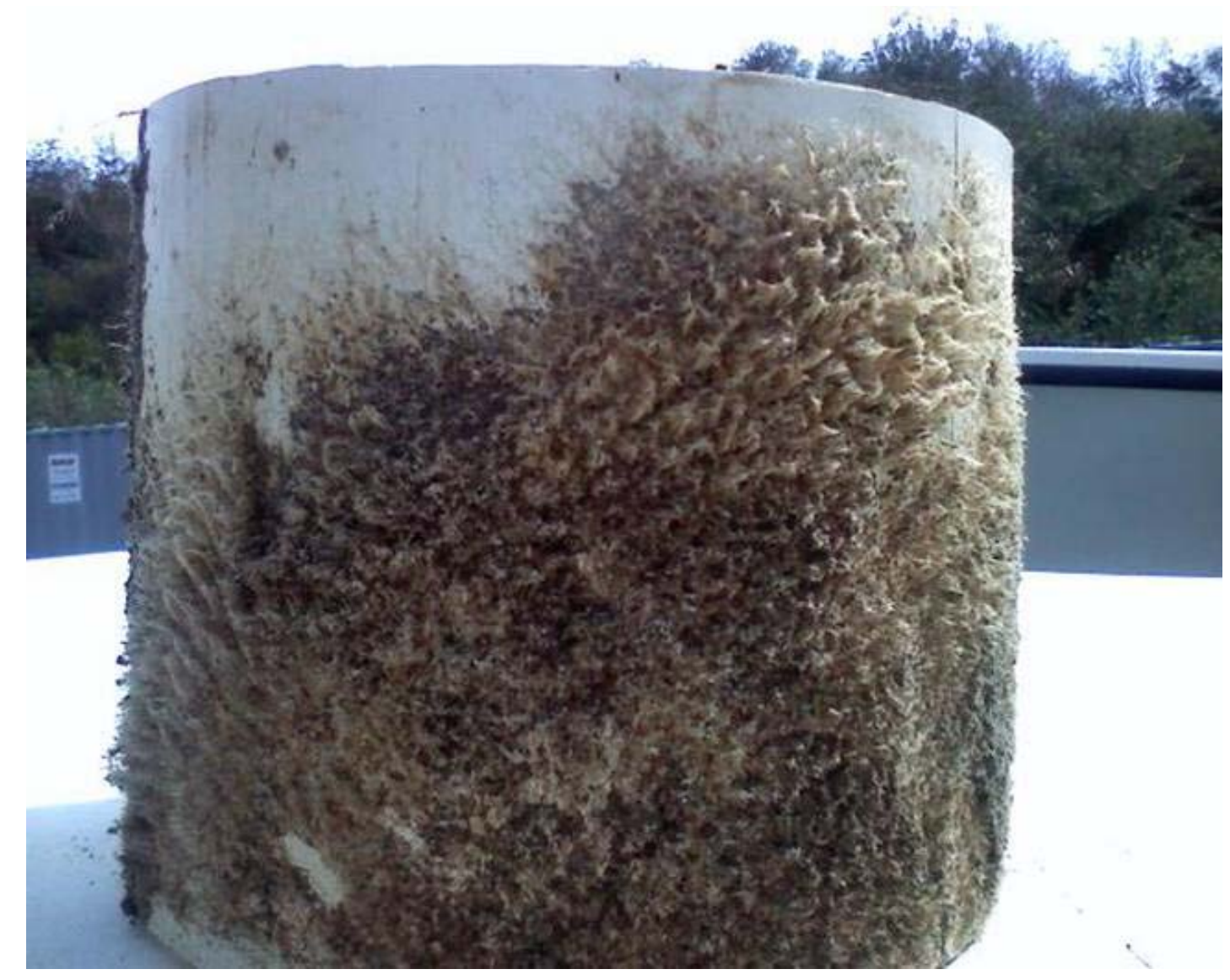

Figure 68 - Observed bio-accumulation on one of three un-treated fouling plates deployed in the high velocity zone of Muskeget Channel. The plate was positioned on the bio-fouling array to represent biofouling occurring in the upper portion of the water column. The bio-accumulation depicted resulted from being submerged for approximately 10 weeks.

\subsection{Survey Area in the Near field to the Bio-fouling Arrays in order to Identify Existing Hard Surface Communities}

Within the high velocity zone of Muskeget Channel in the vicinity of the bio-fouling arrays, the existence of fouling communities upon natural hard structures such as large rocks were examined by diver surveys on two separate occasions. During the initial deployment of the scouring experiment on March 15, 2010, a preliminary survey was performed of the surrounding near field area for naturally occurring hard structures. Utilizing the scouring block as the center point, the diver swam 20-25 feet away and conducted a sweep of the surrounding area. The diver observed sand waves ranging in height from 3-5 feet and composed of highly fluid, medium to coarse sand with shell hash from various shellfish species. Beyond this survey perimeter no large structures were observed. The second diver survey conducted 
within the high velocity zone occurred on April 25, 2011 during the recovery of the ADCP current profilers from the scouring block. Observations made by the divers indicated a change in the bottom topography. Sand waves were present but were reduced in height ranging from 1.5 to 2.0 feet and composed of the same sediment composition. Divers performed a perimeter sweep of the near field area and located no hard structures or fouling communities. Due to the dynamic nature of the high velocity zone the diver surveys were limited by environmental conditions. Dive operations were limited by the small dive window (20 to 25 minutes) at slack tide. This window is significantly reduced as current velocities increase with the changing of the tides. In addition to safe dive conditions, diver visibility was also affected by environmental variables. Divers experienced a bottom visibility ranging from a minimum of 10 feet to a maximum of 25 feet depending on the physical biological conditions during survey operations. No hard structures or hard bottom communities were detected during these surveys.

\section{Field Data Collection (PHYSICAL - Geomorphology of Surficial Sediments)}

\subsection{Side-scan Sonar for High Resolution Bedform Surveying to Characterize Small- scale Roughness and Bedforms Responsible for Bottom Stresses}

It was originally intended that an AUV survey would be conducted over the high velocity zone of Muskeget Channel, however a suitable AUV was not available. In conjunction with a search for the fouling moorings displaced by Hurricane Irene an intensive side scan sonar survey of the area was conducted in October of 2011. The area of coverage is indicated in Figure 69. No evidence was found of the fouling plate moorings. The survey complimented that of the USGS Swath survey. The results of the present survey showed the presence of sand waves throughout the area and no hard structures of significant size. Detailed analysis indicated the presence of many smaller objects, possibly boulders, but man-made debris could not be excluded. While relatively large flat areas were present, reflected signal strength could not discriminate between the coarse sand prevalent in the area from areas of gravel and cobbles which could constitute natural hard bottom substrate. Planned work for the next season includes sub-bottom profiling of the area which should provide a more clear view of the bottom stratigraphy including bedrock outcrops and other non-transient hard bottom habitat. 


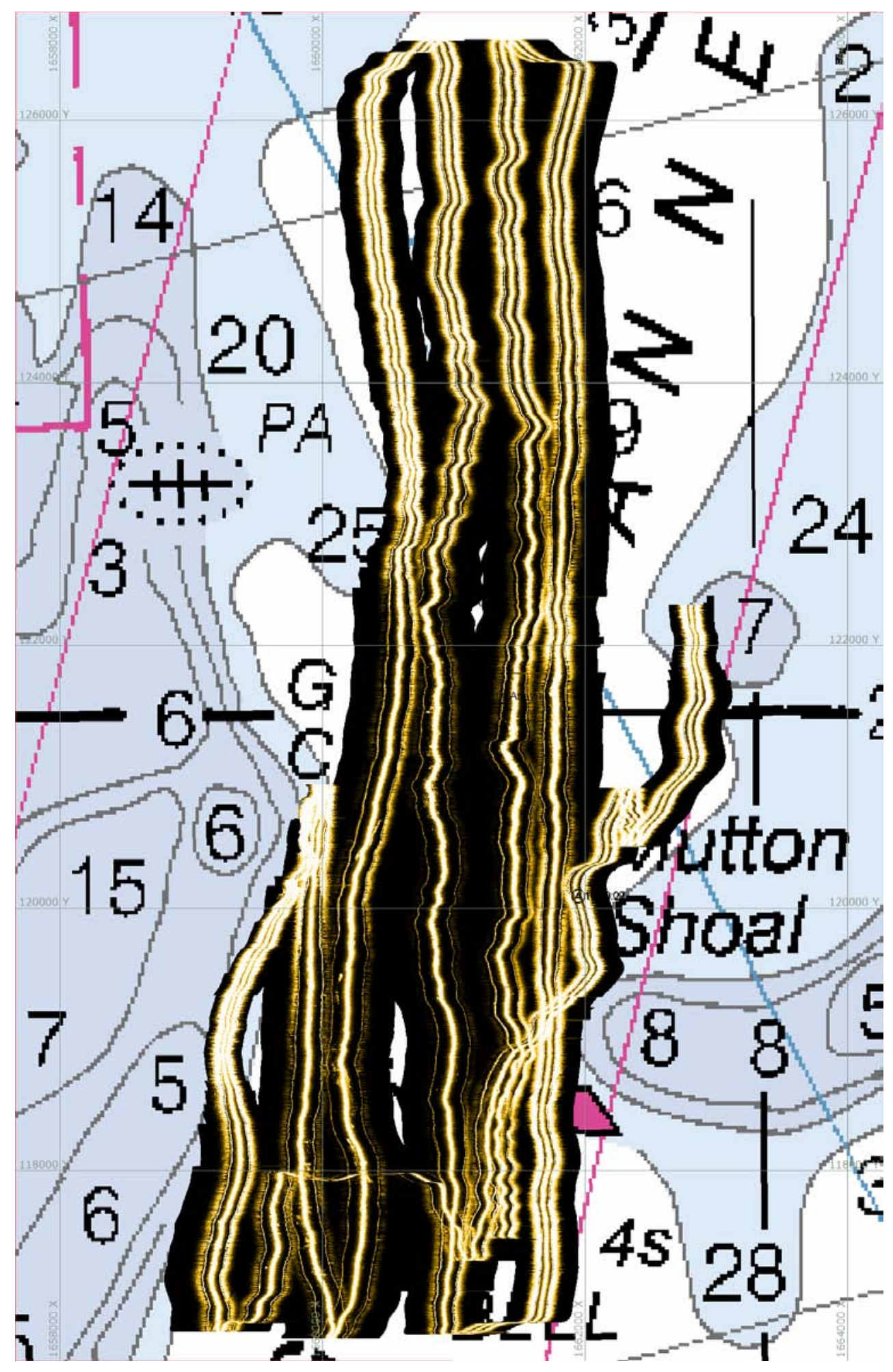

Figure 69 - Map depicting the side scan sonar surveying undertaken in the high velocity zone of Muskeget Channel. Survey data revealed the area was dominated by featureless bottom with the exception of significant sand waves. 


\subsection{Conclusions and Future Work}

The three main data collection programs were successful, despite the influence of two hurricanes during the study period. Tidal elevation data provided precise water surface gradients through the study area. Since it is these gradients which are responsible for the high velocities seen in Muskeget Channel the fine scale data will provide a valuable benchmark to assess future impacts when the hydrokinetic potential of the area is developed. In addition, the Pocha tide gauge suggested that this near shore region being considered as a cable route may be more complicated than first supposed. Preliminary discussions with grant partners have already resulted in possible explanations. Bathymetric surveys were completed for the developmentally viable portion of the channel proper and were both validated and augmented by the USGS Swath survey.

Long term current measurements by bottom mounted ADCP indicated slightly higher velocities than predicted by extended cross channel velocity profiling and provides the basis for power production estimates using different technologies and deployment schemes. The region between Transect 6 and Transect 7 had the highest current velocities and the greatest water depths, ideal for addressing the compromise between navigation concerns and optimizing power generation. Future ADCP deployments will focus on further refinements is this specific region to support predictive modeling of the cross channel velocity field.

Deployment of the scouring block as a surrogate for large scale mooring weights indicated that despite the dynamic nature of the study area equilibrium conditions were reached relatively quickly. Furthermore, the area disturbed by the bottom structure was small extending no more than 1 diameter from the structure.

Fouling studies were interrupted by Hurricane Irene and the arrays have yet to be found and recovered, however, the one untreated section retrieved showed fouling by algae but virtually no indication of faunal colonization. This work will need to be followed up in the future to accurately predict mooring longevity and maintenance schedules for power generators.

The absence of extensive fouling may result from the lack of substantial naturally occurring hard structures in the region. Diver observations indicated the presence of sand waves and occasionally gravel associated with the troughs between the wave crests. Sidescan sonar surveys confirmed these general observations. Small high intensity returns did suggest the presence of some hard structures on the bottom, but these objects could not be identified. In the future higher resolution surveys may be able to resolve whether these objects are natural hard structures typical of the region, but they would remain a very small proportion of the overall habitat. 


\section{Appendix B Woods Hole Report}





\section{The Effect of Tidal Power Generation on Sediment Transport in Muskeget Channel}

\subsection{SWATH Bathymetry Survey and Analysis}

\section{Overview}

A high resolution bathymetric survey of Muskeget channel and surroundings was completed in fall of 2010 (Denny et al., 2012). The chief survey scientist was Jane Denny from the USGS Woods Hole Science Center (WHSC). Rich Signell (USGS, WHSC) helped coordinate the survey design. The survey was conducted using an interferometric sonar unit which can measure bathymetry along a swath on either side of the ship track with a width of roughly seven times the water depth. The goals of the survey were to obtain a baseline high resolution bathymetry dataset for Muskeget Channel, characterize the large scale bedforms in the Channel surroundings, and characterize the bedforms in the vicinity of the two potential routes by which the installation would be connected with Marthas Vineyard.

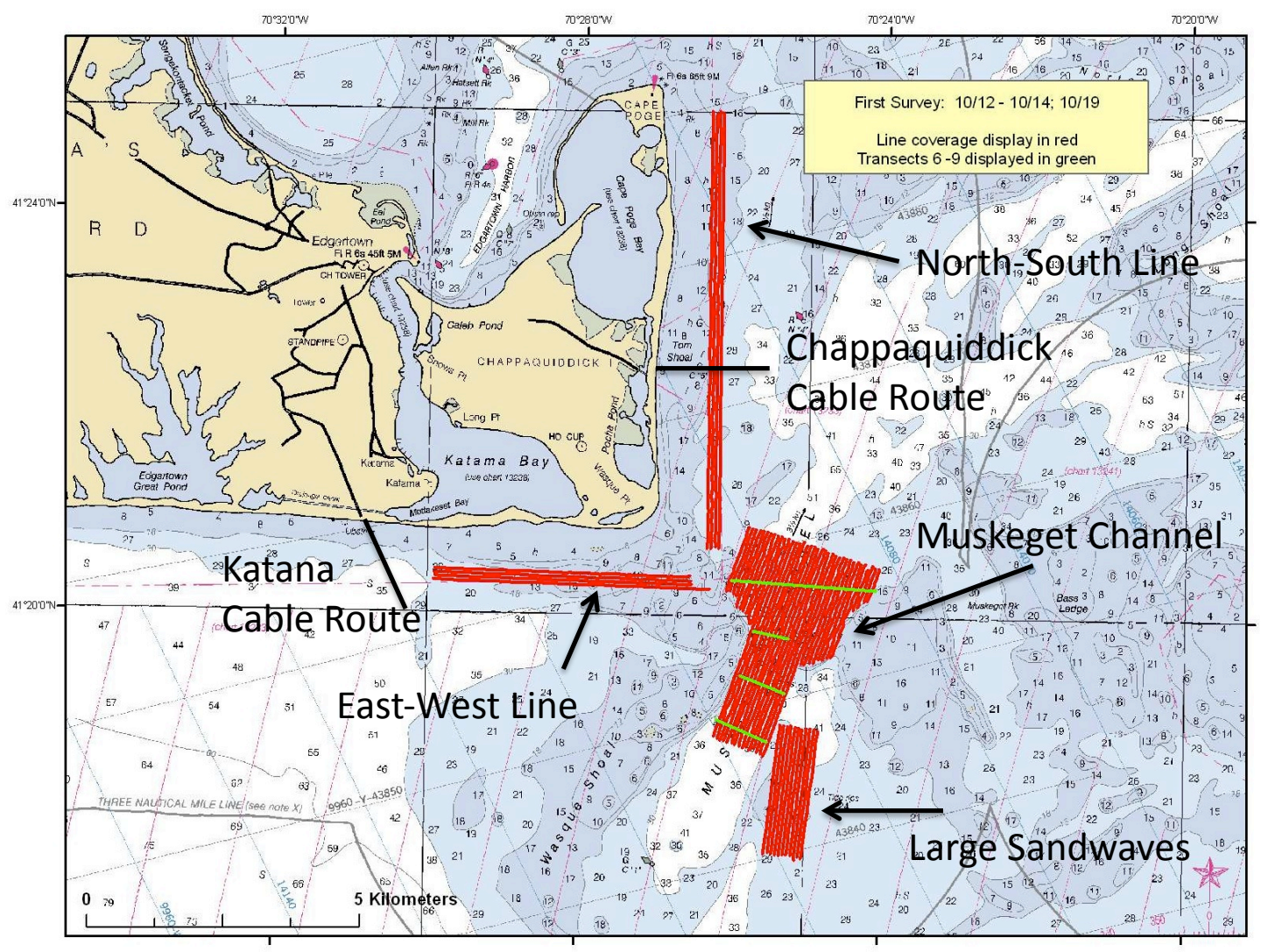

Figure III-1: USGS SWATH Bathymetry Survey Design 


\section{Survey Design}

The first survey was conducted from 10/12/2010-10/14/2010. The survey included the main channel, a region containing large sandwaves to the south of the channel, and two sections along the eastern and southern shores of Marth's vineyard in the vicinity of the two proposed cable connections (Fig. III-1). The second survey was completed in a single day on 11/16/2010. Due to survey constraints, only the areas containing large sand waves and the two cable route transects were re-surveyed. The resulting data provides a monthly snapshot at these three locations. A DGPS-RTK was used for navigation and to adjust for tides. The data was projected to the local state plane, gridded at 1-m resolution, and is available for download or access through opendap capable software on a USGS Thredds server at: http://geoport.whoi.edu/thredds/dodsC/usgs/data0/muskeget/.

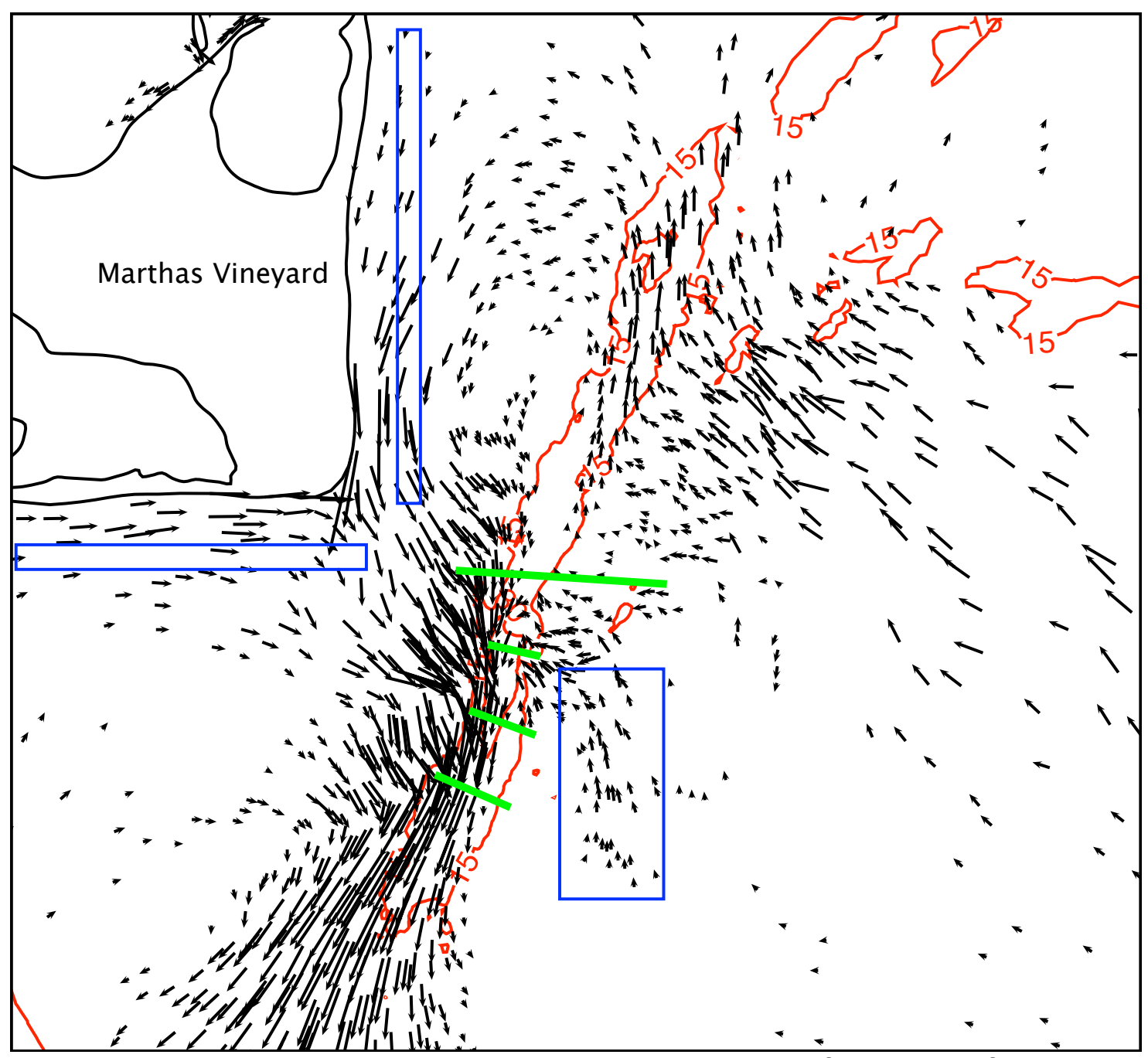

Figure III-2: Model-computed vertically-averaged tidal residual flow vectors for $\mathrm{M}_{2}$ boundary forcing. SMAST Coastal Systems Program ADCP Transects 6-9 (green lines) and $15-\mathrm{m}$ isobath shown for reference. Blue boxes: Approximate locations of Large Sandwaves, East-West Line and North-South Line of USGS SWATH bathymetry survey (ref: Fig III-1). 


\section{Characterization of Bedforms}

\section{Muskeget Channel}

The deepest part of Muskeget Channel (Figure III-3) contains a series of fairly symmetric rolling bedforms of roughly $5-\mathrm{m}$ height and $100-\mathrm{m}$ wavelength. These large bedforms are most closely located to transects 7 and 8 of the SMAST Coastal Systems Program ADCP Survey. These transects also show the most promise for TKE extraction (ORPC, 2010). Given the extremely high shear stresses and mobility of the local dominant substrates these bedforms should be re-surveyed to assess potential impact on structures, stays, and cable routes. The bedform characteristics and fan extending in the direction of the strong residual current are reminiscient of the well studied bedforms of San Francisco Bay.
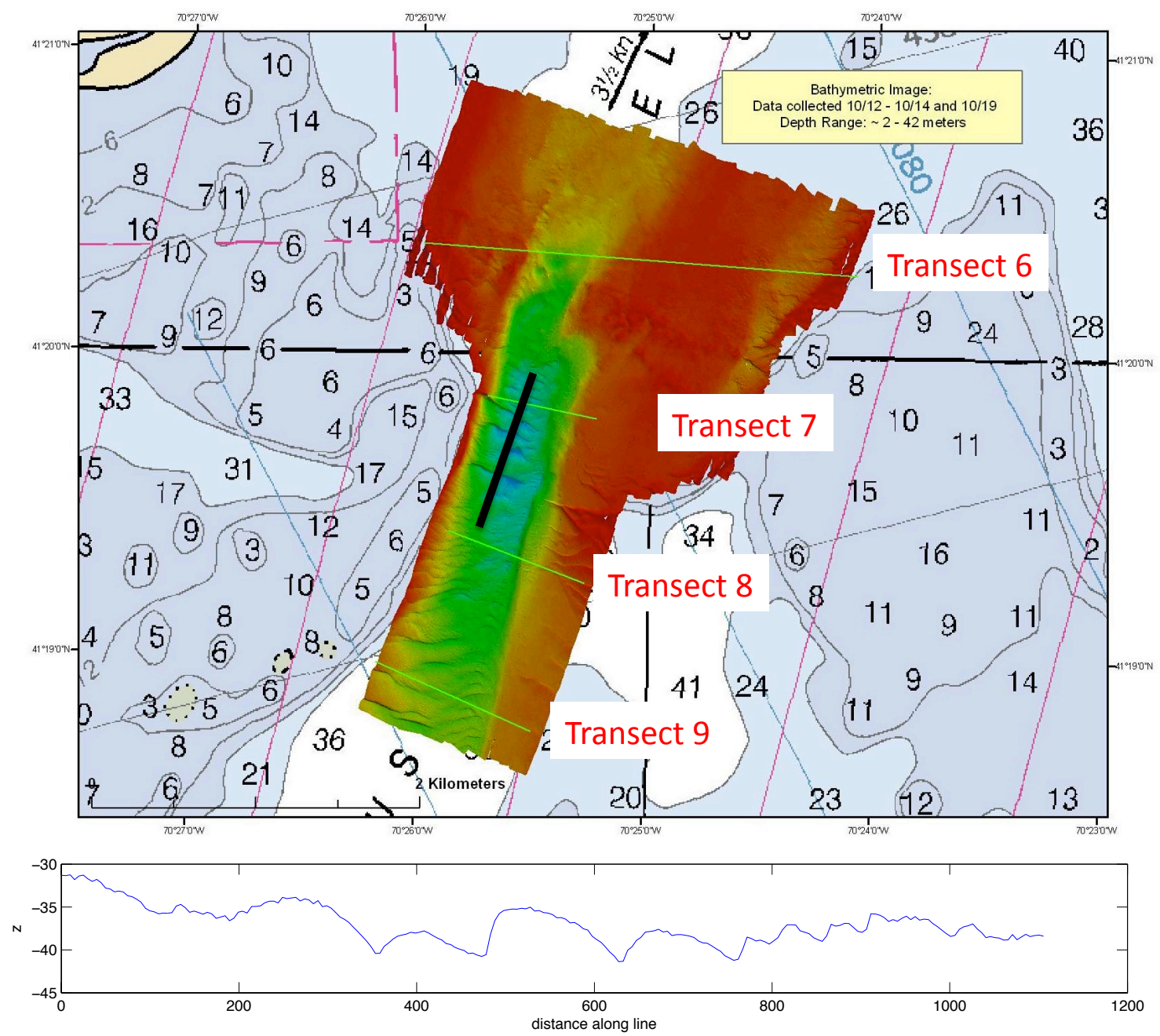

Figure III-3: Upper: Bathymetry of Muskeget Channel derived from the USGS SWATH Bathymetry Survey. SMAST Coastal Systems Lab ADCP Transects 6-9 (green lines) shown for reference. Lower: topographic profile $(\mathrm{m})$ along the main channel (black line) from SW to NE. 


\section{Large Amplitude Sand Waves}

The large amplitude sand waves (Figure III-4) have an average wavelength of $225 \mathrm{~m}$ and an average height of $4.5 \mathrm{~m}$. The average upstream slope is .025 and average slip face slope is .08. They are of similar scale to the well-studied sand waves in the Bay of Fundy. Their ratio of height to wavelength falls within two well-known relationships derived from the Bay of Fundy data (Figure III-7). While the tidal residual flow in the main Muskeget Channel is predominantly to the south (Figure III-2), the large amplitude sandwaves lie off the main channel in an area with weak northward residual flow.
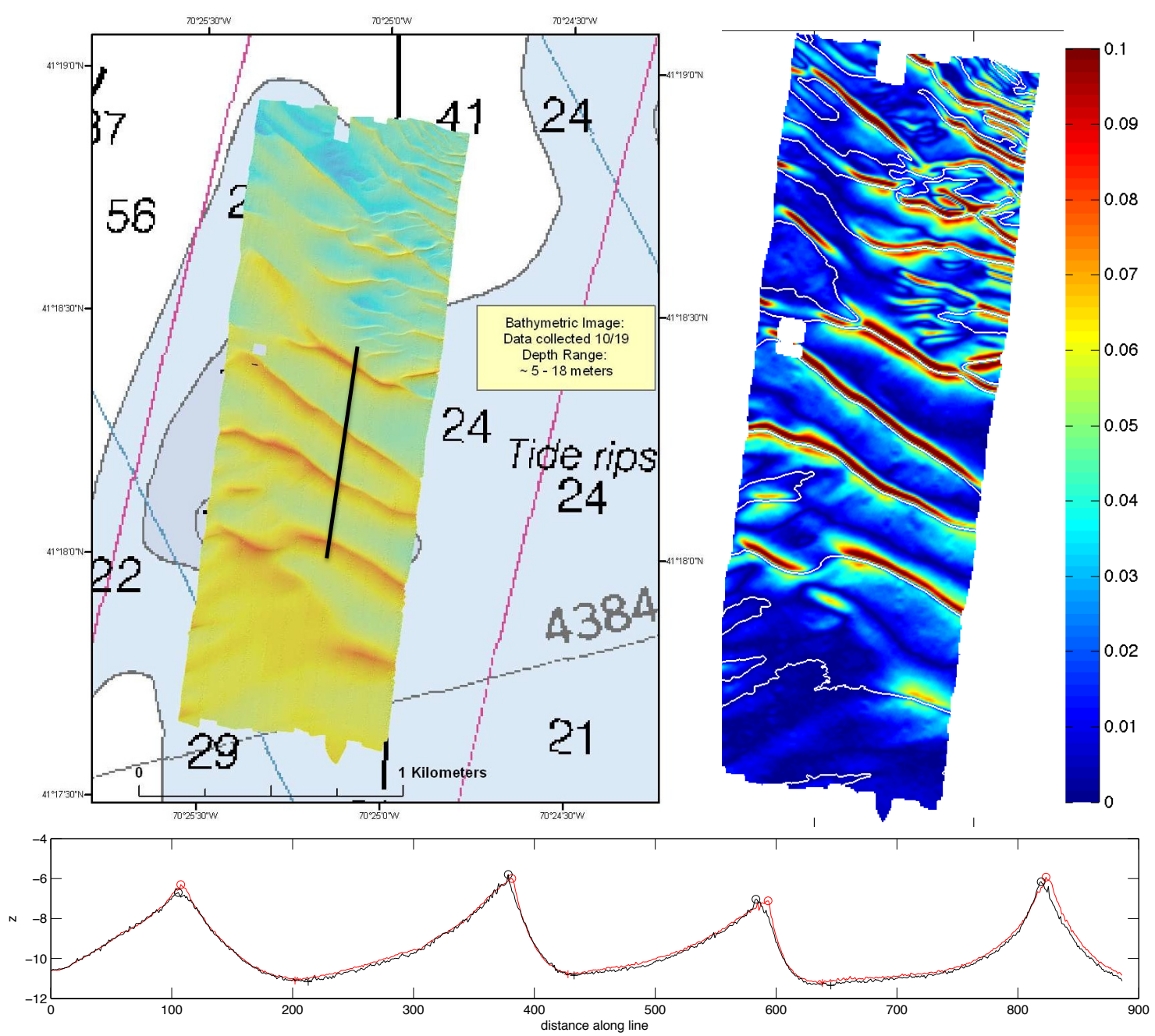

Figure III-4: Upper left: Bathymetry of large sand waves derived from the USGS Muskeget SWATH Bathymetry Survey. Upper right: Bed slope $(\mathrm{m} / \mathrm{m})$ and location of wave crests (white lines) for the large sand wave field south of Muskeget Channel. Lower: bed profile normal to wave crests [ref: black line in upper left figure] from South to North. [Red: survey 1, Black: survey 2] 
The large sand waves have a clear slip face oriented towards the North which is consistent with the direction of this residual current. If the same transect is taken through the second survey (one month later), crests have moved an average of $5 \mathrm{~m}$ towards the south. Based on crest motion this would imply a net motion of $17 \mathrm{~cm} /$ day which is similar in magnitude to migration speeds in the Bay of Fundy. However, the profile indicate that the slip face is becoming less steep and that the crest motion is more likely a result of the sand wave relaxing rather than a rigid translation of a fixed waveform.

\section{North-South survey}

The North-South survey bisects the proposed route of the Chappaquidick cable route and thus is useful for determining the necessary dredge depth. Sandwaves along the N-S transect can be divided into two groups. The northern group are roughly $90 \mathrm{~m}$ in length and $0.7 \mathrm{~m}$ in height and have slip faces oriented to the north. The southern group are shorter with a mean wavelength of $40-\mathrm{m}$ and height of $0.8 \mathrm{~m}$. This group has a reversed orientation with the slip face on the south side. The slip face orientation of the southern group is also more clearly defined.

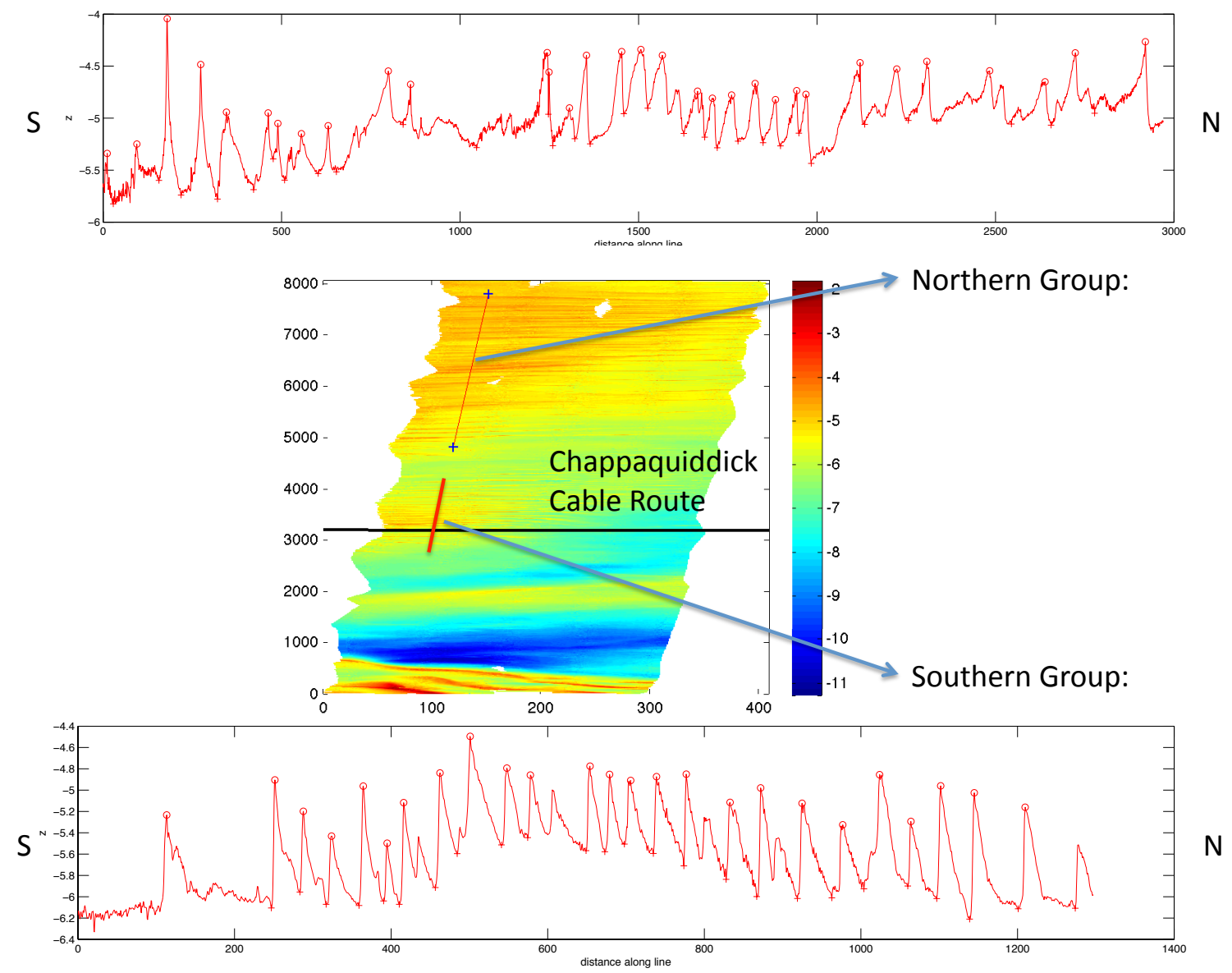

Figure III-5: Upper: bathymetric profile $(\mathrm{m})$ from south to north normal to wave crests in the northern group of bedforms east of Chappaquiddick (ref: thin red line in central panel). Center: bathymetry along North-South line of SWATH Bathymetry Survey (ref 
Fig: III-1). Bottom: bathymetric profile $(m)$ from south to north normal to crests in the southern group of bedforms east of Chappaquiddick (ref: thick red line in central panel).

The proposed Chappaquiddick cable route intersects the southern group. Based on the model-computed residual currents (Figure III-2), the tidally-driven flow is predominantly southward in the nearshore region of the east-facing portions of Chappaquiddick. The magnitude of the residual current increases towards the Southeast point of Marthas Vineyard.

\section{East-West survey}
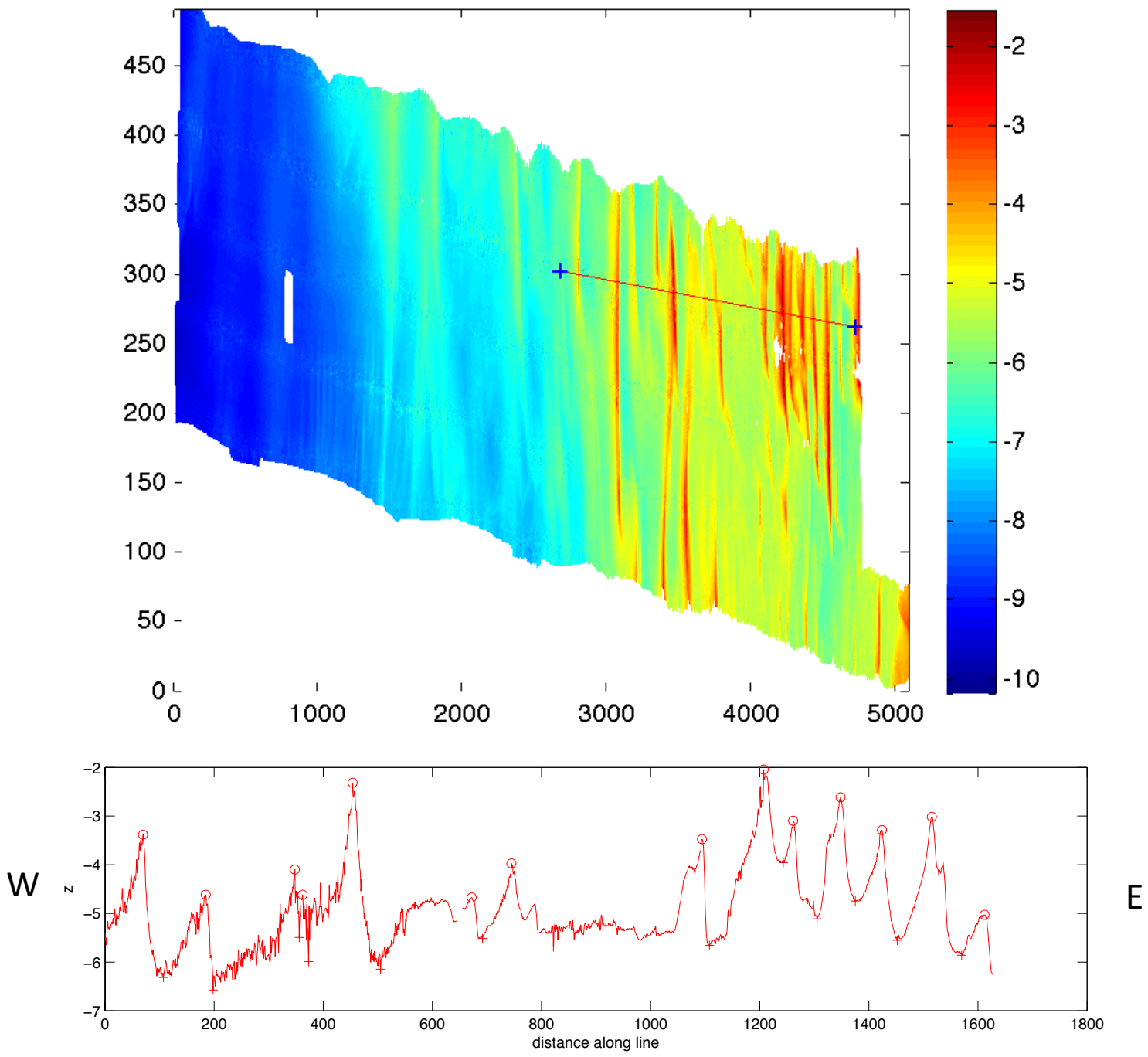

Figure III-6: Upper: bathymetry along East-West line of USGS SWATH Bathymetry Survey (see Fig: III-1). Bottom: bathymetric profile $(\mathrm{m})$ from west to east normal to wave crests south of Katama Bay (ref: red line in upper fig). 


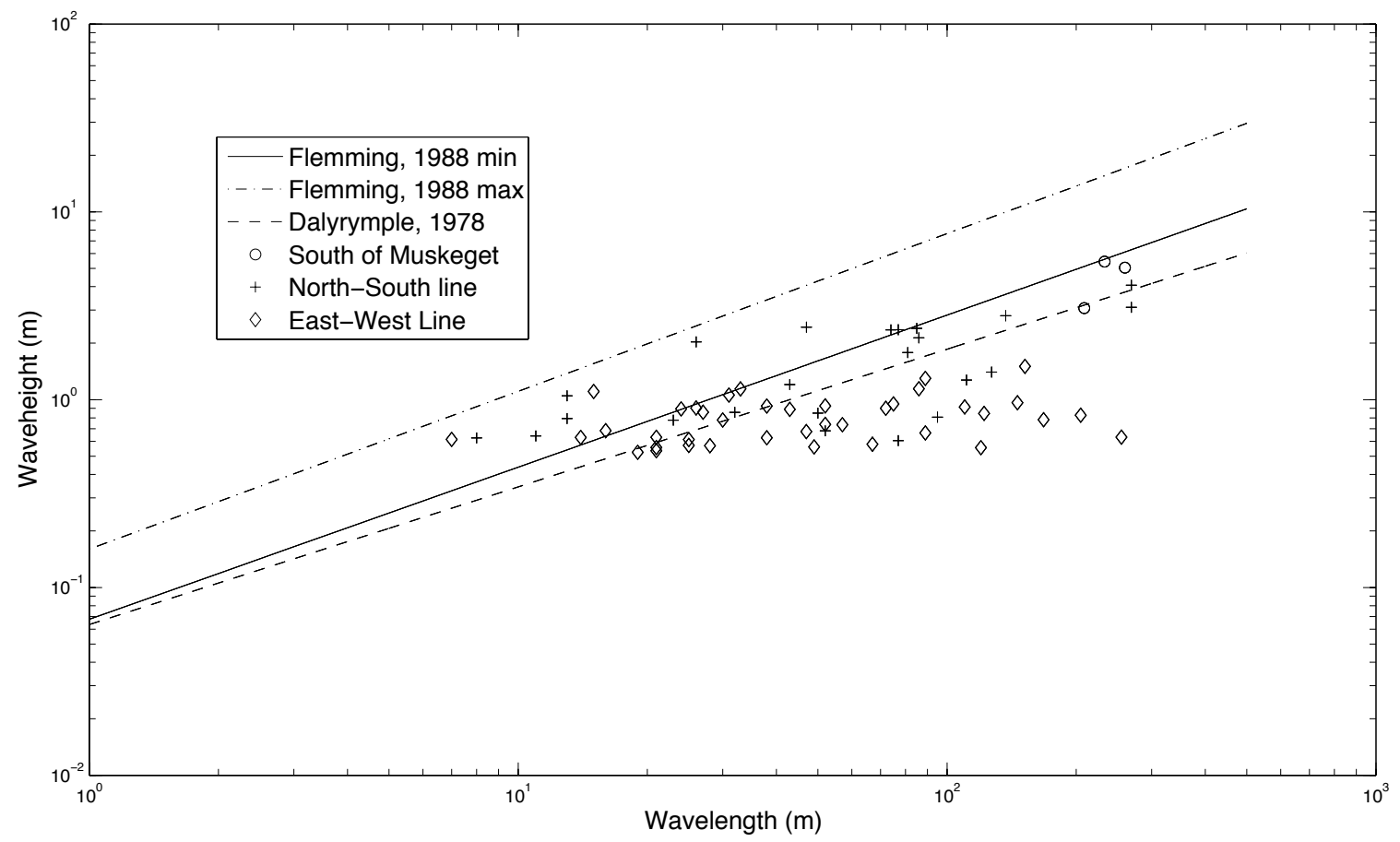

Figure III-7: Comparison of bedform characteristics in the vicinity of Muskeget Channel with wave height - wavelength relationships from empirical relationships.

The bedforms along the E-W survey have a mean wavelength of $120 \mathrm{~m}$ and height of $2 \mathrm{~m}$. The slip face is to the east which corresponds with the residual flow direction (Fig. III-2). These sandwaves are occuring roughly $3 \mathrm{~km}$ to the east of the proposed Katama cable route. An inlet to Katama Bay was created during the Patriots Day storm (April, 2007) and may have some influence on the formation of bedforms in this region through both modifications to hydrodynamic forcing and potentially sediment supply (R. Geyer, P. Traykovski, personal communication). The inlet is migrating eastward. 


\subsection{Impact Modelling Studies}

\section{Approach}

\section{Hydrodynamic Model}

FVCOM is a Fortran90 software package for the simulation of ocean processes in coastal regions (Chen et al., 2003, 2006; Cowles, 2008). The publicly available model has a growing user base and has been employed in a wide variety of applications. The kernel

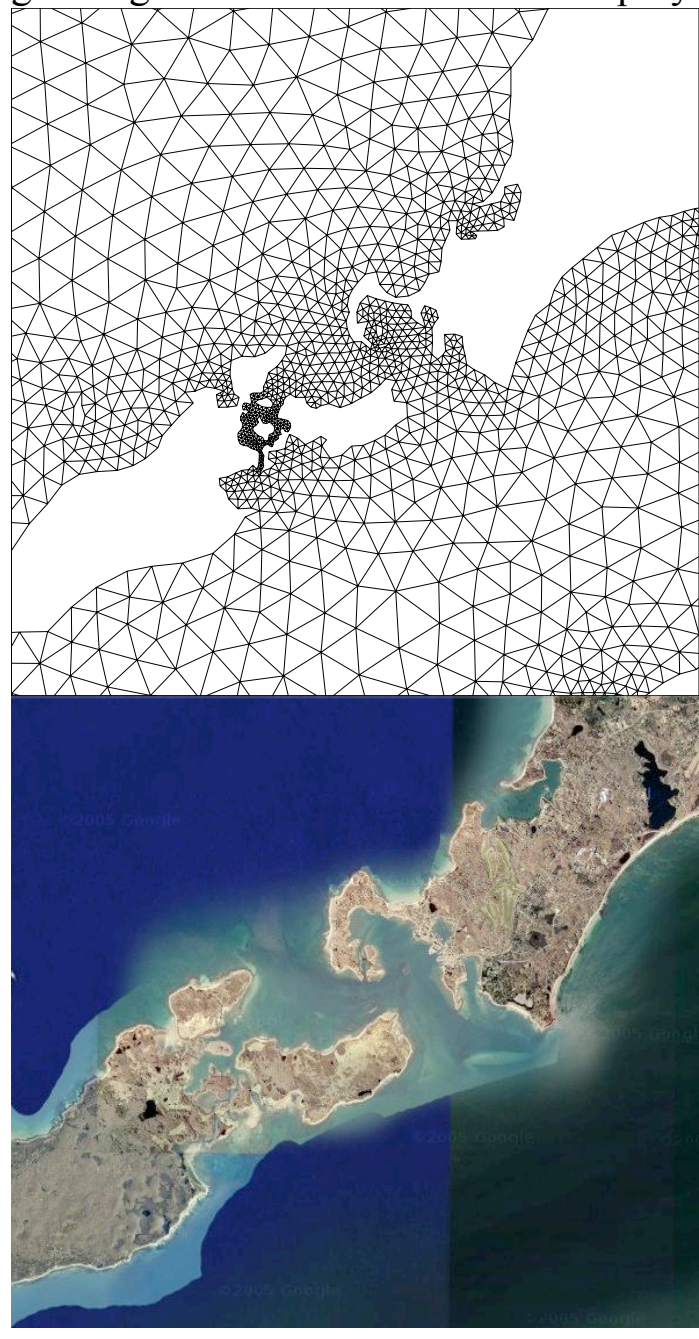

Figure III-8: FVCOM mesh near Woods Hole. MA of the code computes a solution of the hydrostatic primitive equations on unstructured grids using a finite-volume flux formulation. The unstructured grid modeling approach is highly advantageous for resolving dynamics in regions with complex shorelines and bathymetry such as the Massachusetts coastal region (Fig. III-8). The horizontal spatial fluxes are discretized using a secondorder accurate scheme (Kobayashi, 1999). For the vertical discretization, a generalized terrain-following coordinate is employed. FVCOM is interfaced to the General Ocean Turbulence Model (GOTM) libraries to provide an array of turbulence closure schemes including the standard MellorYamada 2.5 and k-epsilon approaches. An explicit mode splitting technique is used to integrate the model forward in time (Madala and Piascek, 1977). In this method, the barotropic (vertically-homogenous) mode is integrated separately from the baroclinic motion using the shorter time steps required by the gravity wave speed. The baroclinic (three-dimensional) mode can be stepped at a time step constrained by the maximum internal wave speed. In a general application, this results in approximately a ten-fold increase in the allowable stable time step. The model is fully parallelized using a Single Program Multiple Data (SPMD) approach

(Cowles, 2008). Message passing is programmed using the Message Passing Interface (MPI) standard using non-blocking sends and receives. The parallelized code scales well on modern machines, is highly portable to numerous architectures, and greatly increases the capabilities of the original core scheme by extending practical model simulation timescales and spatial resolution. 


\section{$\underline{\text { Sediment Model }}$}

The FVCOM Sediment model is based on the Community Sediment Transport Modeling System (CSTMS) (http://www.cstms.org) as implemented in the Regional Ocean Modeling System (ROMS) (Warner et al, 2006). The model includes transport of both the suspended load and bedload. The number of sediment classes is flexible, and for each class, parameters such as critical shear stress, mean diameter, and settling velocity must be defined. Complex bed dynamics are included with a user-prescribed number of layers defined by the layer number, fractions of each sediment class, an age, and a thickness. Due to sharp gradients in the concentration profile that can occur near the bottom, a fluxlimited scheme is used in FVCOM for the settling equation. This scheme introduces antidiffusion by means of a minmod limiter and maintains second order spatial accuracy away from extrema. The bedload is treated using the MPM (Meyer-Peter and Müeller, 1948) scheme to calculate the local load and fluxes from the bed are then determined by calculating the divergence of the local load.

\section{Turbine Parameterization}

To model the impact of the turbines on the fluid we use a volumetric subgridscale parameterization. The momentum loss in the water column due to the device is given by

$$
S_{u}=\frac{1}{2} C_{p} A_{d e v} \rho U^{2}
$$

where $C_{p}$ is the hydrodynamic efficiency of the device, $A_{d e v}$ is the effective cross sectional area, $U=U(x, y, z)$ is the fluid velocity, and $\rho$ is the fluid density. This term is added to the three-dimensional $\mathrm{x}$ - and $\mathrm{y}$-direction momentum equations as a sink term. This approach has been used successfully in wake studies of wind turbines (Réthoré et al., 2010).

\section{Model Setup}

Domain and Bathymetry

The model domain includes the entirety of the Massachusetts Coastal waters (Fig. III-9). The coastline was based on a high resolution product developed by the Massachusetts Coastal Zone Management. The Bathymetry is a composite set which incluced the USGS 3-Arc Second Gulf of Maine database complemented by the NOAA 1/3 Arc-second Nantucket Inundation DEM in the southern portions of Nantucket Sound and the USGS Muskeget SWATH Bathymetry in the main Muskeget Channel. The mesh is locally refined in the vicinity of Muskeget Channel for the purpose of capturing the spatial complexity of the currents in the impact studies. A sequence of three models were developed providing coarse, medium, and fine resolution (Table III-1). This enabled more rapid model development and a formal assessment of grid independence in the results of the impact studies. 


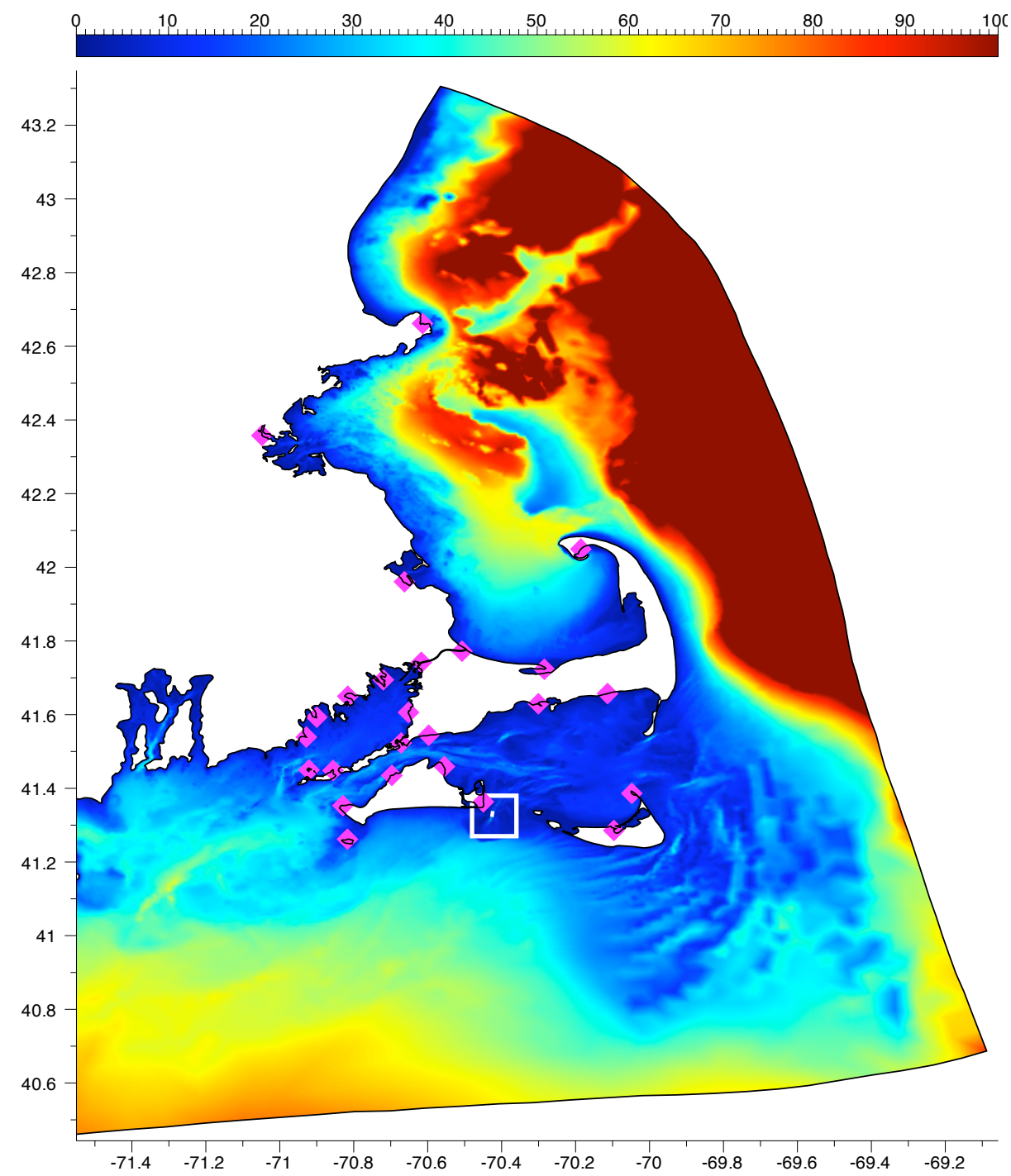

Figure III-9: Domain and bathymetry $(\mathrm{m})$ for the Mass Tidal Model (MTM) series. Muskeget region (white box) and tidal harmonics observation sites shown for reference.

\section{Forcing}

The model is forced at the open boundary using 6 tidal constituents $\left[\mathrm{M}_{2}, \mathrm{~S}_{2}, \mathrm{~N}_{2}, \mathrm{O}_{1}, \mathrm{~K}_{1}, \mathrm{M}_{4}\right]$. These consitituents were extracted from a large scale tidal model (Chen et al., 2011) and adjusted to improve the harmonic response of sea surface elevation with the domain.

\begin{tabular}{|l|l|l|l|l|}
\hline Model & \#Elements & $\begin{array}{l}\text { Resolution }(\mathrm{m}) \\
{[\text { Muskeget/Coastal }]}\end{array}$ & Time Step (s) & $\mathrm{T}_{\text {month @ 100 Gflop }}$ \\
\hline $\mathrm{mtm}-4$ & $60 \mathrm{~K}$ & $150 / 100$ & 10 & 10 hours \\
\hline $\mathrm{mtm}-2$ & $120 \mathrm{~K}$ & $70 / 50$ & 5 & 50 hours \\
\hline $\mathrm{mtm}-1$ & $285 \mathrm{~K}$ & $30 / 25$ & 2.5 & 100 hours \\
\hline
\end{tabular}

Table III-1: Specifications of Mass Tidal Models 


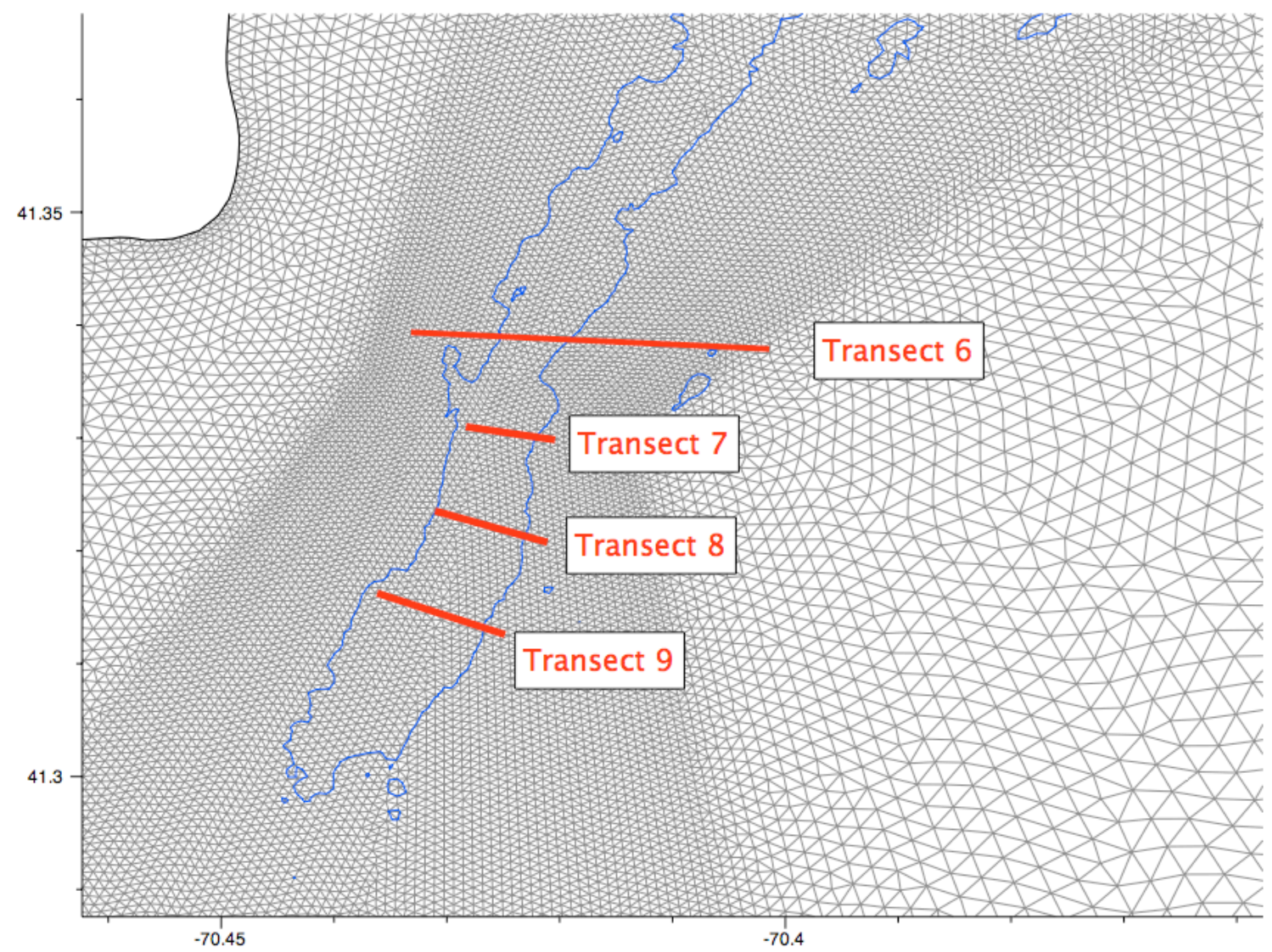

Figure III-10: FVCOM model mesh in the vicinity of Muskeget Channel with ADCP Transects from SMAST Coastal Systems Lab ADCP survey. 15-m isobath shown for reference (blue line).

\section{Model Validation}

Tidal Harmonics and Mean Annual Power Density

Tidal harmonics at 24 stations are used to validate the five principal components $\left(\mathrm{M}_{2}, \mathrm{~S}_{2}, \mathrm{~N}_{2}, \mathrm{~K}_{1}, \mathrm{O}_{1}\right)$ as well as the principal overtide $\mathrm{M}_{4}$. The tidal dynamics south of the Cape are complex owing to the prominent convergence of two large scale tidal waves, one approaching from the Gulf of Maine through the Great South Channel and the other propagating across the New England Shelf (Chen et. al, 2011). Capturing the correct phase and amplitude requires accurate forcing and a model that can resolve properly the coastline and small-scale bathymetric features. Standard deviations of model-computed and observed amplitude and phase differences are $1.45 \mathrm{~cm}$ and $6.1^{\circ}$ for $\mathrm{M}_{2}, .85 \mathrm{~cm}$ and $3.1^{\circ}$ for $\mathrm{N}_{2}, 0.6 \mathrm{~cm}$ and $11.0^{\circ}$ for $\mathrm{S}_{2}, 2.6 \mathrm{~cm}$ and $3.2^{\circ}$ for $\mathrm{K}_{1}$, and $1.7 \mathrm{~cm}$ and $6.5^{\circ}$ for $\mathrm{O}_{1}$. Measurement uncertainty is provided at only a few stations and thus it is not possible to determine if the model-observation differences are within the range. 


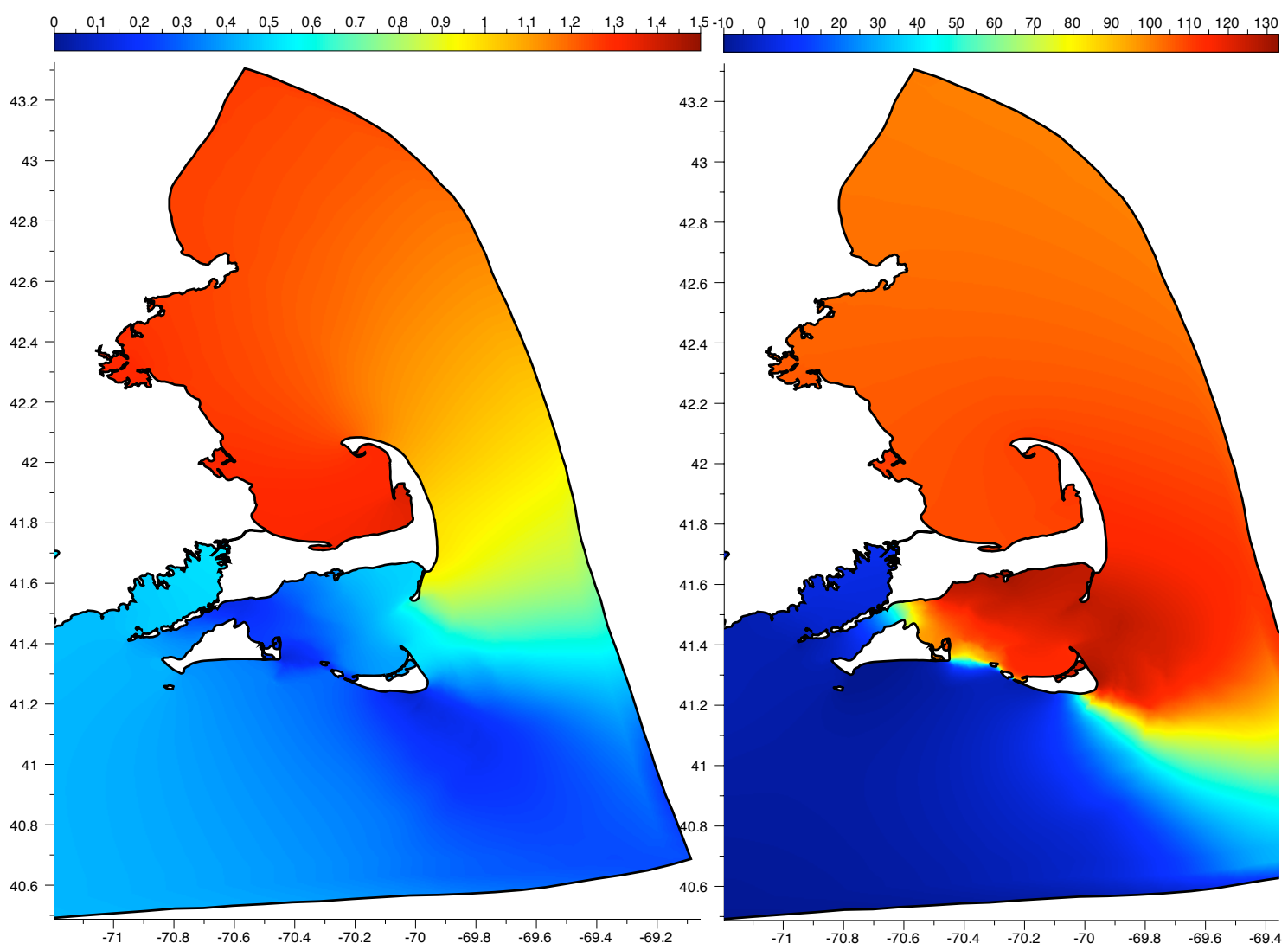

Figure III-11: $\mathrm{M}_{2}$ Amplitude $(\mathrm{m})$ [left figure] and phase $\left({ }^{\circ} \mathrm{G}\right)$ [right figure] computed using the FVCOM mtm-1.

\section{$\underline{\text { ADCP Transects }}$}

The model-computed velocity fields through transects 6-9 were compared with measurements made by the SMAST Coastal Systems Program (provided by B. Howes). These measurements were made during large spring tide in June, 2009. The model was run over the same period as the measurements using 6 components of tidal forcing at the boundary $\left(\mathrm{M}_{2}, \mathrm{~S}_{2}, \mathrm{~N}_{2}, \mathrm{~K}_{1}, \mathrm{O}_{1}, \mathrm{M}_{4}\right)$. The model captures well the magnitude of the currents (Figure III-12a-d) and is able to resolve the complex structure of the flow in the channel. During flood the peak velocity resides in the east part of the channel and during ebb, it shifts towards the central and western edge of the channel. This is evident at both transects 7 in the deeper portion of the Channel and transect 9 in the shallower regions near the southern extent of Muskeget Channel. There is significant vertical shear in both the observed and model-computed velocity fields. Optimal placement of turbines will likely require working within exclusion constraints from navigation, minimizing loading from survey waves while trying to capture as much of the greater power near the surface. 


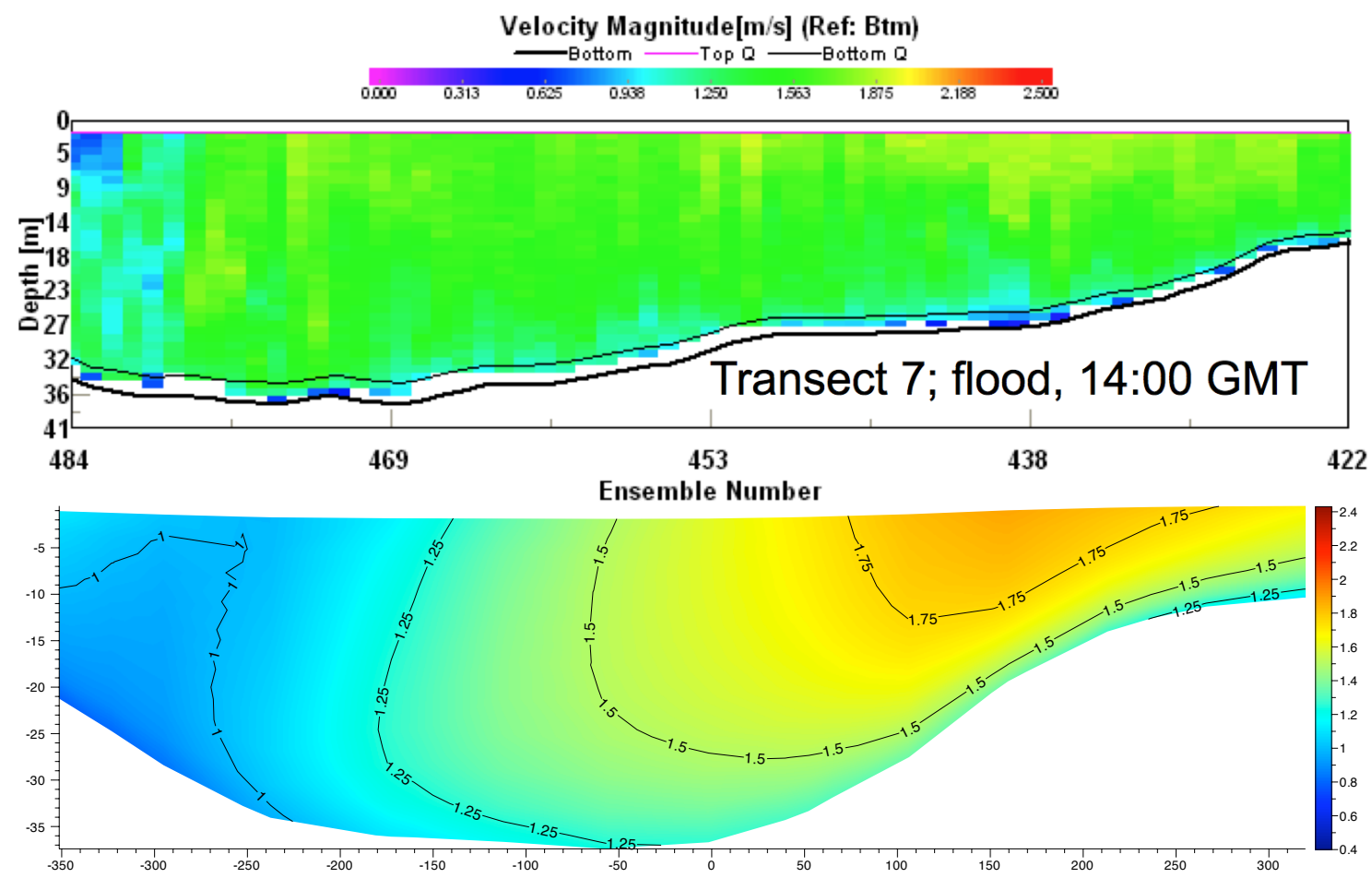

Figure III-12a: Velocity (m/s) through Transect 7 during large spring flood tide. Upper: ADCP-measured. Lower Model-computed.
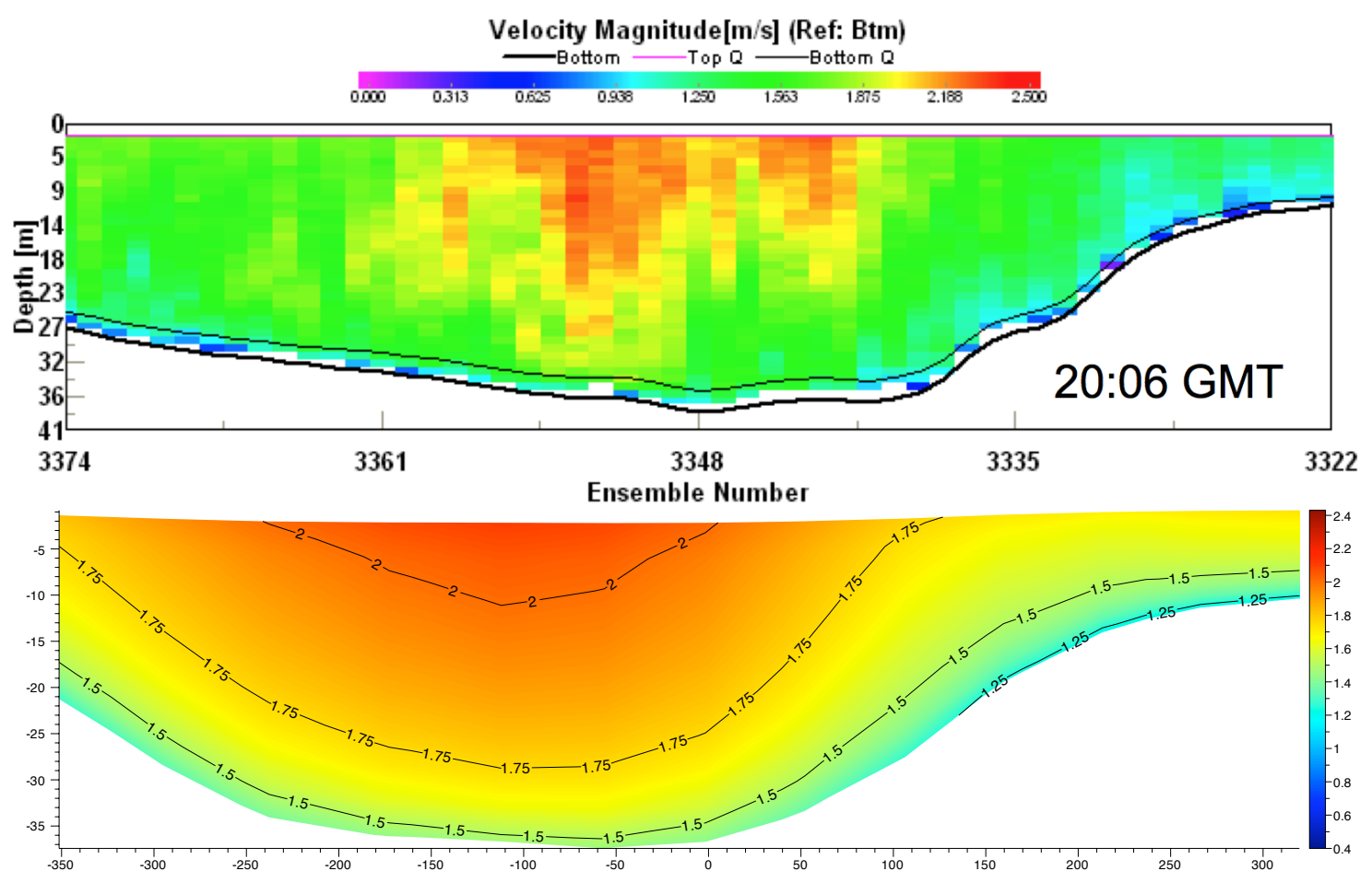

Figure III-12b: Velocity (m/s) through Transect 7 during large spring ebb tide. Upper: ADCP-measured. Lower Model-computed. 


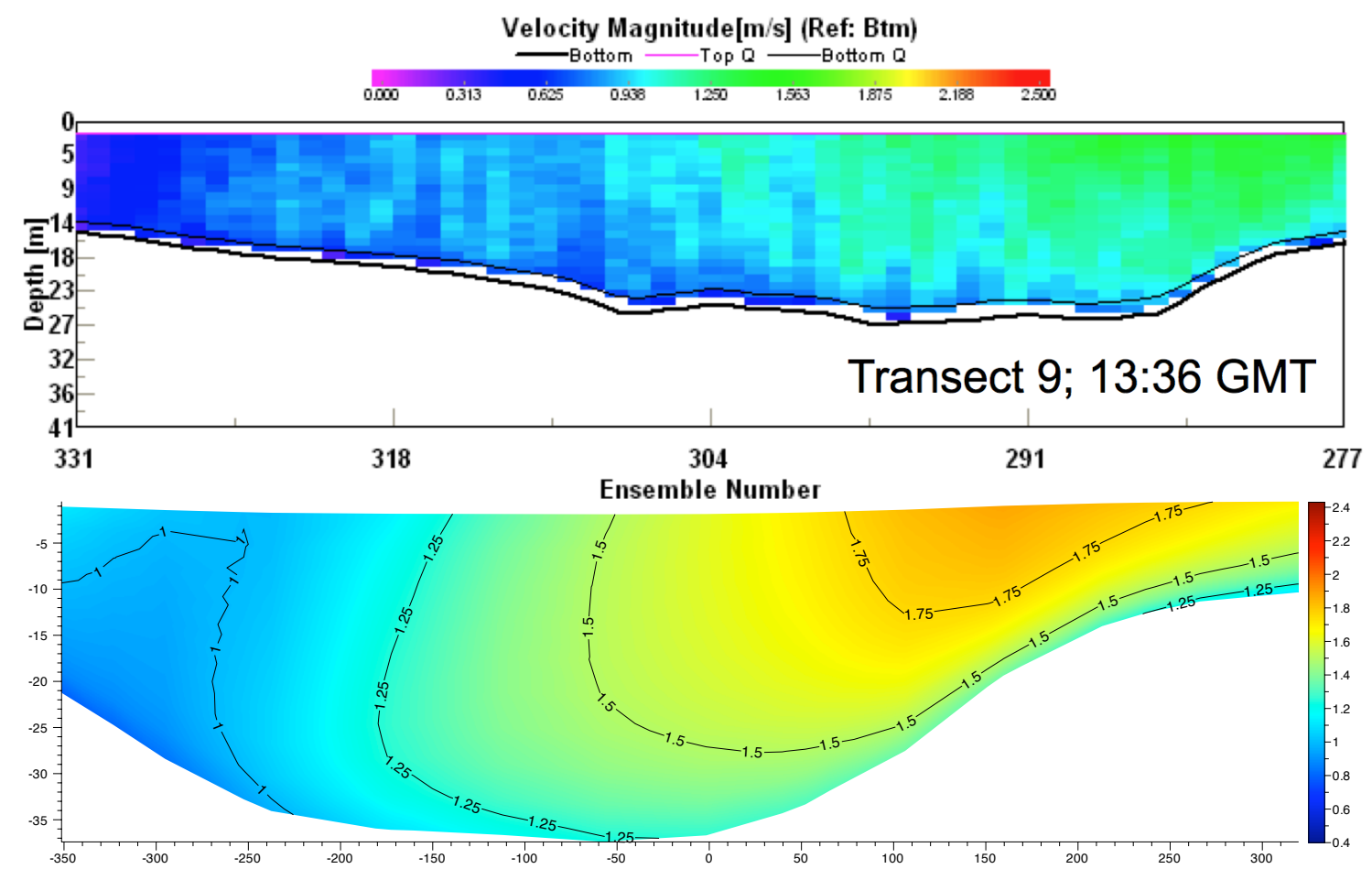

Figure III-12c: Velocity $(\mathrm{m} / \mathrm{s})$ through Transect 9 during large spring flood tide. Upper: ADCP-measured. Lower Model-computed.

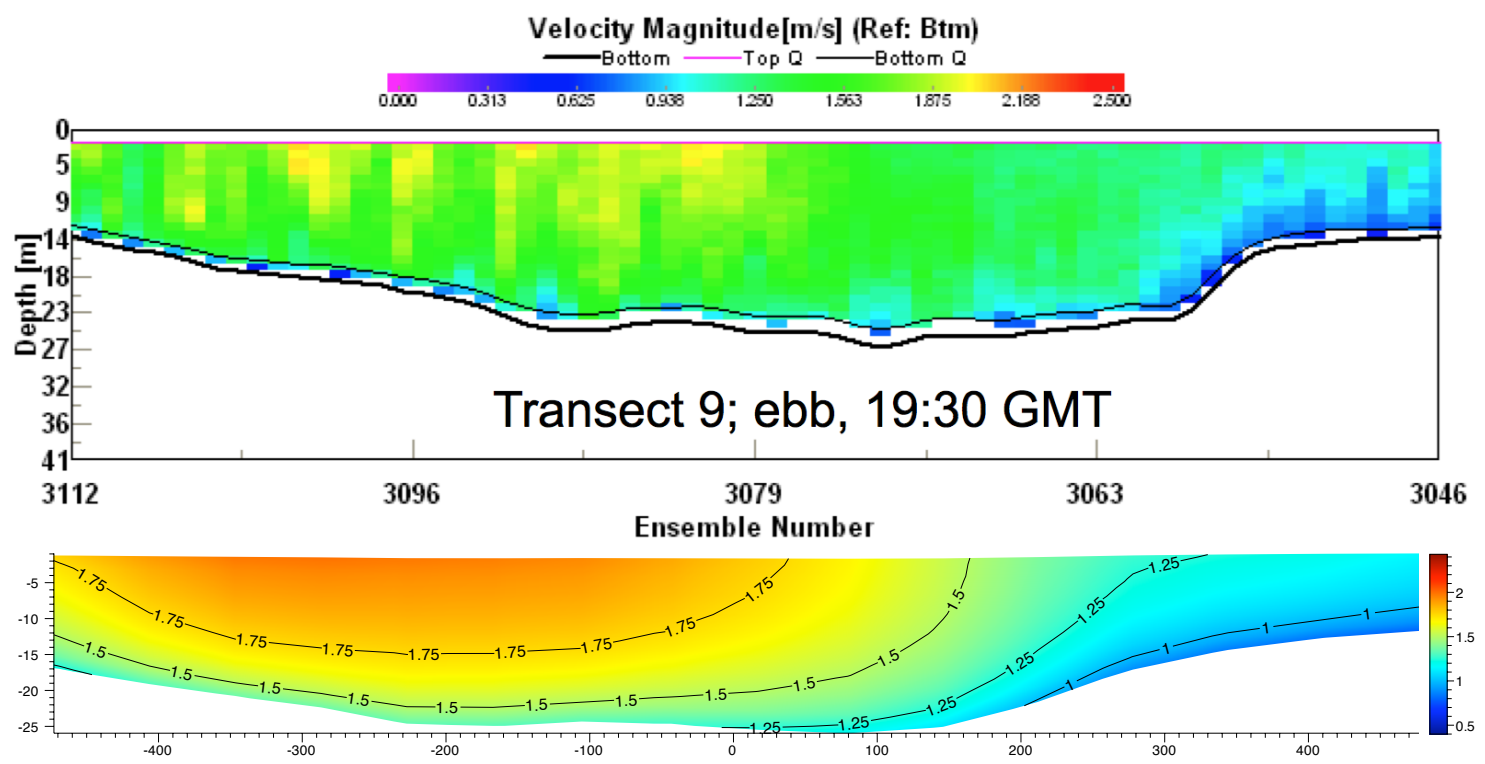

Figure III-12d: Velocity (m/s) through Transect 9 during large spring ebb tide. Upper: ADCP-measured. Lower Model-computed. 


\section{Impact Experiments}

\section{Setup}

To drive the sediment model an initial distribution of grains must be prescribed. Due to the heterogeneity of the substrate, there were not sufficient measurements in the region to derive the distribution directly from observations. For this reason we chose to let the model sort the grains under tidal forcing. A two-layer bed was initialized with equal distributions of eight grain sizes ranging from coarse silt $(\phi=4.5)$ to coarse granule $(\phi=-$ $2.5)$ in the Wentworth scale (Table III-2). All sediments are treated as non-cohesize and the larger sediments (very coarse sand to granule) are generally transported as bedload . Although larger size sediments have been observed (cobble, boulders), much of this would be heterogenous, glacial in origin, and unlikely to be highly mobile at the time scales of our interest given the shear stresses predicted by the model. Parmeterizing the effects of such scattered roughness elements on bed stress at the larger model scale is an active area of research. The model was forced by tides for a period of sixty days at which point the majority of discrete bed points in the model had reached a quasi-steady state distribution. The resulting distribution of mean surficial grain size compares well with spatial distribution derived from the US Seabed (Poppe et al., 2003) database and measurements acquired by the SMAST Coastal Systems Lab with support from this project (Fig III-13). Coarser sediments are present in the main channel and along the flanks in areas of high stress. Finer sediments are present along Wasque shoals and where the circulation and sediment availability allow for finite fractions to persist. The resulting spatial distribution of fractions of the eight size classes is saved and used to initialize the bed in the ISE experiments described below.

\begin{tabular}{|l|l|l|l|l|l|}
\hline Class & $\begin{array}{l}\text { Grain } \\
\text { Size }(\mathrm{mm})\end{array}$ & $\phi$ & $\begin{array}{l}\text { Settling } \\
\text { Velocity }(\mathrm{mm} / \mathrm{s})\end{array}$ & $\begin{array}{l}\text { Critical Shear } \\
\text { Stress (N) }\end{array}$ & Porosity \\
\hline Coarse Silt & .04 & 4.5 & 1.2 & .1 & 0.5 \\
\hline Very Fine Sand & .09 & 3.5 & 4.73 & .133 & 0.5 \\
\hline Find Sand & .18 & 2.5 & 17.64 & .165 & 0.5 \\
\hline Medium Sand & .35 & 1.5 & 47.21 & .213 & 0.5 \\
\hline Coarse Sand & .71 & .5 & 90.32 & .340 & 0.5 \\
\hline Very Coarse Sand & 1.41 & -.5 & 142.8 & .740 & 0.5 \\
\hline Coarse Granule & 2.83 & -1.5 & 210.3 & 1.92 & 0.5 \\
\hline Granule & 5.66 & -2.5 & 301.63 & 4.70 & 0.5 \\
\hline
\end{tabular}

Table III-2: Sediment Classes and Characteristics for ISE Impact Studies 


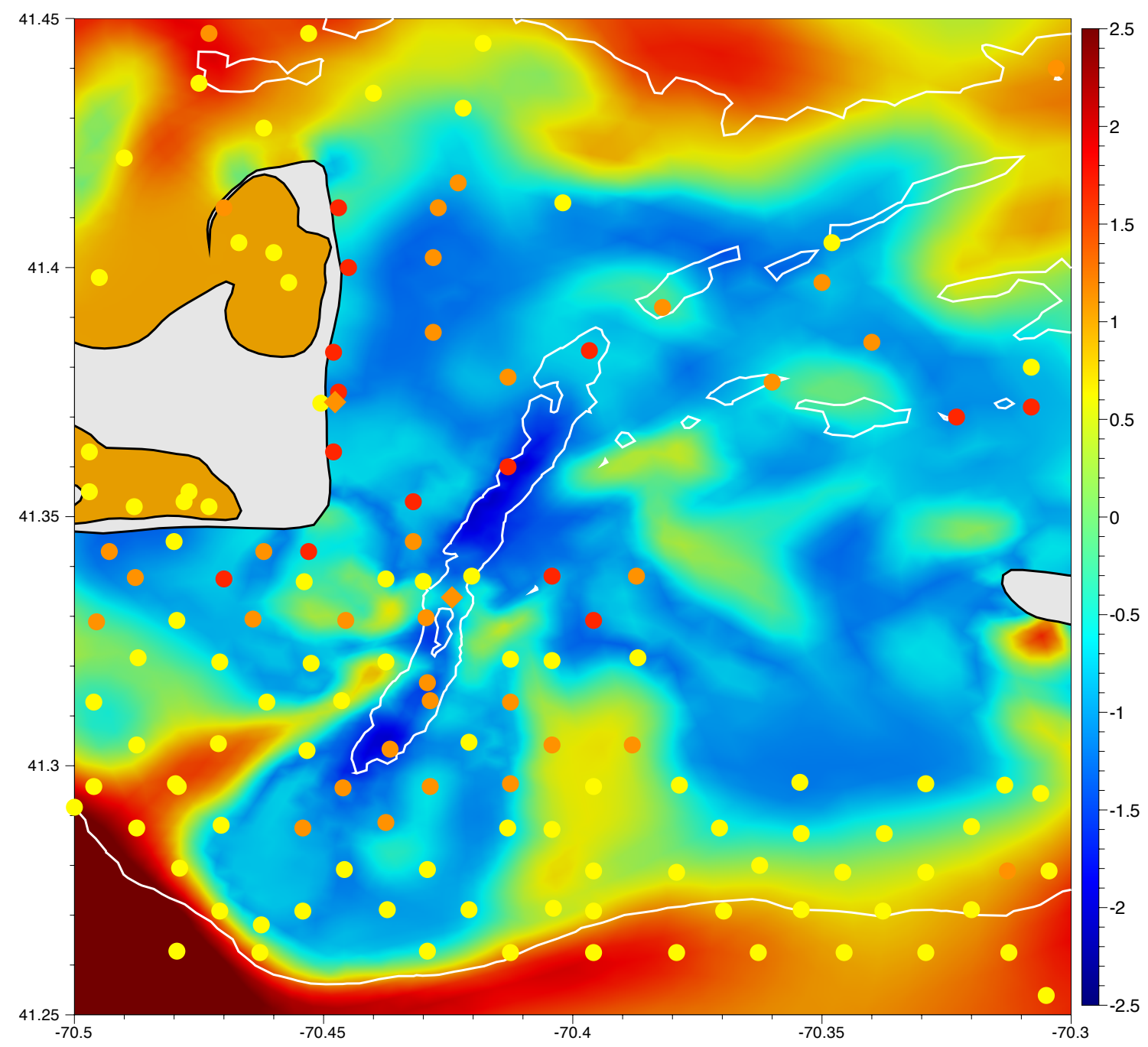

Figure III-13: Surficial median grain size distribution (phi) used to initialize the model impact experiments with USGS Seabed (circles) and SMAST CSP (diamonds) measurements for comparison (red = gravel, orange = gravelly sediment, yellow $=$ sand). $15-\mathrm{m}$ and $35-\mathrm{m}$ isobaths are included for reference.

Turbine layout and sizing was based on a preliminary assessment for tidal energy in Muskeget Channel by the Ocean Renewable Power Company (ORPC, 2010). Using velocity distributions from ADCP transects acquired by the SMAST Coastal System Program in combination with channel bathymetry, ORPC determined the optimal layout for their crossflow turbines for transects 6-9 (Table III-3). Their basic turbine design allows for efficient site-specific configuration. These configurations were used to establish the spatial distribution of parameters in Eq III-1 within the FVCOM mesh. The power coefficent $\mathrm{C}_{\mathrm{p}}$ was determined using the ratio of reported rated power to freestream tidal power through the cross-sectional area of the housing (ORPC, 2010). 


\begin{tabular}{|c|c|c|c|c|}
\hline Transect & $\begin{array}{c}\text { Baseline } \\
\text { Config }\end{array}$ & \# Configs & Total width $[\mathrm{m}]$ & Total area $\left[\mathrm{m}^{2}\right]$ \\
\hline 6 & $2-\mathrm{TGU}$ & 6 & 166 & 1412 \\
\hline 7 & $4-\mathrm{TGU}$ & 9 & 249 & 4238 \\
\hline 8 & $4-\mathrm{TGU}$ & 5 & 138 & 2354 \\
\hline 9 & $2-\mathrm{TGU}$ & 5 & 138 & 1177 \\
\hline
\end{tabular}

Table III-3: Turbine subgridscale parameterization for Impact Studies.

\section{$\underline{\text { Power Computations }}$}

Fields for the turbine subgridscale parameterization were extracted from the hourlyarchived model data to reconstruct the installation power. Figure III-14 (upper panel) shows a comparison of the power (MW) for both the coarse grid (mtm-4, dashed lines) and fine grid ( $\mathrm{mtm} 1$, solid lines) solutions for installations on transects 6-9 using $\mathrm{M}_{2}$ tidal forcing. In comparison with the fine grid, the coarse grid does remarkably well capturing the power generation and is much more efficient (Table III-1).
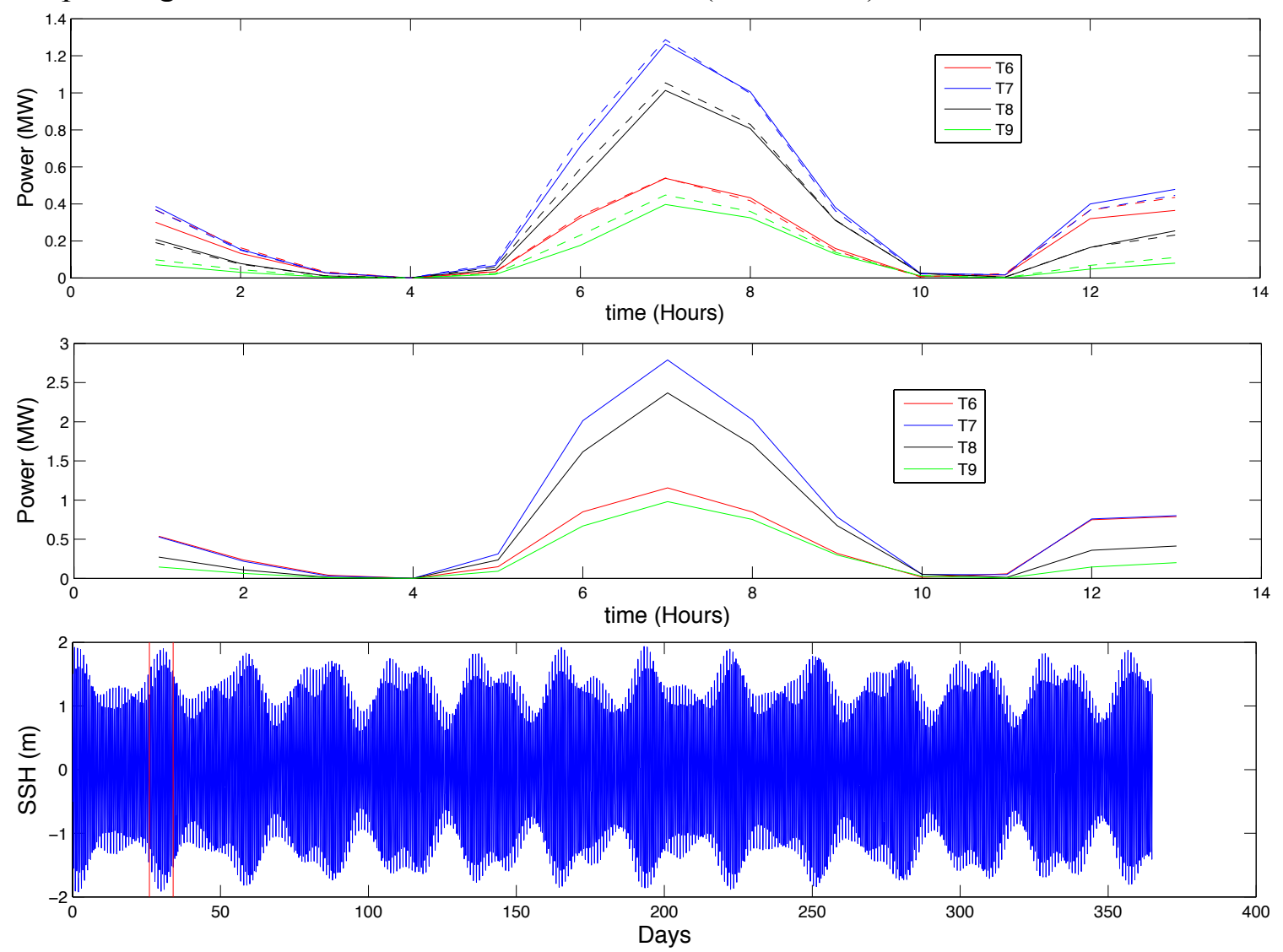

Figure III-14: Upper: Power captured by device array through transects $6-9$ forced by $\mathrm{M}_{2}$ tidal forcing using MTM1 (solid line) and MTM4 (dashed line) models. Middle: Power captured by device array through transects 6-9 forced by the dominant six components of tidal forcing using MTM4. Lower: sea surface elevation $(\mathrm{m})$ at the open boundary for model forced by six components of tidal forcing. Red bars show time frame containing tidal cycle for power curves in central panel. 
Power curves for the coarse grid $(\mathrm{mtm} 4)$ for a solution forced by the six major tidal components are shown in Figure III-14 (center panel). These curves was extracted over a larger spring tide (red zone, Fig. III-14, lower panel) which would be comparable to the large spring tide during which the ADCP data was acquired by the SMAST Coastal Systems Program. The peak power occurs during ebb tide and is good agreement with the estimates made by ORPC based on the ADCP data. As these estimates required obtaining an average observed velocity along a transect and rounding to the nearest knot to apply the rated power, it would not be possible to get perfect agreement. Installations along the intermediate transects $(7,8)$ in the deeper sections are able to provide the most power while the northernmost (6) and southernmost (9) sections have decreased potential due to the limited depth of water. It should be noted that in the subgridscale parameterization, it is assumed that the devices are always oriented perfectly normal to the flow. The flow through the northern portion of Muskeget is more or less rectilinear so it is possible to meet this condition with a fixed orientation device. At the southernmost transect (6), there is more appreciable deviation in flood and ebb direction which would result in a decrease in efficiency in a fixed-orientation device.

\section{Sea Surface Height Perturbation}

The turbine-induced modification to sea level is quite small. Muskeget is effectively a broad open channel and there is little lateral constraint. Reduced impacts on sea level are an advantage of using a TISEC approach to energy extraction vs. a head-based approach such as a barrage. In the region of Muskeget Channel as defined by the $15-\mathrm{m}$ isobath, the change in sea surface height (SSH) induced by the installations is roughly $3 \mathrm{~mm}$ (Fig. III-15). The head builds up against the device and relaxes downstream (Fig. III-16). The adverse slope in the upstream section $(\sim 1.5 \mathrm{e}-6 \mathrm{~m} / \mathrm{m})$ represents a pressure gradient with a driving force on par with a local wind blowing at 15 knots in $30-\mathrm{m}$

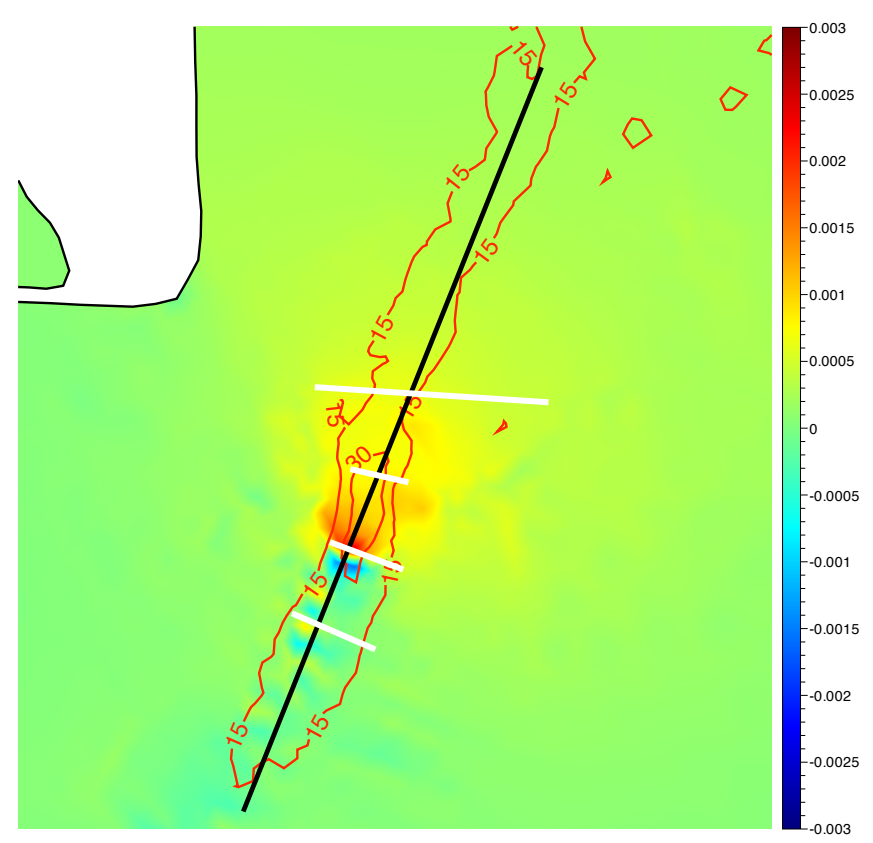

Figure III-15: Difference in model-computed free surface height between Transect-8 water. This adverse pressure gradient is responsible for the relative decrease in velocity upstream of the turbine (Figure III-17). 


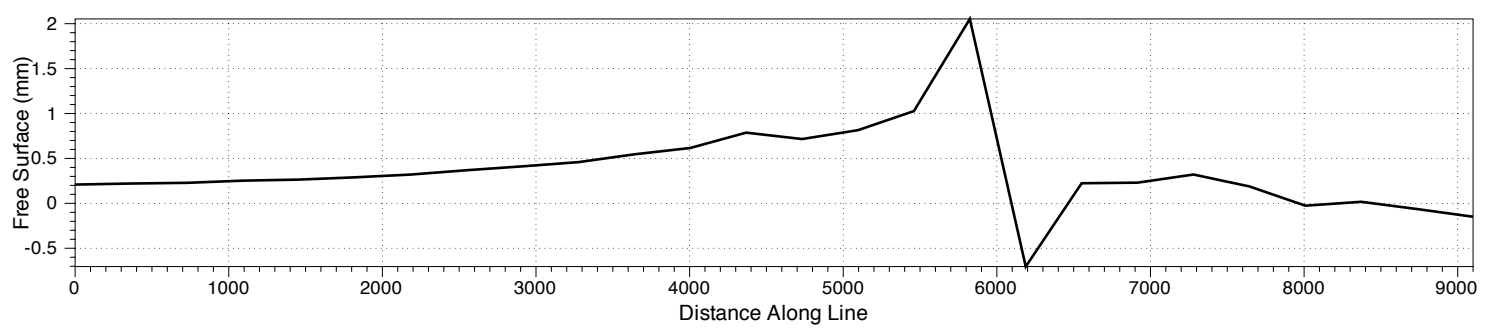

Figure III-16: Difference in model-computed free surface height ( $\mathrm{mm}$ ) along the main channel from North to South between a simulation of Transect-8 installation and natural conditions (ref: black line in Figure III-15). The approximate location of the installation along the transect is at $\mathrm{x}=6000$.

Vertically-Averaged Velocity and Bed Stress Perturbation

The extraction of momentum by the turbines modified the velocity field in region around the turbine. This is best examined by subtracting the natural (no turbine) flowfields from the turbine-modified as the perturbations are generally small compared to the background flow. A momentum deficit forms in the wake (Fig. III-17, left panels), extending downstream. During ebb, the velocity defect associated with energy extraction is roughly $5 \mathrm{~cm} / \mathrm{s}$. The velocity magnitude is also reduced upstream of the turbine but the magnitude of the impact is less than $1 \mathrm{~cm} / \mathrm{s}$. In association with the decreased velocities and reduction of momentum is a lateral pressure gradient which drives the flow around the turbine which can be thought of as a partial fence in the water column. The velocity is increased on the flanks of the Channel by roughly $2 \mathrm{~cm} / \mathrm{s}$. The modification to the vertically-averaged flow on flood (Fig. III-17, lower left) is spatially similar with a reduced magnitude as the Channel is strongly ebb dominant. Associated with the modifications to the velocity field are perturbations to the bed stress which generally scales as the square of the velocity. During ebb the model-computed bed stress for an installation at Transect 8 is decreased in the main channel by roughly $0.25 \mathrm{~N}$ and increased along the flanks the Channel by rough $0.1 \mathrm{~N}$. On flood tide, a similar pattern appears but the magnitude of bed stress perturbations is reduced accordingly. Spatial distribution of bed stress perturbations for installations at other transects follows the same general pattern with reduced stresses in the channel and enhanced stresses along the edges. In our sediment simulations, it is the current-induced bed stresses that drive the sediment model and thus changes in sediment fluxes are induced solely by pertubations. 

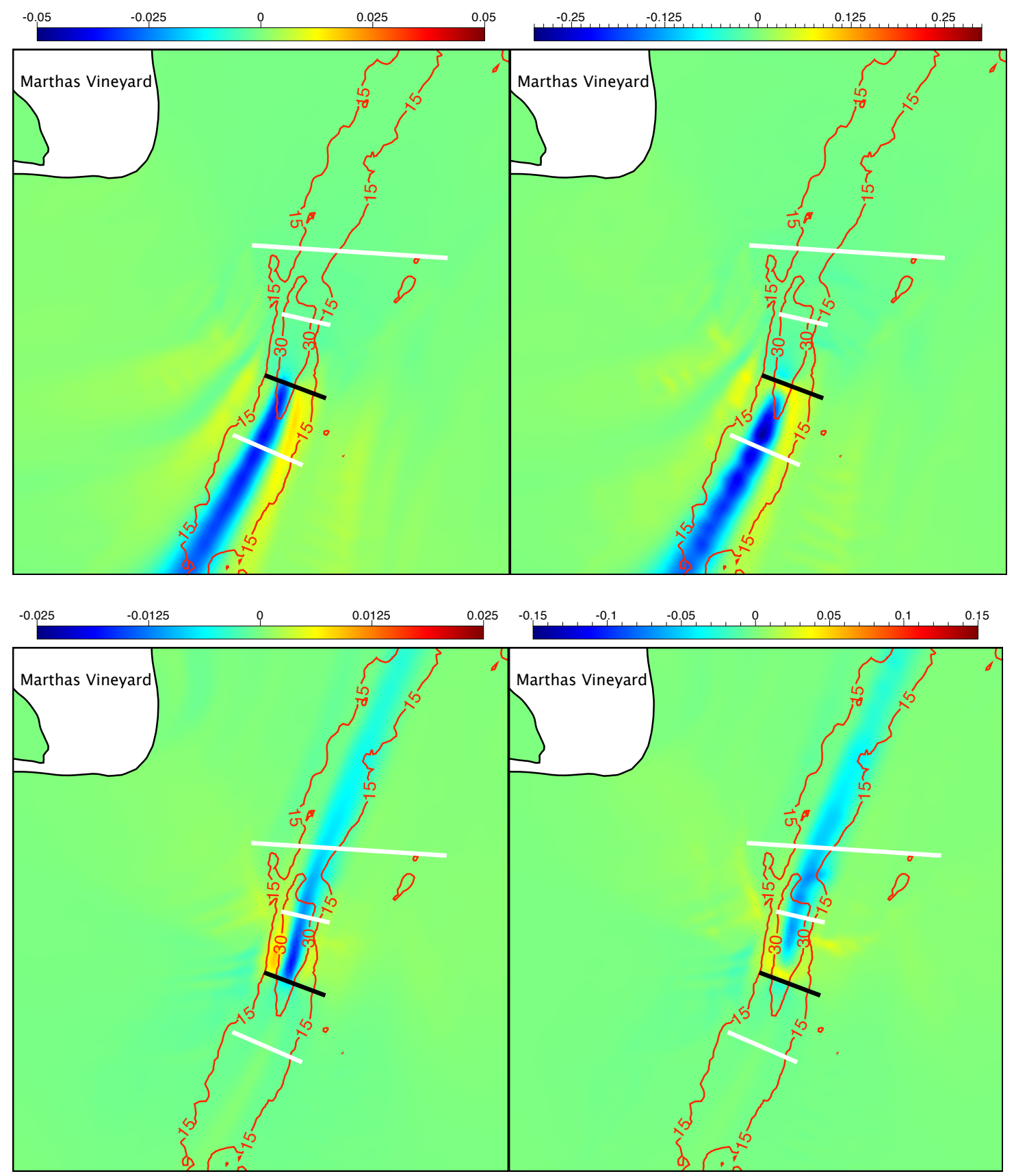

Figure III-17: Upper Panels: difference in model-computed vertically-averaged velocity magnitude $(\mathrm{m} / \mathrm{s})$ and bed stress $(\mathrm{N})$ during ebb for simulations with turbine installation at transect 8 and natural conditions. Lower Panels: difference in model-computed vertically-averaged velocity magnitude $(\mathrm{m} / \mathrm{s})$ and bed stress $(\mathrm{N})$ during flood for simulations with turbine installation at transect 8 and natural conditions. 


\section{Large Scale Modification to Bed Height}

In an initial sediment and erosion (ISE) experiment, hydrodynamic and sediment transport computations are made based on the assumption of an invariant bed topography. Such an approach is widely used as the computational effort is constrained and the difficulties associated with the implementation and solution of an evolution equation for the bed height are avoided. However, since the morphodynamic feedback is not included in an ISE model, the results must be interpreted with caution. The net erosion/deposition predicted by the model are useful for evaluting the spatial variation in the initial adjustment of the bed but will not be accurate over the long term where the resulting bathymetric changes feed back to the flowfield. Such morphodynamic modeling was beyond the scope work in this project but would be a logical next step in future efforts. The experiments here were initialized using a spatial distribution of sediment fractions with median size shown in Figure III-13. The bed was then allowed to evolve based on net deposition and erosion of the eight sediment classes for 30 days under $\mathrm{M}_{2}$ forcing both with and without turbines. We focused here on the single tidal consitituent as it can be more easily upscaled through a number of tidal cycles. By including all six constituents, approximately a full year is needed to experience the entire tidal range.

The relative change in bed heights $(\mathrm{m})$ between turbine-modified and natural simulations forced by $\mathrm{M}_{2}$ tides is shown in Figure III-18. These fields should not be interpreted as actual accretion or erosion, rather a net accretion or erosion relative to evolution of the bed in natural flow conditions. In all three cases there is a net positive change in the bed height which is consistent with effects of the turbines as energy needed to erode and trasnsport sediment is being removed from the system. This net accretion was approximately $15 \%$ of the total absolute change in model computed bed thickness for all four turbine installations. In all four cases the spatial distribution of relative changes follows the basic pattern of changes in bed stress resulting from the momentum removal (Figure III-17). However sediment erosion and deposition is more closely related to the divergence of the bed stress. For installations at all sites there is a positive change in bed thickness in the main channel with a negative change on the flanks of the Channel. Over the thirty day period this net bed change is approximately $5-10 \mathrm{~cm}$ at the central transects and $2-5 \mathrm{~cm}$ at the northern (transect 9) and southern (transect 6) installations. The total volume associated with the relative change in bed thickness within the domain shown in Figure III-18 is shown in Figure III-19. It is seen to be monotonically related to the power extracted by the devices. As these experiments were conducted with $\mathrm{M}_{2}$ forcing only, the actual installations would have larger power output (roughly 220\%) and accordingly, larger relative changes in bed heights over a given period. 

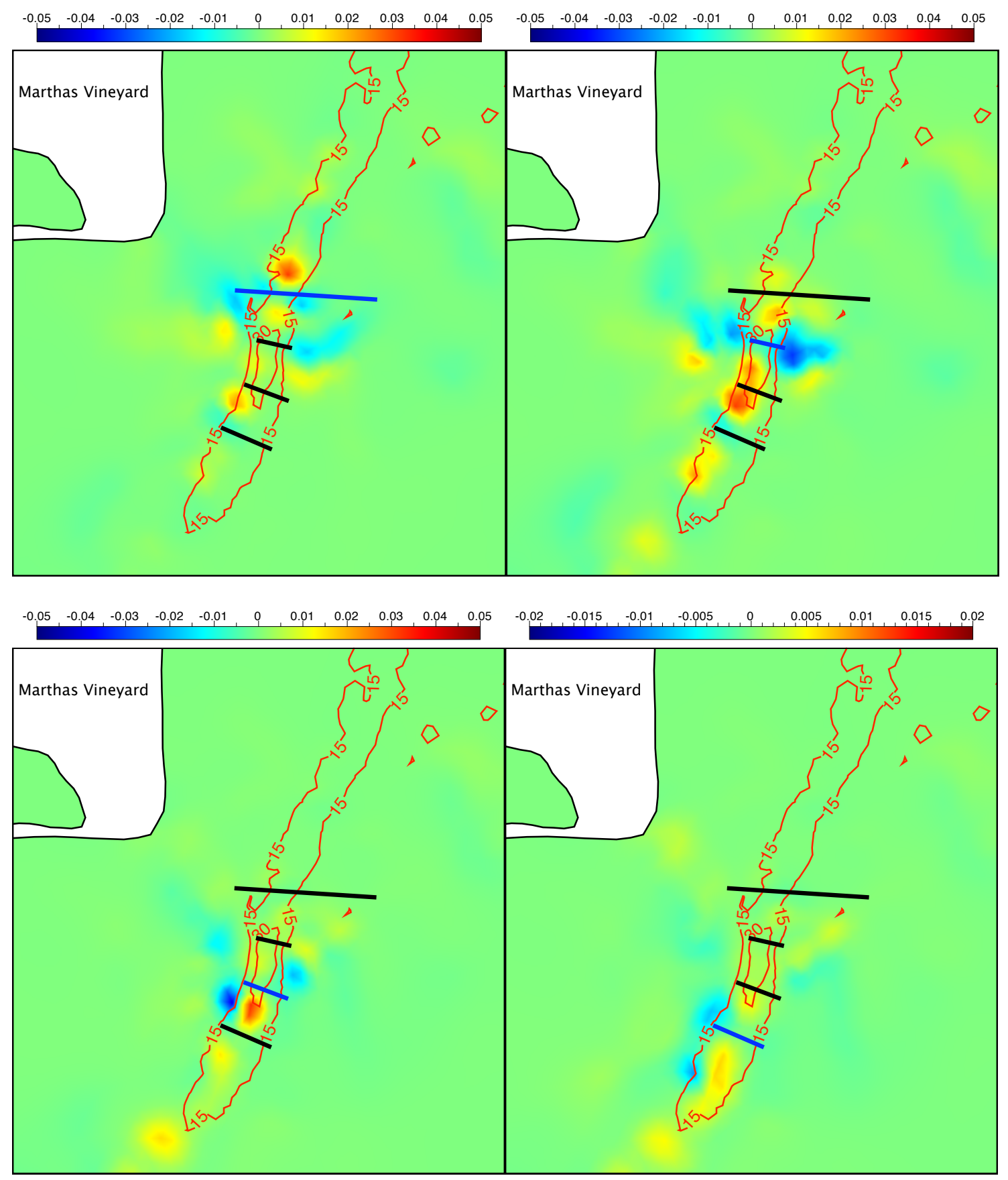

Figure III-18: Differences in model-computed and natural bed thickness $(\mathrm{m})$ over a 30day period for a simulation driven by $\mathrm{M}_{2}$ tides for installations at four different transects. Clockwise from Upper Left: Transect 6, Transect 7, Transect 8, Transect 9 (ref: blue line is transect of turbine installation). 


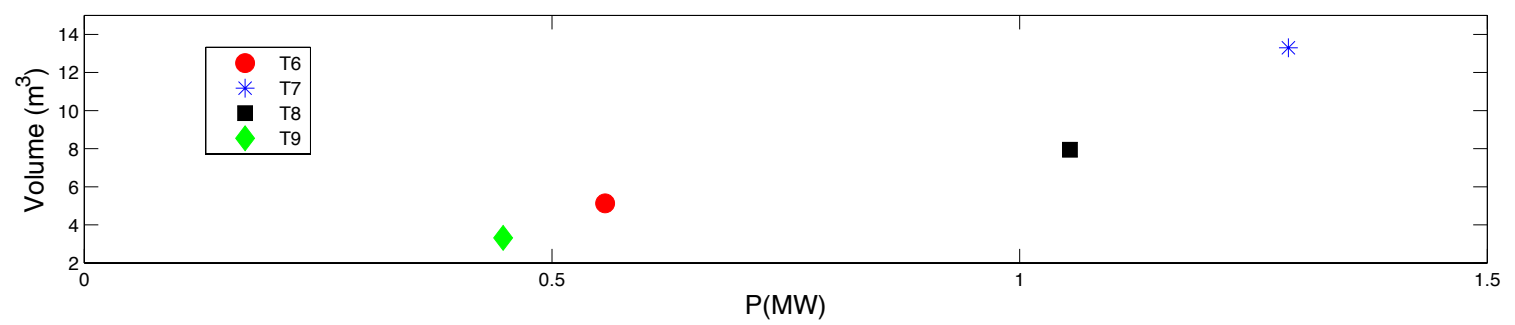

Figure III-19: Total absolute difference in bed volume over 30 days in the region enclosed in Figure III-19 between simulation with turbines and natural flow $\left(\mathrm{m}^{3}\right)$ vs the max power captured by the turbine array (MW). Simulations here used $M_{2}$-forcing only.

\section{Modification to Sediment Fluxes}

Fluxes of sediment through the Channel were examined along three transects: one north of the area of interest in energy extraction, one south, and one intersecting the primary area of interest between ADCP survey transects 7 and 8 (Fig. III-20). During flood the model-computed sediment loads are on the order of $1 \mathrm{~kg} /(\mathrm{m}-\mathrm{s})$ at the central and northern transects with weaker values along the southern transect indicating a convergence of sediment from the east and west flanks of the Channel (Fig. III-20). During ebb, values are approximately $50 \%$ higher corresponding to the greater shear stress (Fig. III-21) deriving from the ebb-dominant flow in the nearfield of the main channel (Fig. III-2).

The effect of energy extraction can be evaluted by subtracting the instantaneous sediment fluxes computed with the subgridscale turbine model in place by the fluxes computed in natural conditions (Fig. III-20,III-21). Flux perturbations are $\mathrm{O}(10) \mathrm{g} /(\mathrm{m}-\mathrm{s})$ corresponding to approximately $1 \%$ of the natural fluxes.

During flood, the perturbations to the transect fluxes due to augmentations in the deviceinfluence flowfield are most significant along the central and northern transects where the along-transect distribution reflects the variations in bed height observed during the sediment experiments. The largest defects in the flux occur in the main channel, particularly where a flux transect is proximal to the installation in the downstream direction (e.g. the influence of an ADCP transect 9 installation on the north flux transect). On the edge of the channel the fluxes are enhanced due to the local increase in bedstress. Transect 9 installation is seen to have only a nominal influence of the load. This is due primarily to the reduced amount of energy harvested at this site in comparison to the proposed installations at transect 7 and 8 .

Ebb tide flux augmentations are essentially the reverse of flood with flux defects occurring in the channel and flux enhancements on the flanks except with greater magnitude. The largest along-channel flux defect, on the order of $0.05 \mathrm{~kg} /(\mathrm{m}-\mathrm{s})$ is observed in the central flux transect just downstream of the transect 7 installation. 


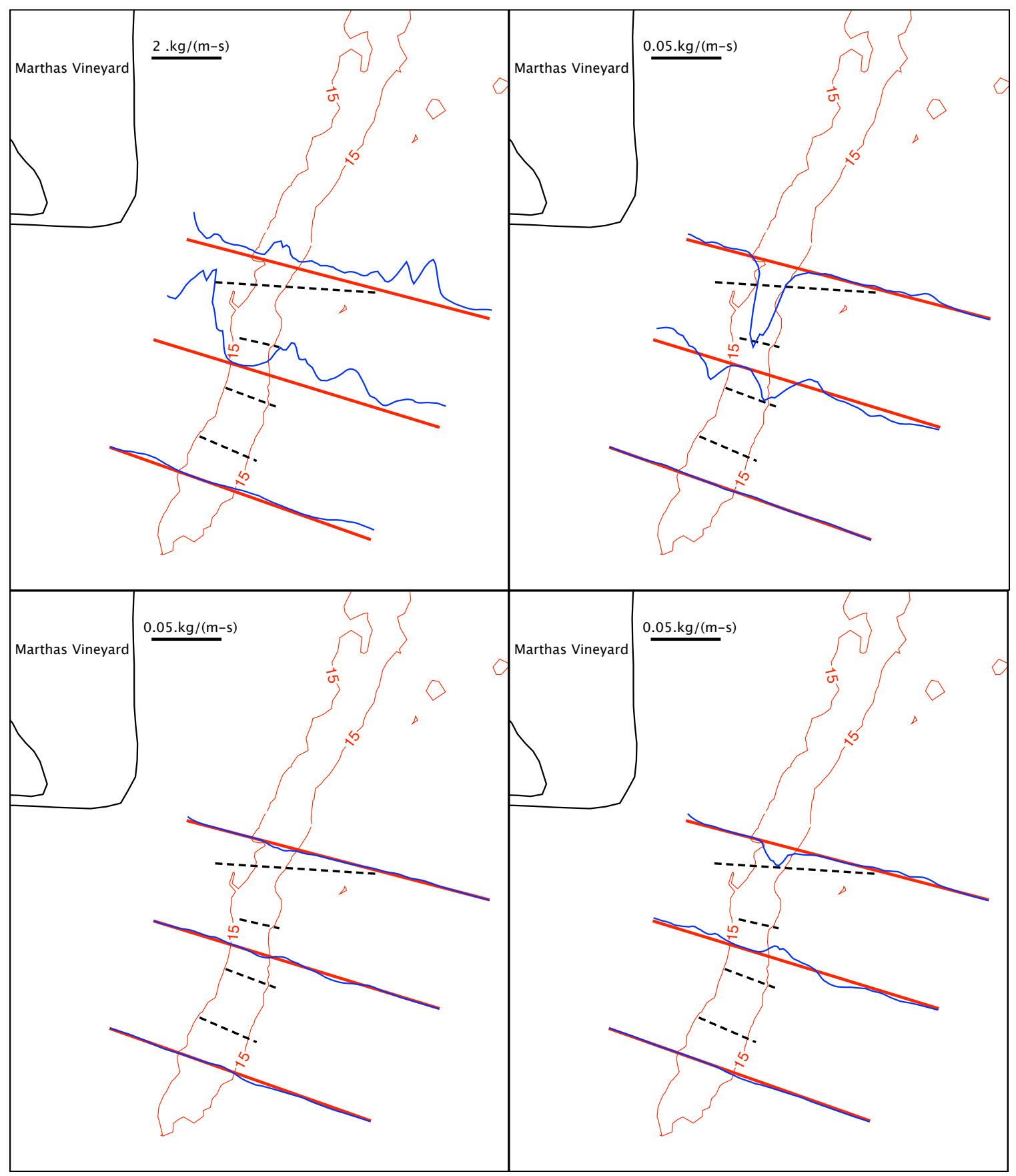

Figure III-20: Total sediment (bedload + suspended load) fluxes across three transects (red lines) during flood tide for a simulation in the $\mathrm{mtm}-4$ domain driven by $\mathrm{M}_{2}$ forcing. Clockwise from upper left: Natural fluxes, (ii) difference between installation-modified and natural fluxes for an installation at ADCP transect 7 (upper right); difference between installation-modified and natural fluxes for an installation at ADCP transect 8 (lower right); and difference between installation-modified and natural fluxes for an installation at ADCP transect 9 (lower left). ADCP transects 6-9 (black dashed lines) and $15-\mathrm{m}$ isobath shown for reference 


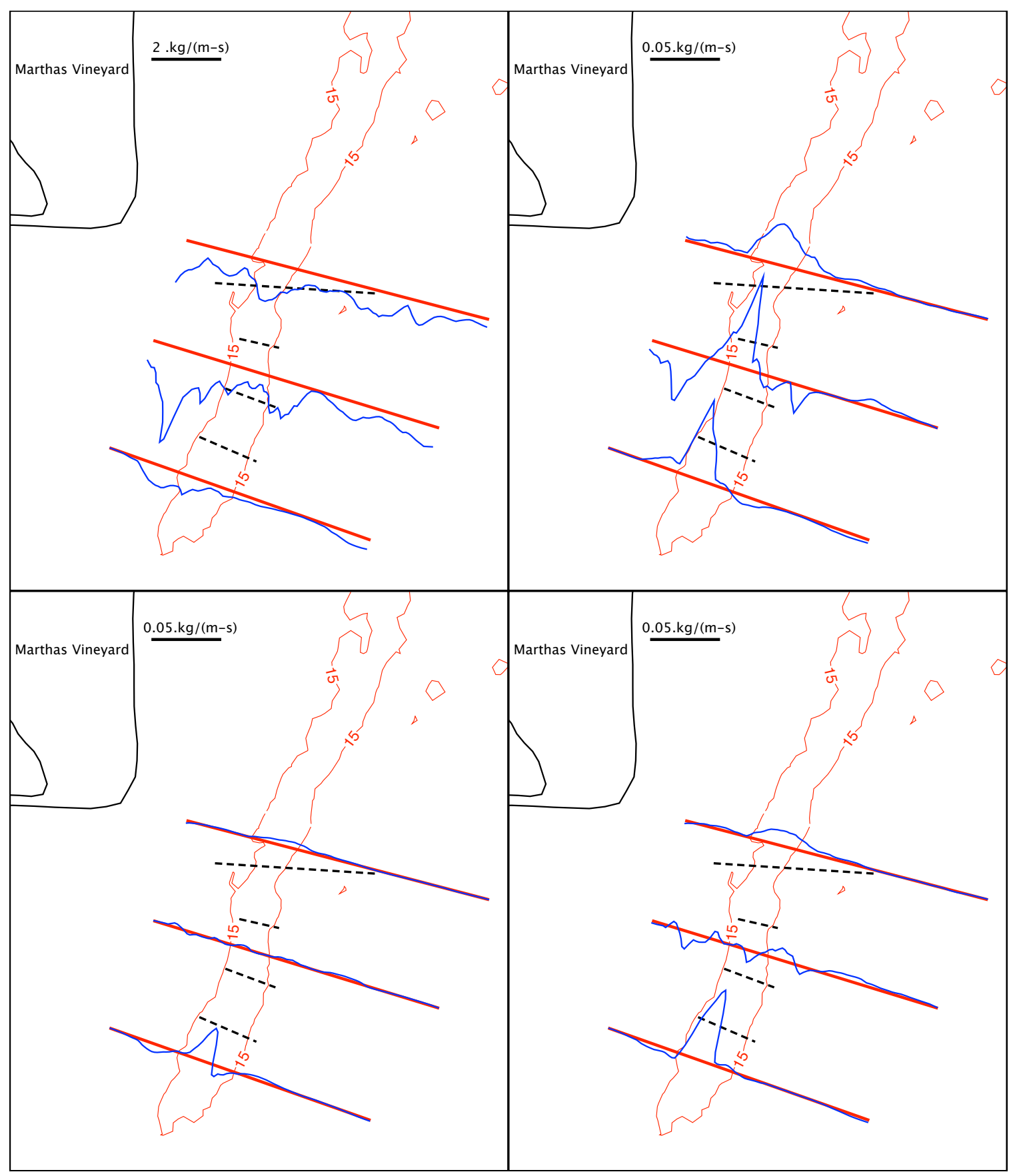

Figure III-21: Total sediment (bedload + suspended load) fluxes across three transects (red lines) during ebb tide for a simulation in the $\mathrm{mtm}-4$ domain driven by $\mathrm{M}_{2}$ forcing. Clockwise from upper left: Natural fluxes, (ii) difference between installation-modified and natural fluxes for an installation at ADCP transect 7 (upper right); difference between installation-modified and natural fluxes for an installation at ADCP transect 8 (lower right); and difference between installation-modified and natural fluxes for an installation at ADCP transect 9 (lower left). ADCP transects 6-9 (black dashed lines) and $15-\mathrm{m}$ isobath shown for reference 


\section{SUMMARY}

a. USGS SWATH bathymetry survey data was used to evaluate the characteristics of large scale bedforms in the main Muskeget Channel and outlying regions. The asymmetry of these bedforms indicate they are generated by residual currents and their orientation is consistent with the directionality of model-predicted tidal residual.

b. The proposed cable connection to Marthas Vineyard via Chappaquiddick directly interesects an area of medium sized bedforms of $\mathrm{O}(1 \mathrm{~m})$. Dredge depth would have to be carefully evaluated.

c. The bedform characteristics of Muskeget Channel and vicinity are in the range of empirical relationships for dynamic bedforms derived from other high energy sites.

d. A hydrodynamic model was developed to examine impacts of energy removal in Muskeget Channel. The model was validated using local tidal harmonics as well as comparisons of cross transect velocity with ADCP studies during large spring tides. The model captures well the sea surface elevation as well as the spatial complexity and magnitude of the velocity in the Channel as well as the strong flood-ebb asymmetry.

e. A spatial map of discrete grain fractions was developed by running a coupled hydrosediment model with 8 grain sizes and letting the bed reach a quasi-steady state. The grain sizes reflect well the large scale regional heterogeneity as determined from core samples which range from sands to gravel.

f. Model-computed perturbations to sea level due to proposed installations outlined by ORPC indicate changes on the order of several $\mathrm{mm}$ extending several $\mathrm{km}$ in all directions. Sea surface slope modifications are roughly $1.5 \mathrm{e}-6 \mathrm{~m} / \mathrm{m}$. Given that Muskeget draws tidal power from phase differences rather than a constriction, this limited impact on sea surface height is not surprising.

g. Tidal kinetic energy extraction is associated with reduced velocities in the channel and enhanced over the flanks. Model computed velocity and stress defects in the channel during ebb are on the order $5 \mathrm{~cm} / \mathrm{s}$ and $0.25 \mathrm{~N}$ respectively. On the flanks the velocity and bedstress are enhanced by $\sim 2 \mathrm{~cm} / \mathrm{s}$ and $0.1 \mathrm{~N}$ respectively.

h. Consistent with the spatial distribution of changes in the bed stress, the erosive potential is reduced in the channel upstream and downstream of the device and increased on the flanks of the channel adjacent to the location of installation. Over a 30 -day period, localized areas with net changes in bed height of $\sim 5 \mathrm{~cm}$ are expected as the topography adjusts to the device-augmented flow conditions.

i. Augmentations to instantaneous fluxes on the order of $0.05 \mathrm{~kg} /(\mathrm{m}-\mathrm{s})$ are observed for installation-augmented flow conditions. Flux defects are maximum in the main channel downstream of the turbine installation.

\section{REFERENCES}

Chen, C., H. Huang, R.C. Beardsley, Q. Xu, R. Limeburner, G.W. Cowles, Y. Sun, J. Qi, H. Lin, 2011. Tidal dynamics in the Gulf of Maine and New England Shelf: An application of FVCOM, Journal of Geophysical Research, in press. 
Chen, C, R. C. Beardsley and G. Cowles, (2006). An unstructured grid, finite-volume coastal ocean model (FVCOM) system. Special Issue entitled "Advance in Computational Oceanography", Oceanography, 19(1), 78-89.

Chen, C., H. Liu, and R. Beardsley, (2003) An unstructured grid, finite-volume, threedimensional, primitive equations ocean model: Application to coastal ocean and estuaries. Journal of Atmospheric and Ocean Technology, 20 (1), 159-186.

Cowles, G., (2008), "Parallelization of the FVCOM Coastal Ocean Model", International Journal of High Performance Computing Applications 22(2) 177-193.

Denny, J.F., Danforth, W.W., and Signell, R., (2012), Swath Bathymetric Data collected within Muskeget Channel, MA. USGS Open-File Report, 2012-XXXX (in prep).

Kobayashi, M. H., J. M. C. Pereira and J. C. F. Pereira (1999). A conservative finitevolume second-order-accurate projection method on hybrid unstructured grids. $J$. Comput. Phys., 150, 40-45.

Madala, R. V., and S. A. Piacsek (1977). A semi-implicit numerical mode for baroclinic oceans, J. Comput. Phys., 23, 167-178.

Meyer-Peter, E., Müeller, R., (1948). Formulas for bedload transport. In: Report on the 2nd Meeting International Association Hydraulic Structure Research. Stockholm, Sweden, pp. 39-64.

ORPC, (2010). Preliminary Tidal Energy Assessment for Muskeget Channel. Technical Report prepared for Harris, Miller, Miller, and Hanson Inc. for the Town of Edgartown, MA, $12 \mathrm{pp}$.

Poppe, L.J., Paskevich, V.F., Williams, S.J., Hastings, M.E., Kelley, J.T., Belknap, D.F., Ward, L.G., FitzGerald, D.M., and Larsen, P.F. (2003). Surficial Sediment Data from the Gulf of Maine, Georges Bank, and Vicinity: A GIS Compilation. U.S. Geological Survey Open-File Report 03-001.

Réthoré, P.-E., Sørensen, N.N., and Bechmann, A. (2010). CFD Model of wind turbine wake in atmospheric turbulence using body forces. Proceedings of the IEA Offshore Wake Workshop, Risø, 2009.

Warner, J. C., Sherwood, C. R., Signell, R. P., Harris, C. K., and Arango, H. G. (2008) Development of a three-dimensional, regional, coupled wave, current, and sediment- transport model. Computers \& Geosciences, 34, 1284-1306 



\section{Appendix C PCCS Reports}





\section{Marine Megavertebrates and Fishery Resources in the Nantucket Sound - Muskeget Channel Area}

\section{Ecology and Effects of Marine Renewable Energy Installations}
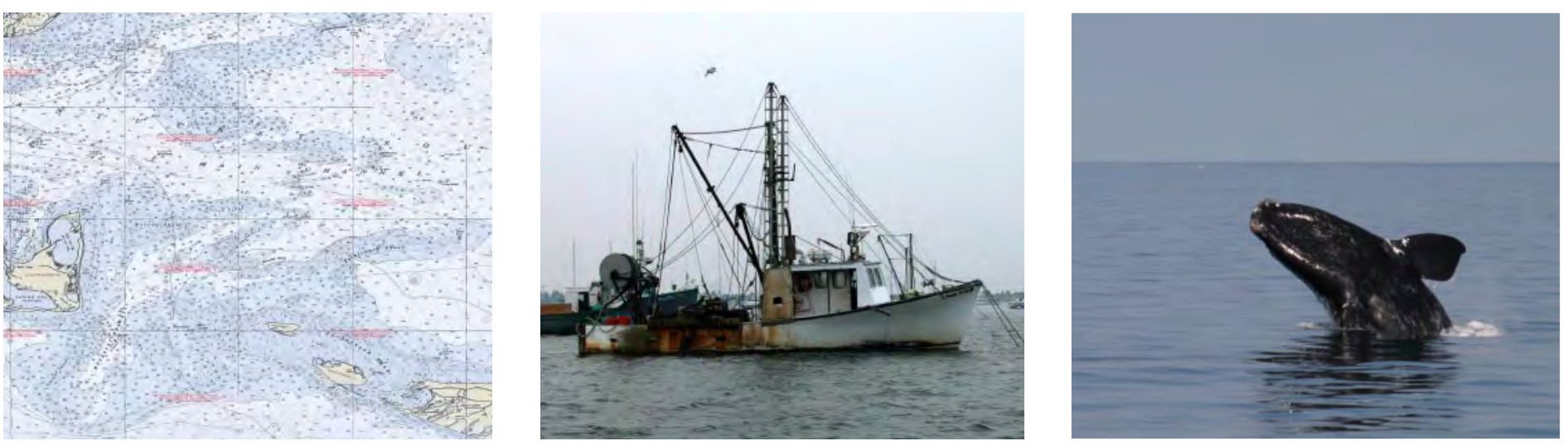

Provincetown Center for Coastal Studies

Ruth Leeney, PhD; Owen Nichols; Lisa Sette and Stephanie Wood LaFond, PhD Patricia Hughes, Project Manager 


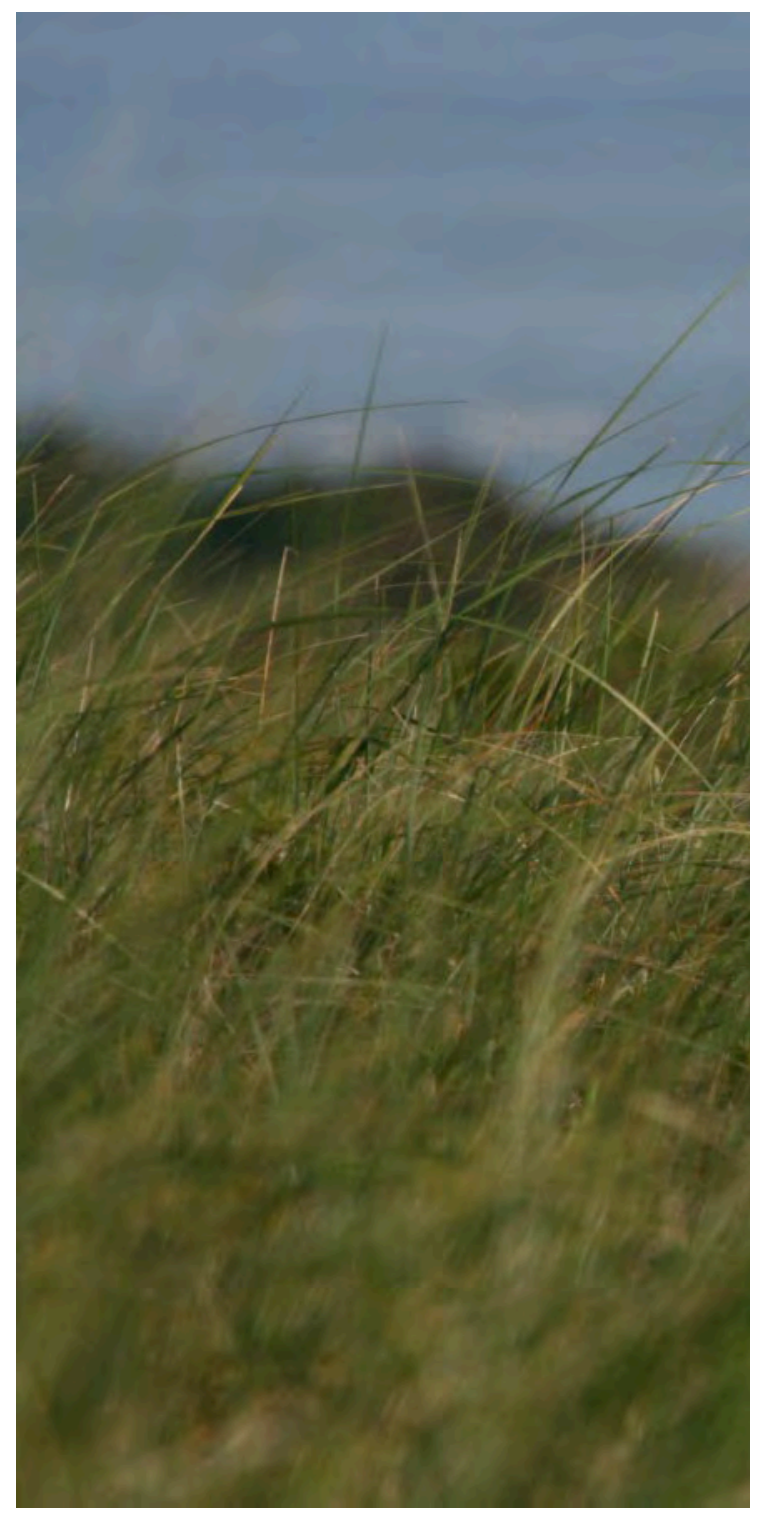

A Report to

Harris Miller Miller \& Hanson Inc for HMMH Project \# 303910

Environmental Impacts of

Sediment Transport Alteration and Impacts on Protected Species: Edgartown Tidal Energy Project

Funding provided by the U.S. Department of Energy under Grant \# DE-EE0002656

September 2010

Cover Images: Chatham fishing boats, O. Nichols; Right whale, Provincetown Center for Coastal Studies image taken under NOAA permit 633-1763, with authority of the U.S. Endangered Species Act

Figures $2.1,2.2,2.13,2.14,2.15,2.16$ created by Battelle

This report should be cited as:

This report should be cited as: Leeney, R.H., Nichols, O.C., Sette, L., Wood LaFond, S. and Hughes P.E.2010. Marine Megavertebrates and Fishery Resources in the Nantucket Sound - Muskeget Channel Area: Ecology and Effects of Renewable Energy Installations. Report to Harris Miller Miller \& Hanson Inc., September 2010. Provincetown Center for Coastal Studies, Provincetown, MA, USA. $88 \mathrm{pp}$.

Available at: www.coastalstudies.org

\section{ProvincetownCenter for Coastal Studies}




\section{Table of Contents}

1 Executive Summary

Chapter 12 Background

Chapter 24 Distribution, Abundance and Habitats of Marine Megavertebrates

5 Cetaceans

10 Pinnipeds

20 Dermochelid \& Chelonids

26 Basking Shark

27 Ocean Sunfish

Chapter 330 Distribution, Abundance and Habitats of Fishery Resources and Activity

33 Species Descriptions

Chapter 438 Data Gaps and Concerns

39 Cetaceans

$40 \quad$ Pinnipeds

41 Dermochelid \& Chelonids

41 Basking Shark \& Ocean Sunfish

42 Fishery Resources and Fishing Activity 
Chapter 544 Effects of Marine Renewable Energy Installations on Marine Megavertebrates

45 General Effects of Construction and Operation

49 Device-specific Effects

53 The Future

Chapter 656 References

Appendix I 80 Supplementary Tables

Appendix II 84 Table of Online Sites Relating to Marine Renewable Energy Developments and Monitoring Methods 


\section{List of Tables}

Table 1: Comparison of strandings data from NOAA Fisheries for animals that stranded on or in the vicinity of Martha's Vineyard, Nantucket, and nearby islands with Right Whale Consortium sightings data for the same region

Table 2: $\quad$ Life Stages of 18 Species (16 fish, 2 invertebrates) for which EFH has been Designated Between $41^{\circ} 20^{\prime}-41^{\circ} 30^{\prime} \mathrm{N}$ and $70^{\circ} 20^{\prime}-70^{\circ} 30^{\prime} \mathrm{W}$

\section{List of Figures}

Figure 2.1: Cetacean sightings in Southern Massachusetts.

Figure 2.2: Seal pupping colonies and haul-out sites in the Nantucket Sound - Muskeget Channel area.

Figure 2.3: Harbor seal abundance in Maine, 1981-2001 (Gilbert et al., 2005).

Figure 2.4: Harbor seal abundance from Plymouth to Woods Hole, Massachusetts (Payne \& Selzer, 1989; Barlas, 1999).

Figure 2.5: Harbor seal abundance 1998-99: Plymouth to Woods Hole (Barlas, 1999).

Figure 2.6: Harbor seal abundance in Woods Hole, Massachustts (deHart, 2002).

Figure 2.7: Harbor seal abundance at the Nantucket, Massachusetts jetties, 2004-08 (NMFS, unpublished data).

Figure 2.8: $\quad$ Seasonal and annual trends in harbor seal abundance in Narragansett Bay, Rhode Island (Schroeder, 2000).

Figure 2.9: Harbor seal abundance on Monomoy Island, Massachusetts (Payne \& Selzer, 1989; Barlas, 1999).

Figure 2.10: Gray seal pup counts on Muskeget Island, Massachusetts, 1991-2008 (Rough, 1995, 2000; Wood LaFond, 2009).

Figure 2.11: Gray seal molt counts for Muskeget Island, Massachusetts, 1992-99 (Rough, 2000; Barlas, 1999).

Figure 2.12: Gray seal molt counts for Monomoy Island, Massachusetts in 1994, 1995 and 1999 (Rough, 2000; Barlas, 1999).

Figure 2.13: Confirmed entangled sea turtle sightings in waters south of Cape Cod as reported to the Massachusetts Sea Turtle Disentanglement Network (MASTDN). Support for this work is provided by ESA Section 6 in conjunction with Massachusetts Division of Marine Fisheries. Data can only be used for the purpose of this literature review and should not be used for any other reason or application without the express written consent of the PCCS.

Figure 2.14: Opportunistic sea turtle sightings recorded by Massachusetts Audubon during aerial surveys of tern activity in Nantucket Sound as part of an assessment for the Cape Wind energy project. Surveys were completed in August and September from 2002-04.

Figure 2.15: Sea turtle sightings documented in the North Atlantic Right Whale Consortium sightings database for Nantucket Sound. Sightings data only indicate presence of animals, rather than patterns of distribution, as survey effort is not plotted.

Figure 2.16: Basking sharks and ocean sunfish sightings data for Southern Massachusetts. 


\section{Appendix I:}

\section{Supplementary Tables}

Table A1: $\quad$ Seals Observed Stranded in Nantucket Sound and along Outer Cape Cod by Species and Year. Data courtesy of the National Marine Fisheries Services (NMFS)

Table A2: $\quad$ Historic and Recent Observations of Harbor Seals in Southern New England

Table A3: Historic and Recent Observations of the Gray Seal in Southern New England

Table A4: $\quad$ Summary of Whalenet Satellite Tags Deployed on Harbor and Gray Seals in Nantucket Sound and Cape Cod Waters

\section{Appendix II:}

Table of online sites relating to marine renewable energy developments and monitoring methods 


\section{Executive Summary}

\section{Marine Megavertebrates and Fishery Resources}

The authors found that there has been little or no directed research on marine megavertebrates in the Nantucket Sound - Muskeget Channel area. While there has been directed research on some species in the Gulf of Maine, survey effort has been very low in the waters immediately south of Cape Cod, including the Muskeget Channel area.

Surveys have been done to estimate population size of harbor and gray seals in this area; however these are now out of date. Most of the data on cetaceans and sea turtles discussed in this report are from opportunistic sightings, strandings and entanglements. With the exception of a tagging program on leatherbacks, there is no systematic survey effort on sea turtles in this area. The lack of systematic survey efforts in the study area precludes an accurate assessment of the abundance and distribution of cetaceans and sea turtles in the Nantucket Sound - Muskeget Channel area. This is also true for basking sharks and ocean sunfish.

There is little readily available data with which to evaluate the specific importance of the Muskeget Channel study area to commercial and recreational fisheries. The Massachusetts Division of Marine Fisheries conducts fall and spring trawl surveys that measure relative abundance of species throughout state waters; however, these surveys are not designed to measure fine-scale distribution patterns.

Section IV of this report discusses these data gaps.

\section{Effects of Marine Renewable Energy Installations on Marine Megavertebrates}

This section provides a summary of the existing literature and knowledge regarding the effects of marine renewable energy installations (MREIs) on marine megavertebrates. The review notes that MREIs have the potential to be both detrimental and beneficial to the environment, and the effects will likely be site-specific. Most studies to date have investigated the effects of offshore wind turbines on marine fauna; data is lacking on other technologies. There is therefore a great need for focused research to address the potential effects of tidal devices on marine ecosystems.

Continuous assessment over longer time periods, in different locations and with appropriate control sites for comparison will be necessary, as marine organisms may respond or adapt differently in different habitats. The many possible impacts of MREIs on marine ecosystems, both positive and negative, will have complex interactions which are difficult to predict. Such interactions will likely be cumulative both temporally and as the number of MREIs grows. In carrying out an environmental impact assessment at any given MREI site, it will be crucial to incorporate solid study design into any monitoring program to allow for reliable detection of effects. It will also be important to assess whether the effects on individual megavertebrates at specific sites will translate into population-level effects. 


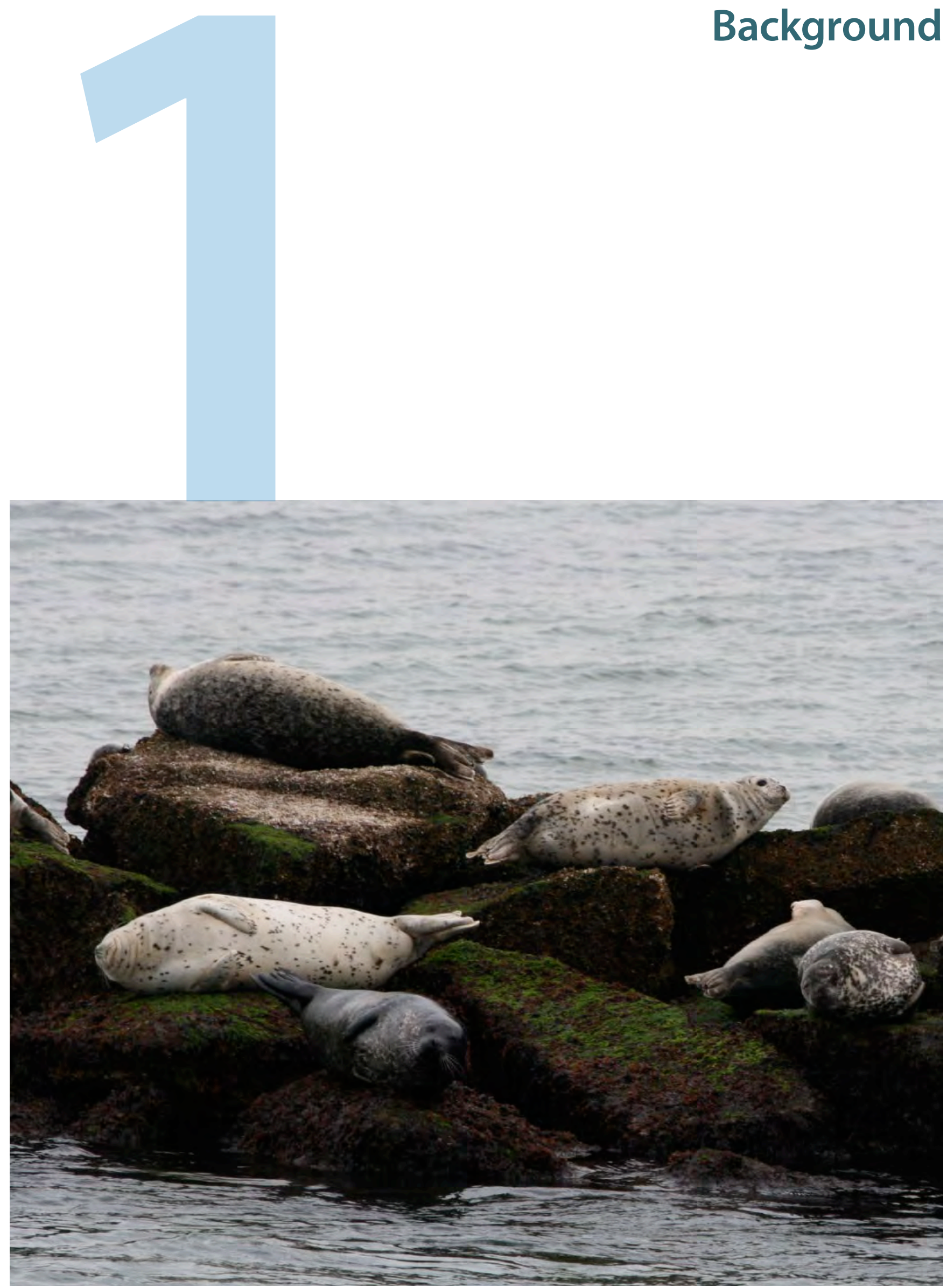

Photo: Harbor seals, Provincetown Center for Coastal Studies image taken under NOAA permit 775-1875 
Muskeget Channel is located between the islands of Martha's Vineyard and Nantucket. Water depths in the channel range between 40 and 160 feet, with Wasque Shoals to the west and Mutton Shoal to the east. Muskeget Channel allows for the exchange of water between Nantucket Sound to the north and the Atlantic Ocean and continental shelf to the south.

The Town of Edgartown is proposing to develop an initial 5MW tidal energy pilot project in Muskeget Channel. Edgartown holds a Preliminary Permit from the Federal Energy Regulatory Commission (FERC), giving it the exclusive right to explore the development of the resource for energy. Edgartown is required to submit a Draft Pilot License Application that will allow the town to deploy, operate and monitor this pilot-scale turbine installation. This application must include information on initial consultation with cooperating federal resource agencies; draft study plans, including one on protected species, and an outline of work that will be completed during deployment of the pilot project.

The Town of Edgartown engaged Harris Miller Miller \& Hanson (HMMH) as its Principal Investigator (PI) and program manager. HMMH was successful in obtaining U.S. Department of Energy funding for the study: Environmental Effects of Sediment Transport Alteration and Impacts on Protected Species: Edgartown Tidal Energy Project.

The Provincetown Center for Coastal Studies (PCCS) is one of four organizations working on this study under the direction of HMMH. The PCCS tasks were to:

1. Conduct a literature review of

- current information on the documented occurrence and habitats of marine megavertebrates - cetaceans, pinnipeds, turtles, basking sharks and sunfish - in the Muskeget Channel region;

- documented distribution of fishery resources and habitats and commercial and recreational fishing activity;

- studies and assessments on the environmental impacts of marine energy conversion projects on marine megavertebrates.

2. Prepare protocols for environmental studies and monitoring of marine megavertebrates specific to Muskeget Channel sufficient to collect data needed to define baseline conditions and evaluate impacts from the operation and maintenance of the tidal energy project.

3. Prepare a synthesis report on the permitting and planning framework for marine energy conversion projects, focusing on the Muskeget Channel region.

This report includes work PCCS completed under Task 1. Work completed under Tasks 2 and 3 is presented in separate reports. 


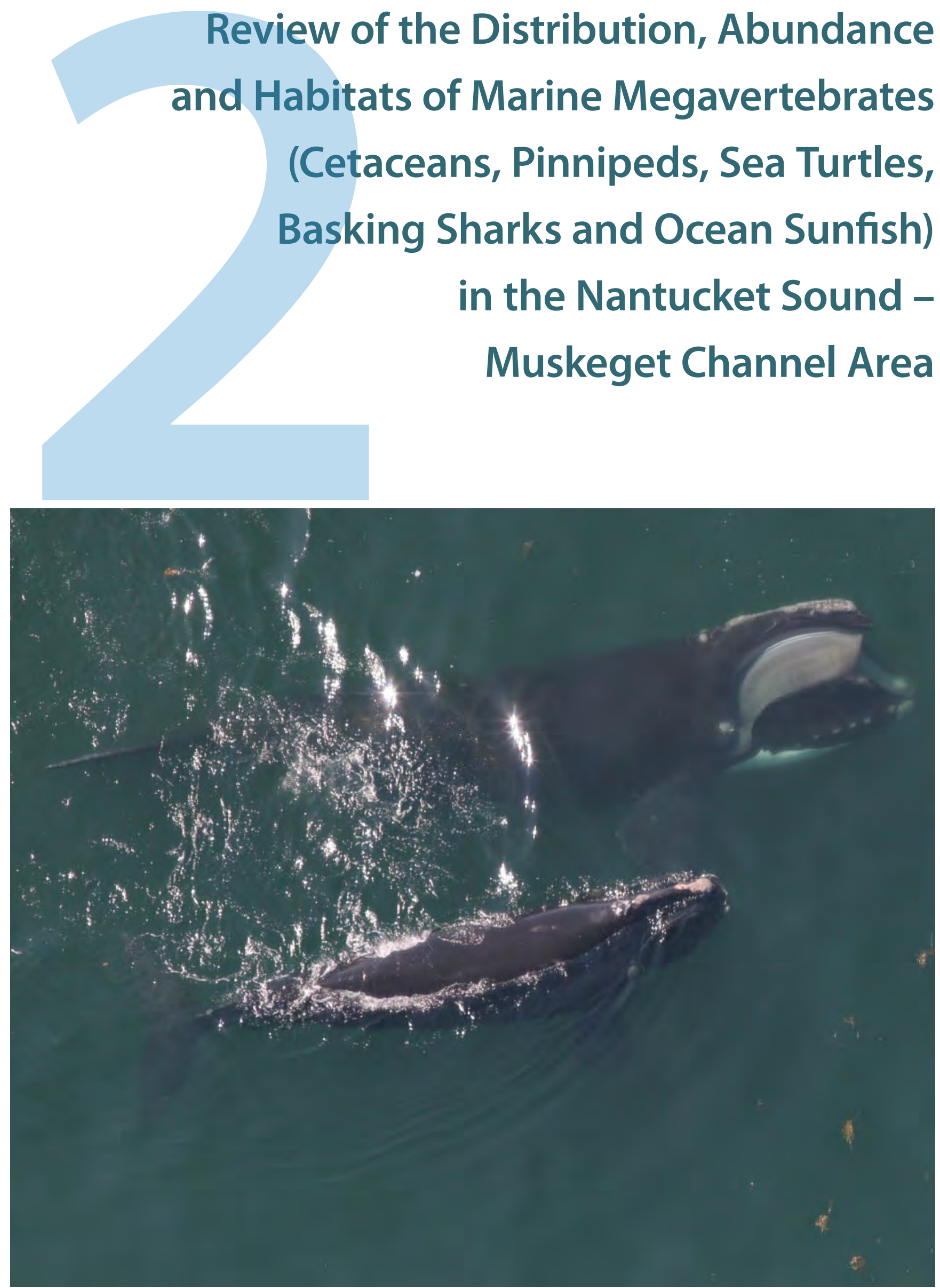




\subsection{Cetaceans}

\subsubsection{Introduction}

Broad-scale seasonal distribution patterns of most cetacean species in the waters of the Northeastern United States are relatively well understood (Kenney and Winn, 1986; Kenney et al., 1996; Pittman et al., 2006). However, systematic survey effort has been very low in the waters immediately south of Cape Cod, including the Muskeget Channel area (Pittman et al., 2006; see also Data Summary). The intent of this section is to summarize available information on the occurrence of cetaceans in the vicinity of the Muskeget Channel region. A separate section is devoted to historical and present-day occurrence of North Atlantic right whales due to the species' critical status (Kraus et al., 2005). The remainder of this section reviews the occurrence of other baleen whales, including endangered fin, sei and humpback whales, and a summary of the occurrence of the endangered sperm whale and several other species of toothed whales.

\subsubsection{Species Descriptions}

\subsubsection{Mysticetes (Baleen Whales)}

\section{North Atlantic right whale (Eubalaena glacialis):}

North Atlantic right whales are listed as endangered under the U.S. Endangered Species Act. A minimum of 415 individuals were thought to be alive in 2007 (Pettis, 2009). Right whales are distributed from winter calving grounds in the waters of the Southeastern United States north to summer feeding grounds in the Bay of Fundy and on the Scotian Shelf, with rare sightings in the Gulf of Mexico and off Greenland and Norway (Winn et al., 1986; Waring et al., 2009). Right whales are present in Cape Cod Bay in winter and spring (Hamilton and Mayo, 1990; Nichols et al., 2008) and the Great South Channel in late spring (Kenney et al., 1995), where they feed on dense concentrations of zooplankton, particularly calanoid copepods (Mayo and Marx, 1990; Beardsley et al., 1996). Pittman et al. (2006) analyzed the limited systematic survey effort available in the area south of Cape Cod, including Muskeget Channel, and noted that right whale sightings-per-unit effort (SPUE) was very low, with 0.1-8.2 whales sighted per 1,000 km of survey effort in most of the area. Given the low survey effort in the area, opportunistic sightings warrant further discussion, as do patterns of historical occurrence.

The nearshore waters off Nantucket Island were productive hunting grounds for shore-based whalers as early as the mid-1600s. Reeves et al. (1999) reviewed catch histories of whalers targeting right whales in Nantucket waters, primarily citing the monographs by Allen (1916) and Little $(1981,1988)$. The above authors gathered 
information from a variety of sources, including whaling logbooks and Nantucket newspapers, and primarily made reference to the abundance and/or seasonality of right whale presence. In the instances where catch locations were reported relative to the location of Nantucket Island, most were distributed to the south or east, and a few were documented in Nantucket Sound.

Schevill et al. (1981) recorded a number of winter and spring right whale sightings in Nantucket waters from 1956-1980, and Mate et al. (1997) tracked a female accompanied by her calf in Nantucket Sound using satellite telemetry in the summer of 1990. The carcass of an entangled one-year-old female drifted ashore on Nantucket in October 2002 (Moore et al., 2004). A number of right whale sightings recorded in the area from assorted platforms $(\mathrm{n}=111)$ are archived in the North Atlantic Right Whale Consortium sightings database (Right Whale Consortium, 2010; Figure 2.1). Of particular interest is the occurrence of a relatively large number of right whales in winter/spring 2010 in Nantucket, Vineyard and Rhode Island Sounds and the waters immediately south of Nantucket (Kenney, 2010). Sightings in the Sounds reported to the North Atlantic Right Whale Sighting Advisory System during winter and spring 2010 ( $\mathrm{n}=105$; most of which occurred in Rhode Island Sound) presented by Kenney (2010) are included in Figure 2.1. These sightings were not yet entered into the Right Whale Consortium sightings database at the time of this writing. The combination of opportunistic sightings in the past few decades and present-day reports suggests that in some years, particularly during the winter and early spring, right whales may still be found in the near-shore waters of Nantucket Island and Martha's Vineyard as well as Nantucket Sound.

Four other species of baleen whales occur frequently in Northeastern U.S. waters: fin (Balaenoptera physalus), sei (Balaenoptera borealis), humpback (Megaptera novaeangliae) and minke whales (Balaenoptera acutorostrata). Sightings of these species are most common in spring, summer and fall (Kenney and Winn, 1986; Kenney et al., 1996; Pittman et al., 2006).

Fin whales are listed as endangered under the U.S. Endangered Species Act. The most recent abundance estimate available for the western North Atlantic fin whale stock is 2,269 (CV = 0.37; Waring et al., 2009). Occurrence in northeast U.S. waters from spring through the fall is associated with distribution of prey, in particular small schooling fish (Kenney et al., 1996). The location of calving, mating and wintering is unknown.

Sei whales are listed as endangered under the Endangered Species Act; no population estimate is available for the Nova Scotia stock, which includes the waters of the Northeastern U.S. in its range (Waring et al., 2009). The species is generally distributed offshore towards the outer continental shelf, although episodic incursions into nearshore waters are associated with reduced competition for their zooplankton prey (Kenney et al., 1996).

Humpback whales are listed as endangered under the Endangered Species Act. Humpback whales off the Northeastern U.S. are considered to be part of the Gulf of Maine stock, which is defined by high individual fidelity to the region during seasonal migrations away from calving and mating grounds in the West Indies and surrounding low-latitude waters (Robbins, 2007; Waring et al., 2009). Several abundance estimates have been generated for this stock, all averaging approximately 500 animals (Waring et al., 2009).

Minke whales are not listed under the Endangered Species Act. Minke whales that occur off the eastern coast of the United States are considered to be part of the Canadian East Coast stock, which is found from the Davis Strait south to the Gulf of Mexico. No population estimate exists for this stock. Peak abundance in continental shelf waters off New England occurs during spring and summer, while during winter the species appears to be largely absent (Waring et al., 2009). Like humpback and fin whales, minke whales in the region are largely piscivorous, and their distribution is affected by that of their prey (Kenney et al., 1996).

\subsubsection{Odontocetes (Toothed Whales, Dolphins \& Porpoises)}

Numerous species of toothed whales occur off the northeastern U.S., including Atlantic white-sided dolphin (Lagenorhynchus acutus), bottlenose dolphin (Tursiops truncatus), common dolphin (Delphinus delphis), harbor porpoise (Phocoena phocoena), pilot whales (Globicephala spp.), pygmy sperm whale (Kogia breviceps), Risso's dolphin (Grampus griseus), sperm whale (Physeter macrocephalus), striped dolphin (Stenella coeruleoalba) and 
white-beaked dolphin (Lagenorhynchus albirostris) (Katona et al., 1993). Of these species, only the sperm whale is listed as endangered under the Endangered Species Act.

Atlantic white-sided dolphins occur in shelf waters from Greenland south to the Carolinas and are most common off the Northeastern U.S. in spring and summer (Pittman et al., 2006; Waring et al., 2009). Like many of the region's toothed whales, white-sided dolphins feed on fish and squid, and their distribution often reflects that of their prey (Kenney et al., 1996). They are mostly found in deeper offshore waters, but can be seen quite close to shore around the Cape Cod region. The best estimate of abundance of the Western North Atlantic stock is 63,368 (CV= 0.27; Waring et al., 2009).

Bottlenose dolphins are rare in Northeastern U.S. waters and are more commonly noted in coastal waters in the Southeastern U.S. (Katona et al., 1993).

Common dolphins occur most often in fall in offshore waters of the Northeastern U.S., although they are known to mass strand on Cape Cod along with white-sided dolphins (Bogomolni et al., 2010).

Harbor porpoises move through the Northeastern U.S. shelf waters throughout the year, with concentrations in the Northern Gulf of Maine in summer, dispersion throughout the region in spring and fall and southern movement in winter. The best estimate of abundance for the Gulf of Maine harbor porpoise stock is 89,054 (CV=0.47; Waring et al., 2009). This species is known to use coastal waters.

Pilot whales are mostly found toward the edges of the continental shelf but are known to occur in Cape Cod waters, often as part of mass strandings (Pittman et al., 2006; Bogomolni et al., 2010). Due to confusion between the short-finned and long-finned pilot whale, population abundance indices for each species are difficult to establish (Waring et al., 2009).

Pygmy sperm whales, Risso's dolphins, sperm whales and striped dolphins all occur in warmer, lower-latitude, offshore waters and only rarely occur in the waters of Northeastern northeast U.S. (Katona et al., 1993). Population information for these species is lacking (Waring et al., 2009). White-beaked dolphins are similarly rare in the area, although they may have been displaced inshore by white-sided dolphins in response to shifts in prey of both species (Kenney et al., 1996).

\subsubsection{Distribution \& Abundance in the Nantucket Sound - Muskeget Channel Area}

\subsubsection{Mysticetes}

In the study area south of Cape Cod, including Muskeget Channel, SPUE of fin, sei, minke and humpback whales was very low or zero (Pittman et al., 2006). Given the low survey effort in the area, all sightings, including those recorded opportunistically, warrant further discussion. Sightings of fin $(n=141)$, sei $(n=1)$, humpback $(n=27)$, and minke $(\mathrm{n}=23)$ whales archived in the North Atlantic Right Whale Consortium sightings database (Right Whale Consortium 2010) were generally distributed to the south of Nantucket Sound (Figure 2.1). However, this does not necessarily reflect spatial distribution patterns, as systematic survey effort in the study area was distributed in a similar manner (See Data Summary). Stranding data obtained from NOAA Fisheries ${ }^{1}$ for animals that stranded on or in the vicinity of Martha's Vineyard, Nantucket and nearby islands included records of fin $(\mathrm{n}=$ $4)$, sei $(n=1)$, humpback $(n=7)$ and minke $(n=9)$ whales. Stranding data must be interpreted with caution, as unhealthy or otherwise compromised animals may not ordinarily occur in the area, and carcasses can drift from distant locations.

1. Data courtesy of Tracy Bowen and Mendy Garron (NOAA Fisheries) and contributing stranding networks spanning 1988-2009.

These data should not be used out of context or without verification. 


\subsubsection{Odontocetes}

Pittman et al. (2006) analyzed survey data for the following species as well as unidentified toothed whales and noted low or zero SPUE throughout the area south of Cape Cod, including Muskeget Channel: Atlantic white-side dolphin, bottlenose dolphin, common dolphin, harbor porpoise, pilot whales, Risso's dolphin and white-beaked dolphin. Sightings of toothed whales archived in the North Atlantic Right Whale Consortium sightings database (Right Whale Consortium 2010) were generally distributed to the south of Nantucket Sound (Figure 2.1). However, this does not necessarily reflect spatial distribution patterns, as systematic survey effort in the study area was distributed in a similar manner (See Data Summary, Appendix I). Stranding data obtained from NOAA Fisheries ${ }^{2}$ for animals that stranded on or in the vicinity of Martha's Vineyard, Nantucket and nearby islands are listed below and compared to the Right Whale Consortium sightings data from the broader area including the waters to the south as defined in the Data Summary. The stranding data included the above species as well as the pygmy sperm whale, sperm whale and striped dolphin. The strandings of sperm whales are noteworthy, as the species is listed as endangered under the U.S. Endangered Species Act.

\section{Table 1:}

Comparison of strandings data from NOAA Fisheries for animals that stranded on or in the vicinity of Martha's Vineyard, Nantucket, and nearby islands with Right Whale Consortium sightings data for the same region

\begin{tabular}{|c|c|c|}
\hline \multirow{2}{*}{ Species } & \multicolumn{2}{|c|}{ Number of animals by data source } \\
\hline & Right Whale Consortium & NOAA Fisheries Strandings \\
\hline Atlantic white-sided dolphin & 759 & 4 \\
\hline Bottlenose dolphin & - & 10 \\
\hline Common dolphin & 65 & 31 \\
\hline Harbor porpoise & 66 & 8 \\
\hline Pilot whale (all spp.) & 133 & 22 \\
\hline Pygmy sperm whale & - & 7 \\
\hline Risso's dolphin & - & 8 \\
\hline Sperm whale & - & 4 \\
\hline Striped dolphin & 1 & 8 \\
\hline White-beaked dolphin & 50 & - \\
\hline
\end{tabular}

Although extreme caution is necessary when interpreting stranding data as well as sightings data due to lack of systematic effort, it is noteworthy that so few Atlantic white-sided dolphins strand on the islands around the study area when compared to the number of animals documented in the Right Whale Consortium sightings data. Such discrepancies may reflect offshore distributions of this and other species (Figure 2.1). 

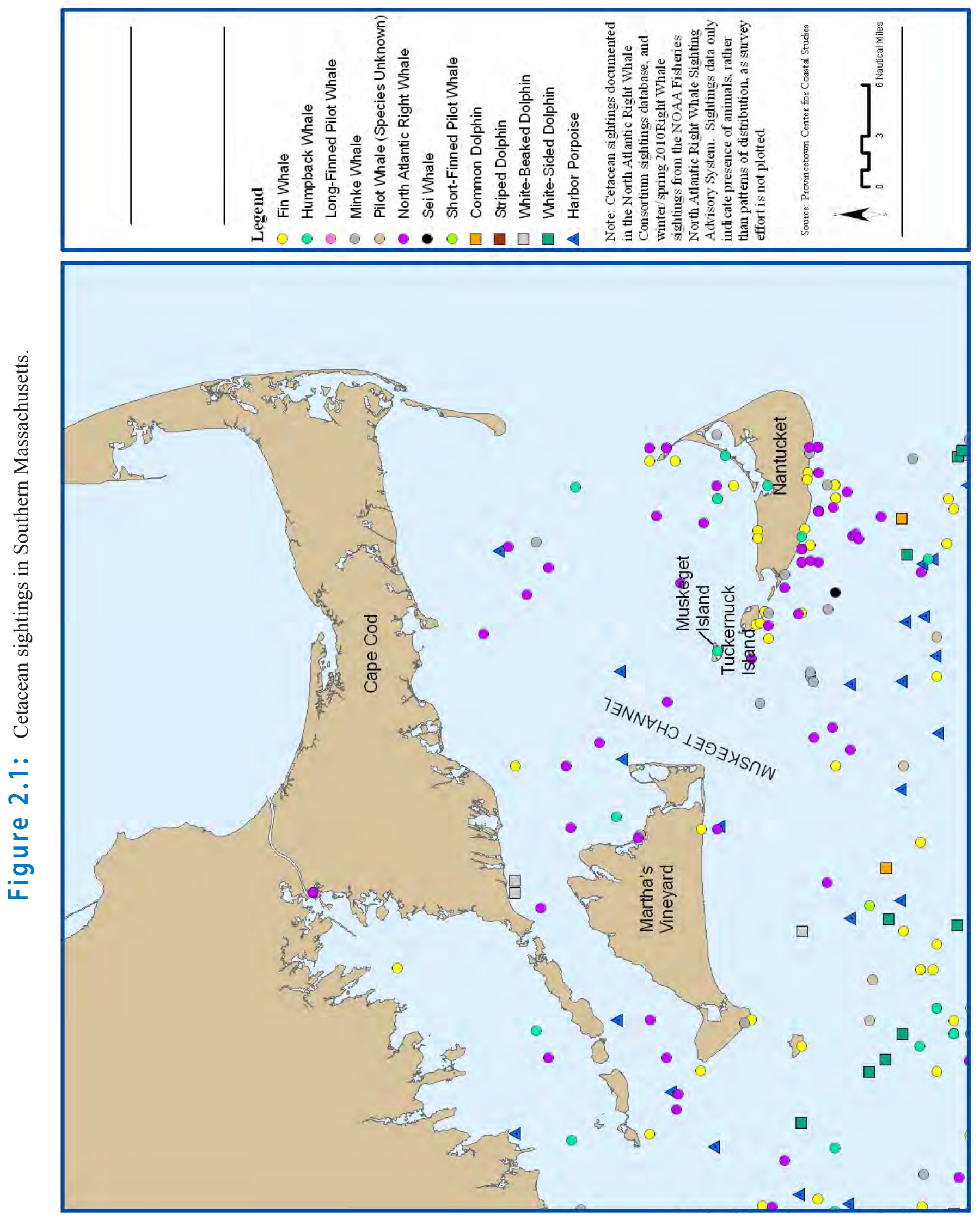


\subsection{Pinnipeds}

\subsubsection{Introduction}

Nantucket Sound is home to a resident gray seal (Halichoerus grypus) population and a seasonal harbor seal (Phoca vitulina concolor) population. Gray seals utilize areas of Nantucket Sound for pupping, molting, foraging and hauling out. Harbor seals are found in Nantucket Sound during the winter months ( September to April) and utilize the Sound for foraging and hauling out. Harbor seals move north of the Massachusetts/New Hampshire border for pupping and molting. Harp (Pagophilus groendlandicus) and hooded (Cystophora cristata) seals also occur sporadically in Nantucket Sound (see Table A1 for strandings data).

All marine mammals, including gray seals and harbor seals, are protected by the Marine Mammal Protection Act of 1972 as amended.

\subsubsection{Species Descriptions}

\subsubsection{Harbor seal (Phoca vitulina)}

Harbor seals are widely distributed, occurring in the North Atlantic and North Pacific Oceans. There are four subpopulations: P.v. vitulina in the Eastern Atlantic, P.v. concolor in the Western Atlantic, P.v. richardsi in the Eastern Pacific and P.v. stejnegeri in the Western Pacific (King, 1980).

Adult males and females can measure up to $1.5 \mathrm{~m}$ and weigh $110 \mathrm{~kg}$ and $90 \mathrm{~kg}$ respectively. Generally, males mature at 4-6 years while females mature slightly younger, at 3-4 years of age (Katona et al., 1993; Burns, 2009). Pups are often born in the inter-tidal zone and therefore can swim minutes after birth (Reeves et al., 1992). In the U.S. Atlantic, harbor seals pups are born in May and June from the Isle of Shoals, New Hampshire northwards along the Maine coast (Gilbert et al., 2005). Harbor seals remain in this region through July and August to molt. In September, a subset of the population moves south into Southern New England and west into Long Island Sound (Schneider and Payne, 1983).

The stock structure of the U.S. Atlantic harbor seal population is not understood. Harbor seals are a non-migratory marine mammal. A subset of Atlantic Coast harbor seals moves to Southern New England from September to April (Schneider and Payne, 1983). Waring et al. (2006) showed that at least some of the seals return to the Maine coast for pupping and molting (May-August). The relationship between the U.S. and Canadian Atlantic harbor seals in unclear, but Rosenfeld et al. (1988) suggested that some Canadian seals over-wintered in the U.S. and thus would be a trans-boundary stock.

\subsubsection{Gray seal (Halichoerus grypus)}

Gray seals are found throughout the cold temperate waters of the North Atlantic (King, 1980). The species is generally divided into three distinct populations based on cranial differences (Rice, 1998) and mtDNA studies (Boskovic et al., 1996): the Baltic Sea, the Northeast Atlantic (U.K.) and the Northwest Atlantic (Canada \& U.S.) population. The time of breeding varies geographically, with seals in the Baltic Sea pupping in March, in the Northeastern Atlantic in September-November and in the Western North Atlantic in December-February (King, 1983).

The gray seal is a large, sexually dimorphic species. Males reach a size of up to $2.3 \mathrm{~m}$ and $300-350 \mathrm{~kg}$, while females reach a maximum size of $2.0 \mathrm{~m}$ and $150-200 \mathrm{~kg}$ (Hannah, 1998). Gray seals are gregarious and gather in large groups during the pupping/breeding and molting seasons. Gray seals are unique in that they can breed on sandy beaches, rocky ledges, ice (Reeves et al., 1992) or in caves (Hewer, 1974). In the U.S. Atlantic, gray seals 
can be found on a year-round basis in Nantucket Sound and Mid-coast Maine (Wood LaFond, 2009). There is no seasonal movement similar to that observed in the harbor seal.

\subsubsection{Diet}

Harbor and gray seals are thought to be generalists that forage on available prey. There have been several seal food habits studies conducted in the Nantucket Sound/Cape Cod area which provide a general idea of which prey species are important in this region. Payne and Selzer (1989) analyzed 248 harbor seal scat samples. Ninety-five percent of these samples came from Race Point (Provincetown), Jeremy Point (Wellfleet) and Monomoy Island and were collected from 1984-1987. Sand lance (Ammodytes americanus) was the single dominant prey found in the Cape Cod samples.

In another study on harbor seal food habits, Ferland (1999) analyzed 172 scat samples collected from December 1998 to May 1999 at three sites on Cape Cod: Jeremy Point (Wellfleet), Chatham Harbor and Gull Island (Elizabeth Islands). Thirty-one of the samples were collected at Jeremy Point where both harbor and gray seals were hauled out. These samples therefore could not be assigned to a seal species. Sand lance was the most frequently occurring (85\%) prey species and also provided the largest percentage of wet mass (50\%) in the seals' diet. This was followed by winter flounder (Pseudopleuronectes americanus) - 32\% wet mass. Ampela (2009) analyzed 305 gray seal scat samples collected on Monomoy and Muskeget Islands from winter 2004 through winter 2008. Sand lance provided the largest percent wet weight (53\%) in this study as well, followed by winter flounder (19\%) and Atlantic Cod (Gadus morhua) (6.4\%).

\subsubsection{Distribution \& Abundance in the Nantucket Sound - Muskeget Channel Area}

\subsubsection{Distribution \& Abundance: Harbor Seal}

In order to understand the abundance and seasonal distribution of harbor seals in Nantucket Sound, it is necessary to consider the U.S. Atlantic harbor seal population as a whole. Harbor seals use Southern New England (including Nantucket Sound) for hauling out and foraging during the fall, winter and spring but return to Maine (or possibly Canada) for pupping, mating and molting (Waring et al., 2006; Figure 2.2). Waring et al. (2006) reported that $75 \%$ of the harbor seals radio-tagged in Chatham, Massachusetts during the month of March relocated to Maine later in the spring. Gilbert et al. (2005) describes a 6.6\% rate of increase in the number of harbor seals hauled out during the pupping season from 1981 to 2001 along the Maine coast (Figure 2.3). The corrected count for 2001 was 99,340 seals and is an estimate of the total U.S. Atlantic harbor seal population. Although not a current estimate, this data set demonstrates a steady increase in the number of harbor seals in U.S. Atlantic waters.

Payne and Selzer (1989) documented winter harbor seal abundance in Southern New England from 1983 through 1987 (Figure 2.4). As with Gilbert's data set, these data provide evidence of an increase in the number of harbor seals in the Atlantic U.S. This trend is even more apparent when Payne and Selzer's counts are compared to Barlas's (1999; Figure 2.4). Barlas (1999) collected aerial survey data in the Plymouth to Woods Hole region between 1998 and 1999. This study provides the most recent harbor seal abundance estimates for Southern Massachusetts including Nantucket Sound (Figure 2.5), and also shows a winter peak in harbor seal abundance. Barlas also surveyed west of Martha's Vineyard and counted 198 harbor seals in March of 1999 on Nomans Land (a National Wildlife Refuge).

deHart (2002) documented peak harbor seal abundance in Woods Hole in the February to April time period. He also found a slight increase in the number of harbor seals hauled out in Woods Hole from $2001(\mathrm{n}=164)$ to 2002 $(\mathrm{n}=184$; Figure 2.6). Counts of harbor seals at the Nantucket jetties (NMFS unpub. data) show presence there during the winter months from 2004 to 2008 (Figure 2.7). Finally, a study of harbor seal abundance and seasonal distribution in Narragansett Bay, Rhode Island (Schroeder, 2000) provides additional evidence of an increase in 
the number of harbor seals in Southern New England and a seasonal peak during the winter in this region (Figure 2.8).

From these data sets, Monomoy Island (a National Wildlife Refuge) is the only location in Nantucket Sound where there has been a documented decline in the number of harbor seals (Figure 2.9). This decline has occurred as the Nantucket Sound gray seal has population has been growing (Figure 2.10).

\subsubsection{Distribution \& Abundance: Gray Seal}

Muskeget Island is the largest gray seal pupping colony in the U.S. Pup counts from aerial survey data are available in Rough $(1995,2000)$ and Wood LaFond (2009) from 1991 through 2008 (Figure 2.10). No data is available for 2000. The number of pups born on Muskeget has increased dramatically over this time period. Only 6 pups were born in 1991. Seventeen years later, on 15 January 2008, a minimum of 2,090 pups were counted.

The data available outside of the pupping season is older and not as continuous. Reports by Rough $(1995,2000)$ and Barlas (1999) contain gray seal counts during the spring molt season at Muskeget and Monomoy Islands for several years in the 1990s (Figures $2.11 \& 2.12$ ). Although out of date, these counts also show an increase in the number of gray seals in Nantucket Sound during the months of April and May. Ampela (2009) collected scat samples at Muskeget and/or Monomoy Islands during every season from winter 2004 to winter 2008 and thereby documented a continued presence of gray seals in Nantucket Sound. In addition to these sites, when Wasque Shoal is available, gray seals utilize it (Wood LaFond, pers. obs.). Wasque Shoal is located between Nantucket and Martha's Vineyard Islands and periodically appears due to strong currents and storms. Sette (unpublished data) has also documented gray seals on tidal haul-outs near Gull and Penikese Islands (Elizabeth Islands). These studies together provide evidence for an increasing, permanent gray seal population in Nantucket Sound.

Whalenet (http://whale.wheelock.edu/), an educational program at Wheelock College funded by the National Science Foundation, has worked with scientists to deploy numerous satellite tags on harbor and gray seals (Table A4). Thirteen of the tagged seals spent time in Nantucket Sound or around Cape Cod.

Results of genetic analyses have shown that U.S. gray seals constitute a trans-boundary stock. To identify the source population for the recovering U.S. gray seal population and to assess the stock structure of gray seals in the Northwestern Atlantic, Wood LaFond (2009) collected a total of 231 tissue samples from both Canadian and U.S. populations for genetic analyses. Samples were collected (mostly from pups) at three sites during the pupping season: Sable Island (Canada), the Gulf of St. Lawrence (Canada) and Muskeget Island (Massachusetts). These analyses showed that there was no significant difference between the three sites sampled, demonstrating that an adequate number of individual gray seals are moving between these pupping sites for the sites to be indistinguishable from each other. See Wood LaFond (2009) for more detail.

\subsubsection{Historic Presence of Seals in Nantucket Sound}

As reported in Ritchie (1969), harbor and gray seal remains were found in archeological sites on Martha's Vineyard. The most extensive sources of information on gray seal sightings throughout the Northeastern U.S. during the $20^{\text {th }}$ century were the reports written to U.S. Federal and State agencies by Valerie Rough, who documented the re-colonization of Muskeget Island in Nantucket Sound by gray seals. Her accounts are summarized in Wood LaFond (2009) and are useful in understanding the status of gray seals in the early to late $20^{\text {th }}$ century in two ways: they document that people were looking for them, and the sparseness of their sightings shows that gray seals were probably truly rare throughout the U.S. during most of the $20^{\text {th }}$ century. Table A 3 summarizes gray seal observations on Cape Cod, Martha's Vineyard Island and Nantucket Island. Unfortunately, such reports do not exist for harbor seals during this time period.

In addition to literature, museum collections were searched for evidence of harbor and gray seals in the Nantucket Sound/Cape Cod area. These collections contained records from 1632 through the present day (Tables A2 \& A3). 
These records demonstrate that both harbor and gray seals had a historic presence in Nantucket Sound.

As summarized in Lelli et al. (2009), seal bounties existed in the states of Massachusetts and Maine during the late $19^{\text {th }}$ and early $20^{\text {th }}$ century. These bounties were not species-specific and likely targeted both harbor and gray seals. Under the bounty systems, hunters were paid \$1-5 U.S. for each seal killed. The Massachusetts bounty existed from years 1888 to 1908 and from 1919 to 1962. The statewide Maine bounty was briefer, only lasting 10 years, from 1895 to 1905 . Through an extensive search of state and county records, (Lelli et al., 2009) found records of 15,690 seal bounties paid in Massachusetts and 24,831 seal bounties paid in Maine during the time of their respective bounties. There is evidence of cheating (e.g. a hunter would turn one seal pelt into multiple noses or tails), so the bounty records probably do not accurately reflect the actual number of seals killed. These records do, however, demonstrate that there was hunting pressure on seals in the Northeastern U.S. well into the middle of the $20^{\text {th }}$ century. In 1965 the state of Massachusetts enacted a law to protect the gray seal, and in 1972 the U.S. government passed the Marine Mammal Protection Act, which provided blanket protection in all states. These two laws acted to protect seals in the U.S. 


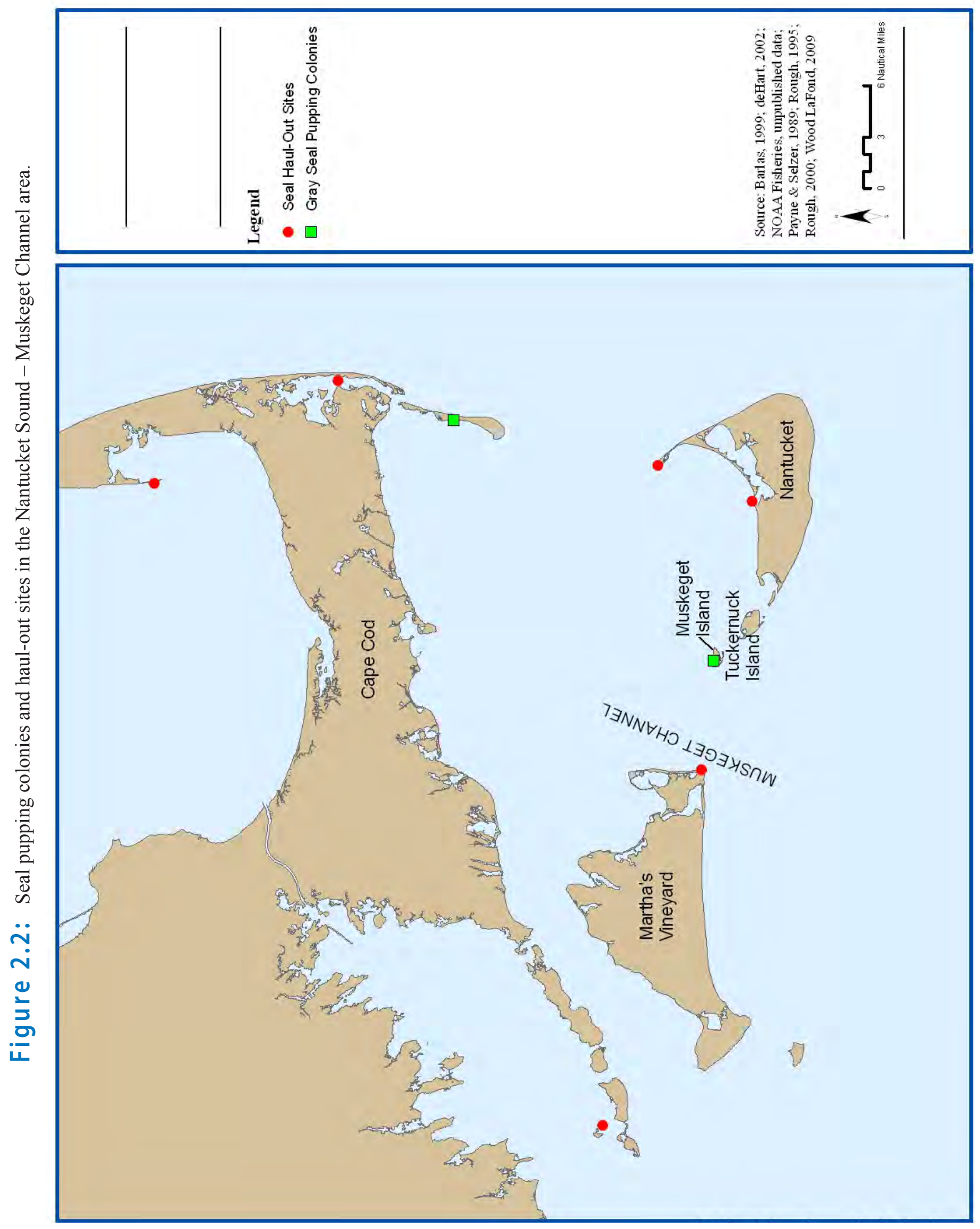


Fig u re 2.3: Harbor seal abundance in Maine, 1981-2001 (Gilbert et al., 2005).

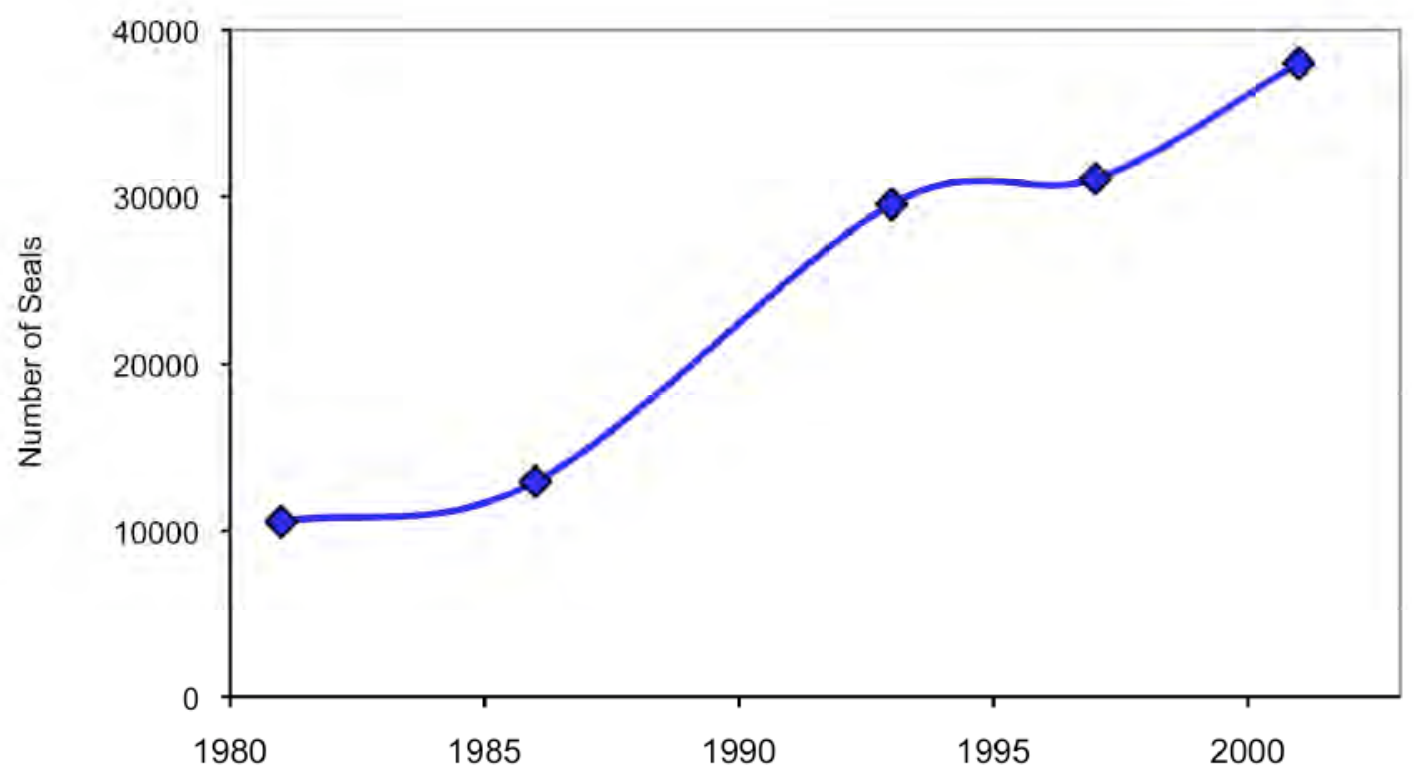

Figure 2.4: Harbor seal abundance from Plymouth to Woods Hole, Massachusetts (Payne \& Selzer, 1989; Barlas 1999).

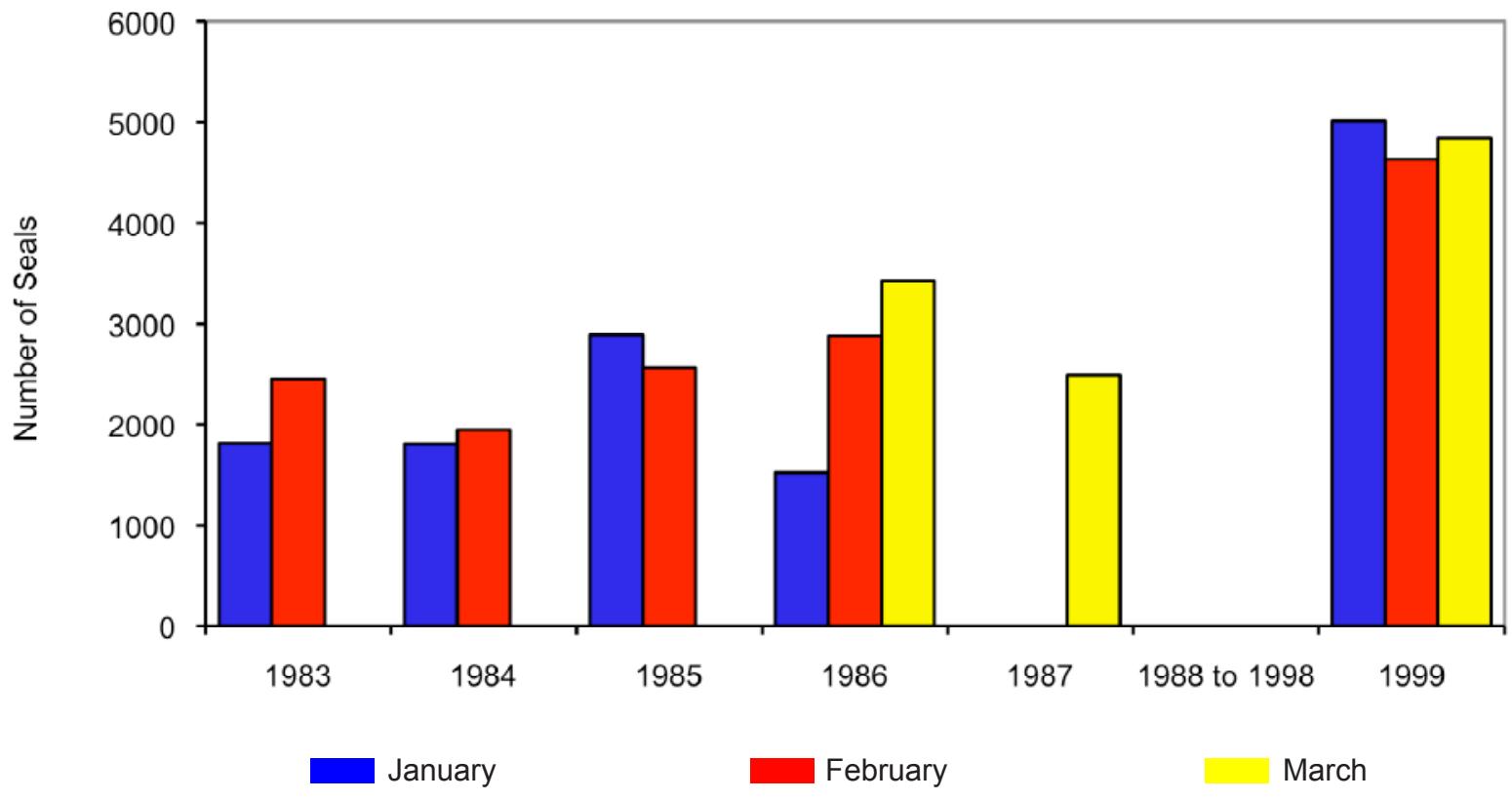


Figure 2.5: Harbor seal abundance 1998-99: Plymouth to Woods Hole (Barlas, 1999).

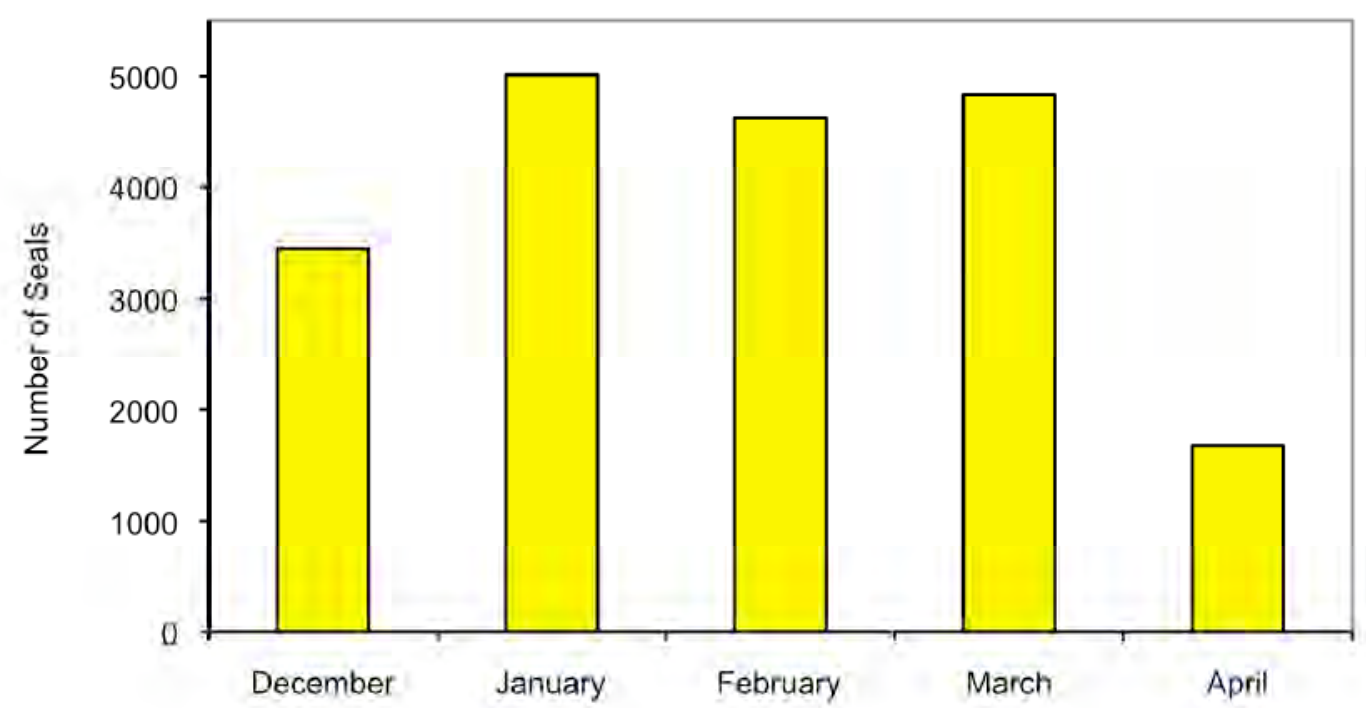

Figure 2.6: Harbor seal abundance in Woods Hole, Massachustts (deHart, 2002).

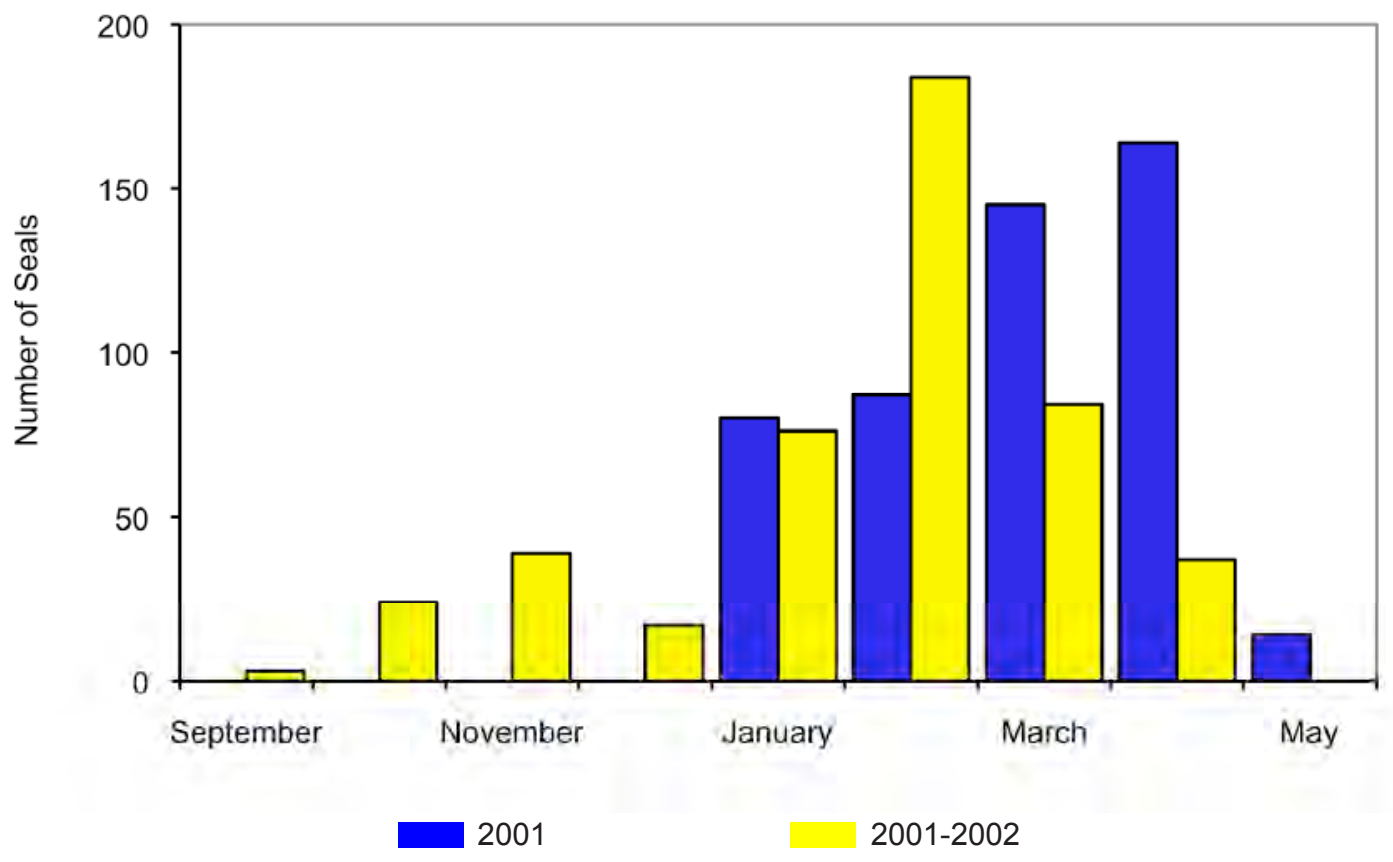


Figure 2.7: Harbor seal abundance at the Nantucket, Massachusetts jetties, 2004-08 (NMFS unpublished data).

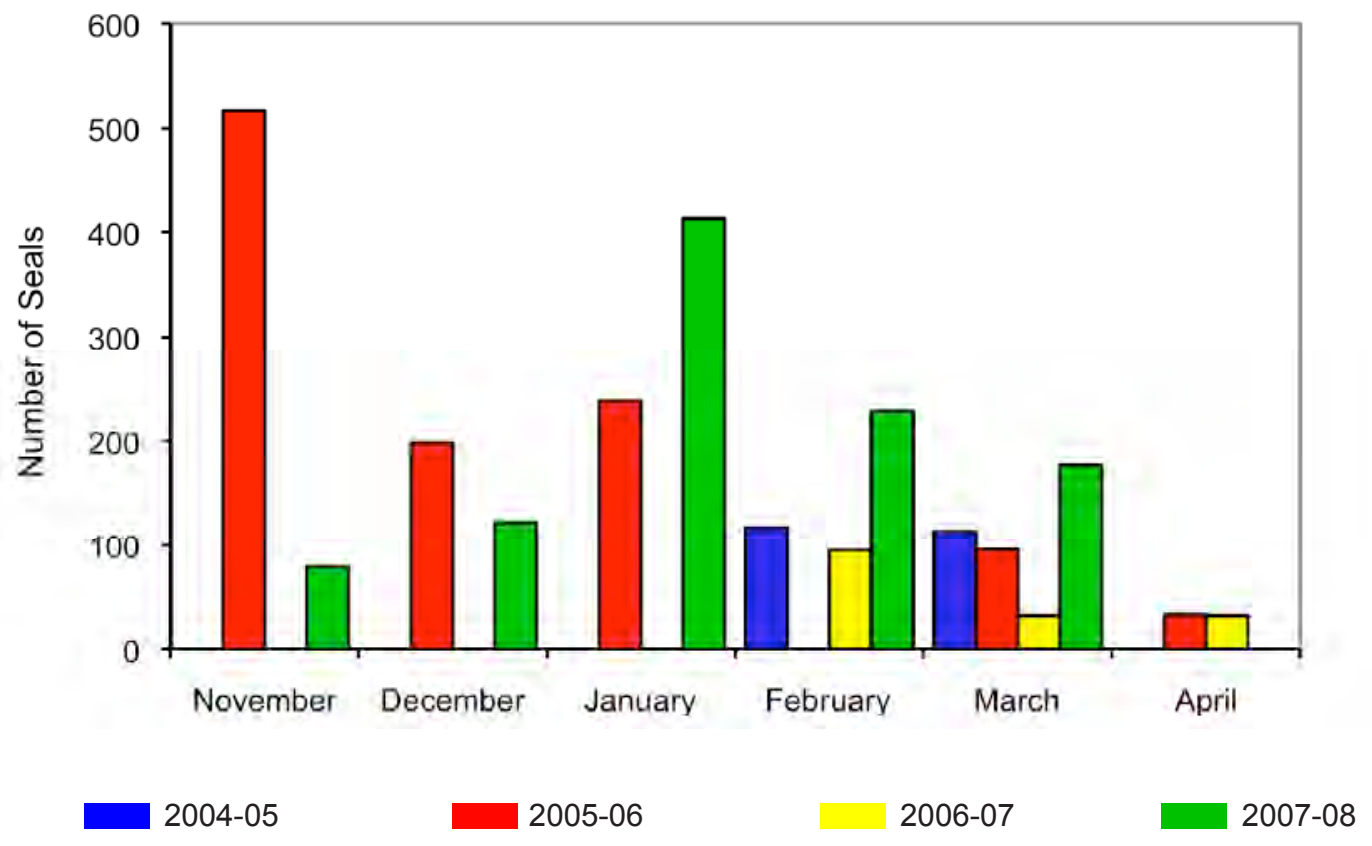

Figure 2.8: Seasonal and annual trends in harbor seal abundance in Narragansett Bay, Rhode Island (Schroder 2000).

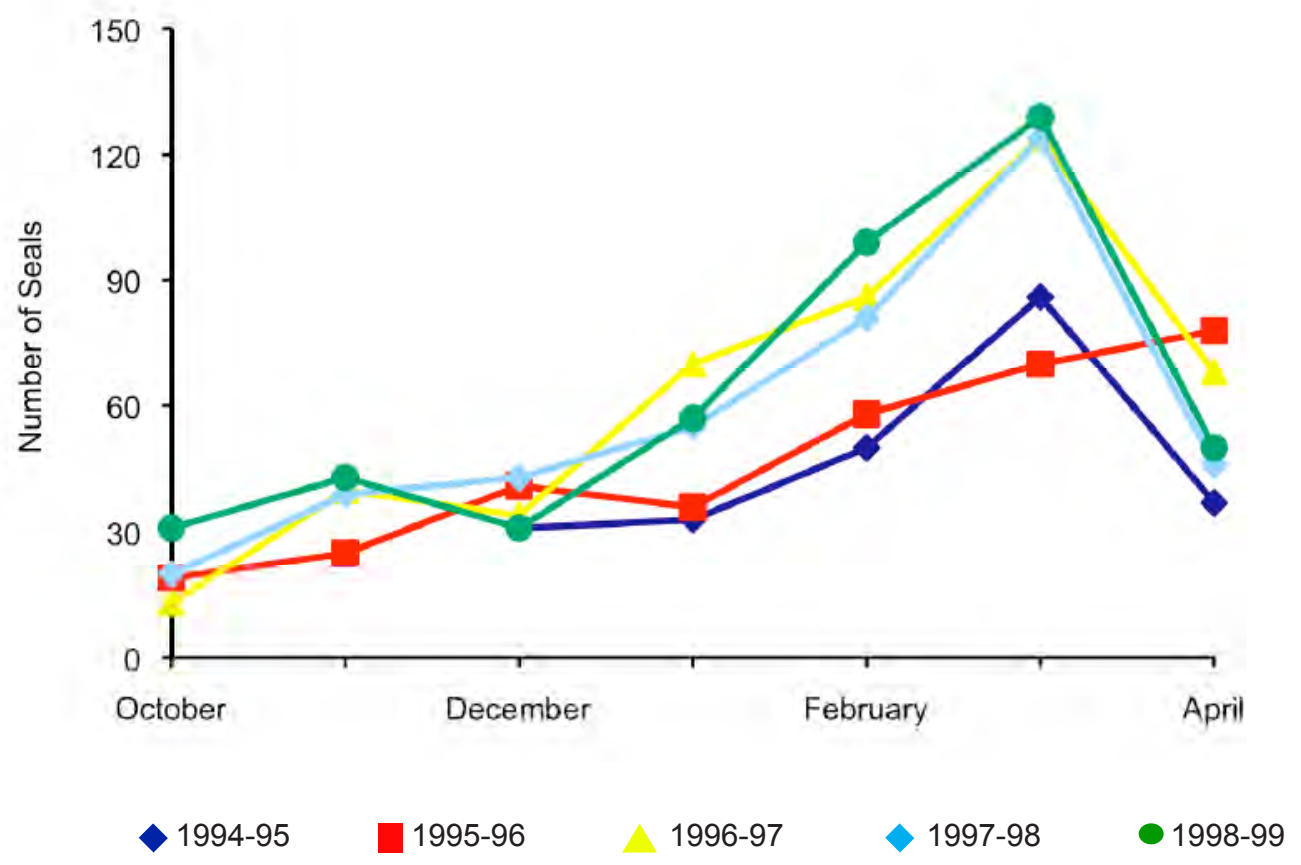


Figure 2.9: Harbor seal abundance on Monomoy Island, Massachusetts (Payne \& Selzer, 1989; Barlas, 1999).

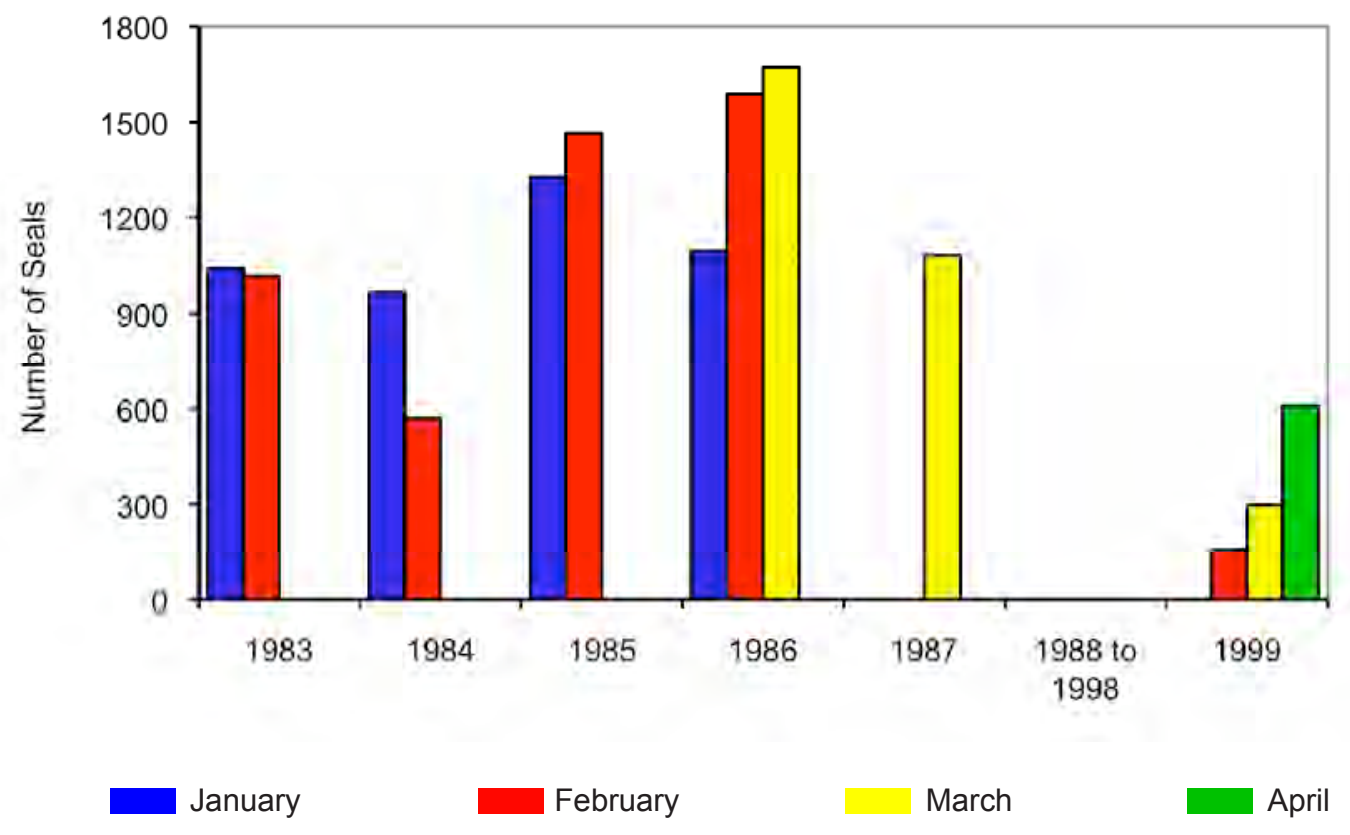

Figure 2.10: Gray seal pup counts on Muskeget Island, Massachusetts, 1991-2008 (Rough, 1995, 2000; Wood LaFond, 2009).

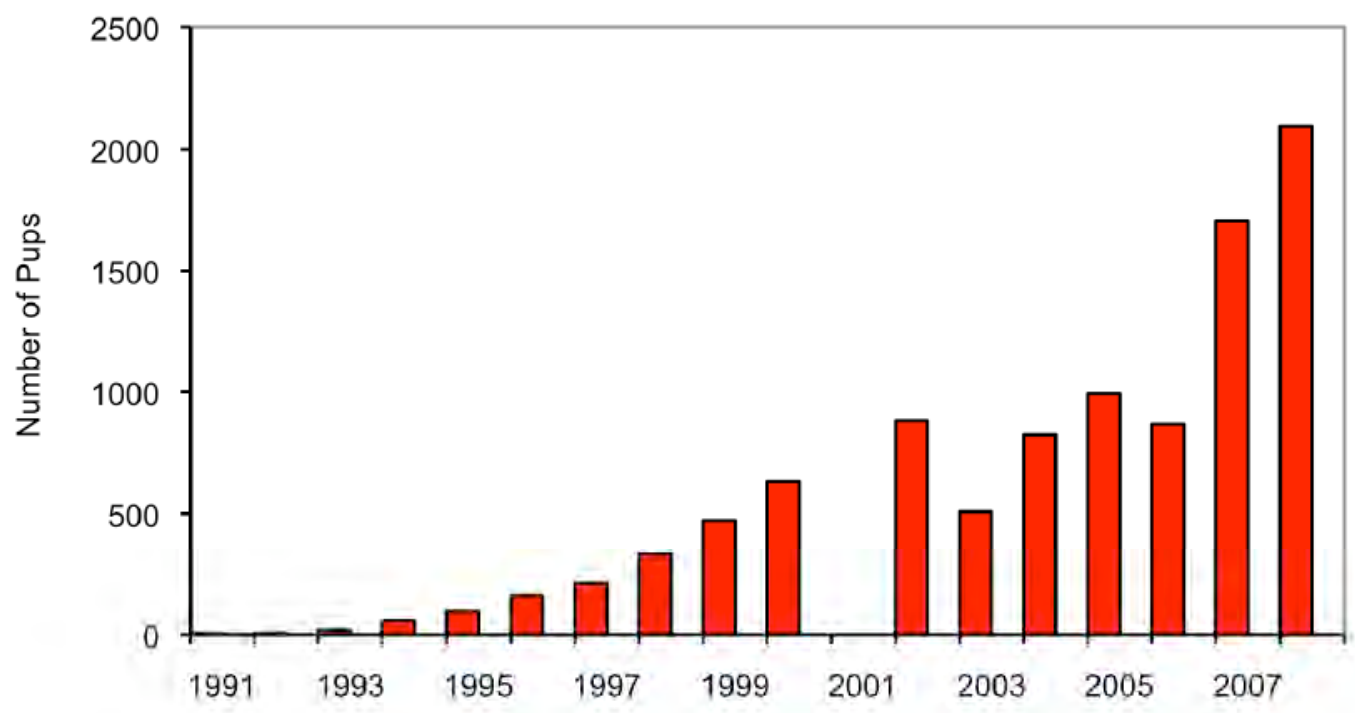


Figure 2.11: Gray seal molt counts for Muskeget Island, Massachusetts, 1992-99 (Rough, 2000; Barlas, 1999).

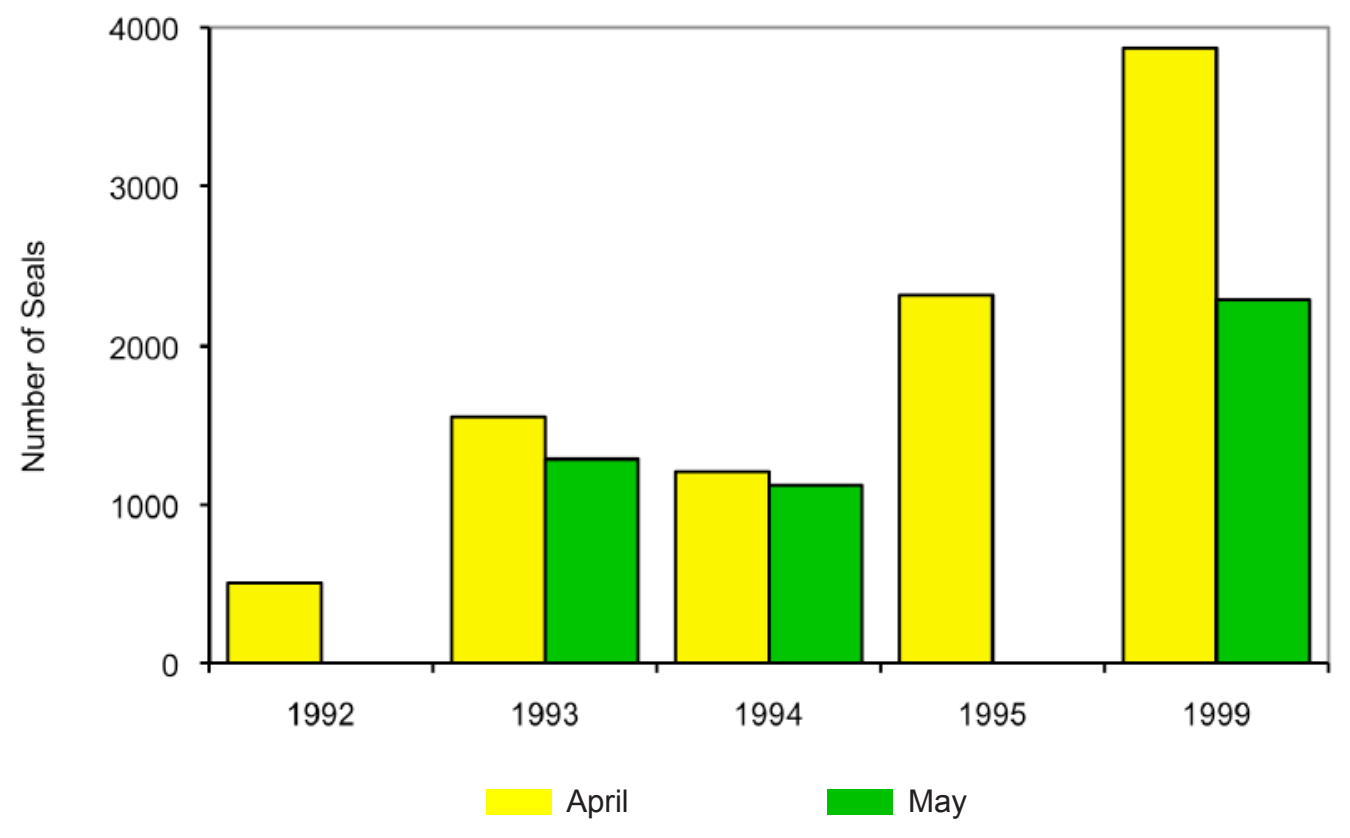

Figure 2.12: Gray seal molt counts for Monomoy Island, Massachusetts in 1994, 1995 and 1999 (Rough, 2000; Barlas, 1999).

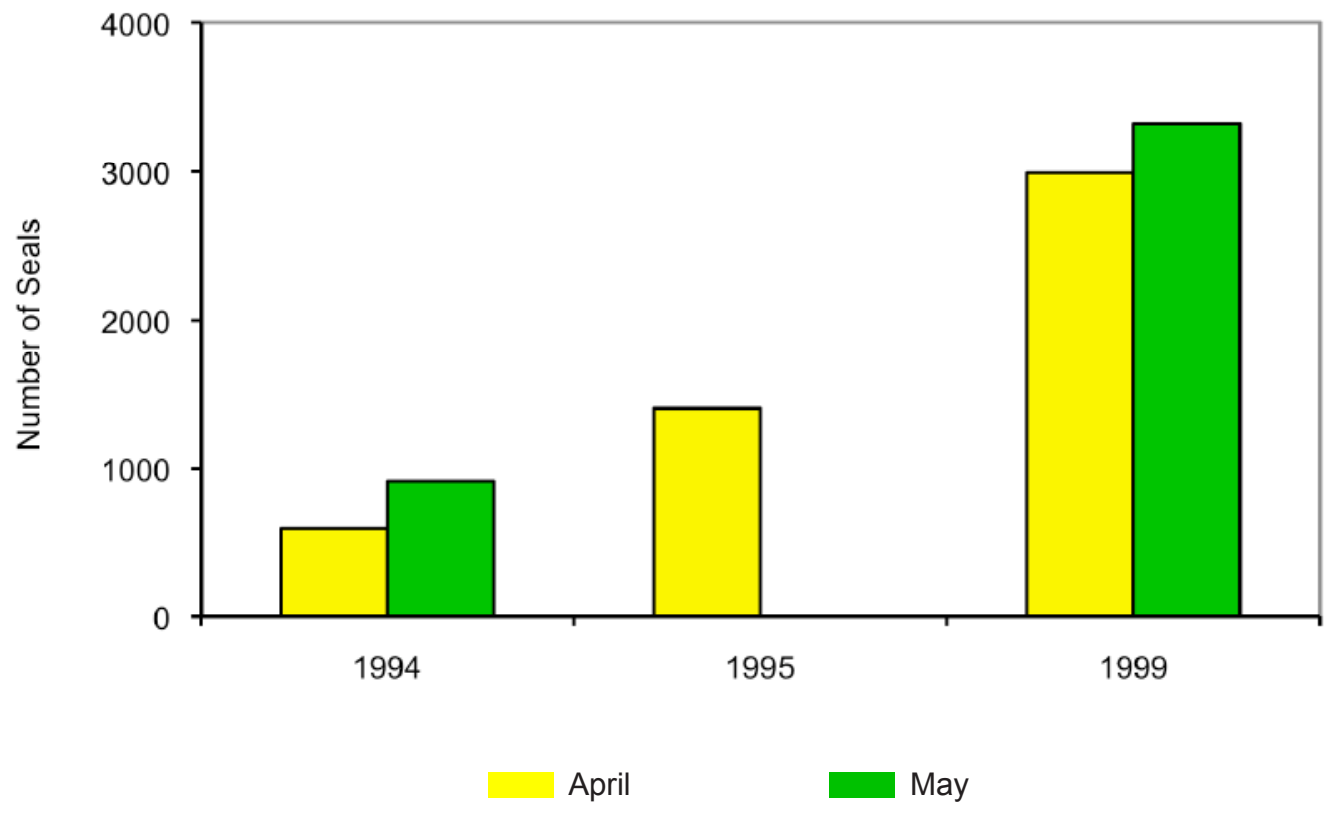




\subsection{Dermochelid \& Chelonids}

\subsubsection{Introduction}

There are four species of sea turtles that have been recorded in Nantucket Sound either seasonally foraging or transiting the waters south of Cape Cod: leatherback (Dermochelys coriacea), loggerhead (Caretta caretta), green (Chelonia mydas) and Kemp's ridley (Lepidochelys kempi) (Jones, 1886; Lazell, 1976; Lazell, 1980; USFWS and NMFS, 1992; Prescott, 1988; Dwyer et al., 2003; Perkins et al., 2003; Morreale and Standora, 2005; Sadoti et al., 2005; Ernst and Lovich, 2009; http:/www.seaturtlesightings.org/, 2010). A fifth species, the hawksbill (Eretmochelys imbricate), is considered to be a "rare" vagrant to New England (Lazell, 1976). Depending on the age and species, sea turtles will typically migrate offshore or south to their nesting beaches in fall as local water temperatures decrease (Bleakney, 1965; Lazell, 1976; Shoop and Kenney, 1992; Wynne and Schwartz, 1999; Ernst and Lovich, 2009).

Another marine reptile, the northern diamond-backed terrapin (Malaclemys terrapin), is a salt marsh turtle and year round resident of Massachusetts. While not considered a sea turtle, the northern diamond-backed terrapin inhabits estuaries, rivers, creeks, salt marshes and mud and is known to nest in dry, sandy uplands near its foraging areas (Babcock, 1926; Lazell, 1976; Lewis, 2002; Brennessel, 2007). There are records of northern diamondbacked terrapin from areas along the southwest coastal region of Cape Cod (Babcock, 1926; Lazell, 1976; Brennessel, 2007).

All sea turtles included in this report are listed under the Endangered Species Act (ESA) of 1973 except for the diamond-backed terrapin, which is listed by Massachusetts as threatened. The leatherback, Kemp's ridley and hawksbill are listed as endangered at the federal and state level; the loggerhead and green are listed as threatened at the federal and state level (NMFS and USFWS, 1991a; NMFS and USFWS, 1991b; USFWS and NMFS, 1992; NMFS and USFWS, 1995; NMFS and USFWS, 1998b; NMFS and USFWS, 2007a, 2007b, 2007c, 2007d; http:// www.mass.gov/dfwele/dfw/nhesp/species_info/mesa_list/mesa_list.htm, 2010). The International Union for Conservation of Nature (IUCN) Red List categorizes loggerhead and green sea turtles as "endangered" (Marine Turtle Specialist Group, 1996a; Seminoff, 2004), while the leatherback, Kemp's ridley and hawksbill are listed as "critically endangered" (Marine Turtle Specialist Group, 1996b; Martinez, 2000; Mortimer and Donnelly, 2008).

\subsubsection{Species Descriptions}

\subsubsection{Dermochelid}

Leatherback turtles are the largest of all sea turtle species and the only living species in the genus Dermochelys

(Lazell, 1976; Ernst and Lovich, 2009). Leatherbacks can be distinguished from all other sea turtles found in New England by their large size and ridged carapace. Leatherbacks lack the hard keratin scutes covering the carapace of other sea turtles. Instead of scutes, they have a thick, leathery skin that covers their carapace (Lazell, 1976; Wynn and Schwartz, 1999; Ernst and Lovich, 2009). The surface of the leatherback's carapace is colored dark grey to black and has pink and white blotches and spots. An adult leatherback carapace can measure up to 1.8 $\mathrm{m}$ in length and it typically weighs $727 \mathrm{~kg}$ to 1 ton (Wynn and Schwartz, 1999; Ernst and Lovich, 2009). Leatherbacks feed almost exclusively on gelatinous animals such as jellyfish and salps (Lazell, 1976; Bjorndal, 1997; Wynn and Schwartz, 1999; Ernst and Lovich, 2009). Leatherback turtle nesting grounds have been documented around the world (Ernst and Lovich, 2009). Adult leatherbacks have been sighted along the entire continental coast of the United States up into the Gulf of Maine and south to Puerto Rico, the U.S. Virgin Islands and into the Gulf of Mexico (Wynne and Schwartz, 1999; Ernst and Lovich, 2009). Recorded sightings of leatherback turtles (Figures 2.13-2.15) suggest that they are typically in New England, including Nantucket Sound, between May and October (Bleakney, 1965; Lazell, 1976; Prescott, 1988; Shoop and Kenney, 1992; Wynne and Schwartz, 1999; NMFS and USFWS, 2001; Sadoti et al., 2005; http://seaturtlesightings.org/speciesmap.html). 


\subsubsection{Chelonids}

Loggerhead turtles, ${ }_{2}$ named for their proportionally large heads, are characterized by their heart-shaped carapace and the brown coloration of adults and subadults. The plastron, or ventral surface of the shell, is generally a pale yellow. The carapace length of adults in the U.S. is approximately $0.92 \mathrm{~m}$ and the average weight of an adult is about $115 \mathrm{~kg}$ (Wynn and Schwartz, 1999; Ernst and Lovich, 2009). Subadult and adult loggerheads feed mainly upon benthic invertebrates such as whelks and conch (Bjorndal, 1997; Wynn and Schwartz, 1999; NMFS and USFWS, 2001; Ernst and Lovich, 2009). Loggerheads are found throughout the temperate and tropical regions of the Atlantic, Pacific and Indian Oceans. Loggerhead turtles have been observed in the Northeast, including Nantucket Sound, as early as June (http://seaturtlesightings.org/speciesmap.html), and the majority leave the Northeast by late fall (Figure 2.14; Shoop and Kenney, 1992; Sadoti et al., 2005; http://seaturtlesightings.org/speciesmap.html). As summarized in Morreale and Standora (2005), the Western North Atlantic is considered to be an important developmental habitat for loggerhead turtles.

Green turtles are hard-shelled sea turtles named for the greenish color of the cartilage and fat deposits that surround their internal organs. However, the carapace of a green sea turtle is typically dark black, brown or greenish yellow with a yellowish white plastron ventrally. Hatchlings are just $50 \mathrm{~mm}$ long, while adults can grow to $1 \mathrm{~m}$ long and an average weight of $150 \mathrm{~kg}$ (Wynne and Schwartz, 1999; Wynne and Schwartz, 1999; Ernst and Lovich, 2009). Adult green sea turtles feed mainly on algae and seagrasses (Bjorndal, 1997; Ernst and Lovich, 2009). Green sea turtles are globally distributed and are generally found in tropical and subtropical waters along continental coasts and islands (Wynn and Schwartz, 1999; Ernst and Lovich, 2009). Green sea turtles are seasonal visitors to the Northeastern waters of Massachusetts typically between May and October (Morreale and Standora, 1998; Wynne and Schwartz, 1999; http://seaturtlesightings.org/speciesmap.html, 2010).

Kemp's ridley turtles are the smallest known sea turtle species in the world (Marquez et al., 2005) with adults generally weighing less than $40-50 \mathrm{~kg}$ and measuring approximately 0.58 to $0.80 \mathrm{~m}$. The color of the carapace changes significantly as they age. The carapace of a hatchling can be grayish black, while adults have a lighter grayish or olive-colored carapace and a creamy white or yellowish plastron (Wynne and Schwartz, 1999; Ernst and Lovich, 2009). Their diet is comprised mainly of crabs but can also include shrimp and mollusks (Bjorndal, 1997; Wynne and Schwartz, 1999; Ernst and Lovich, 2009). Kemp's ridley turtles are known to range from Nova Scotia to Mexico and have been documented in Nantucket Sound and Vineyard Sound (Figure 2.14; Lazell, 1976; Musick and Limpus, 1997; Sadoti et al., 2005; http://seaturtlesightings.org/speciesmap.html). As reported in Morreale and Standora (2005), the Western North Atlantic is considered to be important developmental habitat for Kemp's ridley turtles.

The hawksbill turtle is a small- to medium-sized sea turtle with a narrow pointed beak and small head. The carapace of the hawksbill is uniquely characterized by scutes that overlap with a streaked or marbled yellow or brown coloration. The edge of the carapace is often serrated in younger animals. Hawksbill turtles are typically less than $1 \mathrm{~m}$ in length with an average weight of $82 \mathrm{~kg}$ (Ernst and Lovich, 2009; Wynne and Schwartz, 1999). Hawksbills utilize different habitats at different stages of their life cycle. It is believed that post-hatchling hawksbills are pelagic (Wynne and Schwartz, 1999; NMFS and USFWS, 1993) and then subadults and adults reenter coastal areas and feed primarily on sponges (Bjorndal, 1997; Wynne and Schwartz, 1999; Ernst and Lovich, 2009). The hawksbill is considered to be "rare" in New England waters (Lazell, 1976; http:/www.mass.gov/dfwele/dfw/wildlife/facts/.../herp_list.html), with only three records from Massachusetts (B. Prescott, pers. comm., 19 September 2010).

The northern diamond-backed terrapin is a medium-sized salt marsh turtle (Lewis, 2002; Ernst and Lovich, 2009). The carapace can be grayish, green, black and/or light brown. Northern diamond-backed terrapins have concentric ring patterns on their carapace and a ridged mid-line keel. Adult females range from $15-23 \mathrm{~cm}$ in length and are typically larger than adult males, which range from 10-15 cm. Hatchlings look very similar to adults and are approximately $2.6 \mathrm{~cm}$ length (Lazell, 1976; Lewis, 2002; Ernst and Lovich, 2009). Salt marshes are very important foraging areas for northern diamond-backed terrapins (Lazell, 1976; Lewis, 2002; Ernst and Lovich, 2009). Their diet includes gastropods, crabs, mollusks, insects, fish and carrion (Lazell, 1976; Lewis, 2002; Brennessel, 2007; Ernst and Lovich, 2009). 
During the spring, male and female diamond-backed terrapins come together in coves or small bays to mate (Lewis, 2002; Ernst and Lovich, 2009). Once mated, the females will travel upland as far as $0.4 \mathrm{~km}$ to prepare a nest for her eggs (Lewis, 2002; Brennessel, 2007). Yearicks et al. (1981) reported that northern diamond-backed terrapins hibernate in winter under water, either singly or in groups on the bottom, buried in mud or in the side of mud banks. Diamond-backed terrapins are the only species of chelonid included in this report that overwinter in Massachusetts (Lazell, 1976; Ernst and Lovich, 2009). The northern diamond-backed terrapin's range includes the Atlantic and Gulf Coasts from Cape Cod, Massachusetts to southern Texas and the Florida Keys (Lazell, 1976; Ernst and Lovich, 2009). There are records of northern diamond-backed terrapins from areas along the southwest coastal region of Cape Cod (Babcock, 1926; Lazell, 1976; Brennessel, 2007).

\subsubsection{Distribution \& Abundance in the Nantucket Sound - Muskeget Channel Area}

Data on sea turtle distribution and abundance has been collated from a number of sources.

The Sea Turtle Sighting Hotline for Southern New England Boaters was initiated in 2002. Its primary goals are to document where and when sea turtles are seen in Southern New England waters and to alert boaters to the presence of sea turtles in the summer and fall. Data points included in the hotline database do not represent a systematic survey, nor do they represent an accurate count of sea turtles since multiple calls may report the same individual turtle. The majority of hotline reports are from waters around Cape Cod, including Buzzards Bay, Vineyard Sound, Nantucket Sound and Cape Cod Bay. Hotspots have been noted off Sakonnet Point (Rhode Island) and near Lucas Shoal in Vineyard Sound. Many of the August sightings are from the recreational fishing areas south of Martha's Vineyard and Nantucket Islands. Sightings are plotted on maps posted on the hotline's website: www. seaturtlesightings.org (K. Moore Dourdeville, pers. comm., 24 August 2010).

Since initiating satellite tagging of leatherback turtles in Nantucket Sound, researcher Kara Dodge from the University of New Hampshire Large Pelagics Research Center has tagged twenty leatherbacks off Massachusetts. Based on her track analysis, three of the twenty turtles may have navigated through Muskeget Channel during the monitoring period. No turtles in her study took up residence in Muskeget Channel for any period of time, primarily using it to move between Nantucket Sound and regions south of Martha's Vineyard and Nantucket Islands. In 2008, George Breen, a spotter pilot utilized by the research team, reported seeing three leatherbacks using Muskeget Channel. Based on her work to date, Dodge suggests that leatherbacks appear to favor areas where tidal fronts may entrain and aggregate gelatinous zooplankton, thus forming dense prey patches and enabling leatherbacks to forage efficiently (K. Dodge, pers. comm., 26 August 2010).

In late fall and winter when the ocean environment cools, sea turtles remaining in Massachusetts waters can become "cold stunned," a form of hypothermic reaction caused by prolonged exposure to cold water temperatures (http://www.nero.noaa.gov/prot_res/stranding/cold.html). Severely cold-stunned turtles become lethargic and drift helplessly, resulting in animals coming ashore alive (Lazell, 1976). As summarized in Dodge et al. (2008) from 1979 to 2002, 1,289 sub-adult and adult cold-stunned marine turtles were discovered stranded on Cape Cod beaches. Of those turtles stranded, $76.6 \%$ were Kemp's ridley, $21.1 \%$ loggerhead, $2.3 \%$ green and $0.03 \%$ hybrid. These data and other reports suggest that the northeast coast might be an important foraging area for these species (Lazell, 1976; Lazell, 1980; Burke et al., 1991; Morreale and Sandora, 2005).

The Massachusetts Sea Turtle Disentanglement Network (MASTDN) was formed to respond to and document bycatch issues related to sea turtles in and around the state waters of Massachusetts. From its inception in 2005 to the present (12 September 2010), MASTDN has received 77 confirmed entanglement reports. Of those, 46 reports are from the waters of Nantucket Sound, Vineyard Sound and Buzzards Bay (Fig. 2.13). Entanglement reports are received seasonally from May to October with a peak during August. A majority of the reports in the study area involve leatherback sea turtles $(n=44,96 \%)$, with only two $(n=2,4 \%)$ involving species other than leatherbacks: one loggerhead and one turtle unidentifiable due to decomposition. Support for this work is provided by ESA Section 6 in conjunction with Massachusetts Division of Marine Fisheries. Data can only be used for the purpose of this literature review and should not be used for any other reason or application without the express written consent of PCCS. 


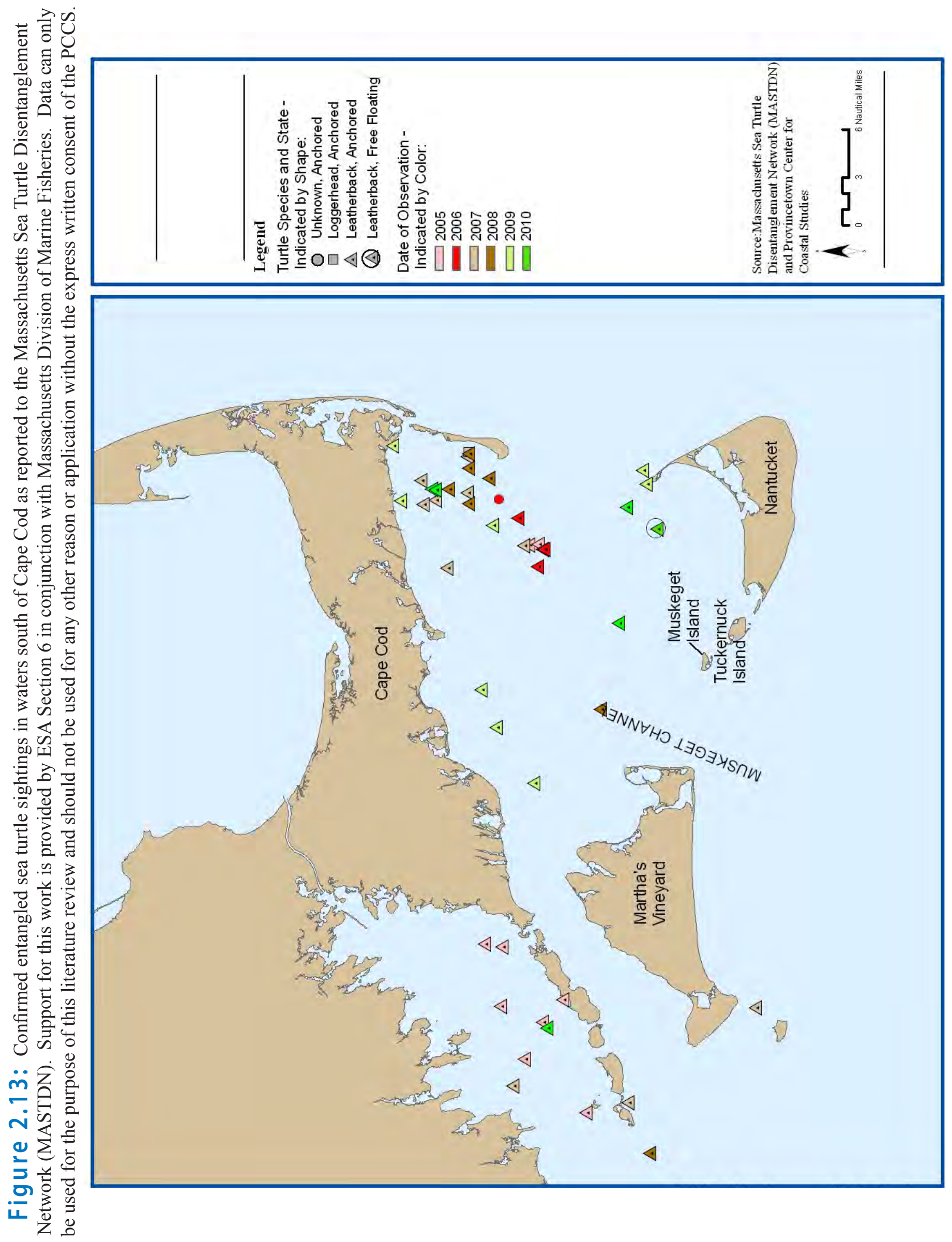




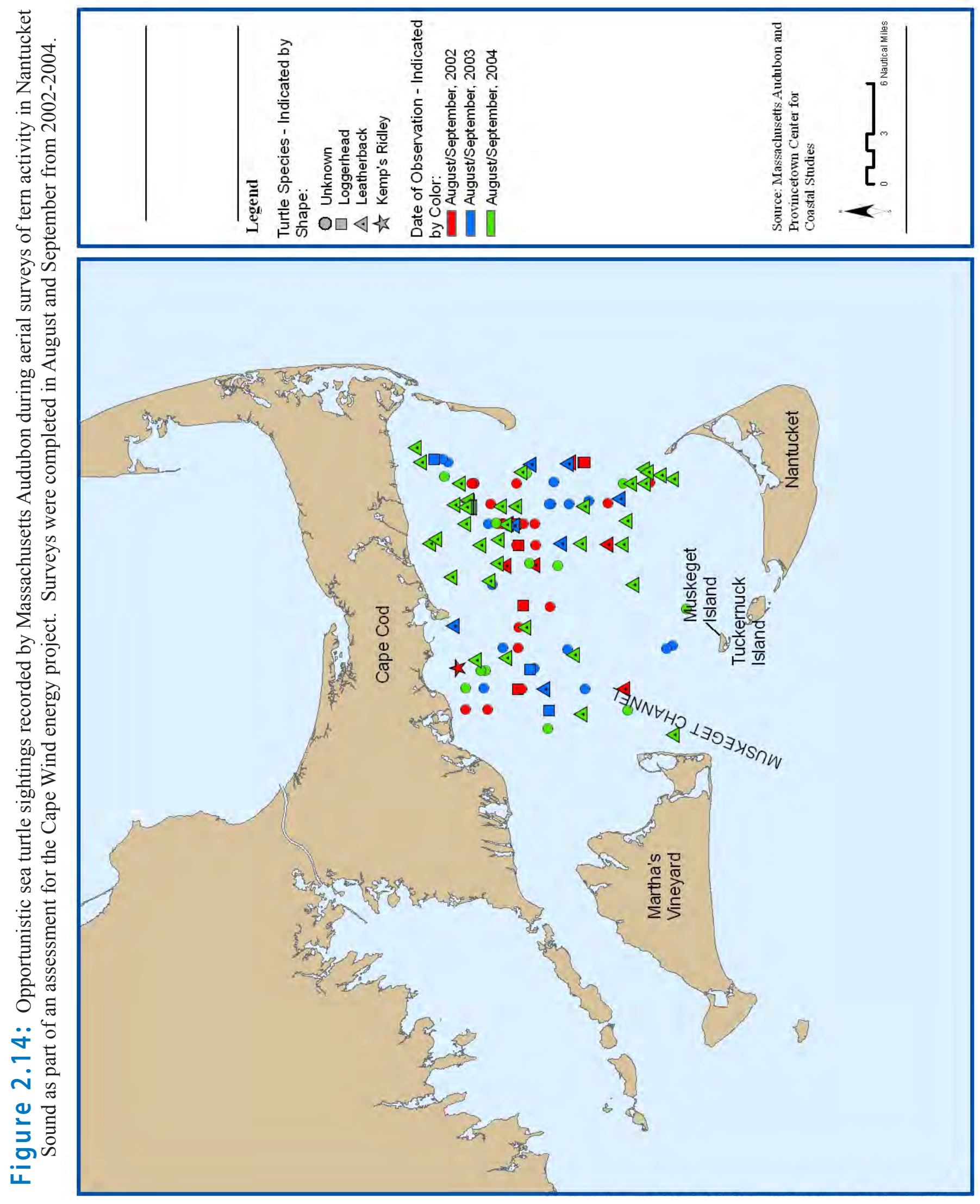




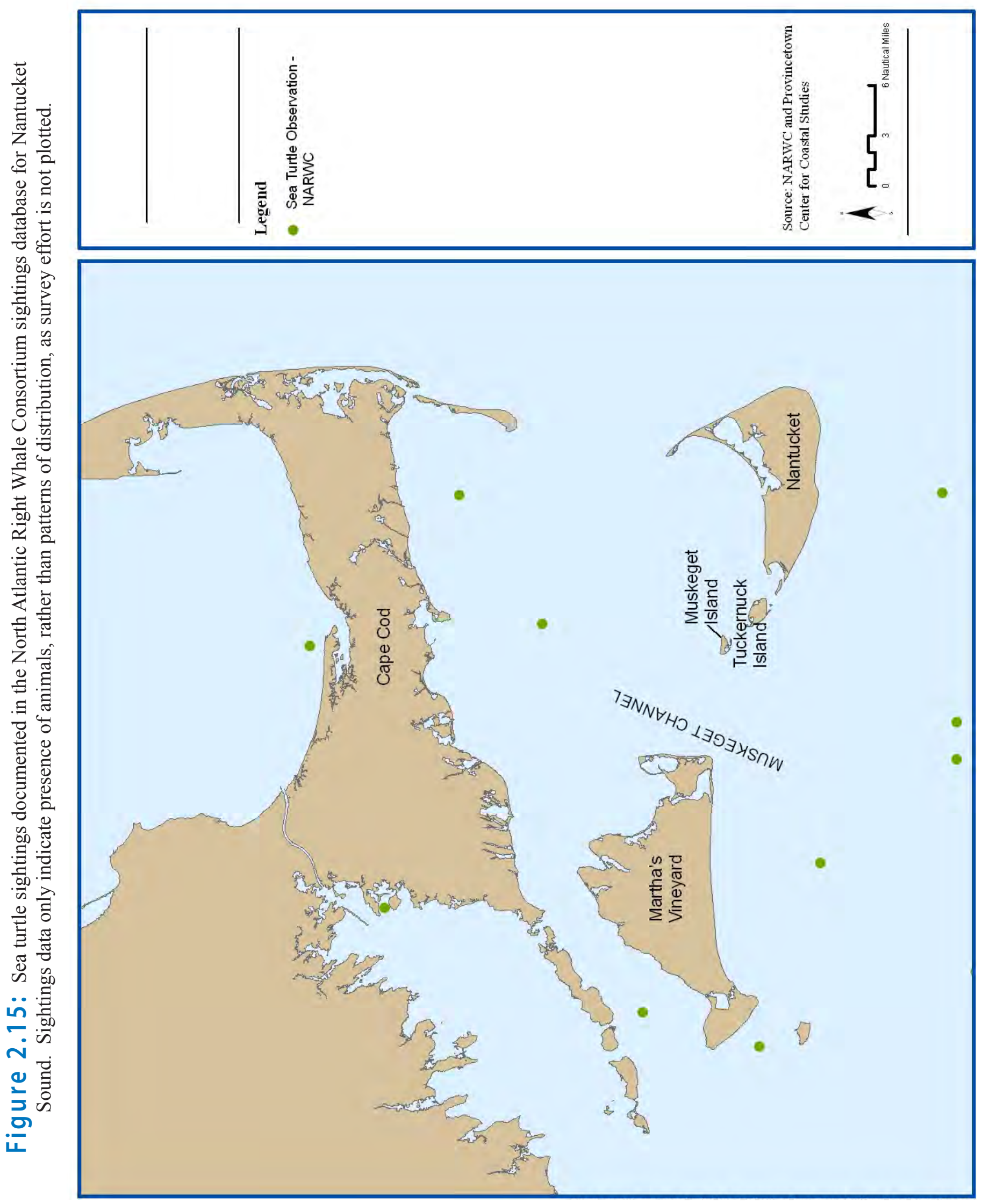




\subsection{Basking Shark}

\subsubsection{Introduction}

The common name of the basking shark, Cetorhinus maximus, refers to its appearance of "basking" while feeding at the surface. The basking shark is the second largest fish in the world (over $9 \mathrm{~m}$ total length), second in size only to the whale shark. Basking sharks are filter feeders, straining zooplankton from the water using gill rakers inside their gill slits, which extend almost completely around the head and are located behind their conical snout and large mouth (Martin and Harvey-Clark, 2004). The aforementioned features render the basking shark easily identifiable.

The basking shark is distributed circumglobally, occurring in the North and South Atlantic Oceans, Mediterranean Sea, North and South Pacific Oceans, Sea of Japan, off southern Australia and around New Zealand (Compagno, 2001). Canadian records from both Atlantic and Pacific waters indicate C. maximus occurs in most coastal temperate waters where temperatures exceed $6-7^{\circ} \mathrm{C}$ (Campana et al., 2008), and recent tagging efforts indicate that migrations to tropical waters also occur (Skomal et al., 2009).

The life history of basking sharks is poorly understood; however, long lifespan, slow growth and low fecundity likely render this species vulnerable to reductions in population (Martin and Harvey-Clark, 2004). Despite advances in understanding of the species' distributional ecology, data are lacking on population structure and size with which to assess conservation status (Sims et al., 2008). Relative abundance indices in U.S. waters have exhibited little variation since 1979 (Campana et al., 2008). Basking sharks are listed under Appendix II of the Convention on International Trade in Endangered Species of Wild Fauna and Flora (CITES) and listed as "vulnerable" globally and "endangered" in the Northeastern Atlantic and in the North Pacific by the International Union for Conservation of Nature (IUCN; Sims, 2008). In U.S. waters, federal regulations prohibit fishermen from possessing basking sharks.

\subsubsection{Distribution \& Abundance in the Nantucket Sound - Muskeget Channel Area}

Sighting frequency of basking sharks off the northeast U.S. is highest from May-August (Kenney et al., 1985; Campana et al., 2008). Sightings in the vicinity of the study area in the North Atlantic Right Whale Consortium sightings database $(\mathrm{n}=104)$ reflected a similar temporal distribution and generally occurred south of Martha's Vineyard and Nantucket Islands (Figure 2.16; Right Whale Consortium, 2010). However, this does not necessarily reflect spatial distribution patterns, as systematic survey effort in the study area was distributed in a similar manner (See Data Summary). Two additional sightings recorded during 2003-2004 aerial seabird surveys conducted by the Massachusetts Audubon Society in Nantucket Sound (See Data Summary) are included in Figure 2.16. Skomal (2007) summarized opportunistic examinations of stranded basking sharks in Massachusetts coastal waters, noting that six of seven fish examined (one of which was stranded on Martha's Vineyard) were immature, suggesting that study area waters may serve as secondary nursery habitat for the species. 


\subsection{Ocean Sunfish}

\subsubsection{Introduction}

The ocean sunfish (Mola mola) is the largest bony fish in mass - a $2.7 \mathrm{~m}$ record-length specimen weighed $2.3 \mathrm{mt}$ (Pope et al., 2010). There are virtually no fisheries for M. mola, although they are frequently bycaught in other fisheries (e.g. Silvani et al., 1999), and much of the species' biology and ecology remains unknown. Distribution is worldwide in temperate and tropical seas, but an accurate accounting of range or abundance is nonexistent due to the lack of fisheries and the associated data collection. No quantitative information exists on diet or habitat requirements, and while many observations indicate near-surface feeding on gelatinous zooplankton, stomach contents and recent telemetry studies indicate than ocean sunfish may be omnivorous and feed throughout the water column (Pope et al., 2010). Bigelow and Schroeder (1953) reported that stomachs of all specimens brought to the Bureau of Fisheries in Woods Hole appeared to contain remnants of jellies, ctenophores,or salps. Due to the lack of data, conservation status of this species is difficult to assess.

\subsubsection{Distribution \& Abundance in the Nantucket Sound - Muskeget Channel Area}

Kenney (1995) estimated ocean sunfish abundance from aerial surveys in the shelf waters from Cape Hatteras north to the Gulf of Maine, noting that abundance in Southern New England waters peaked in summer and declined to zero in winter and distribution patterns were similar to those of leatherback turtles. Sightings in the vicinity of the study area in the North Atlantic Right Whale Consortium sightings database $(n=37)$ reflected a similar temporal distribution and generally occurred south of Martha's Vineyard and Nantucket Islands (Figure 2.16; Right Whale Consortium, 2010). However, this does not necessarily reflect spatial distribution patterns, as systematic survey effort in the study area was distributed in a similar manner (See Data Summary). Sadoti et al. (2005) noted 17 sightings of ocean sunfish in August and September of 2002-2004 during aerial surveys for seabirds in Nantucket Sound, but did not plot sighting locations. Sighting locations from 2003-2004 surveys were obtained from the Massachusetts Audubon Society (See Data Summary) and are included in Figure 2.16. 


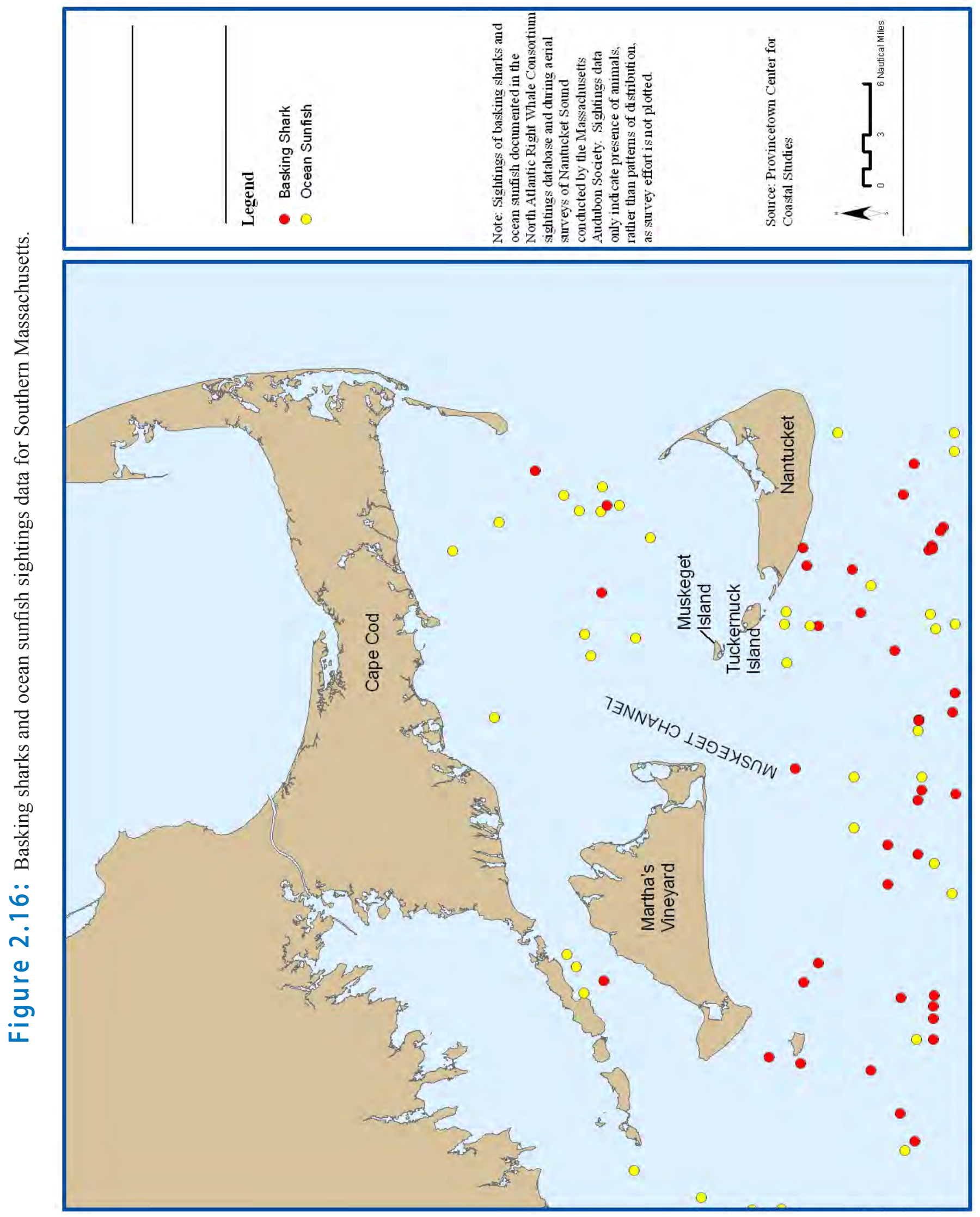




\section{Review of the Distribution of}

Fishery Resources and Habitats and

\section{Commercial and Recreational}

Fishing Activity in the Nantucket Sound Muskeget Channel Area

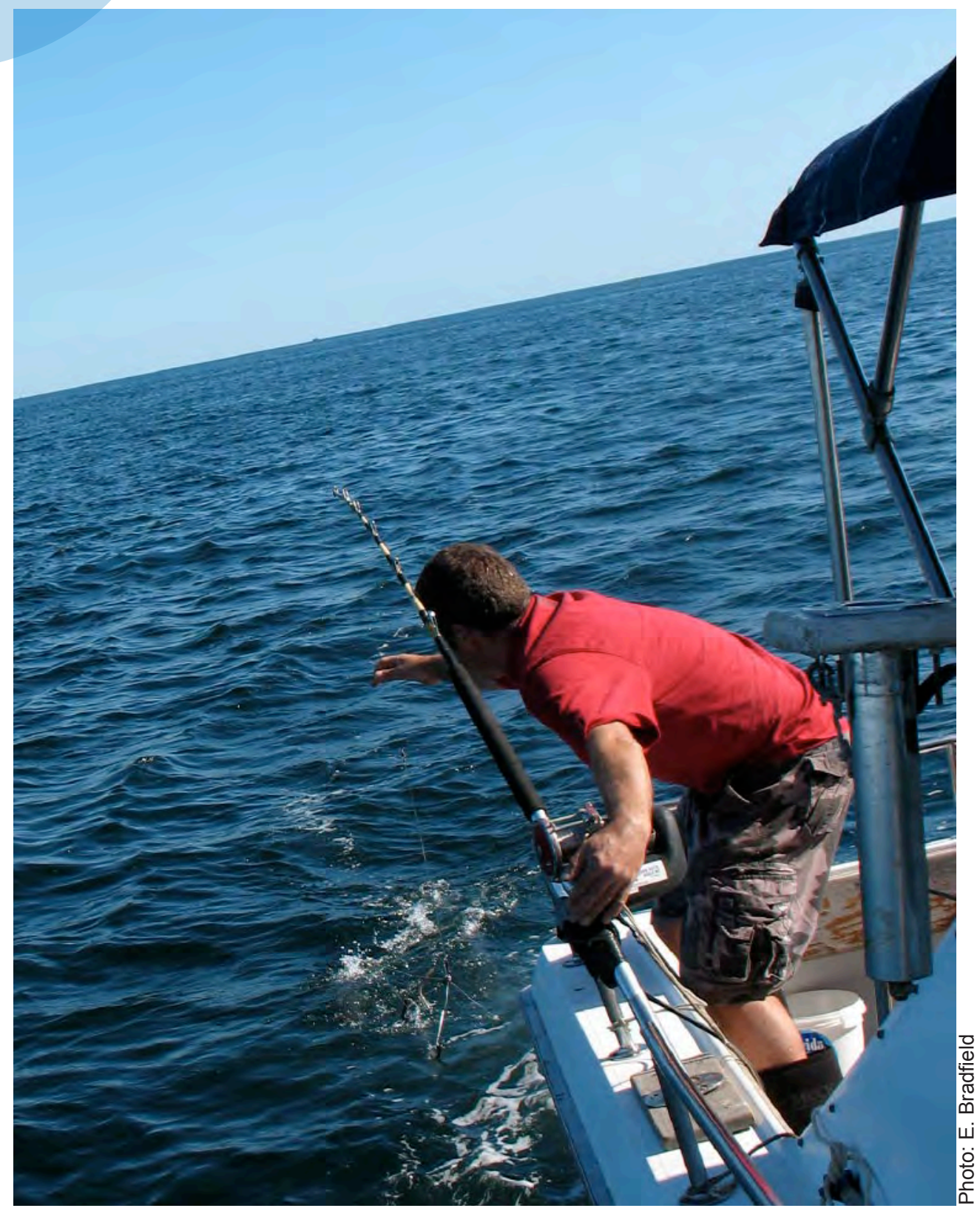




\subsection{Introduction}

There is little readily available data with which to evaluate the specific importance of the Muskeget Channel study area to commercial and recreational fisheries (DT\&A, 2006). During the Massachusetts Ocean Management Plan development process, the Muskeget Channel area was designated as an area of "medium importance" to fisheries resources based on analysis of 30 years of trawl survey data (Commonwealth of Massachusetts, 2009). Mapping of commercial fisheries activity indicated that "low" to "medium" levels of commercial fishing activity occur in Muskeget Channel. The Channel and surrounding waters are considered to be of "high importance" to recreational fisheries based primarily on landings data and interview-based surveys (Commonwealth of Massachusetts, 2009).

While the above analyses used a spatially-explicit approach to identify areas of importance to fisheries ${ }^{1}$, the trawl surveys were designed to measure relative abundance of species rather than fine-scale distribution patterns, and effort is scarce in the Muskeget Channel area (King et al., 2010). Further, many species, including pelagics, shellfish and forage fish, are not vulnerable to capture during the surveys, which occur only in spring and fall (Commonwealth of Massachusetts, 2009; King et al., 2010). The maps of fishing effort were also interpolated from fisheries-dependent data collected at coarser spatial scales. While the Ocean Management Plan process incorporated a detailed spatial analysis, it is impossible to make species- and fishery-specific interpretations of the maps at the scale of an area the size of Muskeget Channel. Therefore, the following section will focus on fisheries activity and resources within the larger Nantucket Sound area, with specific reference to Muskeget Channel when possible.

\subsubsection{Commercial Fisheries}

Recent attempts to characterize the fisheries of Nantucket Sound have been hampered by absent or overlapping data on effort and landings (MMS, 2009). Fisheries-dependent data are generally binned into either state or federal statistical reporting areas. The Muskeget Channel study area falls within Massachusetts Division of Marine Fisheries (DMF) Area 10 (Nantucket Sound) and Area 12 which includes state waters ( $3 \mathrm{~nm}$ from shore) to the south of Martha's Vineyard and Nantucket (http://www.mass.gov/dfwele/dmf/commercialfishing/inshore_areas. $\mathrm{htm})$. Most of the project falls within federal NOAA Fisheries statistical Area 538, which includes Nantucket and Vineyard Sounds as well as Buzzards Bay, although the much larger Area 537 borders the study area to the south. In studies of the fisheries of Nantucket Sound for the Cape Wind Energy Project, a subarea of Area 538 that roughly overlaps DMF Area 10, called Area 075, was used to define federal landings within the Sound (ESS, 2006a). The coarse spatial scale of the publicly available data from Nantucket Sound as assembled by ESS (2006a) and

1 Detailed descriptions of the analytical approach used in the fisheries component of the Massachusetts Ocean Management Plan can be found in the report of the Fisheries Workgroup: http:// www.env.state.ma.us/eea/mop/tech_reports/112608_ocean_mgt_fish_wkgp.pdf 
reviewed by MMS (2009) renders it difficult to make conclusions about specific gears or species within the Muskeget Channel study area. The following is a summary of available information on commercial fisheries within Nantucket Sound, based largely on the review conducted by MMS (2009), except where otherwise cited.

Commercial fisheries in Nantucket Sound are diverse, targeting many species of fish and invertebrates, including squid, conch, quahogs, fluke, sea bass, bluefish, striped bass, Atlantic mackerel and lobster. Fishing gears employed in the Sound include otter trawls, dredges, weirs, seines, traps, pots and hand lines. The dominant gear type in the Sound (Area 538/075) reported via federal Vessel Trip Reports (VTRs) is the otter trawl. Interpretation of landings data even at this large scale must be done with caution due to the overlap between state- and federally-reported fisheries, as well as gaps in federally-reported landings due to vessels with state-only permits (e.g. Massachusetts Coastal Access Permits for squid and fluke; Wiersma, 2008). The top ten federally-reported species of finfish (including squid; annual average catch in weight) from 1998-2007, in decreasing order of percent total catch, were squid, fluke, Atlantic mackerel, black sea bass, scup, bluefish, menhaden, butterfish, winter flounder and king whiting, together comprising 99\% of all landings in Nantucket Sound. Squid accounted for $50 \%$ of total annual average catch, while the second largest component (fluke) was $14 \%$ of the total. Within Massachusetts waters, virtually all squid landings occur within Nantucket Sound and neighboring Vineyard Sound in spring and summer (McKiernan and Pierce, 1995). Federally-reported landings of shellfish are dominated by conch (88\%) and include ocean quahogs, surf clams, hard clams and horseshoe crabs, comprising 99\% of 1998-2007 VTR catches (MMS, 2009).

State-reported landings in Nantucket Sound (DMF Area 10) primarily include squid and finfish catches from hook and line, fish weirs, gillnets lobster and fish pots, as well shellfish landings collected by municipalities. Weir fishing effort occurs primarily in the Northeastern Sound. The top ten state-reported species of finfish (including squid; annual average catch in weight) from 1998-2007, in decreasing order of percent total catch, were black sea bass, Atlantic mackerel, squid, fluke, scup, striped bass, menhaden, bluefish, butterfish and bonito, together comprising $99 \%$ of all landings in Nantucket Sound. State-reported landings of shellfish are dominated by conch (72\%) and include hard clams and lobsters, comprising 99\% of 1998-2007 DMF catches (MMS, 2009).

Distribution of fisheries effort in state waters around the boundaries of the Sound is mapped in the Massachusetts Ocean Management Plan, but is not specific to species or gear type. Federal VTR data were mapped by MMS (2009), indicating that squid catches were concentrated in the central portion of the Sound north of Muskeget Channel, fluke catches were primarily located on the eastern side of the Sound with a small concentration northwest of Muskeget Channel and shellfish landings were concentrated on the eastern side of the Sound. Cape Poge Bay, which lies immediately west of Muskeget Channel, contains eelgrass habitat which supports a variable but productive bay scallop fishery, which contributed 57\% of Martha's Vineyard's total 1991-2004 bay scallop landings (MacKenzie, 2008).

Surveys of commercial fishermen fishing in the Sound indicated that mobile gear fishing effort followed the above patterns, with minimal effort in the Muskeget Channel area (off Cape Poge). Summer hook-and-line fishing for bluefish and striped bass, as well as fall trawling for fluke and hook-and-line fishing for black sea bass and tautog, were among the fishing activities undertaken at a "medium" activity level (15-30\% of active vessels fishing); no activity in the Channel was listed as greater than 30\% of active fishing effort (ESS, 2006b). Hall-Arber et al. (2004) interviewed commercial fishermen who fished in the Sound and noted that fishing primarily occurs during spring, summer and fall, with little winter effort. Participating fishermen mapped their knowledge of fishing effort, indicating that mobile gear effort was concentrated in the central and eastern portions of the Sound, while "other" gears were used in the remainder of the Sound, including the Muskeget Channel area. No mobile gear (e.g. otter trawl) fishing effort was indicated in the Channel. Limited sample sizes and a focus on the area of the proposed Cape Wind energy project indicate that the results of the HallArber et al. (2004) and ESS (2006b) studies should be interpreted cautiously. 


\subsubsection{Recreational Fisheries}

Attempts to assess the extent of recreational fisheries in Nantucket Sound have encountered similar challenges to studies of commercial fishing due to lack of data or absence of spatially-explicit information. In order to examine the potential effects of the Cape Wind project on recreational fisheries, MMS (2009) summarized NOAA Fisheries Marine Recreational Fisheries Statistics Survey (MRFSS) 2005-2007 data and noted that the top eight species, representing $99 \%$ of the catch by weight, were bluefish, scup, striped bass, fluke, black sea bass, little tunny, bonito and tautog. Highest recreational fishing pressure occurs during the summer months, during the seasonal peak of tourism. Shore-based fishing accounted for $73 \%$ of average annual effort, while private/rental vessels represented $25 \%$ and party/charter vessels the remainder (MMS, 2009). Data collected in 1998-2007 from federally-permitted charter vessels subject to VTR reporting requirements indicated that the top species landed were scup (74\%), squid, black sea bass, fluke, bluefish, tautog, striped bass and sea robin, together comprising nearly $100 \%$ of the total catch. Surveys targeting recreational fishing charter/party vessel operators indicated that preferred target species included striped bass, scup and tunas, with other target species including bluefish, bonito, black sea bass and fluke (Battelle, 2003).

Federally-reporting (VTR) charter vessel landings primarily were recorded in the northern portion of the Sound (MMS, 2009). Survey respondents noted that during half-day charters, Muskeget Channel was among the top 40\% of sites fished and the Tuckernuck area to the east was targeted by $24 \%$ of trips, while $9 \%$ of full-day trips targeted shoals around Tuckernuck Island (Battelle, 2003). One charter fisherman from a small sample surveyed by ESS (2006b) noted that he fished 50\% of the time in Nantucket Sound, off Falmouth and off Cape Poge (western side of Muskeget Channel). Surf casting for bluefish and striped bass has been reported to be popular off Wasque Point, on the western side of Muskeget Channel (DT\&A, 2006). As is the case with the surveys of commercial fishermen, the above studies by Battelle (2003) and ESS (2006b) need to be interpreted with caution due to small sample sizes and their focus on the Cape Wind site.

\subsubsection{Fisheries Resources}

The Muskeget Channel study area straddles the boundary between two ten-minute squares within which Essential Fish Habitats (EFH) are designated under the 1996 amendments to the Magnuson-Stevens Fishery Conservation and Management Act (MSFCMA). Most of the study area falls within the 10-minute square between $41^{\circ} 20^{\prime}-41^{\circ}$ $30^{\prime} \mathrm{N}$ and $70^{\circ} 20^{\prime}-70^{\circ} 30^{\prime} \mathrm{W}$. Discussion will be limited to those species with EFH designations found within the above boundaries because the adjacent square to the south encompasses only a small portion of the study area and a larger area of other habitat types south of the Sound. This discussion is intended to highlight species of potential importance should a formal EFH assessment be conducted and is not an exhaustive summary of species for which EFH assessment may be necessary. A formal EFH consultation process coupled with an understanding of the potential project impacts will better inform this discussion and the list of species for which EFH may need to be considered. The table below includes 18 species (16 fish, 2 invertebrates) for which EFH has been designated between $41^{\circ} 20^{\prime}-41^{\circ} 30^{\prime} \mathrm{N}$ and $70^{\circ} 20^{\prime}-70^{\circ} 30^{\prime} \mathrm{W}$ (Table 2), and does not include additional EFHdesignated species in the ten-minute square to the south.

\subsection{Species Descriptions}

The following section is not intended to be an exhaustive list of species found in the study area or potentially affected by the project. In the absence of spatially-explicit data on species distribution, knowledge of the potential extent of project impacts and a formal EFH consultation, the following accounts are intended to summarize information on fish and invertebrate species known to be of importance to commercial and recreational fisheries in the vicinity of the study area. They are loosely ordered according to fishery and taxonomy. Some species are listed despite a lack of EFH designation in the quadrant that encompasses the majority of the study area due 
to their importance to local fisheries. Conversely, some EFH-designated species are not listed, as they are not principal fishery resources in the area. Discussion of ranges is generally confined to Western North Atlantic populations.

\section{Table 2:}

Life Stages of 18 Species (16 fish, 2 invertebrates) for which EFH has been Designated Between $41^{\circ} 20^{\prime}-41^{\circ} 30^{\prime}$ $\mathrm{N}$ and $70^{\circ} 20^{\prime}-70^{\circ} 30^{\prime} \mathrm{W}$

\begin{tabular}{lcccc}
\hline \multicolumn{1}{c}{ Species } & Eggs & Larvae & Juveniles & Adults \\
\hline Atlantic cod (Gadus morhua) & & & & $\mathrm{X}$ \\
Winter flounder (Pleuronectes americanus) & $\mathrm{X}$ & $\mathrm{X}$ & $\mathrm{X}$ & $\mathrm{X}$ \\
Yellowtail flounder (Pleuronectes ferruginea) & & & $\mathrm{X}$ & \\
Long finned squid (Loligo pealei) & $\mathrm{n} / \mathrm{a}$ & $\mathrm{n} / \mathrm{a}$ & $\mathrm{X}$ & $\mathrm{X}$ \\
Atlantic butterfish (Peprilus triacanthus) & $\mathrm{X}$ & $\mathrm{X}$ & $\mathrm{X}$ & $\mathrm{X}$ \\
Atlantic mackerel (Scomber scombrus) & $\mathrm{X}$ & $\mathrm{X}$ & $\mathrm{X}$ & $\mathrm{X}$ \\
Summer flounder (Paralicthys dentatus) & $\mathrm{X}$ & $\mathrm{X}$ & $\mathrm{X}$ & $\mathrm{X}$ \\
Scup (Stenotomus chrysops) & $\mathrm{n} / \mathrm{a}$ & $\mathrm{n} / \mathrm{a}$ & $\mathrm{X}$ & $\mathrm{X}$ \\
Black sea bass (Centropristus striata) & $\mathrm{n} / \mathrm{a}$ & $\mathrm{X}$ & $\mathrm{X}$ & $\mathrm{X}$ \\
Surf clam (Spisula solidissima) & $\mathrm{n} / \mathrm{a}$ & $\mathrm{n} / \mathrm{a}$ & $\mathrm{X}$ & $\mathrm{X}$ \\
King mackerel (Scomberomorus cavalla) & $\mathrm{X}$ & $\mathrm{X}$ & $\mathrm{X}$ & $\mathrm{X}$ \\
Spanish mackerel (Scomberomorus maculatus) & $\mathrm{X}$ & $\mathrm{X}$ & $\mathrm{X}$ & $\mathrm{X}$ \\
Cobia (Rachycentron canadum) & $\mathrm{X}$ & $\mathrm{X}$ & $\mathrm{X}$ & $\mathrm{X}$ \\
Blue shark (Prionace glauca) & & & & $\mathrm{X}$ \\
Bluefin tuna (Thunnus thynnus) & & & $\mathrm{X}$ & $\mathrm{X}$ \\
Shortfin mako shark (Isurus oxyrhyncus) & & & $\mathrm{X}$ & \\
Little skate (Leucoraja erinacea) & & & $\mathrm{X}$ & $\mathrm{X}$ \\
Winter skate (Leucoraja ocellata) & & & $\mathrm{X}$ & $\mathrm{X}$ \\
\hline
\end{tabular}

Sources: http://www.nero.noaa.gov/hcd/STATES4/cape_cod/41207020.html and http://www.nero.noaa.gov/hcd/skateefhmaps.htm

The longfin inshore squid (Loligo pealeii) is distributed in continental shelf and slope waters of the Northwestern Atlantic Ocean from Newfoundland south to the Gulf of Venezuela (Roper et al., 1984). The species is considered a single unit stock within its range of commercial exploitation from Cape Hatteras north to Georges Bank (Hendrickson and Jacobson, 2006). Longfin inshore squid support a highly variable, "boom-or-bust" fishery, particularly in the inshore waters of Nantucket Sound (Brodziak and Rosenberg, 1993). Virtually all Massachusetts squid landings (including a small proportion of shortfin squid, Illex illecebrosus) occur within Nantucket and Vineyard Sounds in spring and summer (McKiernan and Pierce, 1995). Longfin squid were the most frequently captured species during DMF trawl surveys in Nantucket Sound (1978-2007), occurring in 90.5\% and $99.9 \%$ of spring and fall tows, respectively (King et al., 2010). In Nantucket Sound, at least two cohorts of squid arrive in spring and summer: larger animals in late April and early May that spawn in late spring, followed by smaller individuals that spawn in early fall (Brodziak and Rosenberg, 1993; McKiernan and Pierce, 1995). Spawning in Nantucket Sound occurs primarily from May-July (Hatfield and Cadrin, 2002), during which females deposit clusters of egg capsules on the bottom (Arnold and Williams-Arnold, 1977). Arrival and distribution in the Sound are likely correlated with environmental variables, including wind forcing and water temperature, but confirmatory studies have yet to be completed. The species' stock status is undetermined; overfishing is not considered to be occurring (MAFMC, 2010).

The fluke (Paralicthys dentatus), also known as summer flounder, is a demersal flatfish that is distributed from the 
Southern Gulf of Maine to South Carolina. Commercial and recreational fisheries occur from Cape Cod south to Cape Hatteras. Fluke are managed as a single unit stock from North Carolina to Maine (Terceiro, 2006a). Fluke are concentrated in shallow bays and estuaries from late spring through early fall, when an offshore migration to the outer continental shelf occurs. Spawning occurs during fall and early winter, followed by inshore larval transport via prevailing currents. Post-larval and juvenile development primarily occurs within bays and estuaries. Fluke arrive inshore in Massachusetts waters in early May and occur in shallow waters south of Cape Cod and Buzzards Bay, Vineyard Sound, Nantucket Sound and coastal waters around Martha's Vineyard. Offshore migration of fluke from Massachusetts waters begins in late September and October (Packer et al., 1999). Fluke occurred in 55.4\% of spring and 64.6\% of fall tows during DMF trawl surveys in Nantucket Sound from 1978-2007 (King et al., 2010). Fluke are not considered to be overfished, and overfishing is not occurring (MAFMC, 2010).

The Atlantic mackerel (Scomber scombrus) is a pelagic, schooling species distributed in the Northwestern Atlantic from Labrador south to North Carolina. There are two major components of the population: a southern group that spawns primarily in the Mid-Atlantic Bight during April and May and a northern group that spawns in the Gulf of St. Lawrence in June and July. Both groups overlap slightly in winter between Sable Island (off Nova Scotia) and Cape Hatteras, with extensive northerly (spring) and southerly (autumn) migrations to and from spawning and summering areas. Both groups are managed as a unit stock. Atlantic mackerel are targeted by seasonal commercial and recreational fisheries throughout most of their range. Commercial landings are caught primarily between January and May in southern New England and Mid-Atlantic coastal waters and between May and December in the Gulf of Maine, while recreational landings are caught mainly between April and October (Studholme et al., 1999; Overholtz, 2006a). Based on 1978-1996 DMF bottom trawl data summarized by Studholme et al. (1999), juveniles were most common in Vineyard Sound in spring, and adults were most common in Nantucket Sound in spring. A more recent summary of the DMF trawl survey data indicates a relatively low occurrence in Nantucket Sound when averaged across 1978-2007 (King et al., 2010), likely reflecting a decline in landings in recent years reported by many commercial fishermen working in the Sound. The species' stock status is undetermined and overfishing is not considered to be occurring (MAFMC, 2010).

Black sea bass (Centropristis striata) are distributed from Nova Scotia to Florida, with Cape Hatteras serving as a geographic boundary between northern and southern stocks. Structures such as reefs, wrecks or oyster beds form preferred habitats. Spawning in the northern stock primarily occurs from April to June following migration into coastal habitats. Larvae and juveniles develop and grow in inshore habitats. Sea bass remain in coastal habitats until water temperatures decrease in fall into early winter, and then migrate to deeper offshore water along the edge of the continental shelf. In spring, most fish return to the area in which they were distributed the previous fall (Shepherd, 2006a; Drohan et al., 2007). Black sea bass occurred in 30\% of spring and $81 \%$ of fall tows during DMF trawl surveys in Nantucket Sound from 1978-2007 (King et al., 2010). Black sea bass are not considered to be overfished, and overfishing is not occurring (MAFMC, 2010).

The scup (Stenotomus chrysops) is a schooling species found primarily from Massachusetts south to Cape Hatteras. Spring and fall scup migrations are associated with seasonal changes in water temperature. When seawater temperature rises in spring, scup move north and inshore to spawn. Large adult fish arrive off southern New England by early May, followed by schools of sub-adults. Larger scup are found during summer near bay mouths and in the ocean within the 20-fathom contour while smaller fish are found in shallower habitats (Steimle et al., 1999). Scup are managed as a single stock, despite limited evidence from tagging studies for two stocks: one in Southern New England waters and one ranging south from New Jersey (Terceiro, 2006b). Scup occurred in 47.9\% of spring and $99.7 \%$ of fall tows during DMF trawl surveys in Nantucket Sound from 1978-2007 (King et al., 2010). Scup are not considered to be overfished, and overfishing is not occurring (MAFMC, 2010).

Butterfish (Peprilus triacanthus) range from Newfoundland and the Gulf of St. Lawrence south to the Atlantic and Gulf Coasts of Florida, with peak abundance from the Gulf of Maine to Cape Hatteras, where the species is considered a single unit stock (Overholtz, 2006b). The butterfish is a fast-growing, short-lived, pelagic species that forms loose schools, often near the surface. Butterfish winter in Mid-Atlantic Bight outer shelf waters and migrate inshore in the spring into Southern New England and Gulf of Maine waters. In summer, butterfish occur over the entire Mid-Atlantic shelf in nearshore waters, bays and estuaries. In late fall, butterfish migrate southward and offshore as seawater temperatures decrease (Cross et al., 2009). Butterfish occurred in $24.7 \%$ of spring 
and $91.8 \%$ of fall tows during DMF trawl surveys in Nantucket Sound from 1978-2007 (King et al., 2010). The stock status of butterfish is unknown, and overfishing is not considered to be occurring (MAFMC, 2010).

Bluefish_(Pomatomus saltatrix) are distributed in the Western Atlantic from Nova Scotia and Bermuda south to Argentina, with greatest occurrence between Florida and the Gulf of Maine. Bluefish are found in schools of similarly sized fish and undertake seasonal migrations, moving into the Mid-Atlantic Bight during spring and south or farther offshore during fall. Within Mid-Atlantic waters, bluefish occur in large bays and estuaries as well as across the extent of the continental shelf (Shepherd and Packer, 2006). Bluefish are considered a single unit stock (Shepherd, 2006b). Bluefish were caught far more frequently in fall (22.9\%) than spring (0.8\%) during DMF trawl survey tows in Nantucket Sound (King et al., 2010). Bluefish are not considered to be overfished, and overfishing is not occurring (MAFMC, 2010).

The striped bass (Morone saxatilis) spends the majority of its adult life in coastal estuaries or the ocean, undertaking north (summer) and south (winter) seasonal migrations, and ascending rivers to spawn in the spring. After larvae arrive in the riverine and estuarine nursery areas, they mature into juveniles, remaining in coastal sounds and estuaries for two to four years before migration to the North Atlantic. Important wintering grounds are located from offshore New Jersey as far south as Cape Hatteras. With warming water temperatures in the spring, mature adult fish migrate to the riverine spawning areas to complete their life cycle. The Chesapeake Bay spawning area produces the majority of coastal migratory striped bass (ASMFC, 2003). Striped bass are not considered to be overfished, and overfishing is not occurring (ASMFC, 2009).

The Atlantic menhaden (Brevoortia tyrannus) is a euryhaline species that inhabits nearshore and inland tidal waters and is found in large, dense schools from Florida to Nova Scotia. Spawning primarily occurs at sea with some activity in bays and sounds in the northern portion of its range. Eggs hatch at sea and larvae are transported inshore by ocean currents to estuaries, where juvenile development occurs. Distribution of adults occurs by size during the summer, with older, larger individuals found farther north. In fall, Atlantic menhaden migrate south and disperse from nearshore surface waters off North Carolina by late January or early February. Schools of adult fish reassemble in late March or early April and migrate north, redistributed from Florida to Maine by June. Atlantic menhaden are an important forage species for numerous commercially and recreationally sought finfish as well as other piscivores (Ahrenholz, 1991). The species is managed as a single unit stock and is not considered to be overfished, nor is overfishing currently occurring (ASFMC, 2010).

Several other species of interest also occur in the region. The Sound's conch fishery is supported by the channeled whelk (Busycotypus canaliculatus) and knobbed whelk (Busycon carica), large gastropods that feed on bivalve molluscs and other benthic prey (Gosner, 1978). Little information is available on the local distributional ecology of either species, although an expanding fishery is prompting the development of research projects. King et al. (2010) reported the occurrence of channeled whelks (54.7\% spring, $48.7 \%$ fall) and knobbed whelks (26.4\% spring, 53.8\% fall) in survey trawls in Nantucket Sound. Atlantic cod (Gadus morhua) do not support fisheries in Nantucket Sound, however the species' importance to commercial fisheries in other areas and the high occurrence of juveniles in the Sound (53.4\% of spring survey tows; King et al., 2010) warrant consideration. Similarly, winter flounder (Pseudopleuronectes americanus) are not heavily fished in the Sound, but occur at high frequency in spring surveys (87.9\% of tows; King et al., 2010), indicating that the Sound may be important winter habitat for the species. Little skates (Leucoraja erinacea) and winter skates (Leucoraja ocellata) also occur at high frequency during surveys in the Sound (King et al., 2010). Bonito (Sarda sarda) and tautog (Tautoga onitis) are other species that historically have supported commercial and recreational fisheries in the Sound (Hall-Arber et al., 2004) but are not currently reported among the more heavily fished species. Skomal (2007) noted that study area waters (just off Cape Poge) may serve as nursery habitat for several recreationally and commercially important shark species, including smooth dogfish (Mustelis canis), sandbar sharks (Carcharinus plumbeus) and sand tiger sharks (Carcharias taurus). Forty sightings of blue sharks (Prionace glauca) were documented in the region between 1979 and 1992 (Right Whale Consortium, 2010). 


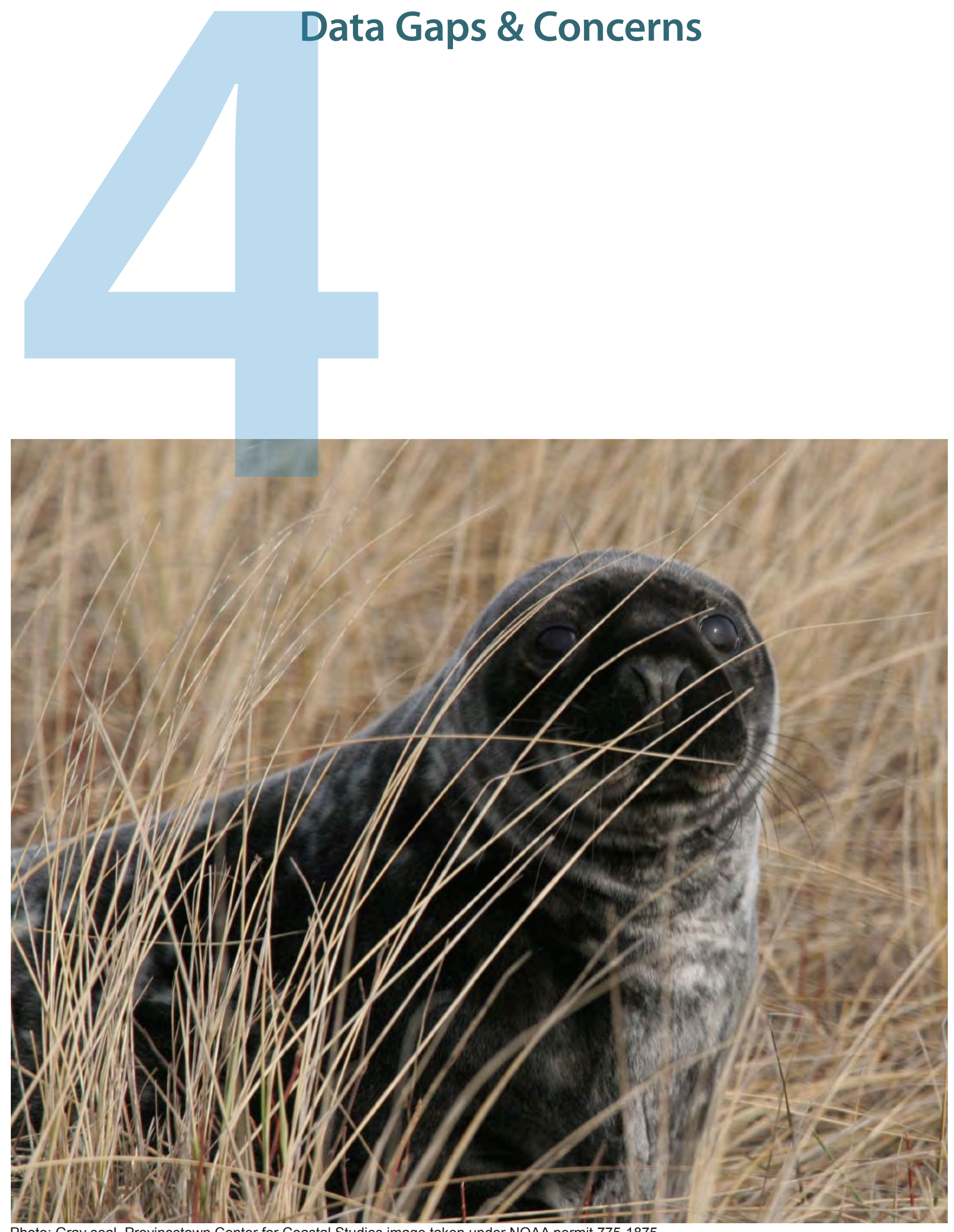

Photo: Gray seal, Provincetown Center for Coastal Studies image taken under NOAA permit 775-1875 


\subsection{Introduction}

Sections 2 and 3 identified the lack of baseline data on marine megavertebrates, fishery resources and fishing activity for the Nantucket Sound - Muskeget Channel area. This lack of data presents significant challenges for an assessment of the potential for environmental impacts of the proposed tidal turbine project in Muskeget Channel and of future marine renewable energy projects in this area.

The following section lists the gaps uncovered during data mining for this report. It also highlights the species likely to be encountered in the Muskeget region for which there are conservation concerns and highlights potential species-specific issues regarding tidal energy technologies. Section 5 provides a more detailed discussion of the known and suggested effects of MREIs on marine megavertebrates. Section 6 provides a more detailed discussion of monitoring techniques and recommends a monitoring program specific to the tidal energy project proposed by the Town of Edgartown for Muskeget Channel.

\subsection{Cetaceans}

\section{Data Gaps}

The lack of systematic survey effort on all species sighted in the study area precludes an accurate assessment of the abundance and distribution of cetaceans in the region.

\section{Concerns}

Many species of cetaceans have experienced severe population decline in recent decades, and still face numerous threats such as bycatch (e.g. Read et al., 2006; Leeney et al., 2008), ship strike (e.g. Cole et al., 2005; Panigada et al., 2006) and habitat degradation (e.g. Bearzi et al., 2008a, b). One species which deserves special consideration with respect to the proposed project in Muskeget Channel is the North Atlantic right whale, Eubalaena glacialis. As detailed in the cetacean discussion in Section 2.1, this species numbers less than 450 individuals and is listed as endangered under the Endangered Species Act (ESA) and depleted under the Marine Mammal Protection Act (MMPA). It is also classified as "endangered" by the IUCN Red List. This species' range is restricted to the east coast of North America, with concentrations occurring fairly predictably in several key habitat areas, one of which 
(Cape Cod Bay) borders on the planned construction area for the Muskeget Channel project.

The main threats to right whales are ship strike and entanglement in fishing gear (e.g. Johnson et al., 2005; Elvin \& Taggart 2008). The risk of ship strike to right whales will be increased with any increase in vessel traffic, such as that which may be associated with maintenance activity around any MREI. Likewise subsurface lines, cables or other non-solid structures in the water column may pose a collision or entanglement risk to subsurface feeding right whales, which often become entangled in fishing gear of various types (Johnson et al., 2005; Cole et al., 2006).

\subsection{Pinnipeds}

\section{Data Gaps}

All of the harbor seal population data available at the time of this report are out of date. Wade and Angliss (1997) recommended that population estimates older than eight years should not be used to calculate the potential biological removal (PBR - a management tool used to estimate how many individuals can be removed without impacting the population). The 2001 estimate by Gilbert et al. (2005) of the U.S. Atlantic harbor seal population is nine years old and outside of this recommended time limit. Barlas' 1999 study was the last comprehensive survey of Southern New England and even older than Gilbert's work. The studies since then (deHart, 2002; NMFS data on Nantucket jetties) are more recent but only cover a very small area of Nantucket Sound.

The stock structure of U.S. Atlantic harbor seals is poorly understood. Waring et al. (2006) provided evidence of individual seals moving from Nantucket Sound to Maine just before the breeding season. The relationship between U.S. and Canadian harbor seals is unknown.

The data on gray seal numbers and seasonal distribution outside of the pupping season (December-February) are also out of date; the most recent counts are from 1999. An accurate determination of the increase in the size of the gray seal population in Nantucket Sound is required. The pup counts from Muskeget Island are recent, continuous and can be used as a proxy for the increase in the Nantucket Sound gray seal population. However, it must be noted that these numbers are single day counts and not estimates of total pup production. The data available outside of the pupping season is over ten years old and out of date. In addition, local movements and habitat use by gray seals is poorly understood. Very little is known about local gray seal movements in Nantucket Sound (around Cape Cod and the Islands).

\section{Concerns}

Pinnipeds face a number of threats throughout their range. Significant levels of mortality due to anthropogenic activities or unusual events can place a population under pressure, making it more vulnerable to other, existing pressures.

An Unusual Mortality Event is defined as a stranding that is unexpected, involves a significant die-off of any marine mammal population and demands immediate response (http://www.nmfs.noaa.gov $/ \mathrm{pr} / \mathrm{health} / \mathrm{mmume} /$ ). There have been two Unusual Mortality Events in the Gulf of Maine (GoM; 2003 and 2006) of undetermined cause. Disease events occurring in the GoM are a threat to the Nantucket Sound harbor seals, as these animals are known to move throughout the GoM region. In their study of stranded marine mammals along Cape Cod and Southeastern Massachusetts, Bogomolni et al. (2010) found that $60 \%$ of harbor seals in their data set died of disease. Stranding data on harbor, gray, harp and hooded seals in Nantucket Sound and along outer Cape Cod are summarized in Table A1.

Pinnipeds often interact with fishing gear, and in some regions fisheries bycatch can have a negative impact 
on pinniped populations. In their study on mortality in stranded animals on Cape Cod and Southeastern Massachusetts, Bogomolni et al. (2010) found that $43 \%$ of the gray seals included in this study conclusively died of human-related causes. The most common human interaction affecting gray seals was entanglement in fishing gear. Waring et al. (2009) estimated the mean annual mortality in the commercial fisheries as $611(\mathrm{cv}=0.15)$ for harbor seals and $331(\mathrm{cv}=0.21)$ for gray seals. Additional lines or structures in the water column, particularly if such structures attract fish, may potentially pose an entanglement risk to seals.

\subsection{Dermochelid \& Chelonids}

\section{Data Gaps}

There is little directed research on sea turtle seasonal distribution and abundance, foraging behavior and diet in the Nantucket Sound - Muskeget Channel area.

There is a lack of data on Northern diamond-backed terrapin foraging habitat in the waters of Nantucket Sound region.

\section{Concerns}

Several anthropogenic factors continue to threaten sea turtle populations. Entanglement in fishing gear (National Research Council, 1990; Lutcavage et al., 1997; Dwyer et al., 2003), incidental catches in fisheries (NRC, 1990; Lutcavage et al., 1997; Witzell, 1999; James et al., 2005), vessel strike (NRC, 1990; Lutcavage et al., 1997), ingestion of marine debris (Carr, 1987; Lutz \& Alfaro-Shulman, 1991; Lutcavage et al., 1997), pollution (NRC, 1990; Lutcavage et al., 1997), decline of habitat along the Western Atlantic coast (NRC, 1990; Lutcavage et al., 1997; Witherington \& Martin, 2000) and loss of nesting habitat (NRC, 1990; Lutcavage et al., 1997) are some of the documented anthropogenic impacts that have led to declines in sea turtle populations. Leatherback turtles are listed as "critically endangered" by the IUCN Red List, with a "decreasing" population trend, and are federallyand state-listed as endangered species. In fact, several species of sea turtles face extinction from unsustainable bycatch in fisheries (NRC, 1990). Anthropogenic noise is thought to be detrimental to sea turtles (Samuel et al., 2005), with likely effects on their behavior and ecology; however, no studies (to our knowledge) have been done specifically addressing the effects on this species group of noise sources generated by MREI construction and operation.

\subsection{Basking Shark \& Ocean Sunfish}

\section{Data Gaps}

Systematic survey effort in the study area is lacking for both basking sharks and ocean sunfish.

\section{Concerns}

The basking shark (Cetorhinus maximus) is listed in Appendix 3 of the Convention on International Trade in Endangered Species (CITES). There remain numerous targeted fisheries for basking sharks, and the IUCN Red 
List lists basking sharks as "vulnerable," with a "decreasing" population trend. Satellite tagging studies in recent years suggest that basking sharks cross the oceans (Gore et al., 2008) and even the equator (Skomal et al., 2009), therefore the world's population is likely smaller than previously thought. Any threat to basking sharks in the Nantucket Sound - Muskeget Channel area should thus be considered a threat to the Atlantic population.

The ocean sunfish is not Red Listed, and its biology and status remain poorly understood. However, any suggested amelioration of conditions for sunfish due to population reductions in predatory species in the world's oceans (Myers \& Worm, 2003) and increases in gelatinous prey (Mills, 2001) may be offset by anthropogenic mortality due to bycatch (Pope et al., 2010; Cartamil \& Lowe, 2004; Silvani et al., 1999). Sunfish engage in much smaller "migration" patterns than basking sharks, which are usually linked to water temperature, and populations appear to be more regionally confined. Any impact on a local population, which is unlikely to be re-stocked by individuals from other regions, would be more detrimental to that particular population than for a wide-ranging species.

Basking sharks and sunfish are probably the most difficult megavertebrate species to assess. In New England waters, both species are most commonly sighted at the surface of the water during summer months, when the water temperatures are warm. But neither speices has to surface to breathe, and thus neither is always detectable

using visual survey methods. Both basking sharks and ocean sunfish are known to dive to considerable depths and to move extensively through the water column (Pope et al., 2010; Sims, 2008; Sims et al., 2005; Skomal et al., 2009), limiting the efficacy of visual survey for detection. The behavioral responses of basking sharks and sunfish to moving objects at depth are difficult to predict, and little information exists on the sensory capabilities of either species.

\subsection{Fishery Resources and Fishing Activity}

\section{Data Gaps}

There is a lack of spatially-specific data on the distribution of species and fishing effort within the Muskeget Channel area and the surrounding waters. Existing trawl survey data are insufficient to assess impacts due to low effort in the immediate vicinity of the project area. Landings data do not reflect effort controls or other management measures intended to aid in the rebuilding of fishery resources. Socio-economic data on local commercial and recreational fisheries are also lacking.

\section{Concerns}

Given the limited study on the topic, it is difficult to define the nature and spatio-temporal extent of potential project-specific impacts. Many of the region's fishery resources and fishing communities have experienced recent declines and may be especially sensitive to ecological or socio-economic impacts (Buchsbaum et al., 2005).

During an informal interview, one of the participants interviewed in the Hall-Arber et al. (2004) study noted that mobile gear fishing activity in the Muskeget Channel area was minimal and also commented that fishing vessels frequently transit the Channel and often deploy their stabilizers or "birds" during passage, which draw as much as 25 feet when fully extended in a rolling sea (Capt. Philip Michaud, F/V Susan C III, pers. comm., 13 September 2010). The latter issue should be considered in any assessment of the area's importance to fishing or navigation. 


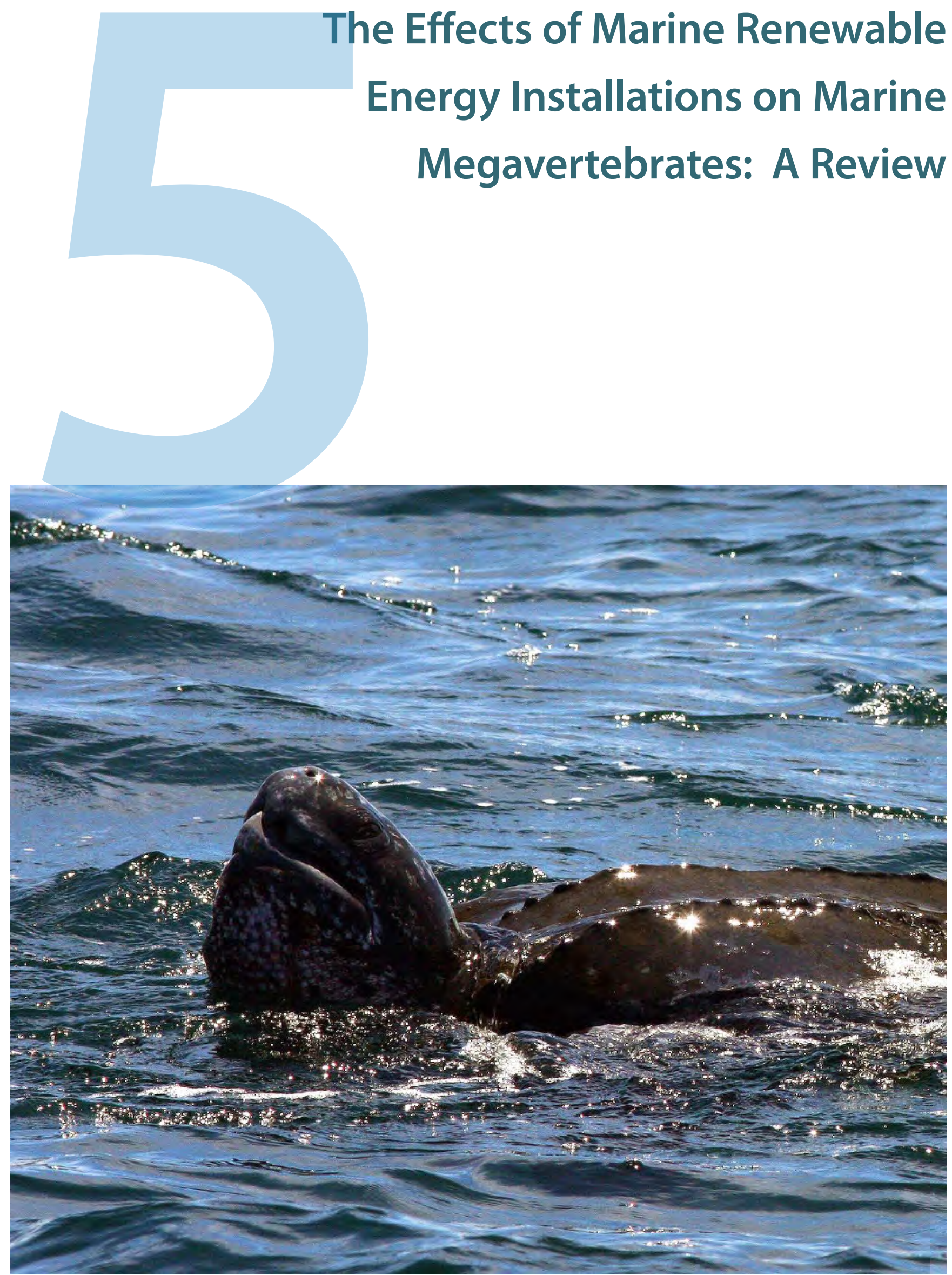

Photo: Leatherback sea turtle, Provincetown Center for Coastal Studies image taken during turtle disentanglement activities conducted under the U.S. Endangered Species Act and Final Rule 50 CFR Part 222 


\subsection{Introduction}

At present, the main form of renewable energy generation in the marine environment is wind power. Wave and tidal energy conversion devices have been in development for many years, with numerous pilot projects for these devices now underway in areas such as Canada, the U.K. and the U.S. While some of the effects of introducing marine renewable energy installations (MREIs) to the marine environment may be the same regardless of the installation involved, other effects will be device-specific. Effects will vary with the stage (construction, operation and decommissioning) and scale of the project and will depend on location and the ecosystem in that area.

This section provides a summary of the existing literature on and knowledge of the effects of MREIs on marine megavertebrates. Here, the term "marine megavertebrates" encompasses all of the larger marine vertebrate species commonly encountered in coastal and offshore habitats; e.g. cetaceans (whales, dolphins and porpoises), pinnipeds (seals and sea lions), marine turtles and large fish including basking sharks and sunfish. Seabirds are often considered to be part of this group and thus are also discussed.

\subsection{General Effects of Offshore Construction and Operation}

The initial means by which any renewable energy device can affect the marine environment is during the period when it is being put in place. Not only does such work involve added vessel traffic in and around the planned location, but it may also involve blasting or drilling of the seafloor in order to attach or anchor the device to the seabed and further disturbances associated with the laying of power transmission cables. The construction phase of such projects will likely cause physical disturbance (e.g. presence of additional vessels and structures in the marine environment, disturbance of sediment) and acoustic disturbance (noise from engines of additional vessels in the area, drilling, pile driving and other construction methods). Many of these activities and their effects will be similar, regardless of the type of installation involved.

\subsubsection{Underwater Noise}

Underwater anthropogenic noise in the oceans is increasing due to activities such as commercial shipping, seismic exploration, marine construction and sonar technology (e.g. NRC 2003, McKenna and IFAW 2008). This is a growing cause for concern as our understanding develops about the negative effects, both immediate and 
long-term, of noise on marine life. Underwater noise is especially relevant for cetaceans, as they rely on sound as their main form of communication, often over distances of tens or hundreds of kilometers (e.g. Weilgart, 2007 and references therein). Depending on the context in which the often-complex vocalizations of cetaceans are produced, their masking by anthropogenic noise could affect foraging efficiency and the ability of conspecifics to maintain group coherence for functions such as reproduction (Croll et al., 2001). Any such disturbances could lead to reduced fitness in a local population. For example, Payne and Webb (1971; referred to in Croll et al., 2001) estimated that low frequency noise from shipping traffic may have reduced the area over which blue and fin whales can communicate by several orders of magnitude; from an estimated $2.1 \times 10^{6} \mathrm{~km}^{2}\left(6 \times 10^{5} \mathrm{~nm}^{2}\right)$ in preshipping times to about $2.1 \times 10^{4} \mathrm{~km}^{2}\left(6 \times 10^{3} \mathrm{nmi}^{2}\right)$ in present-day conditions. Nowacek et al. (2007) provide a comprehensive review of the behavioral and acoustic responses of cetaceans to anthropogenic noise. In response to the recent need for systematic, objective and science-based interpretation of the available data on the effects of anthropogenic noise on protected species, Southall et al. (2007), utilizing the full body of scientific data on marine mammal hearing and the effects of noise on hearing and behavior, developed recommendations regarding noise exposure criteria for marine mammals.

\subsubsection{Underwater Noise Caused by Vessel Traffic}

Noise from vessel traffic is the dominant source of anthropogenic noise in the marine environment, and it is on the increase. Both the physical presence of vessels and the noise generated by their engines can influence the behavior of marine megavertebrates. Parks et al. (2007) reported both short and long-term changes in the calling behavior of North Atlantic right whales that were correlated with increased underwater noise levels. Similar findings have been made for blue whales (Di Iorio and Clark, 2010). Au and Green (2000) observed changes in the behavior of humpback whales in response to vessel noise from whale watch boats. Killer whales have been documented to produce longer calls (Foote et al., 2001) and to increase the amplitude of their calls (Holt et al., 2008) in response to increased vessel noise, and they also appear to change their movement patterns in the presence of "leapfrogging" whale watch vessels (Williams et al., 2002). Lemon et al. (2006) measured changes in visible surface behavior, but not acoustic behavior, of Australian bottlenose dolphins in response to experimental powerboat approaches. In Florida, however, Buckstaff (2004) did detect effects of watercraft noise on the rate of whistle production in bottlenose dolphins. Lesage et al. (1999) observed reduced calling rates and a shift in the frequency band of calls from beluga whales (Delphinapterus leucas) when approached by vessels. Forced changes in behavioral state or a forced change in vocal output to compensate for more noise in an animal's environment may have energetic costs for affected individuals (Oberweger and Goller, 1991). Forced changes could also cause increased stress levels or degradation in communication among individuals, which has potential consequences at the population level of the species.

\subsubsection{Underwater Noise Caused by Construction}

Construction may involve activities such as drilling, controlled explosions, pile driving and the use of sonar to assess the seabed. Blasting of the seabed may be required as part of the construction phase, for example in order to lay cables, and has the potential to cause serious injury to the ears of cetaceans and pinnipeds (Ketten, 1995). There is a considerable gap in our knowledge of the effects of noise on marine mammals, which makes the management and mitigation of noise disturbances difficult. The effects of these noises will vary with environmental conditions such as water depth and propagation conditions as well as the depth of the animals receiving the sound. Controlled exposure experiments (CEEs) have been proposed (Gordon et al., 2003; Tyack et al., 2003) as a means of addressing questions relating to the effects of anthropogenic noise on marine mammals.

Several recent environmental assessments for offshore wind farms have identified pile driving as the activity that has the greatest potential to impact local cetacean populations. Several studies in European waters have used static acoustic monitoring in and around areas of construction of offshore wind farms to examine the effects of such activities on odontocetes. Edrén et al. (2010) reported lower numbers of gray and harbor seals hauling out in a nearby (4 km from construction) seal sanctuary during pile driving activities for a wind farm in Danish waters. 
Brandt et al. (2009) reported that harbor porpoises in Danish waters appeared to leave the area of pile driving activity during and immediately after a pile driving event. The effect appeared to be lessened at greater distances from the activity. Tougaard et al. (2009a) documented longer "waiting times" between acoustic detections of porpoises in the period immediately after a pile driving event when compared with the wind farm construction period as a whole, and they were able to infer that the "zone of responsiveness" within which porpoises were reacting to the noise was greater than $21 \mathrm{~km}$ (the range to which this study was able to detect impacts). Carstensen et al. (2006) reported similar effects of pile driving on acoustically-detected habitat-use by harbor porpoises. It is unclear whether the "displacement" effect, when animals leave areas during periods of intense disturbance, has any longer-term costs for the animals in terms of fitness. However, since increasing the duration of construction phase will likely have increasing ecological impacts for certain marine vertebrate species, this should be taken into consideration at the planning stage of any such project. In addition to the direct effects of noise on marine mammals, there may be effects on fish populations that could have indirect effects for their predators.

There is a huge diversity in hearing capabilities among fish species (Thomsen et al., 2006). Popper and Hastings (2009) detail the range of potential effects that sound could have on fish, from little or no effect through mediumlevel effects such as tissue damage and reduced fitness, behavioral changes and temporary hearing loss to immediate death. The effect will depend on both the species and the nature of the sound source - the levels of intensity and duration being key factors. As well as the physiological effects of noise, it may affect intra-specific communication, which could lead to stress, lowered fitness or changes in behavior. According to Thomsen et al. (2006, and references therein) anthropogenic underwater noise, including sources such as shipping, seismic airguns, pile driving and operational noise from wind turbines, exhibits major energy below $1,000 \mathrm{~Hz}$ and is, therefore, within the frequency range of hearing of most fishes.

In an assessment of the effects of offshore wind farm related noise on selected marine mammal and fish species, Thomsen et al. (2006) suggest that cod (Gadus morhua) and herring (Clupea harengus) may be able to perceive piling noise at distances of up to $80 \mathrm{~km}$ from the sound source and that behavioral effects at this scale may thus be possible. It has been argued that fish are killed if they are sufficiently close to pile driving activities, but data on the percentage of fish killed, differences in susceptibility of various species and variability of effect with distance are limited (Popper \& Hastings, 2009 reviewed in Hastings and Popper, 2005). Furthermore, information on damage to fish outside the "kill zone," which may later die from injuries, does not exist. Additionally, there are numerous complexities within pile driving activities that might affect the effects on fish. Different types of piles (steel or concrete), for example, have different response characteristics and sound spectra. It is also not known whether there is a cumulative effect from being exposed to multiple pile strikes or whether each strike can be considered as an independent effect. Despite the lack of data in this area, it is evident that consideration must be given to the potential impacts of noise on fishes and any indirect effects this may have on their marine predators.

\subsubsection{Increased Vessel Traffic}

The response of small cetaceans to motorized vessels may be a reaction to noise, visual cues or a combination of both (e.g. Richardson et al., 1995; Bejder et al., 1999; Lesage et al., 1999). In addition to affecting cetacean behavior, vessel traffic can be a cause of direct mortality. Collisions between vessels and cetaceans, termed "ship strikes," have been documented in many areas around the world and for numerous species of whale (e.g. Panigada et al., 2006; Douglas et al., 2008; Elvin and Taggart 2008) and dolphin (e.g. Bloom and Jager, 1994; Elwen and Leeney, 2010).

Issues which may arise from the physical presence of vessels include immediate effects such as animal-vessel collisions, medium-term effects such as evasive behavior by animals experiencing stress and longer-term effects such as decreased fitness or even habitual avoidance of areas where disturbance is common (e.g. Constantine, 2001; Hastie et al., 2003; Lusseau, 2004; Lusseau, 2005; Bejder et al., 2006; Lusseau et al., 2009). Vessel traffic will invariably increase in offshore areas where MREIs are planned and located, not only during the construction phase but on an ongoing basis thereafter as maintenance and, eventually, decommissioning and removal of these structures will be required. 


\subsubsection{Electromagnetic Fields}

Electromagnetic fields (EMF) can be emitted from undersea power transmission cables such as those associated with offshore wind farm developments and, possibly, tidal power generators. The magnetic component of EMF has the potential to affect magnetosensitive species such as bony fish, elasmobranchs, marine mammals and sea turtles (Wiltschko and Wiltschko, 2005; Luschi et al., 2007; Gould, 2008). According to Gill et al. (2005), there are many fish species within the U.K. waters which are potentially sensitive to EMF given that these EMF components appear to be within their range of detection. The consequences for the fish, however, are unknown. It is also possible that animals using geomagnetic cues as navigation aids during migration, such as turtles and baleen whales, may be affected by magnetic fields, although the role of such cues for various species remains poorly understood (Lohmann et al., 2008). Overall, the potential effects of EMF are difficult to predict and at present, and much more research is required (Gill, 2005; Gill et al., 2005; Öhman et al., 2007).

\subsubsection{Secondary Impacts}

\subsubsection{Artificial Reefs \& Additional In-water Structures}

The placement of fixed structures on the seabed can have an "artificial reef" effect on the area. An artificial reef is defined as one or more objects of natural or human origin deployed purposefully on the sea floor, usually used to enhance recreational fishing and diving opportunities in the marine environment (Sutton and Bushnell, 2007). Adding vertical profile and surface area to the marine environment allows for growth of sedentary organisms, which in turn support other species. In a study of offshore wind farms in Danish waters, Maar et al. (2009) reported considerable aggregations of blue mussels on turbine pillars which created local hotspots of biological activity and changed ecosystem dynamics in the area. Petersen and Malm (2006) likewise suggest that the reef effect of offshore wind farms can have a significant effect on local species assemblages and biological structure, and that the importance of this impact may have been overlooked in many environmental impact assessments (EIAs) to date. $^{1}$

An increase in the productivity of an area may actually attract marine vertebrates by providing a food resource. While fixed submerged structures are likely to pose little collision risk, cables and chain (which may be used for anchoring submerged structures such as tidal turbines), power lines and free-moving components on the surface or in the water column can present a hazard to some submarine species. Both large and small cetaceans as well as basking sharks and turtles are frequently entangled in fixed fishing gear (e.g. Julian and Beeson, 1998; Berrow, 2004; Garrison, 2005; Read et al., 2006). Seabed-to-surface lines, such as the end-lines of lobster fishing gear, are a well-known entanglement risk for humpback whales, right whales and numerous other species (e.g. Volgenau et al., 1995; Moore et al., 2004; Brillant and Trippel, 2010). Similar structures used in MREI developments may present the same risks to such species.

\subsubsection{Fisheries Exclusion Zones}

The introduction of artificial structures into the marine environment presents an immediate navigational hazard and the risk of fishing gear entanglement. Thus, even without enforced exclusion, the waters inside the boundary of most MREIs will become inaccessible to many fisheries. Extensive installations with numerous devices, in particular tidal stream and wave energy devices, will likely have enforced exclusion zones surrounding them to protect the installations as well as for navigational safety. These exclusion zones will become de facto no-take zones (NTZ).

A growing body of evidence suggests that NTZs and other forms of highly-protected Marine Protected Areas

1 The reef effect and the resulting accumulation of marine life in areas where artificial structures are added to the marine environment also highlights the potential for biofouling of tidal turbine and WEC structures themselves, which in turn would likely affect the operational efficiency of these devices. 
(MPAs) are ecologically beneficial to both the protected area itself and to nearby areas. Benefits include enhanced stocks and individual fish or shellfish size (e.g. Cole et al., 1990; Babcock et al., 1999; Beukers-Stewart et al., 2005; Blyth-Skyrme et al., 2006) due to recovery from overfishing (Thurstan and Roberts, 2010) and protection of benthic environments from damaging fishing techniques such as bottom trawling (e.g. Thrush et al., 1998; Blyth et al., 2004). The changes in community structure that can result from the designation of protected areas can also show higher trophic complexity as well as increased primary and secondary productivity (Babcock et al., 1999).

Although MREIs may act as NTZs, the habitats protected by these installations may not be priority habitats for conservation, fisheries management or restoration, and while protected from fishing, these habitats may be impacted by the MREI itself. MREI sites will be selected primarily based on the quality of the renewable energy resource, suitability of the seabed in respect of construction considerations, location relative to a mainland grid connection and the requirements of other marine stakeholders. Nevertheless, if sites are appropriately managed and designed, they might increase local biodiversity and benefit the wider marine environment, both by protecting living marine resources within their boundaries (Friedlander et al., 2007) and by providing "recruitment subsidy" (Gerber et al., 2003; Sale et al., 2005) and "spillover effects" (DeMartini, 1993), whereby larvae, juveniles and adults produced in or utilizing the protected area will later move to adjacent areas, potentially bolstering fisheries surrounding the MPA.

However, Blyth-Skyrme (2010) highlighted the importance of recognizing the potential disruption to commercial fishing activities, through loss of fishing grounds or gear restrictions, posed by the establishment of MREIs such as offshore wind farms. As the number of these developments increase, support for commercial fishermen and dependent fishing communities may become necessary as well as recognition of the possible displacement of local fishing industry and an assessment of the socio-economic value of that loss.

\subsubsection{Impacts Caused by Construction Activities}

In addition to underwater noise, a number of secondary effects caused by construction activities should be considered. Such impacts are difficult to predict, but could include increased levels of suspended sediment in the water column, which might impair echolocation in odontocetes; avoidance of the area by fish and other prey species and/ or perhaps attraction of marine predators into the area in response to large numbers of disoriented prey species.

\subsubsection{Decommissioning}

If located in Masschusetts state waters, MREI structures are licensed under the state's tidelands law and regula $\neg$ tions (301CMR 9.27). These regulations require the removal of structures "upon nullification, expiration or revocation" of the license. U.S. federal regulations also require that structures be removed and the seafloor cleared of all obstructions (30CFR Chapter II, Part 285.90). A set of impacts similar to those associated with construction are likely during this phase. For structures based on pilings, noise levels during decommissioning could be lower than during construction, as the pilings will likely be cut to below seabed level rather than being fully removed. There will also be no pile driving associated with this phase.

\subsection{Device-specific Effects}

\subsubsection{Offshore Wind Turbines}

Wind power has rapidly increased in capacity in recent years (Herbert et al., 2007). High demand for space on land and aesthetic concerns about terrestrial wind farms (Taylor, 2004), combined with the better wind conditions in offshore areas, has resulted in an escalation in the development of offshore wind farms (Michel et al., 2007). 
Some offshore wind turbine sites have been in place for many years in areas such as the Baltic and North Seas. As a result, of all the categories of MREIs, the greatest knowledge base regarding effects on the marine environment comes from offshore wind turbine developments (e.g. Evans, 2008; COWRIE ${ }^{2}$ ). In a recent review of the environmental effects of coastal and offshore wind energy generation, Wilson et al. (2010) conclude that, while not environmentally benign, the environmental impacts of these developments are comparatively minor and can be mitigated through good siting practices. The authors also suggest that such MREIs provide the opportunity for environmental benefits through habitat creation and protected or inaccessible areas.

Because the operational portion of these devices is above the surface of the water, the only known potential means by which the operation of these devices might affect the marine environment are via the noise of the turbines, which can be transmitted through the base of the turbine to the underwater environment, and the "artificial reef" effects of the bases of the turbines (see Section 2.3). The known underwater noise levels emitted from operating offshore wind farms have been assessed as low relative to any standard (Madsen et al., 2006), but they nonetheless constitute another source of anthropogenic noise in the marine environment. Tougaard et al. (2009b) investigated the operating sounds of three different types of wind turbine and estimated their likely effects on the behavior of harbor porpoises and harbor seals. The authors concluded that, due to the low noise levels, behavioral reactions of porpoises were unlikely except when immediately adjacent to the turbine foundations, while behavioral reactions from seals might occur up to distances of a few hundred meters. In all cases the noise was considered incapable of masking acoustic communication by seals and porpoises. Diederichs et al. (2008) documented no difference between harbor porpoise activity inside and outside two offshore wind farm areas in Danish waters and surmised that the presence of the wind turbines and their operational noise was unlikely to be affecting porpoise activity. Edrén et al. (2010) detected no long-term effects of wind farm construction and operation on the haul-out behavior of either gray or harbor seals at a site in Danish waters. Likewise, Madsen et al. (2006) suggest that noise impact on marine mammals is more severe during the construction of wind farms than during their operation.

Some fish species have been shown to react to the noise generated by wind farms (Andersson et al., 2007), but Wahlberg and Westerberg (2005) suggest that while such noise levels may mask communication and orientation signals, they are unlikely to have destructive hearing effects. Nonetheless, any effect of wind farm noise on prey species may have a secondary effect on predators such as marine mammals.

A final, but significant, concern with regards to offshore wind turbines is the effects of these structures on birds and bats. Barrier effects due to flight avoidance, displacement resulting in habitat loss and fatalities resulting from collisions with turbine blades are the three primary threats to birds (Allison et al., 2008). Erickson et al. (2001) suggested that, relative to other human-made structures such as power lines, buildings and windows, the perstructure rate of avian collision with wind turbines is low. Despite a decade of study on turbine effects on birds, the impacts of terrestrial wind farms on birds at the population level are poorly understood. All that is clear is that the potential for bird impacts depends on the region and the local species complement.

Some studies suggest negative impacts (e.g. Barrios and Rodriguez, 2004; Garthe and Huppop, 2004), but Stewart et al. (2007), reviewing studies of this topic, suggested that the short time frame and poor design of many studies, which often lack good baseline data, make it difficult to truly assess of the effects of wind farms on avian fauna. There are even fewer data available for offshore wind farms. Blew et al. (2007) observed several seabird species using the area inside wind farms in Danish waters, and reported their increased risk of collision with wind turbines. Not all bird species will use areas occupied by wind farms, however, or fly at altitudes which place them at risk of collision with the turbine blades. Even if actual mortality levels due to collisions are low (Drewitt and Langston, 2006), reductions in local abundance may be observed due to avoidance of the area by certain species (Desholm and Kahlert, 2005).

Several studies have reported that migratory species appear to avoid wind farm areas, whereas resident species or those spending extended periods in the area did not (e.g. Krijgsveld et al., 2005; Blew et al., 2007). Non-lethal effects of wind turbines, including disturbance and reduced habitat quality, are at present poorly understood, but initial studies suggest that birds can habituate to these changes (Madsen and Boertmann, 2008). The risk to seabirds and other birds with migratory pathways through areas suitable for wind farms could thus be considerable.

2 Collaborative Offshore Wind Research Into The Environment. Numerous reports available online - http://www.offshorewindfarms.co.uk/Pages/COWRIE/ 


\subsubsection{Tidal Turbines}

More recently, tidally-dynamic areas have become the focus of the renewable energy sector, with projects shifting from barrage systems (e.g. Larsen, 1981; Rulifson and Dadswell, 1987; Fry, 2005) to capturing coastal tidal streams (e.g. Bahaj and Myers, 2003; Myers and Bahaj, 2005; Bryden and Couch, 2006; Sutherland et al., 2007; Block, 2008; Denny, 2009). The development of tidal turbines is increasingly seen as a more predictable alternative to wind generation. Tidal stream energy is derived from the kinetic energy of the moving flow of high velocity sea currents created by the movement of the tides; this is analogous to the way a wind turbine operates in air.

Fine-scale oceanographic features can be of great importance to pelagic predators (Wolanski and Hamner, 1988), providing enhanced concentrations of prey species which can be easily exploited by cetaceans, seabirds and large fishes. Many marine predators are known to forage in tidally driven oceanographic features, where they exploit predictable aggregations of prey. For example, bottlenose dolphins (Tursiops truncates; Mendes et al., 2002), harbor porpoises (Phocoena phocoena; Pierpoint, 2008), foraging seabirds (Hunt and Schneider, 1987) and basking sharks (Cetorhinus maximus; Sims and Quayle, 1998) have been associated with tidal intrusion fronts or tide "races." Harbor porpoises, fin whales (Balaenoptera physalus) and minke whales (Balaenoptera acutorostrata) congregate to feed within localized upwellings and fronts in the Bay of Fundy (Gaskin and Smith, 1979; Watts and Gaskin, 1985; Johnston et al., 2005a, b). Several species of tuna (e.g. albacore, Thunnus alalunga) have also been documented to forage at oceanic fronts (Fiedler and Bernard, 1987). Generally, the energy in marine tidal currents is diffuse, but it may be concentrated at a certain sites where the sea is channeled through restrictive topographies such as straits and between islands, making the use of marine currents attractive (Myers and Bahaj, 2005). The fact that marine megavertebrates and seabirds in coastal environments associate spatially with such areas of high tidal flow highlights a concern for sites where tidal turbine developments are planned.

Outside of the general construction, maintenance and decommissioning phases (which will be common to all devices) and the effects of the presence of large structures on the seafloor (covered in Section 5.2, above), there are several additional means by which tidal turbines may affect marine animals and their environment. The effects of the actual tidal turbines themselves, once they are running, on marine organisms and particularly on marine megavertebrates remain unknown at present.

The disruption and reduction of the net flow of water may affect the distribution of prey species (Parker, 1993; Fry, 2005), water turbidity or the ability of predators to hunt efficiently in these areas. We do not currently have a good understanding of the level to which these effects will occur and how that in turn will impact the predatory species which utilize these areas. Watts and Gaskin (1985) found a decline in the number of porpoises sighted on transects in the Bay of Fundy with increasing current speed, which they suggest is due to avoidance of shallow, turbulent areas which are energetically expensive for the animals to occupy. Gaskin and Watson (1985) also documented greater relative abundance of harbor porpoises in Fish Harbor, Canada during neap tides than during stronger spring tides.

These observations of the effects of natural fluctuations in tidal energy on cetacean habitat use suggest that tidal stream speed is a factor affecting porpoise habitat. This is an important consideration, since tide turbines extract a considerable amount of energy from the tidal flow (Sutherland et al., 2007), thus net flow will be reduced at sites where tide turbines are in operation. A reduction in tidal flow may imply a reduction in feeding efficiency for small cetaceans or a loss of feeding habitat, forcing a local population to shift its range. This could have a significant effect on a given local population of marine megavertebrate in light of the importance of localized regions for feeding as "critical habitats."

Wilson et al. (2007) point out that rotating underwater turbines (models with open blades) present the most likely circumstance for collisions with marine vertebrates. The blade tips of these devices will likely move at speeds of about $12 \mathrm{~ms}^{-1}$, or 23 knots. In collision terms, blades rotating at this speed are akin to the bow of a ship or keel of a yacht, both of which are involved in cetacean-ship strikes, a major cause of mortality for some cetacean species (e.g. IWC, 2001; Knowlton and Kraus, 2001). Given how few tidal turbines are operational and how little data are available to date on their actual effects in relation to marine megavertebrates, it is difficult to evaluate vertebrate collision risks. 
Man-made collision risks are more common than is generally supposed, and behavior in the face of collision risk will vary with age. Juveniles of a given species are at greater risk due to lack of prior experience. The potential for animals to escape collisions with marine renewable devices will vary from species to species and will depend on factors such as body size, social behavior (especially schooling or group structure), foraging tactics, curiosity, underwater agility and sensory abilities (Wilson et al., 2007). Fully aquatic species will of course be at greater risk than those such as diving birds, which only spend a small proportion of their time underwater.

Wilson et al. (2007) developed a model to investigate the potential encounter rate between 100 tidal turbines off the Scottish coast and local populations of harbor porpoises and herring of well-documented abundance. In one year of operation, the model predicted that $2 \%$ of the local herring population and 3.6 to $10.7 \%$ of the porpoise population would encounter an operational turbine. While encounters do not equate to collisions, there is no information at present on how marine organisms will react to such an encounter. If a large proportion of encounters were to result in collisions, the authors concluded that such levels of injury to the porpoise population would have a severe impact at the population level. The findings also show that encounter rate and thus collision risk increases with body size - herring have a lower likelihood of encountering a turbine than do porpoises - thus, animals such as whales and basking sharks will have greater still encounter rates. A detailed and comprehensive description of the collision hazards presented by the variety of tidal turbine technologies and associated mooring equipment, to fish, marine mammals and birds is available in Wilson et al. (2007).

Fraenkel (2006) suggested that collisions between marine wildlife and tidal turbine blades would be unlikely and, if they occurred, probably not fatal due to the smooth and "not very fast moving" surface. The author points out that ship propellers interact with the water at far greater power densities and apply energy to the water rather than removing it, thus posing a more serious risk to wildlife. However, Wilson et al. (2007) highlight the fact that the turbine blades are operating at speeds more similar to the movement of a ship's hull. Marine megavertebrates, especially large whales, often collide with moving vessels (see Section 2.2), therefore, at this point, the presence of moving turbine blades underwater should be considered a possible risk to at least some species.

The tidal turbine in Strangford Loch, Northern Ireland has been in place since 2007 (Bedford and Fortune, 2010; Davison and Mallows, 2005). The evidence so far from environmental impact assessment studies suggests no fatal interactions between seals and the turbine blades (from examination of dead stranded seal carcasses), nor does the turbine appear to present a barrier to harbor porpoise movement (from analysis of acoustic monitoring data).

It has been suggested that tidal flow installations could lead to changes in tidal level, turbidity and sedimentation, which could impact estuary ecosystems (Gordon, 1994). Changes in sediment transport around an installation may particularly affect salt marsh habitats, which in turn could impact species such as the Northern diamond-backed terrapin.

\subsubsection{Wave Power Devices}

The potential to capture wave energy has seen increasing interest, with pilot projects in a number of countries (Dal Ferro, 2006; Cada et al., 2007; Boehlert et al., 2008; Nelson et al., 2008). The technology lags behind that of offshore wind power, but it could, potentially, provide a significant contribution to renewable energy production in areas with suitable wave conditions (Carbon Trust, 2006; Kerr, 2007). Wave energy converter devices, or WECs, tend to involve less rigid structure in the water column, but do consist of significant components at the water surface. There is therefore a risk of collision between marine animals and WECs, especially for species which regularly cross the air-water interface or spend a significant proportion of their time on the surface.

Pinnipeds (seals and sea lions) may be likely to use floating devices as haul-out sites, and birds may use them as landing or roosting areas; thus there may be risks to these animals as they get onto or off of the structures and potentially come into contact with exposed moving or articulated parts (Wilson et al., 2007). Cetaceans are regularly at the water surface to breathe, while basking sharks and sunfish can, in certain seasons, spend extended periods at or very close to the water surface. These species are at risk either of swimming directly into the structures or of being hit if the structures were to pitch down on an animal in rough sea conditions (Wilson et al., 2007). It is 
unclear how aware cetaceans and large fish will be of the presence of such structures and thus how capable they will be of avoiding them.

It is also thought that WECs may act as fish aggregating devices (FADs), a technique used in fisheries whereby floating material is placed in the water to attract fish. In a study of offshore wind farms in Swedish waters, Wilhelmsson et al. (2006) suggested that these structures were functioning as combined artificial reefs and FADs for small demersal fish. Fayram and deRisi (2007) suggest that floating offshore wind turbines (and thus other structures such as WECs) could positively affect multiple stakeholder groups and potentially support higher recreational fish catch. However, any FAD effect will then likely also attract predators (such as marine mammals and birds) to these areas, which in turn may increase collision risk to these species.

\subsection{The Future}

\subsubsection{Possible Long-term Effects}

In anticipating what effect various MREIs have on the marine ecosystems into which they are placed, the immediate and short-term effects of installation and operation at an individual and community level as well as longer-term effects at the population level need to be considered. It is possible that some species will develop avoidance skills to deal with circumstances which may otherwise cause them harm or may become habituated to impacts such as noise and turbidity. They may exhibit short-term changes in behavior in response to anthropogenic disturbance (e.g. Bejder et al., 1999; Hastie et al., 2003; Lusseau, 2003).

Alternatively, certain areas may be abandoned by species whose environment has become compromised through the introduction of MREIs; short-term avoidance strategies may lead to long-term displacement (Lusseau, 2004). Abandonment of otherwise favourable habitats by cetaceans due to anthropogenic disturbance has been observed in the past (e.g. Bryant et al., 1984; Jefferson, 2000). Lusseau (2005) suggested that avoidance of a key habitat area by bottlenose dolphins, as a result of pressure from boat traffic, could have demographic impacts at a population level.

It is also important to recognize that the response of one species of marine megavertebrate to any given source of disturbance will not be indicative of responses by other species. Watkins (1986) documented species-specific changes in behavior, both positive and negative, in relation to vessels over a 25 -year period. Clearly, considerable research effort will be necessary in this field and will require the support and cooperation of the MREI industry. It will also be essential to consider the effects of any planned MREI not in isolation but rather in combination with other MREIs and other anthropogenic impacts in the region, bearing in mind the scales of habitat use relevant to marine megavertebrates.

\subsubsection{Mitigation}

Much in the same way as pingers, seal-scarers and other Acoustic Deterrent Devices (ADDs) have been developed to deter cetaceans and seals away from trawl nets and fish farms (with varying degrees of success; e.g. Hodgson et al., 2007; Berrow et al., 2008; Caretta et al., 2008; Gazo et al., 2008; Leeney et al., 2008), it may be possible to develop new technologies to alert animals to the presence of tidal turbines or other MREI structures which pose a risk. However, even if such devices are initially effective, animals can also become habituated to these devices, making them less effective over time (Dawson et al., 1998; Cox et al., 2001). Deterrents will not work for all species, as different species have different primary senses and different visual, olfactory and auditory capabilities.

Vocalizations and echolocation are essential to communication and environmental exploration for cetaceans, so deterrents using noise work well for this group of species. Sea turtles and pelagic fishes are highly visual preda- 
tors, thus visual cues most likely play an important role (Southwood et al., 2008). The reliance of some species on visual cues may also suggest that detection of MREI devices at night may be compromised; directed research will be required to address whether this will be a concern.

Since many species of megavertebrate are known to exhibit diel patterns of habitat use (e.g. Goold, 2000; Elwen et al., 2006), it will be essential to use acoustic monitoring to at least provide data on cetacean habitat use around MREIs at night as well as during the day, in order to assess risk levels outside of daylight hours. The use of sonar devices to detect approaches by marine megavertebrates, as utilized in the SeaGen tidal turbine project in Stangford Lough, may also be beneficial in addressing this issue (Bedford and Fortune, 2010). 


\section{References}

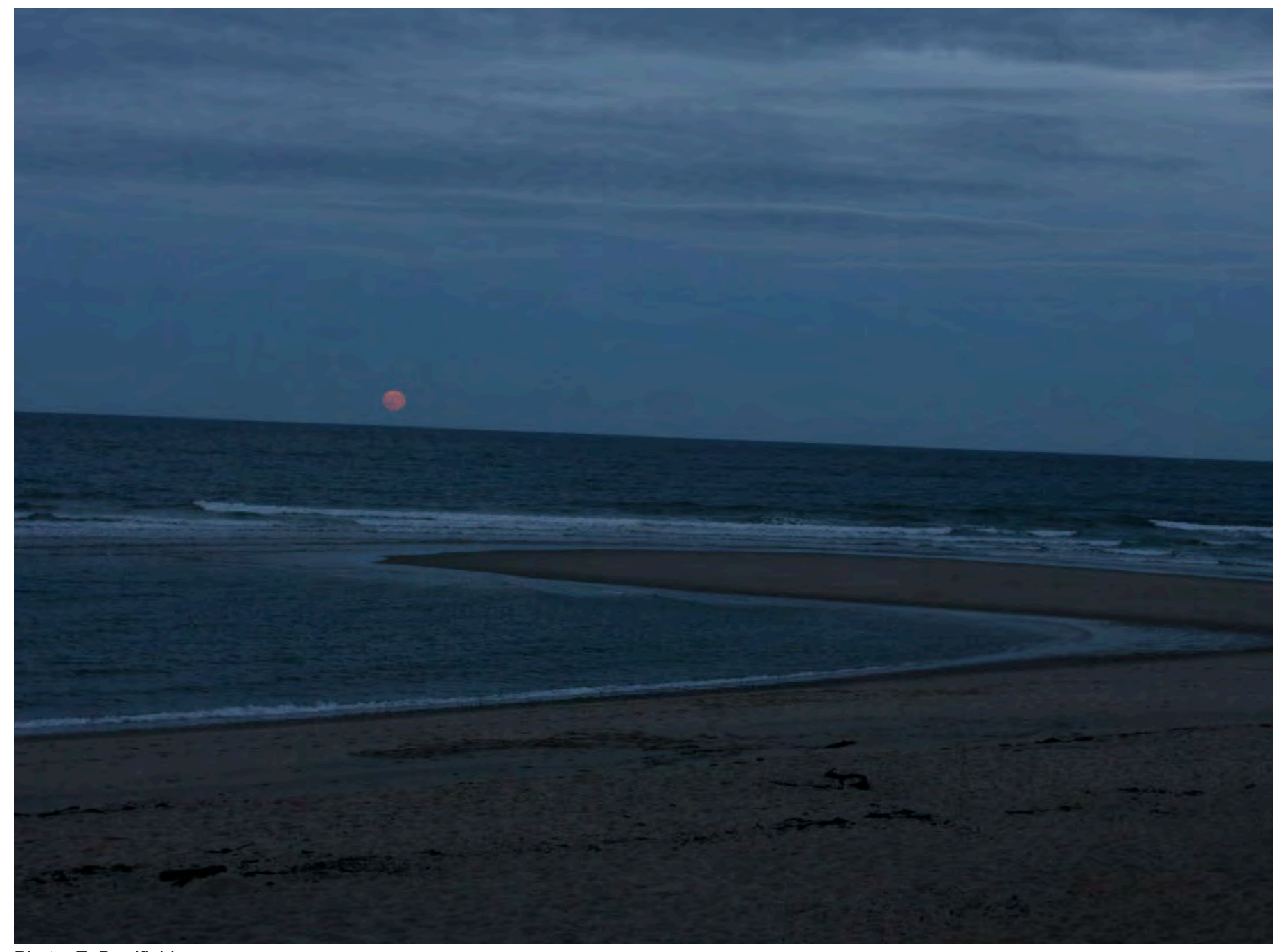




\section{Section 2.1}

\section{Data Summary}

\section{Massachusetts Audubon Society Aerial Surveys:}

Aerial surveys for seabirds were conducted in Nantucket Sound by the Massachusetts Audubon Society in summer and fall 2002-2004 as part of the assessment of the Cape Wind offshore wind energy project (Sadoti et al., 2005). Sightings of sea turtles, ocean sunfish and basking sharks were recorded opportunistically during the surveys ( $\mathrm{T}$. Allison, Massachusetts Audubon Society, pers. comm., 7 September 2010).

\section{North Atlantic Right Whale Consortium Sightings Database:}

The North Atlantic Right Whale Consortium (NARWC) sightings database contains records of thousands of sightings of right whales in the North Atlantic Ocean as well as sightings of many other species of whales, dolphins, sea turtles, seals and large fishes (Kenney, 2001). Most sightings in the sightings database are from aerial and shipboard surveys conducted from the late 1970s to the present. The sightings contained in the database come from a wide variety of contributors, both Consortium members and others. For this report, the database was queried (Right Whale Consortium, 2010) for sightings within the area encompassing Nantucket and Vineyard Sounds and the waters south of Muskeget Channel and Martha's Vineyard and Nantucket Islands ( $41^{\circ} 00^{\prime} \mathrm{N}$ north to $41^{\circ} 45^{\prime}$ $\mathrm{N}$, and $71^{\circ} 10^{\prime} \mathrm{W}$ east to $70^{\circ} 00^{\prime} \mathrm{W}$ ). Sightings data are not effort corrected and purely reflect presence of animals, rather than patterns of distribution.

Approximately 11,000 km of survey effort was conducted in the above area from 1979-2005, most of which was south of the Sounds (R. Kenney, University of Rhode Island/North Atlantic Right Whale Consortium, pers. comm., 2 September 2010). For comparison, 66,466 km of aerial survey effort was conducted during winter and spring 1998-2002 in Cape Cod Bay, a smaller area of known importance to North Atlantic right whales (Nichols et al., 2008).

\section{Massachusetts Sea Turtle Disentanglement Network}

The Massachusetts Sea Turtle Disentanglement Network (MASTDN) was formed in 2005 to respond to and document bycatch issues related to sea turtles in and around the state waters of Massachusetts. MASTDN receives reports from federal, state and municipal agencies as well as the commercial and recreational boating public through 
a dedicated marine animal reporting hotline. Support for this work is provided by ESA Section 6 in conjunction with Massachusetts Division of Marine Fisheries. Data can only be used for the purpose of this literature review and should not be used for any other reason or application without the express written consent of PCCS.

\section{Section 2.2}

\section{Museum Collections:}

American Museum of Natural History (AMNH): http://entheros.amnh.org/db/emuwebamnh/logon.php.

Harvard Museum of Comparative Zoology (MCZ): http://mczbase.mcz.harvard.edu/SpecimenSearch.cfm.

Smithsonian Institute (SI): http://collections.nmnh.si.edu/vzmammals/pages/nmnh/vz/DtlQueryMammals.php.

\section{References:}

Kenney, R.D. 2001. The North Atlantic Right Whale Consortium Databases. Maritimes 43(2): 3-6.

Nichols, O.C., Kenney, R.D. and Brown, M.W. 2008. Spatial and temporal distribution of North Atlantic right whales (Eubalaena glacialis) in Cape Cod Bay, and implications for management. Fishery Bulletin 106: 270-280.

Right Whale Consortium. 2010. North Atlantic Right Whale Consortium Sightings Database 07/08/2010 (New England Aquarium, Boston, MA, U.S.A.).

Sadoti, G., Allison, T., Perkins, S., Jedrey, E. and Jones, A. 2005. A survey of tern activity within Nantucket Sound, Massachusetts during the 2004 fall staging period. Final Report for Massachusetts Technology Collaborative. Massachusetts Audubon Society, Lincoln, MA. 26 pp. 


\section{Literature Cited - Cetaceans}

Allen, G.M. 1916. The whalebone whales of New England. Memoirs of the Boston Society of Natural History 8(2): 107-322.

Beardsley, R.C., Epstein, A.W., Chen, C., Wishner, K.F., Macaulay, M. C. and Kenney, R.D. 1996. Spatial variability in zooplankton abundance near feeding right whales in the Great South Channel. Deep Sea Research II 43 : 1601-1625.

Bogomolni, A.L., Pugliares, K.R., Sharp, S.M., Patchett, K., Harry, C.T., LaRocque, J.M., Touhey, K.M. and Moore, M. 2010. Mortality trends of stranded marine mammals on Cape Cod and southeastern Massachusetts, USA, 2000 to 2006. Diseases of Aquatic Organisms 88: 143-155.

Hamilton, P.K. and Mayo, C.A. 1990. Population characteristics of right whales (Eubalaena glacialis) observed in Cape Cod and Massachusetts Bays, 1978-1986. Reports of the International Whaling Commission Special Issue 12: 203-208.

Katona, S.K., Rough, V. and Richardson, D.T. 1993. A field guide to whales, porpoises and seals from Cape Cod to Newfoundland. Washington, D.C. Smithsonian Institution. 316 pp.

Kenney, R.D. 2010. Right whales in Rhode Island Sound: April 2010. Right Whale News 18(2): 5-10.

Kenney, R.D., Payne, P. M., Heinemann, D.W. and Winn, H.E. 1996. Chapter 10: Shifts in northeast shelf cetacean distributions relative to trends in Gulf of Maine/Georges Bank finfish abundance. The Northeast Shelf Ecosystem: Assessment, Sustainability, and Management. K. Sherman, N. Jaworski, and T. J. Smayda, eds. Cambridge, MA. Blackwell Science.

Kenney, R.D. and Winn, H.E. 1986. Cetacean high-use habitats of the northeast United States continental shelf. Fishery Bulletin 84: 345-357.

Kenney, R.D., Winn, H.E. and Macaulay, M.C. 1995. Cetaceans in the Great South Channel, 1979-1989: right whale (Eubalaena glacialis). Continental Shelf Research 15: 385-414.

Kraus, S.D., Brown, M.W., Caswell, H., Clark, C.W., Fujiwara, M., Hamilton, P.K., Kenney, R.D., Knowlton, A.R., Landry, S., Mayo, C.A., McLellan, W.A., Moore, M.J., Nowacek, D.P., Pabst, D.A., Read, A.J. and Rolland, R.M. 2005. North Atlantic right whales in crisis. Science 309: 561-562.

Little, E.A. 1981. The Indian contribution to alongshore whaling at Nantucket. Nantucket Historical Association Nantucket Algonquian Studies 8: 1-65.

Little, E.A. 1988. Nantucket whaling in the early 18th century. In W. Cowan, ed. Papers of the Nineteenth Algonquian Conference, pp. 111-131. Carleton University, Ottawa.

Mate, B.R., Nieukirk, S.L. and Kraus, S.D. 1997. Satellite-monitored movements of the northern right whale. Journal of Wildlife Management 61: 1393-1405.

Mayo, C.A. and Marx, M.K. 1990. Surface foraging behavior of the North Atlantic right whale, Eubalaena glacialis, and associated zooplankton characteristics. Canadian Journal of Zoology 68: 2214-2220.

Moore, M.J., Knowlton, A.R., Kraus, S.D., McLellan, W.A. and Bonde, R.K. 2004. Morphometry, gross morphology and available histopathology in North Atlantic right whale (Eubalaena glacialis) mortalities (1970-2002). Journal of Cetacean Research and Management 6: 199-214.

Nichols, O.C., Kenney, R.D. and Brown, M.W. 2008. Spatial and temporal distribution of North Atlantic right whales (Eubalaena glacialis) in Cape Cod Bay, and implications for management. Fishery Bulletin 106: 270-280. 
Pettis, H. 2009. North Atlantic Right Whale Consortium annual report card (01 November - 30 April 2009). International Whaling Commission Scientific Committee Meeting SC/61/BRG11.

Pittman, S., Costa, B., Kot, C., Wiley, D. and Kenney, R.D. 2006. Chapter 5: Cetacean distribution and diversity. An Ecological Characterization of the Stellwagen Bank National Marine Sanctuary Region. NOAA National Centers for Coastal Ocean Science. Silver Spring, MD. NOAA Technical Memorandum NOS NCCOS 45. $356 \mathrm{pp}$.

Reeves, R.R., Breiwick, J.M. and Mitchell, E.D. 1999. History and estimated kill of right whales, Balaena glacialis, in the northeastern United States, 1620-1924. Marine Fisheries Review 61(3): 1-36.

Right Whale Consortium. 2010. North Atlantic Right Whale Consortium Sightings Database 07/08/2010 (New England Aquarium, Boston, MA, U.S.A.).

Robbins, J. 2007. Structure and dynamics of the Gulf of Maine humpback whale population. Ph.D. dissertation, University of St. Andrews. 179 pp.

Schevill, W.E., Moore, K.E. and Watkins, W.A. 1981. Right whale, Eubalaena glacialis, sightings in Cape Cod waters. Woods Hole Oceanographic Institution Technical Report WHOI-81-50.

Waring, G.T., Josephson, E., Maze-Foley, K. and Rosel, P.E. (Eds) 2009. U.S. Atlantic and Gulf of Mexico Marine Mammal Stock Assessments - 2009. NOAA Technical Memorandum NMFS-NE-213. 528 pp.

Winn, H.E., Price, C.A. and Sorensen, P.W. 1986. The distributional biology of the right whale (Eubalaena glacialis) in the western North Atlantic. Reports of the International Whaling Commission Special Issue 10: 129-138. 


\section{Literature Cited - Pinnipeds}

Allen, J.A. 1888. History of North American pinnipeds, a monograph of the walruses, sea-lions, sea-bears and seals of North America. U.S. Geological and geographical survey of the territories. Miscellaneous publications. No $12.785 \mathrm{pp}$.

Ampela, K. 2009. The diet and foraging ecology of gray seals (Halichoerus grypus) in the United States Waters. Ph.D. Dissertation. The City University of New York. 176 pp.

Andrews, J.C. and Mott, P.R. 1967. Grey seals at Nantucket, Massachusetts. Journal of Mammalogy 48(4): 657-8.

Barlas, M.E. 1999. The distribution and abundance of harbor seals (Phoca vitulina concolor) and gray seals (Halichoerus grypus) in southern New England, winter 1998- summer 1999. M.A. Thesis. Boston University, $52 \mathrm{pp}$.

Bogomolni A.B., Pugliares, K.P., Sharp, S.M., Patchett, K., Harry, C.T., LaRocque, J.M., Touhey, K.M. and Moore, M. 2010. Mortality trends of stranded marine mammals on Cape Cod and southeastern Massachusetts, USA, 2000 to 2006. Diseases of Aquatic Organisms 88: 143-155.

Boskovic, R., Kovacs, K.M., Hammill, M.O. and White, B.N. 1996. Geographic distribution of mitochondrial DNA haplotypes in grey seals. Canadian Journal of Zoology 74: 1787-1796.

Bowen, D.W., Ellis, S.L., Iverson, S.J. and Boness, D.J. 2003. Maternal and newborn life-history traits during periods of contrasting population trends: implications for explaining the decline of harbor seals (Phoca vitulina), on Sable Island. Journal of Zoology 261: 155-163.

Burns, J.J. 2009. Harbor seal and Spotted Seal. In Encyclopedia of Marine Mammals, 2nd edition. Academic Press, Burlington, MA. pp. 533-542.

deHart, P.A.P. 2002. The distribution and abundance of harbor seals (Phoca vitulina concolor) in the Woods Hole region. M.A. Thesis. Boston University, Boston, MA. 88 pp.

Eaton, G.F. 1898. Prehistoric fauna of Block Island. American Journal of Science 6(32): 137-161.

Ferland, A. 1999. Feeding habits of harbor seals (Phoca vitulina concolor) along the coast of Cape Cod, Massachusetts and the northern Gulf of Maine. M.A. Thesis. Boston University, Boston, MA. 46 pp.

Gilbert, J., Waring, G., Wynne, K. and Guldager, N. 2005. Changes in abundance of harbor seals in Maine, 19812001. Marine Mammal Science 21 (3): 519-535.

Gilbert, J., Schurman, V. R. and Richardson, D.T. 1977. Actual and potential distribution and populations of grey seals in New England. Prepared for the Marine Mammal Commission, Washington D.C. 50 pp.

Hannah, J. 1998. Seals of Atlantic Canada and the Northeastern United States: a field guide. IMMA Inc., Guelph, Canada. 33 pp.

Hewer, H.R. 1974. British Seals. New York, New York: Taplinger Publishing Co. Inc.

Katona, S.K., Rough, V. and D.T. Richardson. 1983. A Field Guide to the Whales Porpoises and Seals of the Gulf of Maine and Eastern Canada, Cape Cod to Newfoundland. 3rd edition. Charles Scribner's Sons. New York. $255 \mathrm{pp}$.

Kenney, R. 2005. Freezer Paleostratigraphy: Rediscovery of an early gray seal stranding from Block Island, RI. Poster presentation at the 16th Biennial Meeting on the Biology of Marine Mammals, San Diego, California.

King, J.E. 1983. Seals of the World. $2^{\text {nd }}$ edition Oxford England: Oxford University Press. 
Lelli, B., Harris, D.E. and Aboueissa, S. 2009. Seal bounties in Maine and Massachusetts, 1888 to 1962 . Northeastern Naturalist 16 (2): 239-254.

National Marine Fisheries Services - Northeast Regional Office. 55 Great Republic Drive, Gloucester, Massachusetts, 01930.

Payne, P.M. and Schneider, D.C. 1984. Yearly changes in abundance of harbor seals, Phoca vitulina, at a winter haul-out site in Massachusetts. Fishery Bulletin 82: 440-442.

Payne, P.M. and Selzer, L.A. 1989. The distribution, abundance and selected prey of the harbor seal, Phoca vitulina concolor, in southern New England. Marine Mammal Science 5(2): 173-192.

Reeves, R.R., Stewart, B.S. and Leatherwood, S. 1992. The Sierra Club Handbook of Seals and Sirenians. Sierra Club Books, San Francisco, CA. 359 pp.

Rice. D.W. 1998. Marine Mammals of the World. Systematics and Distribution. Special Publication Number4. The Society for Marine Mammalogy. Allen Press, Lawrence, KS. 231 pp.

Riedman, M. 1990. The Pinnipeds, Seals, Sea Lions and Walruses. University of California Press, Berkeley, Los Angeles, Oxford. 439 pp.

Ritchie, W.A. 1969. The Archaeology of Martha’s Vineyard. Garden City, NJ: The Natural History Press.

Rosenfeld, M., George, M. and Terhune, J.M. 1988. Evidence of autumnal harbor seal, Phoca vitulina, movement from Canada to the United States. Canadian Field-Naturalist. 102(3): 527-529.

Rough, V. 1981. A Small Population of Grey Seals at Nantucket, MA. Draft Report for NMFS Contract \# 41USC252@3. $92 \mathrm{pp}$.

Rough, V. 1983. Report on Nantucket Grey Seals, Winter and Spring 1983. NMFS PO\# NA-83-FB-A-00075. $11 \mathrm{pp}$.

Rough, V. 1990. Gray seal pupping at Monomoy National wildlife Refuge, winter 1990. Report to the Marine Mammal Commission. 7 pp.

Rough, V. 1991a. Muskeget gray seals, winter and spring, 1991. Report to the Marine Mammal Commission. $14 \mathrm{pp}$.

Rough V. 1991b. Gray seal pupping at Monomoy National wildlife Refuge, winter 1991. Report to the Marine Mammal Commission. 7 pp.

Rough, V. 1992. Muskeget gray seals, winter and spring, 1992. Report to the Marine Mammal Commission. 13 pp.

Rough, V. 1993. Muskeget gray seals, winter and spring, 1993. Report to the Marine Mammal Commission. 17 pp.

Rough, V. 1994. Progress report on southern New England seal surveys, 1 January- 18 February. Report to the Marine Mammal Commission. 4 pp.

Rough, V. 1994. Progress report on southern New England seal surveys, 19 February- 31 March. Report to the Marine Mammal Commission. 5 pp.

Rough, V. 1994. Progress report on southern New England seal surveys, 1 April- 31 May. Report to the Marine Mammal Commission. 4 pp.

Rough, V. 1995. Gray seals in Nantucket Sound, Massachusetts, winter and spring, 1994. Final Report to the Marine Mammal Commission in Fulfillment of Contract T10155615. 28 pp.

Rough, V. 2000. Report on Nantucket Sound gray seals for Natural Heritage \& Endangered Species Program. 8 pp.

Schneider, D.C. and Payne, P.M. 1983. Factors affecting haul-out of harbor seals at a site in southeastern Massa- 
chusetts. Journal of Mammalogy 64 (3): 518-520.

Schroeder, C.L. 2000. Population status and distribution of the harbor seal in Rhode Island waters. M.S. Thesis.

University of Rhode Island, Kingston, RI. 197 pp.

Skomal, G. Massachusetts Marine Fisheries, PO Box 68, Vineyard Haven, MA 02568.

Wade, P.R. and Angliss, R.P. 1997. Guidelines for assessing marine mammal stocks: Report of the GAMMS Workshop April 3-5, 1996, Seattle, Washington. NOAA Tech. Memo. NMFS-OPR-12. 93 pp.

Waring, G.T., Gilbert, J.R., Loftin J. and Cabana, N. 2006. Short-term movements of Radio-tagged Harbor Seals in New England. Northeastern Naturalist 13 (1): 1-14.

Waring, G.T., Josephson, E., Fairfield-Walsh, C.P. and Maze-Foley, K. (Eds). 2009. U.S. Atlantic and Gulf of Mexico Marine Mammal Stock Assessments - 2009. NOAA Technical Memorandum NMFS-NE-210; 440 pp. Retreived from http://www.nmfs.noaa.gov/pr/sars/species.htm.

Waters, J.H. 1967. Gray seal remains from southern New England archaeological sites. Journal of Mammalogy 48 (1): 139-141.

Whitman, A.A. and Payne, P.M. 1990. Age of harbor seals, Phoca vitulina concolor, wintering in southern New England. Canadian Field-Naturalist. 104 (4): 579-582.

Wood, S., Brault, S. and Gilbert, J. 2007. 2002 Aerial Surveys of Grey Seals in the Northeastern United States. NAMMCO Scientific Publication, Volume 6, Grey Seals in the North Atlantic and the Baltic.

Wood LaFond, S.A. 2009. The dynamics of recolonization: a study of the gray seal (Halichoerus grypus) in the Northeast U.S. Ph.D. Dissertation. University of Massachusetts, Boston, MA. 88 pp. 


\section{Literature Cited - Dermochelid \& Chelonids}

Babcock, H.L. 1926. The Diamond-Back Terrapin in Massachusetts. Copeia. No. 150, Jan. 25, 1926, pp. 101-104.

Bjorndal, K.A. 1997. Foraging ecology and nutrition of sea turtles. Pages 199-233. In: P.L. Lutz and J.A. Musick (Eds). The Biology of Sea Turtles. CRC Press, New York.

Bleakney, J.S. 1965. Reports of marine turtles from New England and Eastern Canada. Canadian Field Naturalist. 1965(79): 120-128.

Brennessel, B. 2007. The Northern Diamond-backed Terrapin: Habitat, Management, and Conservation. Wheaton College, Norton, Massachusetts.

Burke, V.J., Standora, E.A. and Morreale, S.J. 1991. Factors affecting strandings of cold-stunned juvenile Kemp's ridley and loggerhead sea turtles in Long Island, NY. Copeia 1991 (4): 1136-1138.

Carr, A. 1987. Impact of non-degradable marine debris on the ecology and survival outlook of sea turtles. Marine Pollution Bulletin. 18: 352-356.

CITES. 2007. "Appendices" (SHTML). Convention on International Trade in Endangered Species of Wild Flora and Fauna. Retrieved from http://www.cites.org/eng/app/appendices.shtml.

Dwyer, K.L., Ryder, C.E. and Prescott, R. 2003. Anthropogenic mortality of leatherback sea turtles in Massachusetts waters. p. 260. In: J.A. Seminoff (compiler). Proceedings of the Twenty-Second Annual Symposium on Sea Turtle Biology and Conservation. NOAA Technical Memorandum NMFS-SEFSC-503.

Dodge, K.D., Prescott, R., Lewis, D., Murle, D. and Merigo, C. 2008. A review of cold-stunned strandings on Cape Cod Massachusetts from 1979-2003. In: Proceedings of the 24th annual symposium on sea turtle biology and conservation. NOAA Technical Memorandum.

Ernst, C.H. and Lovich J.E. 2009. Turtles of the United States and Canada - 2nd Edition. The John Hopkins University Press, Baltimore, Maryland.

Innis, C.J., Tlusty, M., Merigo, C. and Weber, E.S. 2007. Metabolic and respiratory status of cold-stunned Kemp's ridley sea turtles (Lepidochelys kempii). Journal of Comparative Physiology B 177: 623-630.

James, M.C., Ottensmeyer, C.A. and Myers, R.A. 2005. Identification of high-use habitat and threats to leatherback sea turtles in northern waters: new directions for conservation. Ecology Letters 8: 195-201.

Lazell, J.D., Jr. 1976. This broken archipelago: Cape Cod and the islands, reptiles and amphibians. Quadrangle Press, New York Times Book Co., New York, 260 pp.

Lazell, J.D. 1980. New England waters: Critical habitat for marine turtles. Copeia 1980 (2): 290-295.

Lutz, P.L., and Alfaro-Shulman, A.A. 1991. The effects of chronic plastic ingestion on green sea tutles. Report NOAASB21-WCH06134, U.S. Dept. of Commerce, Miami, FL.

Lewis, D. 2002. Diamond-backed Terrapin Summary for Outer Cape Cod. Report to NHESP. Westborough, MA.

Lutcavage, M.E., Plotkin, P., Witherington and Lutz, P.L. 1997. Human impacts on sea turtle survival. In: The Biology of Sea Turtles, Vol. 1. P.L. Lutz and J. Musick (Eds) CRC Press, Boca Raton, Fla. pp. 387-410.

Marine Turtle Specialist Group 1996a. Caretta caretta. In: IUCN 2010. IUCN Red List of Threatened Species. Version 2010.3. Retrieved from http://www.iucnredlist.org.

Marine Turtle Specialist Group 1996b. Lepidochelys kempii. In: IUCN 2010. IUCN Red List of Threatened Species. Version 2010.3. Retrieved from http://www.iucnredlist.org. 
Marquez, M.R., Burchfeild, P.M., Diaz, F.J., Sanchez, P.M., Carrasco, A.M., Jimeniez Q.C., Leo P.A., Bravo G.R. and Pena V.J. 2005. Status of the Kemp's Ridley turtle, Lepidochelys kempii, Chelonian Conservation Biology 4: 761-766.

Massachusetts reptile and amphibian list. 2010. Retrieved from http://www.mass.gov/dfwele/dfw/wildlife/facts/.../ herp_list.htm.

Morreale, S.J. and Standora, E.A. 1993. Occurrence, movement, and behavior of the Kemp's ridley and other sea turtles in New York waters. Final Report April 1988-March 1993. 70 pp.

Morreale, S.J. and Standora, E.A. 1998. Early life stage ecology of sea turtles in northeastern U.S. waters. U.S. Dep. Commer. NOAA Tech. Mem. NMFS-SEFSC-413, 49 pp.

Morreale, S.J., and Standora, E.A. 2005. Western North Atlantic waters: crucial developmental habitat for Kemp's ridley and loggerhead sea turtles. Chelonian Conservation Biology 4: 872-882.

Mortimer, J.A and Donnelly, M. 2008. Eretmochelys imbricata. In: IUCN 2010. IUCN Red List of Threatened Species. Version 2010.3. www.iucnredlist.org. Downloaded 09 September 2010.

Musick, J.A. and Limpus, C.J. 1997. Habitat utilization and migration in juvenile seaturtles. Pp. 137-164 In: Lutz, P.L., and J.A. Musick, (Eds). The Biology of Sea Turtles. CRC Press, New York. 432 pp.

National Research Council. 1990. Decline of the Sea Turtles: Causes and Prevention. National Academy Press, Washington, D.C. 259 pp.

NMFS USFWS (National Marine Fisheries Service and U.S. Fish and Wildlife Service). 2001. Stock assessments of loggerhead and leatherback sea turtles and an assessment of impacts of the pelagic longline fishery on the loggerhead and leatherback sea turtles of the western North Atlantic. NOAA Technical Memorandum. NFSSEFC-455.

NMFS USFWS (National Marine Fisheries Service and U.S. Fish and Wildlife Service). 1992. Recovery Plan for Leatherback Turtles in the U.S., Caribbean, Atlantic and Gulf of Mexico. Silver Springs, Maryland. Retrieved from http://ecos.fws.gov/docs/recovery_plan/920406.pdf.

NMFS USFWS (National Marine Fisheries Srvice and U.S. Fish and Wildlife Service). 2007a. 5-Year Review: Summary and Evaluation, Green Sea Turtle (Chelonia mydas). Silver Spring, Maryland. Retrieved from http:// www.nmfs.noaa.gov/pr/pdfs/species/greenturtle_5yearreview.pdf.

NMFS USFWS (Natinal Marine Fisheries Service and U.S. Fish and Wildlfie Service). 2007b. 5 Year Review: Summary and Evaluation, Leatherback Turtle (Dermochelys coriacea). Silver Spring, Maryland. Retrieved from http://www.nmfs.noaa.gov/pr/pdfs/species/leatherback_5yearreview.pdf.

NMFS USFWS (National Marine Fisheries Service and U.S. Fish and Wildlife Service). 2008. Recovery Plan for the Northwest Atlantic Population of the Loggerhead Sea Turtle (Caretta caretta), Second Revision. Silver Spring, MD. Retrieved from http://www.nmfs.noaa.gov/pr/pdfs/recovery/loggerhead_5yearreview.pdf.

National Marine Fisheries Service and U.S. Fish and Wildlife Service. 1993. Recovery Plan for Hawksbill Turtles in the U.S. Caribbean Sea, Atlantic Ocean, and Gulf of Mexico. National Marine Fisheries Service, St. Petersburg, Florida.

Prescott, R.L. 1988. Leatherbacks in Cape Cod Bay, Massachusetts, 1977-1987. NMFS ESA Section 7 Biological Opinion, Cape Wind Energy Project: 83-84.

Sarti Martinez, A.L. 2000. Dermochelys coriacea. In: IUCN 2010. IUCN Red List of Threatened Species. Version 2010.3. Retrieved from http://www.iucnredlist.org.

Sadoti, G., Allison T., Perkins S., Jedrey E., Jones A. 2005. A survey of tern activity within Nantucket Sound, Massachusetts during the 2004 fall staging period. Final Report for Massachusetts Technology Collaborative. 
Massachusetts Audubon Society, Lincoln, MA. 26 pp.

Seminoff, J.A. 2004. Chelonia mydas. In: IUCN 2010. IUCN Red List of Threatened Species. Version 2010.3. www.iucnredlist.org. Downloaded 09 September 2010.

Shoop C. R. and Kenney R.D. 1992. Seasonal distribution and abundances of loggerhead and leatherback sea turtles in waters of the Northeastern United States. Herpetological Monographs 6: 43-67.

U. S Fish and Wildlife Service and National Marine Fisheries Service. 1992. Recovery Plan for the Kemp's Ridley Sea Turtle (Lepidochelys kempii) National Marine Fisheries Service, St. Petersburg, Florida.

Witherington B.E. and Martin R.E. 2000. Understanding, assessing and resolving light-pollution problems on sea turtle nesting beaches, 2nd ed. Rev. Florida Marine Research Institute Technical Report TR-2.73 pp.

Witzell W.N. 1999. Distribution and relative abundance of sea turtles caught incidentally by the U.S. pelagic longline fleet in the western North Atlantic Ocean, 1992-1995. Fisheries Bulletin 97: 200-211.

Yearicks E.F., Wood, R.C., Johnson W.S. 1981. Hibernation of the Northern diamondback Terrapin (Melaclemys terrapin). Estuaries 4(1): 78-80. 


\section{Literature Cited - Basking Shark \& Ocean Sunfish}

Bigelow, H.B. and Schroeder, W.C. 1953. Fishes of the Gulf of Maine. Fishery Bulletin of the Fish and Wildlife Service Vol. 53. 577 pp.

Campana, S.E., Gibson, J., Brazner, J., Marks, L., Joyce, W., Gosslein, J.F., Kenney, R.D., Shelton, P., Simpson, M. and Lawson, J. 2008. Status of Basking Sharks in Atlantic Canada. Canadian Science Advisory Secretariat Research Document 2008/004. 67 pp.

Compagno, L.J.V. 2001. Sharks of the world. An annotated and illustrated catalogue of shark species known to date. Volume 2: Bullhead, mackerel and carpet sharks (Heterodontiformes, Lamniformes and Orectolobiformes). FAO Species Catalogue for Fisheries Purposes No. 1, Vol. 2: 269 pp. Food and Agriculture Organization of the United Nations. Rome. 269 pp.

Kenney, R.D. 1995. Preliminary assessment of competition for prey between leatherback turtles and ocean sunfish in northeast shelf waters. Pp. 144-147 in Proceedings of the Fifteenth Annual Symposium on Sea Turtle Biology and Conservation. NOAA Technical Memorandum NMFS-SEFSC-387.

Kenney, R.D., Owen, R.E. and Winn, H.E. 1985. Shark distributions off the northeast United States from marine mammal surveys. Copeia 1985: 220-223.

Martin, R.A. and Harvey-Clark, C. 2004. Threatened fishes of the world: Cetorhinus maximus (Gunnerus 1765) (Cetorhinidae). Environmental Biology of Fishes 70: 122.

Pope, E.C., Hays, G.C., Thys, T.M., Doyle, T.K., Sims, D.W., Queiroz, N., Hobson, V.J., Kubicek, L. and Houghton, J.D.R. 2010. The biology and ecology of the ocean sunfish Mola mola: a review of current knowledge and future research perspectives. Reviews in Fish Biology and Fisheries (Online: 19 January 2010). doi: 10.1007/ s11160-009-9155-9

Right Whale Consortium. 2010. North Atlantic Right Whale Consortium Sightings Database 07/08/2010 (New England Aquarium, Boston, MA).

Sadoti, G., Allison, T., Perkins, S., Jedrey, E. and Jones, A. 2005. A survey of tern activity within Nantucket Sound, Massachusetts during the 2004 fall staging period. Final Report for Massachusetts Technology Collaborative. Massachusetts Audubon Society, Lincoln, MA. 26 pp.

Silvani L., Gazo M. and Aguilar A. 1999. Spanish driftnet fishing and incidental catches in the western Mediterranean. Biological Conservation 90: 79-85.

Sims, D.W. 2008. Sieving a living: a review of the biology, ecology and conservation status of the plankton-feeding basking shark Cetorhinus maximus. Advances in Marine Biology 54: 171-220.

Skomal, G.D. 2007. Shark nursery areas in the coastal waters of Massachusetts. American Fisheries Society Symposium 50: 17-33.

Skomal, G.B., Zeeman, S.I., Chisholm, J.H., Summers, E.L., Walsh, H.J., McMahon, K.W. and Thorrold, S.R. 2009. Transequatorial migrations by basking sharks in the western North Atlantic Ocean. Current Biology 19: $1-4$. 


\section{Literature Cited - Fisheries}

Ahrenholz, D.W. 1991. Population biology and life history of the North American menhadens, Brevoortia spp. Marine Fisheries Review 53(4): 1-19

Arnold, J.M., and Williams-Arnold, L.D. 1977. Chapter 5: Cephalopoda: Decapoda. Reproduction of Marine Invertebrates. In: A. C. Geise and J. S. Pearse (Eds). Molluscs: Gastropods and Cephalopods. Volume 4. Academic Press, New York.

Atlantic States Marine Fisheries Commission (ASMFC). 2003. Amendment 6 to the interstate fishery management plan for Atlantic striped bass. Atlantic States Marine Fisheries Commission Fishery Management Report No. $41.63 \mathrm{pp}$.

Atlantic States Marine Fisheries Commission (ASMFC). 2009. 2009 review of the Atlantic States Marine Fisheries Commission fishery management plan for Atlantic striped bass: 2008 fishing year. Retrieved from http://www. asmfc.org/speciesDocuments/stripedBass/reports/fmpreviews/sbfmpreview2009.pdf.

Atlantic States Marine Fisheries Commission (ASMFC). 2010. Atlantic Menhaden Stock Assessment and Review Panel Report. Stock Assessment and Review Report No. 10-02. 325 pp.

Battelle. 2003. Recreational intercept survey. Prepared for Cape Wind Associates, L.L.C. January 2003.

Brodziak, J.K.T. and Rosenberg, A.A. 1993. A method to assess squid fisheries in the north-west Atlantic. ICES Journal of Marine Science 50: 187-194.

Buchsbaum, R., Pederson, J. and Robinson, W.E. (Eds). 2005. The decline of fisheries resources in New England: evaluating the impact of overfishing, contamination, and habitat degradation. MIT Sea Grant College Program Publication No. 05-5. 175 pp.

Commonwealth of Massachusetts. 2009. Massachusetts Ocean Management Plan. December 2009. Retrieved from http://www.env.state.ma.us/eea/mop/final-v1/.

Cross, J.N., Zetlin, C.A., Berrien, P.L., Johnson, D.L. and McBride, C. 1999. Essential fish habitat source document: butterfish, Peprilus triacanthus, life history and habitat characteristics. NOAA Technical Memorandum NMFS-NE-145. 42 pp.

Devine Tarbell \& Associates, Inc. (DT\&A). 2006. Instream tidal power in North America: environmental and permitting issues. Report No. EPRI-TP-007-NA . Prepared for Electric Power Research Institute, Inc. June 2006. $163 \mathrm{pp}$.

Drohan, A.F., Manderson, J.P. and Packer, D.B. 2007. Essential fish habitat source document: black sea bass, Centropristis striata, life history and habitat characteristics. NOAA Technical Memorandum NMFS-NE-200. $68 \mathrm{pp}$.

ESS Group, Inc. (ESS). 2006a. Fisheries data report for the Cape Wind Energy Project. Prepared for Cape Wind Associates, L.L.C. November 2006.

ESS Group, Inc. (ESS). 2006b. Survey of commercial and recreational fishing activities in Nantucket Sound. Prepared for Cape Wind Associates, L.L.C. April 2006.

Gosner, K.L. 1978. A field guide to the Atlantic seashore. Boston, MA. Houghton-Mifflin Co. 329 pp.

Hall-Arber, M., Bergeron, D. and Ryznar, R. 2004. Commercial fishing in Nantucket Sound: considerations pertinent to the proposed wind farm on Horseshoe Shoal. Massachusetts Fishermen's Partnership. Retrieved from http://www.fishermenspartnership.org/pdf/Nantucket-Sound-Report.pdf.

Hatfield, E.M.C. and Cadrin, S.X. 2002. Geographic and temporal patterns in size and maturity of the longfin ins- 
hore squid (Loligo pealeii) off the northeastern United States. Fishery Bulletin 100: 200-213.

Hendrickson, L. and Jacobson, L. 2006. Longfin inshore squid. In: Status of fishery resources off the northeastern US. Retrieved from http://www.nefsc.noaa.gov/sos/spsyn/iv/lfsquid/archives/31_LoligoInshoreSquid_2006. pdf.

King, J.R., Camisa, M.J. and Manfredi, V.M. 2010. Massachusetts Division of Marine Fisheries trawl survey effort, lists of species recorded, and bottom trawl temperature trends, 1978-2007. Massachussetts Division of Marine Fisheries Technical Report TR-38. 157 pp.

MacKenzie, C.L., Jr. 2008. The bay scallop, Argopecten irradians, Massachusetts through North Carolina: its biology and the history of its habitats and fisheries. Marine Fisheries Review 70 (3-4): 6-79.

McKiernan, D.J. and Pierce, D.E. 1995. Loligo squid fishery in Nantucket and Vineyard Sounds. Massachusetts Division of Marine Fisheries Technical Report TR-1. 62 pp.

Mid-Atlantic Fishery Management Council (MAFMC). 2010. Current stock status of MAFMC-managed species. Retrieved from http://www.mafmc.org/MAFMC_Stock_Status_CURRENT.pdf.

Minerals Management Service (MMS). 2009. Cape Wind Energy Project Final Environmental Impact Statement. January 2009. Retrieved from http://www.boemre.gov/offshore/AlternativeEnergy/PDFs/FEIS/Cape\%20 Wind\%20Energy\%20Project\%20FEIS.pdf.

Overholtz, W. 2006a. Atlantic mackerel. In: Status of fishery resources off the northeastern US. Retrieved from http://www.nefsc.noaa.gov/sos/spsyn/pp/mackerel/archives/23_AtlanticMackerel_2006.pdf.

Overholtz, W. 2006b. Butterfish. In: Status of fishery resources off the northeastern US. Retrieved from http:// www.nefsc.noaa.gov/sos/spsyn/op/butter/archives/24_Butterfish_2006.pdf.

Packer, D.B., Griesbach, S.J., Berrien, P.L., Zetlin, C.A., Johnson, D.L. and Morse, W.W. 1999. Essential fish habitat source document: summer flounder, Paralichthys dentatus, life history and habitat characteristics. NOAA Technical Memorandum NMFS-NE-151. 88 pp.

Right Whale Consortium. 2010. North Atlantic Right Whale Consortium Sightings Database 07/08/2010 (New England Aquarium, Boston, MA, U.S.A.).

Roper, C.L., Sweeney, M.J. and Nauen, C.E. 1984. FAO species catalogue. Vol. 3. Cephalopods of the World: an annotated and illustrated catalogue of species of interest to fisheries. FAO Fisheries Synopsis No. 125, Vol. 3. $277 \mathrm{pp}$.

Shepherd, G. 2006a. Black sea bass. In: Status of fishery resources off the northeastern US. Retrieved from http:// www.nefsc.noaa.gov/sos/spsyn/og/seabass/archives/16_BlackSeaBass_2006.pdf.

Shepherd, G. 2006b. Bluefish. In: Status of fishery resources off the northeastern US. Retrieved from http://www. nefsc.noaa.gov/sos/spsyn/op/bluefish/archives/25_Bluefish_2006.pdf.

Shepherd, G., and Packer, D. B. 2006. Essential fish habitat source document: bluefish, Pomatomus saltatrix, life history and habitat characteristics. NOAA Technical Memorandum NMFS-NE-198. 89 pp.

Skomal, G.D. 2007. Shark nursery areas in the coastal waters of Massachusetts. American Fisheries Society Symposium 50: 17-33.

Studholme, A.L., Packer, D.B., Berrien, P.L., Johnson, D.L., Zetlin, C.A. and Morse, W.W. 1999. Essential fish habitat source document: Atlantic mackerel, Scomber scombrus, life history and habitat characteristics. NOAA Technical Memorandum NMFS-NE-141. 35 pp.

Steimle, F.W., Zetlin, C.A., Berrien, P.L., Johnson, D.L. and Chang, S. 1999. Essential fish habitat source document: scup, Stenotomus chrysops, life history and habitat characteristics. NOAA Technical Memorandum NMFS-NE-141. 39 pp. 
Terceiro, M. 2006a. Summer flounder. In: Status of fishery resources off the northeastern US. Retrieved from http://www.nefsc.noaa.gov/sos/spsyn/fldrs/summer/archives/08_SummerFlounder_2006.pdf.

Terceiro, M. 2006b. Scup. In: Status of fishery resources off the northeastern US. Retrieved from http://www. nefsc.noaa.gov/sos/spsyn/og/scup/archives/15_Scup_2006.pdf.

Wiersma, J. 2008. An economic analysis of mobile gear fishing within the proposed wind energy generation facility site on Horseshoe Shoal. Massachusetts Fishermen's Partnership. Retrieved from http://www.fishermenspartnership.org/pdf/HorseshoeShoalEconomicReport.pdf. 


\section{Literature Cited - Review of Impacts of MREIs on Marine Megavertebrates}

Abbasi, S.A. and Abbasi, N. 2000. The likely adverse environmental impacts of renewable energy sources. Applied Energy 65: 121-144.

Akamatsu, T., Hatakeyama, T., Kojima, H. and Soeda, H. 1992. The rate at which a harbor porpoise uses echolocation at night. In: J. A. Thomas, R. A. Kastelein, and A. Y. Supin (Eds). Marine Mammal Sensory Systems. Plenum Press, New York. pp. 299-315.

Allison, T.D., Jedrey, E. and Perkins, S. 2008. Avian issues for offshore wind development. Marine Technology Society Journal 42 (2): 28-38.

Andersson, M.H., Dock-Åkerman, E., Ubral-Hedenberg, R. and Öhman, M.C. 2007. Swimming behavior of roach (Rutilus rutilus) and three-spined stickleback (Gasterosteus aculeatus) in response to wind power noise and singletone frequencies. Ambio 36: 636-638.

Au, W.W.L. and Green, M. 2000. Acoustic interaction of humpback whales and whale-watching boats. Marine Environmental Research 49: 469-481.

Babcock, R.C., Kelly, S., Shears, N.T., Walker, J.W. and Willis, T.J. 1999. Changes in community structure in temperate marine reserves. Marine Ecology Progress Series 189: 125-134.

Barrios, I. and Rodriguez, A. 2004. Behavioral and environmental correlates of soaring-bird mortality at onshore wind turbines. Journal of Applied Ecology 41: 72-81.

Bearzi, G., Agazzi, S., Gonzalvo, J., Costa, M., Bonizzoni, S., Politi, E., Piroddi, C. and Reeves, R.R. 2008 a. Overfishing and the disappearance of short-beaked common dolphins from western Greece. Endangered Species Research 5: 1-12.

Bearzi, G., Fortuna, C.M. and Reeves, R.R. 2008b. Ecology and conservation of common bottlenose dolphins Tursiops truncatus in the Mediterranean Sea. Mammal Review 39(2): 92-123. doi: 10.1111/j.13652907.2008.00133.x.

Bedford, G. and Fortune, F. 2010. SeaGen Biannual EMP update. 21 April 2010. Report ref. 9S8562/R/303719/ Edin, $31 \mathrm{pp}$. Retrieved from http://www.seageneration.co.uk/downloads/SeaGen\%20biannual\%20report\%20 April\%202010.PDF.

Bejder, L., Dawson, S. and Harraway, J.A. 1999. Responses by Hector's dolphins to boats and swimmers in Porpoise Bay, New Zealand. Marine Mammal Science 15: 738-750.

Bejder L., Samuels A., Whitehead H. and Gales N. 2006. Interpreting short-term behavioral responses to disturbance within a longitudinal perspective. Animal Behavior 72: 1149-1158.

Berrow, S.D. 1994. Incidental capture of elasmobranchs in the bottom set gill-net fishery off the south coast of Ireland. Journal of Marine Biological Association UK 74: 837-847.

Berrow, S., Cosgrove, R., Leeney, R.H., O’Brien, J., McGrath, D., Dalgard, J. and Le Gall, Y. 2008. Effect of acoustic deterrents on the behavior of common dolphins (Delphinus delphis). Journal of Cetacean Research and Management 10 (3): 227-233.

Beukers-Stewart, B.D., Vause, B.J., Mosley, M.W.J., Rossetti, H.L. and Brand, A.R. 2005. Benefits of closed area protection for a population of scallops. Marine Ecology Progress Series 298: 189-204.

Block, E. 2008. Tidal power: an update. Renewable Energy Focus 9 (6): 58-61. 
Blyth-Skyrme, R.E. 2010. Options and opportunities for marine fisheries mitigation associated with windfarms. Draft report for Collaborative Offshore Wind Research Into the Environment contract FISHMITIG09. COWRIE Ltd, Nature Bureau, Newbury, UK. 125 pp. Retrieved from http://www.offshorewindfarms.co.uk/Assets/ Windfarms\%20and\%20Fisheries\%20Mitigation\%20Final\%20Report_Draft_1st\%20April.pdf.

Blyth, R.E., Kaiser, M.J., Edwards-Jones, G. and Hart, P.B. 2004. Implications of a zoned fishery management system for marine benthic communities. Journal of Applied Ecology 41: 951-961.

Blyth-Skyrme, R.E., Kaiser, M.J., Hiddink, J., Edwards-Jones, G. and Hart, P.J.B. 2006. Conservation Benefits of Temperate Marine Protected Areas: Variation among Fish Species. Conservation Biology 20 (3): 811-820.

Boehlert, G.W., McMurray, G.E. and Tortorici, C.E. 2008. Ecological Effects of Wave Energy Development in the Pacific Northwest, 174 p. U.S. Department of Commerce, NOAA Technical Memorandum NMFS-F/SPO-92.

Brandt, M., Diederichs, A., Höschle, C., Wollheim, L. and Nehls, G. 2010. The use of seal scarers during offshore pile driving: an effective mitigation measure for harbor porpoises (Phocoena phocoena)? Poster presentation, 24th Conference of the European Cetacean Society, Stralsund, Germany, April 2010.

Brodie, P.F., Sameoto, D.D. and Sheldon, R.W. 1978. Population densities of euphausiids off Nova Scotia as indicated by net samples, whale stomach contents and sonar. Limnology and Oceanography 23: 1264-1267.

Bryant, P.J., Lafferty, C.M. and Lafferty, S.K. 1984. Reoccupation of Laguna Guerrero Negro, Baja California, Mexico, by gray whales. In: M.L. Jones, S.L. Swartz and S. Leatherwood (Eds). The gray whale Eschrichtius robustus. Academic Press, New York, pp. 375-387.

Buckstaff, C. 2004. Effects of boats on dolphin vocal behavior. Marine Mammal Science 20: 709-725.

Cada, G.F., Ahlgrimm, J., Bahleda, M., Bigford, T., Damiani Stavrakas, S., Hall, D., Moursund, R. and Sale, M. 2007. Potential impacts of hydrokinetic and wave energy conversion technologies on aquatic environments. Fisheries 32: 174-181.

Caretta, J.V., Barlow, J. and Enriquez, L. 2008. Acoustic pingers eliminate beaked whale bycatch in a gill net fishery. Marine Mammal Science 24 (4): 956-961.

Carstensen, J., Henriksen, O.D. and Teilman, J. 2006. Impacts of offshore wind farm construction on harbor porpoises: acoustic monitoring of echolocation activity using porpoise detectors (T-PODs). Mar Ecol Prog Ser 321: 295-308.

Constantine, R. 2001. Increased avoidance of swimmers by wild bottlenose dolphins (Tursiops truncatus) due to long-term exposure to swim-with-dolphin tourism. Marine Mammal Science 17: 689-702.

Cox, T.M., Read, A.J., Solow, A. and Tregenza, N. 2001. Will harbor porpoises (Phocoena phocoena) habituate to pingers? Journal of Cetacean Research and Management 3: 81-86.

Croll, D.A., Clark, C.A., Calambokidis, J., Ellison, W.T. and Tershy, B.R. 2001. Effect of anthropogenic low-frequency noise on the foraging ecology of Balaenoptera whales. Animal Conservation 4: 13-27.

Dal Ferro, B. 2006. Wave and tidal energy its emergence and the challenges it faces. Refocus 7: 46-48. doi:10.1016/S1471-0846(06)70574-1.

Davison, A. and Mallows, T. 2005. Strangford Lough Marine Current Turbine Environmental Statement (Nontechnical summary). Royal Haskoning Ltd. June 2005. 4 pp. Retrieved from http://www.seageneration.co.uk/ downloads/EIS Non Technical Summary.pdf.

DeMartini, E.E. 1993. Modelling the potential of fishery reserves for managing Pacific coral reef fishes. Fishery Bulletin 91: 414-427. 
Denny, E. 2009. The economics of tidal energy. Energy Policy 37 (5): 1914-1924.

Di Iorio, L. and Clark, C.W. 2010. Exposure to seismic survey alters blue whale acoustic communication. Biology Letters 6 (1): 51-54.

Diederichs, A., Brandt, M., Wollheim, L., Höschle, C. and Nehls, G. 2010. Responses of harbor porpoises (Phocoena phocoena) to pile driving measured with passive acoustic monitoring. Oral presentation, 24th Conference of the European Cetacean Society, Stralsund, Germany, April 2010.

Diederichs, A., Hennig, V. and Nehls, G. 2008. Investigations of the bird collision risk and the responses of harbor porpoises in the offshore wind farms Horns Rev, North Sea, and Nysted, Baltic Sea, in Denmark. Part II: Harbor porpoises. BioConsult/ Universität Hamburg report. 100 pp.

Douglas, A.B., Calambokidis, J., Raverty, S., Jeffries, S.J., Lambourn, D.M. and Norman, S.A. 2008. Incidence of ship strikes of large whales in Washington State. Journal of the Marine Biological Association of the United Kingdom 88: 1121-1132.

Edrén, S.M., Andersen, S.M., Teilmann, J., Carstensen, J., Harders, P.B., Dietz, R. and Miller, L.A. 2010. The effect of a large Danish offshore wind farm on harbor and gray seal haul-out behavior. Marine Mammal Science 26 (3): 614-634.

Elvin, S.S. and Taggart, C.T. 2008. Right whales and vessels in Canadian waters. Marine Policy 32 (3): 379-386.

Elwen, S.H., Meÿer, M.A., Best, P.B., Kotze, P.G.H., Thornton, M. and Swanson, S. 2006. Range and movements of female Heaviside's dolphins Cephalorhynchus heavisidii as determined by satellite telemetry. Journal of Mammalogy 87: 866-877.

Erickson, W.P., Johnson, G.D., Strickland, M.D., Young Jr., D.P., Sernka, K.J. and Good, R.E. 2001. Western EcoSystems Technology Inc.Avian Collisions with Wind Turbines: A Summary of Existing Studies and Comparisons to Other Sources of Avian Collision Mortality in the United States. Western Ecosystems Technology Inc., August 2001. 62 pp.

Evans, P.G.H. (Ed). 2008. Proceedings of the ASCOBANS/ ECS Workshop - Offshore wind farms and marine mammals: Impacts and methodologies for assessing impacts. ECS Special Publication Series 49, Feb 2008. $68 \mathrm{pp}$.

Fayram, A.H. and deRisi, A. 2007. The potential compatibility of offshore wind power and fisheries: an example using bluefin tuna in the Adriatic Sea. Ocean and Coastal Management 40: 597-605.

Fiedler, P.C. and Bernard, H.J. 1987. Tuna aggregation and feeding near fronts observed in satellite imagery. Continental Shelf Research 7: 871-881.

Foote, A.D., Osborne, R.W. and Hoelzel, A.R. 2004. Whale-call response to masking boat noise. Nature. (London) 428: 910.

Fraenkel, P.L. 2006. Tidal Current Energy Technologies. Ibis 148: 145-151.

Friedlander, A.M., Brown, E. and Monaco, M.E. 2007. Coupling ecology and GIS to evaluate efficacy of marine protected areas in Hawaii. Ecological Applications 17: 715-730.

Fry, C. 2005. All at sea (tidal power). Power Engineer 19: 24-27.

Garrison, L. 2005. Estimated bycatch of marine mammals and turtles in the US Atlantic pelagic longline fleet during 2004. NOAA Technical Memorandum NMFS-SEFSC-531, 57 pp.

Garthe, S. and Huppop, O. 2004. Scaling possible adverse effects of marine wind farms on seabirds: developing and applying a vulnerability index. Journal of Applied Ecology 41: 724-734.

Gaskin, D.E. 1984. The harbor porpoise Phocoena phocoena (L.): regional populations, status and information on 
direct and indirect catches. Report to the International Whaling Commission 34 SC/35/SM24

Gaskin, D.E. and Smith, G.J.D. 1979. Observations on marine mammals, birds and environmental conditions in the Head Harbor region of the Bay of Fundy. In: Scaratt DJ (ed) Evaluation of recent data relative to potential oil spills in the Passamaquoddy area. Fish Mar Serv Tech Rep 901: 69-86.

Gaskin, D.E. and Watson, A.P. 1985. The harbor porpoise, Phocoena phocoena, in Fish Harbor, New Brunswick, Canada: occupancy, distribution and movements. Fishery Bulletin 83: 427-442.

Gazo, M., Gonzalvo, J. and Aguilara, A. 2008. Pingers as deterrents of bottlenose dolphins interacting with trammel nets. Fisheries Research 92 (1): 70-75.

Gerber, L.R., Botsford, L.W., Hastings, A., Possingham, H.P., Gaines, S.D., Palumbi, S.R. and Andelman, S. 2003. Population models for marine reserve design: a retrospective and prospective synthesis. Ecological Applications 87: S47-S64.

Gill, A.B. 2005. Offshore renewable energy: ecological implications of generating electricity in the coastal zone. Journal of Applied Ecology 42: 605-615.

Gill, A.B., Gloyne-Phillips, I., Neal, K.J. and Kimber, J.A. 2005. The potential effects of electromagnetic fields generated by sub-sea power cables associated with offshore wind farm developments on electrically and magnetically sensitive marine organisms - a review. COWRIE 1.5 Electromagnetic fields Review. July 2005, $128 \mathrm{pp}$.

Goold, J. 2000. A diel pattern in vocal activity of short-beaked common dolphins, Delphinus delphis. Marine Mammal Science 16: 240-244.

Gordon, D.C. 1994. Intertidal ecology and potential power impacts, Bay of Fundy, Canada. Biological Journal of the Linnean Society 51: 17-23. doi: 10.1111/j.1095-8312.1994.tb00940.x.

Gould, J.L. 2008. Animal navigation: the evolution of magnetic orientation. Current Biology 18: R482-R484. doi:10.1016/j.cub.2008.03.052.

Hastie, G.D., Wilson, B., Tufft, L.H. and Thompson, P.M. 2003. Bottlenose dolphins increase breathing synchrony in response to boat traffic. Marine Mammal Science 19: 74-84.

Henriksen, O.D., Carstensen, J., Tougaard, J. and Teilmann, J. 2004. Effects of the Nysted offshore wind farm construction on harbor porpoises - annual status report for the acoustic T-POD monitoring programme during 2003. Report to the Ministry of the Environment, Denmark, June 2004. 33 pp. Retrieved from http://193.88.185.141/Graphics/Energiforsyning/Vedvarende_energi/Vind/havvindmoeller/vvm\%20 R\%C3\%B8dsand/havpattedyr/PODnysted_2004.pdf.

Herbert, G.M.J., Iniyan, S., Sreevalsan, E. and Rajapandian, S. 2007. A review of wind energy technologies. Renewable and Sustainable Energy Reviews 11: 1117-1145.

Hodgson, A.J., Marsh, H., Delean, S. and Marcus, L. 2007. Is attempting to change marine mammal behavior a generic solution to the bycatch problem? A dugong case study. Animal Conservation 10: 263-273.

Holt, M.M., Noren, D.P., Veirs, V., Emmons, C.K. and Veirs, S. 2009. Speaking up: Killer whales (Orcinus orca) increase their call amplitude in response to vessel noise. Journal of the Acoustical Society of America 125 (1): EL27-32. DOI: 10.1121/1.3040028

Hunt, G.L. and Schneider, D.C. 1987. Scale-dependent processes in the physical and biological environment of marine birds. In: J.P. Croxall (Ed). Seabirds feeding ecology and role in the marine ecosystems. Cambridge University Press, Cambridge. pp. 7-42.

Inger, R., Attrill, M.J., Bearhop, S., Broderick, A.C., Grecian, W. J., Hodgson, D.J., Mills, C., Sheehan, E., Votier, S.C., Witt, M.J. and Godley, B.J. 2009. Marine renewable energy: potential benefits to biodiversity? An urgent 
call for research. Journal of Applied Ecology 46: 1145-1153.

International Whaling Commission. 2001. Report of the Workshop on Status and Trends of Western North Atlantic Right Whales. The Journal of Cetacean Research and Management Special Issue 2: 61-87.

Jefferson, T.A. 2000. Population biology of the Indo-Pacific humpbacked dolphin in Hong Kong waters. Wildlife Monographs 144: 1-65.

Johnson, A., Salvador, G., Kenney, G., Robbins, J., Kraus, S., Landry, S. and Clapham, P. 2005. Fishing gear involved in entanglements of right and humpback whales. Marine Mammal Science 21 (4): 635-645.

Johnston, D.W., Thorne, L.H. and Read, A.J. 2005a. Fin whales Balaenoptera physalus and minke whales Balaenoptera acutorostratus exploit a tidally driven island wake ecosystem in the Bay of Fundy. Marine Ecology Progress Series 305: 287-297.

Johnston, D.W., Westgate, A.J. and Read, A.J. 2005b. Effects of fine-scale oceanographic features on the distribution and movements of harbor porpoises Phocoena phocoena in the Bay of Fundy. Marine Ecology Progress Series 295: 279-293.

Julian, F. and Beeson, M. 1998. Estimates of marine mammal, turtle, and seabird mortality for two California gillnet fisheries: 1990-1995. Fishery Bulletin 96 (2): 271-284.

Ketten, D.R. 1995. Estimates of blast injury and acoustic trauma zones for marine mammals from underwater explosions. In: Sensory Systems of Aquatic Mammals. Kastelein R.A., Thomas J.A., Nachtigall P.E. (ed.s). De Spil Publishers, Woerden, The Netherlands. ISBN 90-72743-05-9.

Knowlton, A.R. and Kraus, S.D. 2001. Mortality and serious injury of the northern right whales (Eubalaena glacialis) in the western North Atlantic Ocean. The Journal of Cetacean Research and Management Special Issue 2: 193-208.

Krijgsveld, K.L., Lensink, R., Schekkerman, H., Wiersma, S., Poot, M.J.M., Meesters, E.H.W.G. and Dirksen, S. 2005. Baseline studies North Sea wind farms: fluxes, flight paths and altitudes of flying birds 2003-2004. Bureau Waardenburg bv and Alterra, commissioned by the National Institute for Coastal and Marine Management, The Hague, $192 \mathrm{~S}$.

Larsen, P. 1981. Potential environmental consequences of tidal power development seaward of tidal barrages. Oceans 13: 908-912.

Lemon, M., Lynch, T.P., Cato, D.H. and Harcourt, R.G. 2006. Response of travelling bottlenose dolphins (Tursiops aduncus) to experimental approaches by a powerboat in Jervis Bay, New South Wales, Australia. Biological Conservation 127 (4): 363-372.

Lesage, V., Barrette, C., Kingsley, M.C.S. and Sjare, B. 1999. The effect of vessel noise on the vocal behavior of belguas in the St. Lawrence River estuary, Canada. Marine Mammal Science 15: 65-84.

Lohmann, K.J., Lohmann, M.F. and Endres, C.S. 2008. The sensory ecology of ocean navigation. Journal of Experimental Biology 211: 1719-1728.

Lusch, P., Benhamou S., Girard C., Ciccione S., Roos D., Sudre J. and Benvenuti S. 2007. Marine turtles use geomagnetic cues during open-sea homing. Current Biology 17: 126-133.

Lusseau, D. 2003. Effect of tour boats on the behavior of bottlenose dolphins: Using Markov chains to model anthropogenic impacts. Conservation Biology 17 (6): 1785-1793

Lusseau, D. 2004. The hidden cost of tourism: Effects of interactions with tour boats on the behavioral budget of two populations of bottlenose dolphins in Fiordland, New Zealand. Ecology and Society 9 (1): art. 2.

Lusseau, D. 2005. Residency pattern of bottlenose dolphins Tursiops spp. in Milford Sound, New Zealand, is related to boat traffic. Marine Ecology Progress Series 295: 265-272. 
Lusseau, D., Bain, D.E., Williams, R. and Smith, J.C. 2009. Vessel traffic disrupts the foraging behavior of southern resident killer whales Orcinus orca. Endangered Species Research 6: 211-221.

Maar, M., Bolding, K., Petersen, J.K., Hansen, J.L.S. and Timmermann, K. 2009. Local effects of blue mussels around turbine foundations in an ecosystem model of Nysted off-shore wind farm, Denmark. Journal of Sea Research 62: 159-174.

Madsen, P.T., Wahlberg, M., Tougaard, J., Lucke, K. and Tyack, P.L. 2006. Wind turbine underwater noise and marine mammals: Implications of current knowledge and data needs. Marine Ecology Progress Series 309: 279-295.

Mendes, S., Turrell, W., Lütkebohle, T. and Thompson, P. 2002. Influence of the tidal cycle and a tidal intrusion front on the spatio-temporal distribution of coastal bottlenose dolphins. Marine Ecology Progress Series 239: 221-229.

Michel, J., Dunagan, H., Boring, C., Healy, E., Evans, W., Dean, J.M., McGillis, A. and Hain, J. 2007. Worldwide Synthesis and Analysis of Existing Information Regarding Environmental Effects of Alternative Energy Uses on the Outer Continental Shelf. pp. 254. U.S. Department of the Interior, Minerals Management Service, Herndon, VA,MMSOCS Report 2007-038.

Morton, A.B. and Symonds, H.K. 2002. Displacement of Orcinus orca (L.) by high amplitude sound in British Columbia, Canada. ICES Journal of Marine Science 59: 71-80.

Myers, L. and Bahaj, A.S. 2005. Simulated electrical power potential harnessed by marine current turbine arrays in the Alderney Race. Renewable Energy 30: 1713-1731.

Nedwell, J.R., Langworthy, J. and Howell, D. 2004. Assessment of sub-sea acoustic noise and vibration from offshore wind turbines and its impact on marine wildlife; initial measurements of underwater noise during construction of offshore windfarms, and comparison with background noise. Subacoustech Report Reference: 544R0424, November 2004, To: COWRIE, The Crown Estate, 16 Carlton House Terrace, London, SW1Y 5AH. 68 pp. Retrieved from http://www.subacoustech.com/information/downloads/reports/544R0424.pdf.

Nelson, P.A., Behrens, D., Castle, J., Crawford, G., Gaddam, R.N., Hackett, S.C., Largier, J., Lohse, D.P., Mills, K.L., Raimondi, P.T., Robart,M., Sydeman, W.J., Thompson, S.A. and Woo, S. 2008. Developing Wave Energy in Coastal California: Potential Socio-Economic and Environmental Effects. California Energy Commission, PIER Energy-Related Environmental Research Program \& California Ocean Protection Council CEC500- 2008-083.

Nowacek, D.P., Thorne, L.H., Johnston, D.W. and Tyack, P.L. 2007. Responses of cetaceans to anthropogenic noise. Mammal Review 37 (2): 81-115.

NRC (National Research Council). 1990. Decline of the sea turtles: causes and prevention. National Academy Press, Washington, D.C.

NRC (National Research Council). 2003. Ocean Noise and Marine Mammals. National Academies Press, Washington, D.C.

Oberweger, K. and Goller, F. 2001. The metabolic cost of birdsong production. Journal of Experimental Biology 204: 3379-3388.

Öhman, M.C., Sigray, P. and Westerberg H. 2007. Offshore wind farms and the effects of electromagnetic fields on fish. Ambio 36: 630-633.

Panigada, S., Pesante, G., Zanardelli, M., Capoulade, F., Gannier, A. and Weinrich, M.T. 2006. Mediterranean fin whales at risk from fatal ship strikes. Marine Pollution Bulletin 52 (10): 1287-98.

Parks, S.E., Clark, C.W. and Tyack, P.L. 2007. Short- and long-term changes in right whale calling behavior: the 
potential effects of noise on acoustic communication. Journal of the Acoustical Society of America 122 (6): 3725-31.

Parker, D.M. 1993. Environmental implications of tidal power generation. Science, Measurement and Technology, IEE Proceedings A 140: 71-75.

Payne, R. and Webb, D. 1971. Orientation by means of long range acoustic signaling in baleen whales. Annals of the New York Academy of Science 188: 110-141.

Pelc, R. and Fujita, R.M. 2002. Renewable energy from the ocean. Marine Policy 26: 471-479.

Petersen, J.K. and Malm, T. 2006. Offshore windmill farms: threats to or possibilities for the marine environment. Ambio 35: 75-80.

Pierpoint, C. 2008. Harbor porpoise (Phocoena phocoena) foraging strategy at a high energy, near-shore site in south-west Wales, UK. Journal of the Marine Biological Association of the UK 88 (6): 1167-1173.

Popper, A.N., Fewtrell, J., Smith, M.E. and McCauley, R.D. 2003. Anthropogenic sound: effects on the behavior and physiology of fishes. Marine Technology Society Journal 37: 35-40.

Popper, A.N. and Hastings, M.C. 2009. The effects of human-generated sound on fish. Integrative Zoology 4: 43-52.

Read, A.J., Drinker, P. and Northridge, S. 2006. Bycatch of Marine Mammals in U.S. and Global Fisheries. Conservation Biology 20 (1): 163-169.

Richardson, W.J., Greene, Jr. C.R., Malme, C.I. and Thomson, D.H. 1995. Marine Mammals and Noise. Academic Press, San Diego, California.

Rulifson, R. and Dadswell, M. 1987. Mortality of fish passing through tidal, low-head hydropower turbines and possible mitigation strategies. Oceans 19: 944-949.

Sale, P.F., Cowen, R.K., Danilowicz, B.S., Jones, G.P., Kritzer, J.P., Lindeman, K.C., Planes, S., Polunin, N.V.C., Rus, G.R., Sadovy, Y.J. and Steneck, R.S. 2005. Critical science gaps impede use of no-take fishery reserves. Trends in Ecology and Evolution 20: 74-80.

Samuel, Y., Morreale, S.J., Clark, C.W., Greene, C.H. and Richmond, M.E. 2005. Underwater, low frequency noise in a coastal sea turtle habitat. Journal of the Acoustical Society of America 117: 1465-1472.

Sekiguchi, K. 1995. Occurrence, behavior and feeding habits of harbor porpoises (Phocoena phocoena) at Pajaro Dunes, Monterey Bay, California. Aquatis Mammals 21: 91-103.

Sims, D.W. and Quayle, V.A. 1998. Selective foraging behavior of basking sharks on zooplankton in a small scale front. Nature 393: 460-464.

Southall, B., Bowles, A.E., Ellison, W.T., Finneran, J.J., Gentry, R.L., Greene Jr., C.R., Kastak, D., Ketten, D.R., Miller, J.H., Nachtigall, P.E., Richardson, W.J., Thomas, J.A. and Tyack, P.L. 2007. Marine Mammal Noise Exposure Criteria: Initial Scientific Recommendations. Aquatic Mammals 33 (4).

Stewart, G.B., Pullin, A.S. and Coles, C.F. 2007. Poor evidence-base for assessment of wind farm impacts on birds. Environmental Conservation 34: 1-11.

Sutherland, W.J., Bailey, M.J., Bainbridge, I.P., Brereton, T., Dick, J.T.A., Drewitt, J., Dulvy, N.K., Dusic, N.R., Freckleton, R.P., Gaston, K.J., Gilder, P.M., Green, R.E., Heathwaite, L., Johnson, S.M., Macdonald, D.W., Mitchell, R., Osborn, D., Owen, R.P., Pretty, J., Prior, S.V., Prosser, H., Pullin, A.S., Rose, P., Stott, A., Tew, T., Thomas, C.D., Thompson, D.B.A., Vickery, J.A., Walker, M., Walmsley, C., Warrington, S., Watkinson, A.R., Williams, R.J., Woodroffe, R. and Woodroof, H.J. 2008. Future novel threats and opportunities facing UK biodiversity identified by horizon scanning. Journal of Applied Ecology 45: 821-833. 
Sutherland, G., Foreman, M. and Garrett, C. 2007. Tidal current energy assessment for Johnstone Strait, Vancouver Island. Proceedings of the Institution of Mechanical Engineers, Part A: Journal of Power and Energy 221 (2): 147-157.

Taylor, D. 2004. Wind energy. In: G. Boyle (Ed). Renewable Energy: Power for a sustainable future. Oxford University Press, Oxford. pp. 244-293.

Teilmann, J., Henriksen, O.D. and Carstensen, J. 2001. Status report of the pilot project: "Porpoise detectors (PODs) as a tool to study potential effects of offshore windfarm on harbor porpoises at Rødsand". Technical report. Ministry of the Environment and Energy, Denmark, June 2001.

Teilmann, J., Henriksen, O.D., Cartensen, J. and Skov, H. 2002. Monitoring effects of offshore windfarms on harbor porpoises using PODs (porpoise detectors). Ministry of the Environment, Denmark. 95 pp.

Thompson, P.M., Lusseau, D., Barton, T., Simmons, D., Rusin, J. and Bailey, H. 2010. Assessing the responses of coastal cetaceans to the construction of offshore wind turbines. Marine Pollution Bulletin 60: 1200-1208.

Thomsen, F., Lüdemann, K., Kafemann, R. and Piper, W. 2006. Effects of offshore wind farm noise on marine mammals and fish. Biola, Hamburg, Germany on behalf of COWRIE Ltd.

Thorpe, T.W. 1999. Economic Analysis of Wave Power Devices. AEA Technology, Oxfordshire, UK. 6 pp. Retrieved from http://www.wave-energy.net/Library/Economic\%20Analysis\%20of\%20Wave\%20Power.pdf

Thrush, S.F., Hewitt, J.E., Cummings, V.J., Dayton, P.K., Cryer, M., Turner, S.J., Funnell, G.A., Budd, R.G., Milburn, C.J. and Wilkinson, M.R. 1998. Disturbance of the marine benthic habitat by commercial fishing: Impacts at the scale of the fishery. Ecological Applications 8: 866-879. doi:10.1890/10510761(1998)008[0866:DOTMBH]2.0.CO;2.

Thurstan, R.H. and Roberts, C.M. 2010. Ecological Meltdown in the Firth of Clyde, Scotland: Two Centuries of Change in a Coastal Marine Ecosystem. PLoS ONE 5(7): e11767. doi:10.1371/journal.pone.0011767

Tougaard, J., Carstensen, J., Henriksen, O.D., Skov, H. and Teilmann, J. 2003: Short-term effects of the construction of wind turbines on harbor porpoises at Horns Reef. Technical report to Techwise A/S. Hedeselskabet Roskilde, Denmark. 72 pp.

Tougaard, J., Carstensen, J., Henriksen, O.D., Teilmann, J. and Hansen J.R. 2004: Harbor porpoises on Horns Reef - effects of the Horns Reef wind farm. National Environmental Research Institute, Roskilde, Denmark. 69 pp.

Tougaard, J., Carstensen, J., Teilmann, J., Skov, H. and Rasmussen, P. 2009a. Pile driving zone of responsiveness extends beyond $20 \mathrm{~km}$ for harbor porpoises (Phocoena phocoena (L.)). Journal of the Acoustical Society of America 126 (1): 11-14.

Tougaard, J., Henriksen, O.D. and Miller, L.A. 2009b. Underwater noise from three types of offshore wind turbines: Estimation of impact zones for harbor porpoises and harbor seals. Journal of the Acoustical Society of America 125 (6): 3766-3773.

Tyack, P., Gordon, J. and Thompson, D. 2003. Controlled exposure experiments to determine the effects of noise on marine mammals. Marine Technology Society Journal 37 (4): 41-53.

Volgenau L., Kraus S.D. and Lien J. 1995. The impact of entanglements on two substocks of the western North Atlantic humpback whale, Megaptera novaeangliae. Canadian Journal of Zoology 73: 1689-1698.

Wahlberg, M. and Westerberg, H. 2005. Hearing in fish and their reactions to sound from offshore wind farms. Marine Ecology Progress Series 288: 295-309.

Watts, P. and Gaskin, D.E. 1985. Habitat index analysis of the harbor porpoise Phocoena phocoena in the southern coastal Bay of Fundy, Canada. Journal of Mammalogy 66: 733-744. 
Weilgart, L.S. 2007. The impacts of anthropogenic ocean noise on cetaceans and implications for management. Canadian Journal of Zoology 85: 1091-1116.

Wilhelmsson, D., Malm, T. and Öhman, M.C. 2006. The influence of offshore windpower on demersal fish. ICES Journal of Marine Science 63: 775-784.

Williams, R., Bain, E., Trites, A. and Ford, J. 2002. Behavioral responses of killer whales to a 'leapfrogging' vessel. Journal of Cetacean Research and Management 4: 305-310.

Wilson, B. Batty, R. S., Daunt, F. and Carter, C. 2007. Collision risks between marine renewable energy devices and mammals, fish and diving birds. Report to the Scottish Executive. Scottish Association for Marine Science, Oban, Scotland, PA37 1QA. 110 pp.

Wilson, J.C., Elliot, M., Cutts, N.D., Mander, L., Mendão, V., Perez-Dominguea, R. and Phelps, A. 2010. Coastal and Offshore Wind Energy Generation: Is It Environmentally Benign? Energies 3: 1383-1422.

Wiltschko, W. and Wiltschko, R. 2005. Magnetic orientation and magnetoreception in birds and other animals. Journal of Comparative Physiology A - Neuroethology and Sensory Neural and Behavioral Physiology 191: 675-693. doi:10.1007/s00359-005-0627-7.

Wolanski, E. and Hamner, W.M. 1988. Topographically controlled fronts in the ocean and their biological significance. Science 241: 177-181.

Yen, P.P.W., Sydeman, W.J. and Hyrenbach, K.D. 2004. Marine bird and cetacean associations with bathymetric habitats and shallow-water topographies: implications for trophic transfer and conservation. Journal of Marine Systems 50: 79-99. 
APPENDIX I:

Supplementary Tables

\section{Table A1:}

Seals Observed Stranded in Nantucket Sound and along Outer Cape Cod by Species and Year. Data courtesy of the National Marine Fisheries Services (NMFS)

\begin{tabular}{lcccccc}
\hline & $\mathbf{2 0 0 5}$ & $\mathbf{2 0 0 6}$ & $\mathbf{2 0 0 7}$ & $\mathbf{2 0 0 8}$ & $\mathbf{2 0 0 9}$ & Species total \\
\hline Harbor & 35 & 27 & 15 & 35 & 17 & 129 \\
Harp & 38 & 14 & 30 & 24 & 30 & 136 \\
Gray & 31 & 27 & 50 & 50 & 45 & 203 \\
Hooded & 3 & 8 & 2 & 2 & 0 & 15 \\
Yearly Total & 107 & 76 & 97 & 111 & 92 & 483 \\
\hline
\end{tabular}


Table A2:

Historic and Recent Observations of Harbor Seals in Southern New England

\begin{tabular}{|c|c|c|}
\hline Decade & Observation & Source \\
\hline $1860-1869$ & $\begin{array}{l}\text { Allen describes harbor seals occurring in } \\
\text { Wellfleet and Provincetown (rare). He also } \\
\text { describes hundreds of seals on the Boston } \\
\text { Harbor Islands in the summer. }\end{array}$ & Allen (1869) \\
\hline $1870-1879$ & $\begin{array}{l}\text { A harbor seal was collected on Penikese } \\
\text { Island (Elizabeth Islands) in } 1873\end{array}$ & $\mathrm{MCZ}$ \\
\hline 1890-1899 & $\begin{array}{l}\text { A harbor seal was collected in Chatham in } \\
1893\end{array}$ & $\mathrm{MCZ}$ \\
\hline 1900-1929 & No observations & \\
\hline 1930-1939 & $\begin{array}{l}\text { Harbor seals were permanent residents on } \\
\text { Cape Cod and pupping occurred through out } \\
\text { Massachusetts. }\end{array}$ & $\begin{array}{l}\text { Prescott (1981) as reported in } \\
\text { Payne \& Schneider (1984) }\end{array}$ \\
\hline 1940-1949 & $\begin{array}{l}\text { Harbor seals were permanent residents on } \\
\text { Cape Cod and pupping occurred through out } \\
\text { Massachusetts. }\end{array}$ & $\begin{array}{l}\text { Prescott (1981) as reported in } \\
\text { Payne \& Schneider (1984) }\end{array}$ \\
\hline $1950-1959$ & No observations & \\
\hline 1960-1969 & $\begin{array}{l}\text { A harbor seal was collected on Muskeget Is- } \\
\text { land in the late spring or early summer } 1960 . \\
\text { Another harbor seal was collected in Cape } \\
\text { Cod Bay in May } 1962 .\end{array}$ & $\mathrm{MCZ}$ \\
\hline 1970-1979 & $\begin{array}{l}\text { There are } 15 \text { harbor seal records in the } \\
\text { Smithsonian Institute's collections and } 8 \text { in } \\
\text { the American Museum of Natural History's } \\
\text { collections. All seals were collected on } \\
\text { Cape Cod or Islands. }\end{array}$ & SI, AMNH \\
\hline 1980-1989 & $\begin{array}{l}\text { There are } 28 \text { harbor seal records in the } \\
\text { American Museum of Natural History } \\
\text { collected on Cape Cod or the Islands. The } \\
\text { MCZ holdings contain } 3 \text { harbor seals. }\end{array}$ & $\mathrm{AMNH}, \mathrm{MCZ}$ \\
\hline
\end{tabular}


Table A3:

Historic and Recent Observations of the Gray Seal in Southern New England

\begin{tabular}{|c|c|c|}
\hline Decade & Observation & Source \\
\hline $1920-29$ & Two adult males were killed on Muskeget Island (MA). & $\begin{array}{l}\text { Andrews \& Mott } \\
\text { (1967) }\end{array}$ \\
\hline 1930-39 & No observations available & \\
\hline $1940-49$ & $\begin{array}{l}4 \text { mummified pups observed on Muskeget (MA) in } 1948 . \\
\text { Interviews with local Nantucket (MA) residents indicate that bounties } \\
\text { were paid on approximately } 40 \text { gray seals (mostly mothers and pups) in } \\
\text { the late 1940's and early 1950's. }\end{array}$ & $\begin{array}{l}\text { Rough (1981) } \\
\text { Andrews \& Mott } \\
\text { (1967) }\end{array}$ \\
\hline $1950-59$ & $\begin{array}{l}\text { Mr. Clint Andrews brings the skull of a large skeleton and that of a pup } \\
\text { to the MCZ for identification in } 1958 \text { (pup was collected on Muskeget Is- } \\
\text { land, MA prior to 1958). According to the MCZ's records, the seals were } \\
\text { collected in 1948, MCZ51282 \& MCZ51283. } \\
\text { Massachusetts paid bounties on approximately } 25 \text { gray seals from 1958- } \\
1962 \text { (likely but the latter date is unclear). }\end{array}$ & $\begin{array}{l}\text { Andrews \& Mott } \\
\text { (1967) \& MCZ } \\
\text { Andrews \& Mott } \\
\text { (1967) }\end{array}$ \\
\hline $1960-69$ & $\begin{array}{l}\text { Massachusetts bounty is repealed in } 1962 . \\
\text { Three pups were born at Muskeget (MA) in } 1963 . \\
\text { An adult female was shot for bounty (despite its repeal) at the Elizabeth } \\
\text { Islands (MA) in 1964. This is probably MCZ51488, collected in Lack- } \\
\text { ey's Bay (Elizabeth Islands) in } 1964 . \\
\text { Massachusetts legislation passed in } 1965 \text { protects the gray seal. } \\
\text { Less than } 1 \text { pup per year was observed in Nantucket Sound (MA) 1964- } \\
1970 .\end{array}$ & $\begin{array}{l}\text { Massachusetts } \\
\text { Acts \& Resolves } \\
\text { Rough (1983) } \\
\text { Andrews \& Mott } \\
(1967) \\
\text { MCZ } \\
\text { Massachusetts } \\
\text { Acts \& Resolves } \\
\text { Rough (1983) }\end{array}$ \\
\hline $1970-79$ & $\begin{array}{l}\text { A white coat pup was observed on Nantucket (MA) in March } 1973 . \\
\text { Aerial surveys flown during January-April, 1977, found no pups in Nan- } \\
\text { tucket Sound. } \\
\text { A white coat pup was observed on } 10 \text { February } 1978 \text { in Provincetown, } \\
\text { MA. }\end{array}$ & $\begin{array}{l}\text { Gilbert et al. } \\
\text { (1977) }\end{array}$ \\
\hline 1980-89 & $\begin{array}{l}\text { MCZ58032, a gray seal that stranded on a beach in Orleans, MA in } 1980 \\
\text { and later died at the New England Aquarium, Boston, MA. } \\
\text { A juvenile gray seal stranded and died on Block Island in } 1980 . \\
\text { MCZ60654, a juvenile gray seal that stranded and died on Martha's Vine- } \\
\text { yard in 1987. }\end{array}$ & $\begin{array}{l}\text { MCZ } \\
\text { Kenney (2005) } \\
\text { MCZ }\end{array}$ \\
\hline
\end{tabular}


Table A4:

Summary of Whalenet Satellite Tags Deployed on Harbor and Gray Seals in Nantucket Sound and Cape Cod Waters

\begin{tabular}{|c|c|c|c|}
\hline Seal ID & Species & Release Date & Important Locations \\
\hline 91088 & Gray & 3 May 2009 & Muskeget Channel \\
\hline 39387 & Gray & 23 June 2009 & $\begin{array}{l}\text { Chatham Harbor } \\
\text { N. Monomoy I. }\end{array}$ \\
\hline 39392 & Gray & 15 April 2008 & South of Nantucket I. \\
\hline 39391 & Gray & 20 June 2007 & Monomoy I. \\
\hline 39389 & Gray & 5 August 2007 & $\begin{array}{l}\text { Monomoy I. } \\
\text { Outer Cape Cod }\end{array}$ \\
\hline 47823 & Harbor & 26 April 2005 & Muskeget Channel \\
\hline 47822 & Harbor & 29 December 2004 & $\begin{array}{l}\text { Monomoy I. } \\
\text { Outer Cape Cod }\end{array}$ \\
\hline 44861 & Harbor & 15 March 2005 & $\begin{array}{l}\text { Monomoy I. } \\
\text { Nantucket I. } \\
\text { Muskeget Channel? }\end{array}$ \\
\hline Solange & Gray & 7 February 2004 & $\begin{array}{l}\text { Nantucket I. } \\
\text { Monomoy I. }\end{array}$ \\
\hline Hopper & Harbor & 17 June 2004 & $\begin{array}{l}\text { Buzzard's Bay } \\
\text { Cape Cod Canal }\end{array}$ \\
\hline Jersey Girl & Harbor & 10 January 2003 & $\begin{array}{l}\text { Buzzard's Bay } \\
\text { Cape Cod Canal }\end{array}$ \\
\hline Bristol & Harbor & 22 October 1998 & Monomoy I. \\
\hline McHenry & Gray & 23 November 1998 & $\begin{array}{l}\text { Monomoy I. } \\
\text { Muskeget I. } \\
\text { Tuckernuck I. } \\
\text { Elizabeth Islands }\end{array}$ \\
\hline
\end{tabular}


Table of Online Sites Relating to Marine Renewable Energy Developments and Monitoring Methods

\begin{tabular}{|c|c|c|c|c|c|c|c|c|}
\hline website & ב & $\sum_{i}^{2}$ & : & 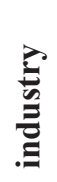 & 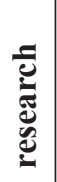 & $\frac{\stackrel{y}{n}}{2}$ & other & notes \\
\hline http://www.seageneration.co.uk/ & & & $x$ & $\mathrm{x}$ & $\mathrm{x}$ & $\mathrm{X}$ & & $\begin{array}{l}\text { SeaGen tidal tubine in Strangford } \\
\text { Lough, Northern Ireland }\end{array}$ \\
\hline http://www.wavec.org/ & & & & $\mathrm{x}$ & $\mathrm{x}$ & & & $\begin{array}{l}\text { Wave Energy Centre - development } \\
\text { and promotion of ocean wave energy } \\
\text { - Portugal }\end{array}$ \\
\hline $\begin{array}{l}\text { http://www.sams.ac.uk/research/ } \\
\text { departments/research/research- } \\
\text { themes/theme-3-marine-renew- } \\
\text { able-energy }\end{array}$ & $\mathrm{x}$ & $\mathrm{X}$ & $\mathrm{x}$ & & $\mathrm{x}$ & & & $\begin{array}{l}\text { Scottish Association of Marine Sci- } \\
\text { ence (SAMS) }\end{array}$ \\
\hline http://www.mrec.umassd.edu/ & $\mathrm{x}$ & $\mathrm{X}$ & $\mathrm{x}$ & & $\mathrm{x}$ & & & $\begin{array}{l}\text { New England Marine Renewable En- } \\
\text { ergy Center - USA }\end{array}$ \\
\hline http://www.emec.org.uk/ & & $\mathrm{X}$ & $\mathrm{x}$ & & $\mathrm{x}$ & & & $\begin{array}{l}\text { European Marine Energy Centre. Test } \\
\text { site in Orkney, Scotland }\end{array}$ \\
\hline $\begin{array}{l}\text { http://www.seai.ie/Renewables/ } \\
\text { Ocean_Energy/AMETS/ }\end{array}$ & & $\mathrm{X}$ & $\mathrm{x}$ & & $\mathrm{x}$ & $\mathrm{x}$ & & $\begin{array}{l}\text { Atlantic Marine Energy Test Site - } \\
\text { Ireland }\end{array}$ \\
\hline http://nnmrec.oregonstate.edu/ & & $\mathrm{X}$ & $x$ & & $\mathrm{x}$ & & & $\begin{array}{l}\text { Northwest National Marine Renew- } \\
\text { able Energy Center - USA }\end{array}$ \\
\hline http://www.oregonwave.org/ & & $\mathrm{X}$ & & & $\mathrm{x}$ & & $\begin{array}{l}\text { non- } \\
\text { profit }\end{array}$ & $\begin{array}{l}\text { Oregon Wave Energy Trust (OWET) } \\
\text { - supports responsible development } \\
\text { of wave energy in Oregon. Envi- } \\
\text { ronmental research at http://www. } \\
\text { oregonwave.org/our-work-overview/ } \\
\text { environmental-research/ }\end{array}$ \\
\hline $\begin{array}{l}\text { http://www.pge.com/about/envi- } \\
\text { ronment/pge/cleanenergy/wave- } \\
\text { connect/ }\end{array}$ & & $\mathrm{x}$ & & & $\mathrm{x}$ & & & $\begin{array}{l}\text { Humboldt WaveConnect project - test } \\
\text { site for multiple devices in California }\end{array}$ \\
\hline $\begin{array}{l}\text { http://www.smru.co.uk/renew- } \\
\text { able-energy.aspx }\end{array}$ & & & $\mathrm{x}$ & & $\mathrm{x}$ & & & $\begin{array}{l}\text { Sea Mammal Research Unit Ltd - EIA } \\
\text { services \& research }\end{array}$ \\
\hline http://www.nrel.gov/ & & & & & $\mathrm{x}$ & & & $\begin{array}{l}\text { Research, development, commercial- } \\
\text { ization and deployment of renewable } \\
\text { energy - USA }\end{array}$ \\
\hline
\end{tabular}




\begin{tabular}{|c|c|c|c|c|c|c|c|c|}
\hline website & 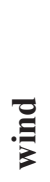 & $\sum_{i}^{2}$ & : & 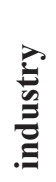 & 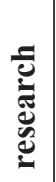 & 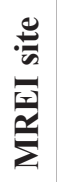 & other & notes \\
\hline http://www.bwea.com/ & $\mathrm{x}$ & $\mathrm{x}$ & $\mathrm{x}$ & $\mathrm{x}$ & & & & $\begin{array}{l}\text { Renewable UK - trade and profession- } \\
\text { al body for the UK wind and marine } \\
\text { renewables industries }\end{array}$ \\
\hline $\begin{array}{l}\text { http://www.fredolsen-renewables. } \\
\text { com/ }\end{array}$ & $\mathrm{X}$ & $\mathrm{x}$ & $\mathrm{X}$ & $\mathrm{x}$ & & & & $\begin{array}{l}\text { Fred Olsen Renewables - Norway \& } \\
\text { UK }\end{array}$ \\
\hline http://www.vattenfall.com/en & $\mathrm{x}$ & & & $\mathrm{x}$ & & & & Vattenfall - UK \& Scandinavia \\
\hline $\begin{array}{l}\text { http://www.dongenergy.co.uk/ } \\
\text { Pages/ }\end{array}$ & $\mathrm{X}$ & & & $\mathrm{X}$ & & & & $\begin{array}{l}\text { Dong Energy - offshore wind develop- } \\
\text { ments, Europe }\end{array}$ \\
\hline $\begin{array}{l}\text { http://www.aquamarinepower. } \\
\mathrm{com} /\end{array}$ & & $\mathrm{x}$ & & $\mathrm{X}$ & & & & $\begin{array}{l}\text { Aquamarine Power - "the oyster;" } \\
\text { Scotland }\end{array}$ \\
\hline http://www.aegirwave.com/ & & $\mathrm{x}$ & & $\mathrm{x}$ & & $\mathrm{x}$ & & Wave power test sites - Shetland (UK) \\
\hline http://www.pelamiswave.com/ & & $\mathrm{x}$ & & $\mathrm{X}$ & & & & $\begin{array}{l}\text { Pelamis - wave power technology } \\
\text { developer, UK }\end{array}$ \\
\hline http://www.wavebob.com/ & & $\mathrm{x}$ & & $\mathrm{x}$ & & & & Wavebob - Ireland \\
\hline http://www.seapower.ie/ & & $\mathrm{x}$ & & $\mathrm{x}$ & & & & Sea Power Ltd - Ireland \\
\hline $\begin{array}{l}\text { http://www.oceanpowertechnolo- } \\
\text { gies.com/ }\end{array}$ & & $\mathrm{X}$ & & $\mathrm{x}$ & & & & $\begin{array}{l}\text { Ocean Power Technologies - USA } \\
\text { - includes projects at Kanoehe Bay, } \\
\text { Hawaii; Coos Bay, Oregon \& the } \\
\text { Wavehub, UK }\end{array}$ \\
\hline http://www.marineturbines.com/ & & & $\mathrm{x}$ & $\mathrm{x}$ & & & & $\begin{array}{l}\text { Marine Current Turbines - includes } \\
\text { projects at the Skerries, North Wales } \\
\& \text { Bay of Fundy, Canada }\end{array}$ \\
\hline $\begin{array}{l}\text { http://www.oceanrenewablepow- } \\
\text { er.com/ocgenproject_alaska.htm }\end{array}$ & & & $\mathrm{x}$ & $\mathrm{x}$ & & $\mathrm{x}$ & & $\begin{array}{l}\text { Ocean Renewable Power Company - } \\
\text { Alaska projects including Cook Inlet } \\
\text { tidal energy project }\end{array}$ \\
\hline $\begin{array}{l}\text { http://www.atlantisresourcescor- } \\
\text { poration.com/ }\end{array}$ & & & $\mathrm{X}$ & $\mathrm{X}$ & & & & $\begin{array}{l}\text { Atlantis Resources Corporation - } \\
\text { technology (turbine) development, } \\
\text { resource assessment, project manage- } \\
\text { ment. London \& Singapore }\end{array}$ \\
\hline $\begin{array}{l}\text { http://www.renewableenergy- } \\
\text { world.com/rea/home }\end{array}$ & $\mathrm{x}$ & $\mathrm{x}$ & $\mathrm{X}$ & & & & & $\begin{array}{l}\text { Renewable Energy World - online } \\
\text { news re renewable energy }\end{array}$ \\
\hline $\begin{array}{l}\text { http://www.offshorewindfarms. } \\
\text { co.uk/Pages/COWRIE/ }\end{array}$ & $\mathrm{x}$ & & & & & & & $\begin{array}{l}\text { COWRIE (Collaborative Offshore } \\
\text { Wind Research Into The Environment) }\end{array}$ \\
\hline $\begin{array}{l}\text { http://www.hornsrev.dk/Engelsk/ } \\
\text { default_ie.htm }\end{array}$ & $\mathrm{X}$ & & & & & $\mathrm{x}$ & & $\begin{array}{l}\text { Horns Rev offshore wind farm (EIA } \\
\text { reports at http://www.hornsrev.dk/ } \\
\text { Engelsk/default_ie.htm ) }\end{array}$ \\
\hline
\end{tabular}




\begin{tabular}{|c|c|c|c|c|c|c|c|c|}
\hline website & 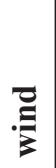 & 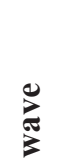 & 莡 & 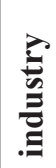 & 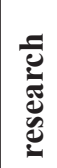 & 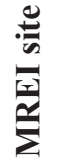 & other & notes \\
\hline $\begin{array}{l}\text { http://www.dongenergy.com/ } \\
\text { Nysted/EN/Pages/ }\end{array}$ & $\mathrm{x}$ & & & & & $\mathrm{x}$ & & Nysted offshore wind farm - Denmark \\
\hline $\begin{array}{l}\text { http://www.renewableenergyfo- } \\
\text { cus.com/ }\end{array}$ & & $\mathrm{X}$ & $x$ & & & & $\begin{array}{l}\text { magazine } \\
\& \text { online } \\
\text { resource }\end{array}$ & $\begin{array}{l}\text { Renewable Energy Focus - forum cov- } \\
\text { ering renewable energy industry topics }\end{array}$ \\
\hline http://www.wavehub.co.uk/ & & $\mathrm{x}$ & & & & $\mathrm{x}$ & & $\begin{array}{l}\text { Wave Hub - test site for multiple de- } \\
\text { vices in Cornwall, UK }\end{array}$ \\
\hline $\begin{array}{l}\text { http://www.racerocks.com/rac- } \\
\text { erock/energy/tidalenergy/tidalen- } \\
\text { ergy2.htm }\end{array}$ & & & $x$ & & & & & $\begin{array}{l}\text { Race Rocks tidal energy project - } \\
\text { Canada }\end{array}$ \\
\hline $\begin{array}{l}\text { http://www.environmentalex- } \\
\text { change.info/Links/ }\end{array}$ & & & & & & & $\begin{array}{l}\text { list of } \\
\text { links }\end{array}$ & $\begin{array}{l}\text { Environmental Impacts of Offshore } \\
\text { Renewable Energy Developments } \\
\text { for the Exchange of Information (on } \\
\text { behalf of OSPAR) }\end{array}$ \\
\hline http://www.peventuresllc.com/ & & & & & & & & $\begin{array}{l}\text { Consulting and business develop- } \\
\text { ment firm - services include project } \\
\text { development, regulatory coordination, } \\
\text { stakeholder engagement \& project } \\
\text { financing }\end{array}$ \\
\hline http://www.oreg.ca/ & & & & & & & $\begin{array}{l}\text { activities } \\
\text { unclear }\end{array}$ & $\begin{array}{l}\text { Ocean Renewable Energy Group - } \\
\text { Canada }\end{array}$ \\
\hline http://www.iea-eces.org/ & & & & & $\mathrm{x}$ & & & $\begin{array}{l}\text { International Energy Agency - devel- } \\
\text { opment of alternative energy sources, } \\
\text { energy research and development }\end{array}$ \\
\hline
\end{tabular}




\section{Marine Megavertebrates and Fishery Resources in the Nantucket Sound - Muskeget Channel Area}

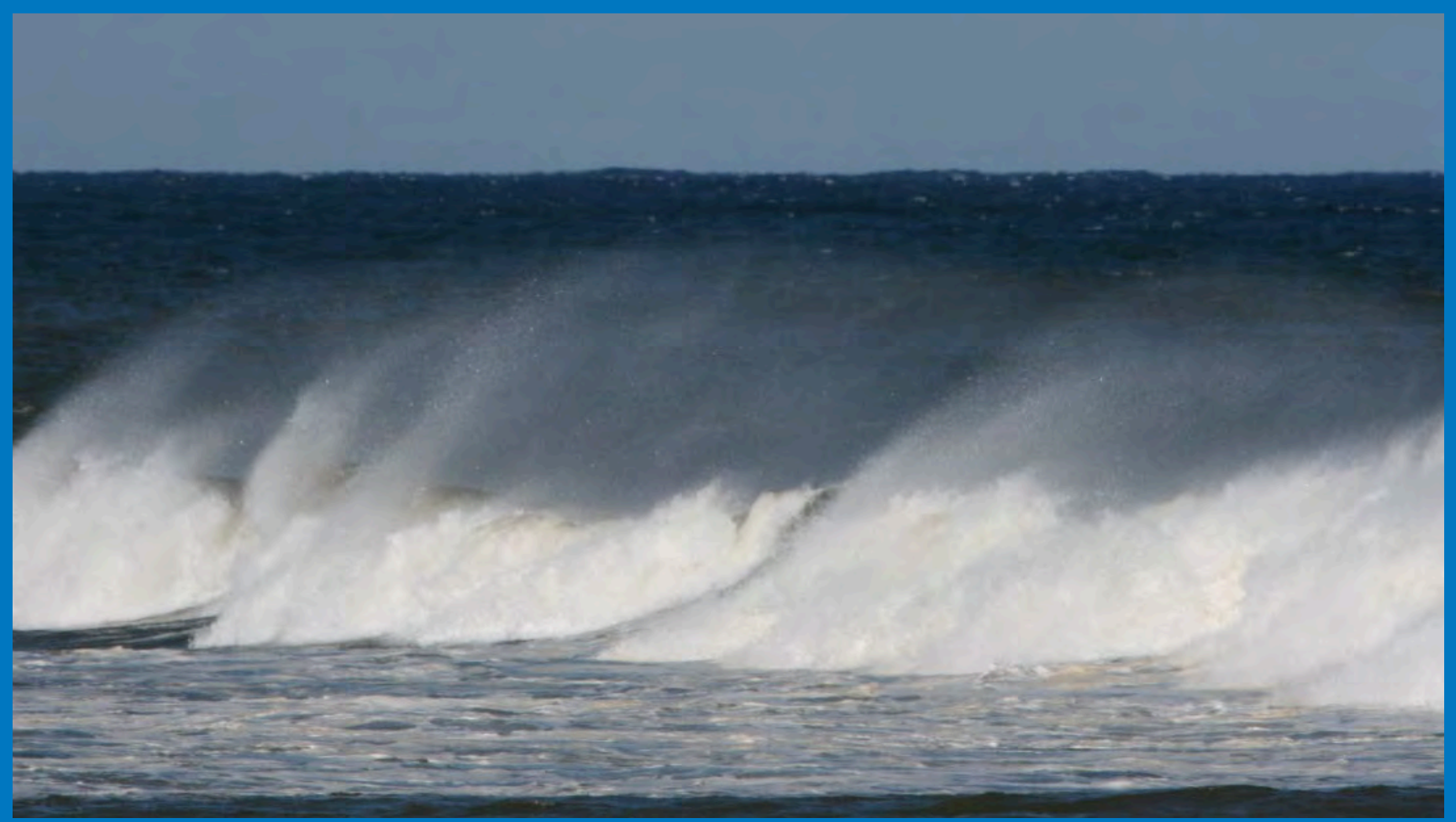

Provincetown Center for Coastal Studies. Wh w. Coastalstudies.org 


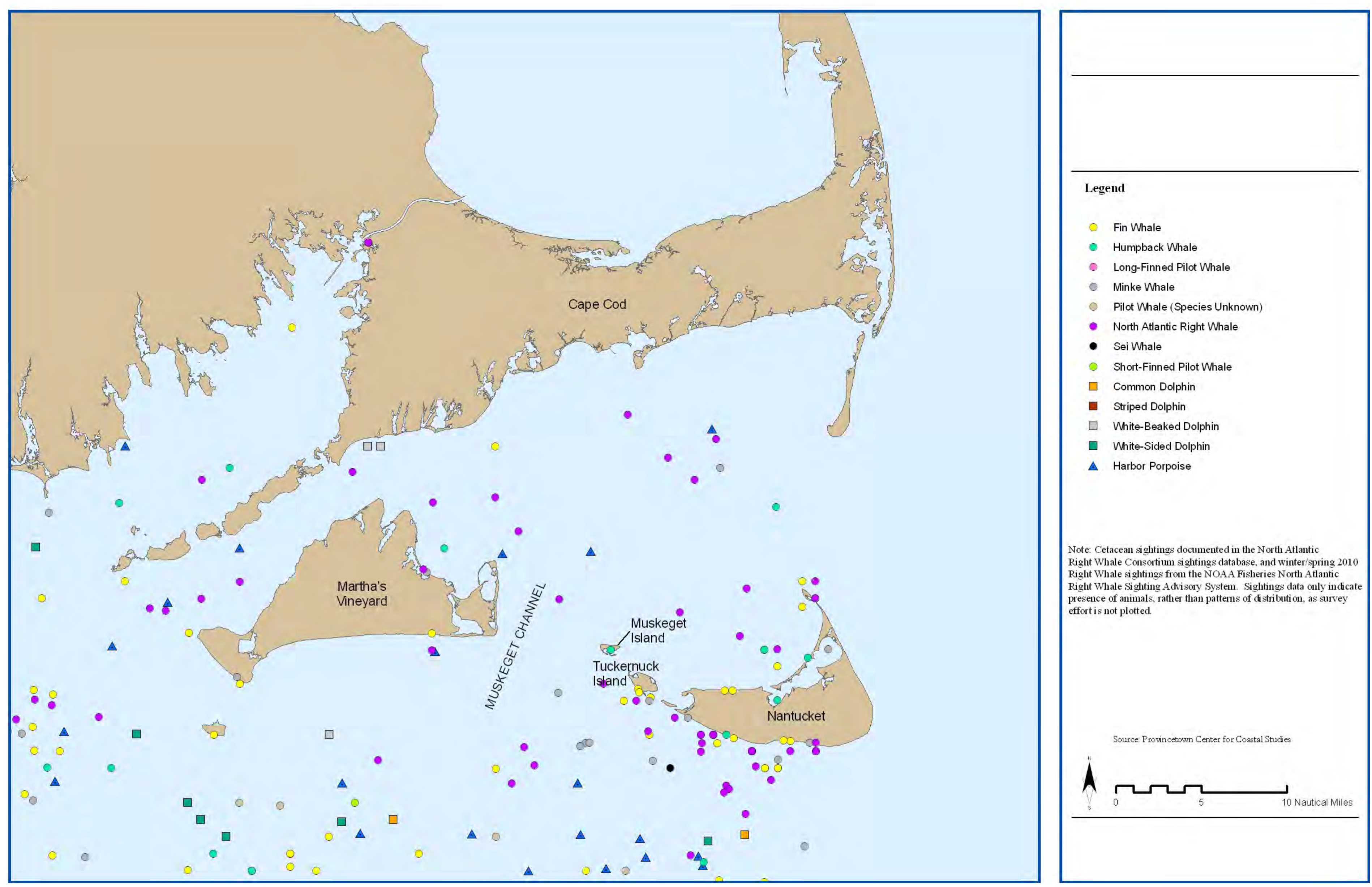

Fig u re 2.2: Seal pupping colonies and haul-out sites in the Nantucket Sound - Muskeget Channel area.
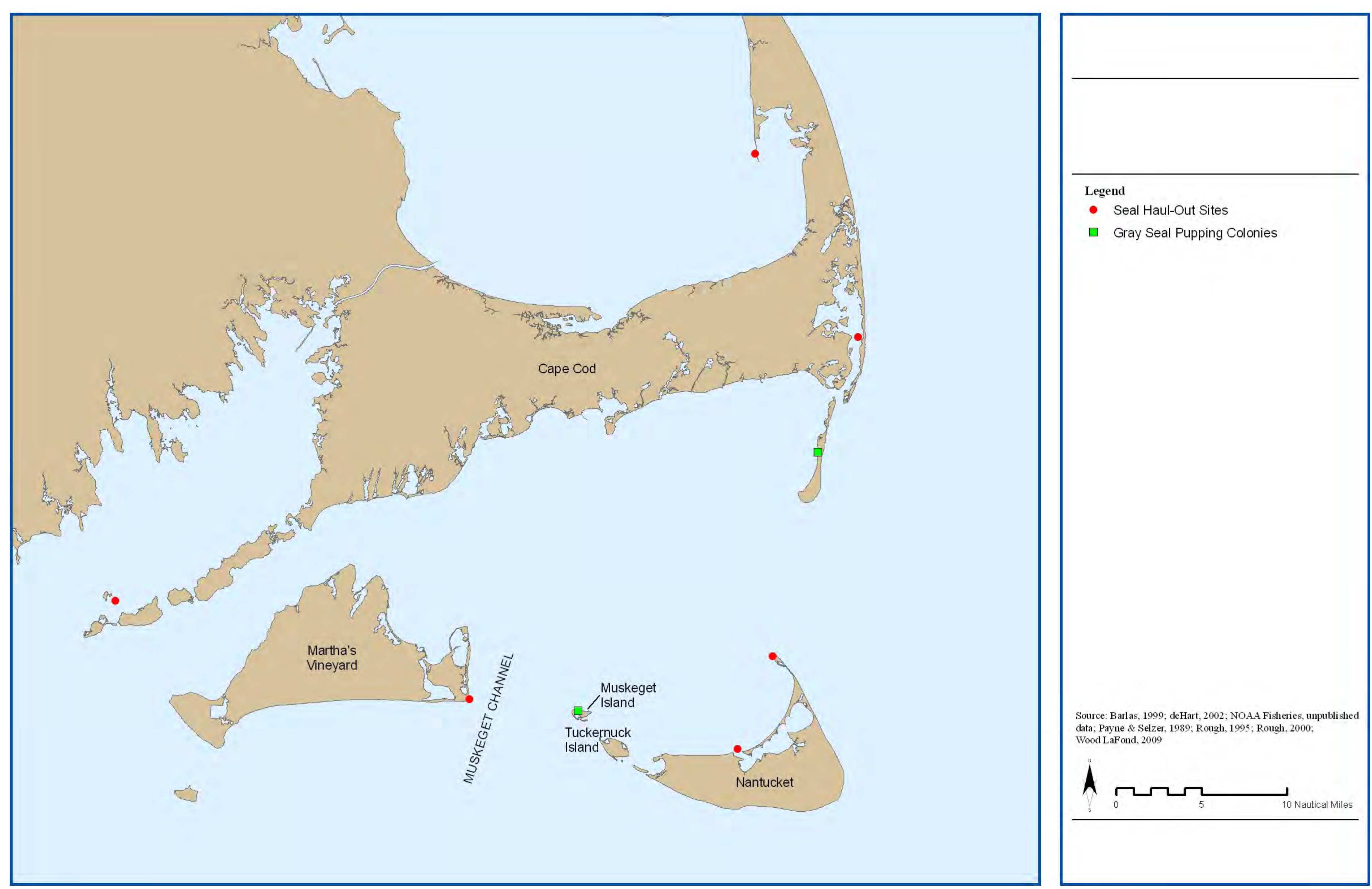



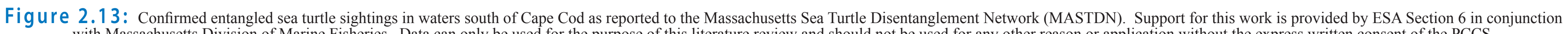
with Massachusetts Division of Marine Fisheries. Data can only be used for the purpose of this literature review and should not be used for any other reason or application without the express written consent of the PCCS.

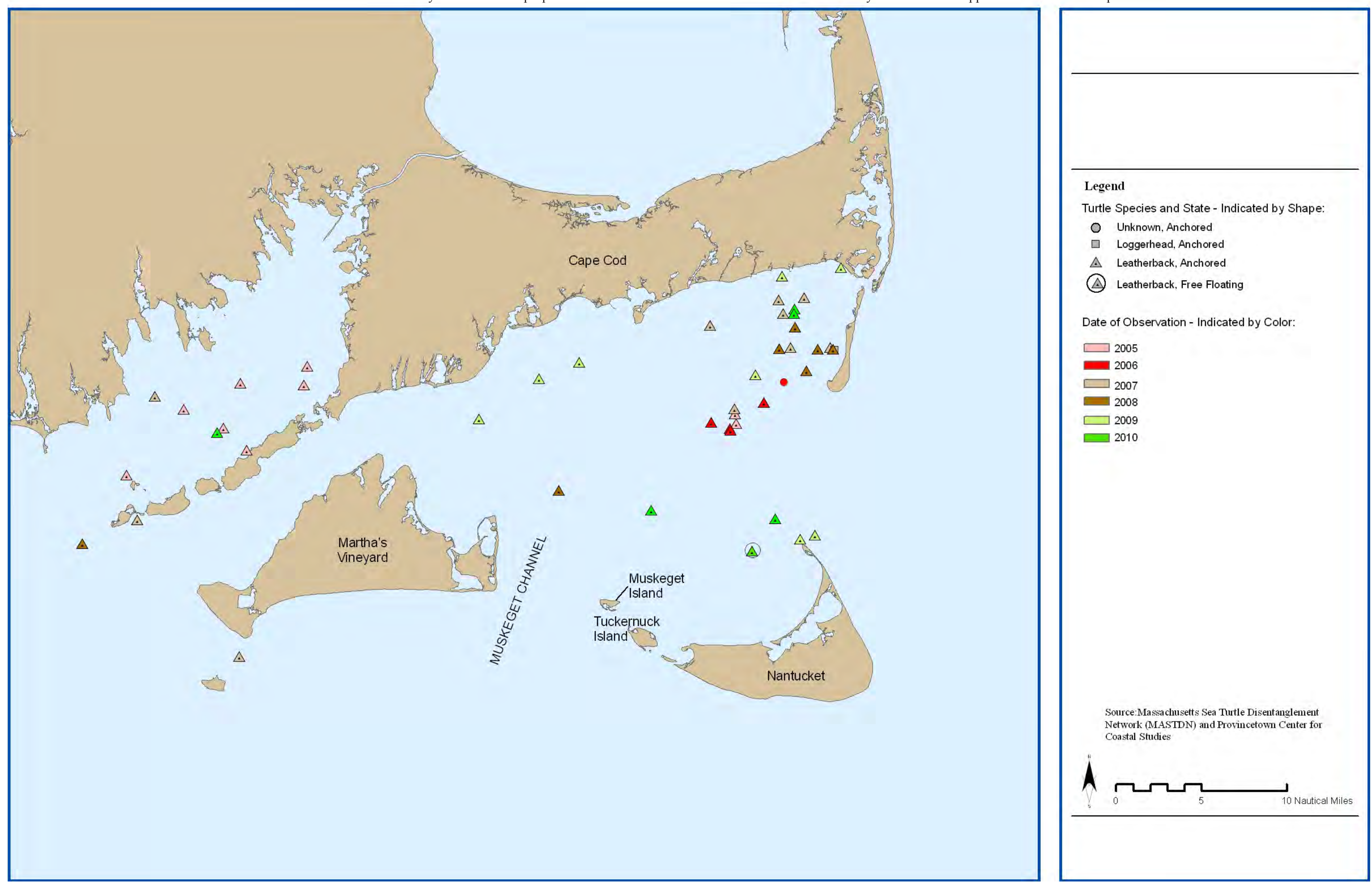



Fig u re 2.14: Opportunistic sea turtle sightings recorded by Massachusetts Audubon during aerial surveys of tern activity in Nantucket Sound as part or an assessment for the Cape Wind energy project. Surveys were completed in August and September from 2002-2004.
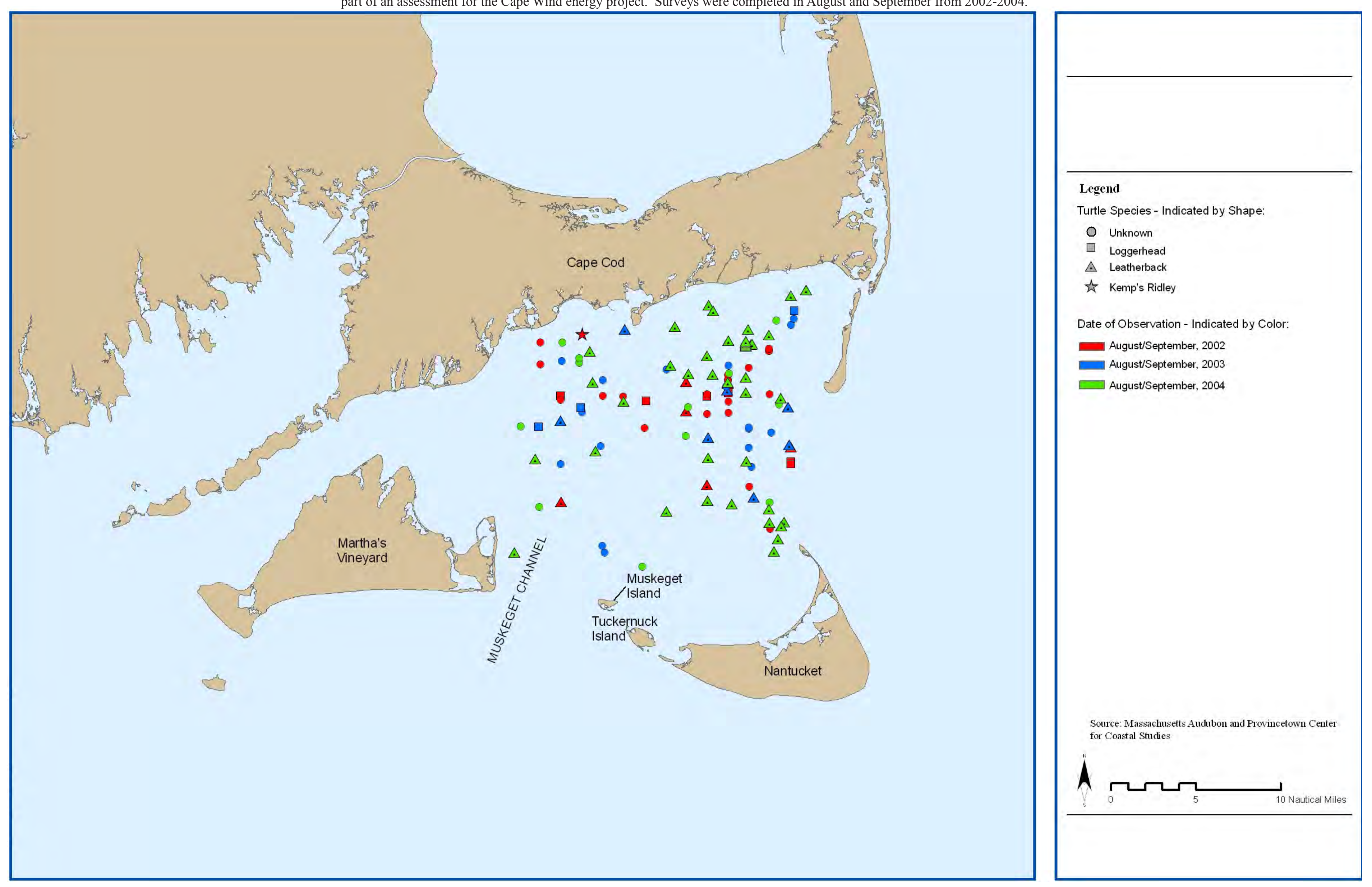

Fig u re 2.15: Sea turtle sightings documented in the North Atlantic Right Whale Consortium sightings database for Nantucket Sound. Sightings
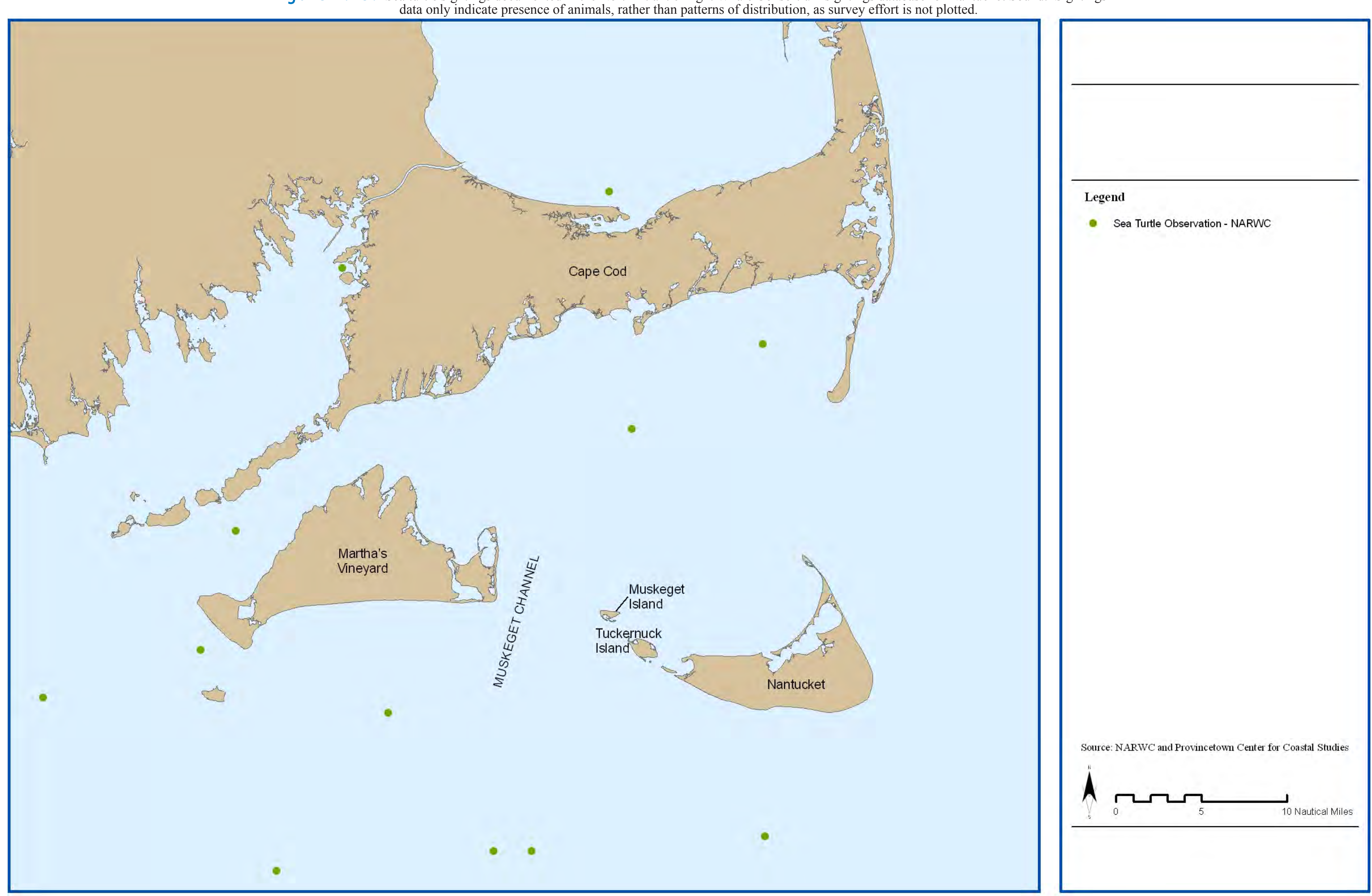

Figu re 2.16: Basking sharks and ocean sunfish sightings data for Southern Massachusetts.

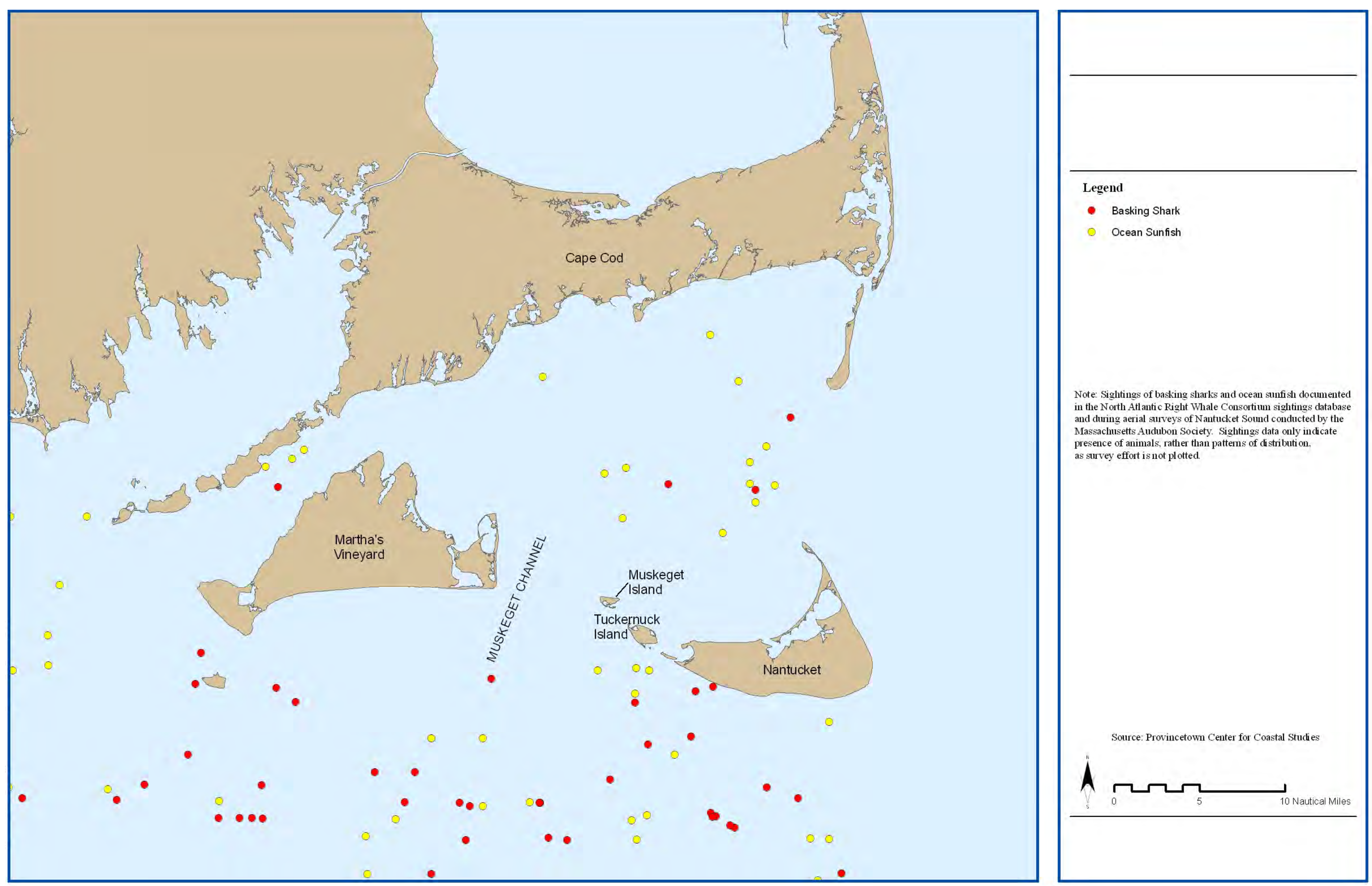





\section{Marine Megavertebrates and Fishery Resources in the Nantucket Sound - Muskeget Channel Area}

\section{Assessing Impacts of Marine}

Renewable Energy Installations on Marine Megavertebrates Recommendations for the Proposed Muskeget Channel Tidal Energy Project
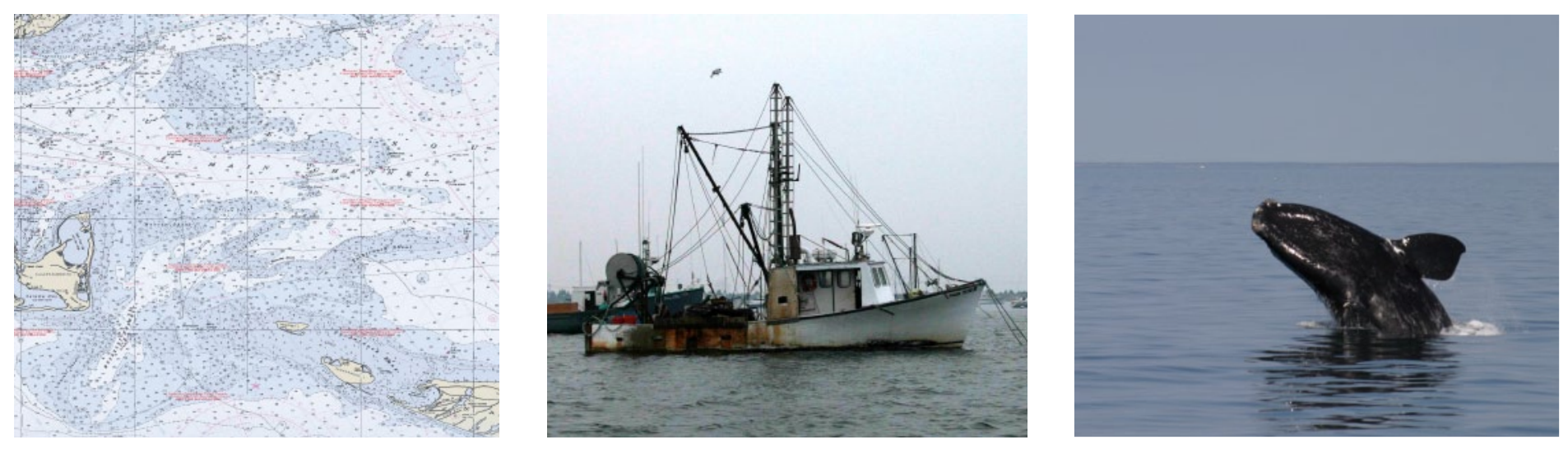

Provincetown Center For Coastal Studies

Ruth Leeney, PhD; Owen Nichols; Lisa Sette and Stephanie Wood LaFond, PhD Patricia Hughes, Project Manager 


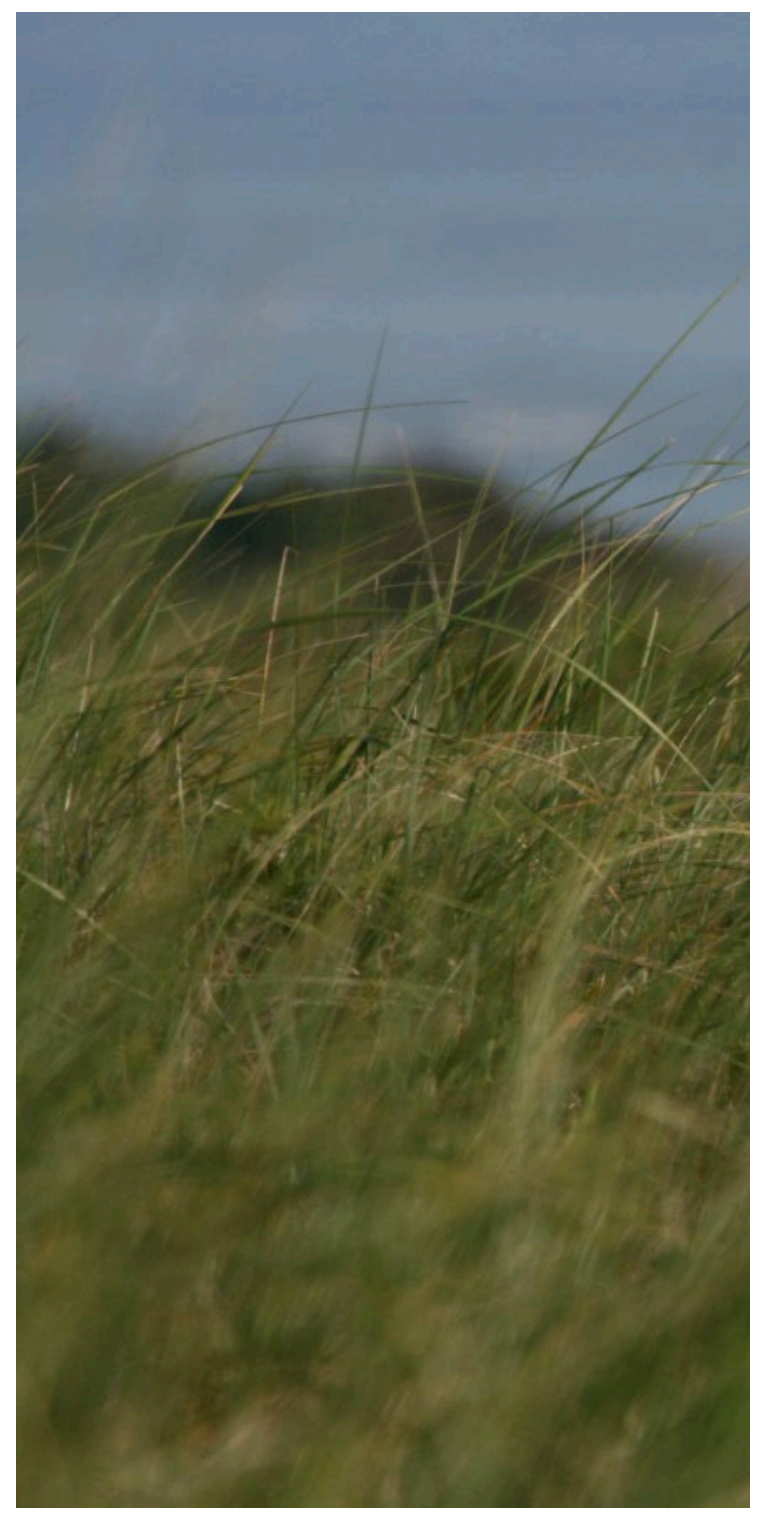

A Report to

Harris Miller Miller \& Hanson Inc for HMMH Project \# 303910

Environmental Impacts of

Sediment Transport Alteration and Impacts on Protected Species: Edgartown Tidal Energy Project

Funding provided by the U.S. Department of Energy under Grant \# DE-EE0002656

September 2010

Cover Images: Chatham fishing boats, O. Nichols; Right whale, Provincetown Center for Coastal Studies image taken under NOAA permit 633-1763, with authority of the U.S. Endangered Species Act

Figures $2.1,2.2,2.13,2.14,2.15,2.16$ created by Battelle

This report should be cited as:

Leeney, R.H., Nichols, O.C., Sette, L., Wood LaFond, S. and Hughes P.E.2010. Marine Megavertebrates and Fishery Resources in the Nantucket Sound - Assessing Impacts of Marine Renewable Energy Installations on Marine Megavertebrates - Recommendations for the Proposed Muskeget Channel Tidal Energy Project. Report to Harris Miller Miller $\&$ Hanson Inc., September 2010. Provincetown Center for Coastal Studies, Provincetown, MA, USA. 24 pp.

Available at: www.coastalstudies.org

\section{ProvincetownCenter for Coastal Studies}




\section{Table of Contents}

1 Executive Summary

Chapter 11 Background

Chapter 23 Methods for Assessing Environmental Impacts of Marine Renewable Energy Installations on Marine Megavertebrates

4 Outline of Survey Methods

8 Environmental Risk Thresholds

Chapter 310 Methodology Plan for Proposed Muskeget Channel Tidal Energy Project

Chapter $4 \quad 18$ References

List of Tables

Table 1: Operational Objectives for the Muskeget Tidal Turbine Environmental Monitoring and Mitigation Program

Table 2: $\quad$ Summary of Advised Monitoring Program Elements 


\section{Executive Summary}

This report draws on the body of environmental assessment work done on marine renewable energy installations (MREI) in other regions, particularly in Europe, and summarized in a companion report - Ecology and Effects of Marine Renewable Energy Installations. A combination of several techniques is required in order to appropriately monitor marine megavertebrate species around tidal turbine sites; these techniques are reviewed, and some of the particular challenges of monitoring at tidal turbine sites are identified.

A methodology plan specific to the proposed tidal energy project for Muskeget Channel by the Town of Edgartown is outlined in this report. This methodology plan is based on accepted survey and mitigation techniques, previous research and practical experience at other MREI sites and established, good scientific practice.

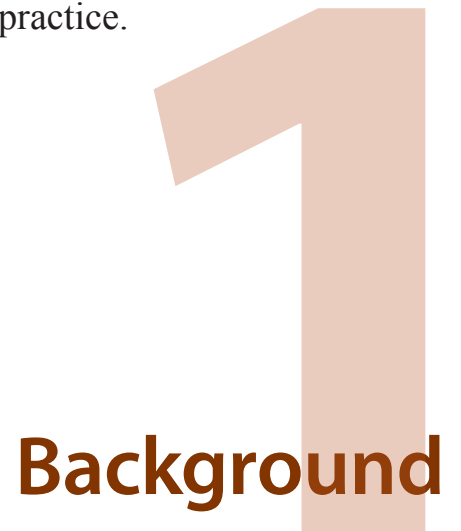

Muskeget Channel is located between the islands of Martha's Vineyard and Nantucket. Water depths in the channel range between 40 and 160 feet, with Wasque Shoals to the west and Mutton Shoal to the east. Muskeget Channel allows for the exchange of water between Nantucket Sound to the north and the Atlantic Ocean and continental shelf to the south.

The Town of Edgartown is proposing to develop an initial 5MW tidal energy pilot project in Muskeget Channel. Edgartown holds a Preliminary Permit from the Federal Energy Regulatory Commission (FERC), giving it the exclusive right to explore the development of the resource for energy. Edgartown is required to submit a Draft Pilot License Application that will allow the town to deploy, operate and monitor this pilot-scale turbine installation. This application must include information on initial consultation with cooperating federal resource agencies; draft study plans, including one on protected species, and an outline of work that will be completed during deployment of the pilot project.

The Town of Edgartown engaged Harris Miller Miller \& Hanson (HMMH) as its Principal Investigator (PI) and program manager. HMMH was successful in obtaining U.S. Department of Energy funding for the study: Environmental Effects of Sediment Transport Alteration and Impacts on Protected Species: Edgartown Tidal Energy Project. 
The Provincetown Center for Coastal Studies (PCCS) is one of four organizations working on this study under the direction of HMMH. The PCCS tasks were to:

1. Conduct a literature review of

- current information on the documented occurrence and habitats of marine megavertebrates - cetaceans, pinnipeds, turtles, basking sharks and sunfish - in the Muskeget Channel region;

- documented distribution of fishery resources and habitats and commercial and recreational fishing activity;

- studies and assessments on the environmental impacts of marine energy conversion projects on marine megavertebrates.

2. Prepare protocols for environmental studies and monitoring of marine megavertebrates specific to Muskeget Channel sufficient to collect data needed to define baseline conditions and evaluate impacts from the operation and maintenance of the tidal energy project.

3. Prepare a synthesis report on the permitting and planning framework for marine energy conversion projects, focusing on the Muskeget Channel region.

This report includes work PCCS completed under Task 2. Work completed under Task 1 and Task 3 is presented in separate reports.

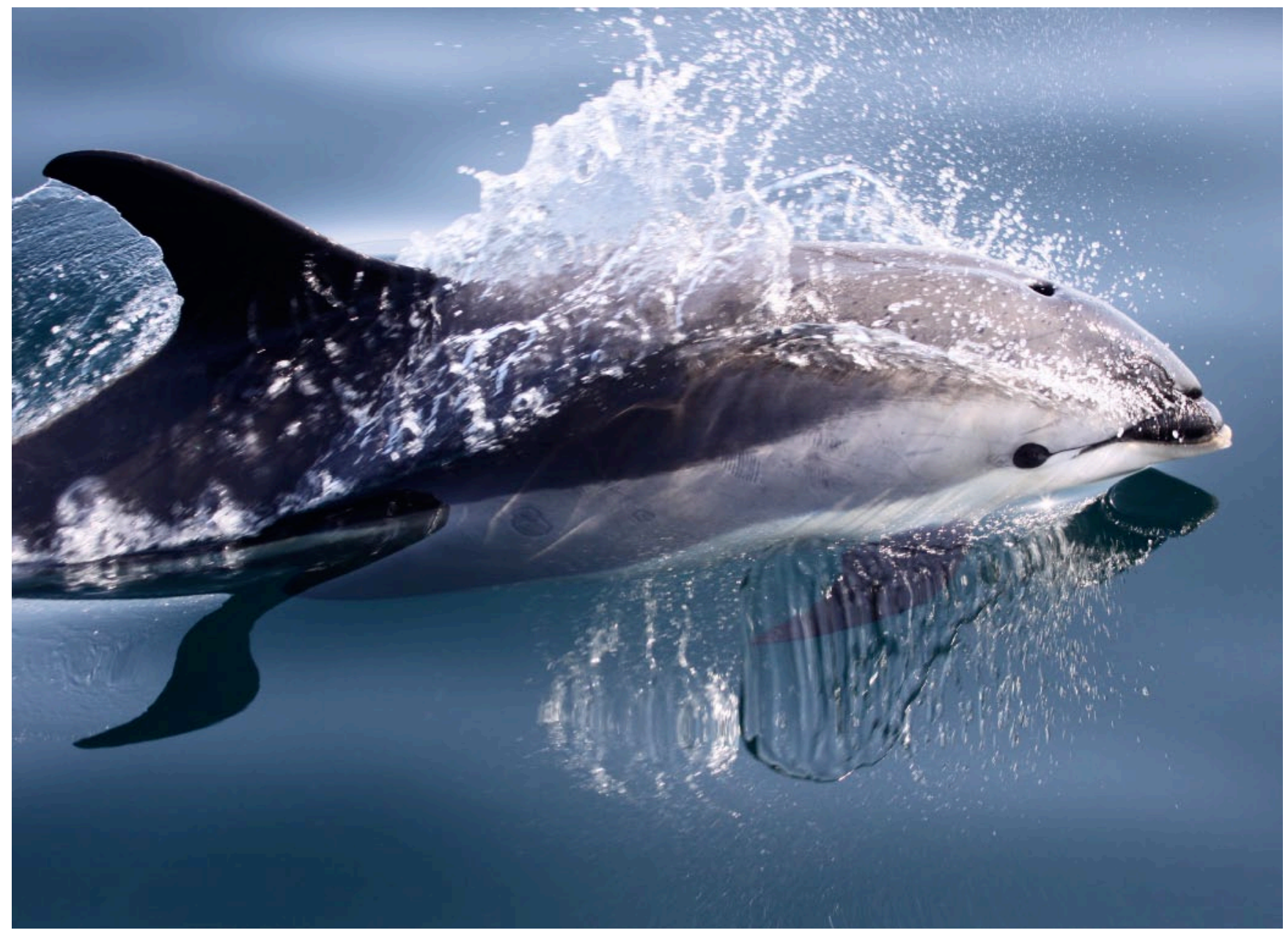

Photo: Atlantic white-sided dolphin, E. Bradfield 


\section{Methods for Assessing Impacts of Marine Renewable Energy Installations on Marine Megavertebrates}

\subsection{Introduction}

In designing environmental monitoring protocols for sites of proposed MREIs, no single standard will be universally applicable. The survey techniques, size of the study area, design and duration of the survey will all depend upon the area itself, the species found there and their conservation status, the nature and scale of the planned MREI and the duration of the construction period. As highlighted in Inger et al. (2009), a systematic review of previous experience and studies in the field of impact assessments for MREIs (as provided in Section 5) combined with solid study design are key to appropriately assessing the impacts of MREIs.

Since the Muskeget Channel project is one of nine tidal turbine sites proposed for the U.S. East Coast and the larger region is a proposed research site for MREIs (Northeast Offshore Renewable Energy Innovation Zone, NOREIZ), it will be essential for this project to set a precedent for exemplary environmental monitoring protocols. This report outlines methods for monitoring marine megavertebrate populations and for documenting spatiotemporal variation in patterns of habitat use and behavior. It then provides a set of objectives for monitoring the impacts to marine megavertebrate populations, specific to the Muskeget Channel MREI project to insure that no significant impacts occur to any marine megavertebrate populations in the region. A recommended methodology plan is outlined.

\section{Tidal Turbine Sites: A Unique Challenge}

A combination of several techniques is required to appropriately monitor marine megavertebrate species around tidal turbine sites. Visual data collection for marine megavertebrates involves frequent boat-based surveys and/ or aerial surveys, and these techniques are more suitable for some species (e.g. turtles, cetaceans) than for nonairbreathing species such as basking sharks. The use of Static Acoustic Monitoring (SAM) at offshore wind farm sites is now standard practice in many areas (e.g. Tougaard et al., 2004; Carstensen et al., 2006). This method facilitates long-term monitoring; however, it is also more suitable for some species (e.g. odontocetes) than others. A number of issues, detailed below, will likely arise with the use of this method at tidal sites. Proposed sites for tidal power developments will present a very specific and unique set of challenges for monitoring. Environmental monitoring methods for marine megavertebrates can be very difficult to carry out in tidally dynamic areas, as the very nature of these sites dictates that they are characterized by strong tides and complex oceanographic features.

Environmental monitoring methods also demand considerable forays into new areas such as the investigation of 
underwater behavior of megavertebrates around turbines, the development and testing of new moorings for submersible instruments and SAM capabilities and limits in extremely high-flow environments.

\subsection{Outline of Survey Methods for Marine Megavertebrates}

\subsubsection{Visual Survey Platforms}

Visual surveys (aerial and/or boat-based) are an accepted and well-established methodology for assessing abundance and distribution of most cetacean species. Such platforms allow for the collection of valuable species presence information for less common cetacean species or those for which acoustic monitoring is not yet welldeveloped. By using Distance sampling methodology (Buckland et al., 2001), which is the accepted means of generating absolute abundance estimates for these species, region-specific abundance estimates can be calculated. In order to be useful, Distance sampling surveys must be carried out frequently and according to a strict survey design with even coverage throughout the study area.

Aerial surveys are an effective means of covering large study areas within a manageable period of time. They are also less weather-dependent than boat-based surveys, although detection probabilities, especially for smaller species such as harbor porpoises, are affected by higher sea states just as for shipboard surveys (Palka, 1995; Teilmann, 1995).

Aerial surveys are well-established as an acceptable method for surveying for cetaceans (e.g. SCANS I \& II; Hammond et al., 2002), seals (e.g. Matthiopoulos et al., 2004; Cronin et al., 2006) and turtles (e.g. Marsh \& Saalfeld, 1989; Jean et al., 2010), and they have also been used to assess relative or "apparent" abundance of fish species such as basking sharks and sunfish (Leeney et al., in review; Houghton et al., 2006; Campana et al., 2008). In fact, for basking sharks and species such as right whales, which can spend long periods of time just beneath the water surface rendering them invisible to vessel-based observers, aerial surveys can be an excellent means of detection. This method can also be used to collect valuable photo-identification data on endangered species such as the North Atlantic right whale (e.g. Leeney et al., 2008, 2009).

\subsubsection{Static Acoustic Monitoring (SAM)}

Acoustic monitoring is becoming widely accepted as an efficient way to collect valuable long-term datasets on cetacean habitat use for EIS purposes (e.g. Teilmann et al., 2002; Carstensen et al., 2006; Tougaard et al., 2009; Thompson et al., 2010). Diederichs et al. (2009) reported that SAM using T-PODs (the predecessors of C-PODs) or other devices provides good data on harbor porpoises, and potentially other odontocete species, at a high temporal but low spatial resolution. Deploying several SAM devices in the area of interest overcomes the issue of spatial resolution. Statistical analysis from areas with low and high porpoise densities proved that a $30 \%$ change in harbor porpoise presence can be proved with a sample size of 3-11 SAM units (Diederichs et al., 2009). The initial baseline data review should inform, to a great extent, the choice of acoustic monitoring technique to be used. The species present, their detectability using acoustic techniques and how necessary it is deemed to have fine-scale data on spatio-temporal patterns of habitat use of particular species should all factor into the choice of acoustic monitoring tool.

C-PODs are only suitable for monitoring cetacean species which use echolocation. They have been used extensively to monitor spatio-temporal patterns of habitat use for many species of odontocetes including harbor porpoises (e.g. Tougaard et al., 2009) and bottlenose dolphins (e.g. Leeney et al., 2007; Philpott et al., 2007). Autonomous seafloor recording units, referred to as "pop-ups," are considerably more expensive and complex to deploy. They are used to collect data on vocalizations from baleen whales such as North Atlantic right whales (Clark et al., 2010). 
SAM at tidal energy sites will present a number of unique challenges that will need to be addressed in order to effectively collect, analyse and interpret the data collected by this means.

- Moorings for SAM equipment present a very specific challenge in areas where tidal turbines are planned, since the characteristics of these areas necessarily pose a risk that gear will move or be swept away. Moorings need to be flexible but extremely resilient to deal with the dynamic nature of this environment.

- Noise-modelling specific to a given site will need to be conducted. Tidally dynamic areas are high-noise areas since there is both water moving at high speeds and transfer or movement of bottom sediment. Noise-modelling will provide an understanding of the acoustic environment so that the detectability of various species, the range at which they can be detected and the variability in those parameters with temporal and environmental conditions can be well understood and incorporated into any analysis of SAM data.

- Background research on the species likely to be encountered in the region, as well as the types of vocalizations each species produces, will be essential in order to first select the most appropriate SAM technology to be used in the area and then to interpret the data collected. There is a paucity of data on vocalizations, especially echolocation, of many cetacean species.

- Focal studies are needed on certain species for which data are lacking. Such studies should be carried out prior to commencement of monitoring and should involve direct hydrophone recordings of the vocalizations of the target species in concert with data collection on group size and behavior.

- Calibration of SAM equipment will be essential to insure that the outputs are comparable between units and/or sites. The assumption should not be made that all units, even of any one design, have identical sensitivities and detection functions unless this is guaranteed by the manufacturer. On a wider scale, there is a great need for a detailed comparison of various pieces of acoustic monitoring equipment to be made. This will allow for rates of detection, habitat use, activity and behaviors to be compared between projects and over much wider regions.

\subsubsection{Visual Surveys from Platforms/land}

Land-based counts of hauled-out seals (pinnipeds) have been used extensively as a means of calculating population size and patterns of habitat use (e.g. Pomeroy et al., 2005; Leeney et al., 2010). Relative to other methodologies for studying marine mammals, it is a safe and easy method. Numbers of seals hauling out also varies with season, and so counts throughout the year will provide data on this seasonal pattern.

Visual surveys, from both land-based sites and at-sea platforms, provide site-specific data on temporal variation and can also provide the opportunity to collect useful data on surface behaviors. By carrying out visual surveys at a range of tidal states and times of day over several years, a fuller understanding of the temporal patterns of habitat use specific to a site can be gained. This, combined with data on species which might be inclined to dive or swim in the vicinity of tidal turbines or which appear unable to detect the moving turbines underwater from a safe distance, can then lead to an assessment of "high risk" species and time periods (e.g. seasons, states of tide, times of day) of greatest collision risk. Behavior sampling can be carried out using Ad Libitum or Focal-Animal sampling techniques (Altmann, 1974), depending on the context, and should likewise be collected in a range of conditions and in both impact and control situations. 
Table 1: Operational Objectives for the Muskeget Tidal Turbine Environmental Monitoring and Mitigation Program

\begin{tabular}{|c|c|c|}
\hline ELEMENT & OBJECTIVE & MEASUREMENT \\
\hline \multirow[t]{5}{*}{$\begin{array}{l}\text { Marine } \\
\text { mammals } \\
\text { (general) }\end{array}$} & $\begin{array}{l}\text { Required: No marine mammal } \\
\text { mortalities (directly or indirectly as a } \\
\text { result of a non-fatal injury) occur as } \\
\text { a consequence of physical interaction } \\
\text { with the turbine rotors. }\end{array}$ & $\begin{array}{l}\text { 1. Post mortem evaluation of carcass strandings } \\
\text { and assessment of cause of death. } \\
\text { 2. Investigation of any carcasses sighted during } \\
\text { aerial surveys. } \\
\text { 3. Health assessment of large whales during } \\
\text { aerial surveys; collection of observational data } \\
\text { on seal condition during haul-out counts. } \\
\text { 4. Platform-based observations*/video of be- } \\
\text { havior near turbines, if possible. }\end{array}$ \\
\hline & $\begin{array}{l}\text { Recommended: Establishment of an } \\
\text { active sonar system which detects } \\
\text { marine megavertebrates at sufficient } \\
\text { range from the turbine to allow a } \\
\text { precautionary shutdown to occur } \\
\text { automatically a. }\end{array}$ & $\begin{array}{l}\text { 1. Number of sonar detections and shutdown } \\
\text { events. } \\
\text { 2. Matching of sonar detections to platform- } \\
\text { based sightings for species identification, where } \\
\text { possible.* }\end{array}$ \\
\hline & $\begin{array}{l}\text { Relative abundance of marine mam- } \\
\text { mals in Muskeget Channel is not } \\
\text { significantly modified by the opera- } \\
\text { tion of the turbines. }\end{array}$ & $\begin{array}{l}\text { 1. Assessment of abundance and distribution in } \\
\text { control and impact sites, before, during and after } \\
\text { construction. An adequate baseline ("before") } \\
\text { dataset would comprise two years of data. } \\
\text { 2. Statistical comparison of patterns of variation } \\
\text { in abundance and distribution (aerial, haul-out } \\
\text { and platform-based* counts). } \\
\text { 3. Similar comparison of hauled-out seal counts } \\
\text { in the region over the same time scale. }\end{array}$ \\
\hline & $\begin{array}{l}\text { Sub-surface noise generated by the } \\
\text { turbines does not cause a level of } \\
\text { disturbance to marine mammals suf- } \\
\text { ficient to displace them from areas } \\
\text { important for foraging and social } \\
\text { activities. }\end{array}$ & $\begin{array}{l}\text { 1. Measurement of zone of audibility and zone } \\
\text { of disturbance at full power operation; descrip- } \\
\text { tion of noise environment. } \\
\text { 2. Assessment of overlap of augmented (with } \\
\text { turbine operation) noise environment with vo- } \\
\text { calization and hearing frequency ranges of most } \\
\text { common species (and species of key interest). } \\
\text { 3. Number of marine mammals underwa- } \\
\text { ter sighted in close proximity ( } \sim 50 \mathrm{~m} \text { ) to the } \\
\text { turbines per hour (if possible, from platform or } \\
\text { imaging techniques) }{ }^{\mathrm{b}} \text {. }\end{array}$ \\
\hline & $\begin{array}{l}\text { Recommended: The turbines operate } \\
\text { in such a way as to stop when marine } \\
\text { mammals are within } 50 \mathrm{~m} \text { of the ro- } \\
\text { tors. }\end{array}$ & $\begin{array}{l}\text { 1. Assessment of the (combined) surface*, } \\
\text { underwater }{ }^{\S} \text { (and sonar) detection events with } \\
\text { automatic shutdown when a mammal is within } \\
50 \mathrm{~m} \text { of turbine rotors. } \\
\text { 2. Post mortem evaluation of carcass strandings/ } \\
\text { sightings and assessment of cause of death. }\end{array}$ \\
\hline
\end{tabular}




\begin{tabular}{|c|c|c|}
\hline \multirow{3}{*}{$\begin{array}{l}\text { Marine } \\
\text { mammals: } \\
\text { Pinnipeds (seals) }\end{array}$} & $\begin{array}{l}\text { The turbines do not cause a signifi- } \\
\text { cant change in the use of important } \\
\text { seal haul-out sites within or adjacent } \\
\text { to the region. }\end{array}$ & $\begin{array}{l}\text { Haul-out site seal numbers from aerial surveys } \\
\text { and haul-out site counts }{ }^{b} \text {. }\end{array}$ \\
\hline & $\begin{array}{l}\text { Seals are not excluded from important } \\
\text { foraging habitat or social areas within } \\
\text { the Muskeget Channel area as a result } \\
\text { of the installation and operation of the } \\
\text { turbines. }\end{array}$ & $\begin{array}{l}\text { Comparison of sightings frequency over space } \\
\text { and time (from haul-out site counts and aerial } \\
\text { survey data) in pre-operational, construction and } \\
\text { operational periods }^{\text {b. }}\end{array}$ \\
\hline & $\begin{array}{l}\text { The number of harbor and gray seal } \\
\text { adults and pups does not decline sig- } \\
\text { nificantly as a result of the installation } \\
\text { and operation of the turbines. }\end{array}$ & $\begin{array}{l}\text { Population estimates derived from aerial survey } \\
\text { and haul-out counts to establish baseline data for } \\
\text { "local" populations. Estimates to be set within } \\
\text { the context of historical data. }\end{array}$ \\
\hline \multirow[t]{2}{*}{$\begin{array}{l}\text { Marine } \\
\text { mammals: } \\
\text { Cetaceans } \\
\text { (whales and } \\
\text { dolphins) }\end{array}$} & $\begin{array}{l}\text { Cetaceans are not excluded from } \\
\text { important foraging habitat or social } \\
\text { areas within the Muskeget Channel } \\
\text { area as a result of the installation and } \\
\text { operation of the turbines. }\end{array}$ & $\begin{array}{l}\text { 1. Abundance and distribution (from aerial } \\
\text { survey data) in pre-operational, construction and } \\
\text { operational periods. } \\
\text { 2. Comparison of SAM data between before } \\
\text { and after construction/operation and in control } \\
\text { and impact sites. SAM data may also provide } \\
\text { indices of behavior (e.g. assessment of buzz train } \\
\text { production rate associated with feeding). }\end{array}$ \\
\hline & $\begin{array}{l}\text { The turbines do not displace ceta- } \\
\text { ceans from the immediate region or } \\
\text { adjacent areas. }\end{array}$ & $\begin{array}{l}\text { 1. SAM data analysis at a range of scales. } \\
\text { 2. Sighting data from platform-based observers } \\
\text { if possible. }\end{array}$ \\
\hline \multirow[t]{2}{*}{$\begin{array}{l}\text { Basking sharks } \\
\& \text { sunfish }\end{array}$} & $\begin{array}{l}\text { No mortalities of basking sharks or } \\
\text { sunfish (directly or indirectly as a } \\
\text { result of a non-fatal injury) occur as } \\
\text { a consequence of physical interaction } \\
\text { with the turbine rotors. }\end{array}$ & $\begin{array}{l}\text { 1. Post-mortem evaluation of carcass strandings } \\
\text { and assessment of cause of death. } \\
\text { 2. Investigation of any carcass sighted during } \\
\text { aerial surveys. }\end{array}$ \\
\hline & $\begin{array}{l}\text { The turbines do not cause a signifi- } \\
\text { cant change in habitat use by these } \\
\text { species. }\end{array}$ & $\begin{array}{l}\text { 1. Comparison of sightings frequency over space } \\
\text { and time (from aerial survey data) in pre-opera- } \\
\text { tional, construction and operational periods). }\end{array}$ \\
\hline Turtles & $\begin{array}{l}\text { The turbines do not injure or displace } \\
\text { turtles from areas they might other- } \\
\text { wise utilize. }\end{array}$ & $\begin{array}{l}\text { 1. Post-mortem evaluation of carcass strandings } \\
\text { and assessment of cause of death. } \\
\text { 2. Comparison of sightings frequency over space } \\
\text { and time (from aerial survey data) in pre-opera- } \\
\text { tional, construction and operational periods). }\end{array}$ \\
\hline Seabirds & $\begin{array}{l}\text { The turbines do not injure or displace } \\
\text { foraging diving birds from important } \\
\text { areas within Muskeget Channel. }\end{array}$ & $\begin{array}{l}\text { 1. Sightings frequency of diving and rafting } \\
\text { birds as well as behavior data from platform- } \\
\text { based*, video }^{\S} \text { and/or aerial surveys }{ }^{c} \text {. }\end{array}$ \\
\hline
\end{tabular}

a. The SeaGen turbine in Strangford Lough uses a sonar device to detect marine mammals close to the turbine and to instigate shutdown (Bedford \& Fortune, 2010). An initial period with a similar system at the Muskeget site is recommended, if possible, to collect data on initial avoidance/ approach by various species.

b. At the SeaGen site, seals were satellite tagged and the resulting telemetry data provided supplementary information as to how individuals were using the site both before and during operation of the turbine. Although expensive, telemetry can provide extremely useful insights into changes, or lack thereof, in habitat use by marine mammals.

c. Injured or dead birds will be difficult to detect and impossible to assess from aerial survey platforms. The best way to detect collision victims for this species group would be from a platform among the turbines; in the absence of this, a submerged camera on one or more turbines could be trialled (see Methodology Plan section).

* If platform-based, at-sea observations are possible for the Muskeget project.

$\S$ If underwater video/sonar imaging methods prove possible for the Muskeget project 


\subsection{Environmental Risk Thresholds}

In working to meet the above objectives, it will be essential to define the terms "significant change/ modification" and "significant decline," for the purposes of conservation management. Firstly, the change must be detected. This will be achieved using an appropriate sampling design and monitoring techniques. The magnitude of the change having been evaluated, it must be attributed either to an effect of the MREI or to something else. Finally, the magnitude of the change must be set in the context of local, regional and national trends in abundance and distribution in order to determine whether such a level of change is considered significant for a population. That is, are the effects likely to be long-term or to be of detriment to the population of a whole? EMEC (2008) provide a table detailing the criteria to be used to assess potential and residual environmental impacts, including both ecological and socio-economic effects, which may prove a useful reference in addressing the above issues.

Similarly, the use of the term "important" in reference to habitat areas for marine mammals also requires definition. In this case, if a species is rare (e.g. North Atlantic right whale) or locally rare (such as a species at the limit of its range) and is found to utilize the habitat at all, or if it is numerous but large numbers (a percentage of the regional population should be defined here) utilize the habitat at least seasonally, the area should be considered important. For all cetacean and pinniped species, it will be necessary to refer to the US Endangered Species and Marine Mammal Protection Acts for guidance relating to the significance of a given impact at the individual, community and population level.

It should also be noted that the detection of significant change does not necessarily signify a negative effect of the turbine installation. Some changes to the area may benefit marine megavertebrates and may support greater levels of habitat use; these will nonetheless be important to document. However, natural and cyclical variations in the environment should be accounted for within the survey design and thus should not be a source for significant differences between datasets. 


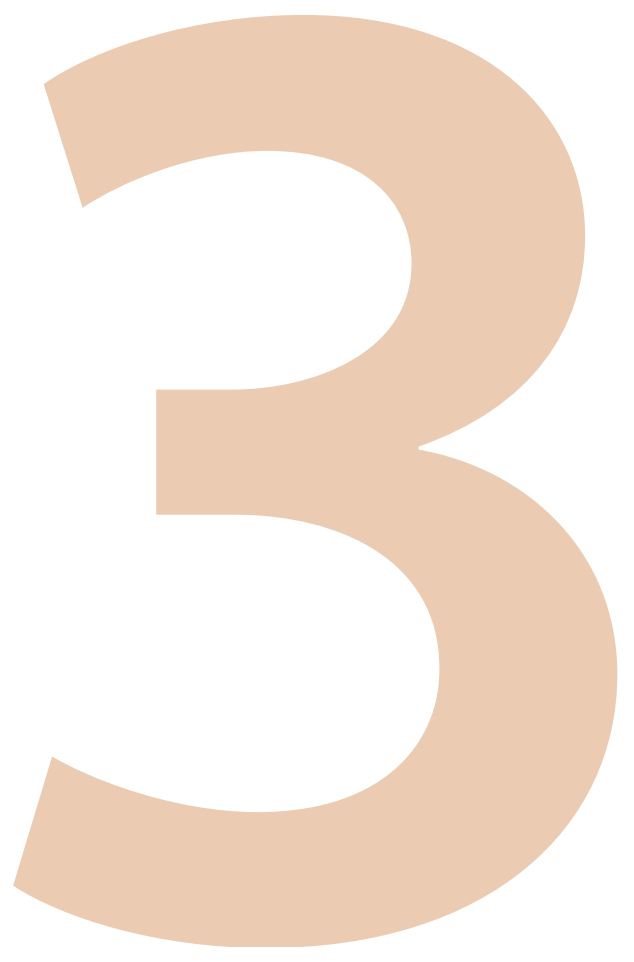

\section{Methodology Plan for Proposed Muskeget Channel Tidal Energy Project}

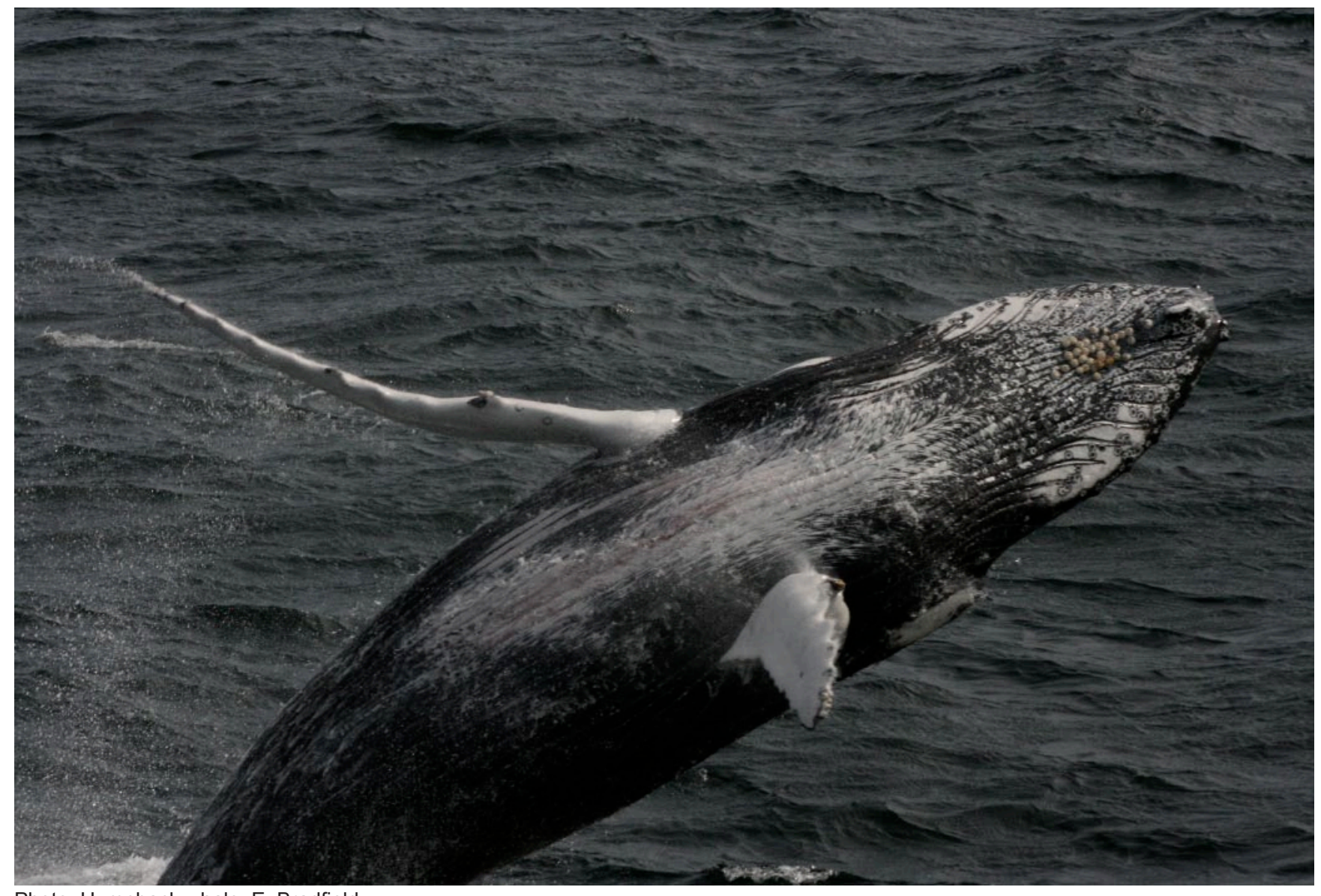


Table 1 outlines the objectives to be achieved by the monitoring and mitigation program for the proposed Muskeget Channel tidal energy project. The methods to be used to address these objectives are detailed below. This methodology plan is based on accepted survey and mitigation techniques, previous research and practical experience at other MREI sites and established, good scientific practice. Reference has been made to the Environmental Impact Assessment guidelines developed by the European Marine Energy centre (EMEC, 2008). Modification of the advised methodology will result in reduced certainty of any detected "effect" of the MREI development on the ecology and welfare of the marine megavertebrates in the region. In addition to the "recommended" methods for detection and monitoring of marine megavertebrates, several "advised" methodologies have been included as a means of generating higher-quality data and furthering our understanding of the effects of tidal turbines on the biodiversity at this site.

\subsection{Study Design}

A scientifically sound monitoring design is essential to accurately detect potential impacts when monitoring changes associated with conservation management (Underwood, 1994, 1995). As a case in point, although terrestrial wind farms have been in place for several decades, their impacts on bird populations remain unclear. Some studies have suggested negative impacts on local avian populations (e.g. Langston and Pullan, 2003; Garthe and Huppop, 2004; Pearce-Higgins et al., 2008). However, in a recent review of such assessments, Stewart et al. (2007) propose that evidence for determining the effects of wind farms is lacking, largely due to short time scales of previous studies and methodological weaknesses such as lack of replication or control sites.

As highlighted in Inger et al. (2009), a solid study design is crucial to understanding the true impacts of any MREI. For impact studies in relation to offshore wind farms, a BACI (Before-After/Control-Impact) design has been recommended (Diederichs et al., 2009). A BACI design adds power to EIA monitoring by providing comparative datasets for the area prior to any construction or operation (i.e. a baseline) as well as during construction and/ or operation at the planned MREI site and at an area outside the zone of impact. It thus incorporates and reflects the effects of any natural cycles or additional impacts in the area unrelated to the impact of the MREI.

However, while BACI study design provides the conceptual framework within which to detect anthropogenic effects, there are many practical problems associated with detecting human influences on population abundance and distribution. One main issue is that the temporal variance of many populations is great; that is, abundance data for any given population in a given area, particularly for highly mobile marine megavertebrates, is very "noisy." Thompson et al. (2010) documented a response by harbor porpoises to wind turbine installation activities using SAM. Their findings highlighted the fact that uncertainty regarding cetacean distribution and the scale of disturbance effects limits the effectiveness with which BACI studies can be interpreted. Another key issue is that temporal patterns in regional abundances of a given species are rarely the same from one place to another. 
These two problems create difficulties in identifying unusual patterns of change in what is already a very interactive and variable measurement. The power to accurately detect such changes due to anthropogenic effects can be significantly increased by using asymmetrical design. That is, using one impacted site and several control locations (Underwood, 1994). The incorporation of more than one control site is key because there will be different temporal patterns at different sites, and in a comparison of the impacted site with only one "control," there is the possibility that the two sites will have very different patterns of variation. This would results in a false positive an apparent effect of construction or operation when there is no actual effect - which could cost a developer time, money or even the entire project. By investing in a comprehensive "beyond BACI" design sampling framework, the developer will be compensated by a vast reduction in the risk of false positive results and will insure that any effects detected are fully understood and can be put into an ecosystem context.

Planning ahead of time is essential to the implementation of an effective environmental impact assessment. Diederichs et al. (2009) suggest that impact studies on offshore wind farms should ideally comprise two years of "before impact" data, the construction period itself and at least two years of the operational phase. The authors advise that if longer-lasting effects are detected, the study should be extended during the operational phase.

\subsection{Methods}

\section{Aerial Surveys (Recommended)}

Aerial surveys will enable the detection of most marine megavertebrate species of interest - cetaceans, seals and turtles. Sunfish and basking sharks may be seasonally detectable, depending on water temperature and other conditions. Aerial surveys should cover not only the offshore proposed study site and at least two control sites (beyond-BACI design), but also all known nearby seal haul-out areas (South Monomoy Island, Muskeget Island, Wasque Shoal, Great Point Nantucket and Nantucket Harbor), so that the number of seals on land can be assessed.

Recommended frequency: Two per month, per site

Recommended methodology: Distance sampling (Buckland et al., 2001). This will generate abundance estimates within the study area and will thus enable a more accurate assessment of any effect of construction or operation within a BACI-structured study design. Aerial surveys of seal haul-out sites do not require transect methodology and would thus be best placed at the start or end of a survey flight or run as a separate flight. Seal haul-out surveys may need to employ photography and generate counts from post-survey photo analysis.

Communication with local right whale aerial survey teams (PCCS and NEFSC) will be extremely useful in ascertaining whether any injured right whales are observed in adjacent areas. Data collected within the Muskeget Channel area can also supplement the data collected by the teams, since this region currently falls outside of the focal study areas of both teams but is, nonetheless, of considerable interest for this species. During the 2010 PCCS right whale monitoring season, right whales were sighted in the Rhode Island Sound area adjacent to Muskeget Channel, thus it is likely that some individuals utilized these waters (T. Cole, pers. comm., May 2010).

If, during the Distance sampling protocol aerial surveys for the Muskeget project, right whales are sighted in either control or impact sites, it is recommended that the sighting be passed immediately to both teams, whereupon they can arrange, if practical, for a second flight in the area to collect detailed photo-identification data on the individual right whales utilizing this habitat. This will be of benefit not only to the New England Aquarium North Atlantic Right Whale Catalogue and the scientific community's overall understanding of the ecology of this species, but it will also provide additional data for the Muskeget team on the proportion of this endangered population using the installation area. This in turn will inform how best to mitigate for potential disturbance effects to this species, which will require special consideration.

Safety is a key concern for aerial surveys of marine megavertebrates; surveys generally utilize small aircraft and operate at low altitudes ( $750 \mathrm{ft}$ recommended). It is advisable to follow a comprehensive safety protocol 
such as that prepared for PCCS (Leeney and Chronic, 2010).

Vessel Strikes: U.S. Federal law and Massachusetts state law prohibit any vessel from approaching a right whale closer than 500 yards unless permitted by NMFS (some limited exemptions). All vessel traffic associated with the construction and development of the tidal turbines should be made aware of these regulations, and a reporting scheme should be set up for these vessels, with particular emphasis on the sighting of right whales. An awareness campaign for boaters (both recreational and other) using the Muskeget Channel area might also be of benefit. Discussions should also take place to determine whether an immediate shut-down of turbines should be effected if and when right whales are detected within a given distance from the turbines.

\section{Acoustic Monitoring (Recommended)}

It is important to first characterize the acoustic environment, or background, over which cetaceans will be producing vocalizations. Ongoing acoustic monitoring at control and impact sites will allow for the description of patterns of habitat use by odontocetes (dolphins and porpoises), mysticetes (baleen whales) or both, depending on the SAM system used. A third effort involving targeted sampling from specific odontocete species is recommended to strengthen the later analyses of SAM data.

Acoustic environment monitoring Mapping the "soundscape" of the site, i.e. measuring the zone of audibility and the zone of disturbance at full power operation and describing the full spectrum of frequencies and noise levels produced and the variability therein with different conditions (e.g. sea state, weather) is important to be able to separate "background" noises from those of odontocetes. This will allow for a detection of change in the acoustic environment with the installation of the turbines and of potential acoustic threats to marine megavertebrates as a result. These measurements will facilitate the fine-tuning of SAM for cetaceans by creating a good understanding of the "background noise" and variations therein, over which cetacean vocalizations will have to be detected.

Recommended methodology: Use of a broadband frequency hydrophone at both the impact and control areas to collect information on the type of background noise that is usual. Replicate samples should be collected at a range of tidal states (slack tide and at a range of ebb and flood speeds) in all months of the year or, at the very least, during spring tides or the days leading up to peak spring tide, when the environment will be noisiest. Sampling should occur about a kilometer up- and downstream of the intended turbine deployment location, and the sampling regime should be repeated both before and after the installation.

Recording for some distance away from the exact location provides a description of the receiving environment. Ideally this work should be carried out in standardized conditions. If there is considerable ferry or working boat traffic in the area, this makes the task more difficult. Other inconstant noise sources also need to be considered.

Equipment: The use of SAMS drifting ears is recommended. These recorders summarize the soundscape at frequencies from $50 \mathrm{~Hz}$ to $46 \mathrm{kHz}$ and allow the representation of these data in map format for the site (developed by the Scottish Association of Marine Scientists and used by EMEC, Scottish Power Renewables, Scottish Government and OpenHydro in the U.K. and North America). Higher frequency recordings using a hydrophone could be carried out in parallel from the vessel used to deploy and recover the drifters.

Challenges: Moored hydrophones in high-flow areas present considerable problems. At peak flow rates, which are the periods of greatest interest and also likely of highest collision risk for megavertebrates, recording needs to be free of noise generated within the hydrophone. Since flow noise associated with the passage of water around a hydrophone unit increases with flow speed, this issue is difficult to resolve.

Safety: Working at sites of high tidal currents is challenging even in good weather conditions. A moderate wind against a running tide can present dangerous conditions which pose a risk to personnel and also may cause the loss of equipment. Any boat-based sampling must be carried out according to a strict safety protocol and only in ideal conditions. 
Static Acoustic Monitoring (SAM)

All odontocetes studied to date appear to produce echolocation clicks as a means of searching for prey, exploring their environment and possibly for inter-species communication. A study by Akamatsu et al. (2007) documented an almost continuous use of echolocation by wild, tagged harbor porpoises; less than $4 \%$ of the tagged time comprised silent periods lasting more than 50 seconds. This behavior makes species such as the harbor porpoise especially well-suited to monitoring by acoustic means.

Methodology: Placement of multiple SAM units at both control and impact sites, in such a way as to allow for calculation of the effect of distance from the impact (construction at the turbine site and, eventually, the turbine itself). The SAM data can also provide habitat use indices (e.g. Detection-Positive Minutes per hour) which can be used in statistical analyses as abundance data would be, thus allowing for a beyond-BACI analysis. Environmental impact assessments in Danish and German waters have used various numbers and layouts of T-PODs (the predecessor to the C-POD) depending on the site and resources available (Leeney and Tregenza, 2006).

Replicate units (allowing for both replication and for back-up in case of unit malfunction) should be placed at increasing distance increments from the turbines to examine the impact range. As some studies have documented an effect of pile driving on cetaceans beyond $21 \mathrm{~km}$ from the source, it is recommended that SAM units are placed at distances of between 2 and $5 \mathrm{~km}$ out to a distance of at least $30 \mathrm{~km}$. The same deployment structure should be in place at control site(s).

Equipment: C-PODs (www.chelonia.co.uk) or a similar technology (Aquatec and Woods Hole Oceanographic Institute have produced similar monitoring tools).

\section{Species-specific descriptive acoustic studies (Advised)}

Several species which are likely to occur in the control and impact sites have not been studied before using CPODs. Additionally, there are not good existing data on the echolocation characteristics of many species, such as the Atlantic white-sided dolphin (Lagenorhychus acutus). In order for the SAM effort to be most effective, supporting work is recommended to characterize the click characteristics of at least several species that are very likely to be encountered in the area, for which data on echolocation characteristics are deficient.

Methodology: This will involve targeted vessel-based searches for specific species followed by acoustic sampling in the close vicinity of these species using a hydrophone with high sampling rates which can measure frequencies above $200 \mathrm{kHz}$. Collection of data on species, group size and behavior will accompany the acoustic sampling. These data will then inform how best to set the C-PODs for monitoring the area of interest and will also enable a more accurate analysis of the resulting SAM data.

Equipment: Calibrated hydrophone, amplifier and sound card or oscilloscope.

\section{Land-based Surveys for Stranded Pinnipeds (Recommended)}

On the islands of Monomoy and Muskeget, regular (2-4 per month) searches for beached carcasses of seals should be carried out in every month of the year. Any carcasses should be extensively photographed and standard data collection for stranded pinnipeds should be carried out. Any animals displaying injuries which could be associated with turbine blade trauma should be removed for necropsy, if possible.

\section{At-sea, Platform-based Observations (Advised)}

The SeaGen turbine in Strangford Lough, Northern Ireland, is one of the world's first full-scale, operational tidal turbines (http://www.seageneration.co.uk/). It has been in place since 2008. The structure of this turbine, with 
a platform above water, is such that observations of the water directly surrounding the turbine could be made. Marine mammal observers have now been replaced by active sonar, which shuts down the turbine operation when any marine mammal is detected within a $50 \mathrm{~m}$ radius of the turbine (Bedford and Fortune, 2010). Such a setup, allowing for in situ observations of the occurrence of marine megavertebrates in close vicinity to the turbines, would be beneficial to understanding the effect these structures have on the Muskeget Channel environment. Platform observations would allow the collection of detailed data on occurrence and behavior of various species in the immediate vicinity of the turbines as well as direct confirmation of any immediately apparent negative or nonnegative effects.

\section{Underwater Imaging for Behavioral and Abundance Studies (Advised as trial methodology)}

There remain several questions that will be difficult to address, such as the underwater response of diving birds as well as species such as basking sharks to submerged, moving turbine blades. Although the underwater environment is likely to be turbid, a trial of an underwater video camera affixed to one of the turbine bodies is recommended. For comparatively little effort, such a technique may provide a rare glimpse of the behaviors exhibited by certain species in close proximity to these structures.

Equipment: A camera such as the DeepSea Power \& Light Multi SeaCam 1060. Video capturing device and power supply also required.

An alternative method that shows promise is sonar imaging. A multi-beam imaging sonar, such as Dual-Frequency Identification Sonar (DIDSON) has already been proposed as part of the draft fisheries study plan for the site and, if incorporated into the study plan, will be deployed on one of the turbine structures to record information on fish behavior and direct impacts from the tidal turbines. Such technology is able to produce images of targets that pass through its sonar field-of-view.

The DIDSON produces a near-video quality that allows observation of underwater behaviors of various species in turbid and nighttime conditions. Although not established as a technique for surveying marine megavertebrates, a sonar imaging system has been used with some success at the Strangford Lough tidal turbine (Bedford and Fortune, 2010). Since small fish species can be detected with this technique, it is likely to work for larger animals as well.

Equipment: The DIDSON Long Range model maximizes the amount of observable area in front of and behind the module. This model has an approximately $29^{\circ}$ beam width and a $14^{\circ}$ beam elevation. http://www. soundmetrics.com/

These monitoring elements are summarized in Table 4, along with target species for each method, recommended sampling frequency, duration of the sampling and any notes regarding safety or other considerations. 


\subsection{Mitigation}

In their guidelines for minimizing the risk of disturbance and injury to marine mammals from pile driving (2009), the U.K.'s Joint Nature Conservation Committee (JNCC) notes that the "soft-start" procedure and protocols for piling operations (not proposed for use in this project) required for the protection of marine mammals may also be appropriate for marine turtles and basking sharks. In the U.K., JNCC now recommends, but does not yet require, the use of Acoustic Deterrent Devices (ADDs, also known as Acoustic Mitigation Devices, AMDs) to clear an area of marine mammals prior to a soft-start process for pile driving or blasting (JNCC, 2009).

In theory, ADDs have the potential to reduce the risk of injury to marine mammals and are relatively cost effective. Their use would be in conjunction with visual and/or acoustic monitoring. ADDs have been used in Denmark and at other European wind farm construction sites (e.g. Edrén et al., 2010). However, evidence relating to the efficacy of such acoustic deterrents is limited and likely varies considerably among species (e.g. Berrow et al., 2009; Leeney et al., 2007; Cox et al., 2003; Johnston, 2002); habituation is also likely after some time. Kastelein et al. (2010) reported considerable differences in detection distances of AMDs depending on the model of AMD, background noise levels and propagation conditions in the marine environment. If these devices are considered, the potential effectiveness of candidate devices on the key marine mammal species likely to be present in the area should be assessed as part of the environmental impact assessment process for the proposed activity.

Equipment: ADDs are available from a number of different suppliers such as Fumunda (http://pleskunasdesign.com/ pages/specs.html ), Aquatec (http://www.aquatecgroup.com/aquamark.html) and Dukane (http://www.dukane.com/ seacom/default.htm 
Table 2: Summary of Advised Monitoring Program Elements

\begin{tabular}{|c|c|c|c|c|}
\hline Method & Target & Sampling frequency & Duration & Comments \\
\hline Aerial surveys & All megavertebrates & $\begin{array}{l}2 \text { per month (mini- } \\
\text { mum), per site }\end{array}$ & $\begin{array}{l}\text { Two years prior to } \\
\text { turbine installation } \\
\text { through operation }\end{array}$ & $\begin{array}{ll}\text { - } & \text { Communicate with local } \\
& \text { aerial survey teams } \\
\text { - } & \text { Safety protocol \& } \\
& \text { equipment required }\end{array}$ \\
\hline $\begin{array}{l}\text { Strandings } \\
\text { surveys }\end{array}$ & Seals & $\begin{array}{l}\text { 2-4 per month, per site } \\
\text { (Monomoy \& Mus- } \\
\text { keget) }\end{array}$ & $\begin{array}{l}\text { During turbine in- } \\
\text { stallation \& at least } \\
\text { first year of opera- } \\
\text { tion }\end{array}$ & \\
\hline $\begin{array}{l}\text { Static Acoustic } \\
\text { Monitoring (1) }\end{array}$ & Odontocetes & Continuous at 3 sites & $\begin{array}{l}\text { Two years prior to } \\
\text { turbine installation } \\
\text { and through opera- } \\
\text { tion }\end{array}$ & \multirow{2}{*}{$\begin{array}{l}\text { SAM costs may require } \\
\text { choice of one/ other } \\
\text { technique. What are } \\
\text { priority species? }\end{array}$} \\
\hline $\begin{array}{l}\text { Static Acoustic } \\
\text { Monitoring (2) }\end{array}$ & $\begin{array}{l}\text { My (\& Od, de- } \\
\text { pending on system } \\
\text { employed) }\end{array}$ & Continuous at 3 sites & $\begin{array}{l}\text { Two years prior to } \\
\text { turbine installation } \\
\text { and through opera- } \\
\text { tion }\end{array}$ & \\
\hline $\begin{array}{l}\text { Seascape } \\
\text { acoustic } \\
\text { mapping }\end{array}$ & Background noise & $\begin{array}{l}\text { Minimum } 3 \text { replicate } \\
\text { samples per year, over } \\
\text { spring tides, in each } \\
\text { project phase, at each } \\
\text { site }\end{array}$ & $\begin{array}{l}\text { Two years prior to } \\
\text { turbine installation } \\
\text { and through opera- } \\
\text { tion }\end{array}$ & $\begin{array}{l}\text { Safety protocol required } \\
\text { for boat-based work } \\
\text { during strong tides }\end{array}$ \\
\hline $\begin{array}{l}\text { Species- } \\
\text { specific } \\
\text { acoustic } \\
\text { sampling }\end{array}$ & Odontocetes & $\begin{array}{l}\text { Intensive period of 2-3 } \\
\text { weeks prior to com- } \\
\text { mencement of SAM } \\
\text { likely to suffice for key } \\
\text { species }\end{array}$ & One month & $\begin{array}{l}\text { Identification of } \\
\text { data-deficient species } \\
\text { required }\end{array}$ \\
\hline $\begin{array}{l}\text { Platform- } \\
\text { based } \\
\text { monitoring }\end{array}$ & All megavertebrates & $\begin{array}{l}\text { Regular 3-4 h samples } \\
\text { at least once per week }\end{array}$ & $\begin{array}{l}\text { Two years prior to } \\
\text { turbine installation } \\
\text { and during turbine } \\
\text { operation }\end{array}$ & $\begin{array}{l}\text { - Likely only possible at } \\
\text { impact site }\end{array}$ \\
\hline $\begin{array}{l}\text { Sonar } \\
\text { detection }\end{array}$ & $\begin{array}{l}\text { All megavertebrates } \\
\text { (especially targeted } \\
\text { at Se, Od, My \& } \\
\text { CM) }\end{array}$ & $\begin{array}{l}\text { Continuous; initially } \\
\text { carried out simultane- } \\
\text { ously with platform- } \\
\text { based observations }\end{array}$ & $\begin{array}{l}\text { Two years prior to } \\
\text { turbine installation } \\
\text { and during turbine } \\
\text { operation }\end{array}$ & $\begin{array}{l}\text { Further investigation } \\
\text { required - does this re- } \\
\text { quire on-site shut-down } \\
\text { capacity? } \\
\text { Likely only possible at } \\
\text { impact site }\end{array}$ \\
\hline $\begin{array}{l}\text { Video/ Sonar } \\
\text { imaging }\end{array}$ & $\begin{array}{l}\text { All megavertebrates } \\
\text { (esp. Se, Av \& CM) }\end{array}$ & $\begin{array}{l}\text { Trial period over 3-4 } \\
\text { weeks at start of project }\end{array}$ & $\begin{array}{l}\text { If successful, short } \\
\text { periods of monitor- } \\
\text { ing (e.g. } 24 \text { h per } \\
\text { week) in each phase } \\
\text { of project }\end{array}$ & $\begin{array}{l}\text { - Only practical at impact } \\
\text { site }\end{array}$ \\
\hline
\end{tabular}

Species groups codes: Od - Odonotcetes; My - Mysticetes; $\mathrm{CM}$ - basking shark; Tu - turtles;

Se - seals; MM - sunfish; Av - birds.

(1) Using C-PODs or another method for detecting odontocetes.

(2) SAM for Mysticetes - will require greater investment in equipment and considerable additional data processing time 


\section{References}

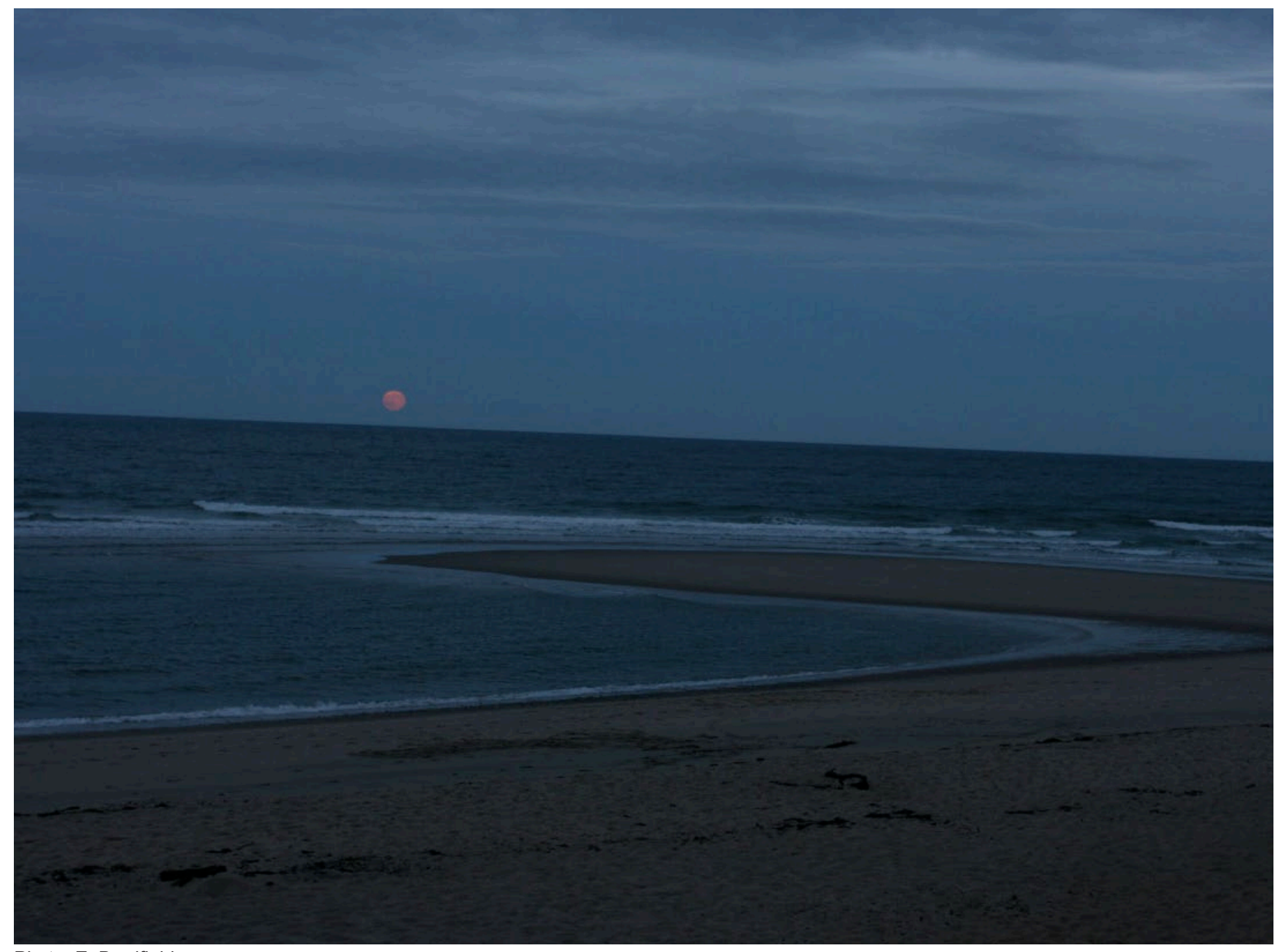




\section{Literature Cited - Methods}

Akamatsu, T., Teilmann, J., Miller, L.A., Tougaard, J., Dietz, R., Wang, D., Wang, K., Siebert, U. and Naito, Y. 2007: Comparison of echolocation behavior between coastal and riverine porpoises. Deep-Sea Res. 54: 290-297.

Altmann, J. 1974. Observational study of behavior: sampling methods. Behavior 49: 227-267.

Bedford, G. and Fortune, F. 2010. SeaGen Biannual EMP update. 21 April 2010. Report ref. 9S8562/R/303719/

Edin, 31 pp. Retrieved from http:/www.seageneration.co.uk/downloads/SeaGen\%20biannual\%20report\%20 April\%202010.PDF.

Berrow, S., Cosgrove, R., Leeney, R.H., O’Brien, J., McGrath, D., Dalgard, J. and LeGall, Y. 2008. Effects of acoustic deterrents on the behavior of common dolphins (Delphinus delphis). Journal of Cetacean Research and Management 10: 227-233.

Buckland, S.T., Anderson, D.R., Burnham, K.P., Laake, J.L., Borchers, D.L. and Thomas, L. 2001. Introduction to Distance Sampling. Estimating abundance of biological populations. Oxford University Press, Oxford, UK.

Campana, S.E., Gibson, J., Brazner, J., Marks, L., Joyce, W., Gosselin J.F., Kenney, R. D., Shelton, P., Simpson, M. and Lawson, J. 2008. Status of Basking Sharks in Atlantic Canada. Canadian Science Advisory Secretariat Research Document 2008/004. 67 pp.

Carstensen, J., Henriksen, O.D. and Teilmann, J. 2006. Impacts of offshore wind farm construction on harbor porpoises: acoustic monitoring of echolocation activity using porpoise detectors (T-PODs). Marine Ecology Progress Series 321: 295-308.

Clark, C.W., Brown, M.W. and Corkeron, P. 2010. Visual and acoustic surveys for North Atlantic right whales, Eubalaena glacialis, in Cape Cod Bay, Massachusetts, 2001-2005: Management implications. Marine Mammal Science DOI: 10.1111/j.1748-7692.2010.00376.x.

Cox, T.M., Read, A.J., Swanner, D., Urian, K. and Waples, D. 2003. Behavioral responses of bottlenose dolphins, Tursiops truncatus, to gillnets and acoustic alarms. Biological Conservation 115: 203-212.

Cronin, M.A., Duck, C.D. and O'Cadhla, O. 2006. Aerial surveying of grey seal breeding colonies on the Blasket Islands, Co. Kerry, the Inishkea Group, Co. Mayo and the Donegal Coast, Ireland. Journal for Nature Conservation 15: 73-83.

Diederichs, A., Nehls, G., Dähne, M., Adler, S., Koschinski, S. and Verfuß, U. 2008. Methodologies for measuring and assessing potential changes in marine mammal behavior, abundance or distribution arising from the 
construction, operation and decommissioning of offshore windfarms. BioConsult SH report to COWRIE Ltd. $91 \mathrm{pp}$. Retrieved from http://www.offshorewindfarms.co.uk/Assets/CHANGE0607\%20Final\%20version\%20 2010.pdf.

Diederichs, A. Hennig, V. and Nehls, G. 2008. Investigations of the bird collision risk and the responses of harbor porpoises in the offshore wind farms Horns Rev, North Sea, and Nysted, Baltic Sea, in Denmark. Part II: Harbor porpoises. Final Report. 96 pp.

Edrén, S.M., Andersen, S.M., Teilmann, J., Carstensen, J., Harders, P.B., Dietz, R. and Miller, L.A. 2010. The effect of a large Danish offshore wind farm on harbor and gray seal haul-out behavior. Marine Mammal Science 26 (3): 614-634.

EMEC (European Marine Energy Centre). 2008. Environmental Impact Assessment (EIA) guidance for developers at the European Marine Energy Centre. 22 pp. Retrieved from http://www.emec.org.uk/pdf/EMEC\%20 EIA\%20Guidelines\%20GUIDE003-01-03\%2020081106.pdf.

Garthe, S. and Huppop, O. 2004. Scaling possible adverse effects of marine wind farms on seabirds: developing and applying a vulnerability index. Journal of Applied Ecology 41: 724-734.

Hammond, P.S., Berggren, P., Benke, H., Borchers, D.L., Collet, A., Heide-Jørgensen, M.P., Heimlich, S., Hiby, A.R., Leopold, M.F. and Øien, N. 2002. Abundance of harbor porpoise and other cetaceans in the North Sea and adjacent waters. Journal of Applied Ecology 39: 361-376.

Hays, G.C., Farquhar, M.R., Luschi, P., Teo, S.L.H. and Thys, T.M. 2009. Vertical niche overlap by two ocean giants with similar diets: oceanic sunfish and leatherback turtles. Journal of Experimental Marine Biololgy and Ecology 370:134-143. doi:10.1016/j.jembe.2008.12.009.

Houghton, J.D.R., Doyle, T.K., Davenport, J. and Hays, G.C., 2006. The ocean sunfish Mola mola: insights into distribution, abundance and behavior in the Irish Sea and Celtic Seas. Journal of the Marine Biological Association of the United Kingdom 86, 1237-1243.

Inger, R., Attrill, M.J., Bearhop, S., Broderick, A.C., Grecian, W. J., Hodgson, D.J., Mills, C., Sheehan, E., Votier, S.C., Witt, M.J. and Godley, B.J. 2009. Marine renewable energy: potential benefits to biodiversity? An urgent call for research. Journal of Applied Ecology 46: 1145-1153.

Jean, C., Ciccione, S., Ballorain, K., Georges, J.-Y. and Bourjea, J. 2010. Ultralight aircraft surveys reveal marine turtle population increases along the west coast of Reunion Island. Oryx 44: 223-229.

Johnston, D.W. 2002. The effect of acoustic harassment devices on harbor porpoises (Phocoena phocoena) in the Bay of Fundy, Canada. Biological Conservation 108 (1): 113-118.

Joint Nature Conservation Committee. 2009. Annex B - Statutory nature conservation agency protocol for minimising the risk of disturbance and injury to marine mammals from piling noise. Retrieved from https://www. og.decc.gov.uk/environment/jncc_pprotocol.pdf.

Kastelein, R.A., Hoek, L., Jennings, N., de Jong, C.A.F., Terhune, J.M. and Dieleman, M. 2010. Acoustic mitigation devices (AMDs) to deter marine mammals from pile driving areas at sea: Audibility and behavioral response of a harbor porpoise and harbor seals. COWRIE Ref: SEAMAMD-09, Technical Report 31st July 2010. Retrieved from http://www.offshorewindfarms.co.uk/Assets/Final\%20report\%20COWRIE\%20Ref\%20 SEAMAMD-09.pdf.

Langston, R.H.W. and Pullan, J.D. 2003. Windfarms and birds: an analysis of windfarms on birds, and guidance on environmental assessment criteria and site selection issues. RSPB/BirdLife International Report to the Council of Europe (Bern Convention). T-PVS/Inf (2003) 12.

Leeney, R.H., Berrow, S., McGrath, D., O’Brien, J., Cosgrove, R. and Godley, B.J. 2007. Effects of pingers on the behavior of bottlenose dolphins. Journal of the Marine Biological Association, UK 87: 129-133. 
Leeney, R.H., Broderick, A.C., Mills, C., Sayer, S., Witt, M.J. and Godley, B.J. 2010. Abundance, distribution and haul-out behavior of grey seals (Halichoerus grypus) in Cornwall and the Isles of Scilly, UK. Journal of the Marine Biological Association of the UK. Published online, June 2010.

Leeney, R.H., Broderick, A.C., Witt, M.J., Richardson, P.B., Jarvis, D.S., Buchanan, J. and Godley, B.J. (In review) Marine megavertebrates of Cornwall and the Isles of Scilly: relative abundance and distribution.

Leeney, R.H. and Chronic, J. 2010. PCCS Right Whale Aerial Survey Program Safety Policy and Operating Procedures Manual. Produced for the Provincetown Center for Coastal Studies. 28 pp.

Leeney, R.H., Stamieszkin, K., Mayo, C.A. and Marx, M. 2009. Surveillance, monitoring and management of North Atlantic right whales in Cape Cod Bay and adjacent waters - 2009. Report to DMF. Provincetown Center for Coastal Studies, USA.

Leeney, R.H., Stamieszkin, K., Jaquet, N., Mayo, C.A., Osterberg, D. and Marx, M. 2008. Surveillance, monitoring and management of North Atlantic right whales in Cape Cod Bay and adjacent waters - 2008. Report to DMF. Provincetown Center for Coastal Studies, USA.

Leeney, R.H. and Tregenza, N.J.C. (Eds) 2006. Proceedings of the workshop: Static Acoustic Monitoring of Cetaceans, held at the 20th Annual Meeting of the European Cetacean Society, Gdynia, Poland, 2nd April 2006. ECS Newsletter 46 - Special Issue, July 2006. Retrieved from http://www.seaturtle.org/mtrg/personnel/ SAM_report.shtml.

Marsh, H. and Saalfeld, W.K. 1989. Aerial Surveys of Sea Turtles in the Northern Great Barrier Reef Marine Park. Australian Wildlife Research 16: 239-49.

Matthiopoulos, J., McConnell, B., Duck, C. and Fedak, M. 2004. Using satellite telemetry and aerial counts to estimate space use by grey seals around the British Isles. Journal of Applied Ecology 41: 476-491.

Palka, D. 1995. Effects of Beaufort sea state on the sightability of harbor porpoises in the Gulf of Maine. Report to the International Whaling Commission SC/47/SM26.

Pearce-Higgins, J.W., Stephen, L., Langston, R.H.W. and Bright, J.A. 2008. Assessing the cumulative impacts of wind farms on peatland birds: a case study of golden plover Pluvialis apricaria in Scotland. Mires \& Peat 4: 1-13. Retrieved from http://www.mires-and-peat.net/map04/map_04_01.pdf.

Philpott, E., Englund, A., Ingram, S. and Rogan, E. 2007. Using T-pods to the echolocation of coastal bottlenose dolphins. Journal of the Marine Biological Association 87: 11-17.

Pomeroy, P.P., Redman, P.R., Ruddell, S.J.S., Duck, C.D. and Twiss, S.D. 2005. Breeding site choice fails to explain interannual associations of female grey seals. Behavioral Ecology and Sociobiology 57: 546-556. doi 10.1007/s00265-004-0882-6.

Sims, D.W., Queiroz, N., Doyle, T.K., Houghton, J.D.R. and Hays, G.C. 2009. Satellite tracking of the world's largest bony fish, the ocean sunfish (Mola mola) in the North East Atlantic. Journal of Experimental Marine Biology and Ecology 370: 127-133. doi:10.1016/ j.jembe.2008.12.011.

Sims, D.W., Southall, E.J., Tarling, G.A. and Metcalfe, J.D. 2005. Habitat-specific normal and reverse diel vertical migration in the plankton-feeding basking shark. Journal of Animal Ecology 74: 755-761.

Teilmann, J. 1995. Influence of seastate on abundance estimates of harbor porpoise (Phocoena phocoena). Report to the International Whaling Commission SC/47/SM45.

Teilmann, J., Henriksen, O.D., Cartensen, J. and Skov, H. 2002. Monitoring effects of offshore windfarms on harbor porpoises using PODs (porpoise detectors). Ministry of the Environment, Denmark. 95 pp.

Thompson, P.M., Lusseau, D., Barton, T., Simmons, D., Rusin, J. and Bailey, H. 2010. Assessing the responses of coastal cetaceans to the construction of offshore wind turbines. Marine Pollution Bulletin 60: 1200-1208. 
Tougaard, J., Carstensen, J., Henriksen, O.D., Teilmann, J. and Hansen, J.R. 2004. Harbor porpoises on Horns Reef - effects of the Horns Reef wind farm. National Environmental Research Institute, Roskilde, Denmark, $69 \mathrm{pp}$.

Tougaard, J., Carstensen, J., Teilmann, J., Skov, H. and Rasmussen, P. 2009. Pile driving zone of responsiveness extends beyond $20 \mathrm{~km}$ for harbor porpoises (Phocoena phocoena (L.)). Journal of the Acoustical Society of America $126(1): 11-14$.

Underwood, A.J. 1994. On beyond BACI: sampling designs that might reliably detect environmental disturbances. 4(1): 3-15.

Underwood, A.J. 1995. Ecological research and (and research into) environmental management. Ecol. Appl. 5(1): 232-247.

Wilson, B. Batty, R.S., Daunt, F. and Carter, C. 2007. Collision risks between marine renewable energy devices and mammals, fish and diving birds. Report to the Scottish Executive. Scottish Association for Marine Science, Oban, Scotland, PA37 1QA. 110 pp. 


\section{Marine Megavertebrates and Fishery Resources in the Nantucket Sound - Muskeget Channel Area}

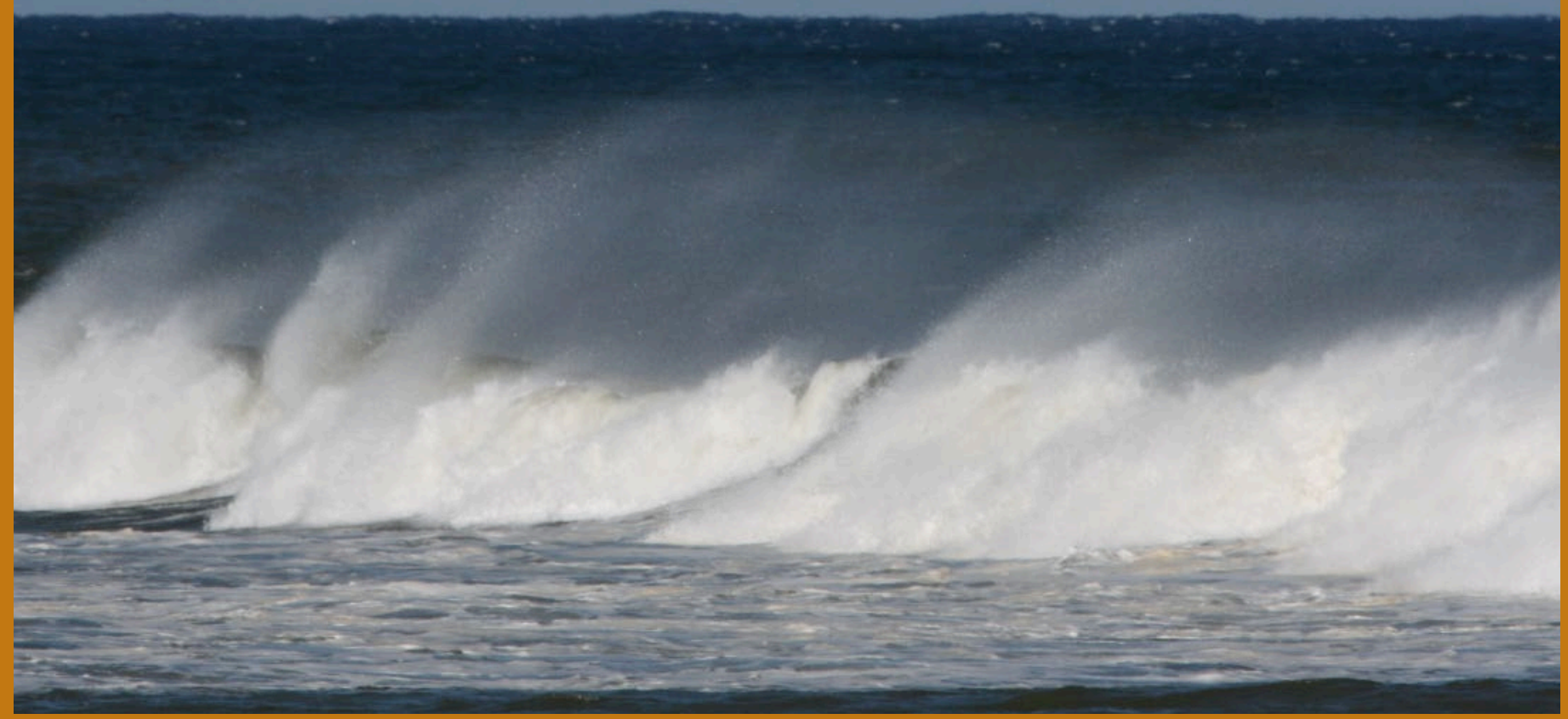

Provincetown Center for Coastal Studies. Wh w. Coastalstudies.org 



\section{Appendix D PCCS Field Report}





\title{
2012 Field Studies of Marine Mammals and Sea Turtles in the Nantucket Sound-Muskeget Channel Area
}

\author{
A Report to \\ Harris Miller Miller \& Hanson Inc \\ For \\ HMMH Project \# 303910 \\ Environmental Impacts of \\ Sediment Transport Alteration and \\ Impacts on Protected \\ Species: Edgartown Tidal Energy Project \\ Prepared by the \\ Provincetown Center for Coastal Studies
}

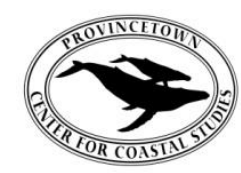

October 2012
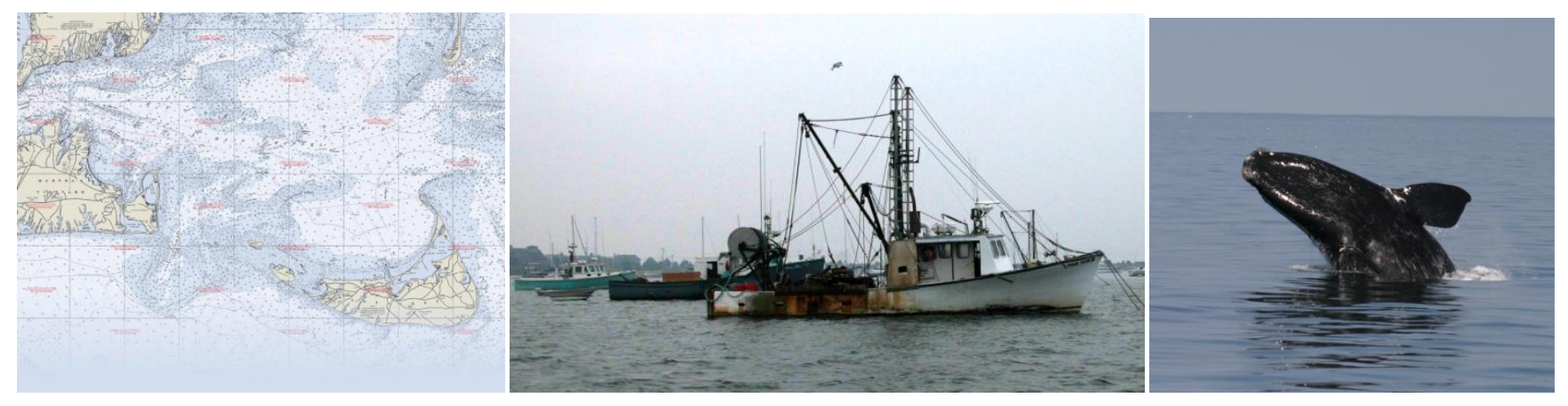

Funding for this field program, in whole or in part, was provided through the Department of Energy Grant DE-EE0002656, awarded to Harris Miller Miller \& Hanson Inc. on behalf of the Town of Edgartown, Massachusetts. This field program was conducted under the direction of the Provincetown Center for Coastal Studies (PCCS) and in collaboration with the Large Pelagics Research Laboratory at the University of Massachusetts-Amherst, the International Fund for Animal Welfare (IFAW), Dr. David Johnston of Duke University and Dr. Stephanie Wood-LaFond. 


\section{Background}

Muskeget Channel is located between the islands of Martha's Vineyard and Nantucket. Water depths in the channel range between 40 and 160 feet, with Wasque Shoals to the west and Mutton Shoal to the east. Muskeget Channel allows for the exchange of water between Nantucket Sound to the north and the Atlantic Ocean and continental shelf to the south. The Town of Edgartown is proposing to develop an initial 5MW tidal energy pilot project in Muskeget Channel. Edgartown holds a Preliminary Permit from the Federal Energy Regulatory Commission (FERC), giving it the exclusive right to explore the development of the resource for energy. Edgartown is required to submit a Draft Pilot License Application that will allow the town to deploy, operate and monitor this pilot-scale turbine installation. This application must include information on initial consultation with cooperating federal resource agencies; draft study plans, including one on protected species, and an outline of work that will be completed during deployment of the pilot project.

The Town of Edgartown engaged Harris Miller Miller \& Hanson (HMMH) as its Principal Investigator (PI) and program manager. HMMH was successful in obtaining U.S. Department of Energy funding for the study: Environmental Effects of Sediment Transport Alteration and Impacts on Protected Species: Edgartown Tidal Energy Project. In 2011, the Provincetown Center for Coastal Studies (PCCS) completed a literature review of the ecology of large marine vertebrates in the Muskeget Channel area. PCCS also completed a literature review of the effects of marine renewable energy installations on large marine vertebrates and, based on these two reviews, recommended environmental studies and monitoring protocols for proposed tidal energy installations in Muskeget Channel ${ }^{1}$.

In 2012, HMMH provided additional funding to PCCS under this same grant to conduct field studies on marine mammals and seas turtles in the Nantucket Sound- Muskeget Channel area focused on seasonal movement, habitat use and oceanographic associations of two protected species, the gray seal and leatherback turtle. While limited in scope and duration, this field program can provide some baseline data on the occurrence, distribution and habitat use of marine megavertebrates in the area. The field program begins to address the lack of data on marine megavertebrates in the Nantucket SoundMuskeget Channel area.

Given the limited time within which to conduct the field work (June-September) and the limited amount of funding, PCCS proposed to collaborate with existing projects in the area. These included PCCS's Nantucket Sound Water Quality Program and the leatherback turtle project as the University of Massachusetts-Amherst Large Pelagics Research Laboratory. PCCS also worked with IFAW and Dr. David Johnston of Duke University on the gray seal tagging work. Dr. Stephanie Wood-LaFond, who worked with PCCS on literature reviews, assisted in the initial design of the field studies.

\footnotetext{
${ }^{1}$ Leeney, R.H., Nichols, O.C., Sette L., Wood LaFond, S. and Hughes, P.E. 2010. Marine Megavertebrates and Fishery Resources in the Nantucket Sound-Muskeget Channel Area: Ecology and Effects of Renewable Energy Installations. Report to Harris Miller Miller \& Hanson Inc., September 2010. Provincetown Center for Coastal Studies, Provincetown, MA, USA. 88 p. and Leeney, R.H., Nichols, O.C., Sette L., Wood LaFond, S. and Hughes, P.E. 2010. Marine Megavertebrates and Fishery Resources in the Nantucket Sound-Muskeget Channel Area - Assessing Impacts of Marine Renewable Energy Installations on Marine Megavertebrates - Recommendations for the Proposed Muskeget Channel Tidal Energy Project. Report to Harris Miller Miller \& Hanson Inc., September 2010. Provincetown Center for Coastal Studies, Provincetown, MA, USA 24 pp.
} 
Funding from this project supported the project manager of the leatherback turtle tagging project and one tagging cruise; staff time on the gray seal tagging project and the marine mammal and sea turtle observers on PCCS's Nantucket Sound sampling cruises.

\section{Field Studies}

\section{A. Leatherback Turtle Tagging}

In 2012, seven GPS-linked satellite tags (ridgemount model MK10-AF, Wildlife Computers, Inc.) were deployed on leatherback turtles off Cape Cod and the Islands. Flights were conducted to search for leatherbacks during the months of July, August and September. Leatherback aggregations in Nantucket Sound and on Nantucket shoals were located by a spotter pilot during the month of August, and leatherbacks were captured with a break-away hoopnet from the F/V Sea Holly. Details for each turtle can be found in Table 1. Captured turtles were carefully placed on our vessel where we conducted a health assessment, PIT tagging, flipper tagging, and electronic tagging (Figures $1 \& 2$ ). Health assessments were performed by our New England Aquarium collaborators as part of a Section 6-funded study with the Massachusetts Division of Marine Fisheries, UMass-Amherst, and Provincetown Center for Coastal Studies. All leatherback research activities were conducted under NMFS Permit 15672.

\begin{tabular}{|c|c|c|c|c|c|c|c|c|c|c|}
\hline $\begin{array}{l}\text { Turtle } \\
\text { ID }\end{array}$ & $\begin{array}{l}\text { PTT } \\
\text { Number }\end{array}$ & $\begin{array}{l}\text { CCL } \\
(\mathbf{c m})\end{array}$ & Age & Sex & $\begin{array}{l}\text { Capture } \\
\text { method }\end{array}$ & Tag Model & $\begin{array}{l}\text { Tagging } \\
\text { location }\end{array}$ & $\begin{array}{l}\text { Tagging } \\
\text { date }\end{array}$ & $\begin{array}{l}\text { Days at } \\
\text { liberty }\end{array}$ & $\begin{array}{l}\text { Breeding } \\
\text { origin }\end{array}$ \\
\hline A & 111644 & 136.7 & $\mathrm{~S}$ & $\mathrm{U}$ & Hoopnet & MK10-AF & $\begin{array}{l}\text { Nantucket } \\
\text { Sound }\end{array}$ & 2-Aug-12 & $60 *$ & NA \\
\hline B & 121005 & 143.5 & A & M & Hoopnet & MK10-AF & $\begin{array}{l}\text { Nantucket } \\
\text { shoals }\end{array}$ & 9-Aug-12 & $53 *$ & NA \\
\hline $\mathrm{C}$ & 121006 & 153.2 & A & $\mathrm{F}$ & Hoopnet & MK10-AF & $\begin{array}{l}\text { Nantucket } \\
\text { shoals }\end{array}$ & 9-Aug-12 & $53 *$ & Trinidad \\
\hline $\mathrm{D}$ & 121007 & 156.0 & A & $\mathrm{F}$ & Hoopnet & MK10-AF & $\begin{array}{l}\text { Nantucket } \\
\text { shoals }\end{array}$ & 9-Aug-12 & $53 *$ & St. Kitts \\
\hline $\mathrm{E}$ & 121008 & 148.1 & A & $\mathrm{F}$ & Hoopnet & MK10-AF & $\begin{array}{l}\text { Nantucket } \\
\text { Sound }\end{array}$ & 2-Aug-12 & $60 *$ & NA \\
\hline $\mathrm{F}$ & 121009 & 156.0 & A & $\mathrm{F}$ & Hoopnet & MK10-AF & $\begin{array}{l}\text { Nantucket } \\
\text { shoals }\end{array}$ & 8-Aug-12 & $54 *$ & $\begin{array}{l}\text { French } \\
\text { Guiana }\end{array}$ \\
\hline G & 121010 & 151.6 & A & M & Hoopnet & MK10-AF & $\begin{array}{l}\text { Nantucket } \\
\text { shoals }\end{array}$ & 8-Aug-12 & $54 *$ & NA \\
\hline
\end{tabular}

Table 1. Summary data for seven leatherback turtles, Dermochelys coriacea, equipped with satellite tags off of Massachusetts, USA in 2012. PTT = platform transmitter terminal; $\mathrm{CCL}=$ curved carapace length; $\mathrm{S}=$ subadult; $\mathrm{A}=$ adult $; \mathrm{M}=$ male; $\mathrm{F}=$ female; $\mathrm{U}=$ unknown sex; $\mathrm{MK} 10-\mathrm{AF}=$ Argos and Fastloc GPS locations. ${ }^{*}=$ still transmitting

As of the completion of this report, all seven leatherbacks continue to report daily dive behavior and 
location data. To date, we have received 9,592 ARGOS locations and 4,430 Fastloc GPS locations from the turtles, for a combined transmission time of 387 days and 2,453 km (Table $1 \&$ Figure 3 ). Based on tag programming parameters, we calculated a battery life of approximately 90 days for each tag. A full data analysis is pending cessation of all tag transmissions; we anticipate analyses will be completed in early 2013. The turtle tracks are hosted online at http://www.wildlifetracking.org/index.shtml?project_id=666, and have been viewed almost 4000 times by people in 42 different countries.

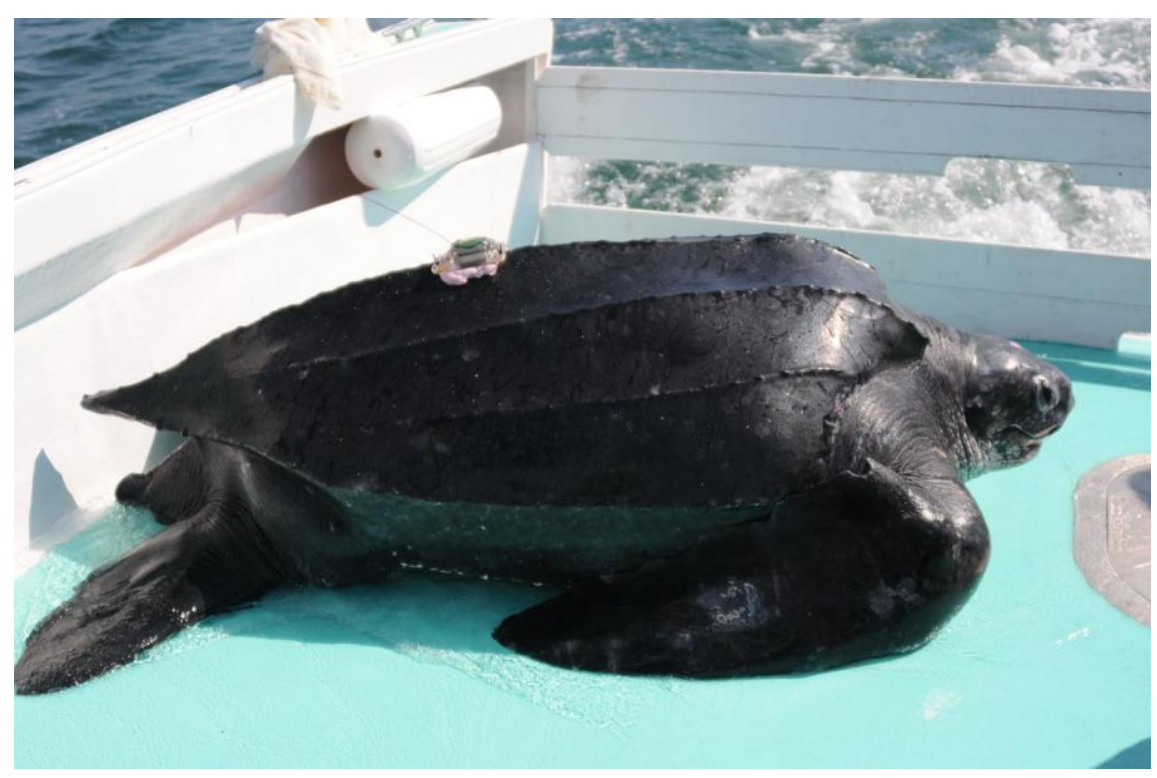

Figure 1. Adult female leatherback turtle with GPS-linked satellite tag, Nantucket Sound, Cape Cod, MA. Research conducted under NMFS permit 15672. Photo: Kara Dodge

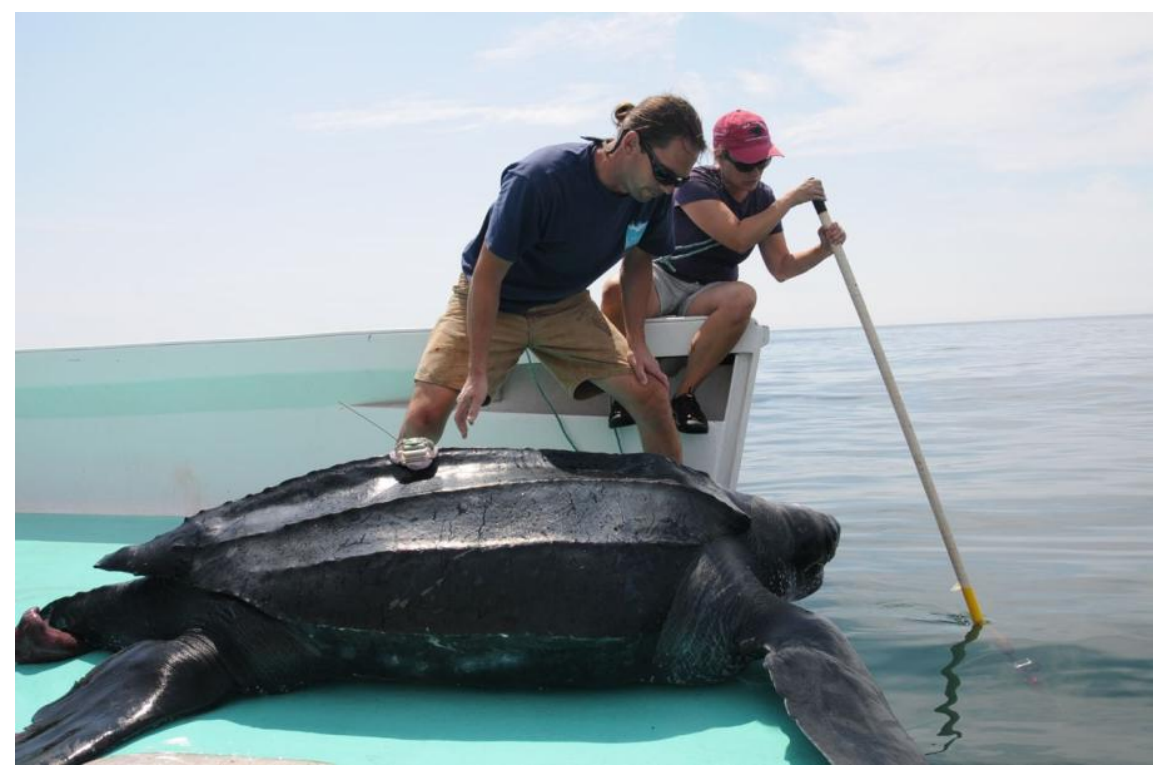

Figure 2. Adult male leatherback turtle with GPS-linked satellite tag, Nantucket shoals, Cape Cod, MA. Research conducted under NMFS permit 15672, Photo: Connie Merigo 


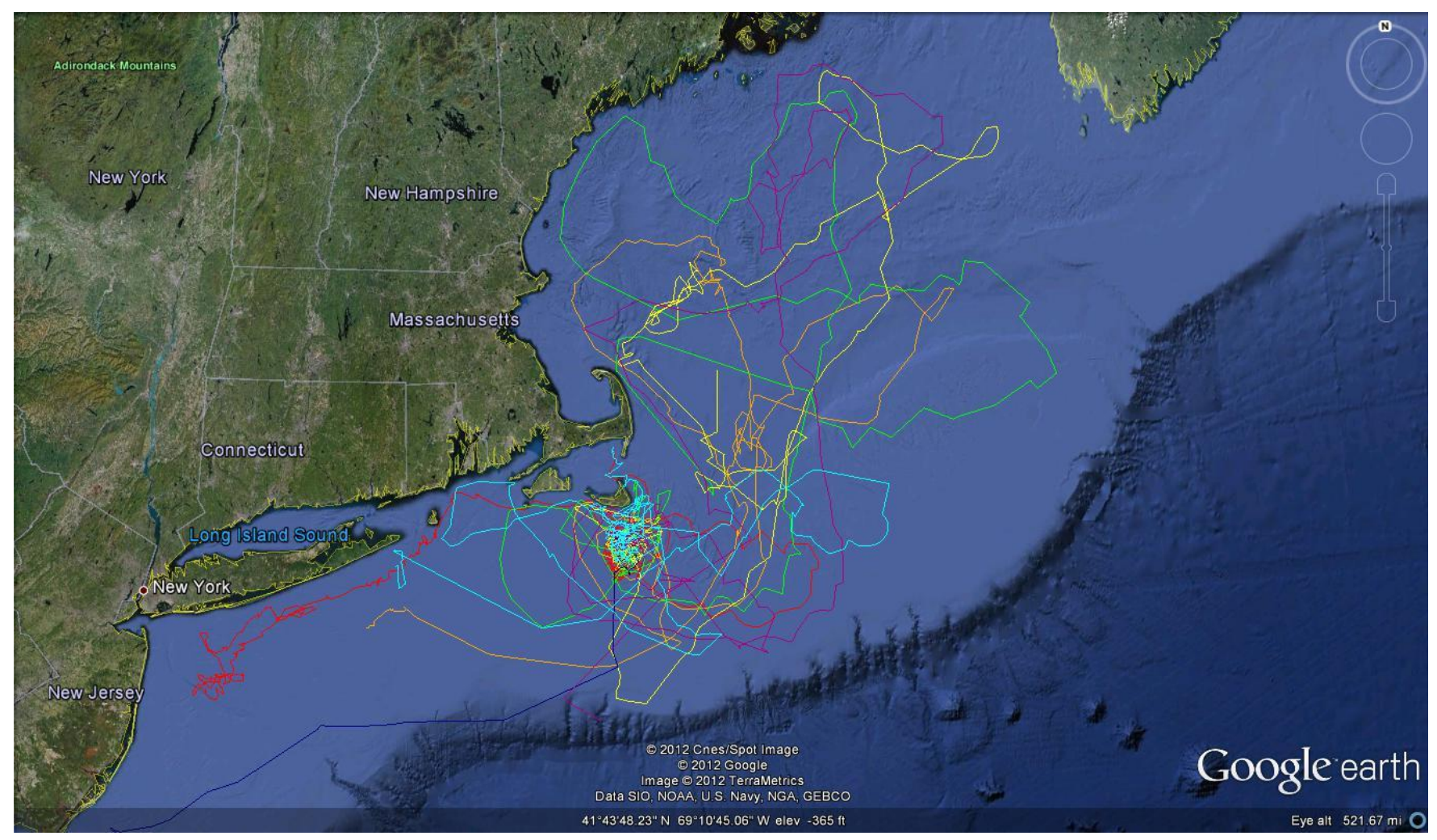

Figure 3. GPS tracks of seven leatherbacks on the NEUS shelf as of 1 October, 2012. Research conducted under NMFS permit 15672. Unpublished data (C) UMass- Amherst Large Pelagics Research Center.

\section{B. Gray Seal Satellite Tagging}

PCCS proposed to conduct one or more cruises in the Nantucket Sound-Muskeget Channel area to capture and satellite tag one or two gray seals. PCCS proposed to conduct one or more cruises in the Nantucket Sound-Muskeget Channel area to capture and satellite tag one or two gray seals. We also proposed to collaborate with IFAW under their federal stranding agreement. The capture and tagging of gray seals in the water requires additional federal review and authorization that could not be obtained in time for this field season. It was possible to tag a juvenile gray seal that had been disentangled by IFAW on May $22^{\text {nd }}$ at Nauset Beach in Orleans. This animal sustained injuries from the entanglement and was taken to the Mystic Aquarium for rehabilitation. The tagging project was a collaborative effort of several agencies and was performed under the authorization granted to IFAW and Mystic Aquarium through their federal Stranding Agreements. The rehabilitated gray seal, named Bronx, was tagged and released into Nantucket Sound on September $11^{\text {th }}$. A scientist from the Riverhead Foundation fitted a GSM tag on the seal and IFAW and their volunteers released the tagged seal at West Dennis Beach in Dennis, MA.

During the winter of 2010/2011 PCCS, in conjunction with Sea Mammal Research Unit (SMRU) from St. Andrews, Scotland, tested a GSM phone tag at known gray seal haul outs and breeding colonies around the Cape and Islands. With the assistance of local fishermen, National Park Service and US Fish and Wildlife Service, PCCS was able to transport and test this tag from SMRU to remote locations around the Cape. The quality of the data results were encouraging and resulted in the tagging of Bronx. The GSM on Bronx was supplied by Dr. David Johnston of Duke University. Unlike a 
satellite tag that transmits data continuously, the GSM tag has a GPS receiver and stores data while the animal is in the water. When the seal hauls out on the beach the local celluar network can pick up the signal. The data can then be transferred across this connection and downloaded to a computer for analysis. The tag also has a depth sensor and a thermistor to capture details on the seals movements, diving behavior and water temperature on foraging trips away from the beach. This seal spent the next 10 days in the water and on September $22^{\text {nd }}$ the seal hauled out on Monomoy Island off of Chatham, Massachusetts and Dr. Johnston downloaded data from the tag for the first time. This description was summarized from, and the following figures were taken from Dr. Johnston's blog:

http://superpod.ml.duke.edu/johnston/2012/09/25/iseal-checks-in-from-monomoy-cape-cod/, where additional information can be obtained about this tagging effort.

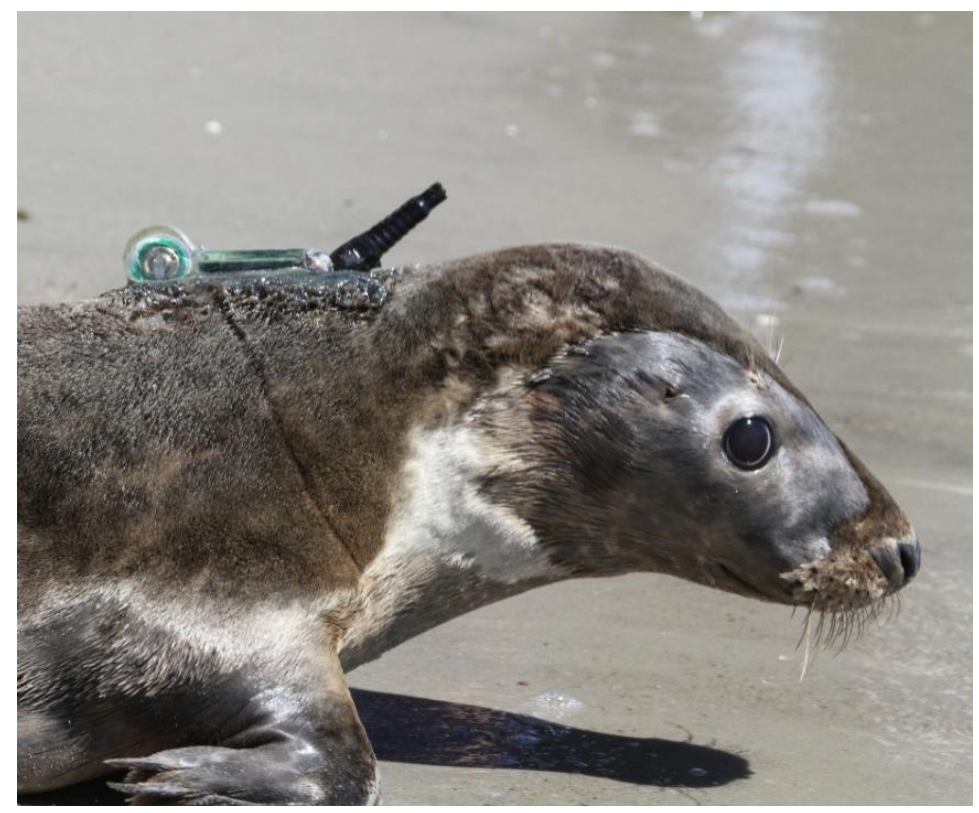

Figure 4: GSM tag on juvenile gray seal, Bronx Photo: PCCS/IFAW

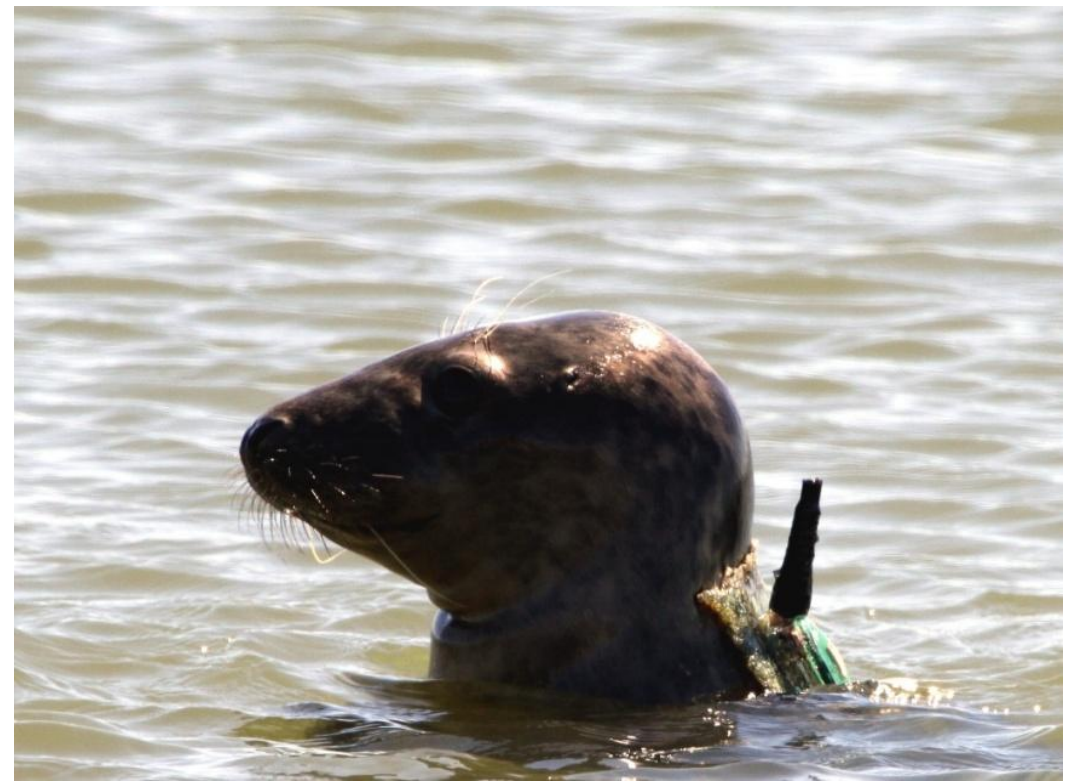

Figure 5: Bronx after release

Photo: PCCS/IFAW 


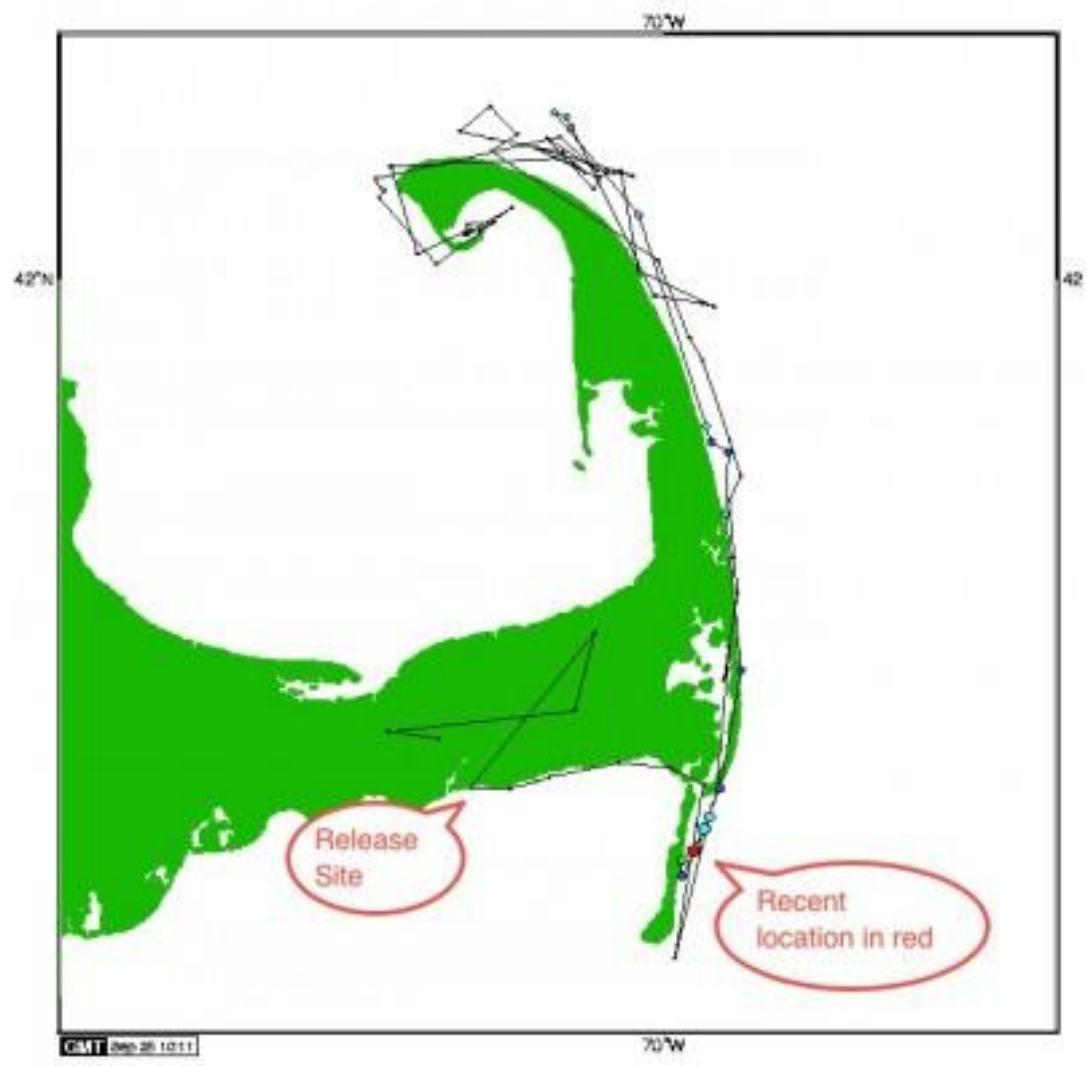

Figure 6: Tracks from GSM-tagged Bronx, released at West Dennis Beach on September 11, 2012

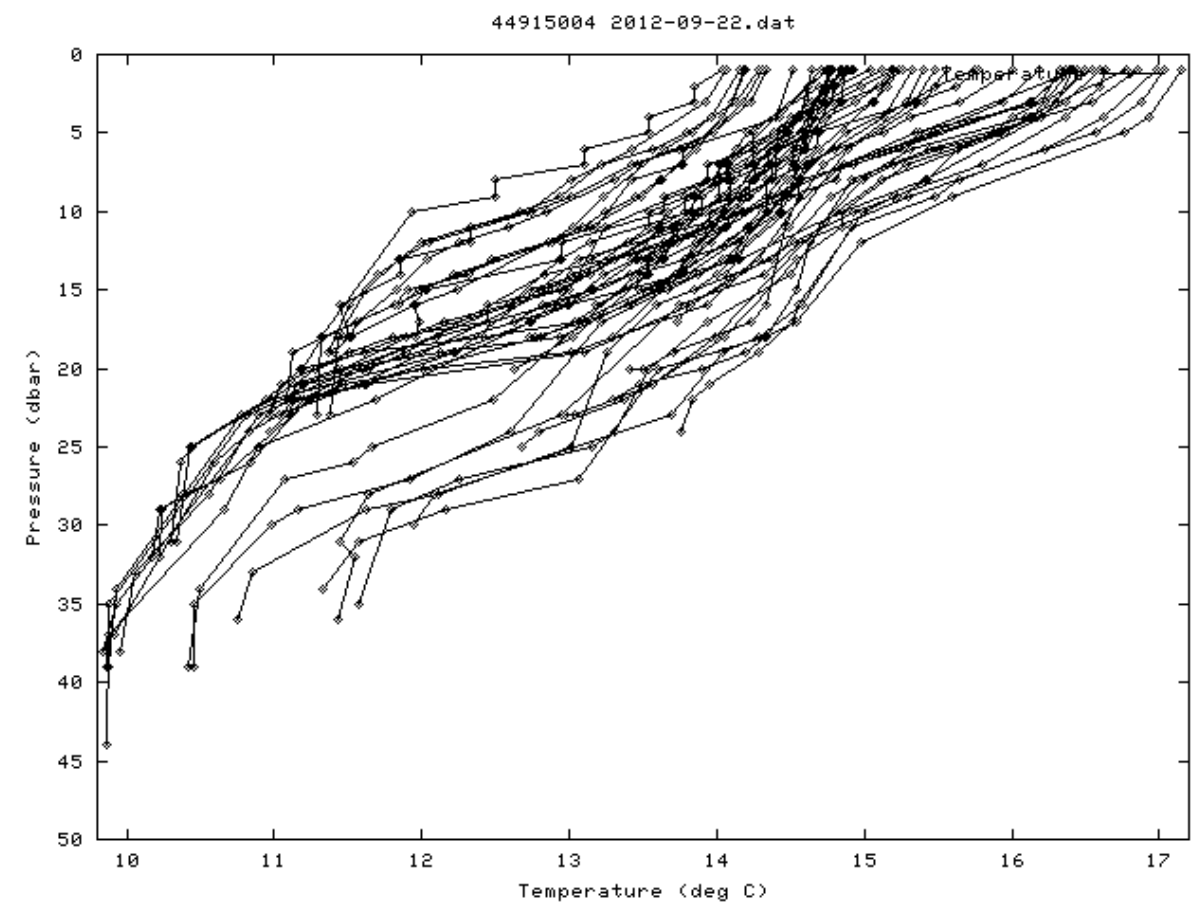

Figure 7: Temperature profiles taken on September 22, 2012 from GSM-tag on Bronx 


\section{Platforms of Opportunities: Marine Megavertebrate Surveys}

PCCS conducts an annual water quality sampling program in Nantucket Sound. In-situ measurements for temperature, salinity and turbidity are taken and water samples are collected twice a month at eight stations throughout the Sound from May through October. The samples are taken to PCCS's statecertified laboratory and analyzed for nitrate+nitrite, ortho-phosphate, ammonia, total nitrogen, total phosphorous and chlorophyll $a$. PCCS had a marine mammal/sea turtle observer on eight sampling cruises: June $12^{\text {th }}$ and the $26^{\text {th }}$; July $10^{\text {th }}$ and the $16^{\text {th }}$; August $1^{\text {st }}$ and $14^{\text {th }}$ and on September $2^{\text {nd }}$ and the $12^{\text {th }}$. A total of two marine mammal and two sea turtle sightings were made during the sampling season: an unidentified seal was sighted during the July $10^{\text {th }}$ cruise off the west side of Monomoy; a gray seal was sighted on August $14^{\text {th }}$ off of Nantucket and a loggerhead was sighted on the same cruise to the east of Great Island in Yarmouth and an live, entangled leatherback was sighted on September $12^{\text {th }}$ off of Waquoit Bay. For the entangled leatherback, the sampling crew called the PCCS hotline and stood by until the disentanglement team reached them and successfully disentangled the turtle. The sampling stations and the sightings are shown in Figure 6. A PCCS observer went out on July16th with the UMass -Dartmouth team as part of the MREC pilot tidal turbine barge test in Muskeget Channel. No marine mammals or turtles were seen. 


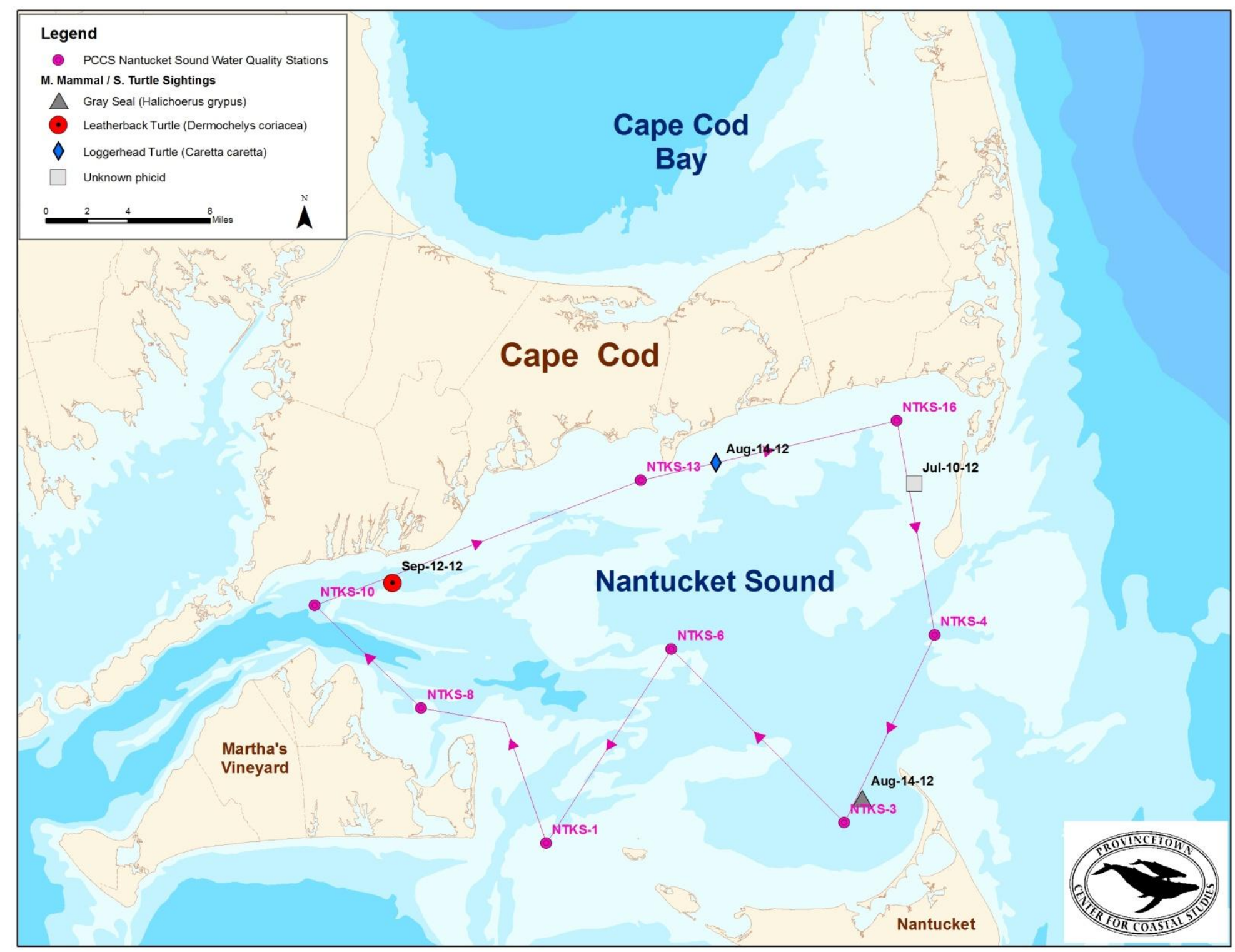

Figure 6: Marine mammal and sea turtle sightings during 2012 PCCS Nantucket Sound Water Quality Monitoring Program. 



\section{Appendix E UMASS Side Scan Sonar Report}





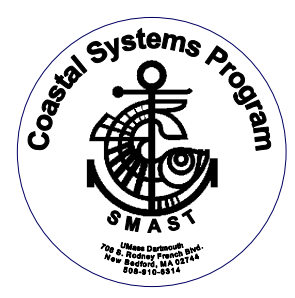

\title{
Environmental Effects of Sediment Transport Alteration and Impacts on Protected Species: Edgartown Tidal Project
}

\author{
Addendum
}

\section{Topic Area II: Marine Science and Hydrokinetic Site Specific Environmental Studies}

\author{
A UMASS Dartmouth Partnership Project between \\ SMAST - Coastal Systems Program (CSP) \\ and \\ Harris, Miller, Miller and Hanson Inc. (HMMH)
}

Submitted by:

Dr. Brian L. Howes

Mr. Roland Samimy, M.S., M.A.

Dr. David Schlezinger

Mr. Michael Bartlett

Mrs. Jennifer Benson

Coastal Systems Program

School of Marine Science and Technology

University of Massachusetts Dartmouth

Submitted to:

United States Department of Energy

December 6, 2012 


\title{
3.8 Side-scan Sonar for High Resolution Bedform Surveying to Characterize Small-scale Roughness and Bedforms Responsible for Bottom Stresses
}

\author{
Side Scan Sonar Survey
}

A detailed side scan sonar survey was conducted October 5, 2012 using an autonomous underwater vehicle (AUV). The AUV was produced by Ocean Server and equipped with a Klein L-3 Model 3500 Sonar, and Sontek Doppler Velocity Log (DVL) for underwater guidance.

Missions were performed $10 \mathrm{~m}$ from the bottom providing an imaging width of $100 \mathrm{~m}$ to either side of the mission path. The last mission (most western transect) was performed at $10 \mathrm{~m}$ from the surface to capture features of the channel wall. All missions were run with the prevailing current direction to conserve battery power. The total distance covered was $20.8 \mathrm{~km}$ and total area surveyed was $2.23 \mathrm{~km}^{2}$ (Figure 1). By utilizing an AUV instead of either a surface mounted or towed array we were able maximize both resolution ( $25 \mathrm{~cm}$ see Figure 2 for example) and survey area (western most transect was bounded by shoals and navigational aids prohibiting the use of towed arrays).

Survey results indicated that the source of most of the sand waves in the channel basin was from shoals to the west of the channel presumably transported by breaking surf produced by prevailing SSW winds (Figure 3). Sand waves within the channel basin appear wide on the western margin and narrow on the eastern margin corroborating a western source as does the orientation northeast to southwest north of gap in the shoals and northwest to southeast south of the gap.

Areas north of the channel basin displayed hallmarks of an erosional to stable environment. Deepest portions of the slope contained laminated sediments suggestive of glacial clay lenses which are common to the region and extremely stable (Figure 4). Further north coarse sand, gravel and boulders dominated the environment (Figure 5) and generally assumed a distribution and orientation consistent with local current direction.

At this time we have not been able to collect sediment samples in the deepest portions of the channel basin to confirm the presence of clay lenses. Despite attempts, depth and high current velocities have prevented the retrieval of samples. If the sediment is indeed consolidated clay which inhibits penetration of coring devices, this may provide a partial explanation for the lack of sediment recovery. Further work under other funding will focus on sediment collection and sub-bottom profiling. 
In general, the sediments underlying the highest current velocities appear to be surficially stable and suitable for many different mooring solutions. However, comparison to lower resolution SWATH multi-beam data collected by the USGS in 2010 over some of the same area indicated that the region may have change significantly over inter-annual time frames. USGS data indicated the presence of larger and more wide spread sand waves throughout the northern portion of the current study area. Results of scour experiments related earlier in the report suggest that the presence or absence of sand waves should not have a significant effect upon the long term stability of traditional anchoring systems. 


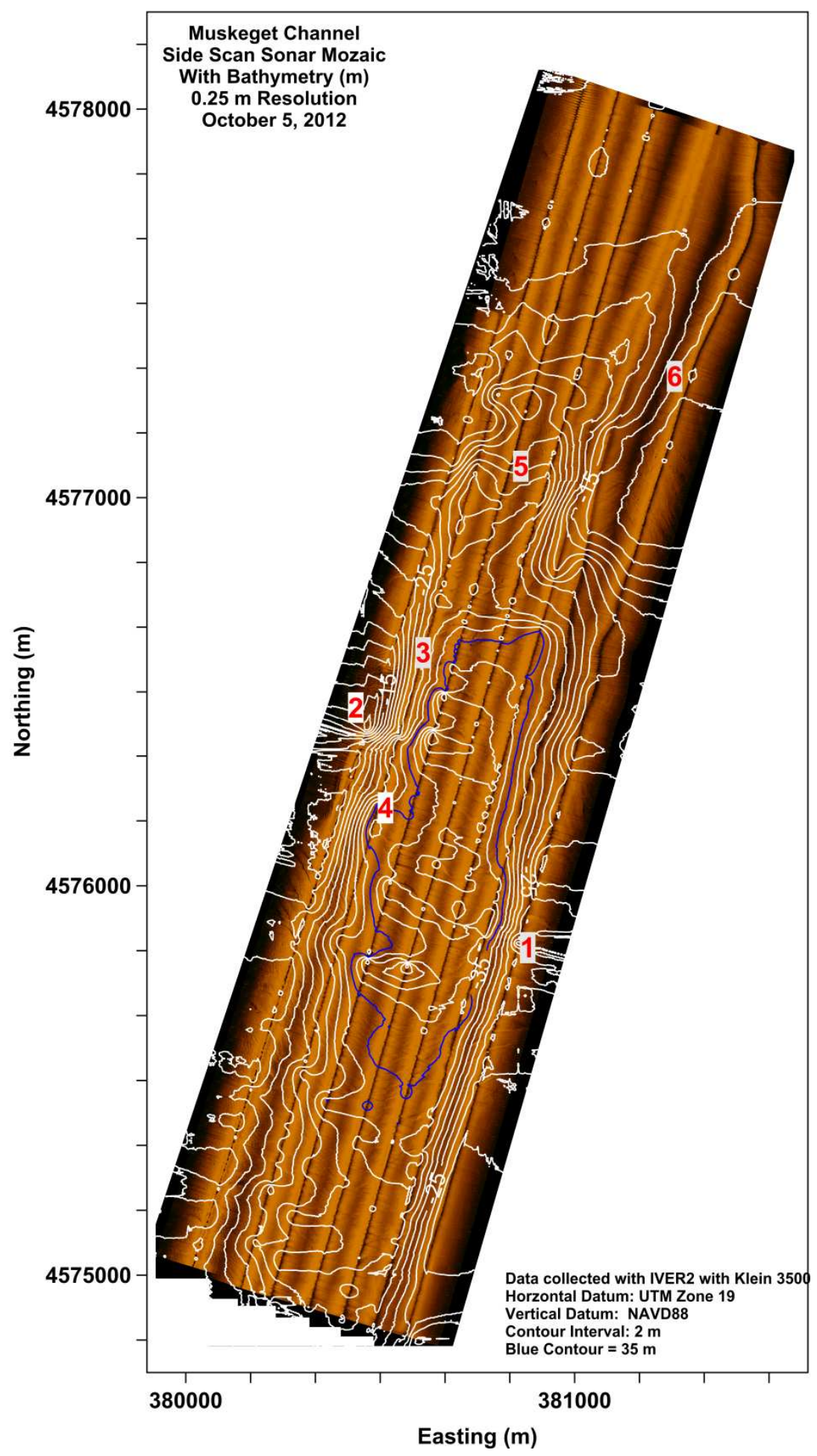

Figure 1. Full side-scan sonar survey area encompassing the entire Muskeget Channel area. Contour lines show depth in meters. Blue contour line indicates $35 \mathrm{~m}$ contour, a depth compatible with largest proposed tidal turbine arrays. 


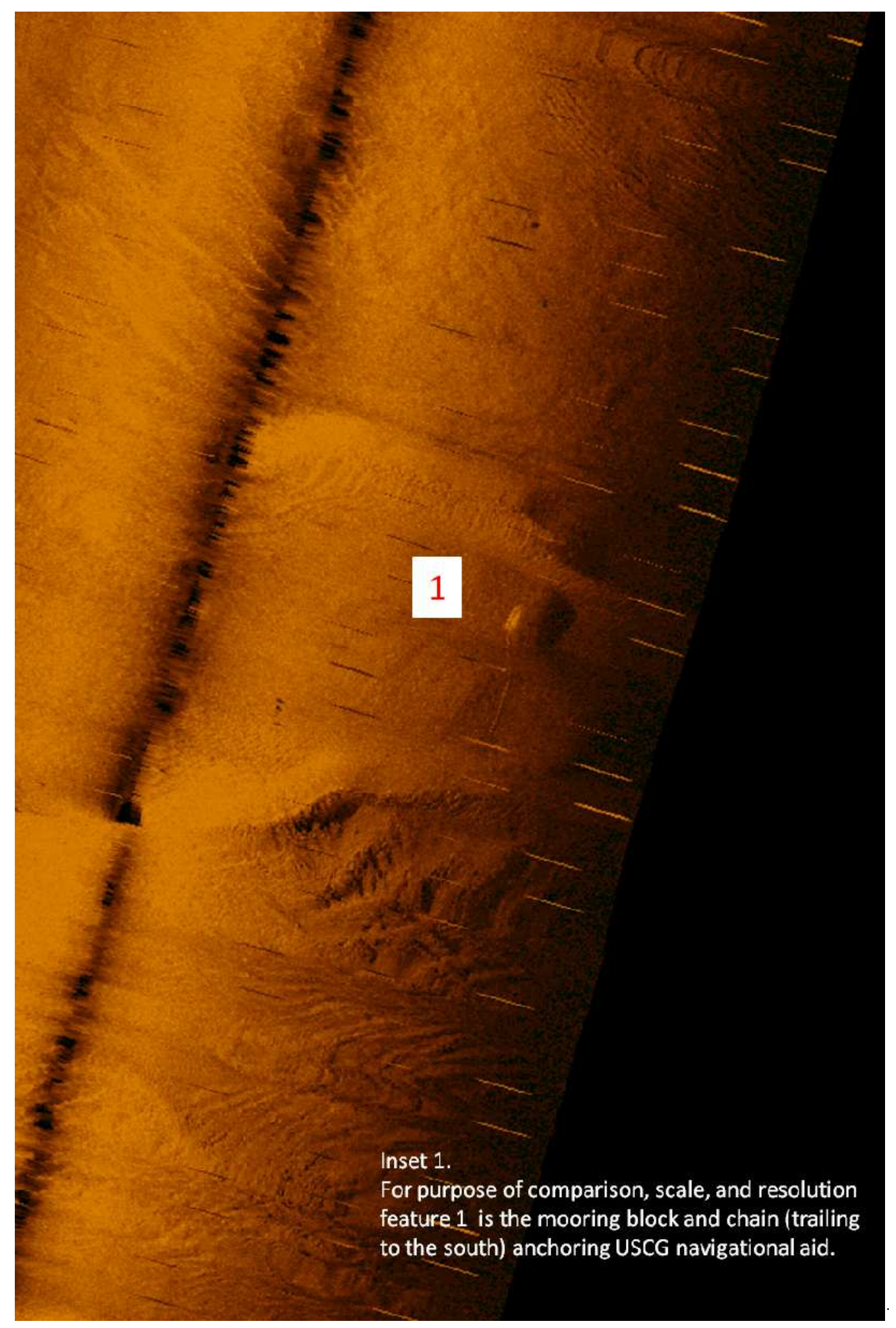

Figure 2. Enlargement showing Location 1 from full map. Mooring weight and chain for navigational aid demonstrate level of overall resolution achieved in survey 


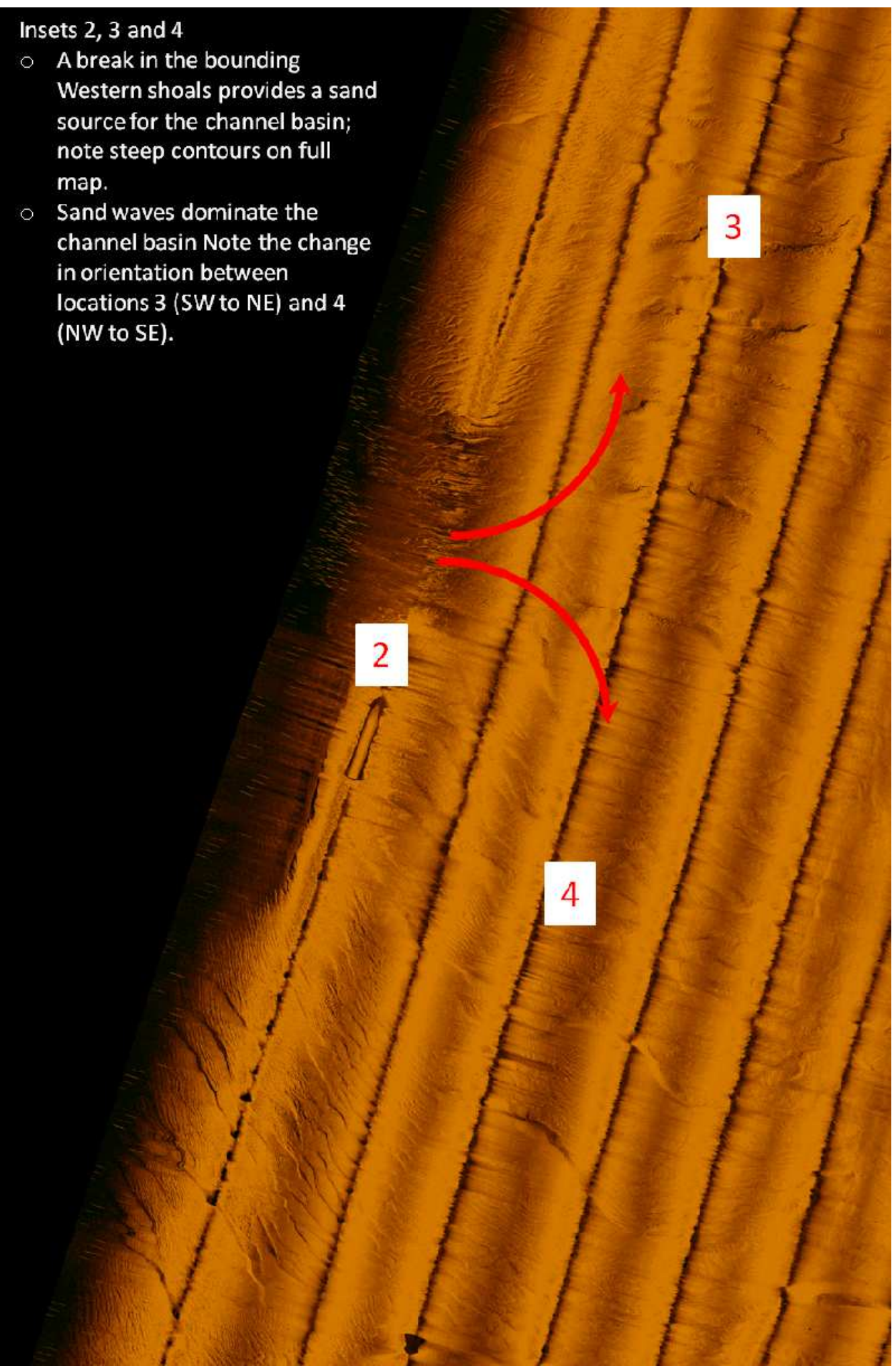

Figure 3. Enlargement showing Location 2, 3 and 4 from full map. Location 2 shows break in western shoal which funnels sand into the channel basin. Locations 3 and 4 indicate sand waves fed by western shoal sand source. 


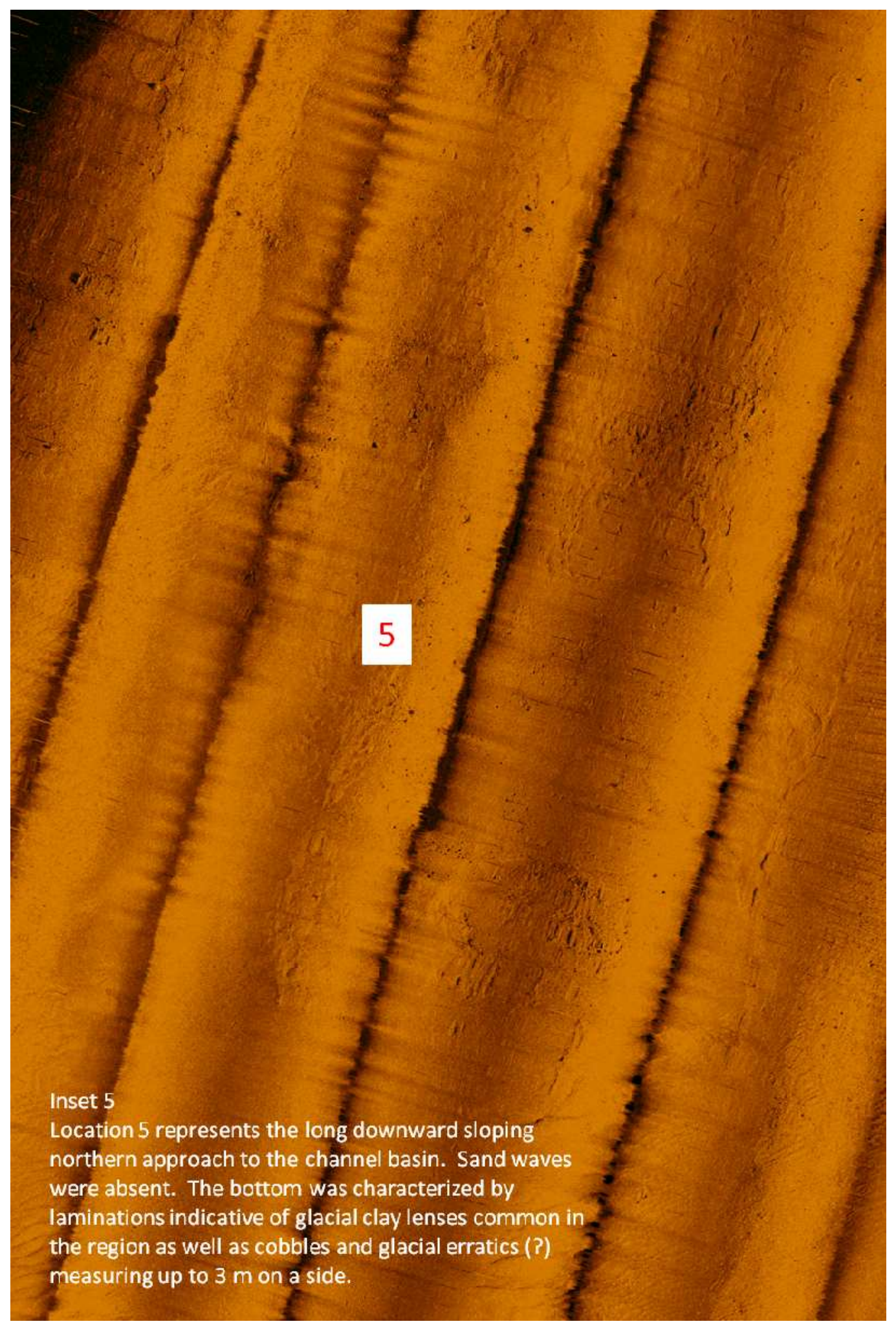

Figure 4. Location 5 in the northern deepest part of the basin displays laminated sediments suggestive glacial clay lenses common in the region. 


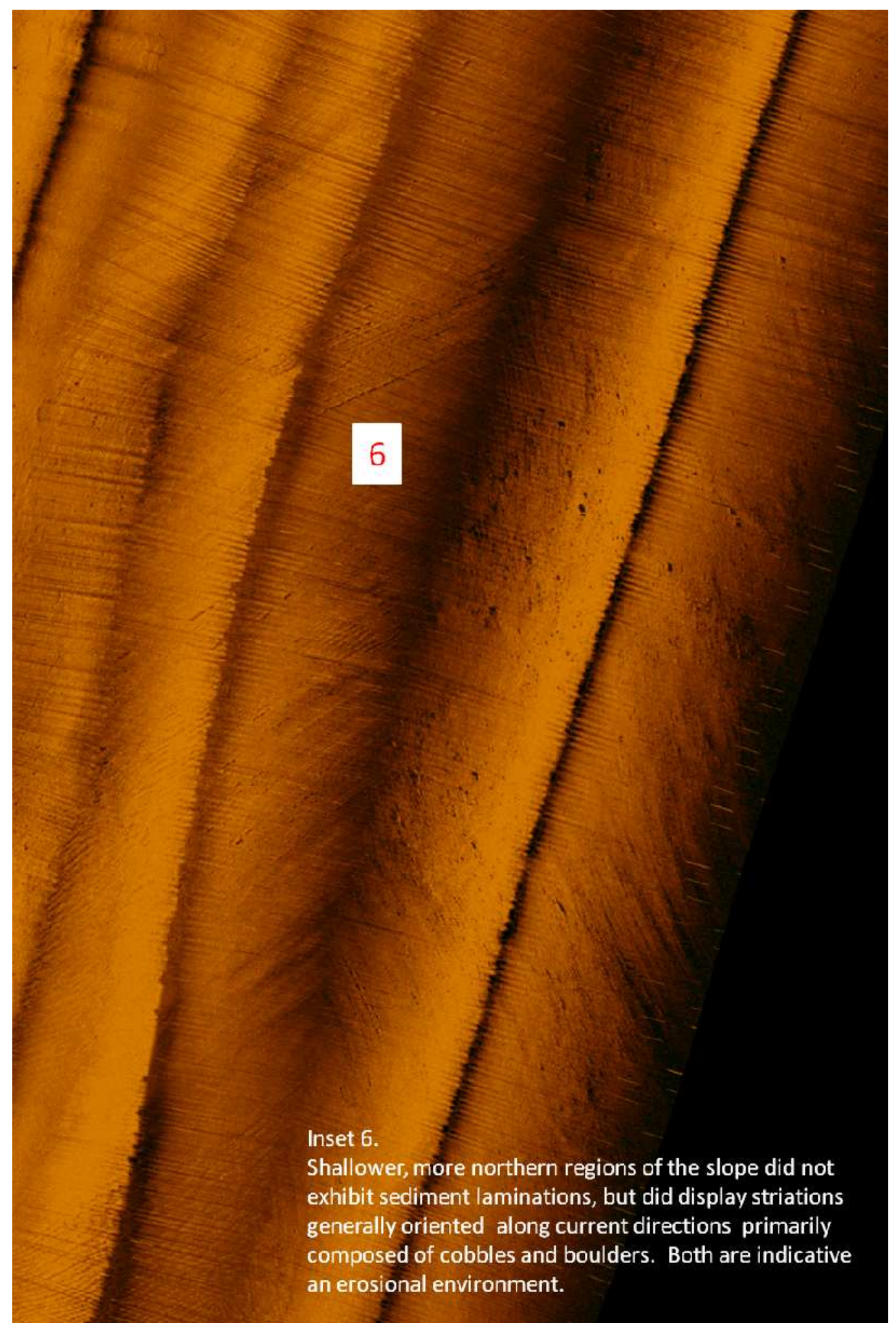

Figure 5. Location 6 in the northern slope display striations indicative of scour and winnowing of fine sediments. Striations are parallel to local current directions. 


\section{Appendix F Regulatory Table}





\begin{tabular}{|c|c|c|c|}
\hline \multicolumn{4}{|c|}{$\begin{array}{c}\text { Overview of Regulatory Review and Permitting for Proposed Muskeget Channel Tidal } \\
\text { Turbine Project }\end{array}$} \\
\hline \multicolumn{4}{|l|}{ Federal } \\
\hline Agency & Authority/Action & Intent/Requirements & Process/Timeline \\
\hline \multirow[t]{2}{*}{$\begin{array}{l}\text { Federal Energy } \\
\text { Regulatory } \\
\text { Commission } \\
\text { (FERC) }\end{array}$} & $\begin{array}{l}\text { Federal Power Act (16 } \\
\text { U.S.C. §§ 791-828 and } \\
\text { CFR } 18 \\
\text { Preliminary Permit }\end{array}$ & $\begin{array}{l}\text { Issued to retain location for potential } \\
\text { hydrokinetic project and provide time to } \\
\text { evaluate site and prepare for pilot licensing } \\
\text { process. }\end{array}$ & $\begin{array}{l}\text { FERC notices receipt of an application on } \\
\text { its e-Docket. Agencies and others have } 60 \\
\text { days from that posting to submit } \\
\text { comments. FERC reviews the initial } \\
\text { application for completeness and can } \\
\text { request additional information. Once } \\
\text { deemed complete FERC issues a letter to } \\
\text { the applicant that, in New England, } \\
\text { requires the applicant to notify the } \\
\text { Department of Interior's Office of } \\
\text { Environmental Affairs, the New England } \\
\text { Division of Army Corps of Engineers and } \\
\text { the Eastern State Office of the Bureau of } \\
\text { Land Management. } \\
\text { Processing of application could take } 6 \\
\text { months or more. Permit is issued for up for } \\
3 \text { years See: } \\
\text { http://www.ferc.gov/industries/hydropower } \\
\text { Lgen-info/licensing/pre-permits.asp }\end{array}$ \\
\hline & Draft Pilot License & $\begin{array}{l}\text { Allows for testing of hydrokinetic } \\
\text { technologies, determination of appropriate } \\
\text { siting of these technologies, and evaluation } \\
\text { of environmental impacts. }\end{array}$ & $\begin{array}{l}\text { The applicant first files a notice of intent to } \\
\text { obtain a pilot license and a complete draft } \\
\text { license application. The application } \\
\text { requirements include: }(1) \text { a description of }\end{array}$ \\
\hline
\end{tabular}




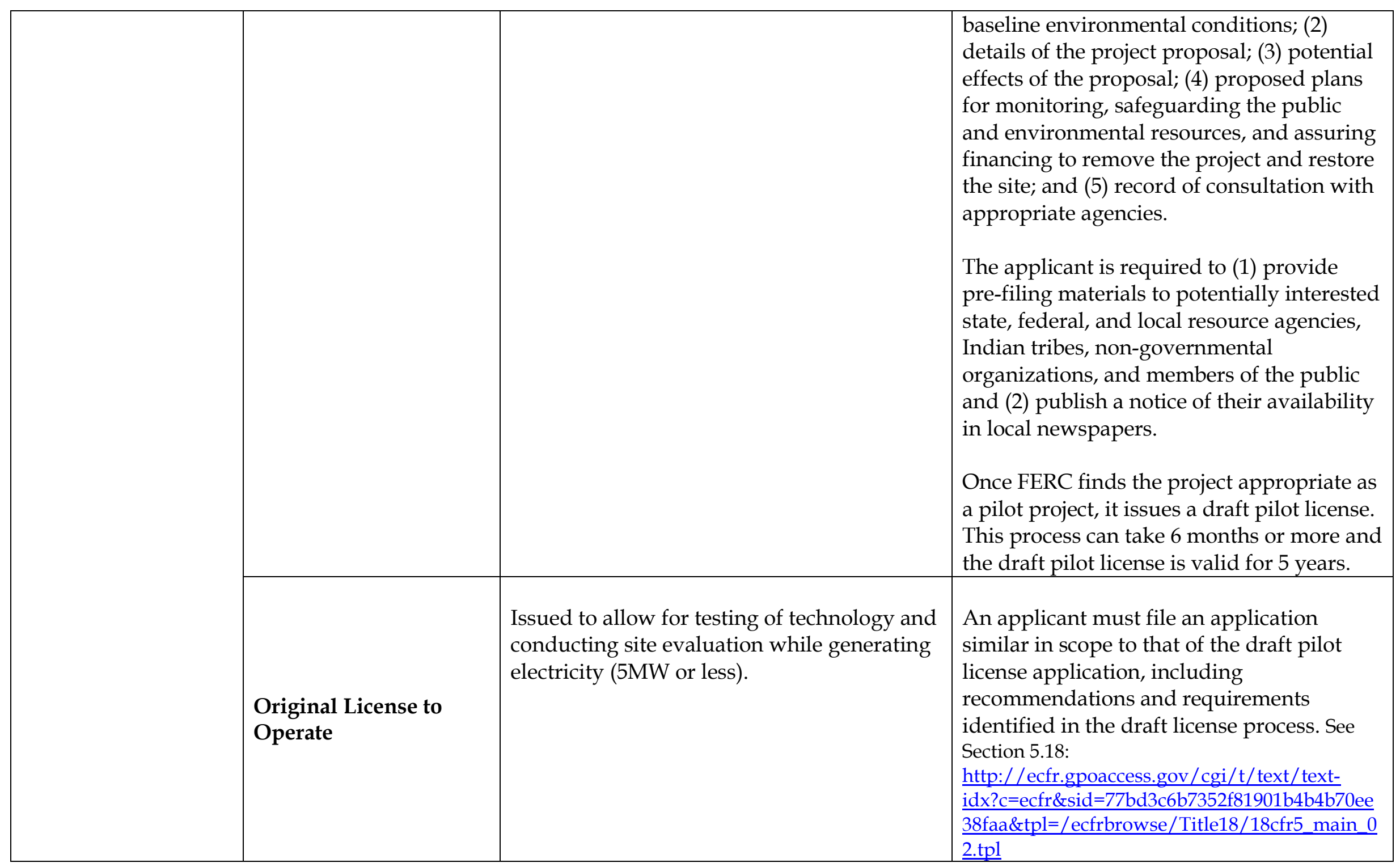




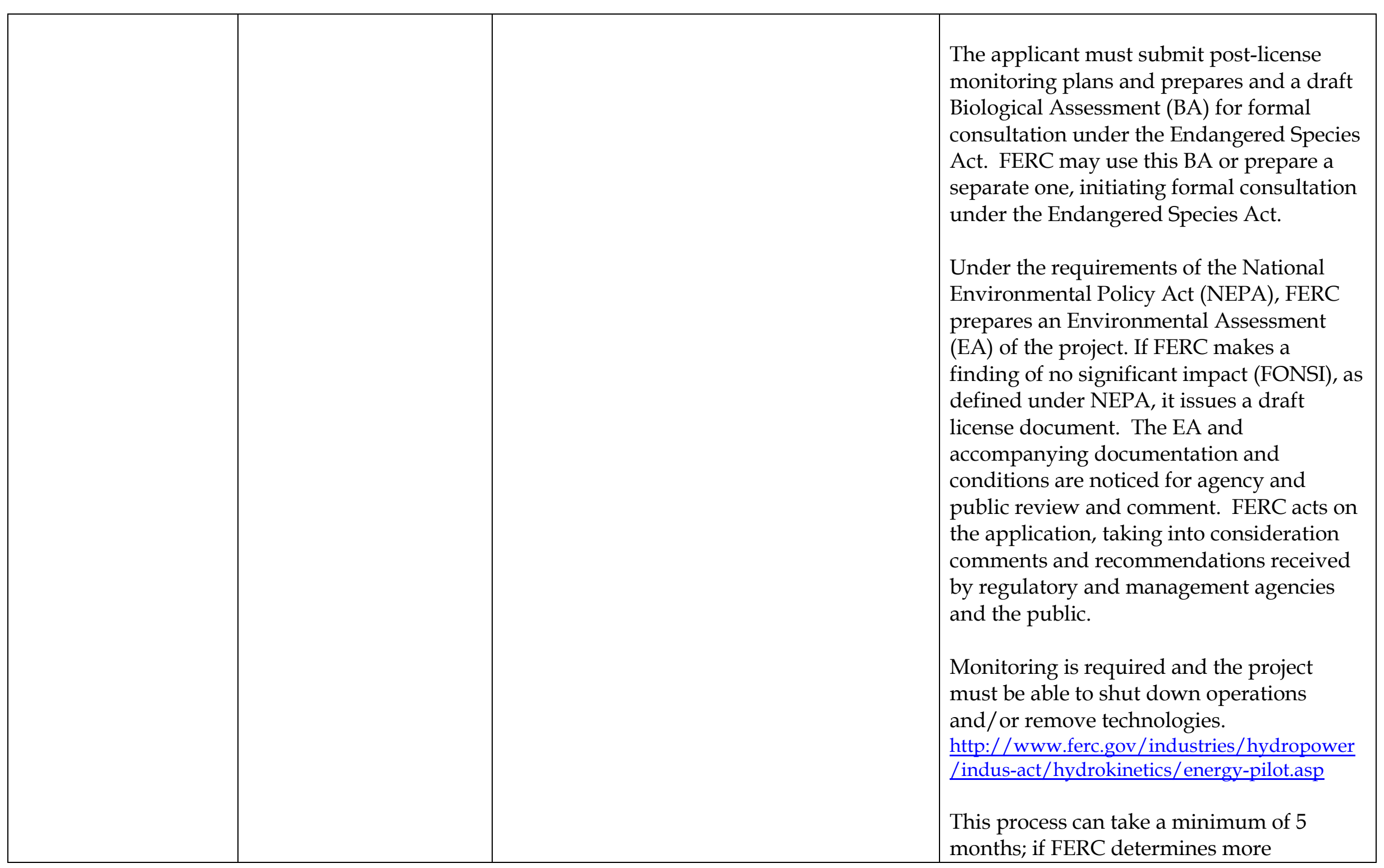




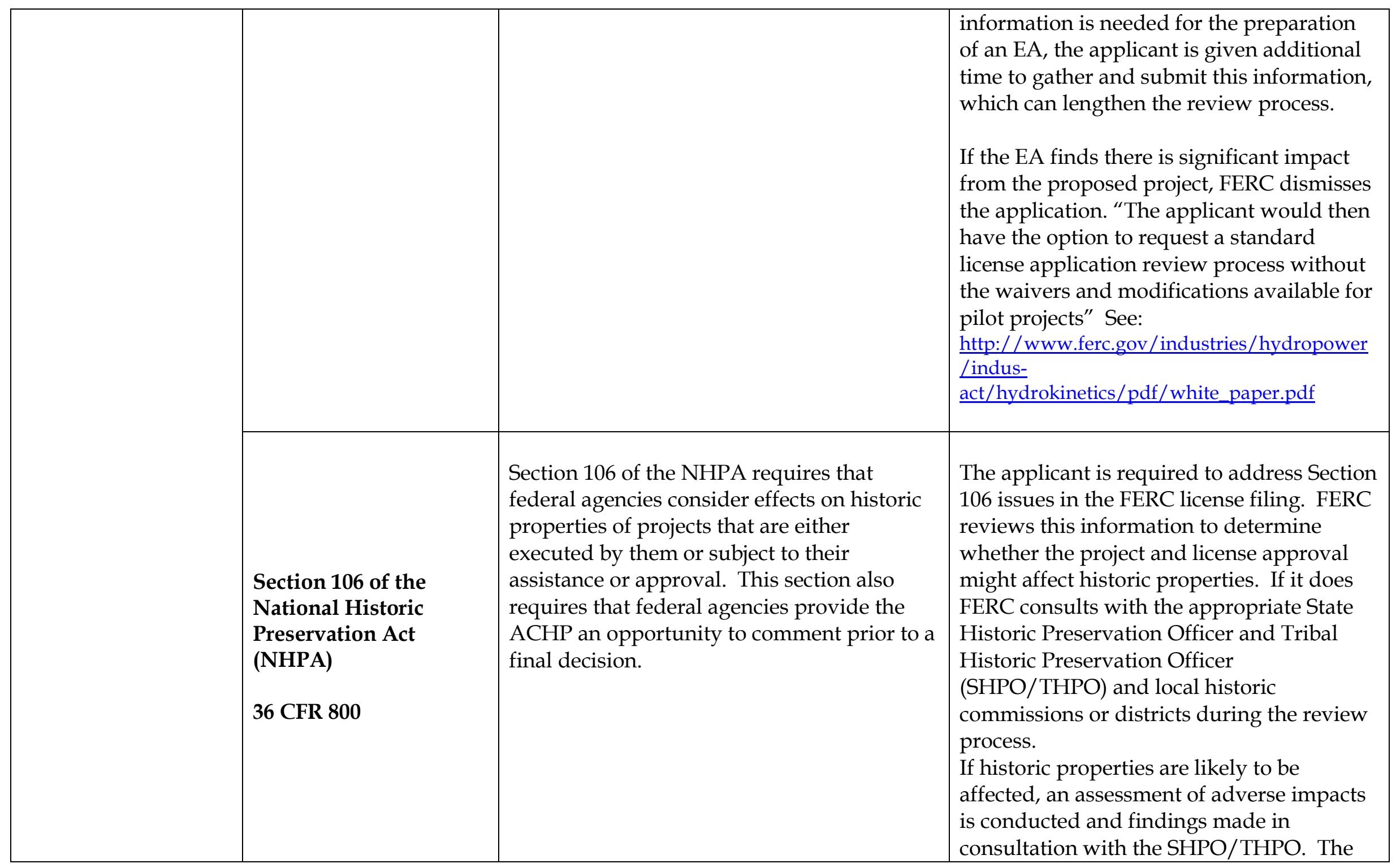




\begin{tabular}{|c|c|c|c|}
\hline & & & $\begin{array}{l}\text { consultation process concludes with a } \\
\text { Memorandum of Agreement (MOA) } \\
\text { detailing the measures the agency and } \\
\text { applicant will take to avoid, minimize, or } \\
\text { mitigate the adverse effects. There is a } \\
\text { process for addressing situations in which } \\
\text { the parties cannot agree on whether there } \\
\text { are adverse impacts or how to address } \\
\text { adverse impacts. } \\
\text { See: http://www.achp.gov/106summary.html }\end{array}$ \\
\hline & $\begin{array}{l}\text { National } \\
\text { Environmental Policy } \\
\text { Act (NEPA) } \\
42 \text { USC } \S 4321-4370 \text { and } \\
40 \text { CFR } \$ \$ 1500-1508\end{array}$ & $\begin{array}{l}\text { The purpose of NEPA is to ensure that } \\
\text { agencies evaluate the potential } \\
\text { environmental impacts of a proposed action } \\
\text { and reasonable alternatives to the proposed } \\
\text { action, before a significant federal action is } \\
\text { taken, i.e. a direct activity or issuance of a } \\
\text { federal permit. }\end{array}$ & $\begin{array}{l}\text { As discussed under FERC- Original License } \\
\text { to Operate- the issuance of a FERC license } \\
\text { to operate triggers NEPA review. If the } \\
\text { agency finds that the project is not likely to } \\
\text { have significant effects, it prepares an } \\
\text { Environmental Assessment (EA) along } \\
\text { with a Finding of No Significant Impact } \\
\text { (FONSI). If FERC determines that there } \\
\text { needs to be more analysis of alternatives } \\
\text { and potential impacts, it will prepare either } \\
\text { an EA or an Environmental Impact } \\
\text { Statement (EIS). } \\
\text { This process, which includes public review } \\
\text { and comment, can take more than a year to } \\
\text { complete. }\end{array}$ \\
\hline $\begin{array}{l}\text { Army Corps of } \\
\text { Engineers } \\
\text { (USACE) }\end{array}$ & $\begin{array}{l}\text { Section } 10 \text { of the } \\
\text { Rivers and Harbors } \\
\text { Act of } 1899\end{array}$ & $\begin{array}{l}\text { The purpose of this law is to protect } \\
\text { navigable waters of the U.S. from being } \\
\text { obstructed or altered without government }\end{array}$ & $\begin{array}{l}\text { When FERC is issuing a license under the } \\
\text { Federal Power Act for activities regulated } \\
\text { under Section 10, the Corps provides }\end{array}$ \\
\hline
\end{tabular}




\begin{tabular}{|c|c|c|c|}
\hline & 33 U.S.C. 401-413 & $\begin{array}{l}\text { oversight. Construction of any structure in } \\
\text { or over any navigable water of the U.S., } \\
\text { dredging or depositing of dredged material, } \\
\text { or the accomplishment of any other work } \\
\text { affecting the course, location, condition, or } \\
\text { capacity of U.S. navigable waters requires } \\
\text { authorization. }\end{array}$ & $\begin{array}{l}\text { comments and recommendations to FERC } \\
\text { regarding the impacts of the activity on } \\
\text { navigation. The Corps does not issue a } \\
\text { separate Section } 10 \text { permit. }\end{array}$ \\
\hline & $\begin{array}{l}\text { Section } 404 \text { of the } \\
\text { Clean Water Act (CWA) } \\
33 \text { CFR } 323\end{array}$ & $\begin{array}{l}\text { This law prohibits discharges of dredged or } \\
\text { fill material into waters of the United States, } \\
\text { including wetlands, without a permit from } \\
\text { the USACE. }\end{array}$ & $\begin{array}{l}\text { Depending on the results of consultation } \\
\text { with the U.S. Fish and Wildlife Service and } \\
\text { the National Marine Fisheries Service with } \\
\text { regard to potential impacts on listed } \\
\text { species and habitat, the proposed Muskeget } \\
\text { tidal energy project may be reviewed as a } \\
\text { Category II project under the USACE's } \\
\text { Massachusetts General Permit. This review } \\
\text { is usually done concurrent with the Section } \\
10 \text { process. } \\
\text { See Appendix A of the Massachusetts GP at: } \\
\text { http://www.nae.usace.army.mil/reg/Permits/ } \\
\text { MA_GP.pdf and } \\
\text { http://www.nae.usace.army.mil/reg/Forms/ } \\
\text { Application_PlanGuidelines.pdf. }\end{array}$ \\
\hline $\begin{array}{l}\text { US Coast Guard } \\
\text { (USCG) }\end{array}$ & $\begin{array}{l}\text { Aids to Navigation } \\
33 \text { CFR } 66.01 \text { and under } \\
\text { provisions of } 46 \text { U.S.C. } \\
\text { and } 33 \text { U.S.C. } § 30\end{array}$ & $\begin{array}{l}\text { The United States Coast Guard has safety } \\
\text { and regulatory jurisdiction over projects } \\
\text { located in navigable waters of the United } \\
\text { States and is responsible for granting } \\
\text { permits for private aids to navigation. }\end{array}$ & $\begin{array}{l}\text { An application addressing the need for aids } \\
\text { to navigation in Massachusetts waters must } \\
\text { be filed with the Coast Guard First District } \\
\text { Commander in Boston. } \\
\text { See: } \\
\text { http://www.uscg.mil/forms/cg/CG_2554.pdf }\end{array}$ \\
\hline
\end{tabular}




\begin{tabular}{|c|c|c|c|}
\hline & & & $\begin{array}{l}\text { Once the application is approved by the } \\
\text { First District Commander, approval for } \\
\text { operation of radar beacons (racons) is } \\
\text { effective for an initial two year period, and } \\
\text { then subject to annual review. See: } \\
\text { http://frwebgate2.access.gpo.gov/cgi- } \\
\text { bin/PDFgate.cgi?WAISdocID=6JjW93/6/2/0\& } \\
\text { WAISaction=retrieve }\end{array}$ \\
\hline $\begin{array}{c}\text { National Oceanic } \\
\text { and Atmospheric } \\
\text { Admin. (NOAA) } \\
\text { National Marine } \\
\text { Fisheries Service } \\
\text { (NMFS) }\end{array}$ & $\begin{array}{l}\text { Marine Mammal } \\
\text { Protection Act (MMPA) } \\
16 \text { USC §§ 1361-1421, et } \\
\text { seq. }\end{array}$ & $\begin{array}{l}\text { The MMPA is the primary federal legislation } \\
\text { that provides for the protection and } \\
\text { management of marine mammals } \\
\text { The MMPA prohibits, with certain } \\
\text { exceptions, the taking of marine mammals } \\
\text { in U.S. waters and by U.S. citizens on the } \\
\text { high seas, as well as the importation of } \\
\text { marine mammals and marine mammal } \\
\text { products into the United States. Under the } \\
\text { MMPA, the National Oceanic and } \\
\text { Atmospheric Administration (NOAA) has } \\
\text { responsibility for ensuring the protection of } \\
\text { cetaceans (whales, porpoises, and dolphins) } \\
\text { and pinnipeds (seals and sea lions), except } \\
\text { walruses. }\end{array}$ & $\begin{array}{l}\text { Section 101(a)(5) (A-D) of the MMPA, as } \\
\text { amended (16 U.S.C. 1371(a)(5)), provides a } \\
\text { mechanism for allowing, upon request, the } \\
\text { "incidental" but not intentional, taking of } \\
\text { small numbers of marine mammals by U.S. } \\
\text { citizens who engage in a specified activity } \\
\text { (other than commercial fishing) within a } \\
\text { specified geographic region. } \\
\text { There are two types of "take"- incidental } \\
\text { and harassment. } \\
\text { An applicant applies for an Incidental } \\
\text { Harassment Authorization (IHA)for an } \\
\text { activity if it can be shown that: } \\
\text { 1. there is no potential for serious injury } \\
\text { or mortality or, } \\
\text { 2. the potential for serious injury or } \\
\text { mortality can be negated through } \\
\text { mitigation requirements that could be } \\
\text { required under the authorization } \\
\text { If the potential for "serious injury" and/or } \\
\text { mortalities exists and there are no } \\
\text { mitigating measures that could be taken to }\end{array}$ \\
\hline
\end{tabular}




\begin{tabular}{|c|c|c|c|}
\hline & & & $\begin{array}{l}\text { prevent this form of 'take' from occurring, } \\
\text { the applicant must obtain an Incidental } \\
\text { Take Authorization or Letter of } \\
\text { Authorization (LOA). } \\
\text { An IHA authorization can take } 3 \text { months or } \\
\text { more to be processed; an LOA can take 6- } 8 \\
\text { months or more. } \\
\text { See:http://www.nmfs.noaa.gov/pr/permits/i } \\
\text { ncidental.htm }\end{array}$ \\
\hline & $\begin{array}{l}\text { Endangered Species } \\
\text { Act (ESA) } \\
16 \text { U.S.C. } \$ \S 1531-1544 \text {, } \\
50 \text { CFR } 17.00\end{array}$ & $\begin{array}{l}\text { The Endangered Species Act is directed at } \\
\text { conserving the ecosystems upon which } \\
\text { endangered and threatened species depend } \\
\text { and implementing programs for the } \\
\text { conservation of such species. Under the ESA } \\
\text { all Federal agencies are required to } \\
\text { participate in conserving these species. }\end{array}$ & $\begin{array}{l}\text { Section } 7(\text { a)(2) of the ESA requires that } \\
\text { agencies, through consultation with the } \\
\text { National Oceanic and Atmospheric } \\
\text { Administration (NOAA) and the U.S Fish } \\
\text { and Wildlife Service (USFWS), ensure their } \\
\text { activities are not likely to jeopardize the } \\
\text { continued existence of listed species or } \\
\text { adversely modify designated critical } \\
\text { habitats. } \\
\text { Informal consultation under the ESA } \\
\text { occurs during the filing and review of the } \\
\text { FERC draft pilot license. If FERC } \\
\text { determines that the project is not likely to } \\
\text { adversely affect a listed species or } \\
\text { designated critical habitat, and NMFS } \\
\text { concurs in writing, the informal } \\
\text { consultation is concluded. Formal } \\
\text { consultation may be required if FERC finds } \\
\text { that listed species may be affected by a } \\
\text { proposed project. }\end{array}$ \\
\hline
\end{tabular}




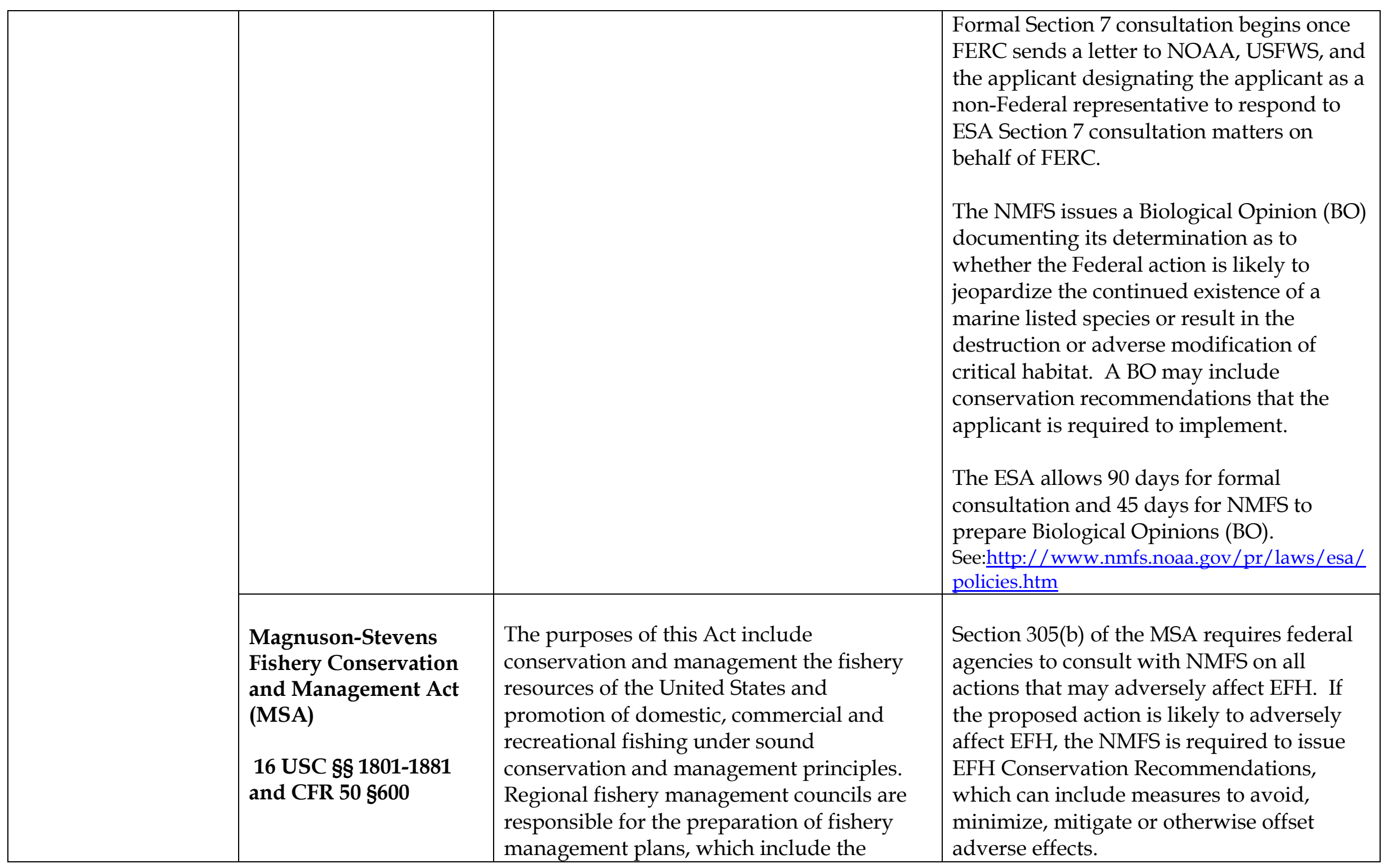




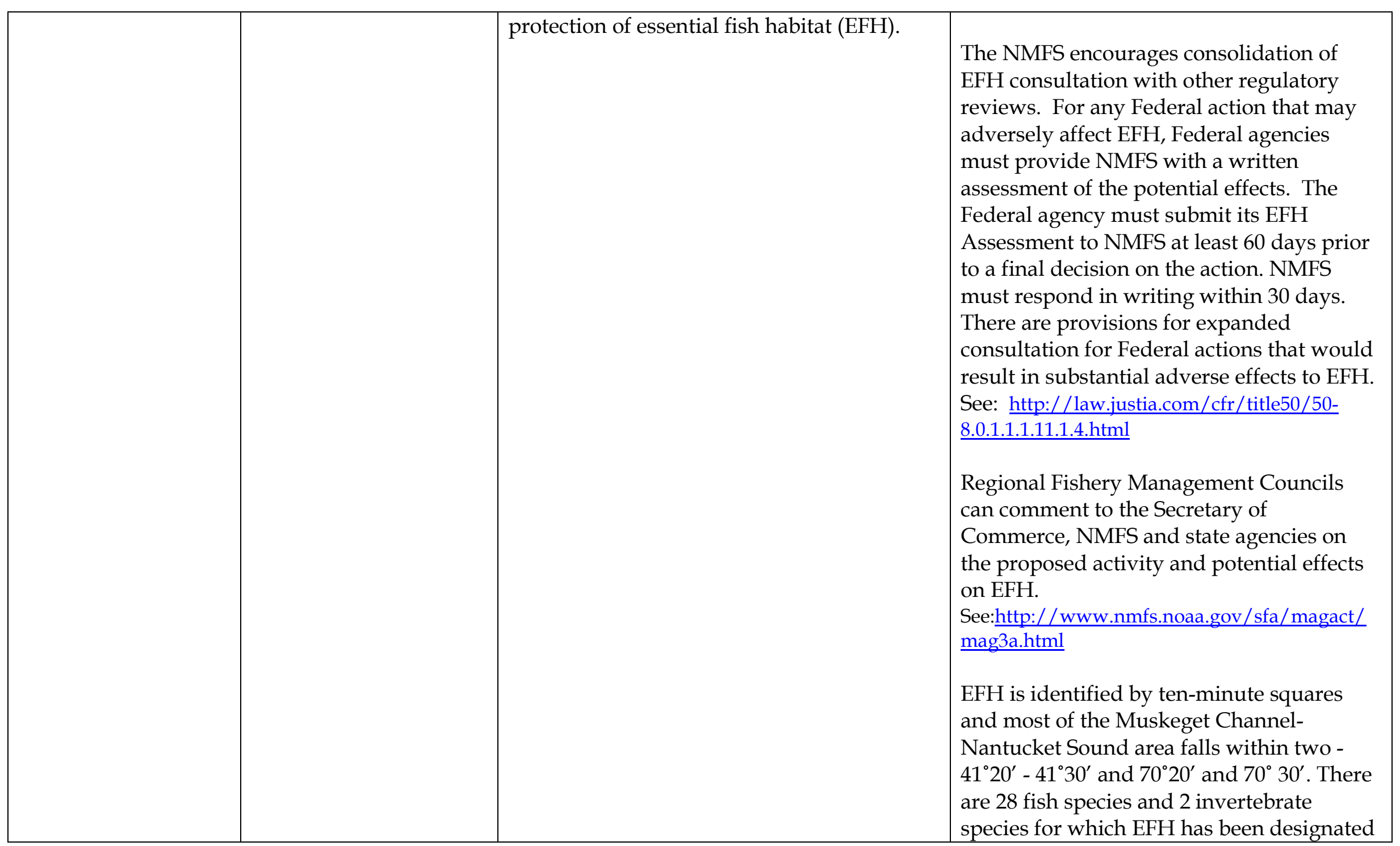




\begin{tabular}{|c|c|c|c|}
\hline & & & in this area. \\
\hline $\begin{array}{l}\text { Department of the } \\
\text { Interior } \\
\text { US Fish and } \\
\text { Wildlife Service } \\
\text { (USFWS) }\end{array}$ & $\begin{array}{l}\text { Fish and Wildlife } \\
\text { Coordination Act } \\
16 \text { USC 661, et seq. }\end{array}$ & $\begin{array}{l}\text { The purpose of the Act is to recognize the } \\
\text { contribution of wildlife resources to the } \\
\text { Nation and to help ensure that wildlife } \\
\text { conservation receives equal consideration } \\
\text { and be coordinated with other aspects of } \\
\text { water-resources development programs. }\end{array}$ & $\begin{array}{l}\text { Generally the U.S. Fish and Wildlife Service } \\
\text { and the National Marine Fisheries Service } \\
\text { execute their responsibilities under this Act } \\
\text { through their review of USACE Section } 10 \\
\text { and/or Section } 404 \text { permits for coastal and } \\
\text { marine projects. The USACE is required to } \\
\text { notify these agencies early in the project } \\
\text { development or project review process. } \\
\text { See: } \\
\text { http://el.erdc.usace.army.mil/emrrp/emris/e } \\
\text { mrishelp5/fish_and_wildlife_coordination_act } \\
\text { legal_matters.htm } \\
\text { In its } 1991 \text { report to Congress - Northeast } \\
\text { Coastal Areas Study: Significant Coastal } \\
\text { Habitats of Southern New England and } \\
\text { Portions of Long Island, New York- the } \\
\text { USFWS identified Muskeget Channel, } \\
\text { Muskeget and Tuckernuck Islands, and the } \\
\text { Coastal Sandplain and Beach Complex of } \\
\text { Martha's Vineyard as significant coastal } \\
\text { habitats. The report also notes that } \\
\text { Muskeget Island is a designated National } \\
\text { Natural Landmark, due primarily to the } \\
\text { presence of breeding gray seals and beach } \\
\text { voles. } \\
\text { See: } \\
\text { http://www.buzzardsbay.org/bbpreports/sig }\end{array}$ \\
\hline
\end{tabular}




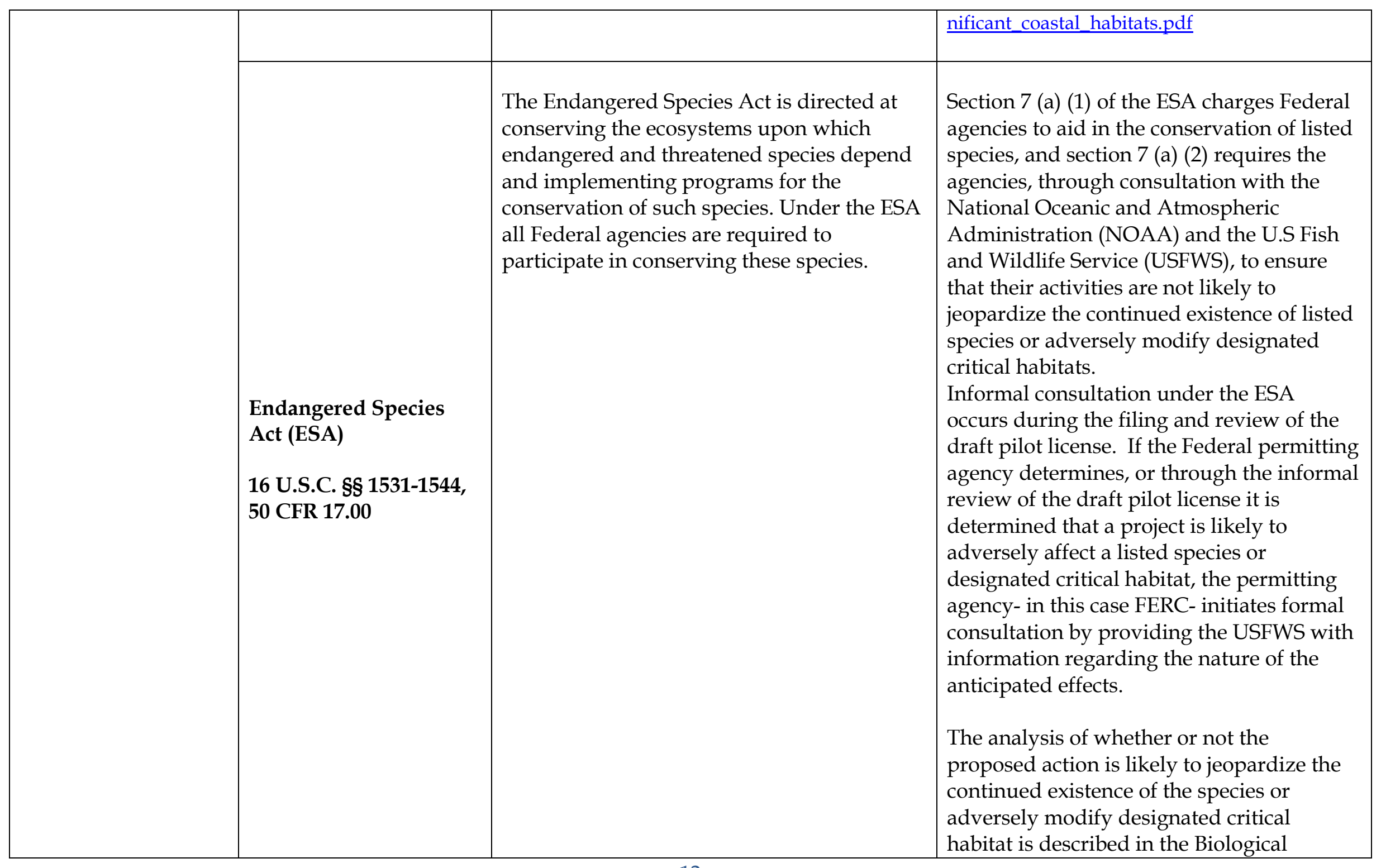




\begin{tabular}{|c|c|c|c|}
\hline & & & $\begin{array}{l}\text { Opinion (BO). If a jeopardy or adverse } \\
\text { modification determination is made, the } \\
\text { BO must identify reasonable and prudent } \\
\text { alternatives that could allow approval and } \\
\text { implementation of the project. } \\
\text { See: http://www.fws.gov/endangered/esa- } \\
\text { library/pdf/consultations.pdf and } \\
\text { http://www.fws.gov/newengland/Endangere } \\
\underline{\mathrm{dSpec}-\text { Consultation_Project_Review.htm and }} \\
\text { \%ttp://www.fws.gov/newengland/pdfs/MA } \\
\text { \%20ecies\%20by\%20town.pdf }\end{array}$ \\
\hline & $\begin{array}{l}\text { Migratory Bird } \\
\text { Executive Order } 13186 \\
\text { (EO) }\end{array}$ & $\begin{array}{l}\text { The EO requires any federal agency taking } \\
\text { actions that have, or are likely to have, a } \\
\text { measurable negative effect on migratory } \\
\text { bird populations to develop and implement } \\
\text { a Memorandum of Understanding (MOU) } \\
\text { with the U.S. Fish and Wildlife Service to } \\
\text { promote the conservation of migratory bird } \\
\text { populations. }\end{array}$ & $\begin{array}{l}\text { In March 2011, FERC and the USFWS } \\
\text { signed an MOU regarding implementation } \\
\text { of Executive Order } 13186 . \\
\text { Review under this EO is done in } \\
\text { conjunction with other reviews and } \\
\text { interagency coordination required under } \\
\text { other authorities, i.e. USACE permitting, } \\
\text { etc. } \\
\text { See: } \underline{\mathrm{http}: / / \text { www.ferc.gov/legal/maj-ord- }} \\
\text { reg/mou/mou-fws.pdf }\end{array}$ \\
\hline $\begin{array}{l}\text { Environmental } \\
\text { Protection Agency } \\
\text { (EPA) }\end{array}$ & $\begin{array}{l}\text { National Pollution } \\
\text { Discharge Elimination } \\
\text { System (NPDES) } \\
33 \text { U.S.C. } \$ 1251 \text { et seq.: } \\
\text { Federal Water } \\
\text { Pollution Control Act; } \\
\text { 40 CFR } 122\end{array}$ & $\begin{array}{l}\text { The EPA regulates water quality, sediment, } \\
\text { and pollutant discharge into U.S. waters } \\
\text { under the NPDES program }\end{array}$ & $\begin{array}{l}\text { Operators of large and small construction } \\
\text { activities must obtain authorization under } \\
\text { the NPDES construction stormwater } \\
\text { permit. A large construction activity is } \\
\text { defined as one that will disturb five or } \\
\text { more acres of land; a small construction } \\
\text { activity is one that will disturb one or more }\end{array}$ \\
\hline
\end{tabular}




\begin{tabular}{|l|l|l|l|}
\hline & & $\begin{array}{l}\text { but less than five acres of land. } \\
\text { There is a general permit (GP) for small } \\
\text { construction activities. See: } \\
\text { http://cfpub.epa.gov/npdes/stormwater/cgpf } \\
\frac{\text { aqs.cfm\#231 }}{\text { To obtain authorization under the GP, a }} \\
\text { project proponent is required to file a } \\
\text { notice of intent (NOI) through EPA's } \\
\text { electronic filing system See: } \\
\text { http://cfpub.epa.gov/npdes/stormwater/enoi } \\
\text {.cfm }\end{array}$ \\
\hline
\end{tabular}

\begin{tabular}{|c|c|c|c|}
\hline \multicolumn{4}{|l|}{ State } \\
\hline Agency & Authority/Action & Intent/Requirements & Process/Timeframe \\
\hline $\begin{array}{c}\text { Exec. Office of } \\
\text { Energy and } \\
\text { Environmental } \\
\text { Affairs (EOEEA) }\end{array}$ & $\begin{array}{l}\text { Mass. Environmental } \\
\text { Policy Act (MEPA) } \\
\text { M.G.L. c. } 30, \S \S 61-62 \mathrm{H} \\
\text { and } 301 \text { CMR } 11.00 \\
\text { Certificates on } \\
\text { Environmental } \\
\text { Notification Form } \\
\text { (ENF) and/or Final } \\
\text { Environmental Impact } \\
\text { Report (EIR) }\end{array}$ & $\begin{array}{l}\text { The intent of the MEPA review is to provide } \\
\text { an opportunity for project proponents, state } \\
\text { agencies and the public to review potential } \\
\text { adverse environmental impacts of a } \\
\text { proposed project during its planning phase. } \\
\text { MEPA identifies specific thresholds for state } \\
\text { permitted or funded projects that require } \\
\text { filing of either an ENF or an EIR. }\end{array}$ & $\begin{array}{l}\text { A project proponent files an Environmental } \\
\text { Notification Form (ENF) with the MEPA } \\
\text { Program. Depending on the review } \\
\text { thresholds, a proposed project may also be } \\
\text { required to submit a mandatory EIR. In } \\
\text { their review of the ENF, state agencies } \\
\text { identify aspects of the proposal that will } \\
\text { require additional description or analysis } \\
\text { before the agency can issue its } \\
\text { permit/approval. } \\
\text { Within the } 30 \text { day public comment period, } \\
\text { the Massachusetts Secretary of Energy and } \\
\text { Environmental Affairs issues a certificate }\end{array}$ \\
\hline
\end{tabular}




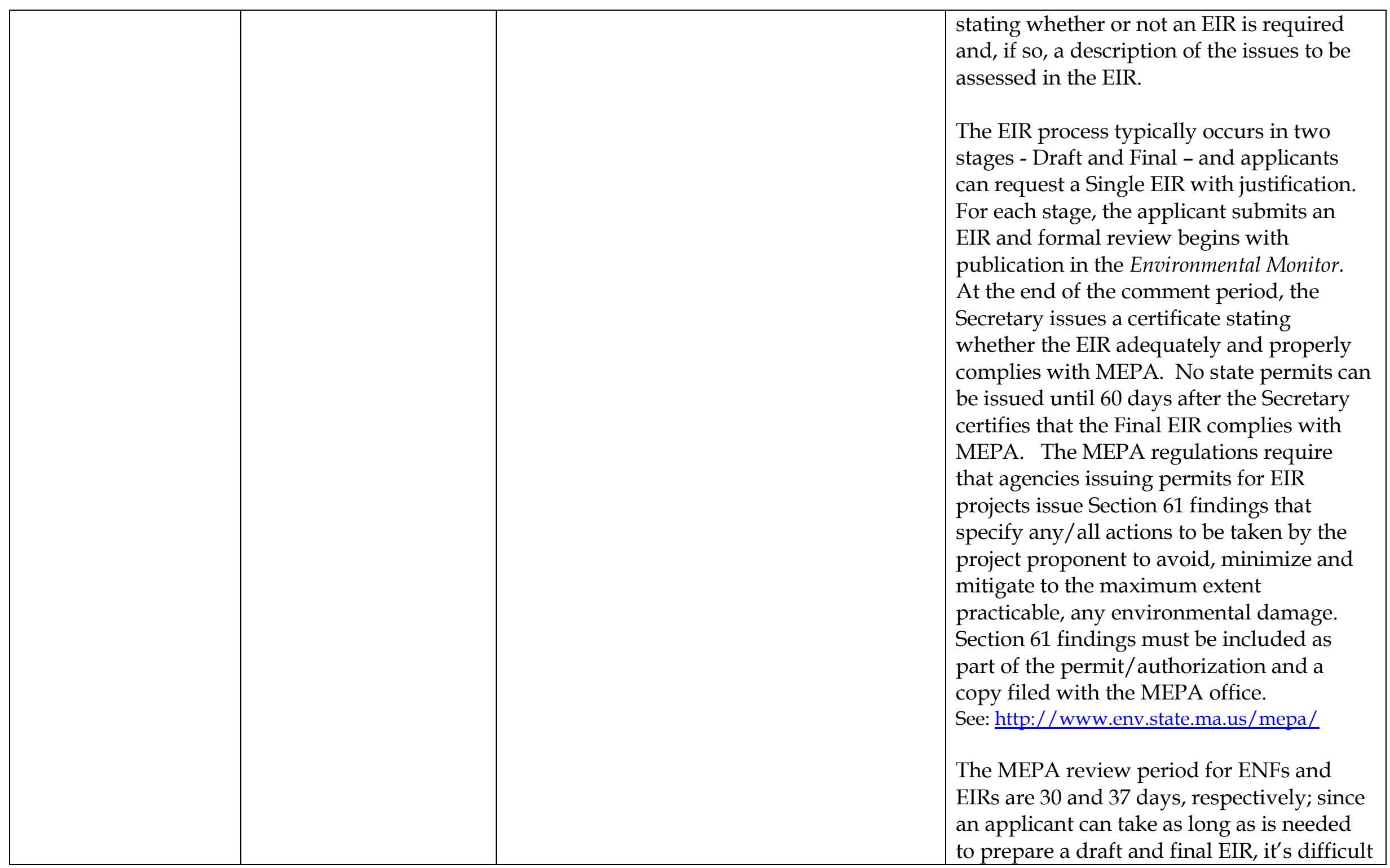




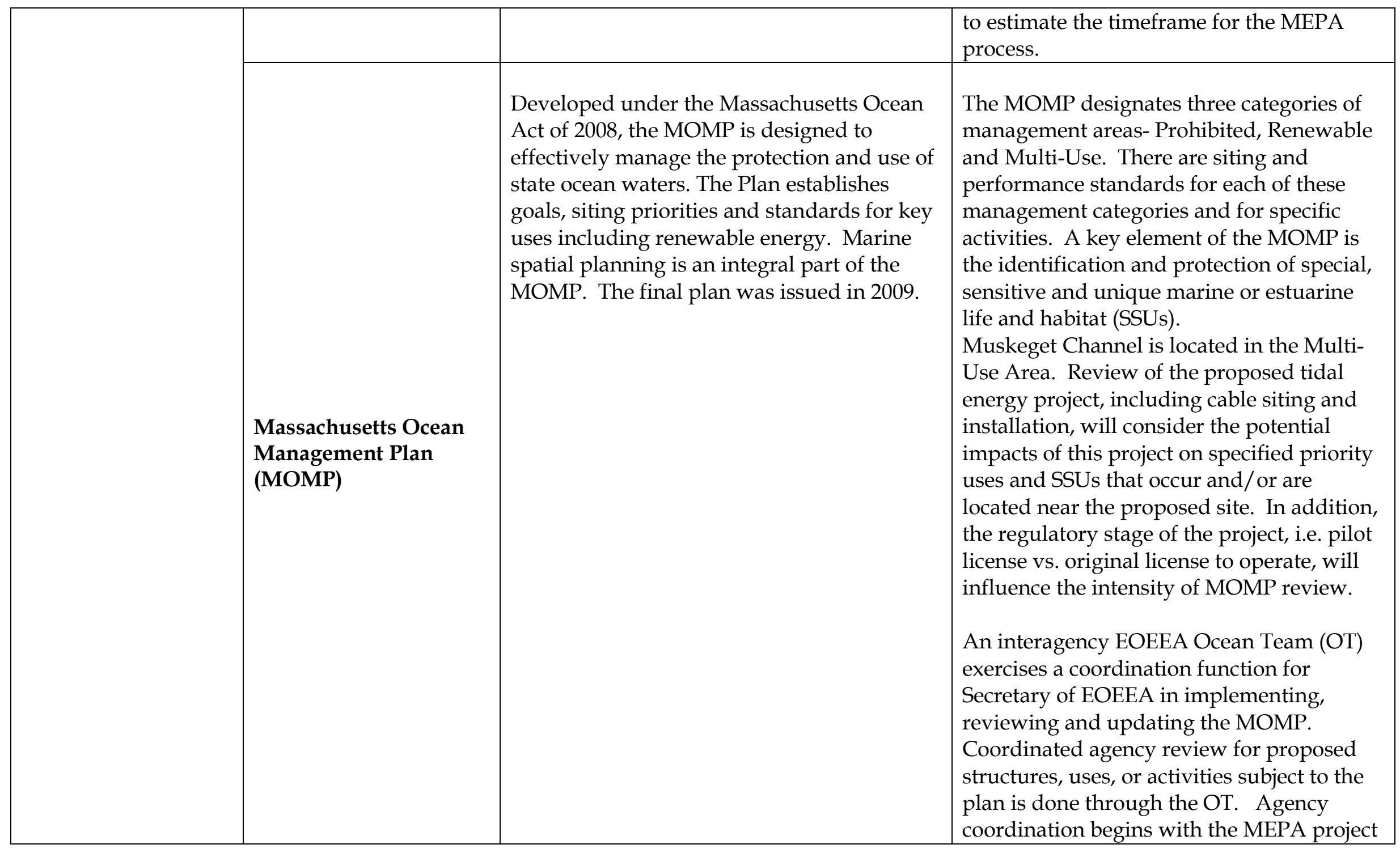




\begin{tabular}{|c|c|c|c|}
\hline & & & $\begin{array}{l}\text { review process and continues through } \\
\text { individual permit reviews by the regulatory } \\
\text { agencies. } \\
\text { See: } \\
\text { http://www.mass.gov } / \text { ?pageID=eoeeaterminal } \\
\text { \&L=3\&L0=Home\&L1=Ocean+\%26+Coastal }+ \\
\text { Management\&L2=Massachusetts+Ocean+Plan } \\
\text { \&sid=Eoeea\&b=terminalcontent\&f=eea_oceans } \\
\text { _mop\&csid=Eoeea }\end{array}$ \\
\hline \multirow[t]{2}{*}{$\begin{array}{l}\text { Mass. Dept. of } \\
\text { Environmental } \\
\text { Protection } \\
\text { (MaDEP) }\end{array}$} & $\begin{array}{l}\text { Water Quality } \\
\text { Certificate } \\
\text { Section } 401 \text { of the } \\
\text { Federal Clean Water } \\
\text { Act } \\
33 \text { U.S.C. } \$ 1341 \text { et seq. } \\
\text { and } 314 \text { CMR } 9.0\end{array}$ & $\begin{array}{l}\text { A Water Quality Certificate is required for } \\
\text { projects proposing dredging, filling, water } \\
\text { withdrawals, or site disturbances in the } \\
\text { state's inland and coastal waters. } \\
\text { Certification affirms that a project avoids, } \\
\text { minimizes, or mitigates impacts to areas } \\
\text { subject to Section } 401 \text { of the Clean Water Act } \\
\text { and complies with Massachusetts Water } \\
\text { Quality Regulations. }\end{array}$ & $\begin{array}{l}\text { An application is filed and publically } \\
\text { noticed in a paper(s) serving the affected } \\
\text { community. Comments are due to MADEP } \\
\text { within } 21 \text {-days of the notice. } \\
\text { State regulations allow for joint filing of the } \\
\text { public notification if the proposed project is } \\
\text { also subject to the Wetlands Protection Act } \\
\text { and / or Chapter } 91 \text { licensing. This notice } \\
\text { must also be filed with the Board of Health } \\
\text { in the town where the activities are to } \\
\text { occur. Issuance of a Water Quality } \\
\text { Certificate can take up to } 2 \text { months. } \\
\text { See: } \\
\text { http://www.mass.gov/dep/service/regulation } \\
\text { s/314cmr09.pdf }\end{array}$ \\
\hline & $\begin{array}{l}\text { Chapter } 91 \text { Waterways } \\
\text { License } \\
\text { M.G.L. c. } 91 \text { and } 310 \\
\text { CMR } 9.00\end{array}$ & $\begin{array}{l}\text { Chapter } 91 \text { governs lands owned by the } \\
\text { Commonwealth out to the limits of the } \\
\text { territorial sea and held in trust for its } \\
\text { citizens. The law protects the public's } \\
\text { rights to access the waterfront. Any project } \\
\text { proposed in, under, or over flowed or filled }\end{array}$ & $\begin{array}{l}\text { The license application made to MADEP } \\
\text { includes submitting a set of plans and } \\
\text { documentation that the project has } \\
\text { completed its MEPA review and obtained } \\
\text { any local or other permits for the project. }\end{array}$ \\
\hline
\end{tabular}




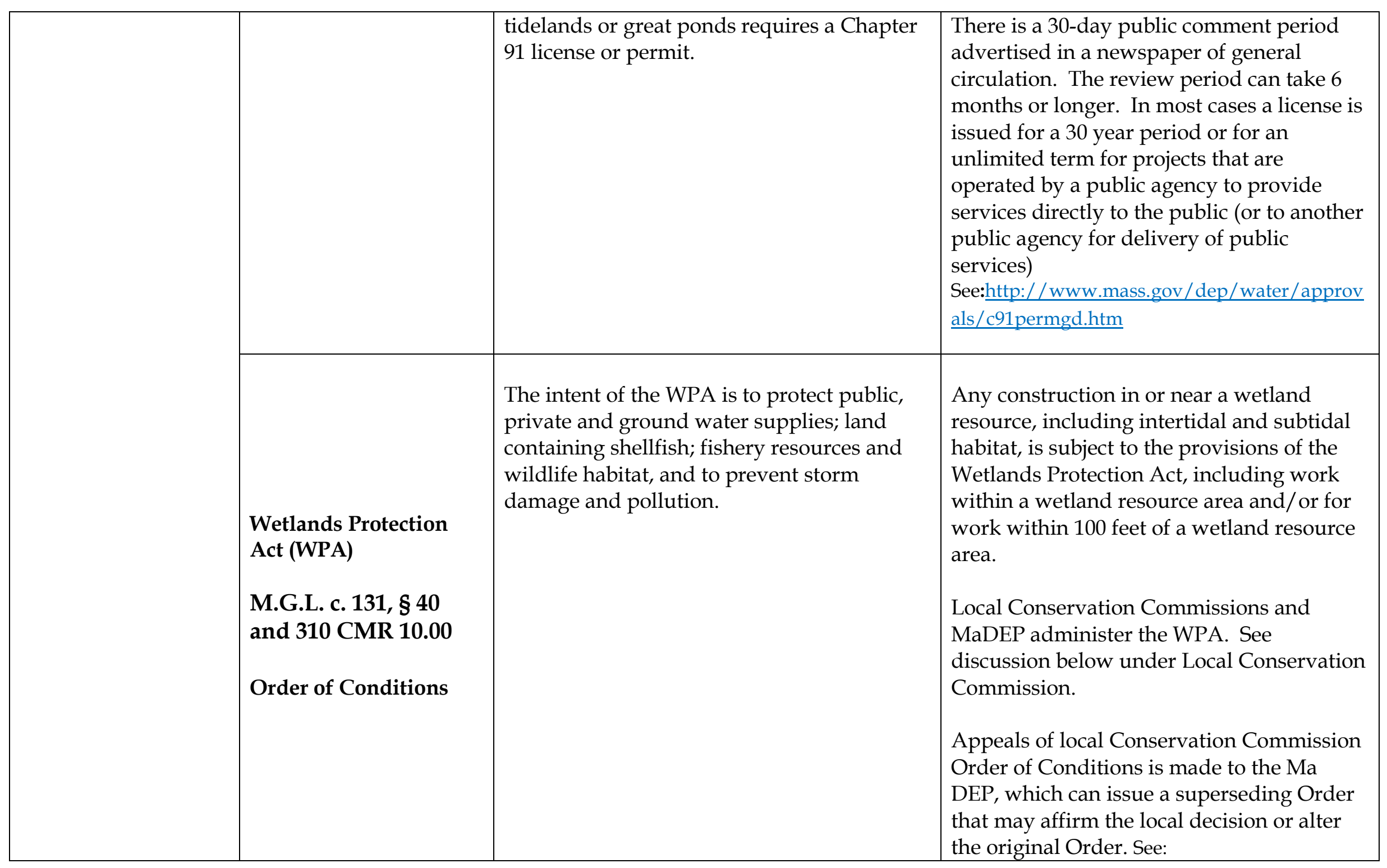




\begin{tabular}{|c|c|c|c|}
\hline & & & $\begin{array}{l}\text { http://www.mass.gov/dep/water/laws/regul } \\
\text { ati.htm\#wl }\end{array}$ \\
\hline $\begin{array}{c}\text { Division of } \\
\text { Fisheries and } \\
\text { Wildlife } \\
\text { Natural Heritage } \\
\text { and Endangered } \\
\text { Species Program } \\
\text { (NHESP) }\end{array}$ & $\begin{array}{l}\text { Massachusetts } \\
\text { Endangered Species } \\
\text { Act (MESA) } \\
\text { MGL c.131A and } \\
321 \text { CMR } 10.00 \\
\text { Conservation and } \\
\text { Management Permit } \\
\text { (CMP) }\end{array}$ & $\begin{array}{l}\text { The MESA protects habitats of federal and } \\
\text { state listed endangered, threatened and } \\
\text { special concern species. The NHESP } \\
\text { maintains the state Natural Heritage Atlas, } \\
\text { which catalogues Priority and Estimated } \\
\text { Habitats to be protected under MESA. }\end{array}$ & $\begin{array}{l}\text { If a project is proposed in protected } \\
\text { habitats, the applicant must file a Rare } \\
\text { Species Information Request Form with the } \\
\text { NHESP. Once the application and } \\
\text { supporting materials are deemed complete } \\
\text { the NHESP has } 60 \text { days to make its } \\
\text { determination as to whether the proposed } \\
\text { project will engage in a "take" of a listed } \\
\text { species/habitat. This time period may be } \\
\text { extended for two consecutive 20-day } \\
\text { periods. The regulations include } \\
\text { performance standards for obtaining a "no } \\
\text { take" determination. If the NHESP } \\
\text { determines that a project results in a "take", } \\
\text { it may work with the applicant to redesign } \\
\text { the project to avoid a "take". If this is not } \\
\text { possible then projects resulting in a "take" } \\
\text { may qualify for a Conservation and } \\
\text { Management Permit (CMP). } \\
\text { See:http://www.mass.gov/dfwele/dfw/nhesp } \\
\text { /regulatory_review/reg_review_home.htm and } \\
\text { http://www.mass.gov/dfwele/dfw/nhesp/re } \\
\text { gulatory_review/pdf/cmpermitguide06.pdf } \\
\text { The Division of Fisheries and Wildlife } \\
\text { coordinates with the MaDEP on filing } \\
\text { under both the MESA and the Wetlands } \\
\text { Protection Act. The Division also } \\
\text { coordinates with the National Marine }\end{array}$ \\
\hline
\end{tabular}




\begin{tabular}{|c|c|c|c|}
\hline & & & $\begin{array}{l}\text { Fisheries Service and the U.S. Fish and } \\
\text { Wildlife Service in the implementation of } \\
\text { the federal Endangered Species Act. }\end{array}$ \\
\hline $\begin{array}{c}\text { Coastal Zone } \\
\text { Management } \\
\text { Program (MCZM) }\end{array}$ & $\begin{array}{l}\text { Federal Consistency } \\
\text { Review } \\
\text { 16 U.S.C. } 1451 \text { et seq } \\
\text { and 15 CFR 930; M.G.L. } \\
\text { c. 21A, \$\$ 2, 4: and } 301 \\
\text { CMR 20.00 and } 301 \\
\text { CMR } 21.00\end{array}$ & $\begin{array}{l}\text { The intent of federal consistency review is to } \\
\text { ensure that federal activities in or affecting } \\
\text { Massachusetts coastal resources are } \\
\text { consistent with the state coastal policies, as } \\
\text { defined and described in the Massachusetts } \\
\text { Coastal Zone Program (CZMP) } \\
\text { Consistency review is conducted on projects } \\
\text { undertaken by a federal agency, or requiring } \\
\text { a federal permit, a federal offshore oil and } \\
\text { gas lease, or receiving federal funding that is } \\
\text { in or may affect the land or water resources } \\
\text { or uses of the Massachusetts coastal zone. }\end{array}$ & $\begin{array}{l}\text { Once a final MEPA Certificate has been } \\
\text { issued, the applicant submits a copy of the } \\
\text { Certificate along with copies of the federal } \\
\text { license or permit application(s), and a } \\
\text { federal consistency certification to MCZM } \\
\text { that describes the project's compliance with } \\
\text { CZM's policies. MCZM notices this } \\
\text { submittal in the Environmental Monitor, } \\
\text { initiating a } 21 \text { day comment public } \\
\text { comment period. } \\
\text { After a review of public comment and state } \\
\text { licenses and permits, MCZM may concur } \\
\text { with an applicant's federal consistency at } \\
\text { any time; however MCZM has a maximum } \\
\text { of } 180 \text { days to complete its review. If } \\
\text { MCZM finds that the project proposed is } \\
\text { not consistent with the state's coastal } \\
\text { policies, the applicant can appeal that } \\
\text { decision to the U.S. Secretary of Commerce. } \\
\text { No federal agency can take any regulatory } \\
\text { or project action until MCZM certifies that } \\
\text { the project is consistent with the CZMP or } \\
\text { until the Secretary of Commerce had made } \\
\text { her/his decision on the appeal. See: } \\
\text { http://www.mass.gov/czm/plan/docs/czm_p }\end{array}$ \\
\hline
\end{tabular}




\begin{tabular}{|c|c|c|c|}
\hline & & & olicy_guide_may2011.pdf \\
\hline & $\begin{array}{l}\text { Ocean Sanctuary Act } \\
\text { (OSA) } \\
\text { M.G.L. c. 132A, §§ 12A- } \\
\text { 16F, } 18 \text { and CMR } 5.00\end{array}$ & $\begin{array}{l}\text { The OSA is administered by MCZM, and } \\
\text { prohibits activities that may significantly } \\
\text { alter the ecology or appearance of the } \\
\text { ocean, seabed, or subsoil of a designated } \\
\text { sanctuary. }\end{array}$ & $\begin{array}{l}\text { The OSA was amended by the Oceans Act } \\
\text { of } 2008 \text { to allow "appropriate scale" } \\
\text { offshore renewable energy facilities in state } \\
\text { waters, except in the Cape Cod Ocean } \\
\text { Sanctuary, if they are consistent with the } \\
\text { Massachusetts Ocean Management Plan. } \\
\text { There is no separate permitting process } \\
\text { associated with the OSA. MCZM review is } \\
\text { incorporated into the MEPA and Chapter } \\
91 \text { and Ocean Management Plan review } \\
\text { processes }\end{array}$ \\
\hline & $\begin{array}{l}\text { Board of Underwater } \\
\text { Archeological } \\
\text { Resources (BUAR) } \\
\text { M.G.L. c.6, §§ 179-180, } \\
\text { and M.G.L. c.91, §63 } \\
\text { and 312 CMR 2.0-2.15 }\end{array}$ & $\begin{array}{l}\text { The BUAR is responsible for encouraging } \\
\text { the discovery and reporting, as well as the } \\
\text { preservation and protection, of underwater } \\
\text { archaeological resources in the waters of the } \\
\text { Commonwealth. }\end{array}$ & $\begin{array}{l}\text { BUAR staff comment on proposed projects } \\
\text { through the MEPA process. Projects that } \\
\text { may be located in areas of known and } \\
\text { potential submerged cultural resources } \\
\text { may be required to conduct cultural } \\
\text { resource surveys and the BUAR may be } \\
\text { consulted in the development of survey } \\
\text { methods. BUAR works closely with the } \\
\text { Massachusetts Historical Commission. }\end{array}$ \\
\hline $\begin{array}{c}\text { Division of Marine } \\
\text { Fisheries } \\
\text { (MarineFisheries) }\end{array}$ & $\begin{array}{l}\text { Review and Comment } \\
\text { on Projects under } \\
\text { MEPA and State } \\
\text { Regulatory Review }\end{array}$ & $\begin{array}{l}\text { The mission of MarineFisheries is "to manage } \\
\text { the Commonwealth's living marine } \\
\text { resources in balance with the environment } \\
\text { resulting in sustainable fisheries and } \\
\text { contributions to our economy, stable }\end{array}$ & $\begin{array}{l}\text { MarineFisheries has management and } \\
\text { regulatory responsibilities for fishery } \\
\text { resources and habitats, and marine } \\
\text { mammal and sea turtle resources and } \\
\text { habitats in Massachusetts coastal and ocean }\end{array}$ \\
\hline
\end{tabular}




\begin{tabular}{|c|c|c|c|}
\hline & & $\begin{array}{l}\text { availability of diverse, healthy seafood and } \\
\text { enriched opportunities that support our } \\
\text { coastal culture." }\end{array}$ & $\begin{array}{l}\text { waters. One of its efforts is to identify and } \\
\text { map habitats. These mapping resources are } \\
\text { used by other state agencies, as well as local } \\
\text { boards and commissions, in their decision- } \\
\text { making. } \\
\text { See: http://www.mass.gov/dfwele/dmf/ }\end{array}$ \\
\hline $\begin{array}{l}\text { Mass. Historical } \\
\text { Commission } \\
\text { (MHC) }\end{array}$ & $\begin{array}{l}\text { M. G. L. c. } 9 \S \S 26-27 C \\
\text { and } 950 \text { CMR } 71 \text { and } \\
\text { Section } 106 \text { of the } \\
\text { National Historic } \\
\text { Preservation Act }\end{array}$ & $\begin{array}{l}\text { The MHC was established to promote the } \\
\text { protection and restoration of historical and } \\
\text { archeological properties/sites within the } \\
\text { state's jurisdiction. }\end{array}$ & $\begin{array}{l}\text { Any project that requires funding, licenses, } \\
\text { or permits from any state agency must be } \\
\text { reviewed by MHC. While the MHC } \\
\text { participates in the MEPA process, it also } \\
\text { requires submittal of a Project Notification } \\
\text { Form (PNF) early in the project review } \\
\text { process. Within } 30 \text { days of receipt of a } \\
\text { PNF the MHC responds in writing to the } \\
\text { applicant stating whether the project is } \\
\text { likely to affect historic or archaeological } \\
\text { properties; if further review is needed; } \\
\text { whether additional information is needed } \\
\text { and/or appropriate avoidance or } \\
\text { mitigation actions. There is a consultation } \\
\text { process should the MHC find that a project } \\
\text { will have adverse impacts on historical or } \\
\text { archaeological significant } \\
\text { resources.See:http://www.sec.state.ma.us/mh } \\
\text { c/mhcrevcom/revcomidx.htm } \\
\text { Projects that need federal permits require } \\
\text { consultation with MHC and the Tribal } \\
\text { Historic Preservation Officers. There is } \\
\text { coordinated review under both federal and } \\
\text { state historic preservation laws and } \\
\text { regulations. }\end{array}$ \\
\hline
\end{tabular}




\begin{tabular}{|c|c|c|c|}
\hline \multicolumn{4}{|l|}{ Regional } \\
\hline Agency & Authority/Action & Intent/Requirements & Process/Timeframe \\
\hline $\begin{array}{l}\text { Martha's Vineyard } \\
\text { Commission } \\
\text { (MVC) }\end{array}$ & $\begin{array}{l}\text { Martha's Vineyard } \\
\text { Commission Act } \\
\text { M.G.L. c } 831 \$ 12 \\
\text { Developments of } \\
\text { Regional Impact (DRI) }\end{array}$ & $\begin{array}{l}\text { The Martha's Vineyard Commission (MVC) } \\
\text { is authorized to review Developments of } \\
\text { Regional Impact (DRI) that may affect more } \\
\text { than one town. Section } 5 \text { of the MVC's DRI } \\
\text { Check List - Developments in Harbors, } \\
\text { Great Ponds, Ponds or Oceans - applies to } \\
\text { projects in state waters around Martha's } \\
\text { Vineyard. }\end{array}$ & $\begin{array}{l}\text { Once a DRI application is submitted, the } \\
\text { applicant has a pre-hearing meeting(s) with } \\
\text { MVC's Land Use Planning Committee } \\
\text { (LUPC). The LUPC determines what } \\
\text { additional studies or information are } \\
\text { needed to complete the application. Once a } \\
\text { DRI application is certified as complete, a } \\
\text { public hearing is held before the full MVC } \\
\text { and public comment is accepted. Following } \\
\text { the hearing, the LUPC analyzes whether } \\
\text { the probable benefits of the project will } \\
\text { exceed the probable detriments and } \\
\text { prepares and adopts a recommendation to } \\
\text { the full MVC to approve, approve with } \\
\text { conditions, or deny the application. } \\
\text { Following a full MVC vote on this } \\
\text { recommendation, a final written decision is } \\
\text { prepared for a vote by the full MVC. This } \\
\text { decision is directed at town board(s) or } \\
\text { official(s), not the applicant, since town } \\
\text { board may not issue a required permit or } \\
\text { take any action on a DRI unless the project } \\
\text { is approved by the MVC. If the MVC } \\
\text { denies a project, local boards and officials } \\
\text { cannot take any action. The DRI process }\end{array}$ \\
\hline
\end{tabular}




\begin{tabular}{|c|c|c|c|}
\hline & & & $\begin{array}{l}\text { can take more than a year to complete. } \\
\text { See: } \\
\text { http://www.mvcommission.org/doc.php/DRI } \\
\text { \%20Checklist\%202010-03-01.pdf?id=148 and } \\
\text { http://www.mvcommission.org/dris/index.ht } \\
\underline{\text { ht and }} \\
\underline{\text { RRENT\%20DRI\%20REGS\%202001.pdf?id=702 }}\end{array}$ \\
\hline \multicolumn{4}{|l|}{ Local } \\
\hline Agency & Authority/Action & Intent/Requirement & Process/Timeframe \\
\hline $\begin{array}{l}\text { Edgartown } \\
\text { Conservation } \\
\text { Commission }\end{array}$ & $\begin{array}{l}\text { Wetlands Protection } \\
\text { Act } \\
\text { M.G.L. c. 131, § } 40 \\
\text { and } 310 \text { CMR } 10.00 \\
\text { Order of Conditions }\end{array}$ & $\begin{array}{l}\text { Local Conservation Commissions (CC) } \\
\text { implement the state's Wetlands Protection } \\
\text { Act. The intent of the Act is to protect public, } \\
\text { private and ground water supplies; land } \\
\text { containing shellfish; fishery resources and } \\
\text { wildlife habitat, and to prevent storm } \\
\text { damage and pollution. Generally, a CC has } \\
\text { jurisdiction seaward out to the } 3 \text { mile limit. } \\
\text { Its jurisdiction oversees work that may } \\
\text { remove, fill, dredge or alter areas within, } \\
\text { and in the buffer zone adjacent to, a } \\
\text { wetland, dune, beach, barrier beach, pond } \\
\text { and estuary. }\end{array}$ & $\begin{array}{l}\text { The applicant files a Notice of Intent (NOI) } \\
\text { with the CC, copies MaDEP and provides } \\
\text { notice to all abutters and property owners } \\
\text { within } 100 \text { feet of proposed activity. Other } \\
\text { local permits must be either applied for or } \\
\text { approved prior to filing a NOI. The CC can } \\
\text { request additional information and } \\
\text { analyses to supplement the NOI. } \\
\text { The CC holds a public hearing and, at the } \\
\text { conclusion of its review, issues an Order of } \\
\text { Conditions (OOC). The OOC may allow } \\
\text { the project with conditions that are } \\
\text { necessary to meet the performance } \\
\text { standards of the WPA or the OOC may } \\
\text { prohibit the work. The OOC can be } \\
\text { appealed by the applicant or an intervening } \\
\text { party to the MaDEP. } \\
\text { Issuance of an OOC can take at least } 63\end{array}$ \\
\hline
\end{tabular}




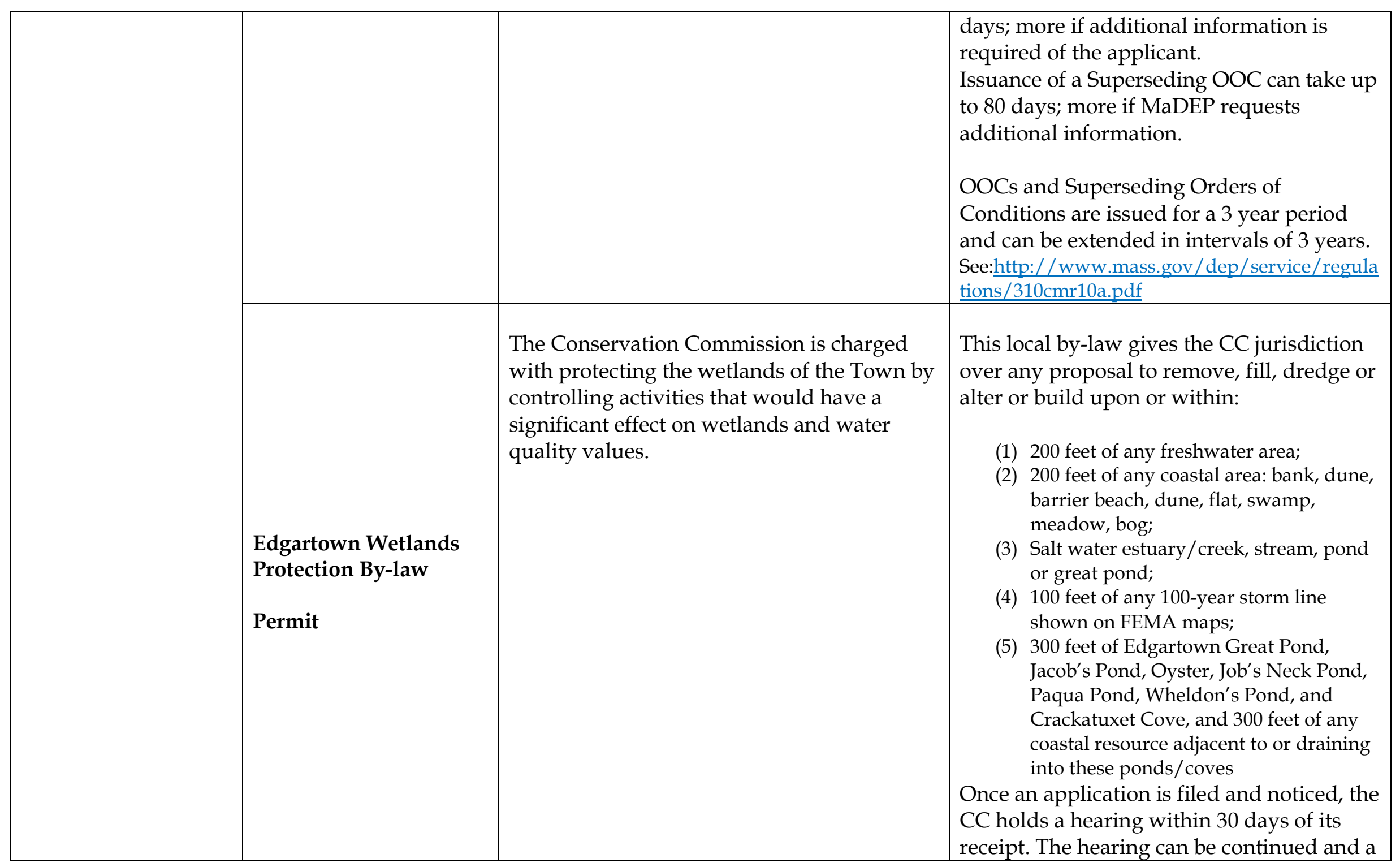




\begin{tabular}{|c|c|c|c|}
\hline & & & $\begin{array}{l}\text { decision is made within } 30 \text { days of the } \\
\text { closure of the hearing. The CC can approve } \\
\text { the project with conditions. The permit is } \\
\text { valid for one year within which time the } \\
\text { work is to be completed. Permits can be } \\
\text { renewed. See: } \text { http://www.edgartown- } \\
\text { ma.us/cms/index.php?option=com_docman\&t } \\
\text { ask=cat_view\&gid=86\&Itemid=504 }\end{array}$ \\
\hline \multirow[t]{2}{*}{$\begin{array}{l}\text { Edgartown } \\
\text { Planning Board }\end{array}$} & $\begin{array}{l}\text { Coastal District of } \\
\text { Critical Planning } \\
\text { Concern (DCPC) } \\
\text { Article XIV-1 of the } \\
\text { Town of Edgartown } \\
\text { Zoning Bylaw } \\
\text { Special Permit }\end{array}$ & $\begin{array}{l}\text { The Coastal DCPC is an Island-wide } \\
\text { designation made in } 1975 \text { by the Martha's } \\
\text { Vineyard Commission. The designation } \\
\text { includes a shore zone and an inland zone to } \\
\text { protect a number of resources, including } \\
\text { wildlife and ecological resources; drinking } \\
\text { water and cultural and historical resources. } \\
\text { The Edgartown Coastal District includes the } \\
\text { land, streams, and wetlands of the town that } \\
\text { lie below ten (10) foot elevation above mean } \\
\text { sea level, or within five hundred (500) feet to } \\
\text { mean high water of a coastal water body } \\
\text { exceeding ten (10) acres, or the ocean and all } \\
\text { land within one hundred (100) feet of the } \\
\text { streams and wetlands draining into the } \\
\text { coastal Great Ponds. The shore zone } \\
\text { generally is all lands from mean low water } \\
\text { to } 100 \text { feet inland of the inland edge of } \\
\text { coastal resources, i.e. beaches, bluffs, } \\
\text { wetlands and coastal ponds. }\end{array}$ & $\begin{array}{l}\text { The applicant must file a special permit } \\
\text { application with the Planning Board. The } \\
\text { Planning Board requests review and } \\
\text { comment from the Board of Health; } \\
\text { Conservation Commission; Board of } \\
\text { Selectmen; Shellfish Committee and the } \\
\text { Building Inspector. The Planning Board } \\
\text { holds a public hearing within } 65 \text { days of the } \\
\text { application filing and must make a decision } \\
\text { within } 90 \text { days o the hearing date. This } \\
\text { date can be extended by mutual consent. } \\
\text { The Planning Board may issue a special } \\
\text { permit for conditionally permitted } \\
\text { activities. The review and approval } \\
\text { process can take } 3 \text { months or longer. } \\
\text { See: page } 48 \text { of the Edgartown Zoning } \\
\text { Bylaw at: } \underline{\text { http://www.edgartown- }} \\
\text { ma.us/cms/index.php?option=com_docman\&t } \\
\text { ask=cat_view\&gid=36\&Itemid=504 }\end{array}$ \\
\hline & $\begin{array}{l}\text { Cape Pogue District of } \\
\text { Critical Planning } \\
\text { Concern }\end{array}$ & The Cape Pogue District was designated to & $\begin{array}{l}\text { A special permit application is filed with } \\
\text { the Planning Board. The Planning Board }\end{array}$ \\
\hline
\end{tabular}




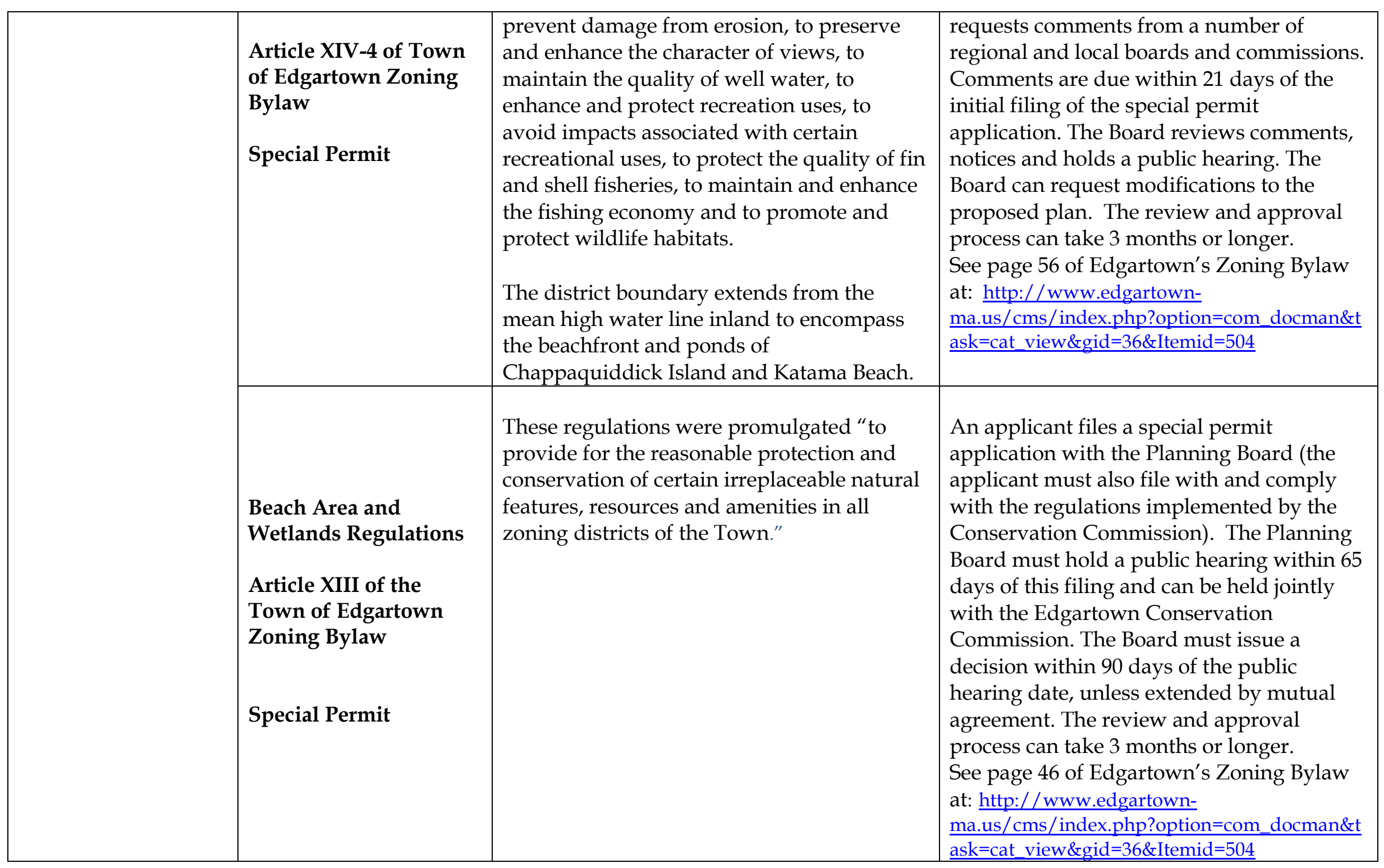




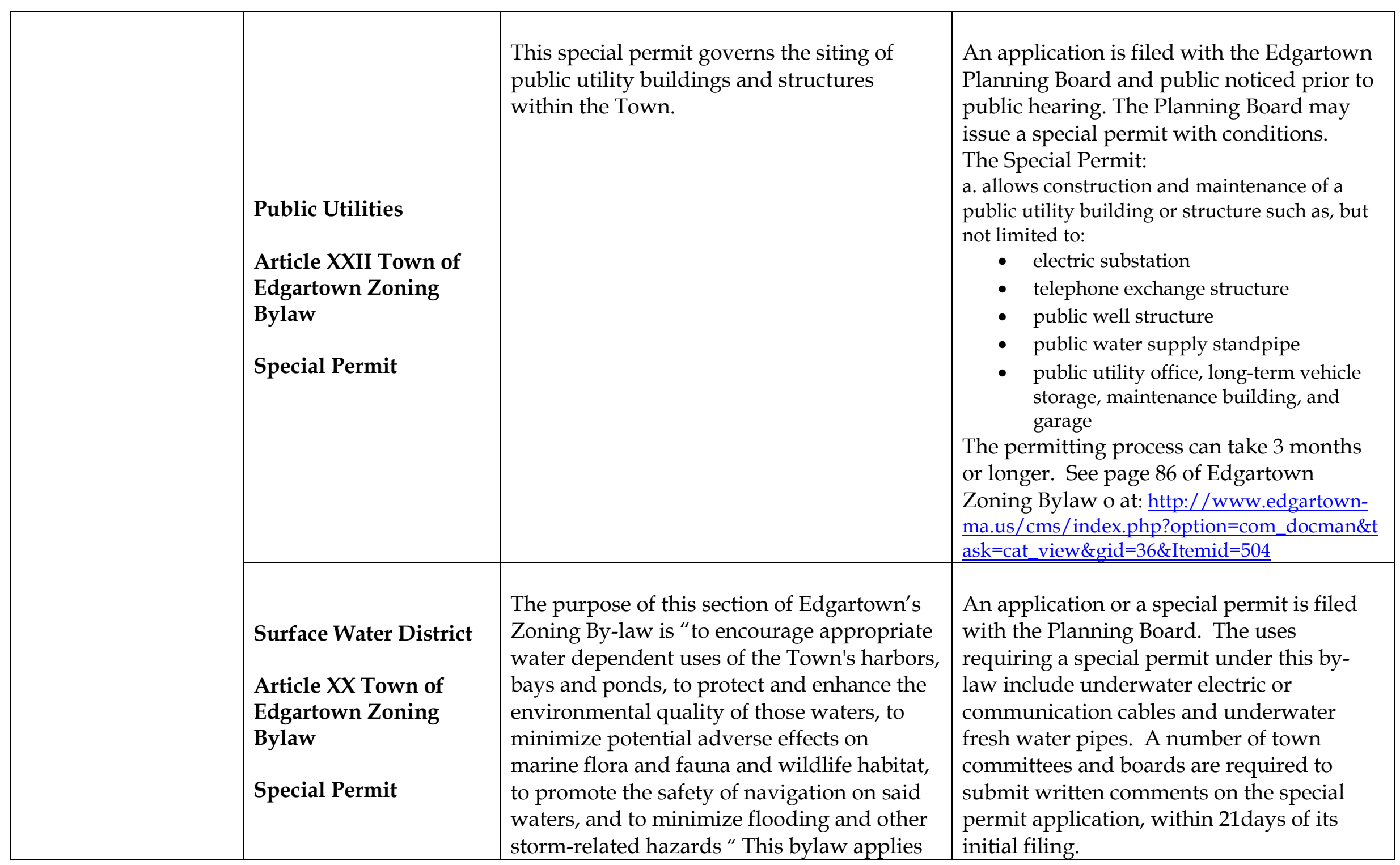




\begin{tabular}{|c|c|c|c|}
\hline & & $\begin{array}{l}\text { to a number of water bodies and areas } \\
\text { within the Town including the waters of } \\
\text { Katama Bay as well as those of Cape Pogue } \\
\text { and Pocha Ponds on Chappaquiddick. }\end{array}$ & $\begin{array}{l}\text { The review process can take up to } 3 \\
\text { months See page } 81 \text { of the Edgartown } \\
\text { Zoning Bylaw at: } \text { http:// } / \text { www.edgartown- } \\
\text { ma.us/cms/index.php?option=com_docman\&t } \\
\text { ask=cat_view\&gid=36\&Itemid }=504\end{array}$ \\
\hline $\begin{array}{l}\text { Edgartown Board } \\
\text { of Appeals }\end{array}$ & $\begin{array}{l}\text { Floodplain Zone } \\
\text { Article XIX Town of } \\
\text { Edgartown Zoning } \\
\text { Bylaw } \\
\text { Special Permit }\end{array}$ & $\begin{array}{l}\text { Regulates the construction of structures and } \\
\text { use of land within the Town's designated } \\
\text { floodplain. }\end{array}$ & $\begin{array}{l}\text { Application is made to the Zoning Board of } \\
\text { Appeals (ZBA). Before granting a special } \\
\text { permit for the alteration of the land form, } \\
\text { the ZBA is required to consider } \\
\text { recommendations from the Conservation } \\
\text { Commission and the Planning Board. } \\
\text { Alteration of the land form is defined in the } \\
\text { bylaw as: "Any man-made change in the } \\
\text { existing character of the land including } \\
\text { filling, grading, paving, dredging, mining, } \\
\text { excavation or drilling operation other than } \\
\text { routine excavation, well-drilling, } \\
\text { backfilling, grading and paving incidental } \\
\text { to the construction of a residence or other } \\
\text { structure for which a building permit has } \\
\text { been issued." } \\
\text { The permitting process can take } 2 \text { months } \\
\text { or longer. See Page } 78 \text { of Edgartown's } \\
\text { Zoning Bylaw at: } \\
\text { http://www.edgartown.ma.us/cms/index.php } \\
\text { ?option=com_docman\&task=cat_view\&gid=36 } \\
\text { \&Itemid=504 }\end{array}$ \\
\hline
\end{tabular}





\section{Appendix G DOE Peer Review Presentation}





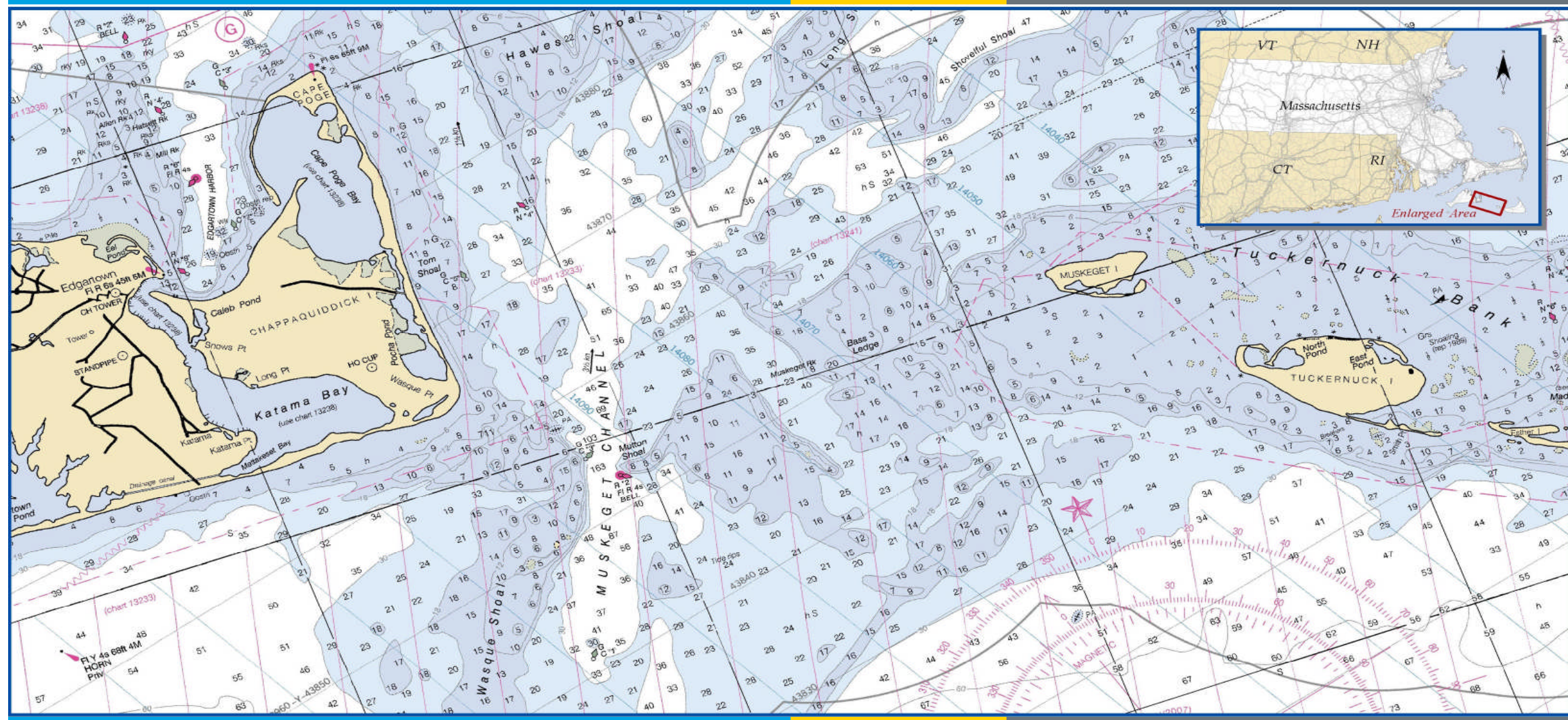

Environmental Effects of Sediment Transport Alteration and Impacts on Protected Species: Edgartown Tidal Energy Project

\section{Stephen Barrett}

Harris Miller Miller \& Hanson Inc.

77 South Bedford Street, Burlington, MA 01803 November 2, 2011 


\section{Purpose, Objectives, \& Integration}

\section{Topic Area 2: Marine and Hydrokinetic Site-specific}

Environmental Studies/Information

Town of Edgartown holds a Preliminary Permit from FERC

Project success requires academic \& government partners

Movement of sediment is a major environmental factor

Protected Species are present and known to the public

This research addresses two fundamental issues to advance design and permitting. Follow-up studies will be required to resolve the next level of questions 

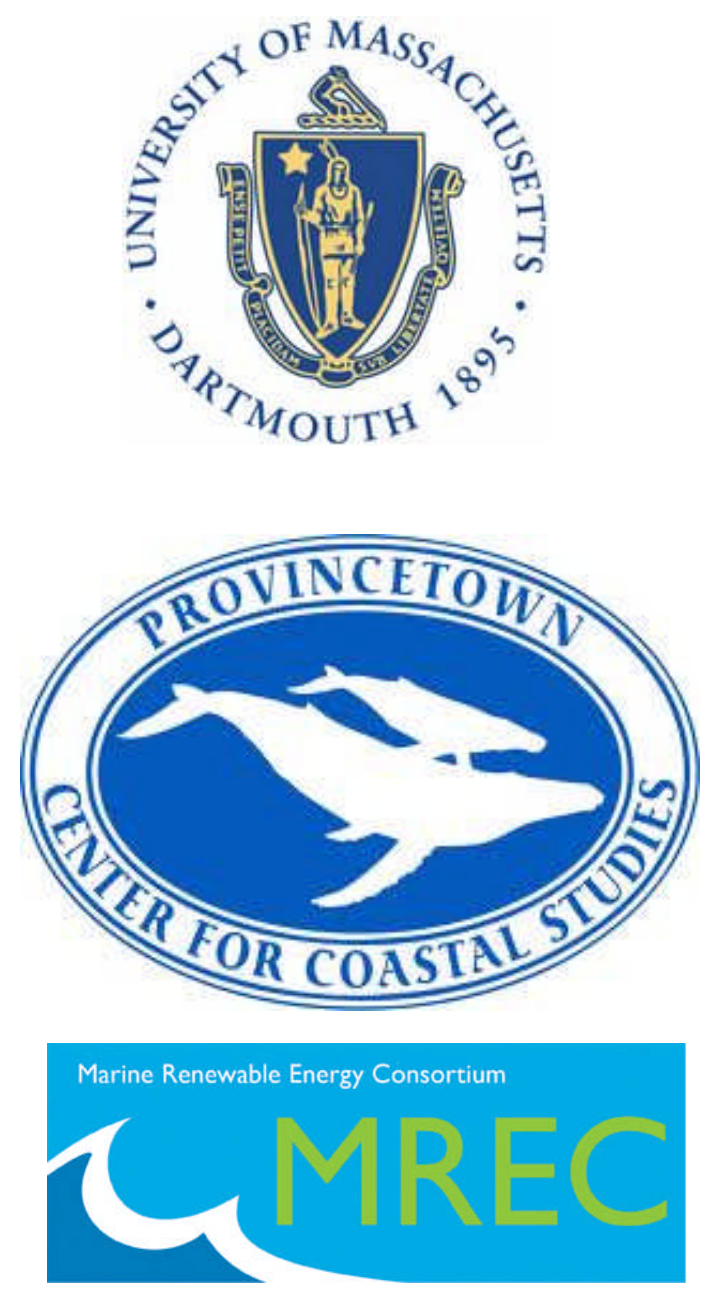

Smast The School for Marine Science and Technology
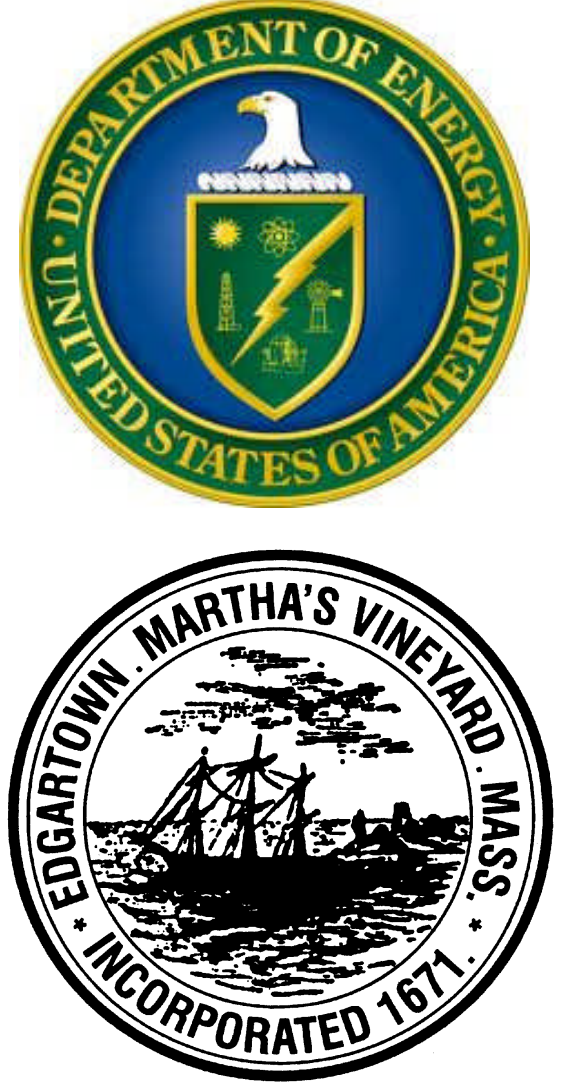

hinuh 


\section{Technical Approach}

Four Tasks:

Oceanography \& Habitat: field data collection on currents, tide level, bathymetry, sediment, macrovegetation

Sediment Transport Modeling

Protected Species and Fisheries

Public Outreach and Communications

All contribute to scientific and social success of project 


\section{Technical Approach}

Ex Energy Efficiency \& GN ER(C) Renewable Energy
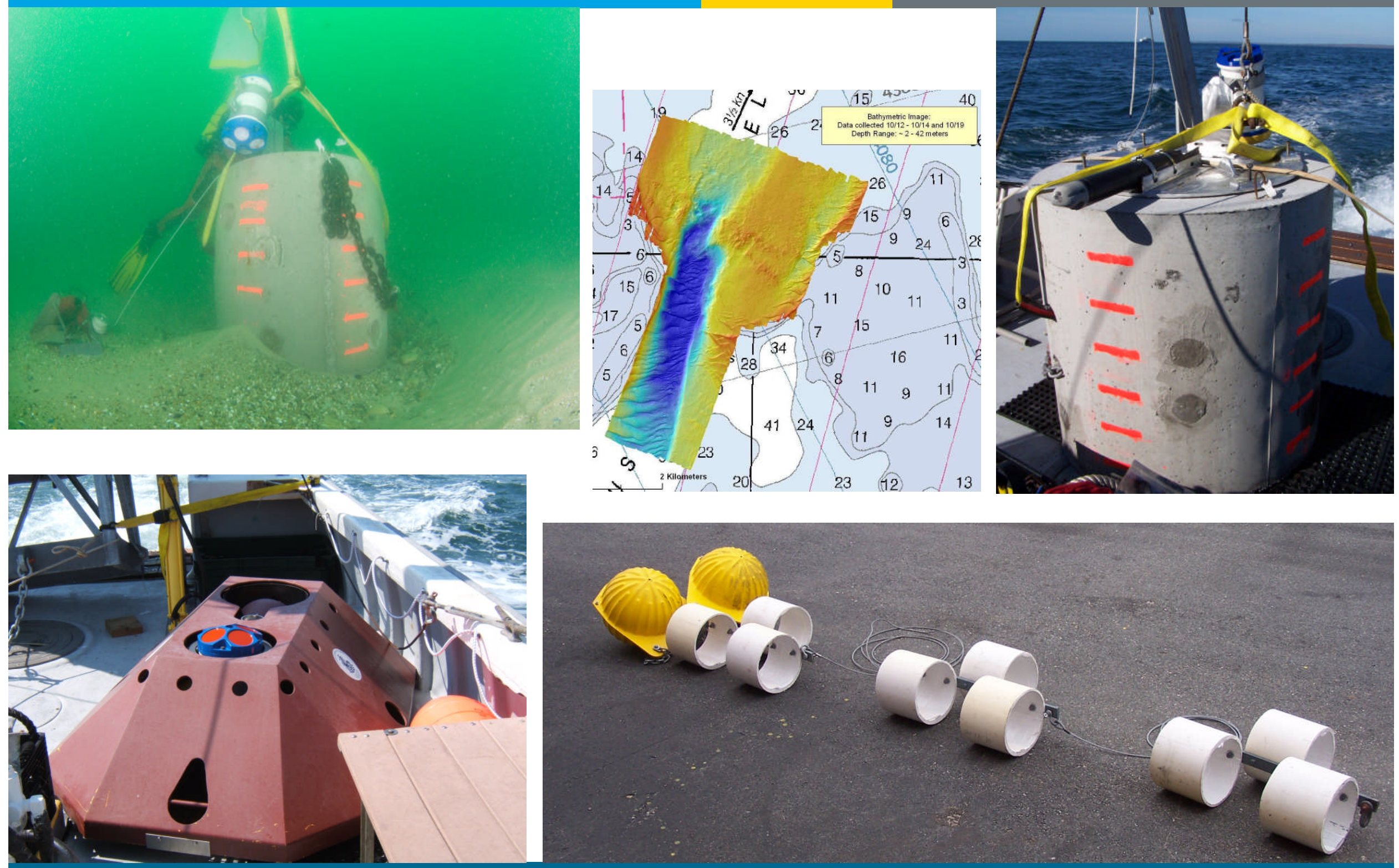


\section{Plan, Schedule, \& Budget}

Schedule

- Initiation date: January 1, 2010

- Planned completion date: December 31, 2011

- Inability to obtain foil material delayed biofouling one year

- Verdant not interested in cooperating to assess different technologies

- Ocean Server ROV not available for micro seabed analysis

- Sediment transport modeling results still under development

Budget:

- Less funds used for GIS, more for regulatory filings

- $90 \%$ of budget expended, project on-schedule

\begin{tabular}{|c|c|c|c|c|c|}
\hline \multicolumn{6}{|c|}{ Budget History } \\
\hline \multicolumn{2}{|c|}{ FY2009 } & \multicolumn{2}{|c|}{ FY2010 } & \multicolumn{2}{|c|}{ FY2011 } \\
\hline DOE & Cost-share & DOE & Cost-share & DOE & Cost-share \\
\hline & & $\$ 300,000$ & - & $\$ 300,000$ & - \\
\hline
\end{tabular}




\section{Accomplishments and Results}

Oceanography - baseline work focuses development site Sediment Transport - results still under development Protected Species - background analysis targets field work Outreach - data development supports Draft License App

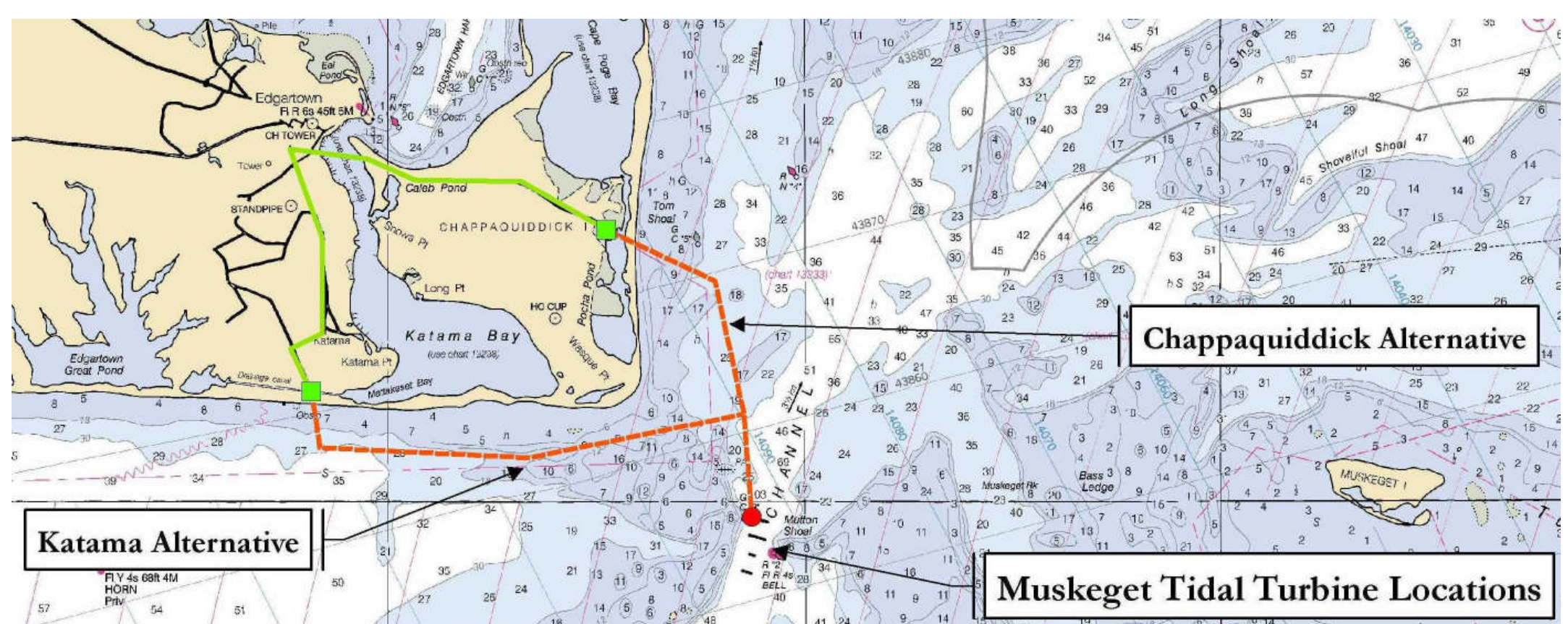




\section{Accomplishments and Results}

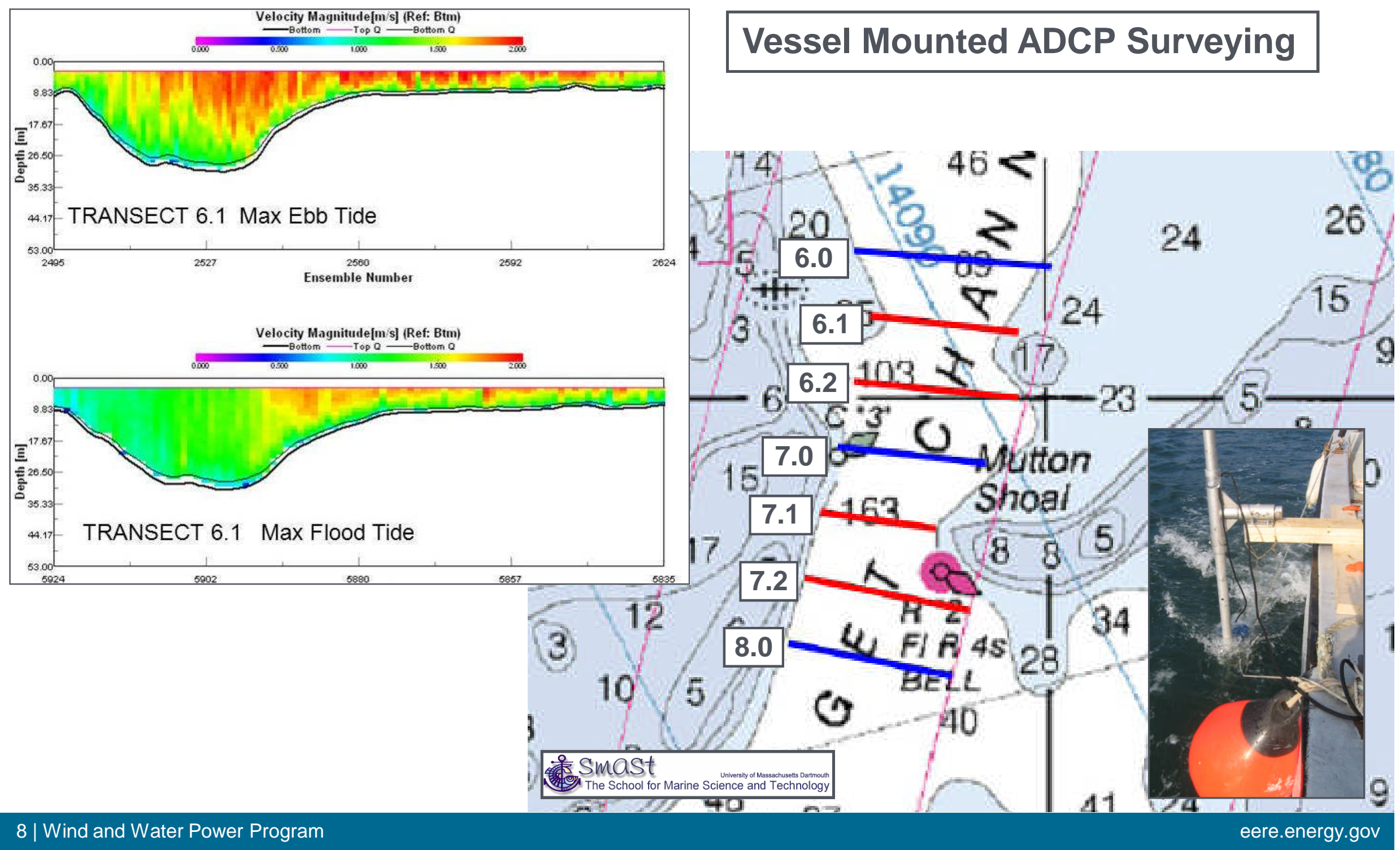




\section{Accomplishments and Results}

\begin{tabular}{l|l} 
U.s. DEPARTMENT OF & $\begin{array}{l}\text { Energy Efficiency \& } \\
\text { Renewable Energy }\end{array}$
\end{tabular}

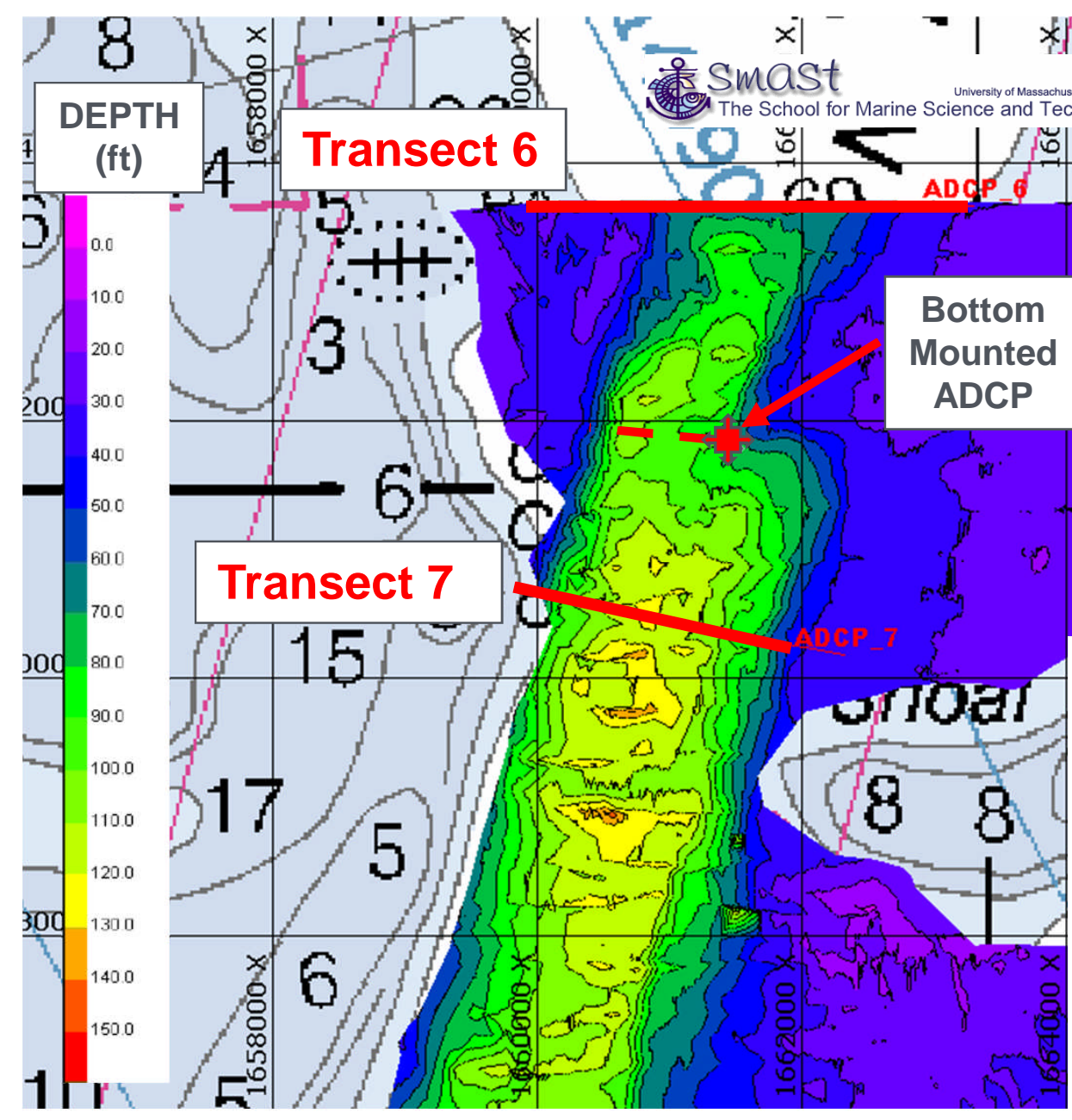

Full Lunar Cycle Deployment of ADCP 


\section{Accomplishments and Results}

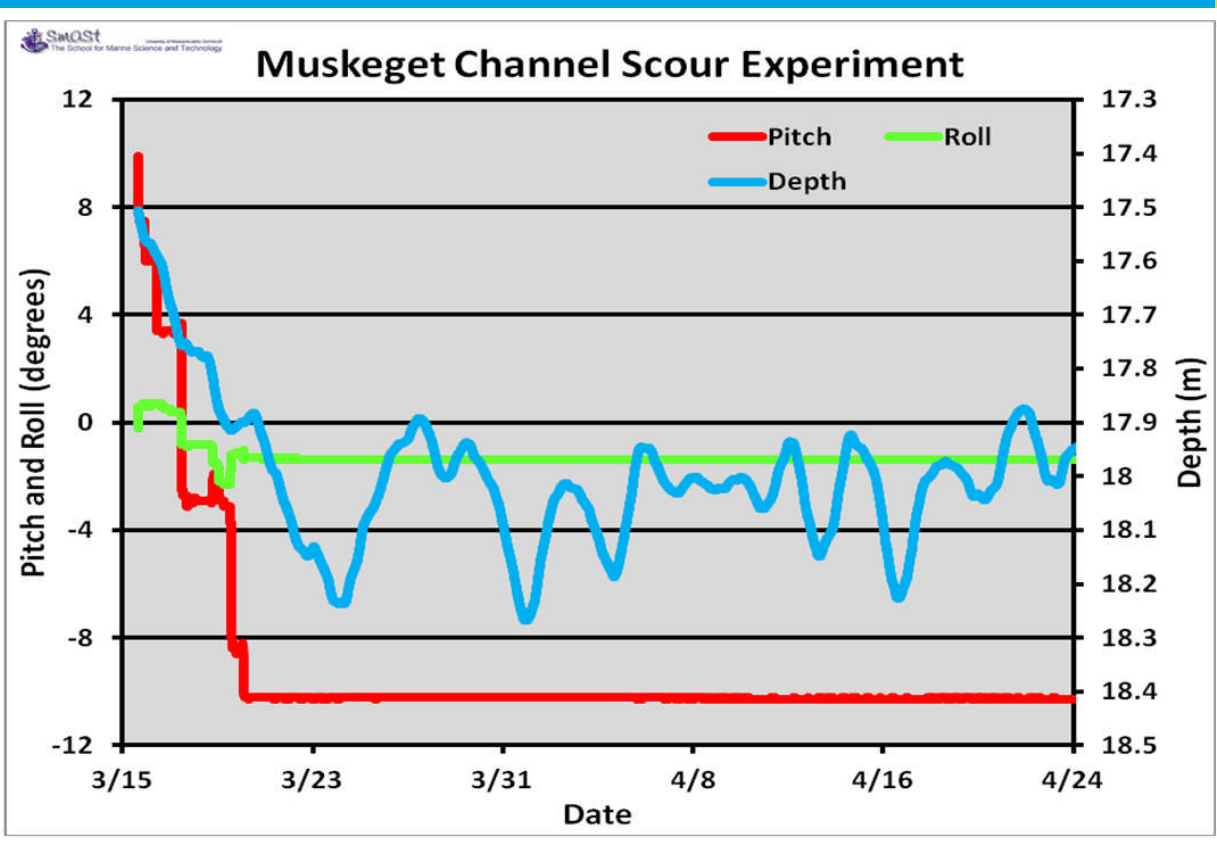

Profiling of near bottom current velocity indicates settling of mooring to a stable gravel/cobble layer with semi-diurnal scouring of sandy sediments around base of mooring.

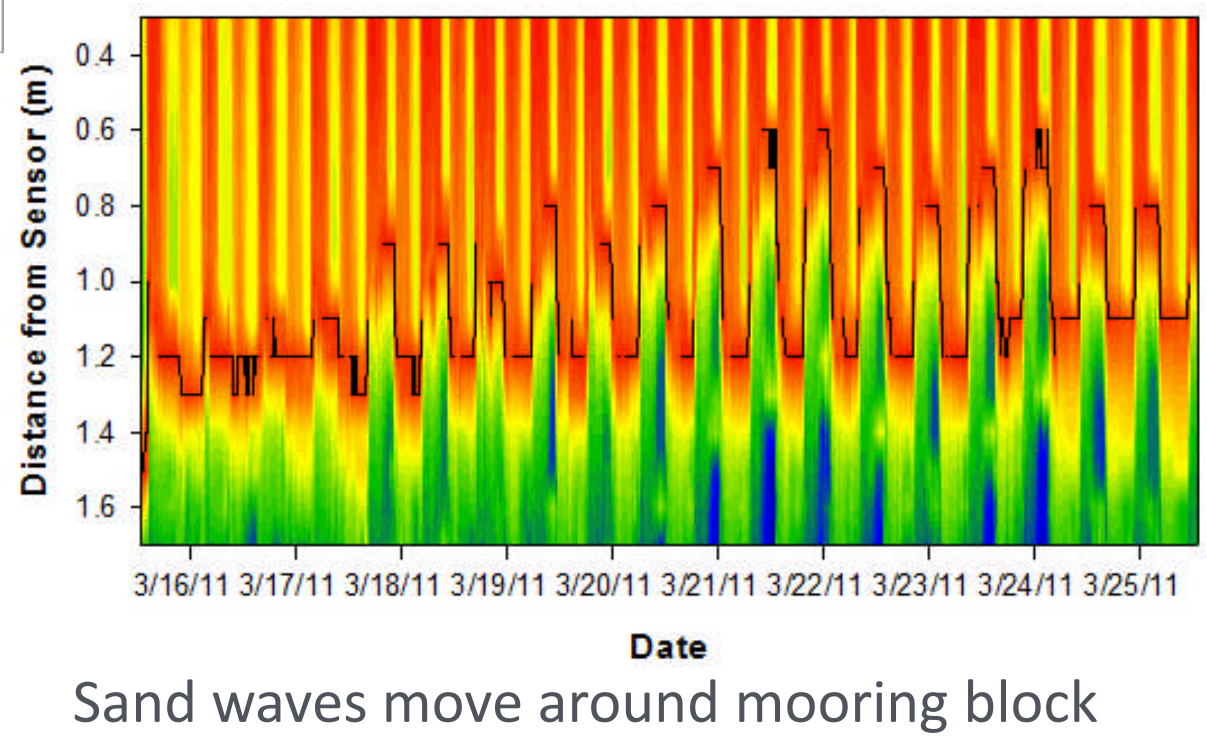




\section{Accomplishments and Results}
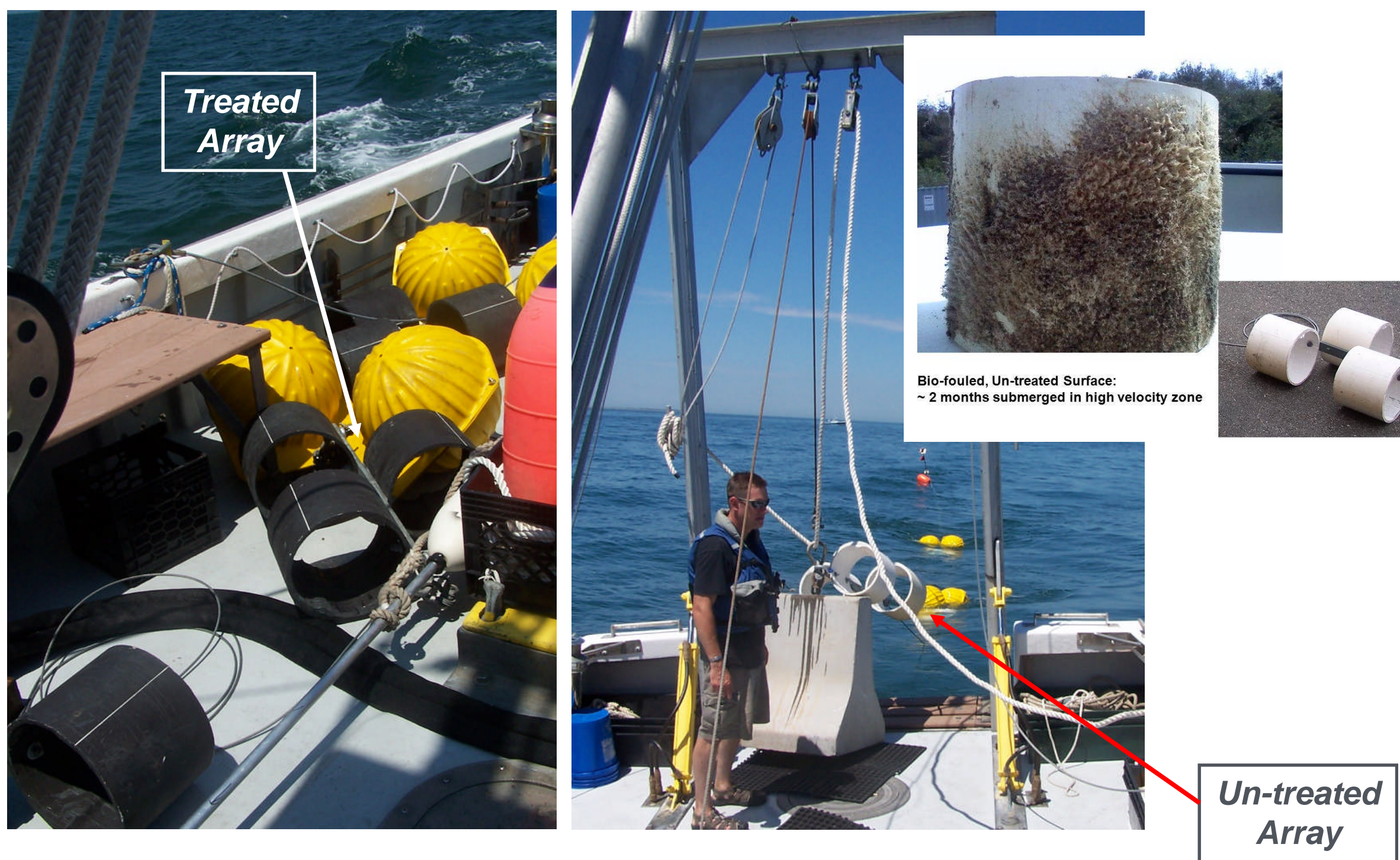


\section{Challenges to Date}

- Diver supported data collection limited by short slack-tide ( 30 minutes),

- Diver bottom time limited by depth ( 30 min. + decompression),

- Above average sea state due to offshore hurricane

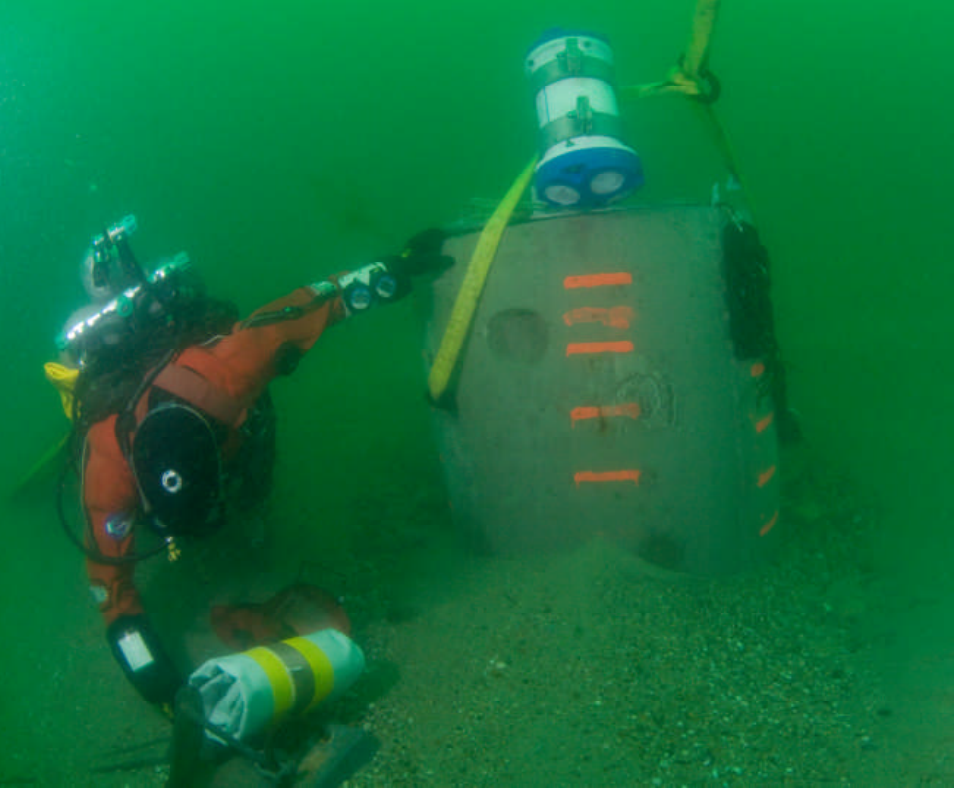

(Igor-summer 2010, Rita - summer 2011),

- Limited access to Autonomous Underwater Vehicle (completing side scan sonar survey using traditional vessel based technology) 
Final Report in preparation; submission by December 31

Seeking funding for additional studies which are presented in the FERC Draft License Application

Mass Clean Energy Center is funding aerial surveys of whales, sea turtles, seals, and sea birds

Other projects seeking funding include fisheries, species tagging, and acoustic studies
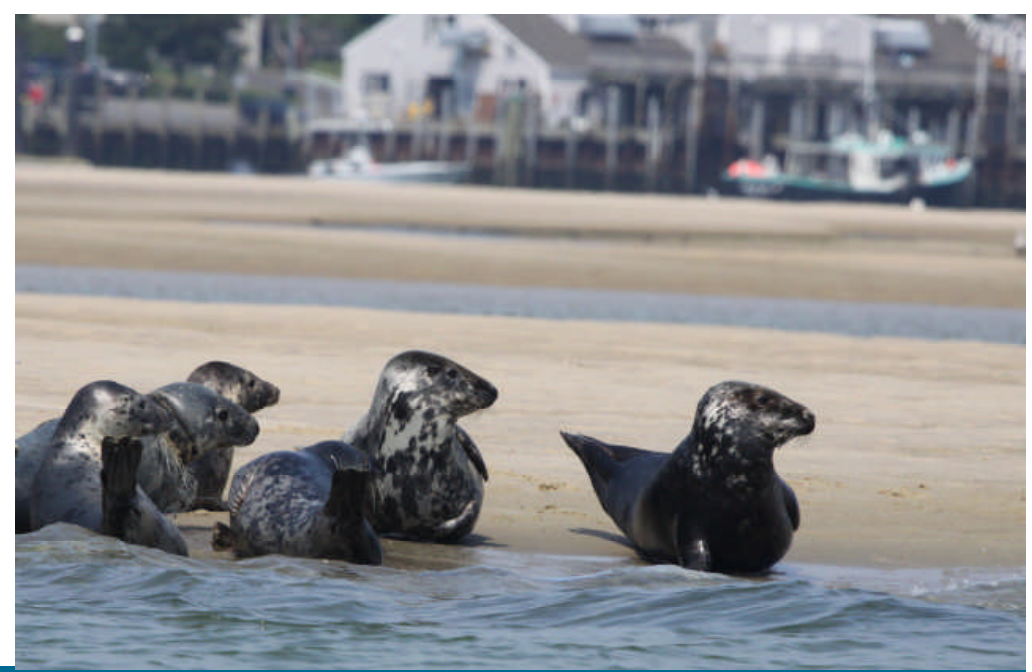
